Maren Büttner und Sabine Horn (Hg.)

\title{
Alltagsleben nach 1945
}

Die Nachkriegszeit am Beispiel der Stadt Göttingen

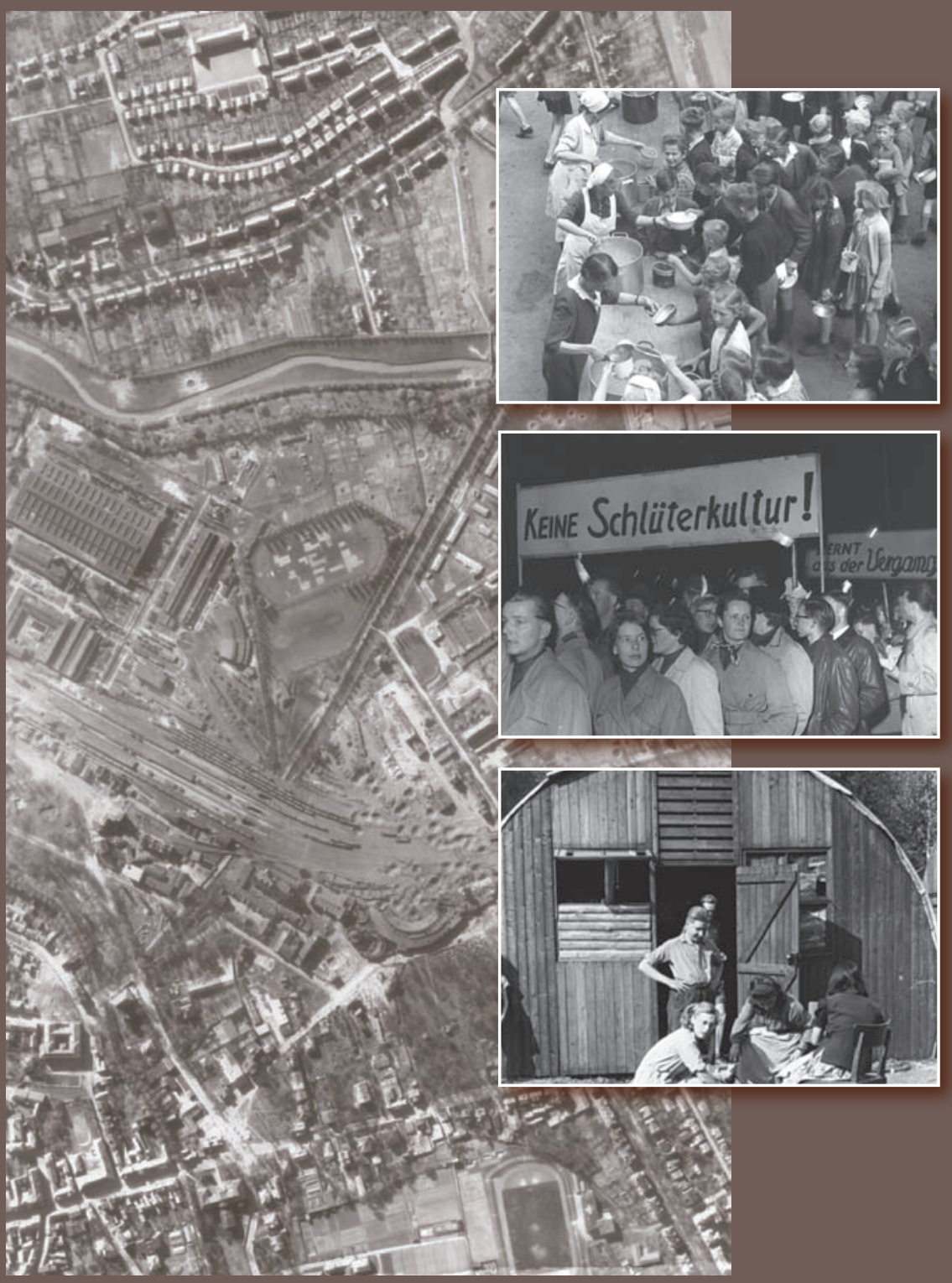

Universitätsverlag Göttingen 
Maren Büttner und Sabine Horn (Hg.)

Alltagsleben nach 1945

This work is licensed under the Creative Commons License 2.0 "by-nd", allowing you to download, distribute and print the document in a few copies for private or educational use, given that the document stays unchanged and the creator is mentioned. You are not allowed to sell copies of the free version.

SOREERIGHIS RESERNED 
erschienen im Universitätsverlag Göttingen 2010 
Maren Büttner und

Sabine Horn (Hg.)

\section{Alltagsleben nach 1945}

Die Nachkriegszeit am

Beispiel der Stadt Göttingen

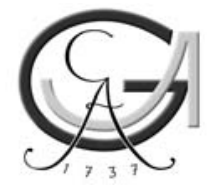

Universitätsverlag Göttingen 2010 


\section{Bibliographische Information der Deutschen Nationalbibliothek}

Die Deutsche Nationalbibliothek verzeichnet diese Publikation in der Deutschen Nationalbibliographie; detaillierte bibliographische Daten sind im Internet über $<$ http://dnb.ddb.de $>$ abrufbar.

\section{Anschrift der Herausgeberinnen}

Dr. Sabine Horn /Maren Büttner M.A.

Georg-August-Universität Göttingen/ Didaktik der Geschichte

Waldweg 26

37073 Göttingen

Diese Publikation wurde mit freundlicher Unterstützung durch Studienbeiträge der Georg-August-Universität Göttingen finanziert

Dieses Buch ist auch als freie Onlineversion über die Homepage des Verlags sowie über den OPAC der Niedersächsischen Staats- und Universitätsbibliothek (http://www.sub.uni-goettingen.de) erreichbar und darf gelesen, heruntergeladen sowie als Privatkopie ausgedruckt werden Es gelten die Lizenzbestimmungen der Onlineversion. Es ist nicht gestattet, Kopien oder gedruckte Fassungen der freien Onlineversion zu veräußern.

Satz und Layout: Birger Lambrecht Umschlaggestaltung: Maren Büttner und Margo Bargheer

Titelabbildungen: Luftbildaufnahme vom Bahnhofsgebiet in Göttingen, 1945.

Schulspeisung in Göttingen, 1946. „Nissenhütte in Göttingen“, ohne Datierung, Der „Fall Schlüter“, 1955.

Veröffentlichung mit freundlicher Genehmigung des Stadtarchivs Göttingen.

(C) 2010 Universitätsverlag Göttingen

http://univerlag.uni-goettingen.de

ISBN: 978-3-940344-81-6 



\section{Inhaltsverzeichnis}

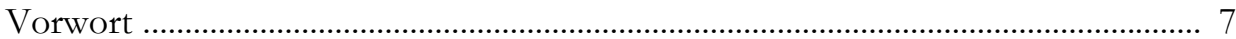

Maren Büttner/Sabine Horn

„Was am folgenden Morgen beginnt, ist ein neues Kapitel“ -

Die ersten Tage unter alliierter Besatzung in Göttingen

Michaela Böttcher

„Die Straße des Verderbens“ -

Schwarzmarkt und Göttinger Nachkriegskriminalität

Karolin Oppermann

„Also lautet ein Beschluss, dass der Mensch was lernen muss.“-

Der Wiederbeginn des schulischen Lebens in Göttingen

nach dem Zweiten Weltkrieg

Marco Dräger

„Jungen und Mädel! Man [...] bietet euch einen Neuanfang" -

Jugend in der Nachkriegszeit

Lisa Brill

Versorgungslage im Göttingen der Nachkriegszeit

Timo Stiehl

Die Verwaltung des Mangels -

Wohnungsnot in der Göttinger Nachkriegszeit

Ulf Gerrit Meyer-Rewerts 
Schildersturm -

Göttinger Straßenumbenennungen nach dem Zweiten Weltkrieg

179

Marco Dräger

Heimkehr aus Krieg und Gefangenschaft

205

Anne-Katrin Poppe

„Displaced Persons“ in Göttingen

243

Hagen Stöckmann

Theater und Kultur in Göttingen in den Nachkriegsjahren 1945-1955

261

Maneja Yazdani

Protestieren muss (wieder) gelernt sein

279

Andreas Brieger 


\section{Vorwort}

\section{Maren Büttner/Sabine Horn}

Die Stadt Göttingen, überstand den Zweiten Weltkrieg - verglichen mit größeren Nachbarstädten wie Kassel, Hildesheim und Hannover - ohne schwerere Bombenangriffe. Die wenigen Luftangriffe richteten nur begrenzte Schäden an und auch die Tage der Befreiung verliefen ohne Todesfälle, da die deutschen Truppen die Stadt kampflos den US-amerikanischen Truppen überließen. Dies war für die Universitätsstadt im Vergleich zu anderen Städten eine große Erleichterung. Schon am 4. August 1945, vier Monate nach dem Einmarsch der amerikanischen Truppen konnte am Deutschen Theater der Stadt die Oper "Die Hochzeit des Figaro" von Mozart aufgeführt werden und wenige Wochen später nahm auch die GeorgAugust-Universität als erste deutsche Hochschule ihren Lehrbetrieb wieder auf. Göttingen bekam so sehr schnell einen besonderen Stellenwert im kulturellen und wissenschaftlichen Leben der westlichen Besatzungszonen bzw. der jungen Bundesrepublik: Im Jahr 1948 wurde die Max-Planck-Gesellschaft und der erste gesamtdeutsche PEN-Club gegründet. Dennoch hatte auch Göttingen noch viele Jahre mit den Nachwirkungen des Krieges und der nationalsozialistischen Herrschaft zu kämpfen. Die über das nahegelegene, im September 1945 eröffnete, Grenzdurchgangslager Friedland in die Stadt kommenden Flüchtlinge - vor allem aus der damaligen Sowjetischen Besatzungszone - ließen die Einwohnerzahlen von etwa $51.000 \mathrm{im}$ Jahr 1939 auf über $80.000 \mathrm{im}$ Jahr 1949 steigen. Die Versorgung dieser Menschen mit Wohnraum, Heizmaterial, Nahrung und Arbeit stellte die Stadtverwaltung und die Göttinger Bevölkerung noch bis weit in die 1950er Jahre vor große wirtschaftliche und soziale Probleme. Die historische Erforschung insbesondere dieser veränderten Lebenssituationen der in Göttingen lebenden Bevöl- 
Maren Büttner/Sabine Horn

kerung wurde deshalb zum Leitgedanken des Seminars „Regionalgeschichtliche Forschung - Alltagsleben in Göttingen 1945-1955“. Gemeinsam gingen wir als Dozentinnen mit den Studierenden in den lokalen Archiven auf Spurensuche nach alltagsgeschichtlichen Quellen über das Kriegsende und die Nachkriegszeit in Göttingen und Umgebung. Das Schwierigste dabei, die Auswahl der zahlreich gefundenen Quellen und ihre anschließende Analyse, meisterten die Studierenden durch engagierte Diskussionen und Redaktionssitzungen mit dem Ziel einer gemeinsamen Publikation. Alltagsgeschichtliche Themen standen dabei im besonderen Fokus der Auseinandersetzung. Wir fragten nach dem alltäglichen Leben und den Erfahrungen der Bewohner in Stadt, Universität und Umland zum Kriegsende und in der frühen Nachkriegszeit. Es interessierten uns die Fragen, über welche Ausprägungen der nationalsozialistischen Herrschaft, Restriktionen, Denunziationen, aber auch Bereicherungen und Benachteiligungen am Kriegsende die lokalen Archive Auskunft geben können. Relevant waren besonders die Auseinandersetzung mit der Flüchtlingsproblematik, den neuen sozialen, politischen und kulturellen Konstellationen, dem Neuaufbau der Göttinger Schulen, der sogenannten „UmErziehung" der Jugend sowie den Umgestaltungen, aber auch den Kontinuitäten in Göttingen nach 1945. Als Ausgangsfragen dienten die folgenden Themenkomplexe: Straßenhandel respektive Schwarzmarkt, Flüchtlinge und Displaced Persons, Heimkehrer, Versorgungslage, Wohnungsnot, Schulalltag, Demonstrationen und neues kulturelles Leben. Die Recherche der Studierenden umfasste insbesondere die Sammlung und Sichtung von Quellen im Stadtarchiv Göttingen, im Städtischen Museum Göttingen, im Hauptstaatsarchiv Hannover und im Archiv des Lagers Friedland. Durch die Sichtung von amtlichen Akten, Flugblättern, Plakaten, Fotos, Filmen, Zeitungsartikeln und Nachlässen kamen sie den historischen Fragen Stück für Stück näher.

Als methodischen Ausgangspunkt verwendeten die Autorinnen und Autoren Fragestellungen der Alltagsgeschichte im Hinblick auf lokalgeschichtliche Dimensionen. Alltagshistorischen Fragestellungen geht es nicht um große politische Ereignisse oder Jahreszahlen, sondern um die Frage, wie Menschen im Alltag lebten und dieses Leben wahrnahmen. Mit der Begründung der Alltagsgeschichte wurde ein Abschied vom ,grand narrative“ eingeleitet und die Erfahrungen von Menschen, ihre Sicht auf die vermeintlich großen Prozesse, ihre Teilhabe an Macht, Herrschaft und historischen Ereignissen sollten im lokalen Raum sichtbar und hörbar gemacht werden. Alltägliches Leben bedeutet dabei zugleich ,konstruktives Hervorbringen einer neuen Welt". ${ }^{\text {. }}$

Der deutsche Zweig der Alltagsgeschichte entstand Mitte der 1980er Jahre. Es sollte das Handeln derer rekonstruiert und verstehbar gemacht werden, deren Existenz bis dahin außer im Rahmen der sozialgeschichtlichen Strukturen nicht als geschichtsmächtig gegolten hatte. Im Gegensatz zur Strukturgeschichte werden die

\footnotetext{
1 Richard Grathoff, Milieu und Lebenswelt. Eine Einführung in die phänomenologische Soziologie und die sozialphänomenologische Forschung, Frankfurt am Main 1989, S. 94.
} 
„großen Prozesse der Geschichte nicht hinter den Rücken der Akteure verlegt, sondern die soziale Praxis, die diese Phänomene hervorbringt, steht im Mittelpunkt. Im Mittelpunkt stehen die Formen, in denen Menschen sich 'ihre' Welt 'angeeignet' und dabei auch stets verändert haben. Handlungsbedingungen sind dabei gleichzeitig gegeben und werden produziert. In den Aneignungen werden sie nuanciert, verändert, variiert."2 Die Alltagsgeschichte zeigt die Bedeutung der einfachen Dinge des alltäglichen Lebens auf und verweist auf die Notwendigkeit des „Nachspürens verborgener Widerstandspotentiale“3

Mit Hilfe der Alltagsgeschichte arbeiteten vor allem Geschichtswerkstätten kritische Themen der Industrialisierungs-, Arbeiter-, Sozial-, Alltags-, Kultur- und Frauengeschichte auf. Der alltagsgeschichtliche Umgang mit lokalen historischen Ereignissen und Biographien sollte unter anderem die Möglichkeit eröffnen, geschichtliches Handeln aus seiner eigenen Logik zu begreifen und zu hinterfragen, in welchem Verhältnis die Einzelnen und kleinen Kollektive zu den „Strukturen“ standen, von denen sie geprägt wurden und die sie ihrerseits prägten. Aspekte der Alltagsgeschichte waren von Anbeginn: Elternhaus, Schulzeit, Ausbildung, Arbeit, Ernährung, Kleidung, medizinische und hygienische Situation, Religion, Sport, Handwerkstechniken und Kriegserfahrungen. Es wurde so eine neue Öffentlichkeit geschaffen, die sich besonders stark mit der Aufarbeitung lokaler NSVergangenheiten auseinandersetzte. ${ }^{4}$

Diese Publikation hat zum Ziel, bisher unbekannte und ungehörte Menschen der Nachkriegszeit in ihren Ereignissen und Erlebnissen zum Sprechen zu bringen und damit neue Aspekte auf die Geschichte der Göttinger Nachkriegszeit aufzuwerfen, die sie nicht in Vergessenheit geraten lassen. Fragen nach Überleben, Erleben und Erfahren von Hunger, Krankheiten, Mangel an Wohnraum und neuen politischen Konstellationen stehen deshalb im Mittelpunkt der kommentierten Quellensammlung. Sie wendet sich dabei vornehmlich an Schulen und die interessierte Göttinger Öffentlichkeit.

Die Studierenden - die Autorinnen und Autoren dieses Buches - präsentieren hier bislang unveröffentlichte Quellen dieser verschiedenen Facetten alltäglicher Problematiken und Aufgaben, mit denen sich die Göttinger Bevölkerung in der unmittelbaren Nachkriegszeit konfrontiert sah, und machen sie somit größtenteils zum ersten Mal einer Öffentlichkeit zugänglich. Ihrem Engagement in dem Buchprojekt gilt unser besonderer Dank.

\footnotetext{
2 Alf Lüdtke, Alltagsgeschichte. Zur Rekonstruktion historischer Erfahrungen und Lebensweisen, Frankfurt am Main/New York 1989, S.12.

3 Berliner Geschichtswerkstatt (Hg.), Alltagskultur, Subjektivität und Geschichte. Zur Theorie und Praxis von Alltagsgeschichte, Münster 1994, S.12

${ }^{4}$ Lutz Niethammer: Anmerkungen zur Alltagsgeschichte, in: Geschichtsdidaktik 5 (1980) 3, S.231242.

5 Adelheid von Saldern, ,Schwere Geburten“. Neue Forschungsrichtungen in der bundesrepublikanischen Geschichtswissenschaft (1960-2000), in: Werkstatt Geschichte 40 (2005), S. 5-30, hier S.13.
} 


\section{Danksagung}

Unser Dank geht an alle, die an der Verwirklichung des Projektes und der Publikation mitgewirkt haben. Zu nennen sind hier insbesondere Dr. Ernst Böhme und seine Mitarbeiter vom Stadtarchiv Göttingen, Dr. Peter Aufgebauer (Seminar für Mittlere und Neuere Geschichte Univ. Göttingen), Klaus Brinkmann, das Städtische Museum Göttingen, das Archiv Friedland, das Göttinger Tageblatt, das Hauptstaatsarchiv Hannover, die Niedersächsische Staats- und Universitätsbibliothek Göttingen, der Universitätsverlag Göttingen, Margo Bargheer, Jutta Pabst, Käthe Thomas, Birger Lambrecht, Karolin Oppermann, Reiner Nolte, Joana Schröer-Reuter - und vor allem die Autorinnen und Autoren, die Studierende im Fach Geschichte an der Georg-August-Universität Göttingen sind.

Die Qualität einiger hier gedruckter Quellen ist leider im Original aufgrund der Nachkriegsmangelwirtschaft schlecht lesbar. Der Druck konnte diesen Mangel nicht beheben. Die betroffenen Quellen sind in der Onlineversion (siehe unter: http://webdoc.sub.gwdg.de/univerlag/2010/Alltagsleben.pdf) besser lesbar. 


\title{
„Was am folgenden Morgen beginnt, ist ein neues Kapitel' ${ }^{{ }^{1}}-$ Die ersten Tage unter alliierter Besatzung in Göttingen
}

\author{
Michaela Böttcher
}

\section{Einleitung}

Die „Scoops from Group“, ein Nachrichtenblatt der US-amerikanischen Armee, berichtet in seiner Auflage vom 9. April 1945, dass Göttingen am vorherigen Tag eingenommen wurde: „American First Army troops are over the WESSER on a 31-mile front and have taken GOTTINGEN, north of KASSEL, after a 13-mile advance yesterday (...)."2 Das Ereignis, das in diesem Bericht scheinbar nebenbei erwähnt wurde, implizierte für die Göttinger Bevölkerung, dass der Krieg für sie beendet war. Doch wie kam es eigentlich dazu? Wie wurde Göttingen eingenommen? Gab es Gegenwehr oder fand eine friedliche Übergabe der Stadt statt? Und welche Auswirkung hatte die Übernahme der Stadt durch die US-amerikanischen Soldaten auf die Zivilbevölkerung? Die Historikerin Wiebke Fesefeldt stellt im Hinblick auf die soziale und gesellschaftspolitische Zusammensetzung der Göttinger Bevölkerung zum Zeitpunkt des Kriegsendes fest: „Der Stadt Göttingen, um die es uns hier geht, waren eigentliche Prüfungen, etwa das Inferno des Bombenkrieges oder der Russeneroberung, erspart geblieben. Sie war ihrer politischen Tradition nach frü-

${ }^{1}$ Hannah Vogt, Aus meinem Tagebuch 1945, 8.4.1945, Stadtarchiv Göttingen, Kl. E. 149 Nr. 50, S. 12.

${ }^{2}$ Scoops from Group (9.4.1945), Bericht über die Erfolge der amerikanischen Armee, Stadtmuseum Göttingen, Fotoarchiv, S. 1. 
her konservativ bis liberal gewesen, ihre Einwohnerschaft gehörte weitgehend dem Mittelstand an. Der Nationalsozialismus hatte guten Boden in ihr gefunden; als ,Hochburg des Nationalsozialismus" hatte sie sich selbst bezeichnet." ${ }^{3}$

\section{2 „Die Amerikaner kommen...“}

Die Tage in Göttingen vor dem 8. April 1945 können als angespannt beschrieben werden. Der Historiker Heinzel beschreibt: „Als die Truppen der Amerikaner auf das südliche Niedersachsen vorrückten, waren die Folgen des Krieges im Göttinger Stadtbild zwar kaum sichtbar. Doch jeder wusste um die schrecklichen Zerstörungen in vielen deutschen Städten (...). "“ Die Tagebucheinträge der Göttingerin Hannah Vogt geben Hinweise darauf, dass in der Bevölkerung Unklarheit darüber bestand, ob die Stadt militärisch verteidigt oder den alliierten Truppen kampflos übergeben werden würde. Dementsprechend unsicher gestalteten sich diese Tage im April für die meisten Göttinger (Q1). Die Bevölkerung wusste allerdings über den britischen Rundfunk, der über Radio empfangen werden konnte, dass Kassel bereits am 5. April 1945 von den US-Truppen eingenommen worden war. Auch Göttingen konnte daher die US-amerikanische Armee erwarten. Am Abend des 7. April 1945 war es dann soweit: die US-amerikanische Luftwaffe flog ihren größten und letzten Luftangriff auf Göttingen. ${ }^{5}$ Das Ziel der US-amerikanischen Air Force war das Bahnhofsgelände. Vorrangig wollte die US-Armee die Rüstungsindustrie des ,Dritten Reiches’ zerstören. Dabei mussten die US-Truppen jedoch feststellen, dass trotz Zerstörung großer Firmen und Industriezentren die Rüstungsindustrie nicht nachhaltig gestört werden konnte. Zum einen existierten diverse unterirdische Werke, in denen Zwangsarbeiter und Häftlinge ohne Rücksichtnahme auf deren Gesundheit zur Arbeit gezwungen wurden; zum anderen gab es viele kleine Firmen, die als Zulieferer für die Rüstungsindustrie fungierten. Verbunden waren diese Firmen und Werke durch das Straßen- und Schienennetz. Daher galt das primäre Ziel der US-amerikanischen Armee in der letzten Phase des Luftkrieges der Zerstörung der Bahnhöfe und Schienen. ${ }^{6}$ Das Hauptgebäude des Bahnhofes stürzte als Folge des Luftangriffes ein; sowohl das Universitätsgebäude der Anatomie als auch das der Zoologie wurden auf Grund ihrer geografischen Nähe zum Bahnhof von Bomben getroffen und die Eisenbahnbrücke wurde komplett zerstört. Wie durch ein Wunder wurde bei diesem Luftangriff kein Mensch getötet; insgesamt forderte der Luftkrieg während des Zweiten Weltkrieges in Göttingen

\footnotetext{
3 Wiebke Fesefeldt, Der Wiederbeginn des kommunalen Lebens in Göttingen. Die Stadt in den Jahren 1945 bis 1948, Göttingen 1962, S. 20. Für weitere Informationen zur nationalsozialistischen Zeit in Göttingen siehe die Dissertation von Cordula Tollmien, Nationalsozialismus in Göttingen (1933-1945), Göttingen 1999.

4 Matthias Heinzel, 1945 - Kriegsende in Göttingen. Zeitzeugen berichten, Göttingen 2005, S. 7.

5 Vgl. Martin Heinzelmann, Göttingen im Luftkrieg. 1935-1945, Göttingen 2003, S. 51.

${ }^{6}$ Vgl. Heinzelmann, Luftkrieg, Göttingen 2003, S. 47.
} 
zwischen 107 und 120 Menschenleben. ${ }^{7}$ „Die dicken Qualmwolken, die ein alliiertes Aufklärungsflugzeug am Tag der Übergabe fotografierte, waren jedoch nicht das Resultat des Bombenangriffs des Vortags: Vor ihrer Flucht aus der Stadt hat die SS die Treibstofflager des Flugplatzes in Brand gesetzt." (Q2)

Göttingen blieb von einer flächendeckenden Bombardierung verschont - anders als die benachbarten Städte Kassel, Hannover oder Braunschweig. Braunschweig erlebte als Teil der „Gegend mit dem höchsten Industrialisierungsgrad in Niedersachsen" in der Nacht vom 14. zum 15. Oktober 1944 unter anderem einen Luftangriff seitens der alliierten Streitkräfte, welcher das öffentliche Leben in dieser Stadt zusammenbrechen ließ. Darüber hinaus starben bei diesem verheerenden Angriff 850 Menschen. Obwohl auch Göttingen in den ersten Monaten des Jahres 1945 US-amerikanische Luftangriffe ertragen musste, war die Situation in der Lazarettstadt Göttingen nicht vergleichbar mit der in der Industriestadt Braunschweig. Zeitzeugen aus Braunschweig berichteten später: „So vergingen im Januar 1945 nur 9 Tage, im Februar und im März nur je ein Tag ohne Fliegeralarm“. ${ }^{10}$ Am Sonntagmorgen des 8. April 1945, $11.30 \mathrm{Uhr}$, gab es „Vollalarm“ in Göttingen; die Artillerie der US-amerikanischen Armee rückte aus Süden an Göttingen heran. ${ }^{11}$ Routinemäßig feuerte sie einige Schüsse ab, um eventuelle Verteidigungsposten zu entdecken. Doch die Stadt wurde nicht verteidigt. Hannah Vogt schrieb in ihrem Tagebuch, dass vermutlich diverse Gerüchte sowie eine Durchsage im Radio dazu geführt hatten, dass keine Verteidigung durchgeführt wurde. Die Stadt wurde friedlich übergeben (Q1). Die in Göttingen lebende freischaffende Autorin und Historikerin Wiebke von Thadden, ehemals Fesefeldt, beschreibt den Ablauf bei der Übergabe Göttingens in ihrem Aufsatz „Der Wiederbeginn des kommunalen Lebens in Göttingen“ wie folgt: „Als die amerikanische Panzerspitze bereits auf dem Marktplatz stand übergaben ihr um 13.30 Uhr Oberbürgermeister Gnade, Stadtrechtsrat Schwetge, Amtsgerichtsrat Schmidt und Professor Baumgarten die Stadt." "12 Die Befehlsgewalt über die Stadt wurde dem Kommandeur des 23. Regiments der 2. Infanteriedivision der US-amerikanischen Armee übergeben.

Albert Gnade, der damalige Oberbürgermeister der Stadt Göttingen, versuchte viele Jahre später, die kampflose Übergabe als seinen Verdienst darzustellen. Er verfasste einen Bericht über die Vorgänge bei der Übergabe der Stadt am 08.04.1945. In der Anlage zu diesem Bericht befindet sich ein Aufruf an die Bevölkerung Göttingens, in dem diese aufgefordert wurde, keinen Widerstand gegen die US-

\footnotetext{
7 Vgl. ebd., S. $51 \mathrm{f}$.

${ }^{8}$ Heinzel, Kriegsende, S. 15.

9 Albrecht Lein, Antifaschistische Aktion 1945. Die „Stunde Null“ in Braunschweig, Göttingen/Frankfurt/Zürich 1978, S. 133.

${ }^{10}$ Ebd., S. 134.

11 Vgl. Heinzelmann, Luftkrieg, S. 56.

12 Vgl. Wiebke von Thadden, Die Stadt Göttingen unter britischer Militärregierung 1945-1947, in: Rudolph von Thadden/Günther J. Trittel (Hg.), Göttingen. Geschichte einer Universitätsstadt. Band 3. Von der preußischen Mittelstadt zur südniedersächsischen Großstadt 1866-1989, Göttingen 1999, S. 275-290, S. 275.
} 
amerikanische Armee zu leisten: „Unter den gegenwärtigen Umständen gilt für unsere Stadt das Wort des Führers, dass nunmehr dafür zu sorgen ist, dass das Volk nicht heroisch untergeht, sondern praktisch erhalten wird..." "13 (Q3). Sowohl in den Quellen als auch in der Sekundärliteratur lässt sich allerdings kein Hinweis finden, dass dieser Aufruf jemals die Bevölkerung erreicht hatte. Im Gegenteil: Matthias Heinzel arbeitete in seinem Zeitzeugenprojekt heraus, dass die Person Gnade und die Handlungen des Oberbürgermeisters hinsichtlich der Übergabe der Stadt ungeklärt und umstritten sind. ${ }^{14}$ Auch der Ausschuss zur Klärung der Vorgänge bei der Kapitulation Göttingens im April 194515, der zwischen 1955 und 1957 die Ereignisse vom 8. April 1945 untersuchte, kam zu dem Schluss, dass eine einzelne Person nicht ,als Retter der Stadt benannt"16 werden kann. Im Gegensatz zum Kriegsende und der Nachkriegszeit war Albert Gnade, der am 31. März 1933 Polizeidirektor in Göttingen und 1938 Oberbürgermeister der Stadt wurde, während seiner Amtszeit sehr beliebt in der Bevölkerung Göttingens gewesen. Dies verdeutlicht die Tatsache, dass er unter den Einwohnern den Spitznamen „Papa Gnade“ führte. Seine Popularität resultierte daraus, dass er zwar SS-Sturmbannführer war, aber keinerlei parteiliche Funktionen inne hatte und daher die Interessen der Stadt über mögliche Ziele der NSDAP stellte. ${ }^{17}$

Nach der Übergabe der Stadt fiel die Versorgung mit Wasser, Strom und Gas für einige Tage aus. ${ }^{18}$ Darüber hinaus hatte sich auch das Stadtbild immens verändert: US-amerikanische Soldaten, bald darauf britische Militäreinheiten, ehemalige Kriegsgefangene, deutsche Flüchtlinge, Displaced Persons (DP), ${ }^{19}$ aber auch Angehörige internationaler und alliierter Behörden und Organisationen waren nun in Göttingen anzutreffen. ${ }^{20}$

\footnotetext{
13 Nachlass Albert Gnade, Bericht über die Vorgänge bei der Übergabe der Stadt am 08.04.1945, Stadtarchiv Göttingen, Kl. E. Nr. 80, I, 11, Anlage.

14 Vgl. Heinzel, Kriegsende, Göttingen 2005, S. $23 f$.

$15 \mathrm{Zu}$ dem Titel dieses Ausschusses muss angemerkt werden, dass der Ausschuss zu dem Ergebnis kam, dass Göttingen sowohl nach rechtlichem als auch militärischem Verständnis nicht kapituliert hatte; das Kriegsende in Göttingen wurde durch eine friedliche Übergabe der Stadt herbeigeführt. Der Titel für diesen Ausschuss ist daher irreführend.

16 Bericht über die Arbeiten des Ausschusses, dem Rat der Stadt Göttingen am 30.03.1957 übergeben; zitiert bei Walther Hubatsch: Wie Göttingen vor der Zerstörung bewahrt wurde. Die Vorgänge vom 1. bis 8. April 1945, in: Göttinger Jahrbuch 1961, Göttingen 1961, S. 118.

17 Vgl. Tollmien, Nationalsozialismus, Göttingen 1999, S. $225 \mathrm{f}$.

18 Vgl. Wiebke von Thadden, Militärregierung, S. 275.

${ }^{19}$ Wie in Hagen Stöckmanns Beitrag „'Displaced Persons“ in Göttingen“ definiert, handelt es sich bei DPs um Zivilpersonen, die sich am Ende eines Krieges aus diversen Gründen nicht in ihrem Heimatland befinden, jedoch dahin zurückkehren oder ein neues Heimatland finden wollen, dies aber nicht ohne fremde Hilfe bewerkstelligen können; dazu zählen sowohl Zwangsarbeiter als auch Kriegsgefangene. Im Falle des Zweiten Weltkrieges zählen auch ehemalige Häftlinge von Konzentrationslagern zu den DPs.
}

${ }^{20}$ Vgl. Wiebke von Thadden, Militärregierung, S. $275 f$. 


\section{Das Leben unter der Besatzungsmacht}

Nachdem Göttingen von den US-amerikanischen Soldaten besetzt worden war, versuchte die Bevölkerung, Ruhe und Ordnung in ihr Leben zu bringen und sich mit den neuen politischen Verhältnissen zu arrangieren. Fesefeldt stellt fest: „Die Göttinger beugten sich ergeben und nicht ungern den erwarteten Anordnungen zur Liquidierung von Militarismus und Nationalsozialismus. Sie begrüßten sehnsüchtig die Wiederherstellung von Ruhe und Ordnung, sie hofften auf die Wiedererrichtung von Recht und Gerechtigkeit, und sie waren in ihrer Mehrheit recht bereit, daran mitzuarbeiten und der Militärregierung guten Willen zu bezeigen. "21

Die Bevölkerung versuchte, Normalität in ihren Alltag zu bringen. Erschwert wurde dieser Wunsch durch die Tatsache, dass die Lebensmittelvorräte knapper waren als in den letzten Tagen unter nationalsozialistischer Herrschaft. Der Grund hierfür war, dass die Läden vor dem 8. April 1945 mit Heeresrationen für die Wehrmacht beliefert wurden. Dies entfiel nun, da Göttingen unter alliierter Besatzung war. Die Göttinger standen in Schlangen um Brot und andere Lebensmittel an. ${ }^{22}$

Die deutsche Zivilbevölkerung sah sich recht bald mit strengen Ausgangs-, Reise- und Informationssperren sowie einer ganzen Reihe von Meldepflichten konfrontiert. ${ }^{23}$ Darüber hinaus begann ein erster Entnazifizierungsprozess: Parteigenossen hatten sich im Rathaus zu melden, wobei einige inhaftiert wurden. So musste sich auch Friedrich Neumann, der sowohl Parteigenosse als auch Professor der Deutschen Philologie und Universitätsrektor der Georg-August-Universität Göttingen von 1933 bis 1938 war, am 12. April 1945 im Rathaus melden (Q4). Friedrich, auch genannt Fritz, Neumann war am 26. April 1933 zum Rektor der Universität gewählt worden und der NSDAP wenige Tage später, am 1. Mai 1933, beigetreten. Die Rektorwahl sei bei der Entscheidung, Mitglied der NSDAP zu werden, ein Grund gewesen, so Fritz Neumann. Darüber hinaus soll eine idealistische Grundidee zur Entwicklung der Gesellschaft ausschlaggebend gewesen sein. Fritz Neumann hatte sich bereits vor 1933 mit der sozialen Konstellation der Gesellschaft beschäftigt. Dabei hatte er geglaubt, dass die NSDAP weit reichende Reformen zur Verbesserung der sozialen Lage diverser Gesellschaftsschichten durchführen würde. ${ }^{24}$

Nachdem sich Friedrich Neumann am 12. April 1945 im Rathaus als Parteigenosse gemeldet hatte, ordnete am 19. Juli 1945 „die britische Militärregierung in Göttingen die Entlassung Friedrich Neumanns aus dem Staatsdienst" ${ }^{\text {25 } 5}$ an. Darü-

\footnotetext{
${ }^{21}$ Fesefeldt, Wiederbeginn, S. 21.

22 Die Versorgungslage ist in diesem Band in Timo Stiehls Beitrag Versorgungslage im Göttingen der Nachkriegszeit ausführlich dargestellt.

${ }^{23} \mathrm{Vgl}$. Wiebke von Thadden, Militärregierung, S. 276.

${ }^{24}$ Vgl. Ulrich Hunger, Friedrich Neumann und der Nationalsozialismus. Eine biographische Fallstudie zum Verhältnis von Wissenschaft und Politik, in: Göttinger Jahrbuch 2005, Göttingen 2005, S. 114.

${ }^{25}$ Ulrich Hunger, Friedrich Neumann, S. 122.
} 
ber hinaus wurde er durch den Entnazifizierungs-Hauptausschuss der Stadt Göttingen im Februar 1949 als „Mitläufer“ eingestuft. Später stufte der Spruchausschuss beim Entnazifizierungs-Hauptausschuss Hildesheim Fritz Neumann als „Entlasteter“ ein. Das niedersächsische Landesministerium versetzte ihn am 15. Mai 1951 in den Ruhestand und Friedrich Neumann wurde drei Jahre später, am 1. April 1954, ordnungsgemäß emeritiert. ${ }^{26}$

Für die Unterbringung der US-amerikanischen Soldaten musste gesorgt werden. Ähnlich wie in anderen Städten wurden in Göttingen Soldaten in Privathäusern untergebracht, während sich die derzeitigen Bewohner vorübergehend eine andere Unterkunft suchen mussten. Dies geschah in der Regel nicht freiwillig, jedoch schien die US-amerikanische Armee nicht auf offene Ressentiments gestoBen zu sein. Ein Beispiel für den unfreiwilligen Umzug stellt die Familie NeumannGraul in Q5 dar. Sie verließ vorübergehend ihr Haus und kam bei ihrem Nachbar, dem Geophysiker Ambronn, unter. Ilse Naumann-Graul notierte damals in ihrem Tagebuch: „Gegen 7 Uhr abends wird unser Haus und die Nachbarhäuser eingehend von einem amerikanischen Offizier und einem dolmetschenden Soldaten besichtigt. ,V ery nice!' (In der Badewanne ist noch etwas Wasservorrat: ,Can it pour?') Wir packen."27 (Q5)

Im Mai 1945 wechselte in Göttingen die Besatzungsmacht: Britische Soldaten lösten die US-amerikanischen ab. Göttingen gehörte von nun an zur britischen Besatzungszone. Die britische Armee marschierte mittels einer Parade in Göttingen ein (Q6) und die Soldaten formatierten sich mit Blick zum Rathaus vor dem Gänseliesl, dem Wahrzeichen von Göttingen (Q7). Die Bevölkerung reihte sich an den Straßenrändern auf, um diesen offen dargestellten Wechsel der Besatzungsmächte zu betrachten. Die neue Besatzungsmacht wurde zwar nicht bejubelt, jedoch befanden sich viele Göttinger auf der Straße, um den Einzug der Armee zu verfolgen (Q6).

Am 22. Juli 1945 lockerte die britische Militärregierung die bis dahin strengen Fraternisierungsverbote: Soldaten des Vereinigten Königreiches Großbritannien und Nordirland durften ab diesem Tag mit deutschen Erwachsenen auf der Straße sprechen (Q8).

\section{Der Mikrokosmos im Makrokosmos}

Die Nachricht von Hitlers Tod erreichte Göttingen über das Radio: „Am Abend des 1. Mai wurde vom Großdeutschen Rundfunk nach vorheriger seelischer Vorbereitung durch ernste Musik von Bruckner mitgeteilt, daß Hitler im Kampf gegen den Bolschewismus ausharrend bis zuletzt gefallen sei"28 schrieb Hannah Vogt in ihr Tagebuch. Aus gegenwärtiger Perspektive wäre zu erwarten gewesen, dass diese Nachricht in der

\footnotetext{
${ }^{26}$ Vgl. ebd., S. 122.

27 Tagebuch-Notizen (1.1.1945-20.12.1947) von Ilse Neumann-Graul, 24.4.1945, Stadtarchiv Göttingen, Kl. E. Nr. 114, I, 1, S. 10.

${ }^{28}$ Hannah Vogt, 4.5.1945, S. 14.
} 
Bevölkerung Reaktionen hervorrief. Die hier betrachteten Quellen lassen aber einen solchen Rückschluss nicht zu. Ilse Neumann-Graul erwähnt den Tod Adolf Hitlers mit einem Satz, um danach über die Geburt eines Kindes zu berichten (Q9). Darüber hinaus beschreibt Hannah Vogt die Göttinger nach der Nachricht: Sie scheint keine Veränderung im Alltag nach sich zu ziehen. Der Name Hitler wird nicht erwähnt (Q10).

Interessanter erscheinen die Unterschiede der Tagebucheinträge vom 6. August 1945 der beiden Frauen: Während der Abwurf der Atombombe auf Hiroshima bei Ilse Neumann-Graul keine Beachtung findet und nicht erwähnt wird, führt Hannah Vogt diverse Gedanken zu diesem Ereignis an (Q11). Zukunftsorientiert versucht sie in Gedanken, Göttingen eine führende Rolle beim Wiederaufbau von Deutschland zuzuschreiben. „Dies Inselhafte unserer Existenz, dieser Woblstand, diese Unversehrtheit - sie verpflichten!' ${ }^{29}$ Auf Grund der Tatsache, dass Göttingen den Zweiten Weltkrieg relativ unbeschadet überstanden hat, sollte es anderen Städten als Vorreiter im Wiederaufbau dienen, doch zunächst sah sich die Stadt mit vielen Aufgaben wie dem hohen Flüchtlingsaufkommen konfrontiert. Nicht nur die Displaced Persons und die deutschen Flüchtlinge sorgten für ein immenses Bevölkerungswachstum in Göttingen nach dem Zweiten Weltkrieg, sondern auch die aus der Kriegsgefangenschaft heimkehrenden Soldaten benötigten Unterkunft und Verpflegung. Obwohl Göttingen nicht zerstört worden war, war die Stadt mit der Problematik der Wohnungsnot konfrontiert. Darüber hinaus mussten die Göttinger lernen, auch mit anderen Problemen umzugehen: knappe Versorgungslage, Neubeginn des schulischen Alltags und der illegale Tauschhandel auf dem Schwarzmarkt.

\section{Literatur zum Weiterlesen}

Wiebke Fesefeldt, Der Wiederbeginn des kommunalen Lebens in Göttingen. Die Stadt in den Jahren 1945 bis 1948, Göttingen 1962.

Matthias Heinzel, 1945 - Kriegsende in Göttingen. Zeitzeugen berichten, Göttingen 2005.

Martin Heinzelmann, Göttingen im Luftkrieg. 1935-1945, Göttingen 2003.

Ulrich Hunger, Friedrich Neumann und der Nationalsozialismus. Eine biographische Fallstudie zum Verhältnis von Wissenschaft und Politik, in: Göttinger Jahrbuch 2005, Göttingen 2005.

Wiebke von Thadden, Die Stadt Göttingen unter britischer Militärregierung 19451947, in: Rudolph von Thadden/Günther J. Trittel (Hg.), Göttingen.

${ }^{29}$ Hannah Vogt, 6.8.1945, S. 21. 
Geschichte einer Universitätsstadt. Band 3. Von der preußischen Mittelstadt zur südniedersächsischen Großstadt 1866-1989, Göttingen 1999, S. 275-290. 
Das einzige Gesprächsthema: Wird Göttingen verteidigt werden? Tausend Gerüchte und Vermutungen laufen um. Es heißt, daß Oberbürgermeister Gnade die Stadt kampflos übergeben will, der Kreisleiter aber auf Verteidigung besteht. Der Kreisleiter soll Sitzungen einberufen haben und den Vorschlag gemacht haben, alle Institute zu sprengen. Endlich ermannt sich die Intelligenz: Professor Stich, der Chirurg, spricht von 3600 Schwerverwundeten, deren Abtransport unmöglich ist. Die Institutsdirektoren erklären, daß Rollkommandos zum Zerstören ihrer Anstalten den Weg über ihre Leichen nehmen müßten. Man hört, daß die Truppen die Stadt verlassen. Nur Volkssturmmänner mit Karabinern sind zu sehen. Das Waffenamt auf dem Lohberg ist auf und davon. Man schöpft daraufhin Hoffnung. In den Zeitungen häufen sich wïste Aufrufe von Bormann, Lauterbacher, Gengler. Man wird wieder zweifelhaft: soll die Stadt tatsächlich Kampfschauplatz werden? Die Gespräche nehmen einen immer offeneren Charakter an. Alles ist sich einig in dem Wunsch, die Stadt erhalten zu wissen und sinnloses Zerstören und Blutvergießen zu vermeiden.

Man sitzt am Radio und lauscht gespannt auf jede Nachricht. Man studiert die Landkarte. Sollte Göttingen etwa liegengelassen werden und der Sto $B$ nördlich von Minden nach Hannover, südlich von Kassel nach Nordhausen gehen? Es wäre niemandem lieb! Jeder möchte durch die letzten Drangsale schnell hindurch.

Ab Freitag, 6.April, spitzen sich die Dinge dramatisch zu. Am Abend vorher berichtete ein Kriegsberichter im englischen Rundfunk, daß der Kommandant von Kassel sich ergeben habe. Gerüchte, daß Panzerspitzen in Soden, in Witzenhausen und in Hannoversch Münden gewesen seien, laufen um. Trotz herannahender Gefahr stehen die Schlangen nach Schnaps häuserlang.

Q 1: Tagebucheintrag von Hannah Vogt (08.04.1945), Stadtarchiv Göttingen, Kl. E. 149 Nr. 50, S. 4. 
Man beunruhigt sich, weil in den Dörfern umher geschanzt wird. Andere Stimmen sagen, daß im Umkreis von $5 \mathrm{~km}$ um Göttingen Schilder angebracht seien, daß Göttingen keine Truppen beherberge. Man möchte das Angenehmste gern glauben.

Am Freitagabend um $10 \mathrm{Uhr}$ sagt der englische Rundfunk, daß Hannoversch Münden gesäubert sei. Die Hausgemeinschaft strömt zusammen. Man fängt an zu kramen und im Keller herumzuräumen. Die Luft lädt sich auf mit Spannung. Um 3/4 12 Uhr Anruf von Dr.Luther: Man könne sicher damit rechnen, daß die Amerikaner noch diese Nacht einrollten. Verlassen der Stadt sei aber nicht nötig, es würde vielleicht zu Plündereien kommen, daher sei Aufsuchen des Kellers ratsam. Aber es sei nichts Ernstliches zu befürchten.

Kurz darauf langes Schellen an der Haustür: die Blockleitung! Mutter und Tochter in desolatem Zustand! Sie teilen uns mit, daß Frauen, Kinder und Männer über 60 Jahren, die die Stadt verlassen wollen, jetzt auf die Herzberger Landstraße gehen sollen, wo sie von Parteiführern empfangen und auf die umliegenden Dörfer gebracht würden. Es sei Feindalarm zu erwarten! Bei uns gedenkt niemand, von diesem Angebot Gebrauch zu machen. Bald danach wird im Radio durch den Gaubefehlsstand diese Meldung widerrufen: es sei jetzt noch nicht an der Zeit; die Bevölkerung werde rechtzeitig zum Verlassen der Stadt aufgefordert! Zuletzt wird eine Ansprache des Kreisleiters in Aussicht gestellt. Ein Teil der Hausgemeinschaft sitzt erwartungsvoll vor dem Kasten. Die Stimme, die dann erklingt, erweckt nicht den Eindruck, als gehöre sie einem Manne, der der Situation gewachsen ist. Es ist ein von vielen "Äähs" und "Aahs" unterbrochenes Gestotter, mit dem die Volksgenossen zur Ruhe ermahnt werden. Unter anderem fällt das Wort:

Q 1: $\quad$ Tagebucheintrag von Hannah Vogt (08.04.1945), S. 5. 
"Sollten wider Erwarten Kampfhandlungen stattfinden..." Daraus schließen wir, daß selbst diese Scharfmacher nicht mehr an eine Verteidigung der Stadt denken. Er versichert uns, daß die Partei uns treulich weiterfuhren und bei uns bleiben würde. Er fordert uns auf, schlafen zu gehen, und wünscht uns mit "Heil Hitler" eine gute Nacht. Wir wären dieser Aufforderung ohnehin nachgekommen und schlafen ruhig bis zum Morgen. Auch dieser beginnt wie alle bisherigen mit Einkäufen. Ich erstehe noch einmal zehn Pfund Brot und sogar den Schnaps. Tagsuber arbeiten wir im Garten. Voralarm und Vollalarm wechseln sich ab. Ich säe die Küchenkräuter, Vater sticht die Wege $a b$ und harkt sie Sauber. Unser Garten sieht wie ein Schmuckkästchen aus.

Q 1: $\quad$ Tagebucheintrag von Hannah Vogt (08.04.1945), S. 6. 


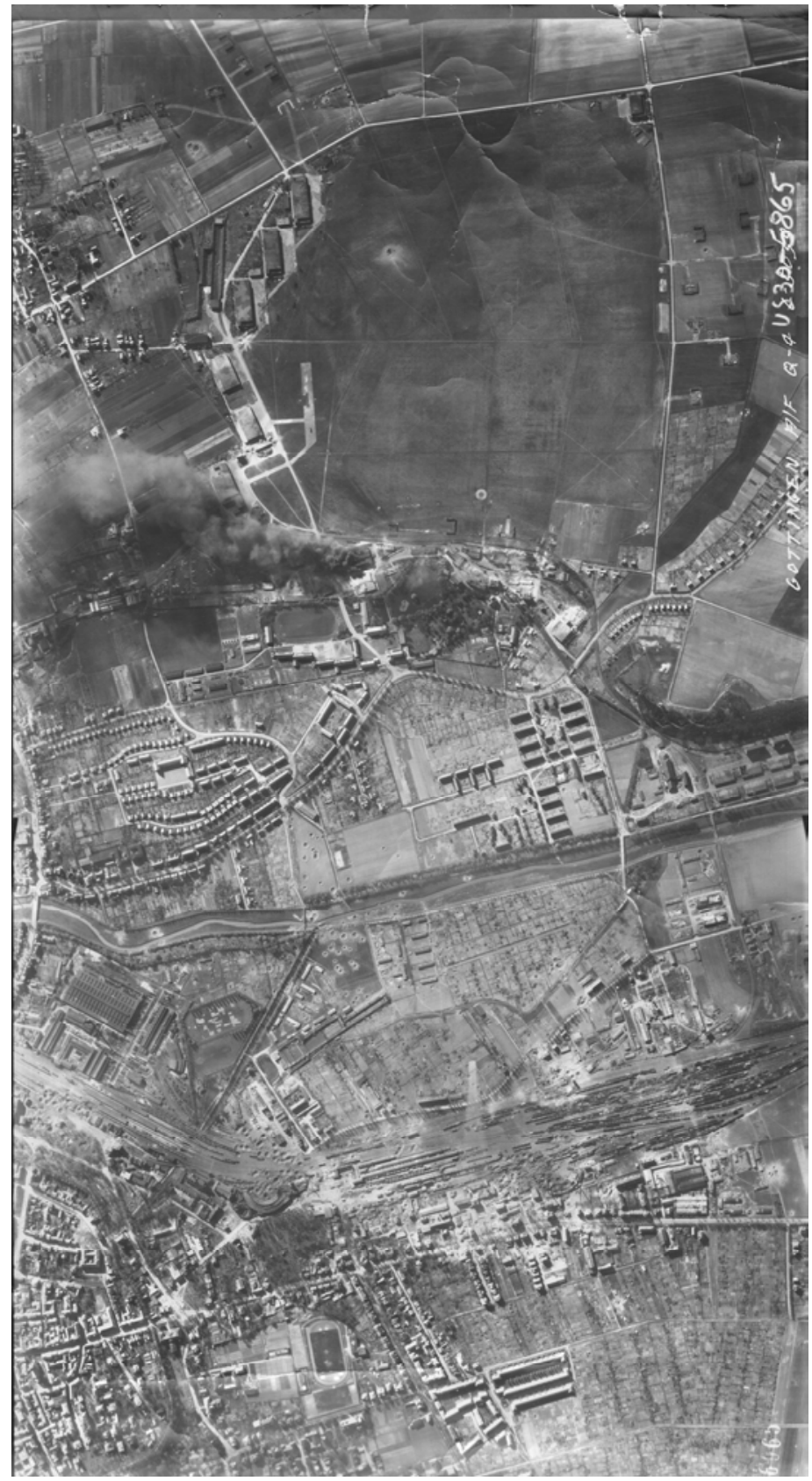

Q 2: U.S. Air Force. Luftaufnahmen der Stadt Göttingen (08.04.1945), Stadtmuseum Göttingen, Fotoarchiv, Original: National Archives, Washington, DC. 


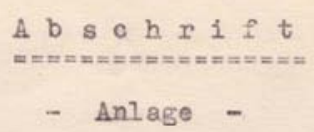

5.) Entwurf: Prof. Baumgarten, Prof. Rein, Dr. Beyer Nacht 7/8. April 1945

$\underline{A b}$ b h r ift

An die Bevölkerung Göttingens !

Die deutschen Truppem haben befehlsmässig das Stadtgebiet verlassen, mit Ihnen die örtilche Parteiführung.

Göttingen ist Iazarettgtadt mit Tausenden von Schwerverwundeten. Ich übergebe daher Göttingen dem Feind als of $f$ e $n$ e Stadt.

Ich fordere die Bevölkerung aus, dem Feind mit Ruhe und Würde zu begegnen. Unter den gegenwärtigen Umständen gilt für unsere Stadt das Wort des Führers, dass nunmehr dafür zu sorgen ist, "dass das Volk nicht heroisch untergeht, sondern praktisch erhalten wird....

Ein Nichtbegehen dieses Weges muss als pelichtvergessenes Verbrechen bezeichnet werden."

Als alter Nationalsozialist fordere ich insbesondere die Jugend auf sich nicht zu unbesonnenen Taten hinreissen zu lassen, die dem Feind. geringen, dem deutschen Volke aber schweren Schaden verursachen würden. Das Verhalten des Feindes bleibt abzuwarten. Sollte er wirklich eine gewaltsame Verschleppung unserer Jugend oder Âhniches unternehmen, so zwänge er und allerdings zu einem berechtigten Verzweiflungskampe.

Wir glauben aber an den Fortbestand unseres Volkes. Der Weg heisst: Arbeit, Ordnung, Gerechtigkeit und Gemeinschaft.

$$
\begin{aligned}
& \text { gez. Gnade } \\
& \text { Oberbïrgermeister }
\end{aligned}
$$

für die Richtigkeit der Abschrift

gez. E. Baumigarten

Ebnet, den 2. 11.49

Q 3: $\quad$ Anlage zum Bericht über die Vorgänge bei der Übergabe der Stadt am 08.04.1945 von Albert Gnade (etwa 1956), Stadtarchiv Göttingen, Kl. E. 80, I, 11. 
Donnerstag, 12.April:

Die Parteigenossen müssen sich auf dem Rathaus melden. Fritz geht hin. Und ich gehe mit Frau Seedorf hin. Am Nachmittag kommt Frau Blume: ihr Mann ist auch verhaftet.- Aus dem Keller räumen wir Sachen nach oben. Und in dieser Woche werden im Garten Kartoffeln gelegt.-

Q 4: Tagebuch-Notizen von Ilse Neumann-Graul (Notizen von 1945, Aufzeichnung auf Grundlage der Notizen 1980), Stadtarchiv Göttingen, Kl. E. Nr. 114, I, 1.

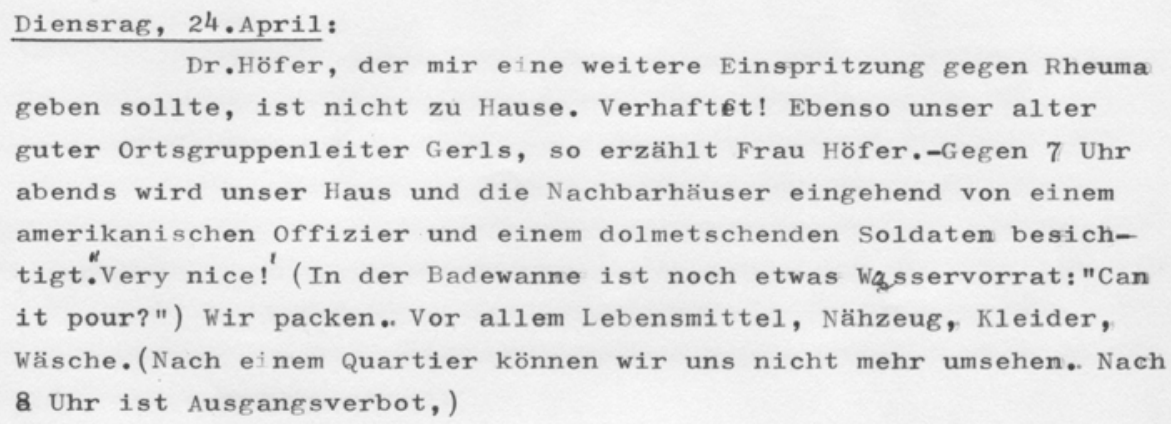

Q 5: Tagebuch-Notizen von Ilse Neumann-Graul (Notizen von 1945, Aufzeichnung auf Grundlage der Notizen 1980), Stadtarchiv Göttingen, Kl. E. Nr. 114, I, 1. 


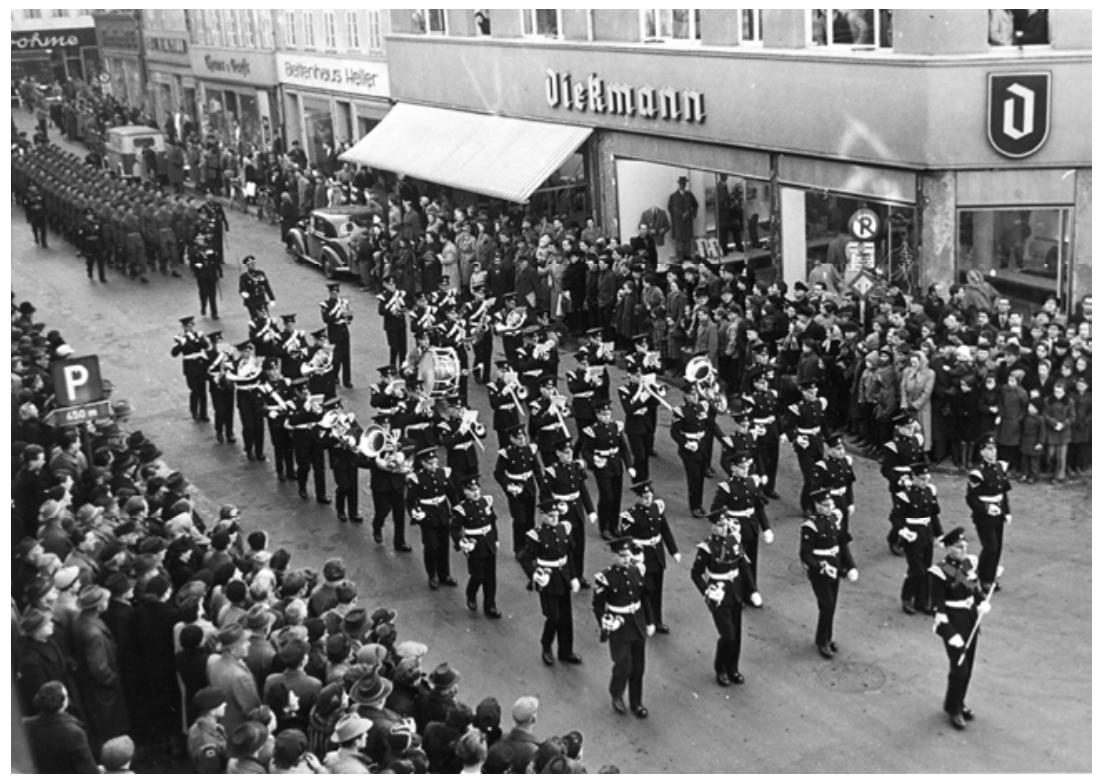

Q 6: Einmarsch der englischen Armee in Göttingen (1945), Stadtmuseum Göttingen, Fotoarchiv.

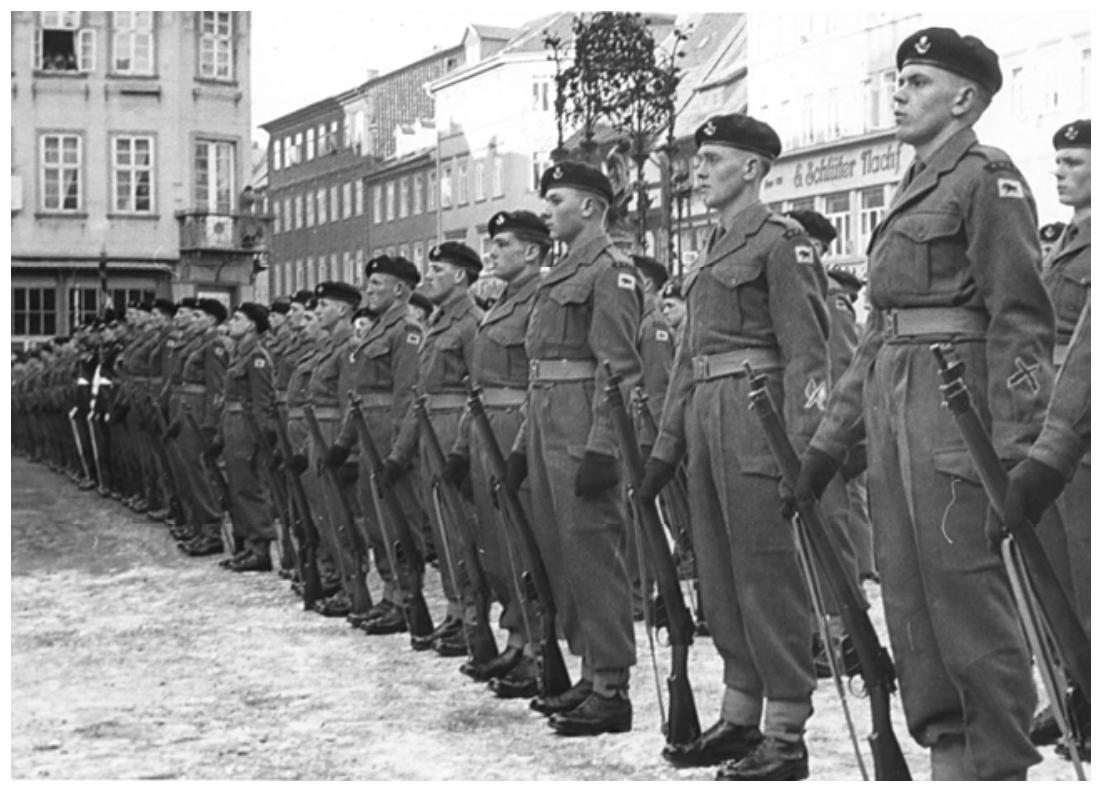

Q 7: Englische Soldaten vor dem Gänseliesl (1945), Stadtmuseum Göttingen, Fotoarchiv. 


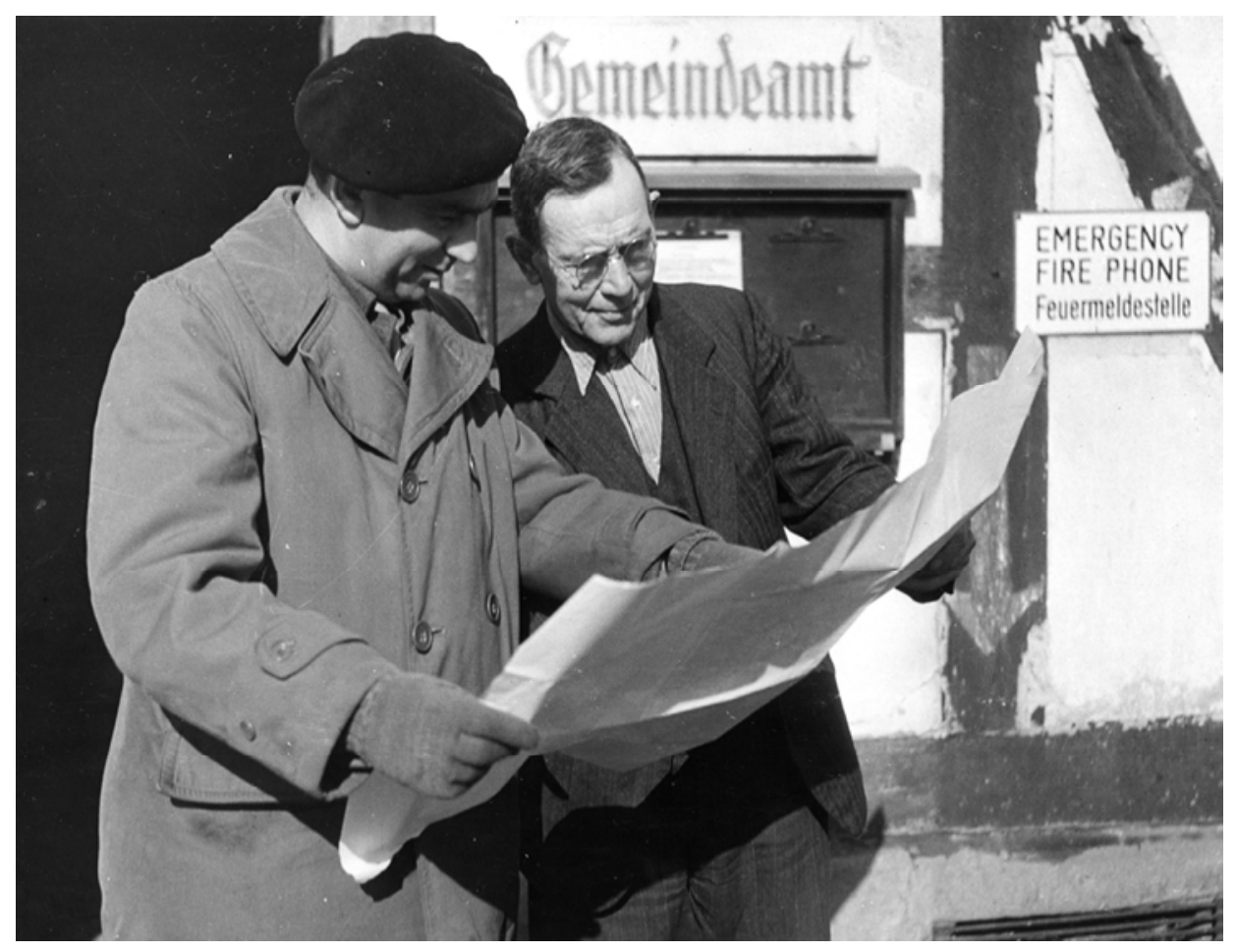

Q 8: Englischer Soldat mit Zivilist (1945), Stadtmuseum Göttingen, Fotoarchiv, Original: Imperial War Museum, London, UK. 


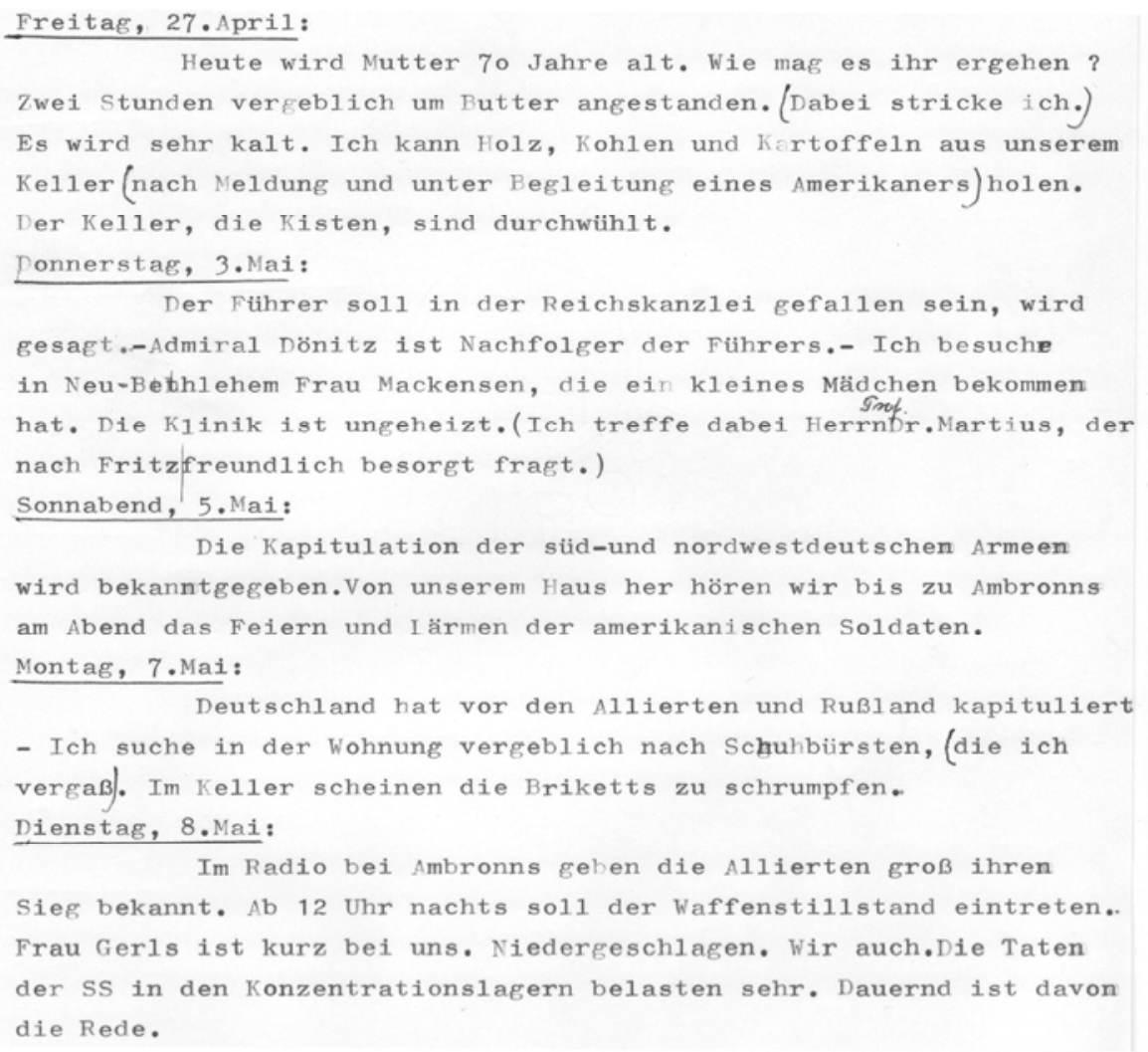

Q 9: Tagebuch-Notizen von Ilse Neumann-Graul (Notizen von 1945, Aufzeichnung auf Grundlage der Notizen 1980), Stadtarchiv Göttingen, Kl. E. Nr. 114, I, 1. 
4.Mai 1945

Am Abend des 1.Mai wurde vom Großdeutschen Rundfunk nach vorheriger seelischer Vorbereitung durch ernste Musik von Bruckner mitgeteilt, daß Hitler im Kampf gegen den Bolschewismus ausharrend bis zuletzt gefallen sei. Am folgenden Morgen $s a B$ und stand ich in einer langen Reihe von Menschen, die Fleisch kaufen wollten, und hörte die Gespräche an, die rund um mich geführt wurden. Hitlers Name fiel kein einziges Mal! Dieses Volk, das ihm vor wenigen Jahren noch uberschwenglich zujubelte, vor Monaten noch sein ganzes Vertrauen in ihn setzte, vor Wochen noch geneigt war, seinen Parolen Glauben zu schenken, heute noch teilweise ihn selbst für eine integre Persönlichkeit hält - dieses Volk nimmt kaum Notiz von seinem Ende! Schmählicher kann ein großer Gaukler und Rattenfänger kaum enden! Man vergißt ihn von heute auf morgen! Niemand betrauert ihn! Sic transit gloria mundi! Betrachtet man dieses Ende, dann gewinnt man den Eindruck, als sei die Liebe des Volkes nur Schein, nur Blendwerk gewesen, als sei hier in der Tat alles auf Sand gebaut gewesen. Wie die Träume zerrinnen, die ein Opiumschläfer in der Höhle des Lasters träumt, so zerrinnt das ganze Dritte Reich wie ein wïster, rauchiger Traum! Es sinkt zurück in das Nichts!

Q 10: Tagebucheintrag von Hannah Vogt (08.04.1945), Stadtarchiv Göttingen, Kl. E. 149 Nr. 50, S. 14. 
Das hat etwas Erschiitterndes: es ist grauenvoll, wie schnell die Menschen ihre angebeteten Götzen zum Haus hinauswerfen, wenn sie ihnen kein Glück mehr bringen! Denn dies ist es: sie tun es deshalb - nicht aber, weil sie erkannt hätten, daß sie Götzen angebetet haben!

\section{Mai 1945}

Man kann jetzt sehr amüsante Beobachtungen über den Militarismus der anderen machen. Es ist erfrischend zu sehen, daß es auch ohne Paraden, ohne Stechschritt, ohne Strammstehen, ohne Hände-an-die-Hosennaht, ohne beständiges Grüßen geht. Die Amerikaner bewegen sich in ihren Uniformen wie Sportler: lässig, bequem, ungeniert. Diese Uniformen selbst erinnern mehr an die Ausrüstung von Skisportlern, als an unsere noch vom alten Preußenstil her geprägten Röcke. Ungemein praktisch ist alles! Die Karabiner, mit denen die Boys den ganzen Tag herumlaufen, sehen kleiner und leichter aus als unser Infanteriegewehr. Die Stahlhelme, die ebenfalls den ganzen Tag getragen werden, sind - wie Rost mir erzählte - großenteils nicht aus Stahl, sondern eine Art von Tropenhelm aus Stoff und Papiermaché. Die bequem und weich aussehenden hellen Lederstiefel sind mit dicken Gummisohlen versehen. So gibt es kein dröhnendes Marschieren der Infanterie, kein lautes Klappern der Posten. Nur die Motoren der zahlreichen Lastautos und kleinen Kuibelwagen brausen knatternd durch die Straßen und oft auch durch den Hainberg. Man hat nicht den Eindruck, als seien dies immer Fahrten im Auftrag! Benzinmangel gibt es hier nicht! Die Boys kutschieren

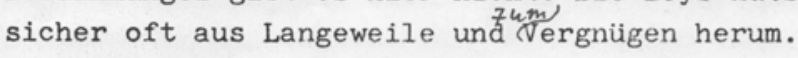

Das Postenstehen ist ein Kapitel für sich. Man könnte auch "Postensitzen" sagen. Jede unnütze und nur dekorative

Q 10: Tagebucheintrag von Hannah Vogt (08.04.1945), S. 15. 


\section{August 1945}

An Japan ist ein Ultimatum gestellt worden, und der Tenno hat es zurückgewiesen. Damit dürfte ein Massen-Selbstmord des japanischen Volkes besiegelt sein! Man weiß ja, wie leicht diese Menschen des Ostens das Leben von sich werfen und wie überreizt ihr Ehrgefül, besonders ihr nationales, ist. Man wird sich dort jedenfalls kaum mit Prozessen gegen Kriegsverbrecher und Generalstäbler aufhalten müssen! Heute wurde bekanntgegeben, daß es in Amerika gelungen ist, die Atomzertrümmerung der Kriegstechnik zunutze zu machen und kleine Bomben von ganz ungeheurer wirkung zu konstruieren. Die Zahlen gehen ins Phantastische und über alles

Begreifen. Diese Teufelsdinger hat man heute auf Japan geworfen. Welche Perspektiven für die künftige Kriegstechnik! Wann wird der Mensch den Erdball in den Äther sprengen?

In einem Gespräch mit dem mir inzwischen sehr liebgewordenen Hermann Stresau* kamen wir auf die besonders glückliche Lage Göttingens zu sprechen. Dies Inselhafte unserer Existenz, dieser Wohlstand, diese Unversehrtheit sie verpflichten! Solche Städte haben jetzt ungeheure Aufgaben! Sie müssen Deutschlands künftiges Weimar und Jena werden! Freilich, das läßt sich nicht machen gottlob läßt es sich nicht machen! Aber wir dürfen wohl einmal daran denken, daß auch wir aufgefordert sind, daß jeder sich regen und helfen muß!

Q 11: Tagebucheintrag von Hannah Vogt (08.04.1945), Stadtarchiv Göttingen, Kl. E. 149 Nr. 50, S. 20 und 21. 


\title{
„Die Straße des Verderbens“ - Schwarzmarkt und Göttinger Nachkriegskriminalität
}

\author{
Karolin Oppermann
}

\section{Einleitung}

Im August 1947 erschütterte ein Skandal die Stadt Göttingen: Die Inhaberin der hiesigen Rossschlachterei, eine gewisse Frau D., wurde angeklagt, ein Schwein, das zuvor mit Brotgetreide gemästet worden war, schwarz geschlachtet zu haben und durch Tauschhandel für das Fleisch Koks, Teppiche und Schnaps erhalten zu haben. Dem nicht genug soll sie beim Wiegen der ihr zum Schlachten anvertrauten Pferde betrogen und das nicht erfasste Fleisch zu ihren Gunsten verwendet haben (Q1). Ihre kriminelle Energie wurde dabei noch um einiges höher eingeschätzt, ließe doch „allein die Menge der vorgefundenen Mangelware und bezugsbeschränkten Waren darauf schließen, daß Fran D. mit diesen Waren einen Tauschbandel gegen Fleisch-oder Fleischwaren getrieben" habe. Es bestünde also dringender Verdacht, ,daß weitaus mehr strafbare Handlungen von Frau D. begangen wurden" (Q2). Die Rossschlachterei wurde zunächst geschlossen und erst, nachdem sich die Wogen geglättet hatten, im Dezember des Jahres 1947 wieder eröffnet - die Stadt hatte bis dahin festgestellt, dass die ,erhobenen Beschuldigungen, namentlich die übertriebenen Pressebekanntmachungen ", unbegründet gewesen seien.

\footnotetext{
1 Schreiben Dr. jur. Günther Gronell an Oberstadtdirektor in Angelegenheit - Frau D., 15.12.1947, Stadtarchiv Göttingen, C 34 Nr. 46, Bl. 34.
} 
Die hier angesprochenen Phänomene Schwarzschlachtung, Tauschhandel, Schwarzmarkt und Kriminalität der unmittelbaren Nachkriegszeit sollen im Mittelpunkt der folgenden Ausführungen stehen. Der Fokus liegt dabei auf den alltäglichen Praktiken des Göttinger Schwarzmarktes, die durch Zeitungsartikel und Gerichtsakten rekonstruiert werden sollen.

\section{Schwarzmarkt - eine Annäherung}

In einem von dem Hamburger Rechtanwalt Dr. Karl Kromer im Jahre 1947 herausgegebenen Ratgeber werden in 500 Fragen und Antworten die dringendsten Rechtsprobleme zum Thema Schwarzmarkt mit Beispielen erläutert. Kromer nimmt in seinem Ratgeber an, dass es im Nachkriegsdeutschland keine lebende Person gebe, die ,sich nicht einmal vom Schwarzmarkt versorgt bätte", und die von ihm skizzierten Fragen folglich jeden angingen. ${ }^{2}$

Unter Schwarzmarkt wird ein Handel verstanden, ${ }^{3}$ der an den gelten Bewirtschaftungs-, Versorgung-, und Preisbestimmungen vorbei abläuft. Das heißt mit Bezug auf die Nachkriegszeit, dass hier Waren erworben wurden, die legal nur durch Lebensmittelkarten oder Bezugsscheine ${ }^{4} \mathrm{zu}$ erhalten waren, „abgezweigt“ oder gestohlen wurden. Sie wurden stets zu höheren Preisen, gegen andere Währungen oder auch Waren verkauft bzw. getauscht als dies nach geltendem Recht gestattet war. Eine wachsende Menge an Gütern wurde dabei der regulären Verteilung entzogen.

In der geschichtswissenschaftlichen Forschung stand das Thema „Schwarzmarkt" lange Zeit nicht im Mittelpunkt des Interesses, wurde aber in jüngerer Zeit vermehrt thematisiert. Von der Vorstellung des Schwarzmarktes als „letzte Bastion der Freiheit" 5 wird dabei zusehends abgesehen und der Schwarzmarkt stattdessen in den zeitgenössischen Kriminalitätsdiskurs eingeordnet sowie mit kulturwissenschaftlichen Fragestellungen verbunden. ${ }^{6}$ Alltagsgeschichtliche Fragestellungen nach Akteuren und Praktiken sind hierbei von besonderer Relevanz.

\footnotetext{
2 Karl Kromer (Hg.), Schwarzmarkt, Tausch- und Schleichhandel in Frage und Antwort mit 500 praktischen Beispielen, Schloss Bleckede an der Elbe 1947, S. 3.

${ }^{3}$ Siehe für eine knappe Definition: Werner Bührer, Schwarzer Markt, in: Wolfgang Benz, u.a. (Hg.), Enzyklopädie des Nationalsozialismus, Stuttgart 1997, S. 72.

4 Siehe dazu den Beitrag von Thimo Stiehl zur Versorgungslage in diesem Band.

5 Willi A. Boelcke, Der Schwarzmarkt 1945-1945-1948. Vom Überleben nach dem Krieg, Braunschweig 1986, S. 6.

${ }^{6}$ Siehe Stefan Mörchen, „Echte Kriminelle“ und ,zeitbedingte Rechtsbrecher“". Schwarzer Markt und Konstruktionen des Kriminellen in der Nachkriegszeit, in: Werkstatt Geschichte 42 (2006), S. 57-76; Malte Zierenberg, „Stadt der Schieber“. Der Berliner Schwarzmarkt 1939-1950 (Kritische Studien zur Geschichtswissenschaft, 179), Göttingen 2008, Ders., Tauschen und Vertrauen. Zur Kulturgeschichte des Schwarzhandels im Berlin der 1940er Jahre, in: Helmut Berghoff; Jochen Vogel (Hg.), Wirtschaftsgeschichte als Kulturgeschichte. Dimensionen eines Perspektivwechsels, Frankfurt a. M. 2004, S. 169-194, Michael Wildt, Der Traum vom Sattwerden. Hunger und Protest, Schwarzmarkt und Selbsthilfe in Hamburg 1945-1948, Hamburg 1986.
} 


\section{Schwarzmarkt vor 1945}

Das Phänomen „Schwarzmarkt“ war keine „Erfindung““ der Nachkriegszeit, sondern bereits im 1. Weltkrieg, in der Zwischenkriegsperiode und auch während des Zweiten Weltkrieges zur Normalität geworden, - dies zeigen zahlreiche Gesetze, Propaganda und Gerichtsverfahren. ${ }^{7}$ Diebstahl, unrechtmäßiger Bezug von Lebensmittelmarken oder gar deren Fälschung gehörten bereits seit Kriegsbeginn zu den illegalen Unternehmungen der Untergrundwirtschaft, die im Laufe des Krieges noch weiter zunahmen, wenn auch versucht wurde, Schwarzhandel durch besonders harte Urteile zu unterbinden. ${ }^{8}$ Unterschieden wurde von den zeitgenössischen Strafbestimmungen zwischen Tausch-, Schleich- und Schwarzhandel. ${ }^{9}$

Der Handel auf dem Schwarzmarkt lief während des Krieges, wie der Historiker Malte Zierenberg jüngst gezeigt hat, vornehmlich an nicht-öffentlichen Plätzen im Rahmen von Tauschnetzwerken ab, deren Mitglieder sich z.B. als Arbeitskollegen kannten. Der Tausch vollzog sich innerhalb sozialer Beziehungsgefüge, die zunächst unabhängig vom Tauschen aufgebaut worden waren und in denen ein hohes Maß an Vertrauen bestand. ${ }^{10}$ Tauschnetzwerke waren so zum einen durch hohen sozialen Druck und zum anderen durch räumliche Nähe gekennzeichnet. ${ }^{11}$ Durchgeführt wurde der Tauschakt häufig in halböffentlichen Räumen, wie z.B. Gaststätten, und war auf diese Weise in das alltägliche Leben mit einbezogen. ${ }^{12}$

\section{Nihil ex nihilo fit - Der Schwarzmarkt in der Nachkriegszeit}

In der Nachkriegszeit hatte der Schwarzmarkt im Unterschied dazu zumeist auf öffentlichen und bekannten Plätzen, die gut zu erreichen waren und an denen auch früher schon Konsum jeglicher Art stattgefunden hatte, ${ }^{13}$ seinen Platz, sodass sich der Handel zwischen unbekannten Personen abspielte und sich der Schwarzmarkt als quasi öffentliche Institution etablierte. In Göttingen war der Schwarzmarkt auf dem Gelände des Hauptbahnhofes, welches in der Mitte der Stadt lag und auch vom ländlichen Umfeld aus gut zu erreichen war, lokalisiert. Da Göttingen im

\footnotetext{
7 Vgl. Boelcke, Der Schwarzmarkt, S. 11. Zwischen 1939 und 1943 wurden im Deutschen Reich insgesamt 59253 Verstöße gegen die Kriegswirtschaftsverordnung vom 4.9.1939 und der Verbrauchsregelungs-Strafverordnung vom 6.9.1940 geahndet. Ab 1941 nahm die Zahl der Delikte sprunghaft zu. Vgl. ebd., S. 16.

8 Vgl. ebd., S. 14-15.

${ }_{9}$ Vgl. ebd., S. 12.

$10 \mathrm{Vgl}$. Zierenberg, Stadt der Schieber, S. 91.

11 Vgl. ebd., S. 127.

12 Vgl. ebd., S. 133.

13 Vgl., ebd., S. 203. Hauptbahnhöfe oder in größeren Städten auch S-Bahnstationen waren häufige Orte des Schwarzmarktes, da sie als natürliche Durchgangsräume konzipiert nur einen engen Zeithorizont zwischen Ankunft und Abfahrt zuließen, als Treff- oder Abholungspunkt sui generis standen und bereits seit den 1920er Jahren als etablierte Konsumräume mit kleinen Kiosken fungierten. Vgl. Zierenberg, Stadt der Schieber, S. 208-209.
} 
Grenzgebiet der britischen, US-amerikanischen und sowjetischen Besatzungszone lag, war das Einzugsgebiet des Schwarzmarktes hier besonders groß, wenn auch mit den bereits gut untersuchten Räumen anderer Städte allein schon wegen der geringeren Größe nicht zu vergleichen. ${ }^{14}$

Die alltägliche Praxis des Handels auf dem Schwarzmarkt setzte sich aus verschiedenen Elementen zusammen. Die Kontaktaufnahme erfolgte in der Regel entweder durch das mehr oder weniger laute Ausrufen bzw. Aufzählen der Ware durch den Anbieter oder durch ein stummes Präsentieren der Ware, die bei Gefahr schnell in die Jacken- oder Manteltasche verschwinden konnte. Danach erfolgte eine eingehende Prüfung des Tauschpartners, die sich vermutlich zumeist an ÄuBerlichkeiten wie der Kleidung, der Hygiene oder anderer körperlicher Merkmale (z. B. Alter und Gesundheit) orientierte, um dadurch Rückschlüsse über die Qualität der Ware ziehen zu können. ${ }^{15}$ Zierenberg betont die Bedeutung von gegenseitigem Vertrauen und das Aussenden von Zeichen der Integrität. ${ }^{16}$ Verhielt man sich zu sicher oder trat zu vertraut mit jeglichen Gepflogenheiten des Schwarzmarktes auf, konnte man sich als Schieber identifiziert sehen und so vom Gegenüber mit Misstrauen und der Unterstellung von Täuschungsabsichten bestraft werden (Q3). ${ }^{17}$ Nach einer Prüfung des Gegenübers erfolgte die Warenbegutachtung. Dabei inspizierte der Kunde die Ware, nachdem sie ihm vom Anbieter ausgehändigt worden war, drehte und wendete sie, durfte sogar an ihr riechen. Bevor die Preisverhandlungen aber in ihre entscheidende Phase traten, wurde die Ware dem Anbietenden zurückgegeben, um dann, nach erfolgreichem Handel, symbolisch übergeben zu werden. ${ }^{18}$ Der ganze Tauschakt erfolgte möglichst unauffällig, so dass zunächst in Gruppen verhandelt, sich dann aber zum Übergeben der Ware zurückgezogen wurde. Dort ,tauschten sie hastig Ware und Gegenleistung aus und stehen Minuten später schon wieder bei anderen Gruppen" (Q3). Der so beschriebene Tauschakt stellte gleichzeitig die Anerkennung einer bestimmen Art des Tauschens dar, deren Regeln bei Entstehung des Marktes durch komplexe Aushandlungsprozesse erarbeitet worden waren. Der Schwarzmarkt erschien so als Raum, an dem sich die mehr und mehr den Alltag bestimmende Tauschkultur am deutlichsten zeigte. ${ }^{19}$ Gleichzeitig war der Schwarzmarkt ein Ort der privaten Initiative. Nur wer selbst handeln und

\footnotetext{
14 Siehe zum Berliner Schwarzmarkt: Zierenberg, Stadt der Schieber und Paul Steege, Black Market, Cold War. Everyday Life in Berlin, 1946-1949, New York 2007; zu Hamburg: Michael Wildt, Der Traum vom Sattwerden; zu Bremen: die noch entstehende Dissertation von Stefan Mörchen, einige Ansätze bereits sind veröffentlicht in: Stefan Mörchen, „Echte Kriminelle“ und „,zeitbedingte Rechtsbrecher" und ders., Schwarzmarkt- und Eigentumsdelikte in den bremischen Häfen der Nachkriegszeit, in: Arbeiterbewegung und Sozialgeschichte. Zeitschrift für die Regionalgeschichte Bremens im 19. und 20. Jahrhundert 13/14 (2004), S. 5-21 sowie für Leipzig, Köln und München die vergleichend angelegte Fallstudie von Rainer Gries, Die Rationen-Gesellschaft. Versorgungskampf und Vergleichsmentalität: Leipzig, München und Köln nach dem Kriege, Münster 1991.

$15 \mathrm{Vgl}$. Zierenberg, Stadt der Schieber, S. 226.

16 Vgl. Zierenberg, Tauschen und Vertrauen, S. 169-171.

${ }_{17} \mathrm{Vgl}$. Zierenberg, Stadt der Schieber, S. $227 \mathrm{f}$.

18 Vgl. ebd., S. 222.

${ }^{19}$ Vgl. Zierenberg, Tauschen und Vertrauen, S. 171-173.
} 
nicht auf das Handeln des Staates vertrauen wollte, trat auf dem Schwarzmarkt mit Erfolg auf. ${ }^{20}$

\section{Die Währung auf dem Schwarzen Markt}

Gespeist wurde der Schwarzmarkt durch verschiedene Warenströme. Als Währung galt auf allen Schwarzmärkten der Nachkriegszeit die Zigarette, die als international gültige Werteinheit letztlich sogar als genormt aufgefasst werden konnte. Begehrt waren v.a. amerikanische Zigaretten, die, obwohl sie pro Packung in Amerika nur 8 bis 10 Cent kosteten, auf dem Schwarzmarkt in Deutschland für bis zu 130 RM gehandelt wurden, sodass einem Dollar ca. 1200 bis 1500 RM entsprachen. ${ }^{21}$ Die flüchtige Konsistenz der Zigarette, die sich beim Rauchen im wahrsten Sinne des Wortes in Luft auflöste, markierte so gleichsam den Übergangscharakter der Währungen ,Lucky Strike“ oder ,Marlboro'.22 Rauchen erschien als Verbrennen von Geld, sodass hier Hierarchien entstanden, die in der Nachkriegszeit besondere Bedeutung gewannen: diejenigen, die rauchten, und diejenigen, die die Zigarettenstummel der Rauchenden auflasen, um so an ,Währung' zu gelangen.

Neben Zigaretten wurden auch andere Waren wie Fleisch, Brot und Benzin zu potentieller Währung (Q3). Dies wurde gesteigert, indem, geschuldet der allgemeinen Notlage, auch solche Güter, die man sich in normalen Zeiten gelegentlich noch hatte leisten können, zu Luxus wurden, die Menge der potentiellen Luxusgüter damit überproportional anstieg.

Neben Gütern, die der Tauschende legal besaß (dazu gehörten auch Karten für Tabak, die ein Nichtraucher zwar zugeteilt bekam, aber selbst nicht verbrauchte), wurde der Schwarzmarkt durch diverse illegale Warenströme gespeist. Besonders gestohlenen und gefälschten Karten kam hier eine immense Bedeutung zu (Q4, 5 und 6). ${ }^{23}$ Auch verschwanden vielfach Waren bei Händlern und Handwerkern, die dies ihrerseits als Verderb, (fingierten) Diebstahl oder schlichtweg als ,Differenz erklärten. ${ }^{24}$ Hinzu kamen Lebensmittel, die durch Hamsterfahrten ${ }^{25}$ erworben, aber in dringender benötigte Waren eingetauscht werden mussten sowie Waren, die durch Schwarzschlachtung oder Betrug, wie im Fall von Frau D., erworben worden waren und nun umgesetzt werden konnten.

\footnotetext{
${ }^{20}$ Vgl. Gries, Rationen-Gesellschaft, S. 309.

21 Vgl. Zierenberg, Stadt der Schieber, S. 280.

22 Vgl. ebd., S. 279-282.

23 Vgl. Gries, Rationen-Gesellschaft, S. 219.

24 Vgl. ebd., S. 217.

25 Hamsterfahrten oder der sogenannte ,Erzeuger-Verbraucher-Verkehr' stellten eine Möglichkeit dar, letzte Habgüter auf dem Land in Lebensmittel umzutauschen. In den Städten wurde er zur puren Notwendigkeit für die Versorgung. Siehe dazu: Der Beitrag von Thimo Stiehl in diesem Band.
} 
Die Tatsache, dass derjenige, der genügend Tauschmittel hatte, auf dem Schwarzmarkt alles bekommen konnte, bildete den Hintergrund für sämtliche Geschäfte.

\section{Schwarzmarkt als krimineller Raum}

Strafbar war das Handeln auf dem Schwarzmarkt für jeden. Unterschieden wurde zwischen den Straftaten des Verbrauchers, den Straftaten des Gewerbetreibenden und denen des Großschiebers. Grundlage der strafbaren Handlung war die Verbrauchsregelungsstrafverordnung (VRStVo), die bereits seit 1941 in Kraft war. Von Bedeutung für die Verbraucher war in diesem Zusammenhang der \2, Abs. 1, der die Bestrafung bei Schwarzmarktvergehen regelte. ${ }^{26}$ Ernährungs- und Wirtschaftsämter konnten zudem zusätzliche Regelungen erlassen. Bezugsbeschränkte Erzeugnisse waren alle Güter, die für den Verbraucher nicht frei zugängig waren wie Eier, Gartenerzeugnisse, Getreide, Kartoffeln, Milch und Fette, Saatgut, Süßwaren, Kakao, Tiere, Zucker, Stoffe, Seife, Kraftstoffe, Öl, Petroleum, Kohlen, Leder, Schreibmaschinen, Fahrräder, Tabakwaren usw. All diese Güter bekam man in der Nachkriegszeit nur durch das Vorweisen von Bezugsscheinen bzw. musste diese erst beantragen - oder sie illegal auf dem Schwarzmarkt erwerben. Wurde man dabei ertappt, drohten Geld- oder in schweren Fällen auch Gefängnisstrafen. Von letzteren wurde gesprochen, wenn die Tat im Zusammenhang mit anderen Straftaten, z.B. Diebstahl oder Hehlerei, begangen wurde oder es sich um eine Wiederholungstat handelte. Die Höchststrafen wurden in den jeweilige Zonen stets härter und ab 1947 wurden als besonders kriminell eingestufte Wiederholungstäter sogar mit zweijährigem Arbeitslager bestraft. ${ }^{27}$ Vielfach wurde auch von Institutionen wie der Presse eine härtere Bestrafung gefordert (Q7). Bei einem milden Fall, z. B. bei besonderer Not, war es möglich, dass die zuständige Behörde nur eine Verwarnung (allerdings inkl. Bearbeitungsgebühr) aussprach (Q7). Abgeurteilt wurden die ,Schwarzmarktverbrecher‘ häufig durch ein Schnellgericht, sofern nicht eine genauere Untersuchung in einer Hauptverhandlung erforderlich war. Wichtig zu betonen ist, dass Handel, Tausch oder Verkauf von Gütern, die man rechtmäBig besaß, also z. B. mit seinen Marken oder durch ein Geschenk erhalten hatte, nicht strafbar war, es sei denn, man verlangte dabei einen höheren Preis als üblich oder tauschte sie gegen Waren ein, die der Tauschpartner nicht rechtmäßig erworben hatte. Unwissenheit schützte auch hier vor Strafe nicht.

Stefan Mörchen hat aufgezeigt, dass Kriminalität - und damit auch Schwarzmarktkriminalität - in der Nachkriegsgesellschaft als gesamtgesellschaftliches Phä-

26 VRStVo \2 (1) Mit Geldstrafe bis zu 150 RM oder mit Haft wird bestraft, wer, ohne in Ausübung eines Gewerbes oder Berufes zu handeln, 1. Bezugsbeschränkte Erzeugnisse ohne Bezugsberechtigung bezieht, eine ihm nicht zustehende Bezugsberechtigung für sich ausnutzt oder die Verfügung über eine Bezugsberechtigung sich gegen Entgelt verschafft oder in der Absicht, sich zu bereichern, einem anderen überlässt.

27 Vgl. Gries, Rationen-Gesellschaft, S. 111 u. S. 220. 
nomen wahrgenommen und teilweise durch die Not entschuldigt wurde. So unterschied die Kriminalistik zwischen ,echten Verbrechern“ und „zeitbedingten Verbrechern“. ${ }^{28}$ Der Fokus der Polizei lag dabei auf der Verfolgung besonders krimineller Gruppen und Personen. Eine Kriminalisierung der einfachen Bevölkerung sollte so verhindert werden. ${ }^{29}$

Die Polizei versuchte zunächst mittels Großrazzien gegen die Schwarzhändler vorzugehen, um so den Handel zu unterbinden. Die Razzien in Göttingen liefen ähnlich zu denen in anderen Städten ab. Mit LKWs und den verfügbaren Kräften der Polizei wurde großräumig das Gebiet um den Schwarzmarkt abgesperrt und alle Personen untersucht. Da die Polizei schlecht ausgerüstet war und die Razzien wenig Erfolg zeigten, sodass sie vermutlich eher als symbolische und verbale Apelle verstanden werden müssen, veränderte die Polizei ihre Methoden, um nicht nur die im Stich gelassene Ware zu beschlagnahmen, sondern auch die eigentlichen Händler zu überführen (Q8). Nun traten die Beamten in Zivil auf und versuchten auf diese Weise die Händler in flagranti zu ertappen. Dass eine solche Vorgehensweise nötig war, zeigt, dass ein bürgerliches Eigentums- und Moralverständnis in den Zeiten der Not auf dem Schwarzmarkt abgelegt worden war. ${ }^{30}$ Eine bereits vorher angewandte Taktik der Göttinger Polizei war es, jugendliche Gruppen, sog. Acht-Groschen-Jungen, einzusetzen, um den Schwarzmarkt zu bekämpfen. In der Presse scheinen diese allerdings krimineller wahrgenommen worden zu sein als die eigentlichen Schwarzhändler. Letztere schienen zumindest entschuldbarer (Q9).

Die hohe Jugendkriminalität ${ }^{31}$ (Q8) ist ein Phänomen, das vermutlich durch die angesprochene Grenzlage Göttingens mit verursacht wurde. 1946 wurden 30\% aller Lebensmitteleinbrüche von Jugendlichen begangen, die bei einem Erwachsenen bereits einen schweren Fall und somit Gefängnis bedeutet hätten. Jugendliche wurden meistens sofort von Gerichten unter die Obhut von Pädagogen befohlen. Auch stieg die Zahl der Schutzaufsichtsmaßnahmen rapide an. ${ }^{32}$ Jugendliche wurden dabei ähnlich wie Displaced Persons, der Berufsverbrecher und die Figur des Großschiebers zu Feindbildern der Bekämpfung des Schwarzen Marktes stilisiert. ${ }^{33}$

\footnotetext{
28 Vgl. Mörchen, „Echte Kriminelle“, S. 60 u. 67.

${ }^{29}$ Vgl. Gries, Rationen-Gesellschaft, S. 308 und Mörchen, „Echte Kriminelle“, S. 61.

30 Die moralische Rechtfertigung für den lockereren Umgang mit dem Eigentum des anderen kam aus der Kirche. In seiner Silvesterpredigt des Jahres 1946/47 befreite Josef Kardinal Frings (18871978), Kölner Erzbischof und Vorsitzender der Fuldaer Bischofskonferenz, zumindest moralisch den Einzelnen von der Strafe, wenn er sich zum eigenen Überleben Lebensmittel organisierte oder Kohlen klaute. „Fringsen“ überbrückte so den Abgrund zwischen juristischem Unrecht und alltäglichen Unrechtsempfinden. Vgl. Gries, Rationen-Gesellschaft, S. 306-307.

31 Zum Themenkreis Jugend den Beitrag von Lisa Brill in diesem Band.

32 Wiebke Fesefeldt, Der Wiederbeginn des kulturellen Lebens in Göttingen. Die Stadt in den Jahren 1945 bis 1948 (Studien zur Geschichte der Stadt Göttingen, Bd. 3), Göttingen 1962, S. 95.

33 Vgl. Mörchen, „Echte Kriminelle“, S. 62-66. Zum Schieberdiskurs auch: Zierenberg, Tauschen und Vertrauen, S.184-187.
} 


\section{Vom Bezahlen, der Katze im Sack und anderen Methoden}

Ein weiteres Phänomen des Schwarzmarktes war das Risiko, das der Einzelne beim Handeln unabhängig von der polizeilichen Verfolgung einging. So gehörte das Panschen von Lebensmitteln und das Betrügen und ,Betrogenwerden' zum potentiellen Risiko des Handels, da es schließlich keine Beschwerde- oder Kontrollinstanzen gab. So z.B. wurden ganze Stangen Lucky Strike „präpariert“, indem die Originalverpackungen ihres Inhalts entledigt und die leeren Hülsen mit Sägemehl gefüllt wurden. ${ }^{34}$ Auch wurden Zucker (Q10) oder Milch gepanscht (Q11), indem Zucker, sogenannter Schlammzucker, mit Melasse, einem Nebenprodukt der Zuckerherstellung, vermischt wurde oder der örtliche Milchverteiler Vollmilch mit Magermilch verdünnte, sodass der Fettgehalt der Milch sank. In beiden Fällen kam es zur Anzeige und im Falle des gefälschten Zuckers sogar zu einer Gefängnisstrafe. Das so entstandene und wohl auch berechtigte Misstrauen gegen Waren und Personen wurde Teil des alltäglichen Erfahrungshaushalt, wodurch die oben beschriebene Prüfung der Ware zum wichtigsten Bestandteil des Tausches wurde, wenn auch ein Betrug trotz eingehender Prüfung nie ganz ausgeschlossen werden konnte. ${ }^{35}$ Um das Risiko des Betrugs zu vermindern, bildeten sich Klientele, sodass sich die Akteure, parallel zu Stammkunden, auch auf dem Schwarzmarkt gerne bei denselben, schon als vertrauenswürdig eingestuften Personen versorgten (Q3). ${ }^{36}$

Neben dem Schwarzen Markt als Ort des Erwerbens von Nahrungsmitteln und anderen Gütern existierte in Göttingen noch eine Innenstadt mit teilweise schon seit Jahrzehnten bestehenden Geschäften und Betrieben. Die zahlreichen Anzeigen wegen verschiedener Verstöße gegen gewerbepolizeiliche Anordnungen ${ }^{37}$ zeigen, dass auch in diese Betriebe der Tauschhandel und die Warenzurückhaltung Einzug genommen hatten. In Mode kamen v.a. sog. Kompensationsgeschäfte, bei denen die Ware nicht (nur) mit Geld, sondern auch mit anderen Waren bezahlt wurde, um den immensen Wertverfall der Reichsmark auszugleichen. Solche Praktiken widersprachen allerdings der damaligen Rechtslage, sodass Anzeigen häufig von Erfolg gekrönt waren (Q12).

\section{Schluss}

Der Schwarzmarkt in Göttingen weist wesentliche Parallelen zu den Schwarzmärkten in anderen Städten auf. Er war am Bahnhof lokalisiert und stellte so einen quasi-öffentlichen Raum dar, in dem der Handel wie auf einem tatsächlichen Markt zwischen einander unbekannten Personen ablief. Beim Handel selbst kam es dabei,

\footnotetext{
34 Vgl. Frank Grube/Gerhard Richter, Die Schwarzmarktzeit. Deutschland zwischen 1945 und 1948, Hamburg 1979, S. 76.

35 Vgl. Zierenberg, Stadt der Schieber, S. 277.

36 Vgl. Zierenberg, Tauschen und Vertrauen, S. 182.

${ }^{37}$ Stadtarchiv Göttingen, Pol. Dir. Fach 127 Nr. 1d, Bd. 1.
} 
v.a. mit dem Hintergrund der eigentlich illegalen Handlung, stets auf gegenseitiges Vertrauen an. Das Phänomen „Schwarzmarkt“ war dabei keine generelle Besonderheit der Zeit nach dem Zweiten Weltkrieg, sondern bestand, wenn auch mit anderen Praktiken, bereits vor dem Krieg.

Aufgrund seiner Notwendigkeit und Erfahrbarkeit wurde der Schwarzmarkt in der Nachkriegszeit in die Alltagspraxis integriert, womit die Kriminalität des Handels letztlich in den Hintergrund trat und entschuldbar wurde - trotz aller Gesetze und Strafen. Die Einführung der Währungsreform am 20. Juni 1948 und die damit verbundenen reich gefüllten Schaufenster stellten einen „,mentalitätsgeschichtlichen

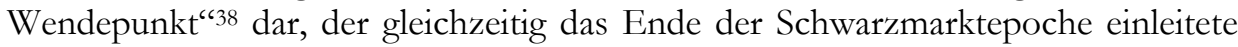
(Q13) und die Rückkehr zu einem bürgerlichen Eigentumsmodell erlaubte. Der Schwarzmarkt wurde nicht mehr gebraucht.

\section{Literatur zum Weiterlesen}

Willi A. Boelcke, Der Schwarzmarkt 1945-194. Vom Überleben nach dem Kriege, Braunschweig 1986.

Stefan Mörchen, „Echte Kriminelle“ und „zeitbedingte Rechtsbrecher“. Schwarzer Markt und Konstruktionen des Kriminellen in der Nachkriegszeit, in: Werkstatt Geschichte 42 (2006), S. 57-76.

Paul Steege, Black Market, Cold War. Everyday Life in Berlin, 1946-1949, New York 2007.

Michael Wildt, Der Traum vom Sattwerden. Hunger und Protest, Schwarzmarkt und Selbsthilfe in Hamburg 1945-1948, Hamburg 1986.

Malte Zierenberger, Stadt der Schieber. Der Berliner Schwarzmarkt 1939-1950 (Kritische Studien zur Geschichtswissenschaft, 179), Göttingen 2008.

Malte Zierenberger, Tauschen und Vertrauen. Zur Kulturgeschichte des Schwarzhandels im Berlin der 1940er Jahre, in: Helmut Berghoff/Jochen Vogel (Hg.), Wirtschaftsgeschichte als Kulturgeschichte. Dimensionen eines Perspektivwechsels, Frankfurt a. M. 2004, S. 169-194.

\footnotetext{
38 Vgl. Michael Wildt, Am Beginn der Konsumgesellschaft. Mangelerfahrung, Lebenshaltung, Wohlstandhoffnung in Westdeutschland in den fünfziger Jahren, Hamburg ${ }^{2} 1995$, S. 35.
} 


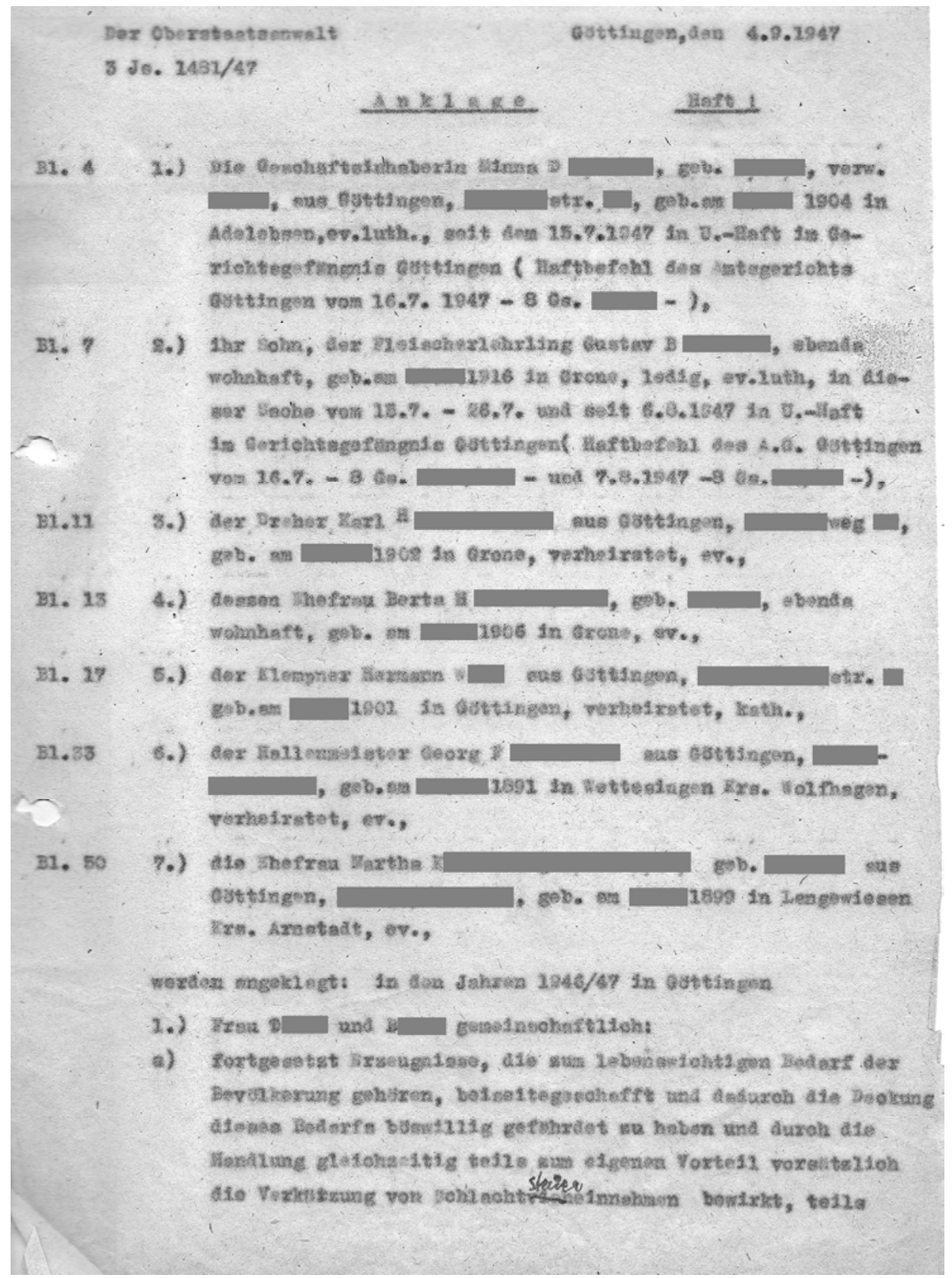

Q1: Anklageschrift in der Sache Frau D. (Durchschlag), C 34, Nr. 46, Bl. 22. 


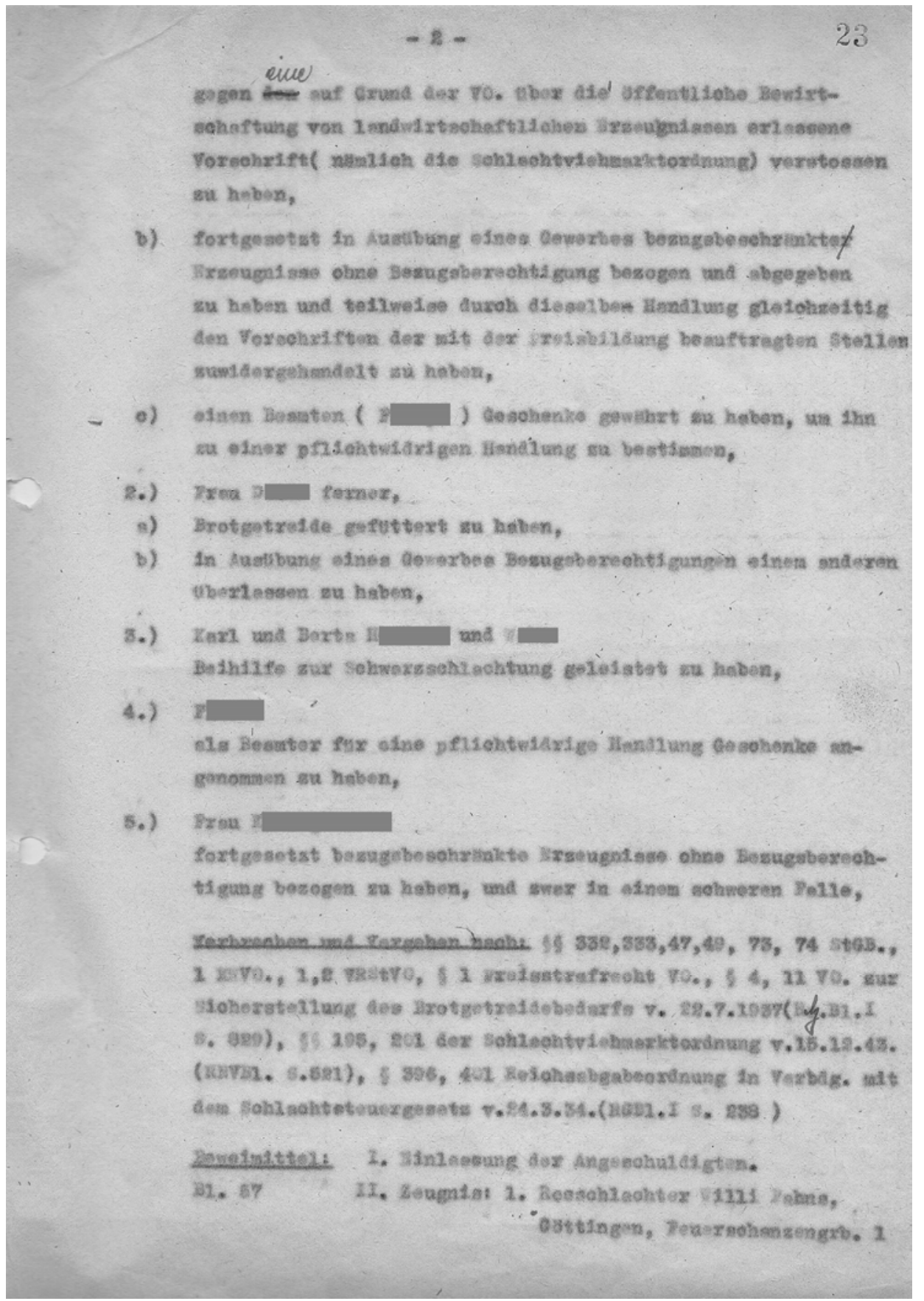

Q1: Anklageschrift in der Sache Frau D., Bl. 23. 


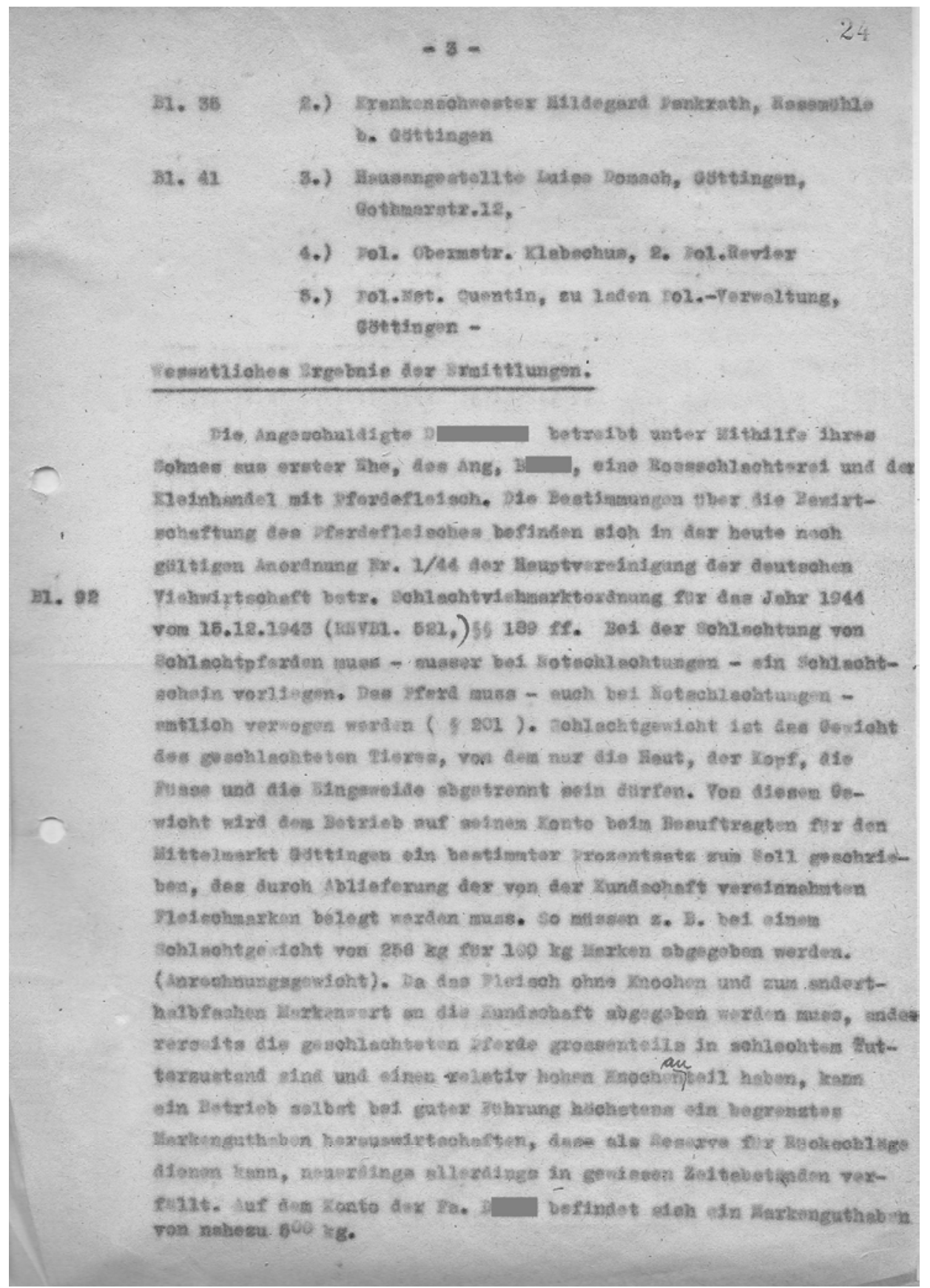

Q1: Anklageschrift in der Sache Frau D., Bl. 24. 


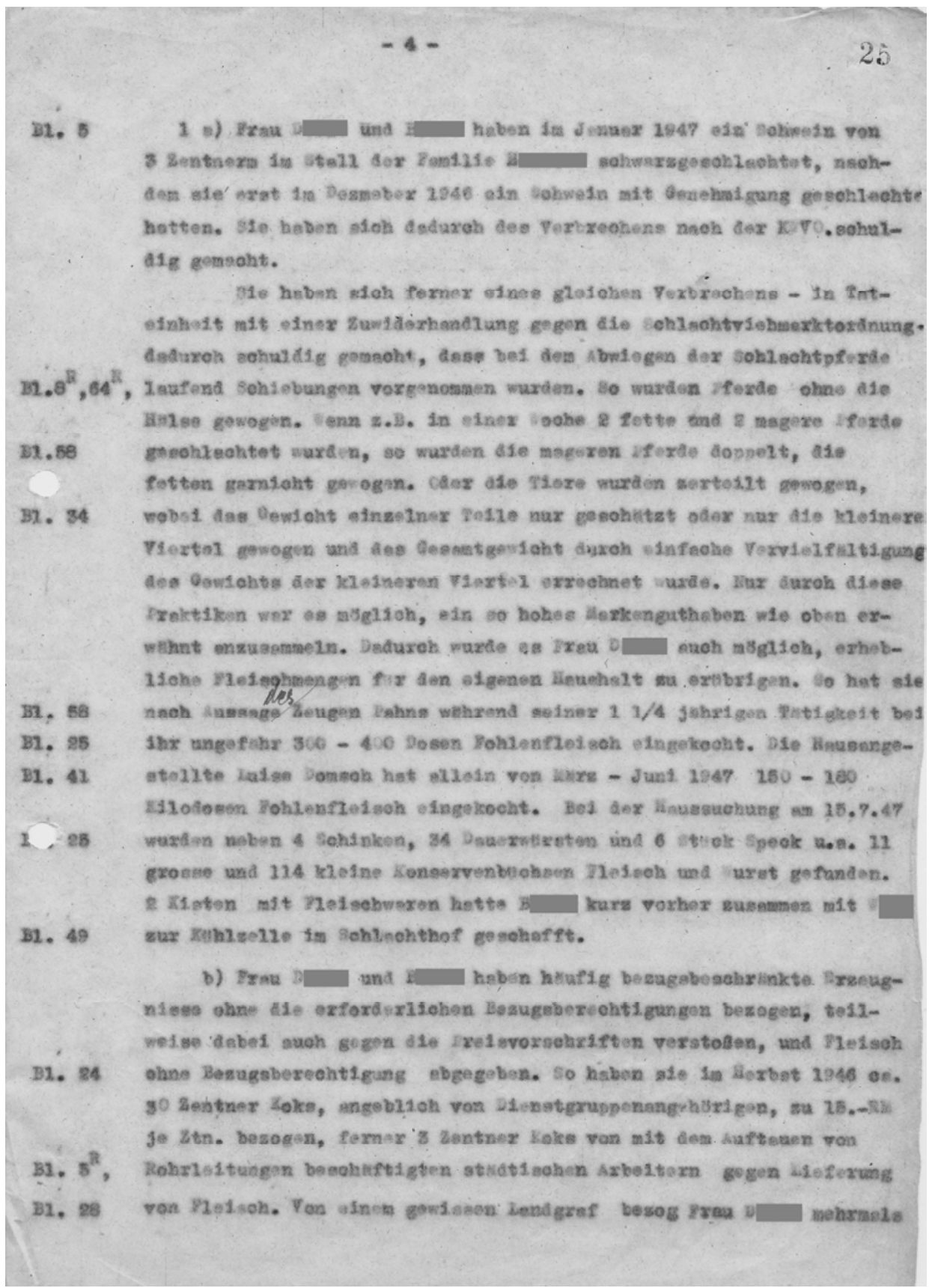

Q1: Anklageschrift in der Sache Frau D., Bl. 25. 


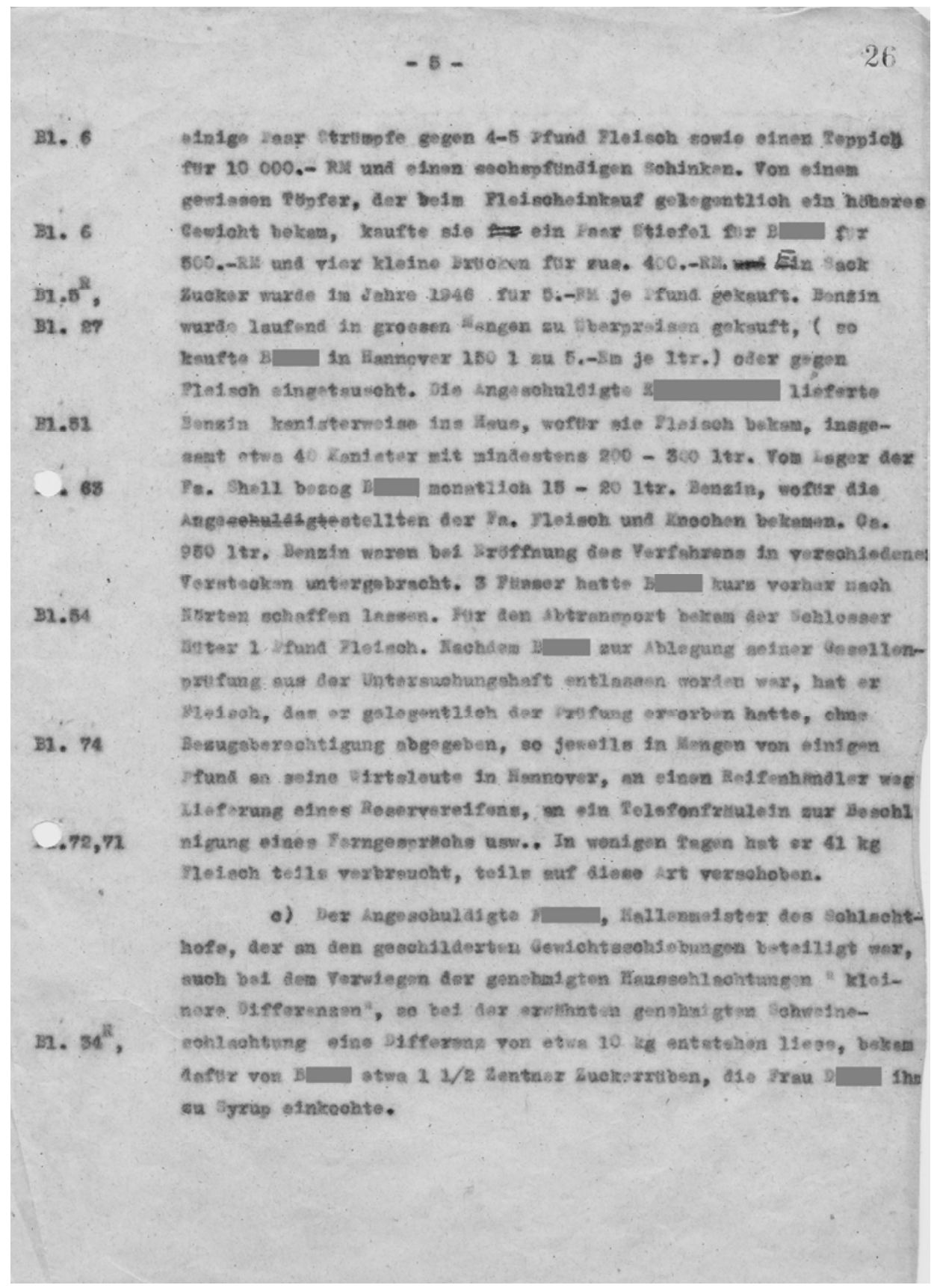

Q1: Anklageschrift in der Sache Frau D., Bl. 26. 


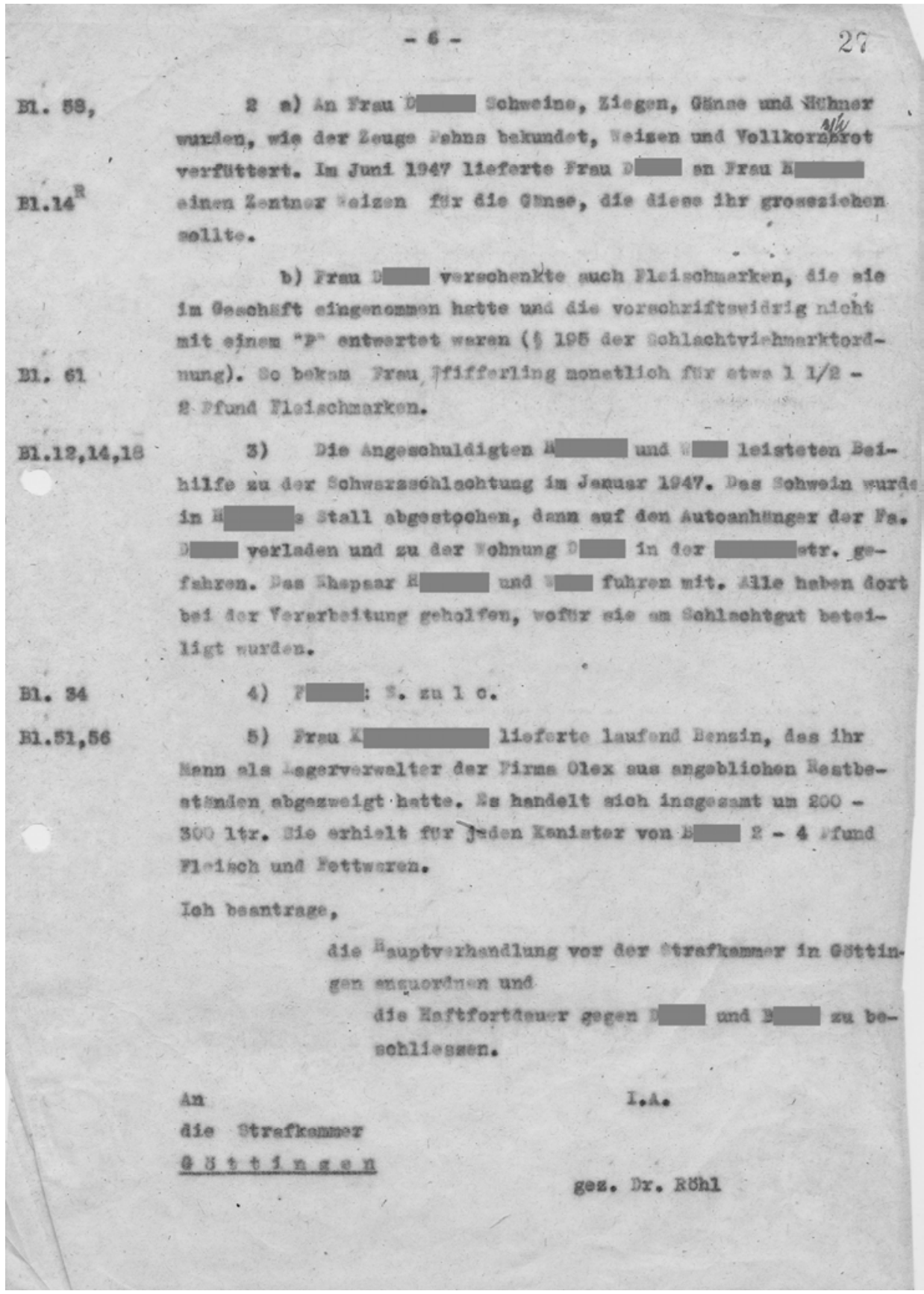

Q1: $\quad$ Anklageschrift in der Sache Frau D., Bl. 27. 


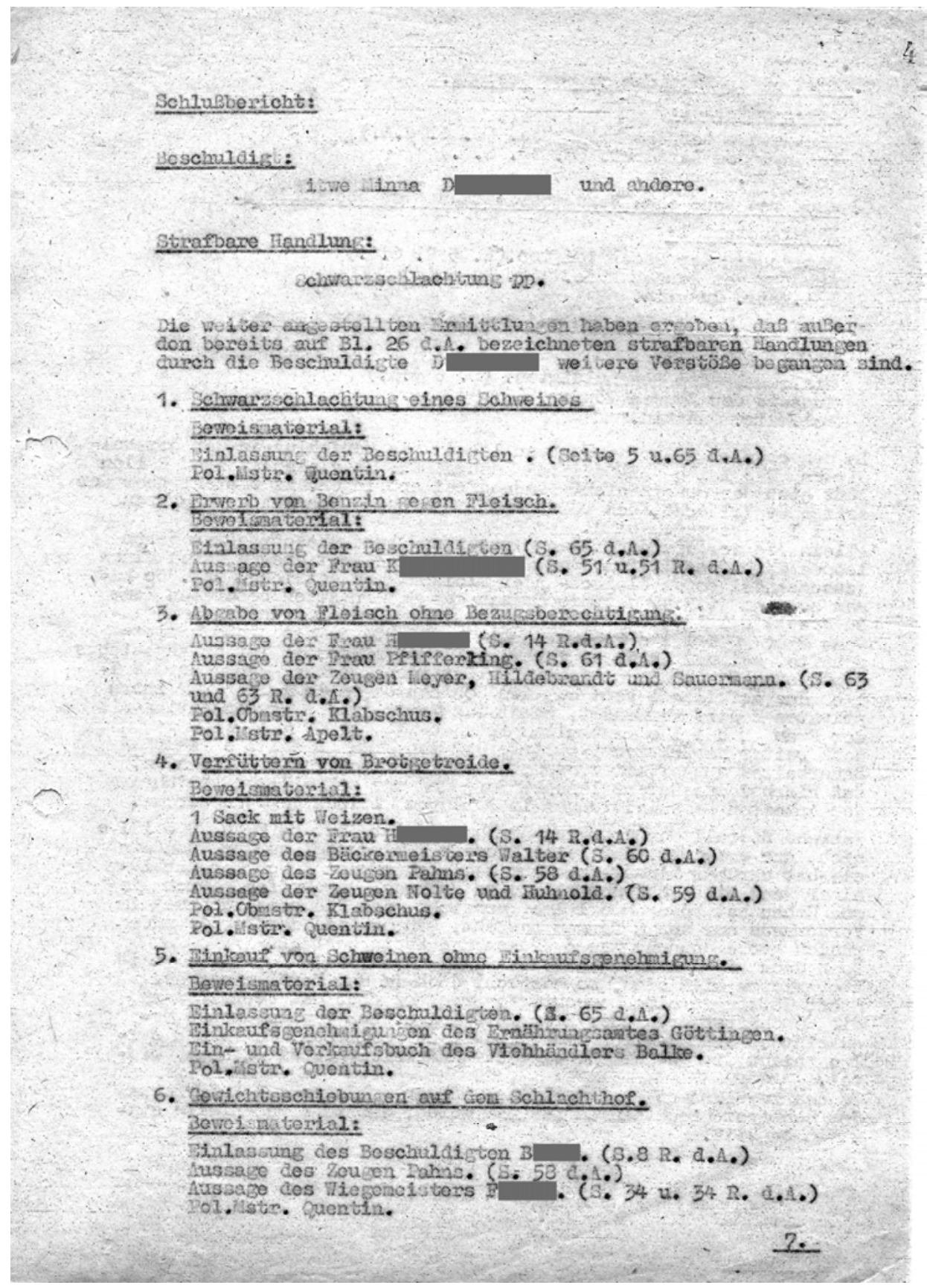

Q2: $\quad$ Schlußbericht in der Sache Frau D., S. 4, C 34 Nr. 46, Bl. 23. 
7. Kaup eines Teopiehs zu tbernoroisen.

Bewoi matomial:

Binlassuib Cor bescibuidsten. (\$. 6. d.A.)

Aussage des Tendgrae. (S. 10 . d. ...)

Po. llstr. Quentin.

8. Kaue von Kolss ome Bezugsberechtisuns zu Upozpieison.

Bewelemetericli:

Binlassurts dor Beschulatgtion.(S. 5 R. d.4.)

Aussege des Zeugen tóde. (3. 24 d....)

Pol.listic. Quentin.

9. Kauf von Jomichbrilclion und Stioforn an thompeison.

Borreistiatorisis

Dinlassurg der Beschulasten. (s. 6 a.A.)

Aussage des Zeugen Töpfor. (s, 16 d....)

Pol. Ists. Quontin.

In den obch angerthipten Punisten I assen die Vorpehlunsen dor Beschul= ditgten D cintranderot nachwoisen. In violen anderen pälien läht sich der Beweis nicht einwandfres. erbingen. Ins besteht aber der dringende Vorlacht, dob wo Lavis wehe strapbaco Hondlungon von, Breu D begangen sind.

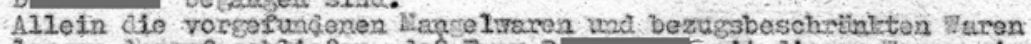
lassen darauf zehriofon, doß Irau $D$ rit dieson laten einen

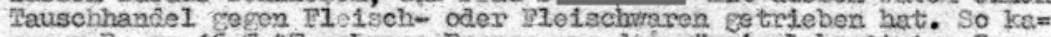
mon z. Bresan 16.7.47 mehrere Fraven aus der rüssisch besotzten Zone

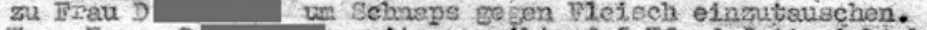

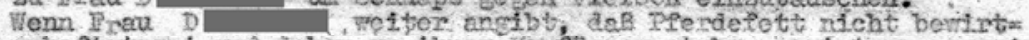

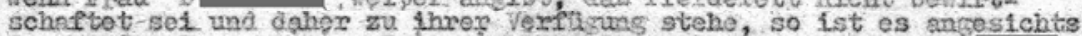

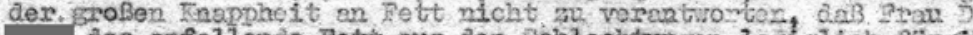
das anfellende Dett aus den Schlachtumgon ledifglich fifr jhreen

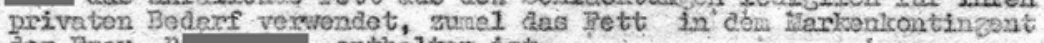
der Frau D enthriten ist.

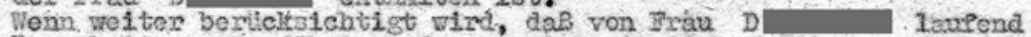
Bauarbolton ausgeforrt wurden, so ist mit sicherhe1t anzunehsen,

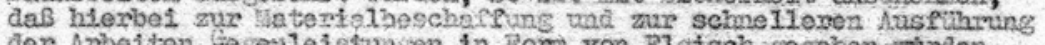

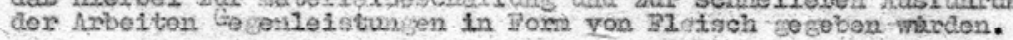

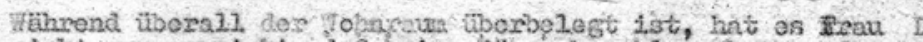

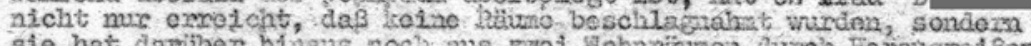

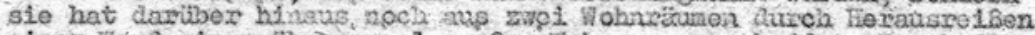
einer Wand ofven thomoral zeoBon wanrauka soschaffen. Zuxacli die= sen Unbau hat Brau of ormeicht, das alo ganze Wolinung in Vorderhans nur aus 2 Räunon bestoht, whicend dio daribostle gelade

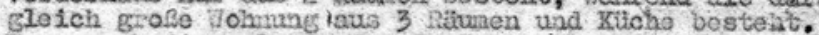

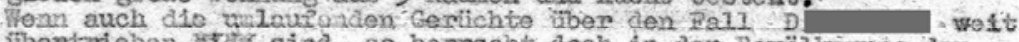

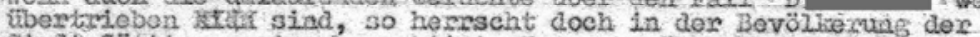

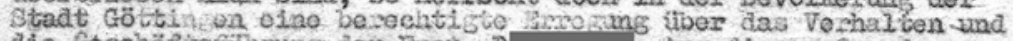

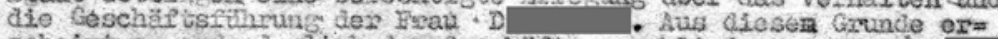
scheint as em ardertich das Gosehart zu sehließon, da Frau D tot.

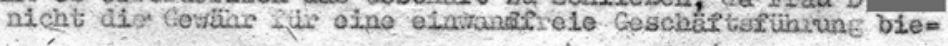

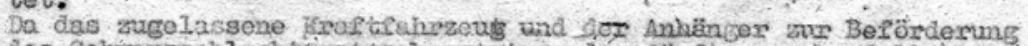
dos schirarschiachtégutes benutzt wurde, durfte or ebenfalls eln= zuziohon soin.

Q2: $\quad$ Schlußbericht in der Sache Frau D., S. 4, C 34 Nr. 46, B1. 23. 


\section{Auf dem "Schwarzen Markt"} Es iäbit sich nicht mehr abstreiten: auch
Göttingen hat seinen. .Schwarzen Merkt", der nun schon seinen festen, wohlbekannten Stasdort hinter den Baracken am Bahnhofsplatz bezogen hat und stets von einer ansehnlichen Menge Käufer und Verkăufer besucht ist. Für einen Fremden ist es nicht so einfach, ins "Geschäft" zu kommen, denn die meisten Partner kennen sich und wissen, was sie voneinander zu halten haben; so ein "Neuer" köhnte sich über die Höhe der Preise oder die Qualităt der Ware mokieren, vielleicht sogar einen „Kriminalen” in Schlepptau haben. Nein, man hat seine feste Kundschaft und will sicher gehen. Außerdem ist nicht geviB, ob die „Sore“ (gestohlenes Gut) gesucht und von jemandein wiedererkannt wird.

In kleinen, zwanglosen Gruppen stehen Händler und Kunden zusammen, anschelnend höchst uninteressiert, dio aromatisch duftende, ausiändische Zigarette im Mundwinkel. Gesprochen wird nicht viel. Ab und zu fallt eine Zähl dann folgt entweder-ein leichtes Kopfschüttein oder die aickende Zustimmung. Die beiden Handelseinigen verschwinden dann etwas abseits, tauschen hastig Ware und Gegenleîstung aus uni stehen Minuten später' schon wieder bei anderen Gruppen, um dort ein neues Geschäft zu machen.

Was wird angeboten und welchè Preise werden gezahlt? $\mathrm{Da}$ sind Zigaretten und Bohnenkaffee, Brot und Benzin, Uhren und Schnaps, Fleisch und Lebensmittelkarten. Geld spielt scheinbar keine Rolle, denn es werden Preise gefordert bis zum bundertfachen ta'tsächlichen Wert. Das Publikum wird von allen Schichten der Bevölkerung gestellt, vom berufsmäßigen Schwarzhăndler bis zur armseligen Arbeiterfrau, die, um den Hunger ihrer Kinder zu-stillen, die karge Zigarettenzuteilung ihres Mannes gegen Brot eintauscht. Vor der "Polente" (Polízei) scheint man keine Angst zu haben. Gefürchtet von allen Beteiligten sind die Ėlemente, die mit der Drohung „Kippe oder Lampen" die Halfte des Gewinnes abhaben wollen oder im Weigerungsfalle mit einer Anzeige rasch zur Hand siná. Dann wird schnell geteilt und die Grüppehen lösen sich eiligst aui, um den Burschen, wonn möglich, an anderer Stelle die Beute wieder abzujagen.

Des "Schwarze Markt" scheint zu einer internationalen Einrichtung geworden zu sein. Wir hören davon aus allen Ländern. Ist damit jedoch schon eine gewisse Legitinitat ge. geben?'Oder sollten Arbeitsamt und Kriminalpolizei durch gemeinseme Aktionen nicht doch so manchen "schweren Jungen" oder Arbeitsscheven wieder einer entsprechenden Tätigkeit zuführen können? Mb.

Q3: Auf dem Schwarzen Markt", Hannoversche Presse, Ausgabe Göttingen 6.9.1946, S. 4, Film Ztg. 627 (GÖK 3.3). 


\section{Alles um den blauen Dunst}

Tauschwunsch brachte Diebstähle und Schwarzmarkțlager ans Lịcht

\section{Göttingen, 18. November.}

Göttingen, 18. November.
der Zivilwachposten eines

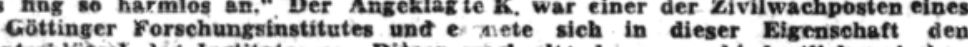
Hauptschlússel des Institutes an. Dieser wechselte dann verschiedentleh awischen K. und dem 19jährigen Horst $\mathbf{R}$, den Besitz, ehe letzterer den Besitz des Sehlüssels dahingehend ausnutzte, daB er - a ngehalten dureh den 33jahrigen Aageklagten Berthold Sch. - bei INacht auf nicht gans einiache Art und Weise eine Sehreibmaschine on sieh nahm und sogl eich auf der StraBe an Sch. abergab, der sohon darauf wartete. Nach getaner Ar beit giagen beide heim zu Seh., dieser seine Masebine heimiabringen, $\mathbb{R}$. um seine versprochene Entlehnung in Empfang xu aehmen: 700 RM und 60 engil sche Zigaretten.

Durch den Tauschversuch. Sch. wollte rür „seine" Schreibmaschine ein Fabriad haben, kam die ganze Sache ans Tageslickt.

$\mathrm{K}$. bekam wegen uneriaubleh Besitzes ailiierten Eigentume 3 Monate Gefängnis, k. dem seine Jugend strafmildernd angerechnet wurde, viegen Diebstahle alfierten Eigentums, 3 Monate Getăng, nis und Jugendfarsorgeuberwachings, una Sch., der ais Hehler einmal, als Anstifter zum Diebstahl zum anderen für schuldig befunden wurde, 6 Monate Gefängnis, wobei den letzten beldon die Untersuchungshaft angerechnet wurde.

Soweit hatten diese Falle ihre Suhne gefunden. Gelegentlich der Haussuchung bel Sch, fand die Kriminalpolizel eine nicht unbedeutende Menge alliterter Zigarettea, die Spuren zum Maschmuhlenweg wiesen.

- Hier war die Beute bel der daraufhin angestellten Haussuchung weltaus größer, fand man doch, wie wir seinerzelt schon kurz berlchteten, 90620 englische Ztgaretten, 163 Tafeln Schokolade, 19 Stuck Selfe, Kognak und Konserven, kurzum, ein "Schwarzmarktobjekt" yon 0,5 Mill. Reichsmark.

Wie, was, woher. - In einer nahen Göttinger Gastwirtschaft hatten stch die vier Komplizen, der 33jährige Angeklagte Berthold-Sch., der 30jährige Willy G., der 20jährige Matthiss $K$. und der 19jăhrige Helnz H. getrofion und efinen umfassenden Plan ausgearbeltet, wie man in den Lagerraum einer allferten Kantine einsteigen konnte.

Beschlossen - getan! In der Nacht vom 13. zum 14. September startete das erste erfolgralche. Unternehmen, das in der Nacht vom 23. zum 24, wegen selnes aicht zu leugnenden Brfolges nochmals wiederholt wurde. Die Beute wurde belde Mrle in die Gastwirtschaft gebracht und dort in funf Teile geteilt, so daB nicht nur die Tater, sondern auch der Wirt fur seine ,.Lfebenswïrdigkeit" entlohnt wurde. Lange dauerte allerdings die Freude uber diesen Raub nicht, die vier Einbrecher bekamen je $\boldsymbol{\theta}$ Monate Gefängnis und der 45jährige Angeklagte Helnrich S.
6 Monata Gelängnis unter Anrechnung der Untersuchungshaft.

Am Rande der Ereignisse erschion noch ein weiterer Angekisgter, der 60jährige Karl P., vor cem Gerichtshot. Bei lihm sollte ursprünglich ein Tell der Waren eingelagert werden. Das batte sich dann allerdings doch zersthlagen und er - be$\mathrm{kam}-\mathrm{um}$ den Diebstahl wissend 500 Zigaretten geschenkt, weitere 500 zur' Aufbewahrung für Sch.; 770 Zigaretten' fand man gelegentlich einer Haussuchung bef $\mathrm{inm}$. Der unerlaubte Besitz alliierten Eigentums brachto auch fhm eine Strafe ein - 1000- RM Geldstrafe, im Nichtbeitreibungsfalle 3 Monate Gefängnis.

Q4: „Alles um den blauen Dunst“, Hannoversche Volksstimme, Ausgabe Südhannover 19.11.1946, S. 4, Film Ztg. 629 (GÖK 3.3). 


\section{Aus böttinger Gerichtssälen}

Grttiagen, 11. November

Zwel Arbeiter aus Hann.-Münden entwendeten mehreren Schlafkameraden die Brieftaschen und verwandten die darin enthaltenen Lebensmittelkarten für sich selbst. Darnit nicht genug, versuchten sie ihr Glück noch auf andere Weise und beteiligten sich, an einem öffent-

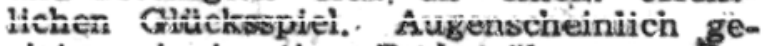
rieten sie in èine Pechstrăhne, wurolen gefabt und erhielten drei bzw. vier Monate Gefănğnis.

Der Fuhrunternehmer Schwerdtfeger aus Göttingen war ein stänơiger Besucher des Schwarzen Marktes. Insgesamt hatte er dort 340 pfund Fleisch aufgekauft und davon große Mengen an die Eheleute Hetzel weiterverikauft. Fetzel war ein starker Abnebmex" Yür Schwarze Waren. So kaufte er auch vom Melkermeister FieB aus Grone 1ㄴ. Zentner Rindfleisch, obwohl tietzel wulte, daB FieB dieses Fleisch aus der Saline Grone gestohlen hatte. Schwerdteger wird nun zeisn

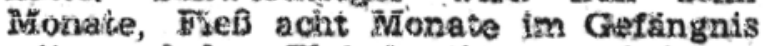
mit normalen Fleischrationen zubringen müssen.

Emma Blume aus Wolfenbittel kasn das Stehlen ansçheinend nicht mehr iassen. Obwohi sie schon zwölîmai gerichtJich vorbestraft ist und schon einmal vier Jahre Zuchthaus wegen Diebstāhls erhielt, reichte das nicht aus. Während eines Urlaubs aus dem Zuchthaus stahl sle in Northeim und Göttingen bei Familien, bei denen sie wohnte, Kleidungsstücke, Wäsche, große Geldbeträge und Lebensmittelkarten. Der kurze Urlaub ist ihr schlecht bekommen. Zehn weitere Jahre wird sie mun im Zuchthaus verbringen mussen.

Q5: Aus Göttinger Gerichtssälen, Hannoversche Volksstimme, Ausgabe Südhannover 12.11.1946, S. 4, Film Ztg. 629 (GÖK 3.3). 


\section{Der Schlag hat sich gelohnt}

Dem "schwarzen Zigaretten-Grokhandel wurde am Freitagabend- in Göttingen ein Schlag versetzt. Nicht weniger als 100000 englische Zigaretten, dazu Konserven, . Schokolade und Seife wurden bei einer Haussuchung am Maschmühlenweg entdeckt. Die "Ware" rührte aus Diebstählen her. Sieben Männer wurden als Diebe und. Hehler festgenommen, bei einem Verhafteten kommt allerdings "nur" Erpressung in Frage, da er sich sein Stillschweigen über die Kenntnis der Diebstähle durch eine Forderung von 1000 Zigaretten erpreBt hatte.

Q6: „Der Schlag hat sich gelohnt“, Hannoversche Presse, Ausgabe Göttingen 8.10.1946, S. 4, Film Ztg. 627 (GÖK 3.3).

\section{Die Polizei versagt auch hier} . Der Göttinger „Schwarzmarkt" floriert noch immer

G bttingen, 27. März. , Dle erfolgreiche Bekämplung des „Sehwarzen Mrarktes" ist" mit zu einer entseheidenden Frage in der deutsehen Wirtschaft geworden. Die Polizel hat diese' Aufgabe nur teilweise gel6at und die Gerichte haben' in ihren Urteilen segen Sehwarzhändler eine unverständliche Milde an den Tag gelegt. Die Umsätze auf dem Sehwarzen Markt sind daher gleieh hoch geblieben und die Sehwarzhändler haben für die „drakoniseken Maßnahmen“ nur noeh Spott ubrig.

Die Zentrale des Gottinger Sohwarzmarktes ist nach wie vor das Bahnhofsgelände." Seit einiger Zeit wird es von der Polizei scharf überwacht, und doch hat sich wenig geändert. Man kann lediglich eine gewisse Gehetzîheit bei der Abwicklung dor Geschäfte feststellen. Der amtliche Bericht kann auf keinen Fall für sich in Anspruch nehmen, ein Bild von der wirklichen Lage zu geben.

Allein wenn man erfährt, daB nur 48 Personen in zwei Monaten zur Anzeige gebracht wứden, so weß $\mathrm{man}$, daß diese Zahl einen geringen Bruchteil der Schwarzhändler ausmacht: Wenn man weiter erfährt, daß im Unterwenlungsverfahren insgesamt. Geldstrafen in Höhe von 3162 RM. verhängt wurden, so können sich die Schwarzhändler zu solchen Richtern nur gratulieren.

Beschlagnahmt wurden 2100 alliierte Zigaretten, 1 Beutel amerikanischer Tabak und zwei ganze Tafeln Schrkolade. Auch die paar Pfund Butter und Zucker, die beschlaǵgnahmt wurden, können angesichts der riesigen Umsätze nư ein Lächeln entlocken.

Der Erfolg , der "drakonischen Strafmaßnahmen ist bisher ausgeblieben. Meint $\backslash$ man einen Schwarzhändler damit beeinflussen zu können, da $\beta$ man inn verwarnt und in die Schwarzhăndlerliste eintragen läßt? . Bei Personenkontrollen auf dem Göttinger? Bahnhof wurden innerhalb von zwei Monaten 133 Personen uberprüft und 51 dem Arbeitsamt zừ Arbeitsvermittlung zugefuhrt. Weitere 17 Personen wurden als Arbeitsscheue dienstverpflichtet.

Mit allen diesen Maßnahmen ist eine grundlegende Aenderung nicht erzielt worden. Der Schwarze Markt floriert wie früher. Die werktätige Bevölkerung, die sich den kargen Lohn mit. ehrlichèr Arbeit verdient, erwartet, daß gegen die Parasiten am deutsehen Wirtschaftskörper endilich durchgreifende Maßnahmen er-. griffen werdan. 
Reportage der Göttinger Wirklichkeit

\section{Die Straße des Verderbens}

Der Polizeibericht meldet:

"In den letzten beiden Monaten wurden Marktes" vom 2 . Polizeirevier Góttingen ein gesetrten Polizeibeamten 48 Personen wegen Schwarzhandels zur Anzeige gebracht Im Unterwerfungsverfahren wurden diese solor
mit insgesamt 3162 Mark Geldstrafe belegt. mit insgesamt 3162 Mark Goldstrafe bolegt. An Ware wurde 'gegen Quittung polizeilich
sichergestellt: e) Zur Verfugung der Milităregierung: 2097 ausländische Zigaretten u. a. b) Zur Verfügung für die deutschen Behörden: Soeck, 297 Zigaretten, 14 Pfund Tabak, 30 Wachslichter u. a. am. 19 Personen muBten in das Polizeigefangnis eingeliefert werden Eine gröbere Menge Diebesgut, vorwiegend Bekleidungs: und Gebrauchsgegenstănde sowie: Lebensmittel u. a. wurde der Kriminal polizei übergeben. 133 Personen wurden zur Wache gebracht, ubberprüt und notfalls in die Schwarzandieriste eingetragen, Si Nichtstue 17 Arbeitsscheue nach außerhatb verp denen 17 Arbeitsscheue nach auderhalb verphichte wurden der weiblichen Polizel uthergeben."

"Wir 'sitzen dem - Polizeikommandenten Gôttingen-Stadt in seinem Dienstzimmer gegenũber. wăhrend draulien auf dem Gang eine Reihe verwegener Gestalten, von einigen Polizisten sorqsam beobachtet, auf die Vernehmung warten. Der Schwarzhandel am Göttinger Bahnhof ist bereits erheblich zurückgegangen. Trotzdem bedarf gerade dieses Gelande elner stăndigen Aulsicht, da durch die Drei-Zonen-Ecke die Versuchung furr reisende gros ist", sagt de: Hauptmann zu uns. Und er beginnt so zwischen den Verhoren von seiner Arbeit gerade auf diesem wichtigen Sektor zu erzăhlen ....

Vor Monaten, als sich die Schwarzhăndler noch zu Hunderten im. Bahnhofsviertel umhertrieben, wurden großzúdge Aktionen mit MP unternommen, d. hi daB die' Straßen mit au Lkw. herangeführter uniformierter Polizel ab. gesperrt und dann die qanze Ecke sorgsam durchgekămmt wurde. Sobald die Schwarzhändlor das merkten, Heßen sie 'die Ware im Stich und versuchten zu entkommen. Man vrollte aber nicht nur die Ware, sondern auch die Tăter haben. Deshálb war ein Wechsel in der Taktik' notwendig. Die Beamten qehen nun nicht mehr th Uniform, sondern in Zivil und Menge. Sle versuchen mit den Sch unter die lem in ein Gesprach und den Geswarzhänd. lern in ein Gesprach und zum "Geschäft" zu
kommen. Kurz - vor Abschluß geben sich die Beamten $z \mathrm{u}$ erkennen und schireiten zur Verhaftung. Bel schwereren Fällen machen sie von der Handschelle Gebrauch. Widerstand ist zwecklos, da alle Polizisten mit miehreren 'Spezialhandwaffen ver-
sehen sind. Und die Strafo-wird dann nur noch

\section{durch den \& 113 (Widerstand gegen die}

Wie setzt sich die "Berufsgruppe Schwarzhöndler" zúsammen' Da sind alle Schichte und Altersklassen. besonders aber Jugendlich die Straße des Verderbens gegangen, sin Kinder der Landstraße geworden, ohne Heimal

Besuch beim Kreisflüchtlingsamt

Das żresffüchtlingsamt ist selbst. wie ein Flüchtling untergebracht. denn die Dienstrāume befinden sicb in 1 Stock eines Hintergẹbaudes dér Bürgerstraße 56. Wir sitzen im Sprechzimmer des Amtsleiters, un an einer der rege:mäBigen Sprẹchstunden te:lzunehmen. Hier laufen die Klagen, Beschwerden und Wünsche
aller Flüchtlinge der 73 Gemeinden des Landkrejses Góttingen zusammen.

Da ist, der Fall K. Eín nicht ganz entbrăunter Einwer ter. Einwohner weigerte sich, fầ eine Flüchtlingsfamilie von sechs Personen zwei Răume
zur Verfógung zu stellen. Die Polizel mußte zu' hilfe genommen werder, und soit dieser'
Stunde haben die neuen Mieter keine ruhige Minute meht Durch vielerlei Schikanen versucht der Vermieter das Leben der Flachtlinge zu erscbweren, Kleinigketten sind AnlaB zu langwierigen Streitigkeiten, kurzum, es ist Un. frieden und Zank im Haus. Hier greift nun der Kreisfluchtlingsbetreuer ein und wird zunăchst erst einmal die tatsăchlichen Verhältnisse fest-
stel!en Beruhen die Angaben des Beschwerde-
fürers auf Watrheit, so wird er zusammen fürers auf Wabtheit, so wird er zusammen gegebenenfalls mit. Zwangsmaßnahmen.

\section{Göttinger Notizbuch}

Am 30. Aprit. 10 Uhr. findot in der' Nikotaistrase 20 In det Zeit yom 2. bis 16. Mat sind an die Stadtiche

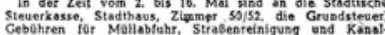

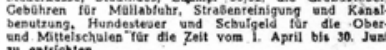

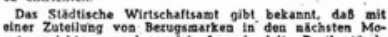

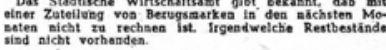

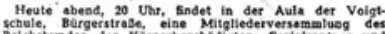

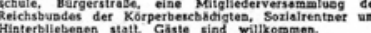

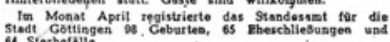

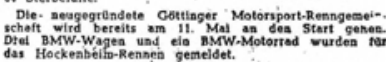
Hevte rehlt das Postant did Versorgunguranten sowio

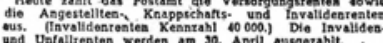

ohne Bindungen, ohae Halt. Die" guten and schlechten "Ecken" aller Stadte sind ihnen beVornit. sile kennen sich untereinander nur mit die Sprache der Ganoven. Es lockt sio nicht diu ehrliche Arbeit und ein geregeltes Lebeh, sondern der muhelose Erwerb, die Unstetheit
der Tage und Nachte und die Gefahr: Sie sind ohne Gesetz und verachten es - und allen daher alle eines Tages unter das Gesetz. "Und trotzdem sind dies nur die schied, denn die Großen sitzen am Schreib. tisch und arbeiten mit Fernsprecher und Tele. graph. Sie zu fassen ist um vielos schwerer-" Mb.

Ganz anders steht es um Mutter A. aus KleizLengden. Sie versucht ihre grobjabhriges Kinder, die sich derzeitlg noch in einer Notwohnung des Kreises Nienburg befioden, nach ihrem jetzigen Aufenthaltsort zu bekominen. Hier kann der Kreisfluchtlingsbetreuer nicht helfen. da das.Gesetz der Famillenvereinigung nur bis zum 21. Lebensjahre der Kínder in Anspruch genommen werden kann und eine Zuzugshohung der Flüchtlings zu verantwortende Erda für die noch wu erwartenden Transporte bis. her keine Quartiere geschafien Transporte bisher keine Quartiere geschaffen werden konn-

Der Kreisffuchtlingsbetreuer erzähtt aus soinem relchen und lebhaften Tageslaus soin Verkehr mit den 32000 Flúchtlingen des Kreises und von vielen Einzelschicksalen, die er perden Mittel reichen allerdings langst nicht aus, um alle Nóte und Sorgen zu bannen. Die Menschen in bitterster und schwerster Not aber kommen meist nicht $\mathrm{zu}$ ihm. sondern mússen ausfindig gemacht werden, da sie sich

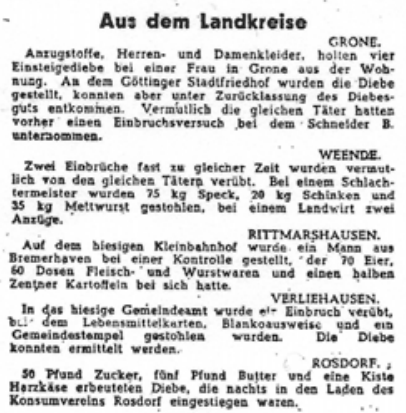
lichkeit eines Wohnungstausches. sónlich bearbeitet hat. Die voollig unzureichen.

Q8: „Reportage der Göttinger Wirklichkeit“. Die Straße des Verderbens, Hannoversche Presse, Ausgabe Göttingen 29.4.1947, S. 3, Film Ztg. 627 (GÖK 3.3). 


\section{Der Schwarze Marlzt bliiht Ungeeignete Methoden der Gọ̈ttinger Kriminalpolizei}

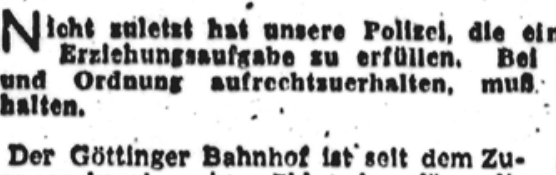
sammenbruch oin Eldorado fur die Schwarzhandier und in letzter zeit tinden laufend Razzlen durch die Kriminal. - polizel statt. Niemand befurwortot es mehr als wir, wenn diesen unsauboren Ge. sel!en das Hondwerk gologt wird. Wie aber geht olne wolcho Razzla vor.sich?

Der aroßo wartesaal wird zur einon Hilfte 'frol gemacht, das Gopalck durcheuch: und dann massen die Einzelnen In Kalte und Wind vor den Baracken otehen. Wen diese Maßnahme trifft, das oind die wirklichen Reloenden, die oft wchon stundenlang in den Zugen getroren haben.

Zum anderen schelnen jich Beamte der Kriminnlpolizel gern dor Acht-Grbwehen-Jungen zu bedicnen. DAese Loute, zum Tell Jugendliche, eind die Ubelston Erscheinungen des Schwarzmarktes. Da sle der Polizel Zutrligerdiensto leisten! glauben ole selber alle Rechte fur sich in Anspruch zu nehmen. Wir haben es beobachtet, das solche. Elemente zum Schein Schwarmarktelnktlufe tatigten; dio. Schwarzhanaler um das Geld prellten, sle-dann der Polizel anzelgten und amschileBond die sachen nicht etwa abtaben, sondern tar sich behalten durften.

Ein Unrecht wird noch lange nicht durch eln zwoltes gutremacht und dieso vlomente oind in den Augen der OeffentIIchkelt Botrüger, die genau so vor den - Richter gohören wio dio Schwarzhładler.

Hier. zeht nach unserer Ansicht die Sache zu woilt. Dem Recht muB auf teden rall zum Sicte verholfen werden, ber nicht mitt diesen Methoden. Solango dieso zwelte Kathegorie von Gaunern sestatzt und redeckt wird, werden wir dieso ublen zolterscheinungen nicht be- seltlgen kðnnen, sondern tinen Schwarzen Markt auf, dem Schwarzen Markt bilden.

G d t I n $z \in \operatorname{n}, 3$. Februar.

Volkspolizel sein sollte, pine große

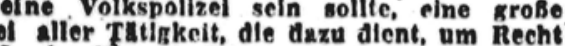
to diege Aufrabe immer Im Auze be-

\section{- Neue Ortsgruppe der KPO}

Befirum, 3. Februar.

Im Anschius an eln Referat des Genossen Spanrenber wurde am 29. Jonuar dic Ortsgruppe Bcttrum der Kommunlatischen Partel gegrundet. Zum politiochen Leiter der neuen Ortagruppe wurde die Genossin Pusch kewăhlt.

\section{Erste Fluichtlinigsversammilung}

, Gr.-Rhuden, 3. Februar.

In der unlängst stattgefundenen ereten Fluchtlingaversammlung sprach Genosso Dorr. Hildeshelm, vor 250. Versamme't^n aber die Notlage der Flachtlinge. Die Betreuung. der Flüchtilinge scheint in Gr.-Rhuden noch Im Rückstand zu acin: denn der Betreuer hehauptet, die Blldung von Flachtlingsausschüssen sel verboton.

Wir hoffen, daß auch in Gr.-Rhuden recht bald eln Fluchtlingsausschuß geblidet wird, der die Interessen aller Flachtlinge vertritt.

\section{Gasvarsorminn mesighart .}

IIameln. 3. Fobruar.

Die Hamelner Stadtwerke konnten jeizt dle orfrculiche Mittellunn machen, da $B$ durch neue Kohlenlieferungen die Gasversorgung tar dle nächsten 14 Tage. sichergostcllt werden kann.

In der Stromveisorgung ist die Lage dagegen ungewiB, und langere Abschaltungen, nuch in den Abendstunden wer:den welterhin unvermeldilich sein.

Q9: „Der Schwarze Markt blüht“, Hannoversche Volksstimme, Ausgabe Südhannover 4.2.1947, S. 3, Film Ztg. 629 (GÖK 3.3). 


\section{Ein kleiner Konig des Schwarzen Marktes}

Der Großumsatz auf dem Schwarzen Markt ernähríe den Serviermeister Gerd $\mathbf{S c h u l z}$ aus Göttingen gut. Den Schwarzhandel betrieb er mit Fleisch- und Wurstwaren. Fischkonserven. Kaffee, Textilien. Ein besondera' gutes Geschäft war der Absatz von. Schlammzucket, einem ungereinigten, verschmutzten Gemisch aus Zucker und Melasse. Für etwa 300 Pfund erzielte en 6500 RM. Das Amtsgericht . Göttingen erkannte gegen Schulz auf sechs Monate Gefängnis und Einziehung vọn 3000 RM Mehrerlös.

Q10: „Ein kleiner König des Schwarzen Marktes“, Hannoversche Neueste

Nachrichten, Ausgabe Südhannover, 23.4.1947, Film Ztg. 623 (GÖK 3.3).

\section{Ausgesiorbener Sehwarzmarki}

hp GOTTINGEN. Der Schwarze Maikt am Bahnhof bietet seit einigen Tagen ein totes Bild. Wenige auf "bessere Zeiten" hoffende Schwarzhändler, die aus Tradition das Geschäft am Bahnhof aufrechterhaiten, setzfen dte létzten hinúbergeietteten Amis für 30 . Pfennity ab. Die übrigen Waren scheinen den Markt nicht mehr zu erreichen. In geringem Umfang und nur an "Stammkunden" von "Tür zu Tür" hạdén die kapitalkräftig gewesenen, größeren Schieber, die einen gewissen Warenbestand aus der Reichsmarkzeit halten konnten, das Pfund Bohnenkaffee schon. für 8 bis 10 Mark, während ein.Pfund Butter für 6 Mark zu beschaffen, keine Schwierigkeiten mehr bereitet. Die Eierpreise dirêkt aus der "Quelle" 'sind' unterschieedlich, sie schwankẹ zwischen 6 und 15 Pfennigen.

Q13: Ausgestorbener Schwarzmarkt", Hannoversche Presse, Ausgabe Göttingen 1.7.1948, S. 4, Film Ztg. 627(GÖK 3.3). 


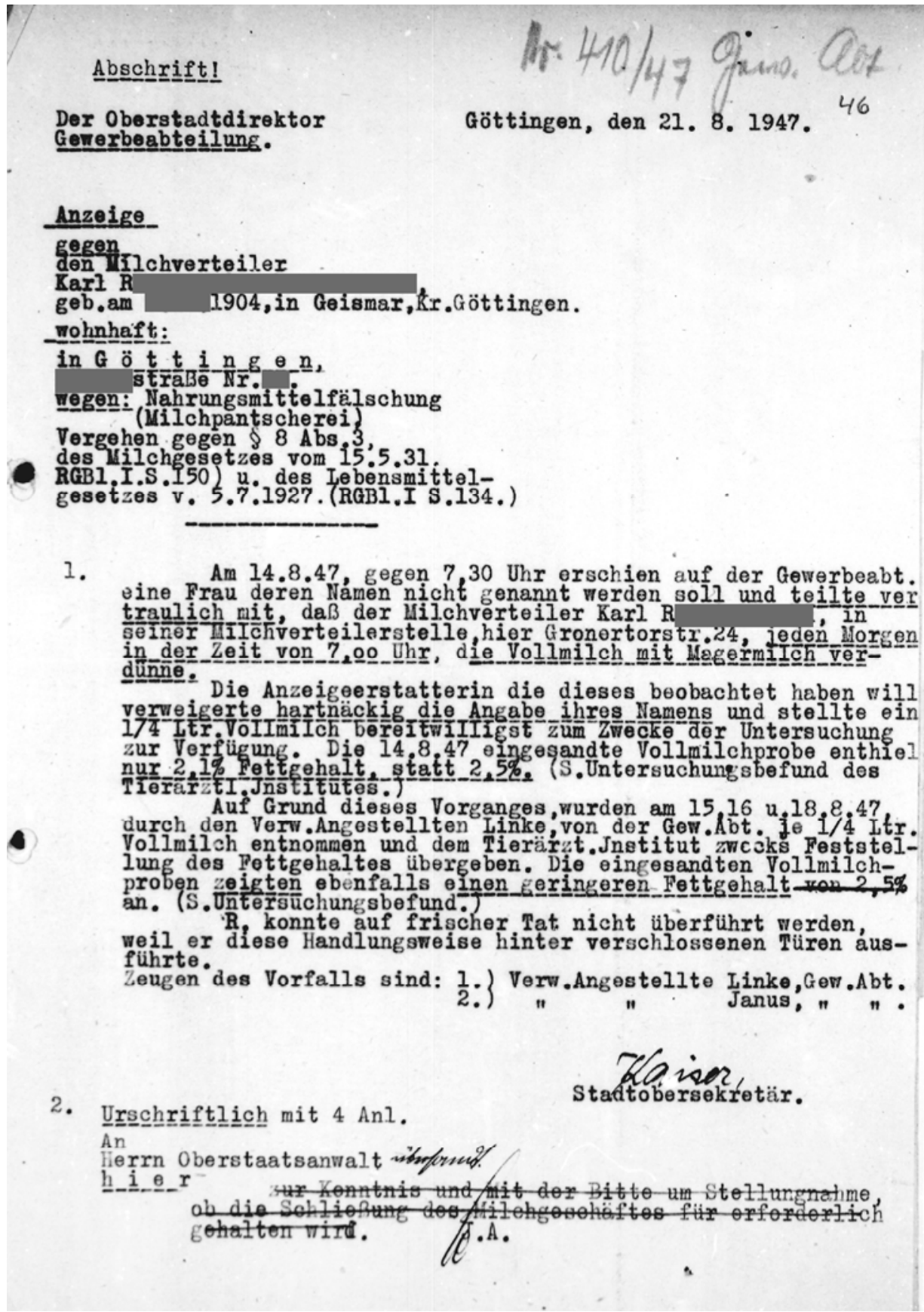

Q11: Anzeige gegen den Milchverteiler Karl R., 21. 8. 1947, Pol. Dir. Fach 127 Nr. 1 d Bd. 1, Bl. 46. 
Die Stadtronaltung

Gewerbeamt

A $\mathrm{n}$ e i g

gegen don Dipi. Optiker

Friedrich Hi

\section{1}

Göttingeu, den 17.3.1948

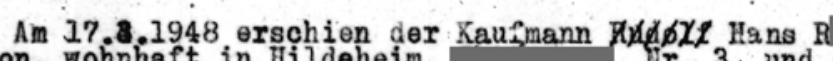
Person, wohnhaft in Hildesheim, of , Fr. 3 , und erstattet

ka ufen. A hi das. vorgelegte Rezept wurden die un war Brillengläger

Geren 11,00 Uhr war ich in den Geschïft yon i und

dienenden Herrn auch dienenden Herrn auch herausgesucht gesagt, daß er die Glâser nur gegen Kompensation abgeben würde, जeil sie ihm Dollar vert sind und mein Papiergeld ihm nichts nuitze.

C. Um Klarheit uber den Vorkauf zu haben. bin ich zum Sche in darauf ein gegangen und habe gefragt ob or Hohl me inte. Darauf sagte er Kehl uber seine Vare. Bs vurden mir dio Gläser, die ich zu meiner $B e=$ rufsausbildung brauchs nicht verkauft.

Die von mir ver?angton Glager waren tatsächlich vorhánden. Zs handelt sich um Zeis Punktalgläser. Vitere Angaben kann ich licht machen.

Bine Abschrift von cem Rezept ist tot beigefugt.

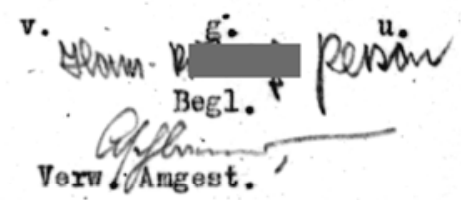

Ich begub mich mit dem Kaufmin Person zu dem Geschäft von il und H $\mathrm{H}$. Hier stellte ich fest, dio ?. von Herrn gabe der Brillongléser nicht ein veil er es sich iberlegt hatte da Porson noch in Besitze einer Brille war,

Verw. Angest.

Q12: Anzeige gegen den Dipl. Optiker Friedrich H., 17.3.1948, Pol. Dir. Fach 127 Nr. 1d Bd.1, Bl. 61. 


\title{
„Also lautet ein Beschluss, dass der Mensch was lernen muss. “1 - Der Wiederbeginn ${ }^{2}$ des schulischen Lebens in Göttingen nach dem Zweiten Weltkrieg
}

\author{
Marco Dräger
}

\section{Einleitung}

Zunächst lautete der Befehl des Obersten Befehlshabers der Alliierten Streitkräfte, General Eisenhower, dass der Unterricht unverzüglich eingestellt werden müsse, um das Bildungswesen zu reorganisieren. ${ }^{3}$ Am 24. August 1945 kündigte aber be-

\footnotetext{
${ }^{1}$ Das Zitat stammt aus dem vierten Streich von Wilhelm Buschs „Max und Moritz“. Im Fazit wird näher auf seine Verwendung eingegangen.

2 Der Unterricht war in Göttingen bereits Ende März 1945 eingestellt worden, Schüler und Lehrer waren schon in den Osterferien (Berthold Michael, Schule und Erziehung im Griff des totalitären Staates. Die Göttinger Schulen in der nationalsozialistischen Zeit von 1933 bis 1945, Göttingen 1994, S. 193).

3 Die „Proklamation Nr. 1 von General Dwight D. Eisenhower an das deutsche Volk“ wurde bereits am Tag der Besetzung Göttingens (8. 4. 1945) dort bekannt gemacht (vgl. Wiebke von Thadden, Göttingen und seine Militärregierung, in: Göttingen 1945. Kriegsende und Neubeginn - Texte und Materialien zur Ausstellung im Städtischen Museum 31. März - 28. Juli 1985, Göttingen 1985, S. 6992, hier S. 73). Publiziert wurde sie im Göttinger Mitteilungsblatt Nr. 1 vom 20. 4. 1945: ,[...] III. Alle deutschen Gerichte, Unterrichts- und Erziehungsanstalten innerhalb des besetzten Gebietes werden bis auf Weiteres geschlossen. Dem Volksgerichtshof, den Sondergerichten, den SS-PolizeiGerichten und anderen außerordentlichen Gerichten wird überall im besetzten Gebiet die Gerichtsbarkeit entzogen. Die Wiederaufnahme der Tätigkeit der Straf- und Zivilgerichte und die Wiedereröffnung der Unterrichts- und Erziehungsanstalten wird genehmigt, sobald die Zustände es zulassen. $[\ldots]^{\text {c }}$
} 
reits der Oberbefehlshaber der britischen Besatzungszone, Feldmarschall Montgomery, an, dass die Schulen zum 1. Oktober 1945 wiedereröffnet werden sollten (Q1). Die Vorbereitungen für die Wiedereröffnung liefen unmittelbar nach der Schließung an und erreichten im Sommer 1945 ihren Höhepunkt. Der Neubeginn stand vor allem unter den Vorzeichen von Entnazifizierung und Reeducation.

Trotz erheblicher Bemühungen sowohl auf Seiten der britischen Militärbehörden als auch seitens der deutschen kommunalen Behörden war der Wiederbeginn des schulischen Lebens zunächst provisorisch - es mangelte an Unterrichtsräumen, Lehrbüchern und Lehrkräften, so dass die Engpässe und Mängel im laufenden Betrieb beseitigt werden mussten. Dieses Prozedere nahm einige Jahre in Anspruch; ein geregeltes Schulleben fand in Göttingen erst wieder ab dem Jahr 1950 statt. ${ }^{4}$ An einem mangelte es in Göttingen jedoch nicht - an Schülern. ${ }^{5}$

\section{2 „Von der Bevölkerung wird dringend gewünscht, daß baldmöglichst der Schulunterricht für die Kinder wieder beginnen möge. ${ }^{\text {66 }}$ - Maßnahmen zur Wiedereröffnung}

Das dringlichste Problem war die Rückgewinnung der Schulgebäude, die zwar größtenteils unbeschädigt bzw. kaum beschädigt waren, aber mittlerweile anderweitig genutzt wurden, z. B. als Lazarett, Flüchtlingslager, Lager für befreite Zwangsarbeiter oder als Quartier für die Verwaltung der britischen Besatzungsmacht. Eine Auflistung der betreffenden Gebäude mit entsprechenden Schülerzahlen sowie die Kennzeichnung der aktuellen Nutzung verdeutlichten die zahlenmäßigen Dimensionen dieses Problems (Q2).

In dieser Angelegenheit war die Zusammenarbeit zwischen dem Stadtkommandanten, Major Ruddy, und den deutschen Behörden äußerst erfolgreich und führte schnell zu positiven Ergebnissen, da beide Seiten eine möglichst zügige Wiedereröffnung anstrebten, um einerseits einer antizipierten „Verwahrlosung“ der Jugend vorzubeugen und andererseits die Ideen der Reeducation umsetzen zu können. ${ }^{7}$ So konnten die Volksschulen bereits am 1. September 1945 wiedereröffnet werden, das Gymnasium (heute Max-Planck-Gymnasium) und die Oberschule für Jungen begannen den Unterricht der unteren Klassen planmäßig im Oktober, die höheren Klassenstufen kamen ab Mitte Dezember hinzu, die Ober-

\footnotetext{
${ }^{4}$ Vgl. Berthold Michael, Die Göttinger Schulen vom Wiederbeginn 1945 bis zur Gegenwart 1989, in: Rudolf von Thadden/Ernst Böhme/Dietrich Denecke (Hg.), Göttingen: Geschichte einer Universitätsstadt, Bd. 3: Von der preußischen Mittelstadt zur südniedersächsischen Großstadt: 1866-1989, Göttingen 1999, S. 511-533, hier S. 516.

${ }_{5}^{5}$ Zur Erklärung der Vielzahl von Menschen in Göttingen siehe den Beitrag von Ulf-Gerrit MeyerRewerts in diesem Band.

${ }^{6}$ Brief des Oberbürgermeisters an den Göttinger Stadtkommandanten Ruddy vom 9.8.1945 (Stadtarchiv Göttingen, D44, Blatt 77).

${ }^{7}$ Vgl. die Korrespondenz zwischen den beiden Protagonisten Major Ruddy und dem Göttinger Oberbürgermeister Schmidt (Stadtarchiv Göttingen, Stadtverwaltung und Militärregierung, D44).
} 
schule für Mädchen (heute Hainberg-Gymnasium) wurde erst im Januar 1946 wiedereröffnet. ${ }^{8}$

Unterricht konnte jedoch nur eingeschränkt stattfinden. In der Regel mussten sich zwei bis drei Schulen ein wiederhergestelltes Schulgebäude teilen; die Schüler wurden an drei Tagen in der Woche im so genannten „KurzstundenSchichtwechsel“9 unterrichtet, so dass sie ca. 15 Stunden anstatt der im Lehrplan vorgeschriebenen 30 Wochenstunden erhielten.

Die Tatsache, dass kein ausreichendes Mobiliar in den Schulen vorhanden war, erschwerte die geordnete Durchführung von Unterricht. ${ }^{10}$ Die bislang praktizierte Notlösung von „Unterricht“ im Freien kam wegen der Witterung nicht mehr in Betracht. ${ }^{11}$ Ebenso beeinträchtigte der Mangel an Heizmaterial12, elektrischem Strom und Glühbirnen ${ }^{13}$ den Unterricht.

Ein weiteres Problem stellte der Lehrermangel dar, der zum einen durch die sich noch in Kriegsgefangenschaft befindenden Lehrer, zum anderen durch die Verfahrensdauer der Entnazifizierung bedingt war. Das Spannungsverhältnis zwischen Entnazifizierung und einer ausreichenden Anzahl an Lehrkräften findet in einem Brief des Stadtkommandanten an den Oberbürgermeister seinen Ausdruck, der um eine Auflistung der demobilisierten, pensionierten und von den Nationalsozialisten entlassenen Lehrern bittet, ${ }^{14}$ um den entstandenen Mangel auf diese Weise zu kompensieren (Q3).

${ }^{8}$ Vgl. Michael, Göttinger Schulen, S. 513-514.

${ }^{9}$ Von Thadden, Militärregierung, S. 89.

10 Zur Neuanschaffung von Mobiliar siehe Stadtarchiv Göttingen, D 45, Blatt 267.

${ }^{11}$ Der schon seit Mitte Juni wieder erlaubte „Unterricht“ kann eigentlich nicht als solcher qualifiziert werden. Er bestand aus den Fächern Religion, Sport und Wandern und diente im Wesentlichen der Beschäftigung der Schüler. Die Behörden versprachen sich davon, die Disziplin der Schüler aufrechtzuerhalten und einer befürchteten Verwahrlosung vorzubeugen. Der Erfolg dieser pädagogischen Maßnahme war nur gering, die Anzahl der Teilnehmer sank beständig und eine Regenperiode in der zweiten Augusthälfte beendete schließlich diese Art der Beschulung (vgl. Wilhelm Schütte, Aus der Schulchronik der ehemaligen Oberschule für Mädchen. Die Schule in der Zeit von April 1945 bis Oktober 1946, in: Göttingen 1945. Kriegsende und Neubeginn - Texte und Materialien zur Ausstellung im Städtischen Museum 31. März - 28. Juli 1985, Göttingen 1985, S. 257-270, hier S. 259-261).

Zusätzlich erschwerten jahreszeitlich bedingte Härten den Unterricht: „Der jetzige Nachmittagsunterricht [im Oktober 1945, MD] in Grone [heute ein Stadtteil von Göttingen, damals selbstständige Gemeinde; das Groner Schulgebäude war 4,5 km vom ursprünglichen Schulgebäude der Oberschule entfernt, $\mathrm{MD}$ ] ist nur ein Notbehelf und war auch von vornherein als solcher gedacht. Er kann nicht mehr länger in dieser Form aufrecht erhalten werden aus folgenden Gründen: Die Dunkelheit bricht schon früh herein. Die Kinder müssen auf den Heimweg geschickt werden, solange es nicht völlig finster ist. Die Zugangswege sind in schlechtem Zustand und nicht beleuchtet. Bei regnerischem Wetter bilden sich große Pfützen auf den Straßen, die von den Kindern in der Dunkelheit schwer bemerket werden. Schon jetzt klagen die Eltern über starken Verschleiß der Schube sowie über nasse Füße der Kinder und die sich daraus ergebenden Erkältungen. Aus all diesen Gründen bitte ich dringend um Unterstützung und Hilfe, damit wir baldmöglich wieder in unser eigenes [...] Scbulgebäude einziehen köonen. Andernfalls bitte ich dafür Sorge tragen zu wollen, daß uns andere geeignete Unterrichtsräume [...] zur Verfügung gestellt werden. " (Ebd., S. 262).

12 Stadtarchiv Göttingen, D 44, Blatt 138.

${ }^{13}$ Stadtarchiv Göttingen, D 44, Blatt 135.

${ }^{14}$ In die Kategorie der von den Nationalsozialisten entlassenen und nun zu rehabilitierenden Lehrkräfte fiel als einzige die Mittelschullehrerin Ingeborg Willrich, die 1936 entlassen wurde, da sie keinen Eid auf Adolf Hitler leisten wollte (Ulrich Popplow, Die Friedensjahre: Göttingen 1933-1939 - 
In der Folgezeit wurde jedoch deutlich, dass der Lehrermangel, der durch die anfangs konsequent betriebene Entnazifizierung verstärkt wurde, nicht durch heimgekehrte oder pensionierte Lehrer kompensiert werden konnte, so dass die Klassengröße weiterhin zwischen 60 und 70 Schülern betrug. Darüber hinaus waren viele Lehrer nicht voll einsatzfähig, da sie wegen unzureichender Versorgung mit Nahrungsmitteln an zahlreichen Krankheiten litten. ${ }^{15}$

Neben die institutionellen Schwierigkeiten traten individuelle Probleme der Schüler, die den geordneten Ablauf des wiederbegonnenen Unterrichts störungsanfällig werden ließen. Die weiten Schulwege in andere Stadtteile und der Mangel an Winterbekleidung, vor allem an Schuhen, deren „Qualität“ die Bilder zur Schulspeisung illustrieren, ${ }^{16}$ führten zu einem häufigen Fernbleiben der Schüler vom Unterricht, so dass im Dezember 1945 die Eltern von Seiten der Stadt nachdrücklich an die Schulbesuchspflicht ihrer Kinder erinnert werden mussten (Q4-Q6).

\section{3 „Sie wollen sofort alle unten aufgeführten Lehrer aus ihren Stellen entlassen.“ ${ }^{17}$ - Entnazifizierung der Lehrerschaft}

Bereits im Sommer 1945 begann die umfangreiche Entnazifizierung, die auch die Göttinger Lehrerschaft betraf. Die ersten Entlassungen erfolgten im Juni 1945 (Q7-Q8). Aufgrund der Vielzahl der zu überprüfenden Fälle und wegen eigener Überlastung ordnete der Hauptausschuss im Mai 1946 an, einen Unterausschuss zur Entnazifizierung der Lehrerschaft zu bilden (Q9). Seine Zusammensetzung war jedoch problematisch, denn er bestand größtenteils aus Lehrern, die über ihre Kollegen entscheiden mussten, so dass ihre Objektivität durch Zuneigung und Sympathie beeinträchtigt wurde.

\footnotetext{
Machterwerb und -teilung, in: Göttingen unterm Hakenkreuz. Nationalsozialistischer Alltag in einer deutschen Stadt - Texte und Materialien, Göttingen 1983, S. 78). Acht Lehrer waren bereits aus dem Krieg zurückgekehrt, fünf waren mittlerweile ausgeschieden, weil sie die Altersgrenze erreicht hatten (Stadtarchiv Göttingen, Stadtverwaltung und Militärregierung, D 44).

15 Jens-Uwe Brinkmann, „Nach Jahren der Entbehrung ...“ - Kultur und Schule, in: Göttingen 1945. Kriegsende und Neubeginn - Texte und Materialien zur Ausstellung im Städtischen Museum 31. März - 28. Juli 1985, Göttingen 1985, S. 217-256, hier S. 247 und Q31-Q33. Als weitere Kompensationsmaßnahme trieb die Militärregierung, die sich bewusst war, dass der Lehrermangel nicht von heute auf morgen behoben werden konnte (vgl. Q1, Punkt 9.), die Ausbildung neuer Lehrer voran. Für die Ausbildung zum Volksschullehrer setzte sie die Aufnahmekriterien herab, neben dem Reifezeugnis als üblicher Zugangsberechtigung forderte sie ausdrücklich auch ,junge Bauern und Arbeiter" zur Bewerbung auf, die ein „,hinreichendes Allgemeinwissen und pädagogische Begabung“ besitzen sollten (Amtliche Bekanntmachungen im Auftrage der Militärregierung sowie sämtlicher Behörden des Stadt- und Landkreises Göttingen Nr. 41 vom 29.12.1945, S. 1). Aufnahmekriterien waren durch eine Prüfung nachzuweisende „notwendige Kenntnisse“ sowie „musikalische Begabung“: „Im Spiel eines Musikinstrumentes (Orgel, Klavier, Geige, Blockflöte, Gitarre, Ziehharmonika) müssen die Grundlagen vorhanden sein.“ (ebd.)

16 Siehe Q26-Q29.

${ }^{17}$ Brief von Major Wilson an den Göttinger Oberbürgermeister vom 15.6.1945 (Stadtarchiv Göttingen, C44, Schulamt Nr. 128).
} 
Im Mai 1947 wandte sich der Ausschuss daher an britische Stellen, um sich enttäuscht über die Rahmenbedingungen und Ergebnisse seiner Arbeit zu beschweren (Q10), die - nach Meinung der Kommission - zu Ungerechtigkeiten geführt habe.

Die Hauptgründe seien zum einen die lange Verfahrensdauer und die dadurch bedingte Suspendierung der Lehrer, die in der Zeit bis zum Urteil ohne Einkommen waren, zum anderen seien die Vorschriften zur Überprüfung der Lehrer besonders streng und drittens böte sich entlassenen Kollegen keine berufliche Perspektive. Die Antworten zweier britischer Dienststellen (Q11-Q12) belegen die ernsthaften Bemühungen der britischen Seite um Entnazifizierung und Reeducation, wohingegen sie mit Befremden und Unverständnis auf die angeführten Klagen des Unterausschusses reagieren.

Aus dem Beschwerdebrief des Ausschusses werden die Gründe für das Scheitern der Entnazifizierung ersichtlich, die - laut Dennis Meyer - immer mehr zu einer „Farce“"18 wurde.

Anfang des Jahres 1947 hatten die Briten das so genannte „Befreiungsgesetz“ von den Amerikanern übernommen, das die Entnazifizierung deutschen Spruchkammern überantwortete. Diese bestanden aus Laien und sollten die ausgefüllten Fragebögen überprüfen und beurteilen, was eine lange Verfahrensdauer zur Folge hatte. Außerdem lag die Verantwortung nun allein in deutscher Hand, so dass die Zusammensetzung der Kammern und die Einstellung der Ausschuss-Mitglieder zu ihrer Arbeit entscheidend für das Ergebnis des Verfahrens waren.

Die Ausstellung so genannter „Persilscheine“19 zog immer weniger Verurteilungen nach sich; das frühere Ziel, die Verstrickung des Einzelnen mit dem Nationalsozialismus aufzuklären und zu bestrafen, geriet in den Hintergrund, stattdessen standen nun politische und soziale Rehabilitation im Vordergrund. ${ }^{20}$

Interessant erscheint in diesem Zusammenhang ein Brief des Göttinger Stadtschulrates Hermann Witte, der zugleich Vorsitzender des Entnazifizierungsausschusses war. Witte, seit 1924 Direktor des Staatlich Preußischen Gymnasiums in Schleusingen (Kleinstadt in Südthüringen), wurde von den Nationalsozialisten im Oktober 1933 zum Studienrat degradiert und nach Naumburg an der Saale versetzt. 1937 wurde er mit 54 Jahren wegen ,judenfreundlicher Haltung“ zwangspensioniert, 1938 zog er nach Göttingen, im Frühsommer 1945 wurde er zum

\footnotetext{
18 Dennis Meyer, „Entnazifizierung“, in: Torben Fischer/Matthias N. Lorenz (Hg.), Lexikon der „Vergangenheitsbewältigung“ in Deutschland. Debatten- und Diskursgeschichte des Nationalsozialismus nach 1945, Bielefeld 2007, S. 18-19, hier S. 18.

19 „Persilschein“ ist - in Anlehnung an das Waschmittel „Persil“ - die Bezeichnung für ein Dokument, welches im Entnazifizierungsverfahren die Unschuld der zu entnazifizierenden Person beweisen sollte. Dafür „stellten sich Nachbarn, Freunde und Kollegen gegenseitig Unbedenklichkeitserklärungen aus" (Meyer, Entnazifizierung, S. 18), um durch diesen guten Leumund entlastet und demzufolge entnazifiziert zu werden sowie von allen Vorwürfen und Anschuldigungen endgültig „,reingewaschen“" zu sein, wobei „Reinheit“ eine Metapher für Unschuld ist.

${ }^{20}$ Vgl. ebd., S. 18-19. Dort finden sich auch weitere Literaturhinweise auf die Frage nach der Bewertung der Entnazifizierung.
} 
Stadtschulrat ernannt. ${ }^{21}$ In dieser Funktion ersucht er den Heiligenstädter Schulrat um ein Gutachten über einen Rektor, dessen unfreundliches Verhalten gegenüber Eltern und Kollegen er mit einer Diabetes-Erkrankung rechtfertigt und dessen politische Einstellung er durch das Gutachten in Erfahrung bringen will (Q13). Trotz vormals erfahrener Repressionen tritt er nicht entschieden für die Entnazifizierung ein, sondern ist durch seine kollegiale Beziehung befangen. Als bedeutender und einflussreicher Exponent unterläuft er aus persönlichen Motiven die Intention der britischen Militärbehörden. Dieses Beispiel verdeutlicht die Diskrepanz zwischen angestrebtem Ideal und vollzogener Praxis im Laufe der Entnazifizierung.

\section{4 „Sie werden persönlich dafür verantwortlich gemacht, daß in allen Exemplaren die Seiten 57 - 63 unleserlich gemacht werden. “22 - Unterrichtsmaterialien und Reeducation}

Neben den organisatorischen Problemen stellte sich vor allem die Frage nach den Unterrichtsinhalten und -methoden. Die Militärregierung setzte enge Grenzen. Ehe Unterricht erteilt werden konnte, behielt sie sich die Zustimmung zum Lehrplan, der eingereicht werden musste, vor; ferner unterlagen die Lehrbücher einer Genehmigung.

Da Papier für den Druck neuer Bücher bzw. für den Nachdruck vorhandener Bücher, die vor 1933 erschienen waren, knapp war, mussten die Lehrkräfte selbst die vorhandenen Exemplare notdürftig „säubern“ und als Übergangslösung weiterhin benutzen (Q14-Q15).

Dieses Vorgehen war jedoch von Seiten der Militärregierung nur als Provisorium gedacht, bis zu dem Zeitpunkt, an dem neue Lehrpläne und Lehrbücher ausgearbeitet sein würden (Q16-Q17). Auch die vorhandenen Unterrichtsfilme aus der Zeit des Nationalsozialismus wurden in zwei Kategorien eingeteilt: Liste A (Q18) enthielt Filme, deren Verwendung in den Schulen genehmigt war, Liste B (Q19) indizierte die verbotenen Filme, die unter Verschluss gehalten und auf Befehl der Militärregierung schließlich vernichtet wurden. Dass die Zensur dabei bisweilen kuriose Formen annahm, zeigt eine Anweisung des britischen Erziehungskontrolloffiziers Captain Bennitt, der den Film „Der Wolf und die 7 Geißlein“ verbot (Q20).

Trotz aller Einschränkungen war aber offensichtlich ein qualitativ guter Unterricht möglich, wie ein Bericht über den Besuch des Leiters der Abteilung Volksund Mittelschulen für die britische Zone illustriert (Q21).

Aber nicht nur die Lehrmittel wurden demokratischer und pluralistischer gestaltet, auch Habitus und Umgangsformen der Schüler sollten durch die Reeduca-

\footnotetext{
${ }^{21}$ Lebenslauf Hermann Witte, undatiert (Stadtarchiv Göttingen, Personalamt Nr. 717, Blatt 2).

22 Brief des Erziehungsoffiziers Sutton an den Geschäftsführer der Wirtschaftskammer Hildesheim, Kreisstelle Göttingen vom 31.10.1945 (Stadtarchiv Göttingen, D45, Blatt 39).
} 
tion verändert, vor allem entmilitarisiert werden. Die neuen Verhältnisse sollten durch neues Schülerverhalten ihren Ausdruck finden, z. B. durch den so genannten „Hackenklappen“-Erlass, der verbot, die Fersen hörbar zusammenzuschlagen (Q22).

\section{5 „Mit dem Essnapf zur Schule“ ${ }^{(23}$ - die Schulspeisung}

Um den Gesundheitszustand und die Versorgungslage der Schüler zu verbessern und somit die regelmäßige Teilnahme am Unterricht zu erhöhen, wurde in der gesamten britischen Zone im Frühjahr 1946 eine Schulspeisung eingeführt, von der aber „Selbst- und Teilselbstversorger“24 ausgeschlossen waren. In Göttingen liefen die Planungen dafür im Februar 1946 an, als Starttermin war zunächst der 1. April geplant, doch verzögerte sich der tatsächliche Beginn bis zum 27. Mai. Seitdem erhielten ca. 8700 Kinder zwischen 6 und 18 Jahren eine warme Zusatzmahlzeit. $^{25}$

Nachdem die Schulspeisung aufgrund von Missverständnissen und Kommunikationsschwierigkeiten sowie bisweilen mangels Nachschub manchmal nur dreimal wöchentlich durchgeführt werden konnte, erfolgte mit der Umstellung auf die Hoover-Speisung ${ }^{26}$ im Herbst 1947 eine regelmäßige sechstägige Speisung, die täglich ca. $350 \mathrm{kcal}$ enthielt und auch in den Ferien stattfand. Doch sogar in den Ferien mussten die Mahlzeiten im Schulgebäude eingenommen werden, es war strengstens verboten, Nahrung mit nach Hause zu nehmen. ${ }^{27}$

Die Schulspeisung beinhaltete keine Delikatessen, sondern war eher von Monotonie und Routine ${ }^{28}$ geprägt. Ein Brief des Stadtschulrates an die zuständige Regierungsabteilung (Q23) berichtet von der Göttinger Ernährungssituation im Mai 1947, als aufgrund der mangelhaften Versorgung mit Lebensmitteln als einzige

\footnotetext{
${ }^{23}$ Fotoarchiv des Städtischen Museums Göttingen, Titel auf der Rückseite des Neg.-Nr.: 245/11.

24 Als Selbstversorger galten Personen, die ihre Nahrungsmittel selbst erzeugten und deshalb keinen Anspruch auf Lebensmittelkarten hatten. Teilselbstversorger war, wer Teile der ihm zustehenden Rationen selbst erzeugen konnte und nur Lebensmittelkarten für Nahrungsmittel erhielt, die er selbst nicht produzieren konnte. In der Regel handelte es sich bei beiden Kategorien um Landwirte im Haupt- bzw. Nebenerwerb (vgl. Werner Abelshauser, Wirtschaft in Westdeutschland 1945 - 1948. Rekonstruktion und Wachstumsbedingungen in der amerikanischen und britischen Zone, Stuttgart 1975, S. 134).

${ }^{25}$ Vgl. Stadtarchiv Göttingen, Stadtverwaltung und Militärregierung, D 100.

${ }^{26}$ Der ehemalige amerikanische Präsident Herbert C. Hoover war Vorsitzender des „Famine Emergency Committee" und wurde im Auftrag des amtierenden Präsidenten Harry S. Truman nach Deutschland gesandt, um die Hungerkrise zu lösen. Neben dem Entwurf eines längerfristigen Hilfsplans schlug er als Sofortmaßnahme „eine tägliche Zusatzspeisung (350 kcal.) für Kinder und alte Menschen“"vor (Günter J. Trittel, Hunger und Politik. Die Ernährungskrise in der Bizone (19451949), Frankfurt am Main und New York 1990, S. 118). Diese Schulspeisung trug ab Herbst 1947 seinen Namen.

27 Vgl. Stadtarchiv Göttingen, Stadtverwaltung und Militärregierung, D 100.

28 Alf Lüdtke, Einleitung: Was ist und wer treibt Alltagsgeschichte?, in: Alf Lüdtke (Hg.), Alltagsgeschichte: Zur Rekonstruktion historischer Erfahrungen und Lebensweisen, Frankfurt am Main und New York 1989, S. 9-47, hier S. 11.
} 
Speise Erbsensuppe angeboten werden konnte - und zwar mehr als vier Wochen lang. Trotzdem bewertet der Schüler Günther Schmalstieg, der in einem Aufsatz den konkreten Ablauf der Schulspeisung beschreibt, insgesamt das Essen als „recht schmackhaft" (Q24). Ein erhaltener Speiseplan vom Dezember 1947 (Q25) bezeugt die Monotonie und Routine der Schulspeisung; er enthält folgende Gerichte: Salzige Haferflockensuppe, Nudelsuppe mit Fleisch, Kakaotunke mit Brötchen, Hülsenfrüchtesuppe mit Fleisch, Haferflocken-Schokolade-Brei und Mehlmus mit Trockenobst. In den folgenden drei Wochen wiederholten sich die Speisen; es war nicht erlaubt, die Reihenfolge zu ändern.

Obwohl bei den Mahlzeiten Gleichförmigkeit vorherrschte, erfreute sich die Schulspeisung, wie Schmalstieg konstatiert, großer Beliebtheit und die Schüler nahmen sie rege in Anspruch, was die Bilder zur Schulspeisung illustrieren (Q26Q29). Gleichzeitig bilden sie aber auch die Notwendigkeit der Schulspeisung ab, indem sie den Ernährungszustand der Kinder und Jugendlichen dokumentieren. Sowohl die Zahl der Teilnahmeberechtigten als auch der Teilnehmerkreis selbst waren ein ständiger Anlass zur Diskussion. Eine bedeutende Streitfrage war dabei die Versorgung der Lehrer. Regierung und Schulamt diskutierten darüber, ob diese berechtigt seien, an der Schulspeisung teilzunehmen, denn mit der Umstellung auf die Hoover-Speisung, die den Kreis der teilnahmeberechtigten Schüler um ca. zwei Drittel kürzte, sollten auch die Lehrer davon ausgeschlossen werden, wogegen sie vehement protestierten. In Eingaben, Petitionen, Berichten und Erklärungen, die einerseits an lokale Entscheidungsträger wie den Stadtschulrat, andererseits an übergeordnete Behörden wie die Regierung in Hildesheim adressiert waren, legten sie die Belastungen ihres beruflichen Alltages sowie die gesundheitlichen Probleme und Erkrankungen dar, die aus einer unzureichenden Ernährung resultierten, um auf diese Weise weiter an der Schulspeisung teilnehmen zu können (Q30-Q33). Trotz zahlreicher Änderungen erfolgte die Schulspeisung noch bis 1949.29

\section{6 „Im Allgemeinen ist die innere Haltung nach allem erstaunlich gut. “30 - Fazit: die Geschichte des Mangels als Erfolgsgeschichte}

Obwohl der Wiederbeginn des Schullebens von zahlreichen Mängeln, Unzulänglichkeiten und Hindernissen geprägt war, so waren trotz widriger Umstände in allen Lebensbereichen der Wille zum Wiederaufbau und der Wunsch, zu einem „,normalen“ Leben mit einem geregelten Alltagsablauf und mit schulischer Routine zurückzukehren, besonders intensiv. ${ }^{31}$ Schule war ein ,Zauberwort" ${ }^{\text {“32. }}$.

\footnotetext{
${ }^{29}$ Michael, Göttinger Schulen, S. 517.

30 Brief des Göttinger Schulrats Hermann Witte an die Regierung Abt. II B2 in Hildesheim vom 15.3.1948. Zur wirtschaftlichen Lage siehe auch den Beitrag von Timo Stiehl in diesem Band.

31 Vgl. Brinkmann, Entbehrung, S. 255.

32 Von Thadden, Militärregierung, S. 89.
} 
Anders als es der Titel dieses Beitrages auf den ersten Blick mit dem Zitat aus Wilhelm Buschs „Max und Moritz" nahe legt, der auf den Beschlusscharakter von Erlassen und Verordnungen der behördlichen Regulierung „von oben“ anspielt, treten auch Schüler, Eltern und Lehrer als handelnde Akteure sichtbar in den Vordergrund. Eigeninitiative und ,zivilgesellschaftliches“ Engagement „,von unten“ ergänzten und korrigierten die behördlichen Vorgaben. In einem Brief an die Regierung in Hildesheim vom 15. März 1948 schrieb der Stadtschulrat Hermann Witte Folgendes: „In beiden Mittelschulen wird den Kindern ein großer Teil der Schulzucht zugeschoben; mit gutem Erfolg. - Die Egelsbergschule hat ein Klassenparlament eingeführt, in einer 6b. Die Mädchen setzten u. a. auf die Tagesordnung: ,Wie können wir in unserer Klasse das Schulschwänzen verringern?' Sie haben beschlossen, mit den Schwänzern oder deren Mutter zu reden und diese Kinder auf dem Schulwege abzuholen. Das unentschuldigte Schwänzen hat fast ganz aufgehört. Daß dem etwa drohenden Pharisäertum vorgebengt wurde, ist selbstverständlich. Wohl jede unserer Schulen könnte Parallelen berichten.

Darüber hinaus erzählen Rektoren und Lebrer oft genug von positiv erfreuenden Zügen. Zum Beispiel: diesen Winter ist der Schulbesuch allgemein wesentlich besser als in den Übergangszeiten 1946/47 - in Zeiten des starken Frostes waren ja damals die Schulen geschlossen. Auch bei nassem Wetter kommen Kinder mit jammervollem Schubwerk zur Schule. Ein Vater fährt bei nassem Wetter seinen schublosen Jungen regelmäßig zur Schule, obwohl er öfters, aufgeschrieben" wurde. [...] Daß auf der Oberschule für Mädchen in einer 12. Klasse einem Flüchtlingsmädchen Reise- und Aufenthaltskosten auf einer Nordseeinsel von den Kameradinnen geschenkt wurde, weil sie es nötig habe; daß in einer anderen Klasse ein Mädchen seine Lebensmittelmarken verkaufte, um ibre [sic] kranke Schwester verpflegen zu können, selbst von der Schulspeisung lebte und aus der Klasse regelmäßig mehrere Portionen angeboten erbielt - bis die Sache entdeckt und andere Hilfe ermöglicht wurde - sei nebenbei erzählt. Auch von solchem guten Kameradschaftsgeist wäre viel zu erzählen.

In der Egelsbergschule ist der Zusammenhalt zwischen Schule, Kindern und Eltern in 11/2 Jabren so fest geworden, daß der Rektor nur zu sagen brauchte: ,wir haben Glas für die Turnhallenfenster, aber uns fehlen 1200 Nägel dazu (als Ersatz für Kitt) - wer bringt welche mit?' und am nächsten Tage hat er über 2000. - Unsere Schulen verschmutzen immer stärker; es fehlt an Reinemachefrauen und-material. In der Mädchenmittelschule fragt eine der älteren Klassen den Rektor: dürfen wir nicht mal den ganzen oberen Flur und die Klassen daran ordentlich reinemachen? Das Material bringen die Mädchen trotz der häuslichen Knappheit mit. Die Egelsbergschule erbielt von den Eltern Reinemachezeng, die größeren Mädchen reinigen regelmäßig die Schule. Ich habe diese Nachrichten nicht gesammelt, sondern schreibe nieder, was mir an einem stillen Abend ins Gedächtnis kommt. Gewiß könnte viel mehr erzä̈hlt werden!"33

Kreative Problemlösungen förderten bei allen Beteiligten gedämpften Optimismus und Lebensfreude trotz der vielen präsenten Probleme, so dass der 1952 amtierende Stadtschulrat Max Buchheim anlässlich der bevorstehenden 1000Jahrfeier Göttingens konstatieren konnte:

${ }^{33}$ Hauptstaatsarchiv Hannover, Hann. 180 Hildesheim Nr. 7199. 
„Wenn diese Betrachtungen angesichts der bevorstehenden 1000 Jahrfeier unserer Stadt angestellt werden, dann sind sie einmal dazu geeignet, die großen Sorgen unserer Stadt auf dem Gebiete der Schulraumnot deutlich zu machen, und zum andern auch im Rückblick auf die letzten Jahre aufzuzeigen, wie viel bereits von der Stadt unternommen worden ist. Göttingen kann mit Recht von sich sagen, daß auf dem Gebiete des Schulwesens alles irgendwie Mögliche getan wurde und braucht nicht erst zu versichern, daß es der Tradition unserer Stadt entsprechend auch weiterhin nicht an Bemühungen zur Behebung und Beseitigung der Schulraumnot fehlen wird. Göttingen war eine Stadt der Schulen, Göttingen ist eine Stadt der Schulen und wird es auch in Zukunft bleiben." 34

\section{Literatur zum Weiterlesen}

Jens-Uwe Brinkmann, „Nach Jahren der Entbehrung ...“ - Kultur und Schule, in: Göttingen 1945. Kriegsende und Neubeginn - Texte und Materialien zur Ausstellung im Städtischen Museum 31. März - 28. Juli 1985, Göttingen 1985, S. 217-256.

Berthold Michael, Die Göttinger Schulen vom Wiederbeginn 1945 bis zur Gegenwart 1989, in: Rudolf von Thadden/Ernst Böhme/Dietrich Denecke (Hg.), Göttingen: Geschichte einer Universitätsstadt, Bd. 3: Von der preußischen Mittelstadt zur südniedersächsischen Großstadt: 1866-1989, Göttingen 1999, S. 511-533.

Wilhelm Schütte, Aus der Schulchronik der ehemaligen Oberschule für Mädchen.

Die Schule in der Zeit von April 1945 bis Oktober 1946, in: Göttingen 1945.

Kriegsende und Neubeginn - Texte und Materialien zur Ausstellung im

Städtischen Museum 31. März - 28. Juli 1985, Göttingen 1985, S. 257-270.

Wiebke von Thadden, Göttingen und seine Militärregierung, in: Göttingen 1945.

Kriegsende und Neubeginn - Texte und Materialien zur Ausstellung im

Städtischen Museum 31. März - 28. Juli 1985, Göttingen 1985, S. 69-92.

Günter J. Trittel, Hunger und Politik. Die Ernährungskrise in der Bizone (19451949), Frankfurt am Main und New York 1990.

\footnotetext{
34 Max Buchheim, Die Göttinger Volks- und Mittelschulen. Eine Darstellung der äußeren Schulverhältnisse der Stadt Göttingen unter Berücksichtigung der Entwicklung seit 1945, in: Göttinger Jahrbuch 1 (1952), S. 83-86, hier S. 86.
} 


\section{Botschaft des Oberbefehlshabers an die Bevölkerung der britischen Zone}

1. Die Nationalsozialisten haben das deutsche Erziehungswesen in den Staub gezogen. Sie wollten Eure Kinder geistig vergiften. Das Wah re haben sie ihnen vorentlialten und haben ihnen dafür falsche Werte gegeben. Sie haben ibnen beigebracht, Freiheit und Duldsamkeit zu verachten, Gewalt und Unterdrückung zu bewundern.

2. Der Plan der Nationalsozialisten wurde nur vereitelt durch die siegreichen Schlachten, die meine Truppen und ihre großen Verbündeten geschlagen haben.

3. Was die Nationalsozialisten angerichtet haben, beabsichtige ich wieder in Ordnung bringen zu lassen.

4. Zuerst werden Schulen und Universităten baldmöglichst wieder eröffnet werden. Das ist keine leichte Aufgabe. Aber in verschiedenen Gebieten machen die Schulen schon wieder auf. Mehr und mehr werden im Laufe des năchsten Monats folgen. Bis zum 1. Oktober dürfen alle veriügbaren Schulen, mit Ausnahme nationalsozialistischer Schulen, wieder in Betrieb sein.

5. Drei Dinge sind nötig, um Schulen wieder aufzumachen: Gebäude, Lehrmaterial und zuverlässige Lehrkräfte.

6. Schulgebäude, die instand gesetzt werden können, werden instand gesetzt. Schulen, in denen meine Truppen oder Fremdarbeiter und Obdachlose oder wichtige Verwaltungsstellen untergebracht werden mußten, werden geräumt werden, sobald es die Umstände erlauben.

7. Die Schulbücher, mit denen die Nationalsozialisten die Kindergemüter vergifteten, werden nicht mehr im Schulunterricht verwendet werden. Ich lasse als Notmaßnahme Neuauflagen von Schulbilichern drucken, die vor den Nationalsozialisten in Gebrauch waren. Neue Schulbücher, von Deutschen in Deutschland geschrieben, Bücher, aus denen ein gesunder Geist spricht, sind in Vorbereitung. Síe werden so rasch wie möglich gedruckt.

8. Der Mangel an Lehrkräften wird ernst sein. Ich werde keinen Lehrer in der Schule dulden, dessen Vergangenheit nicht den eingehendsten Nachforschungen standhält. Lehrer, die von den Nationalsozialisten zu Unrecht entlassen wurden, werden wieder eingesetzt. Ich werde alle kriegsgefangenen Lehrer freilassen, die würdig sind, bei der Neuerziehung Ihrer Söhne und Töchter mitzuarbeiten.

9. Trotz dieser MaBnahmen dürfte aber in vielen Gegenden auf längere Zeit hinaus nur Teilunterricht möglich sein. Um dem abzuhelfen, wird, sobald die Kinder wieder unter gesunden Bedingungen zur Schule gehen, die Ausbildung neuer Lehrer und die Umschulung alter mit Vordringlichkeit durchgefuhrt werden.

10. Das Ansehen der deutschen Universitäten ist unter dem nationalsozialistischen Regime in den Augen der Welt tief gesunken. Die Universitätsgebäude sind während des Krieges schwer beschädigt worden. Ich werde keinen Professor oder Dozenten im Amt lassen, der seine Gaben im Dienste des Nationalsozialismus prostituiert hat. Die Gebäude werden, wo es möglich ist, wieder instand gesetzt werden.

11. Ich werde den Erwachsenen-Unterricht fördern. Dabel soll auf freie Aussprache zwischen deutschen Männern und Frauen aller Schichten, Bekenntnisse und Altersgruppen hingezielt werden.

12. Mein Ziel auf lange Sicht ist, daß deutsche Jungen und Mädel durch eine frohe Schulzeit zu würdigen Staats- und Weltbürgern heranwachsen sollen. Ihre eigene Urteilskraft muß sie vor falschen Lehren der Gewalt und Tyrannei slchern. Auch die dentschen Männer und Frauen müssen ihre Verantwortung lernen, besonders für das, was im Namen der Gemeinschaft geschieht, in der sie leben.

13. In all diesen Dingen werden wir mit den Amerikanern, mit den Russen und den Franzosen zusammenarbeiten.

14. Ich werde Thnen kelne fremden Erziehungsgrundsätze und Lehrmethoden aufzwingen. Es soll Ihnen freistehen, zu experimentieren, neue Ideen auszuprobieren. Meine Offiziere werden Ihnen dabei helfen. Aber was ich niemals dulden werde, ist eine Rückkehr zum Nationalsozialismus, zum Militarismus oder zum Angriff sgeist in irgendeiner Form.

15. Sie, deutsche Väter und Mütter, müssen Ihren Teil dazu beitragen, um Ihre Kinder auf einen gesunden Lebensweg zurückzuführen. Ich werde Ihnen helfen. Sie müssen mir helfen. Das ist mein Befehl.

gez.: B. L. Montgomery

Feldmarschall, Oberbefehlshaber der britischen Zone.

Q1: Neuer Hannoverscher Kurier. Nachrichtenblatt der Alliierten Militärregierung, 1. Jg., Nr. 21 vom 28.8.1945, S. 1. 
Stadt $G$ \& $t$ t $n \&$ \&

tbersicht uber die Schulen.

\begin{tabular}{|c|c|c|c|c|}
\hline Schulart & $\begin{array}{l}\text { Name der } \\
\text { Sohule }\end{array}$ & $\begin{array}{l}\text { Schil- } \\
\text { ler- } \\
\text { zahl }\end{array}$ & $\begin{array}{l}\text { z.Zt. } \\
\text { Verwendung }\end{array}$ & Antrag \\
\hline \multicolumn{5}{|c|}{. } \\
\hline Gymnasium & Staatlich & 300 & Lazarett & \\
\hline $\begin{array}{l}\text { Oberschule } \\
\text { fír Jungen }\end{array}$ & & 600 & Lazarett & Räumung $1 . d .3$ Obersch. \\
\hline $\begin{array}{l}\text { Oberschule } \\
\text { f. Wädchen }\end{array}$ & & 850 & M1l.Gov. & Freigabe \\
\hline $\begin{array}{l}\text { Mittelsch. } \\
\text { f. Jungen }\end{array}$ & $\begin{array}{l}\text { Volgt- } \\
\text { schule }\end{array}$ & 600 & $\begin{array}{l}\text { Rüickwande- } \\
\text { rerheim }\end{array}$ & \\
\hline $\begin{array}{l}\text { Mittelsch. } \\
\text { f. Mädchen }\end{array}$ & $\begin{array}{l}\text { Personn- } \\
\text { schule }\end{array}$ & 550 & Pre1 & \\
\hline \multirow[t]{5}{*}{ Volksschulen: } & Albanisoh. & 950 & Prei & \\
\hline & Iuthersch. & 1000 & $\frac{\text { Krgeff }}{\text { (Deutsche) }}$ & \multirow{2}{*}{$\begin{array}{l}\text { Freigabe, da statt } 400 \\
\text { nur } 20-40 \text { Gefangene } \\
\text { Freigabe für Rückwande- } \\
\text { rerheim. }\end{array}$} \\
\hline & Jahnschule & 950 & Lazarett & \\
\hline & Herbartsch. & 950 & Lazarett & \\
\hline & Egelsbergsch. & .1000 & $\begin{array}{l}\text { Pid.kwande- } \\
\text { rerheim u. } \\
\text { Hilfskr.Hau }\end{array}$ & $\begin{array}{l}\text { Schule, da weit ent- } \\
\text { fernter Ortsteil } \\
\text { us }\end{array}$ \\
\hline $\begin{array}{l}\text { Hilfsschule } \\
\text { f.Schwachbe- } \\
\text { gabte }\end{array}$ & $\begin{array}{l}\text { Pestalozzi- } \\
\text { schule }\end{array}$ & 150 & ere1 & \\
\hline Berufsschule & Gew.-Schule & 1800 & Lazarett & $\begin{array}{l}\text { Freigabe, da Umschulung } \\
\text { der Arbeit glosen drin- } \\
\text { gend notwendig }\end{array}$ \\
\hline Handelsschule & $\begin{array}{l}\text { Handelslehr- } \\
\text { enstalten }\end{array}$ & 900 & $\begin{array}{l}\text { Mil.Gov. } \\
\text { (Royal } \\
\text { Airforce) }\end{array}$ & Freigabe - dagl. \\
\hline
\end{tabular}

Q2: $\quad$ Stadtarchiv Göttingen, D 44, Blatt 43. 


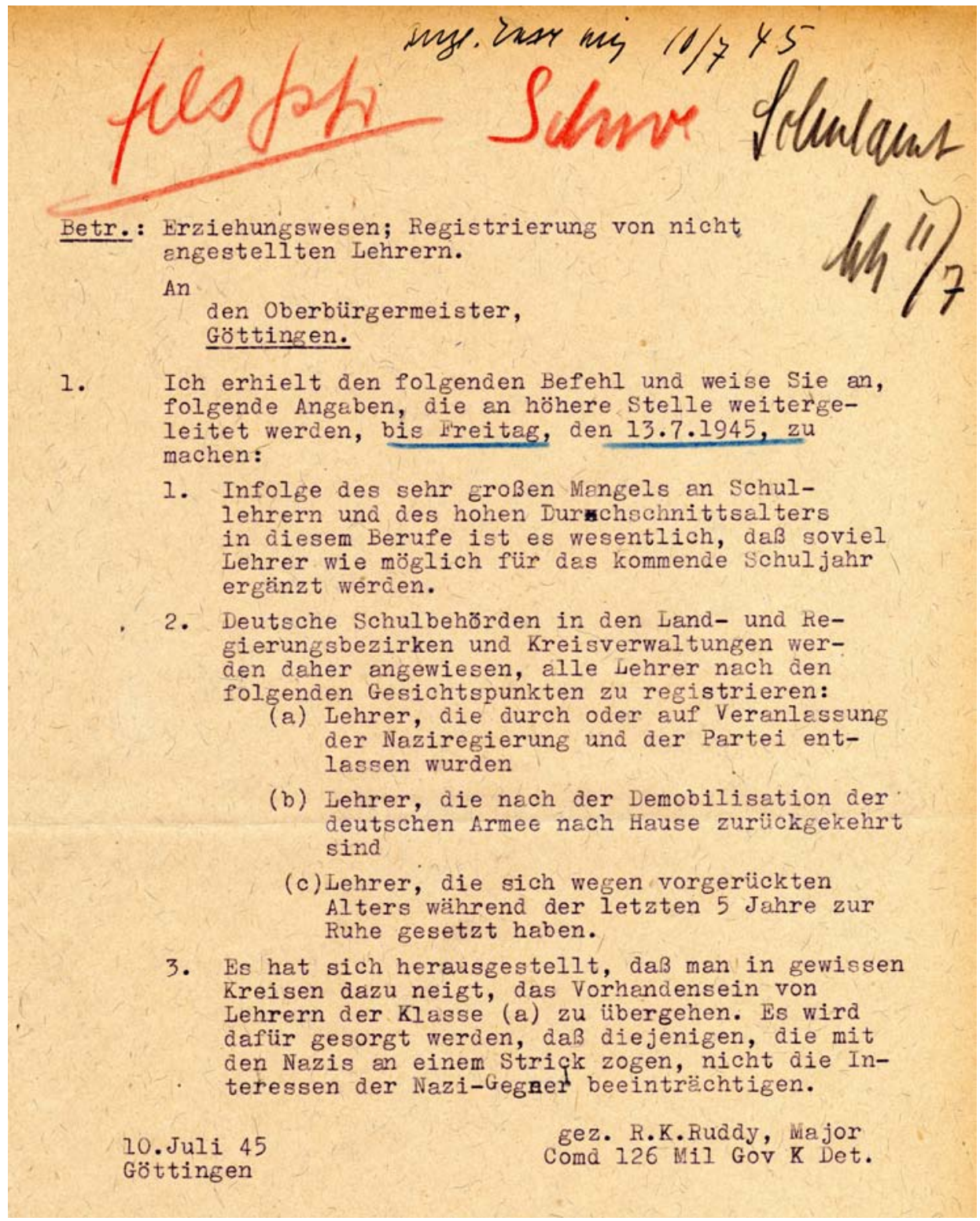

Q3: Stadtarchiv Göttingen, Schulamt Nr. 128: Entnazifizierung der Lehrkräfte 1945-1946. 


\section{Pilicht zum regelmäBigen Schulbesuch}

Die Eltern werden an ifre Pflicht, ihre Kinder zum regelmäBigen Schulbesuch anzuhalten, crinnert.

1. Die Pflicht zum Besuche der Schule umfaßt die Verpflichtung zur regelmäBigen Teilnahme am schulplanmäBigen Unterricht und an allen sonstigen den Unterrichts- und Erzichungszielen der Schule dienenden Schulveranstaltungen, auch wenn sie außerhalb des Schulgrundstücks oder der üblichen Schulzeit stattfinden.

2. Bci Schulversäumñis wegen Krankheit sind die Erzichungsberechtigten verpflichtet, spätestens am 2. Tage die Klassenlehrer zu benachrichtigen.

3. Zu jeder Schulversäumnis aus einem anderen Grund als Krankheit bedarf es der vorherigen Bewilligung von Urlaub durch die Schule, der rechtzeitig beantragt werden muB.

4. Wer den Bestimmunqen über die.Schulpflicht vorsätzlich oder fahrlăssig zuwiderhandelt, wird mit Geldstrafe bis zu 150.- RM. oder mit Haft bestraft, sofern nicht nach anderen Gesetzen eine hŏhere Strafe verwirkt ist.

5. Nicht entschuldbares Zuspätkommen, besonders bei öfterer Wiederholung, unterliegt einer Schulstrafe.

Grttingen, den 6. Dezember 1945.

Der Oberburgermelster. Der Landrat.

Q4: Amtliche Bekanntmachungen. Im Auftrage der Militär-Regierung, sowie sämtlicher Behörden des Stadt- und Landkreises Göttingen, Nr. 39 vom 15.12.1945, S. 1. 
Ubersetzung (weigel)

\section{Shmberec esur in} Bingang: $6.2 .3612 \mathrm{Jhr}$ Rether

(bngl. Original an 126 zurickgegeben)

Hild esheim

subject: shoes for children

1) It is reported that attendance of children at schools is falling off owing to lack of Footwear. It is not so much the question of repair as the greater part of the footwear is beyond repair.

2) In order to submit a bid to HQ Mil Gov Hannovar Region for foowwar for school ohildren a return is required from $K$ Dets giving an approx bid for the number of shoes required in order to overcome the position as shown in para 1 above. This return is required by 10 Febr. 46

signed Hurndall

\section{Betr.: Sohwhe firir Kinder}

1) wird berichtet, dass der sohulbesuch der Kinder absinkt wegen Mangel an Fussbekleldung. Bs 1 st nicht so sehr eine Frage der Reparatur als dass der grösste $T$ ell der Fussbekleidung nioht mehr reparaturfähig 1st.

2) Um der Militärregierung Hannover einen Antrag auf Fussbekleidung fur Schulkinder nnterbroit en zu-können, wird von den $\mathrm{K}$ Detachments ein Berich erbeten mit der ungefähren luenge von schuhen die benótigt werden, um dex in Abs. I geschildert 9 Lage abzuhelfen. Dieser Bericht muss bis zum 10. Februar eing eh en.

31. Jan. 1946

gez. Hurndall

Hildesheim

Q5: Stadtarchiv Göttingen, Schulamt Nr. 99,1: Verfügungen der Militärregierung 1945-1948.

2. Mittel lungen des Oberbiirgermeisters.

a) Der Oberbilrgermeister teilt mit, das or im Auftrage des Rata Professor Windaug za seinem 70.' Geburtstag Blumen und Glikckwinsche tbermittelt habe. Er verliest das. Glückwunschschreiben sowle die Antwort von Professor windaus.

b) Der Oberburgermeister telit mit, daB das Stadtschulamt eine Erhebung tber die sozialen Verhăltnisse der Sohulkinder gemacht habe. Daraus gehe hervor, daB von 6103 Sohulkindern $32,7 \%$ keine Hinterschuhe haben, 27,6 \% haben kelne Hinterstrimple, $11,6 \%$ haben kein eigenes Hemd, 16,4 \% haben 1 igenes Hemd, 28,4 \% schlafen za zwe1t in einem Bett und 3,3 \% sohlafen zu mehr als 2 Kinder in einem Bett. Ohne heizbaren Raum sind $2 \%$ Besondere milsse erwähnt werden, daB von 2657 Kindern 6,4 \% in keinem Bett schlafen. Diese Feststellungen selen erschilternd. Der Oberbirgermeister bat die Vertreter der Militärregierung, ung zu helfen, um dieser aubersten Not Herr zu werden.

Q6: Stadtarchiv Göttingen, Protokoll 01/1947 der Ratsversammlung der Stadt Göttingen vom 17./24.1.1947. 
D.Obgmotr.

1). Präulein

\section{Februar 1946}

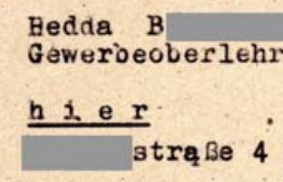

\section{Gegen Zustellungsurkunde.}

Auf Anorảnung der Militär-Regiering werden Sie mit sofortiger Wirkung aus Ihrem Amte entlassen. Sie dürien ohne Genehmigung der Mil.Reg. in keiner erzieherischen. Tk̈tigkeit mehr beschätigt werden. Gegen die Bntlassung kann innerhalb 2 Wochen nach Zustellung Berufung eingelegt werden.

2)

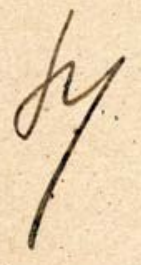

Q7: $\quad$ Stadtarchiv Göttingen, Schulamt Nr. 128: Entnazifizierung der Lehrkräfte 1945-1946. 


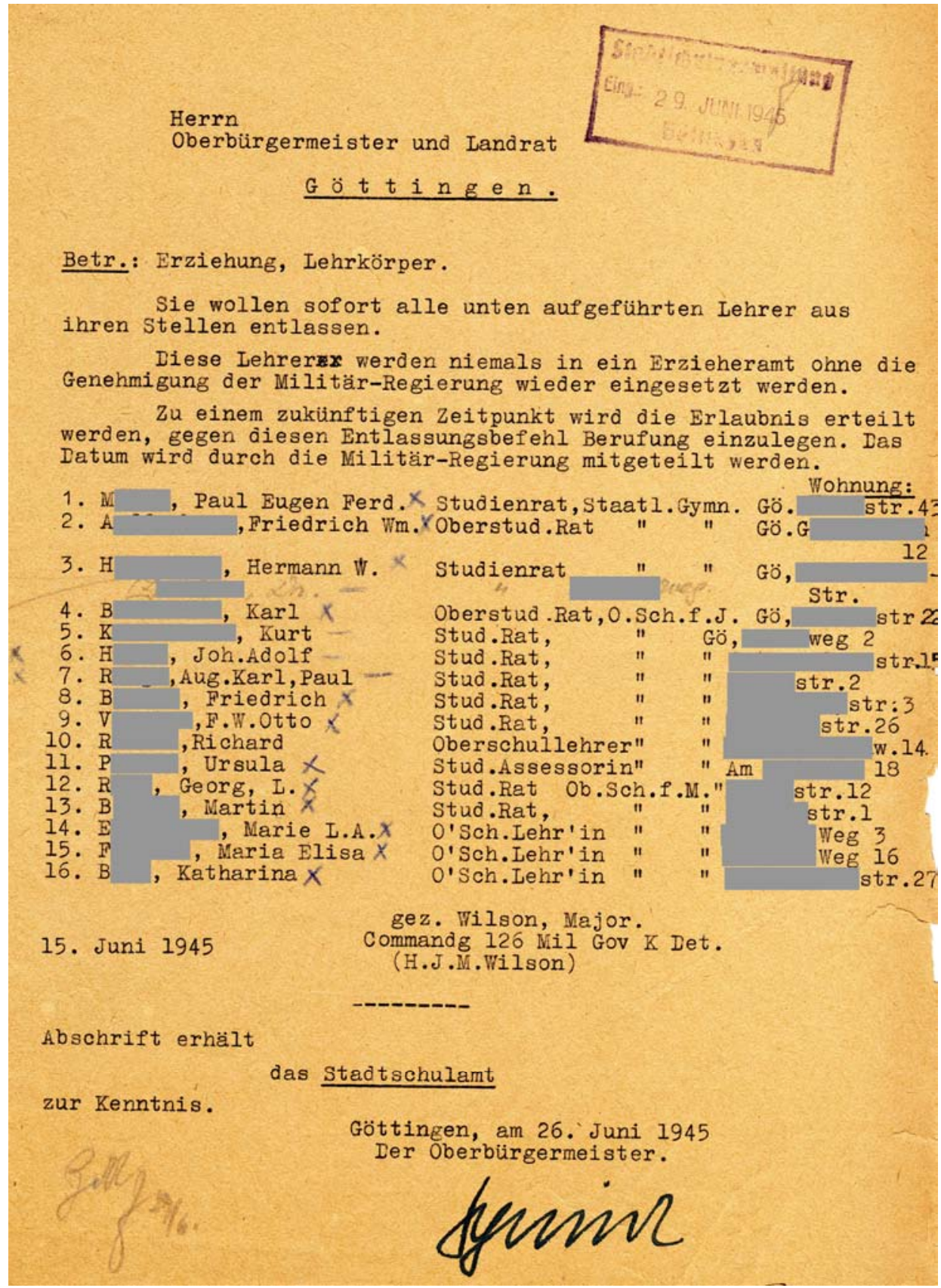

Q8: Stadtarchiv Göttingen, Schulamt Nr. 128: Entnazifizierung der Lehrkräfte 1945-1946. 


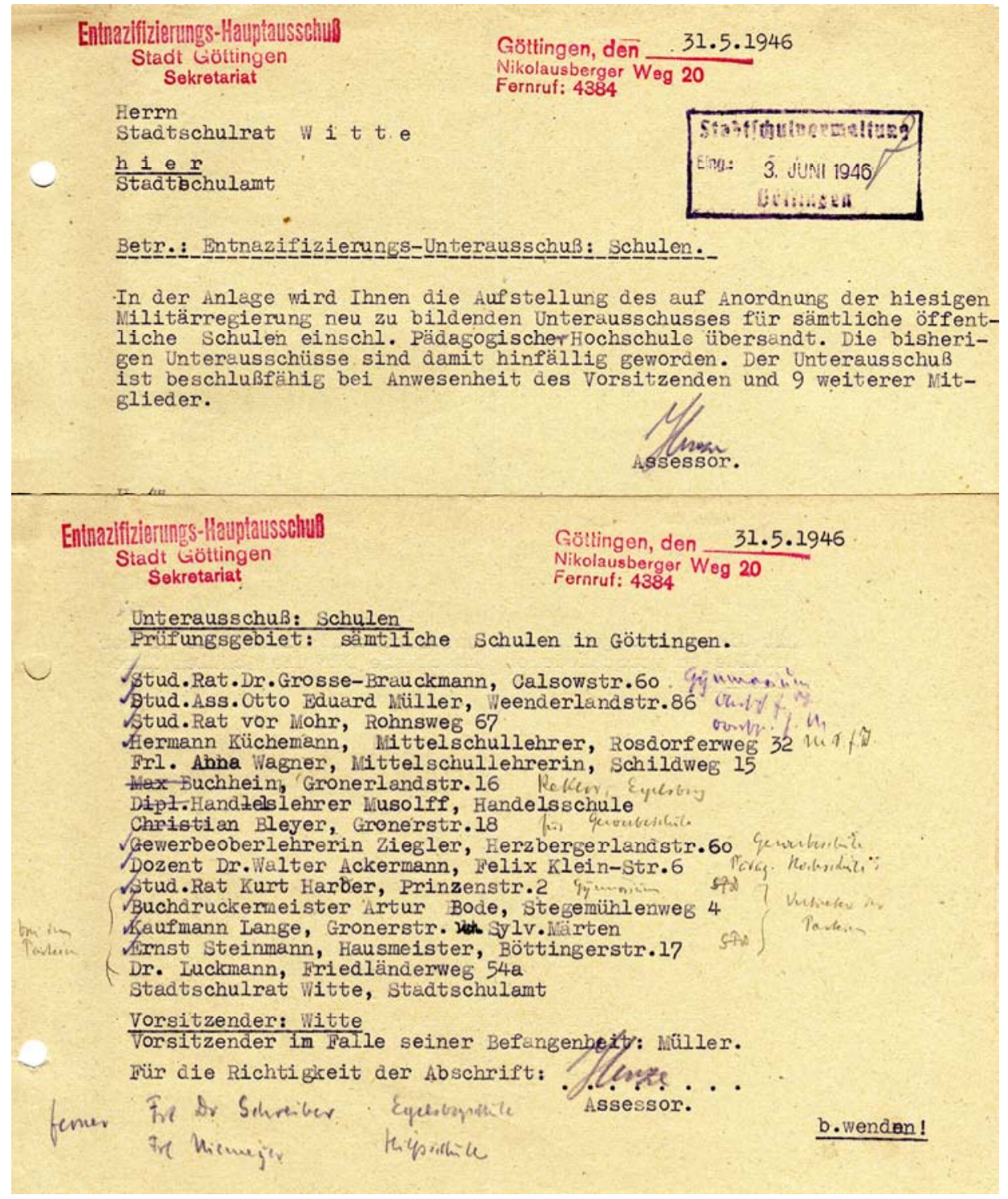

Q9: $\quad$ Stadtarchiv Göttingen, Schulamt Nr. 120: Entnazifizierungsunterausschuß für Lehrer 1946-1947. 
Interaubsolius fur Bohulen

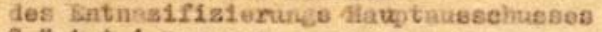

Qst singen, deh 30. Mth1 1947

e s $t$ t 1 n 8 on

Betx.s Intmasieisierú́ dex Behricrifte.

Selt fast einea Jahre erbcitet der Ontoransechul nun. In thex 400 pitilen hat. ex Gutaghten abgegeben; außer in etiva 20 Filizen hat ex seine Beschifieso elastirigig gefabt, in einigen weiteren zulien bel 1 oder 2 Snthnitune on. Dabel iet er aus annern und Prenen ver-

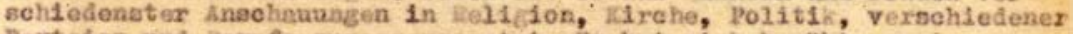
Parteien und Bexufe zusandengesetst. Ir hat sich benithi, gewiesen-

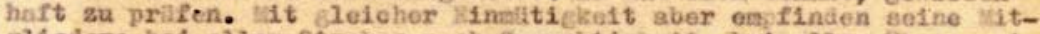

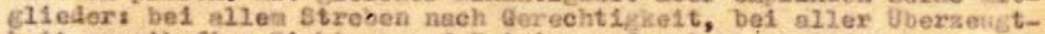
heit ernstharter siahtung und fleinigung dor felirersohnzt mllesen w1x whs eagen, dais aus uneerer krboit Uneerechtigkest ervuohs.

Ais Ungerechtidkeit sehon wir die Verechiedeaheit in der vehndelung der Le $r e x$ wie ali $r$ Beenten an. Sie wurdon bereita in llai 1945 aberprift; viele maxden damals, entiassen und nich 2 volign Jahrean.. sind ihre zilie nlelt cndellitis entgohiedeno is anderen fervifen

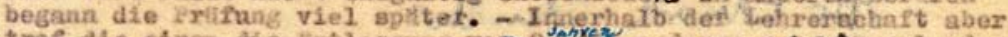

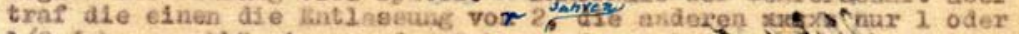

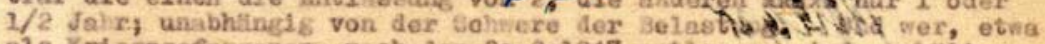
a.s. Xriegsefancener, nach den 20.2.1947 eatzassen vird, behilit

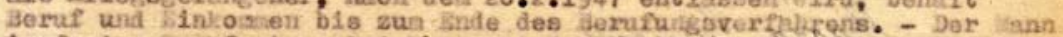

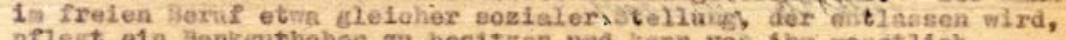
pPlegt elin liankguthaben gu besitsen und tran von this tongtilch 300.- Ril abhobén; viele Leirer sina nicht in dieserlace, indeatens

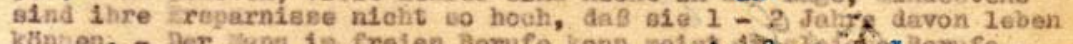

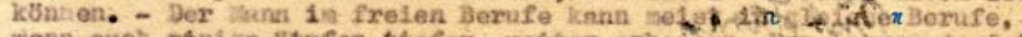

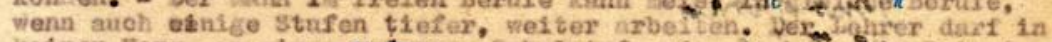

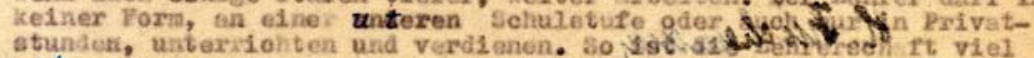
harter von den jntnasisizieruigeverfal xen getroffen als andere Burne. Des wira noeh dedaroh gostelgert, dis ale Beantenachirt und besonders die hehrersolvart elnon Druck der Hasis ansesetst war vie die freien Berufe nieht.

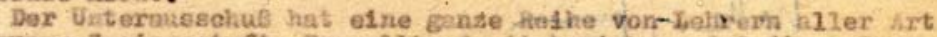
in Gruppe 3 eingeotuft. Br wollte damit bewision, das diese ideranen

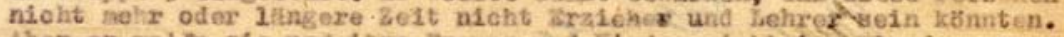
Aber or wollo oie und lare Fraven und Kinder nicht ins liend sblixsen. Nach den Vorsobriften des Kntegor LelerungeverPahrens vilindei

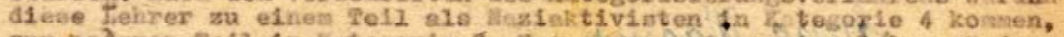

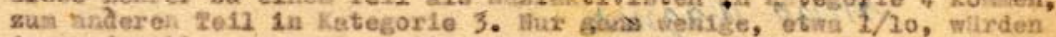
anuernd entlassen werden. Dis lisieten wllrden mit deldetrafen, $\forall \cdot r-$ setzung in den Thaestand und dgl. davon komiten; wai label wilrden die $1-2$ Jahre der Araut and Yergmeiriung angereobnot verden. Alle, soweit aie nicht, wie bereita einige, deribar hinegsterben, wilidea sich in minderbeiastetex Kategorien eayorarbydten kbnnen. Ais der Ausechu in Gruppe 3 vereet te, emertete ex/fica de liategorisieren הhn11olies Vertahren.

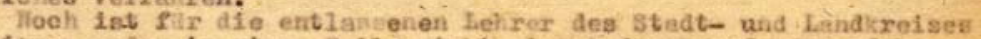
gistingen afer in eines Palle nioht einnil dos Berufunfever?ahren duxohgeruhrt worden - 40 lintinasene-, die ferufung elnzegten, aliein in der stadt, waxten selt panten. Aile alese Herten und arausarike ten eapflndet der Ausachue als Unserecht1etielt. Nx wollte ale nicht, Sie belarten gein Gewiesen.

vie dor quaty os wich wolls.

Q10: Stadtarchiv Göttingen, Schulamt Nr. 120: Entnazifizierungsunterausschuß für Lehrer 1946-1947. 


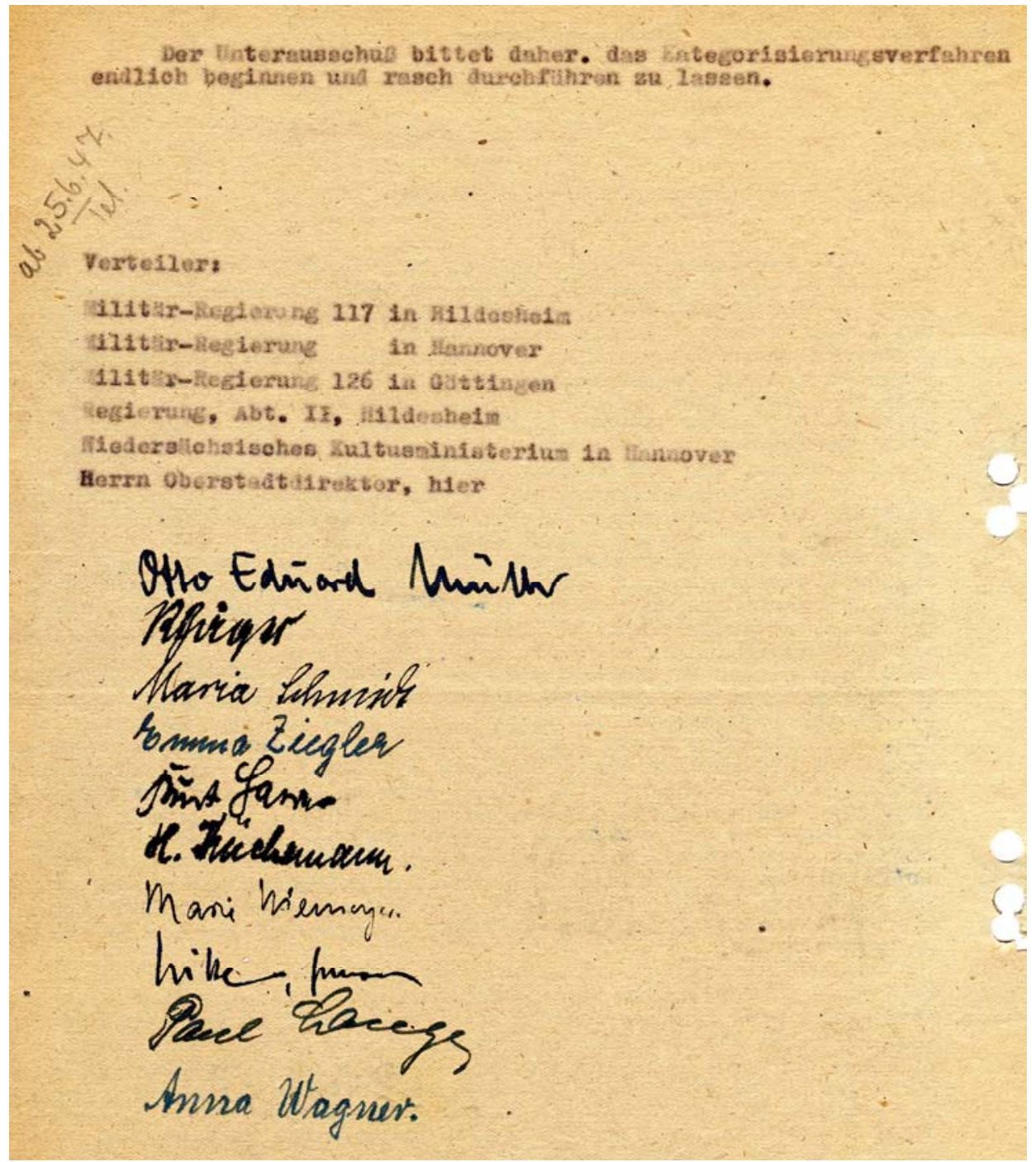

Q10: Stadtarchiv Göttingen, Schulamt Nr. 120: Entnazifizierungsunterausschuß für Lehrer 1946-1947. 


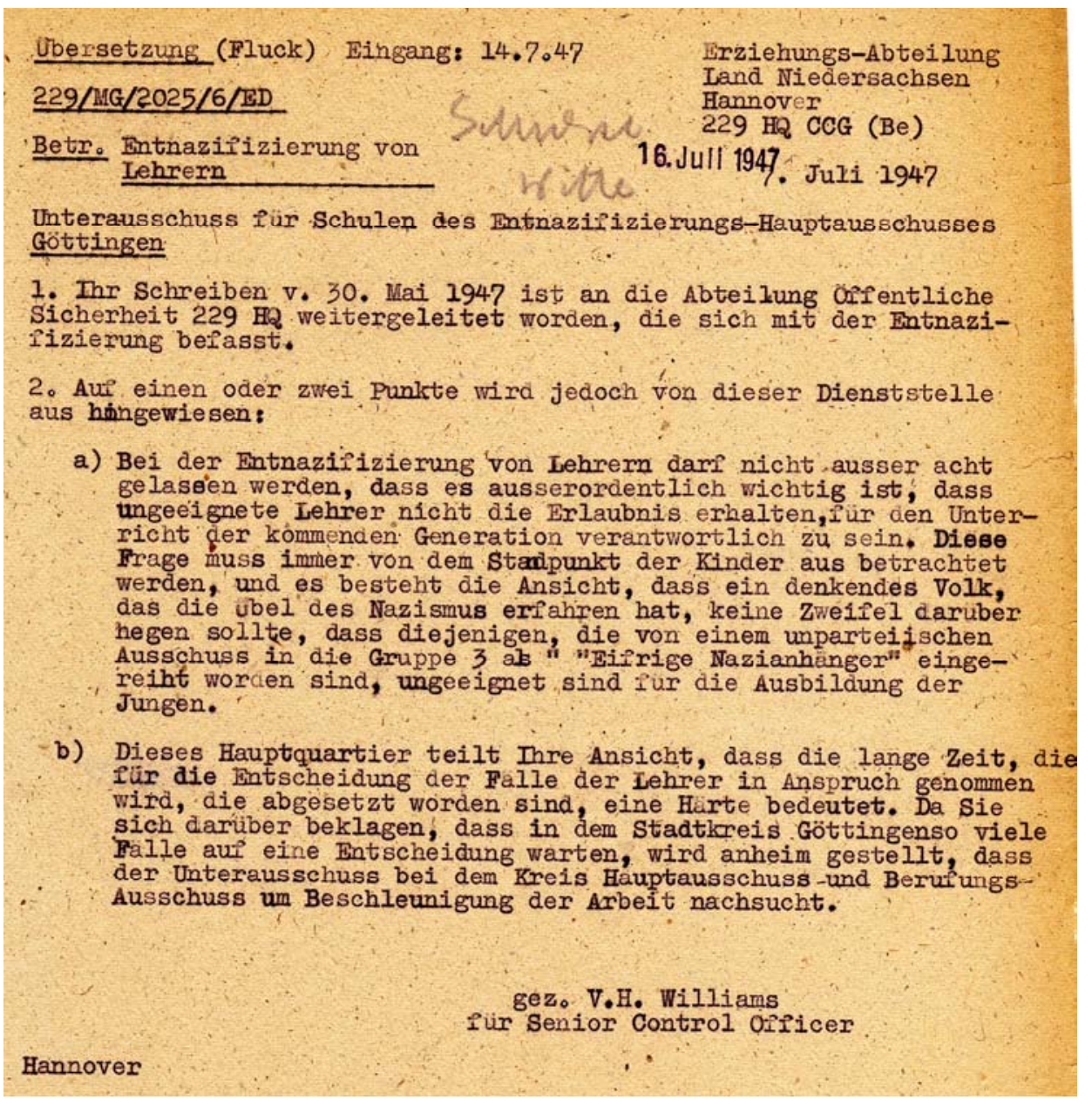

Q11: Stadtarchiv Göttingen, Schulamt Nr. 120: Entnazifizierungsunterausschuß für Lehrer 1946-1947. 


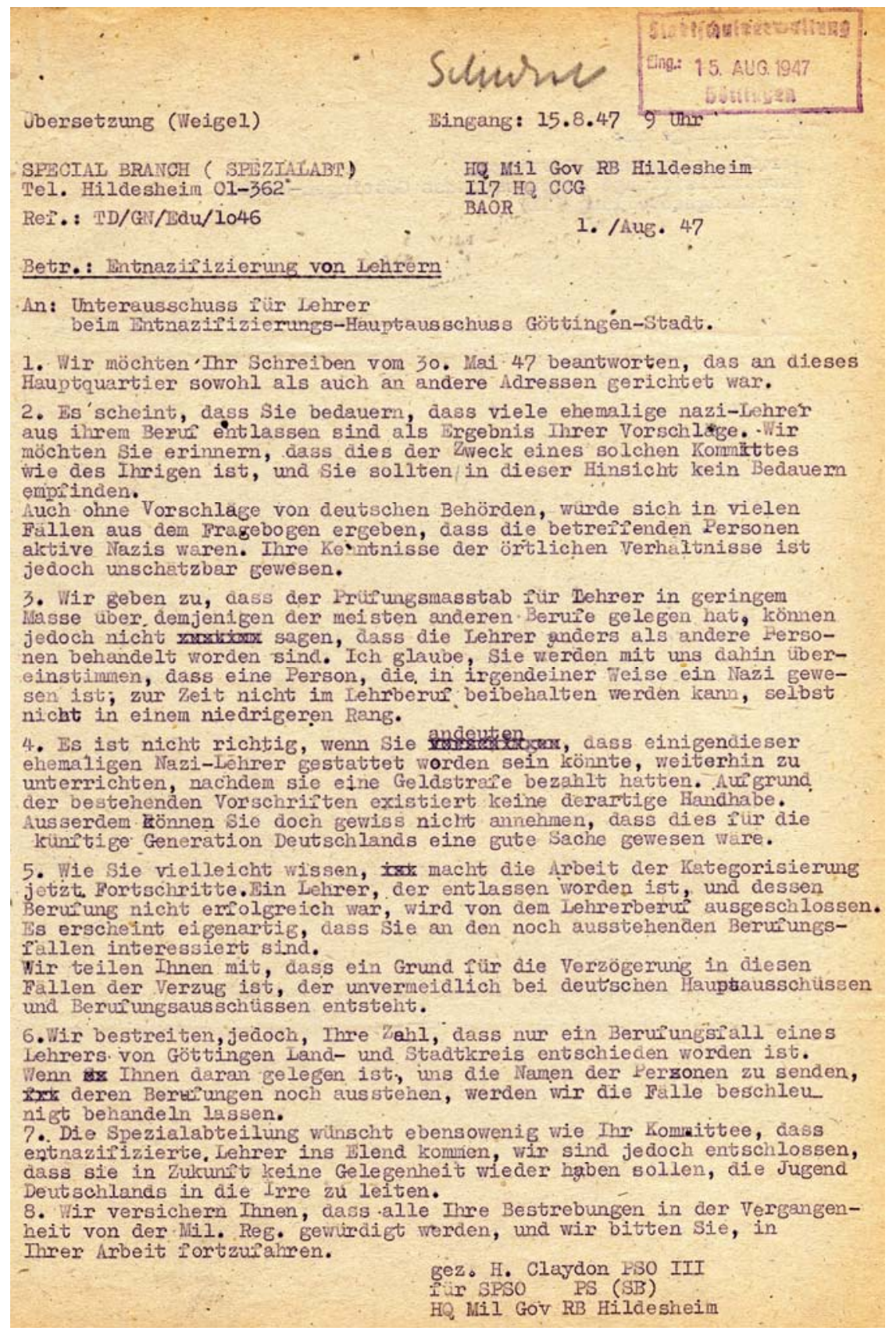

Q12: Stadtarchiv Göttingen, Schulamt Nr. 120: Entnazifizierungsunterausschuß für Lehrer 1946-1947. 


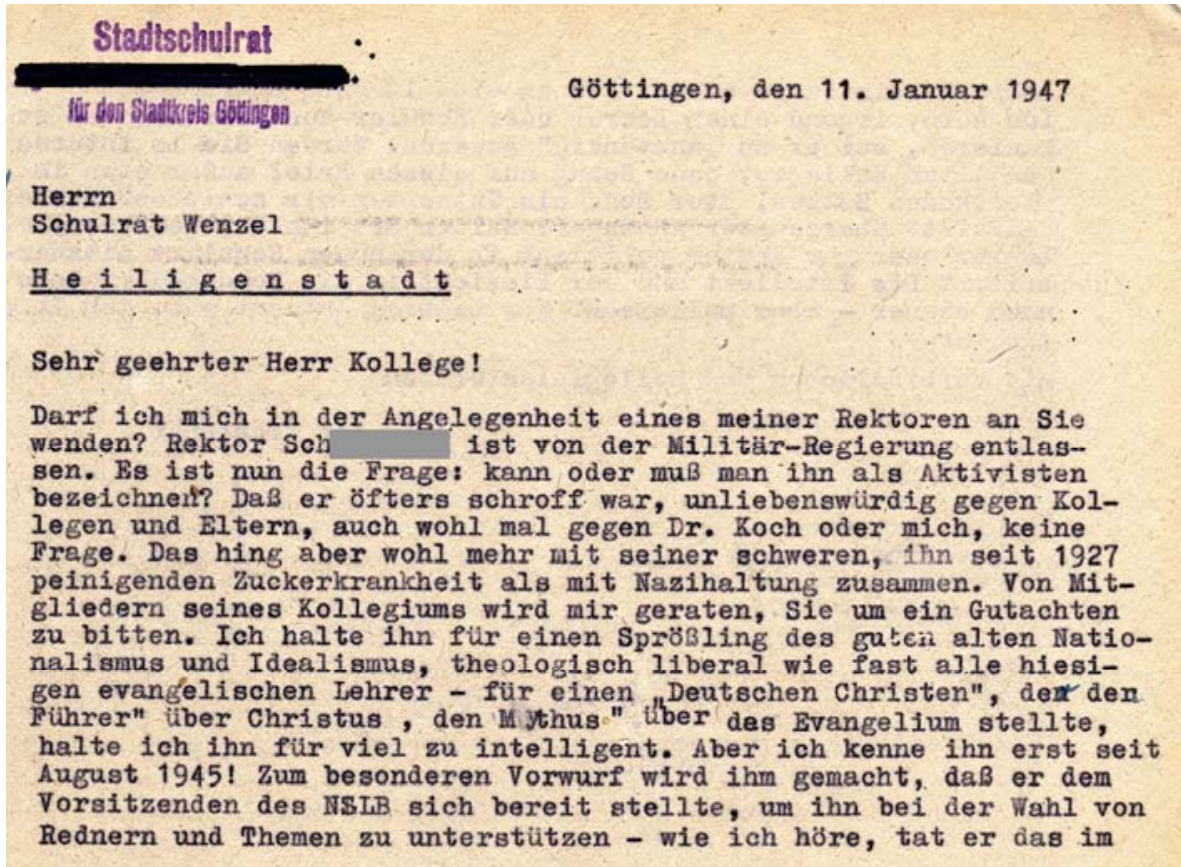

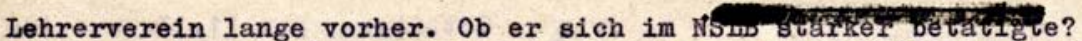
Ich höre, irgend einen Lehrer oder Schüler aus NSGründen zu schikanieren, sei er zu nanständig" gewesen. Würden Sie im Interesse des alten Kollegen, ohne Bezug auf diesen Brief außer etwa in begleitenden Sätzen, über Sch. ein Gutachten mir schicken? War er Aktivist? uberzeugter Anhänger? Halten Sie inn für geeignet, als Lehrer oder gar Rektor politisoh in der neuen Schulart mitzuarbeiten? Dem Intellekt und der Einsicht in die Schulbedürfnisse nach sicher - aber politisch? Für baldige Antwort wäre ich Ihnen dankbar.

mit verbindlichen und kollegialen Grüßen

Ihr ergebener

$$
\begin{aligned}
& \text { 2) } \operatorname{Om} 28.1 .47 \\
& \text { Geschrieben. } \\
& \text { Abgesandt 13.1.47 Schone }
\end{aligned}
$$
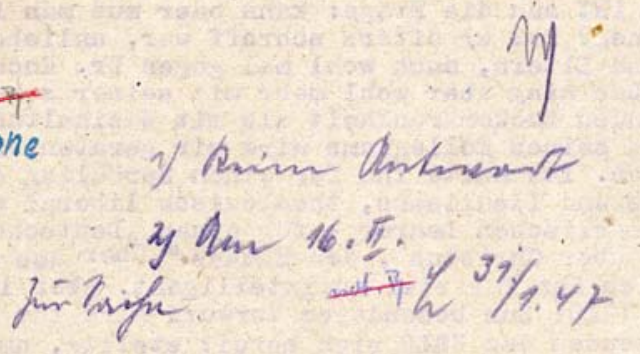

Q13: Stadtarchiv Göttingen, Schulamt Nr. 120: Entnazifizierungsunterausschuß für Lehrer 1946-1947. 


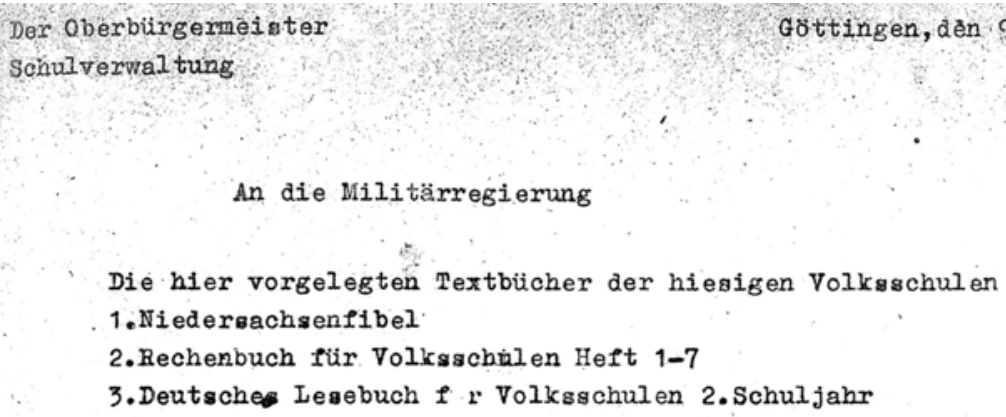

An die Militärregierung

Die hier vorgelegten Textbiucher der hiesigen Volksschulen

1.Niedersachsenfibel

2. Rechenbuch für Volksschilen Heft 1-7

3. Deutsche Lesebuch f r Volksschulen 2. Schuljahr

4.Deutachea Ieaebuch für Volksschulen 2. Band politisch cinvenolfri

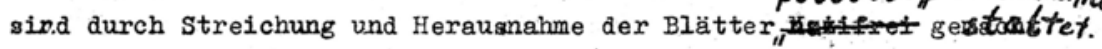

Wen.Die Kommandanten der Dörfer im Iandkreis Gottingen haben zumeig1

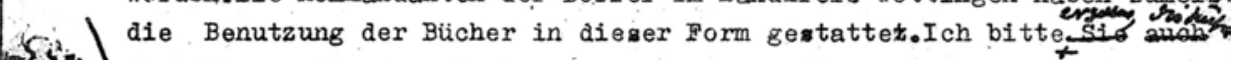

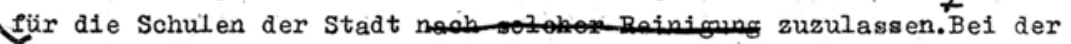
rwew Unmoglichkeit der Beschaffung neuer Bücher und bei der verarmung dẹ

om. Bevblkerung wäre der Verzicht aue diese so geaäuberten Büchér sehr hąrt.

Es gind vorhanden von

1. Niederachsenfibel

\section{Exemplare 7 yo}

2.von den Rechenbüchern Exemplare 2466

3.von den Deutschen Iegeabüchern für Volksschulen 2.Schuljahr

\section{Bxemplare 763}

4. von den Deutschen Lesegbüchern für Volksschulen 2.Band 1239 Bxemplare.

Die Bücher werden nach den vorgelegten bxemplaren durch die Iehrerschart aelbat in die gesäuberte form gebracht werdeh.

Q14: $\quad$ Stadtarchiv Göttingen, D 44, Blatt 2. 


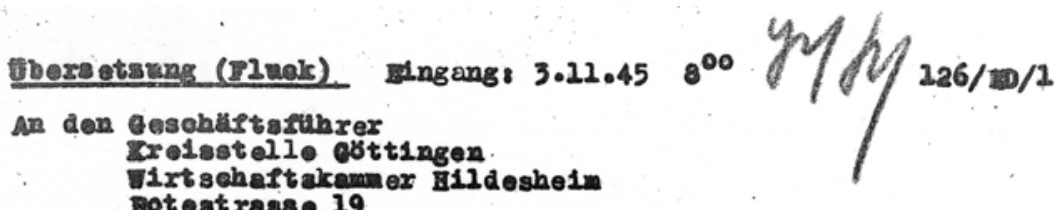

Betr. Textbilaher fir die Handel asahule

1. D1e In der Anlage su Inrem schreiben v. 30.August 45 aufgefibrt on Text blicher sind genehinigt, wit Ausnahme der folgenden:

a) Frans 8 sisoh Fir Beruetätige

si. werdon personiliop daflix verentwortliah gemacht, dass In allon semplaren die seiten 57-63 unleserlich geaseht werden.

b) Do 160010 an burean

810 wordon personlich deflir verantwortlioh gemacht, dass der it ginte bez eiohnote Absatz in dem zuriekgegebenon, Eremplar am Fus von selte 1 in all on Exemplaron whloserlich gemacht

2. 31. wissen bird. brauch dieser bícher inrelohen, dass diese finderung on vorgenommen wordon sind.

3. What ex explare der blich er werden hierdurch zuriakgereicht.

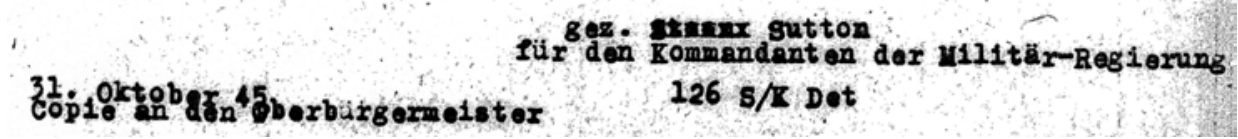

Q15: $\quad$ Stadtarchiv Göttingen, D 46, Blatt 39. 
Te1. Hildesheim 729

Tr. $5427 / 110$

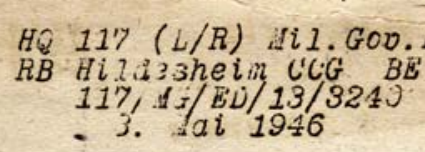

An Heriz Req. Jirektor Dre Bril1.

Betriff: : Aushilfs-Lehruicher.

1. Sie izben dafir zu sorgen, das folgende Tatsacien bezlgl. der Alshilfs-Lenrbucher weitein areisen der deutschen Schulbohörden behannt worden (mindestens bis zi den jchulräten und Direitoren besonderer Schulen).

2: Die Aushilfs-Lehrjucier sind in November 44 und Januar $4 j$ zum Nachdruck ausgewdint worden. sie stellten das ieste dir. was seinerzeit zu finden iazr. Es var damals offiziell ublich, la, die oon der. Ail. Regierung als Aushilfs-Nacharuck herausgegeben:i Bucher keinerlei Aiderungen enthalten sollten. (Line Ausnahme wurde $i m$ Fale eines Buches genacht, bei den eine winde $t$ twinl an Anderungen angejracint wurden.

3. Innerinalb iieser Schranten ist der versuch unternommen worden, einige brauchbare Lehrbicher zum Naciaruck für den Ausinilfsgobrauch an Vjiksschulen herauszufinder. Eine erhebliche Ansainl oon oor 1.33 erschianen Buchern wurde geprift; sie enthieltei sintlich nicht einwandfreles Material in verschiedenem UmJji.3. Die Bucher, die schließ1ich zum Nachdruck ausgewählt wurden, enthielten die wenigsten nicht. einwandfreien Stellen. Sie waren jedoch weit dioon entfernt, als zufriajonstellend angesehen zu werden, und sind nur deshalb nuchgedruckt worden, weil andere Blicher wicht zur Verfügung standen.

4. Sil haben sich daher zu verjejenwärtigen, daß diese Bïcher daterial enthilten, das unter keinen Uimatinden oon der Ail. Regierung filr neue 3icizer $S$ ?nehinigt werden wirde. Alle mit der Vorbereitung neuer Leiriocher beschijtigten Lehrer und Autoren wilden sehr im Irrtum sein, wenn sie diese. Ausnifis-Lehrbucher irgendwie fir die on der ilil. Regierung fur neus Lehrb:cher jeforderte Norn halten wilden.

5. Nie Aushilfs-Lehrbilcher werden on der Mil. Regierung als Notbehelf angesenen, als das Besta, was unter den vor 18 Aonate.2 bestehenden Bedingungen su' finden war: je schneller sie durch Lehrbucher günzich a werer Art und anderen Zwecks ersetzt werden können, listo besser..

6. Das Vorwort zu diesen Buchar $z$ behandelt die meisten dieser Punkte und solfte oon jedem, der init de? Buchern zu tun hat, jelesen werden.

$$
\text { F.T. Bennitt, ('apt. }
$$

Q16: Stadtarchiv Göttingen, Schulamt, Fach 7 C 24,1/II: Verfügungen über Lehr- und Lernmittel. 


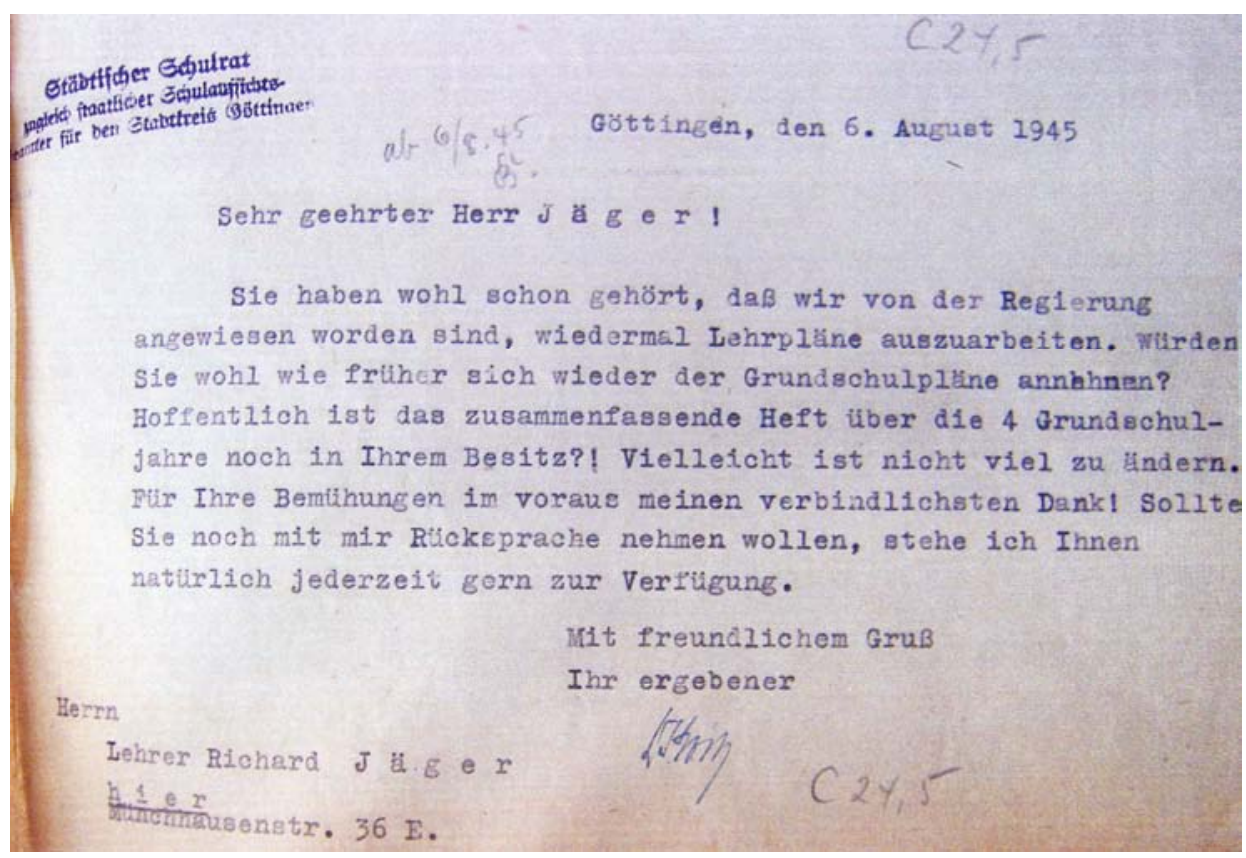

Q17: $\quad$ Stadtarchiv Göttingen, Fach 7 C 24,5: Verfügungen über Lehr- und Lernmittel, Lehrpläne. 


\section{Appendis "A"}

List of Pilms sultable for use in German schools.

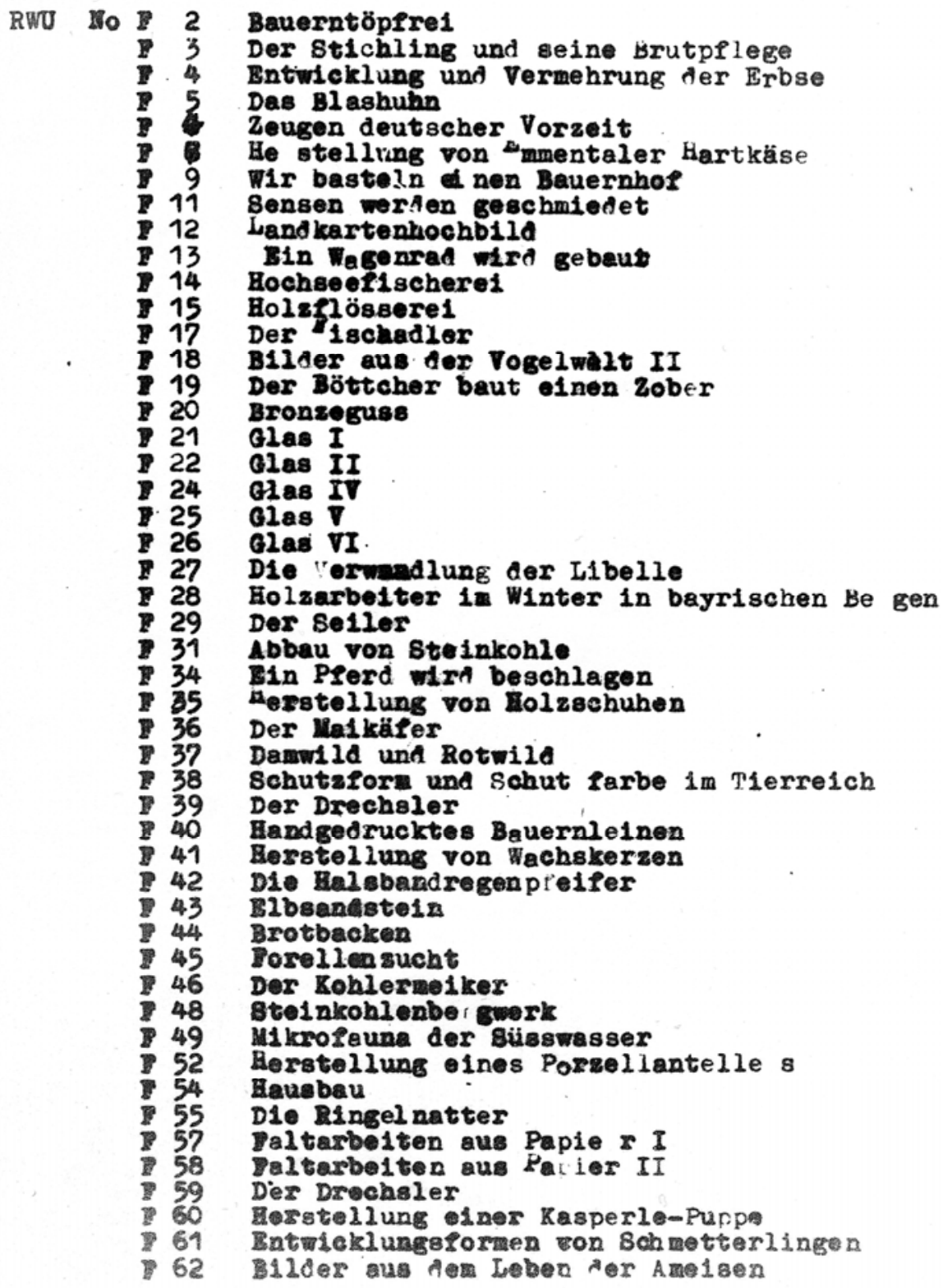

Q18: Stadtarchiv Göttingen, D 45, Blatt 112. 
$V$ V $r$ b $\circ t$ e $n$ e $11 m$ e

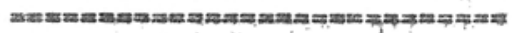

16 Deutsahe Zulturarhe1t in Kamerun

I 47 Hoohze1t in Schonwaid In Oberschlesien

64 Die Deutsche Westgrenze I

68 Madel in Landjahr, Toil I und II

81 B1erbrauen

84 Jegerkinder

85 Kinder aus Lappland

89 Bin Brief wird befördert, Teil I und II

114 Hindenburg

115 D1e Deutsche Westgrenze II

118 Erzbergerk

119 Hochoren I

8120 II

121 "III

122 8tahlwerk I

123 " II

124 "III

125 Walzwerk I

130 Bolzschlag $1 \mathrm{~m}$ ostpreuBlschen Falde

131 Eisernte in Ostpreusen

138 Hochze1t am Tegernsee, Tell I und II

141 Vom Brz gur Sohiene, tell I und II

146 Die Deutsohe Westgrenze II

149 Stzdt1sche Peuerwehr

250 Die Deutsche Vestgrenze IV

F 253 plugmodellbar, Teil I und I:

158 Arbeitodienst, Te1l I und II

160 Boxen der Jugend, Te1I I bis $x$

170 Verkehrselugzeug Im lughafen Berlin

176 Kre1degewinnung auf Rligen

I 184 Heringsischere1

185 Kinder sparen

- 187 Deut sche Kamerun-Bananen

191 Anlegen eines Harn1schs - Deutsches Turnier

198 Bine Bahrt zum Wetterwart auf der Zugspttze

200 In der rindmuhle

201 WHE-Abzeichen aus dem Bayrischer Fald

- 204 EIn Zampltag an der Westront 1918

206 Deutsches O-Boot aue Kaperfahrt

207 Irandung aus Ösel 1917

1 209 Ploriero schlagen elne Bricke

211 pahrsohiffverkehr Deutsohland-schweden

1212 Deutsoher Se1denbau I

214 Stapellaue des Ereuzers "hature Prinz Bugen"

215 Bine Batterie geht in stellung

222 Pollachenleben in Oberliggpten

324 Bin Tag auf einer Irankischen Dorfstrabe

226 Lelbeserzlehung in der Sohule

227 Deutsche Gronland-Expedition, Te1l I, II U. III

7230 In Bauer bestellt oein Feld

231 Bau elnes plugseuges

232 Segelplieger auf der waserkuppe

233 De Deutsche Westgrense von 800 b1s. 1815

fer woll und die fleben Gaiblela

Q19: $\quad$ Stadtarchiv Göttingen, D 45, Blatt 111. 


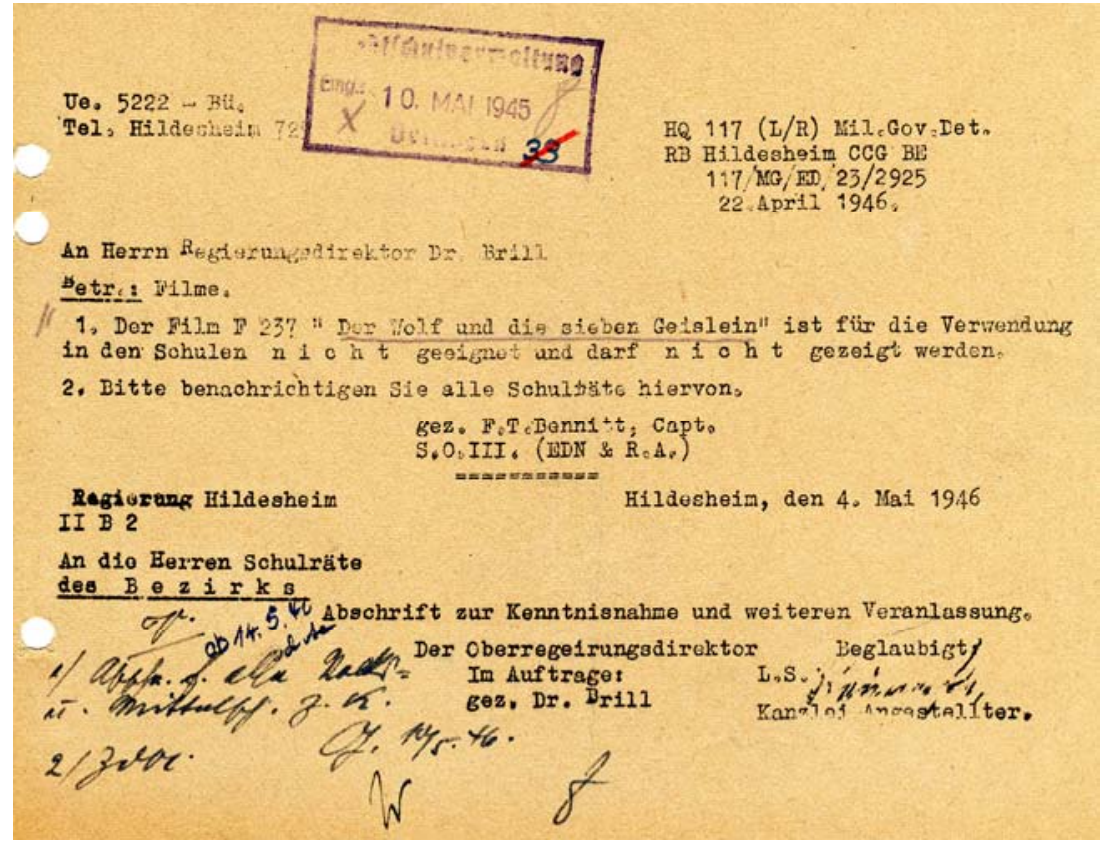

Q20: Stadtarchiv Göttingen, Schulamt Nr. 99,6: Liste der durch die Militärregierung verbotenen und genehmigten Schulfilme.

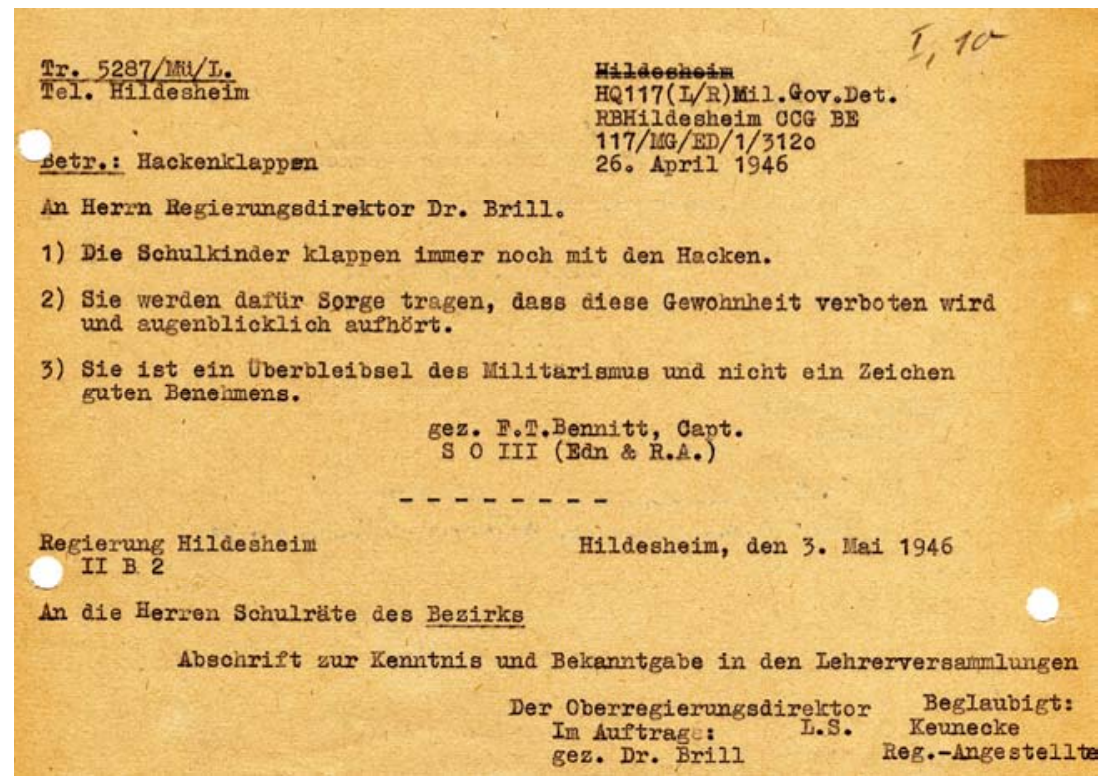

Q22: Stadtarchiv Göttingen, Schulamt C 45 Per. Nr. 12. 


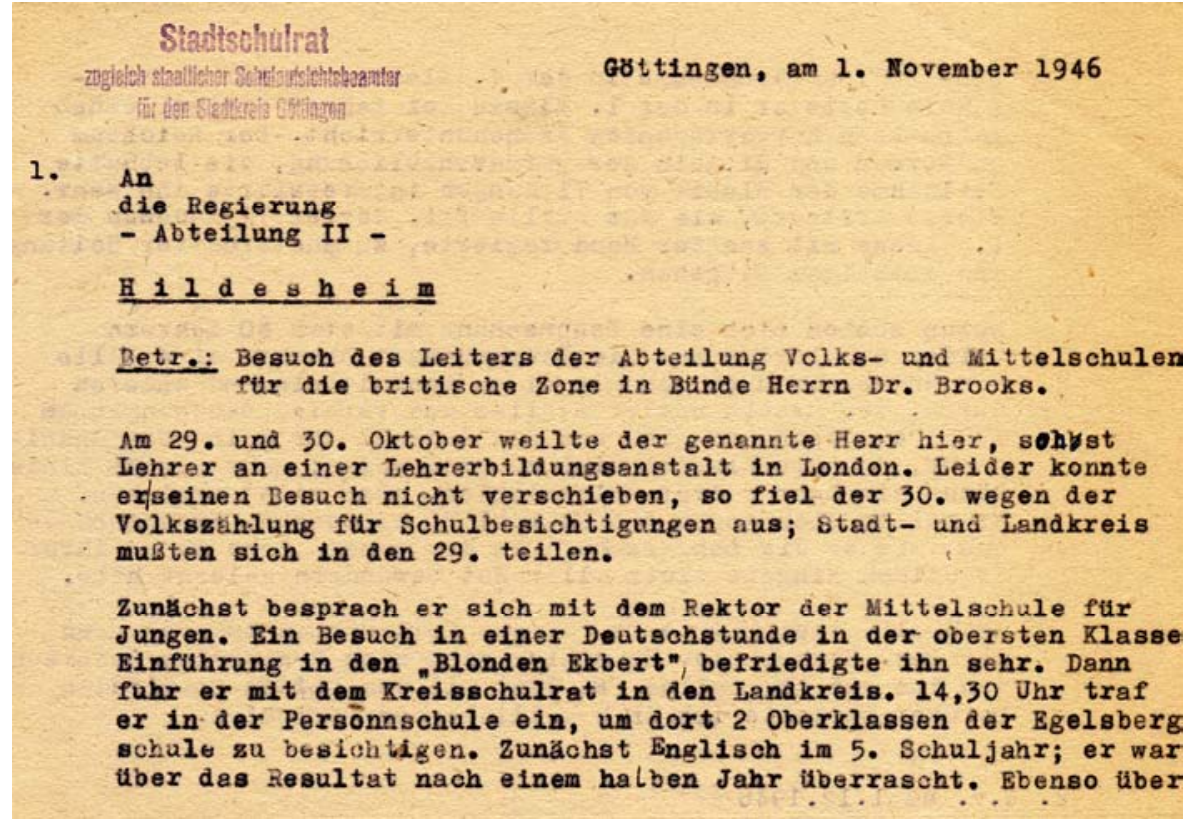

eine Gediahtdurohnahme in der 7. Klasse. In der Herbartschule hörte ex in der 1. Klasse bel Lehrer Greiser einen methodisch hervorragenden Rechenunterricht. Der Reichtum an Formen und Mitteln der Veranschaulichung, die lebhafte. Teilnahme der 21 psse von 71 , Jungen interessierte ihn sehr. Ebenso erstaunte, wie das stille Prl. Wagner 72 Midchen der 1. KIasse mit sanfter Hand regierte, su dusterhafter Haltung und geistigem Uitgehen.

Daran schloß aich eine Besprechung mit etwa 80 Lehrern beider Schulerten an. Die Lehrerschaft hrochte eine piille von Nrtan vor Uber den Miangel an Lehruitteln uná anderen llaren. Dr. Brooks notierte alles und verhieb Berilihungen um Abhilfe. Besonders groß wer der Beifall flur gein Verstlindnis daftur, daß die Klassen viel zu grob soien; mehr els 35 Kinder konne ein Lehrer swar unterrichten, aber nicht erziehen. Er wollte sich gegen die MeBzahl 70 einsetzen. Br sprach es aus, wie er die Lehrerschaft in der ganzen Zone wegen ihrer freualgen Hingabe trotz aller Not bewundern gelernt habe.

Am 30.10. besichtigte Dr. Brooks Vorlesungen und Uebungen der Paa. Hochschule. Bs schloß sich eine 2-stünige Besprechung von $1 \mathrm{hm}$, und $\mathrm{Mr}$. Culion (Bd.126) mit den belden Schulraton an Daruber berichte ioh in 2 belliegonden Berichten.

2. W.v. am 1.12.1946 nod.sch.

Geschrieben.119. 46 Sch. Abgesandt $4 / 14.6$ Schore

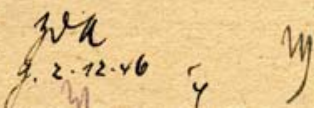

Q21: Stadtarchiv Göttingen, Schulamt Fach 10 C 29,1: Revisionen durch Schulaufsichtsbeamte. 


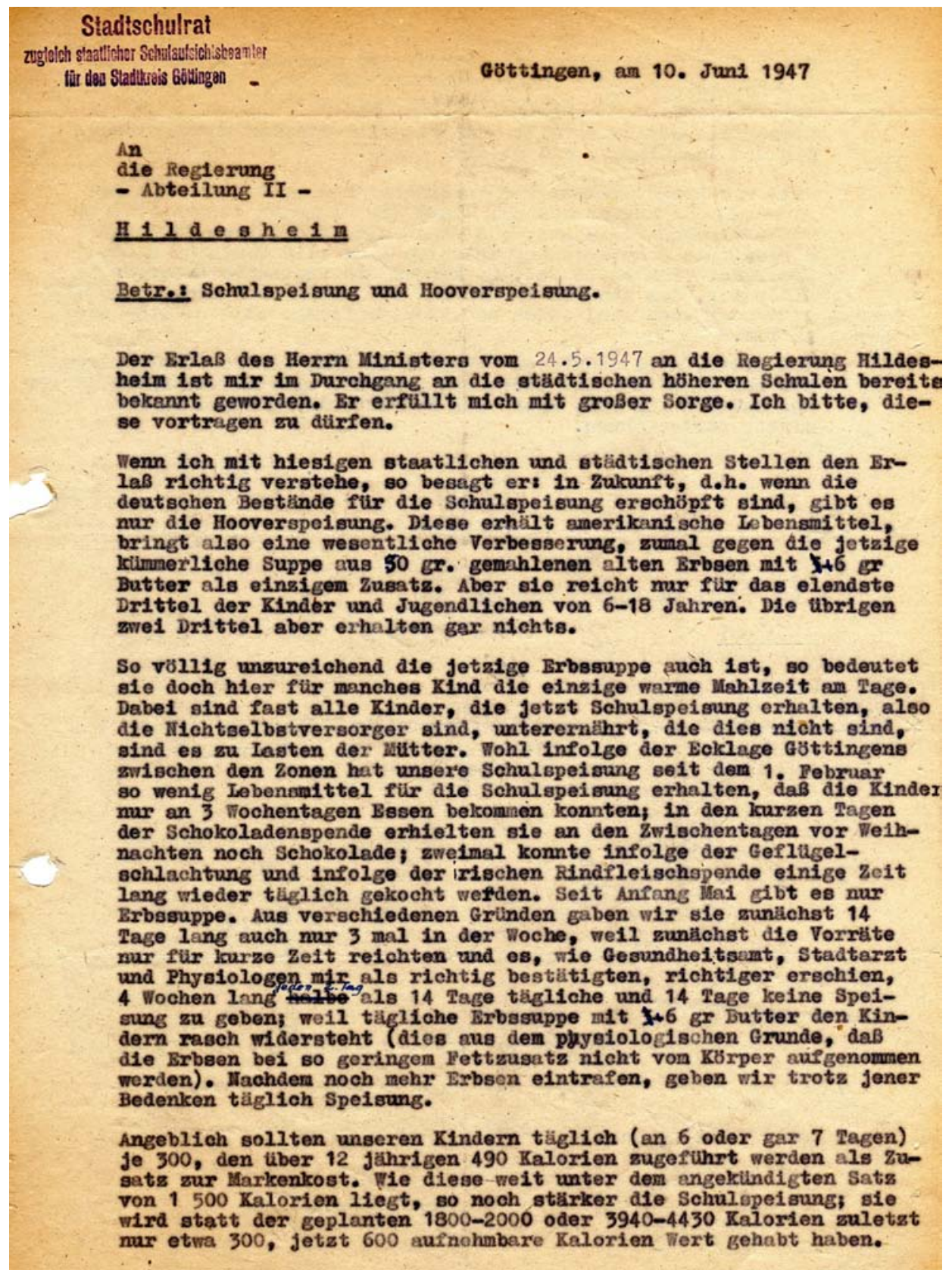

Q23: Stadtarchiv Göttingen, Schulamt Nr. 100: Schulspeisung 1945-1947. 


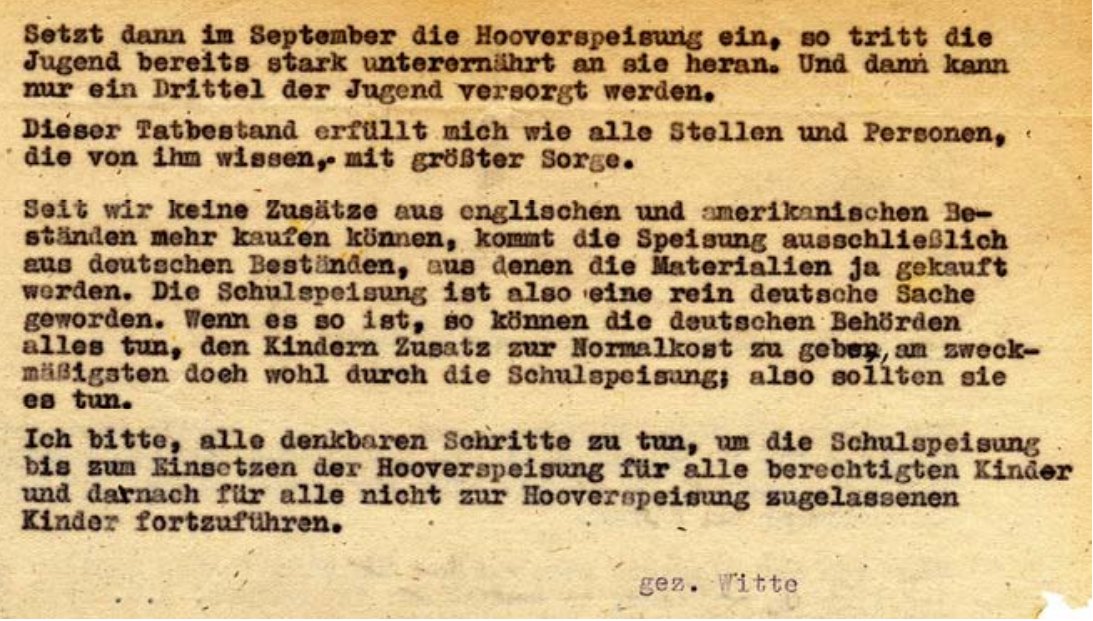

Q23: Stadtarchiv Göttingen, Schulamt Nr. 100: Schulspeisung 1945-1947.

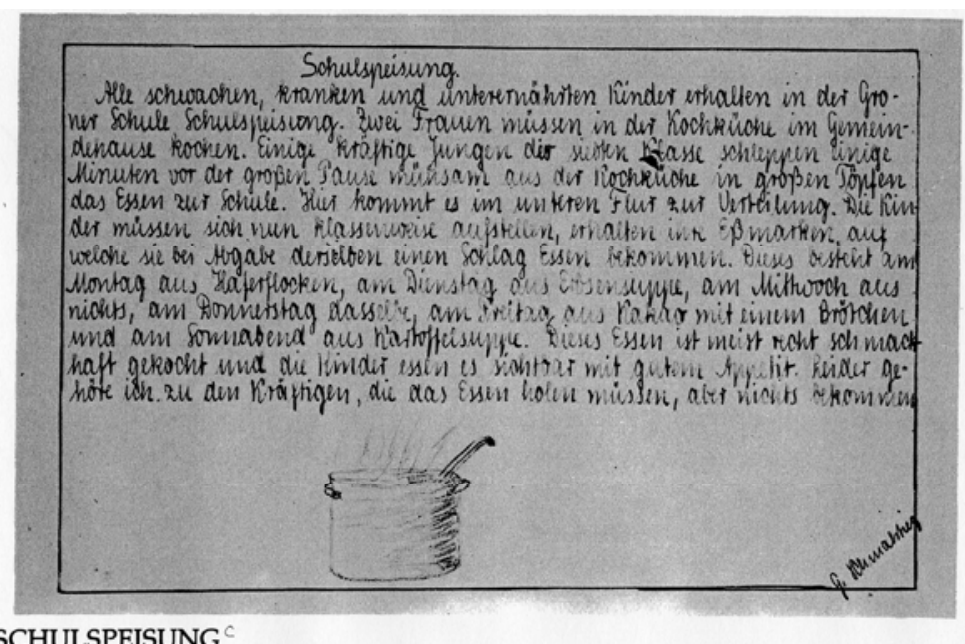

\section{SCHULSPEISUNG}

Alle schwachen, kranken und unteremährten Kinder erhalten in der Groner Schule Schulspeisung. Zwei Frauen müssen in der Kochküche im Gemeindehaus kochen. Einige kräftige Jungen der siebten Klasse schleppen einige Minuten vor der großen Pause mühsam aus der Kochküche in großen Töpfen das Essen zur Schule. Hier kommt es im unteren Flur zur Verteilung. Die Kinder müssen sich nun klassenweise aufstellen, erhalten ihre EBmarken, auf welche sie bei Abgabe derselben einen Schlag Essen bekommen. Dieses besteht am Montag aus Haferflocken, am Dienstag aus Erbsensuppe, am Mittwoch aus nichts, am Donnerstag dasselbe, am Freitag aus Kakao mit einem Brötchen und am Sonnabend aus Kartoffelsuppe. Dieses Essen ist meist recht schmackhaft gekocht, und die Kinder essen es sichtbar mit gutem Appetit. Leider gehöre ich zu den Kräftigen, die das Essen holen müssen, aber nichts bekommen. Günther Schmalstieg

Q24: Werner König (Hg.), Göttingen, Stadt der Schulen: 100 Jahre öffentliche Volks- und Realschulen, Göttingen 1976, S. 107. 


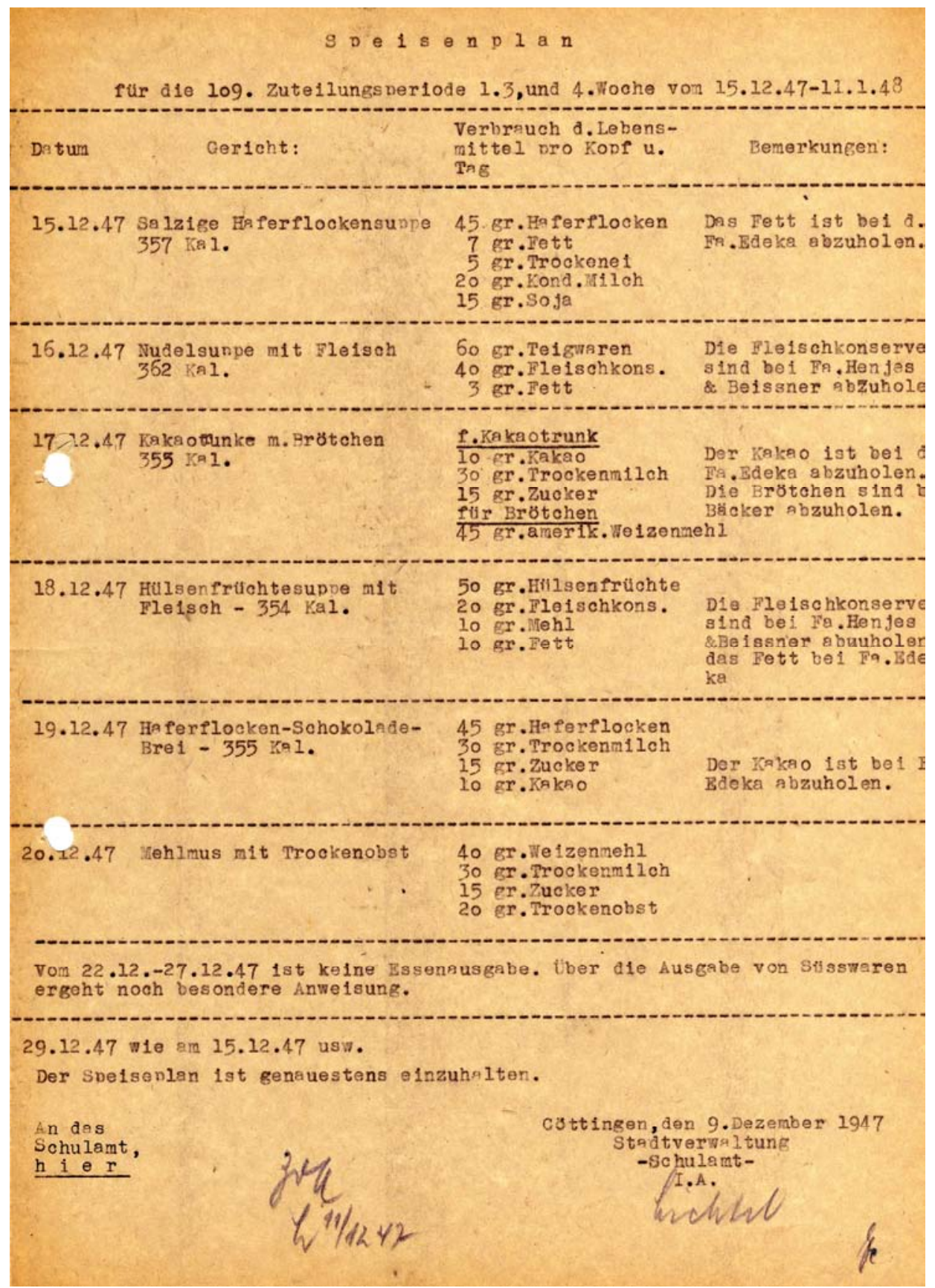

Q25: Stadtarchiv Göttingen, Schulamt Nr. 100: Schulspeisung 1945-1947. 


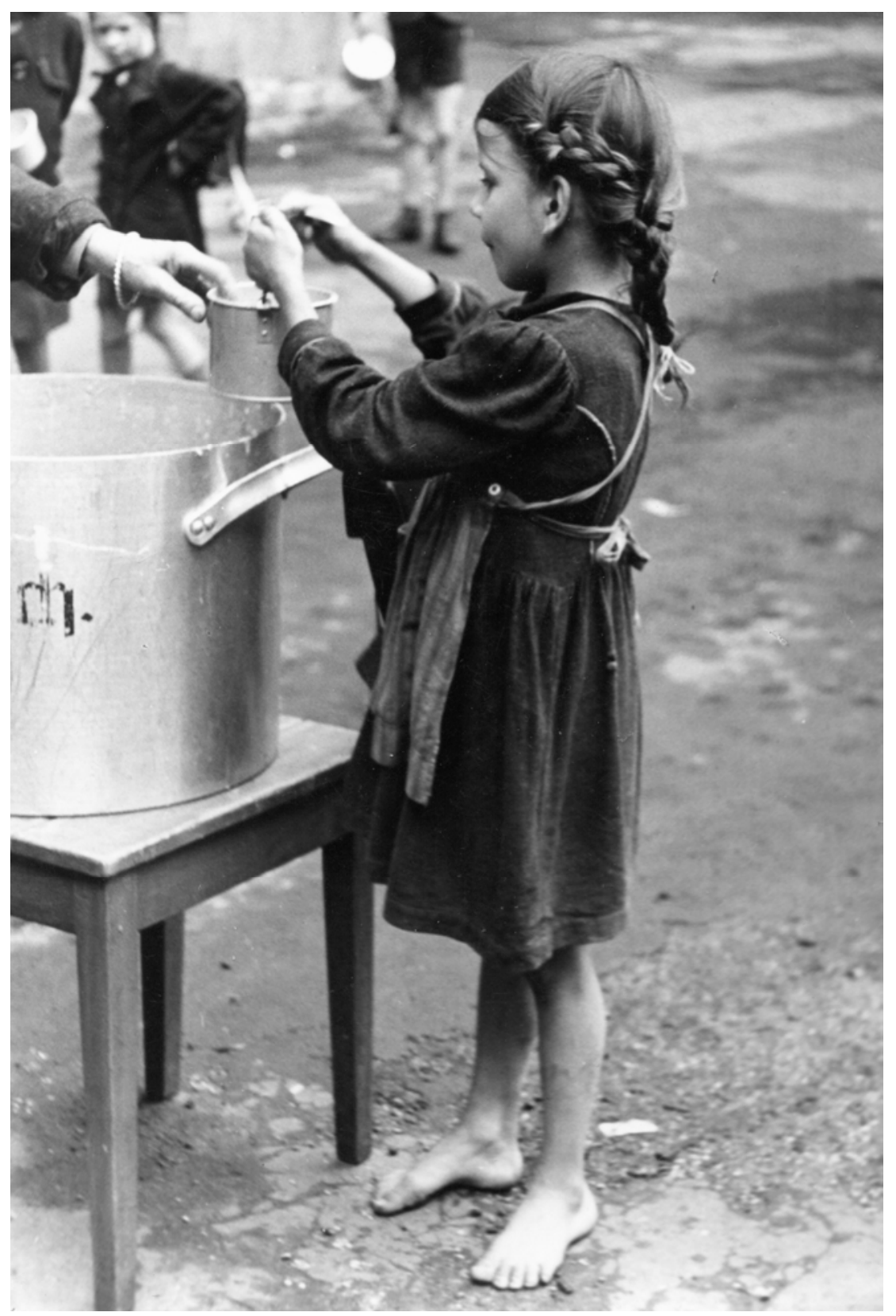

Q26: Städtisches Museum Göttingen, Fotoarchiv, Akte: „Ereignisse 1946. Beginn der Schulspeisung in Göttingen am 27.5.“, Neg.-Nr.: 245/8. 


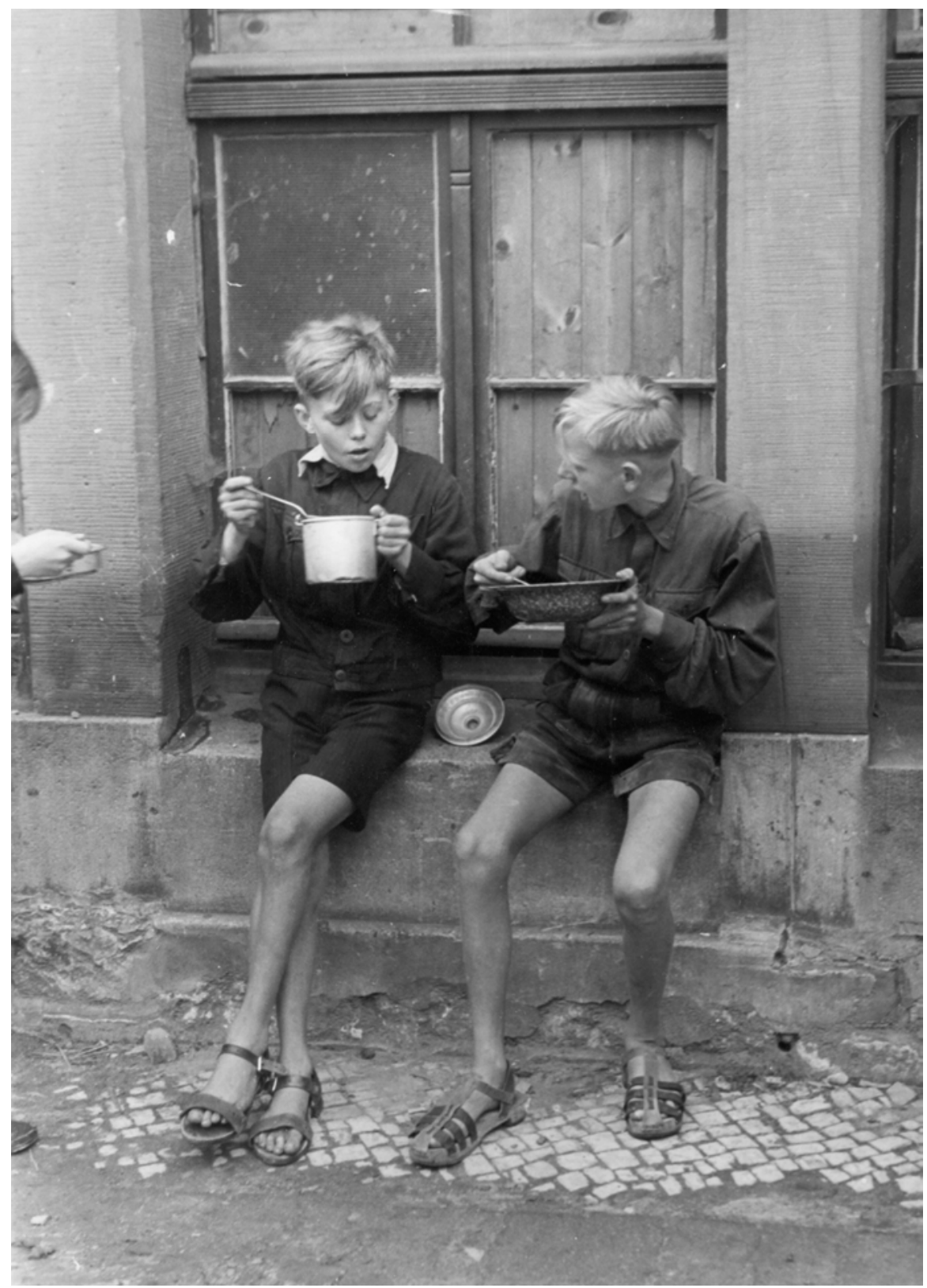

Q27: Städtisches Museum Göttingen, Fotoarchiv, Akte: „Ereignisse 1946. Beginn der Schulspeisung in Göttingen am 27.5.“, Neg.-Nr.: 245/10. 


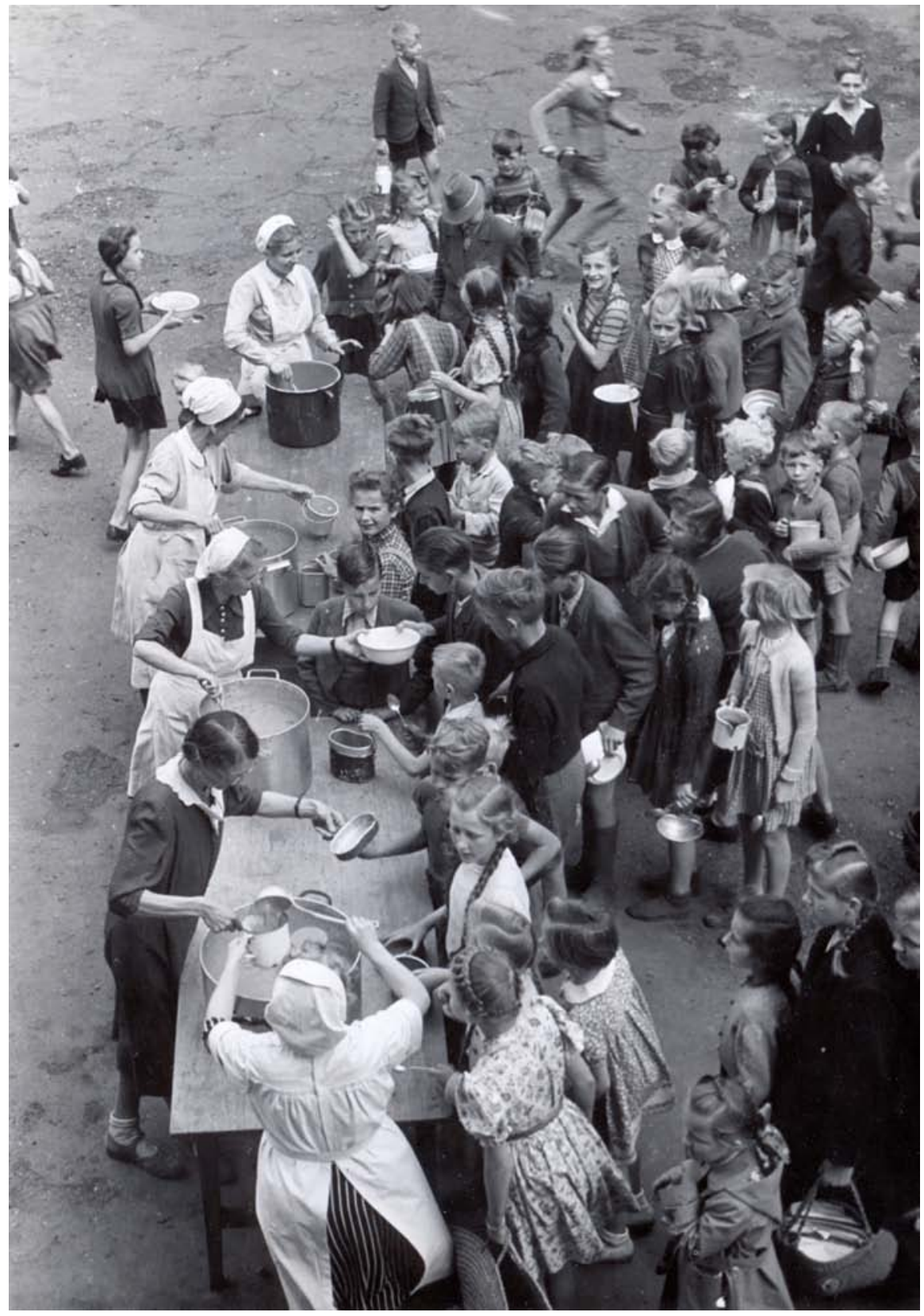

Q28: Städtisches Museum Göttingen, Fotoarchiv, Akte: „Ereignisse 1946. Beginn der Schulspeisung in Göttingen am 27.5.“, Neg.-Nr.: 245/7. 


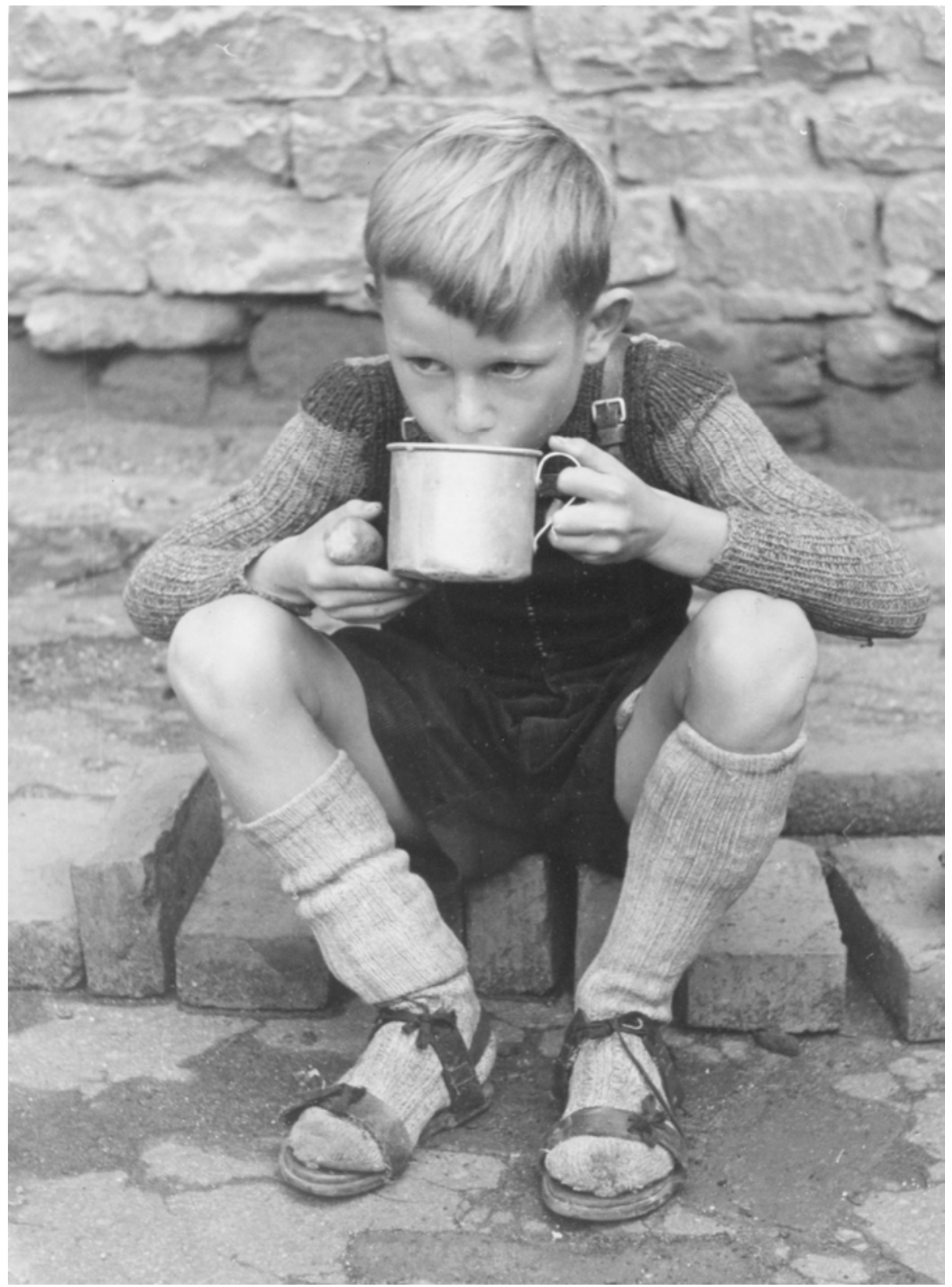

Q29: Städtisches Museum Göttingen, Fotoarchiv, Akte: „Ereignisse 1946. Beginn der Schulspeisung in Göttingen am 27.5.“, Neg.-Nr.: 245/9. 
Der Direktor

der Stëdt. Gewerbeschule. A. /B.

An den

Herrn Stadtschulrat, $h$ e $r$.

Betr.: Schulspeisung fur Lehrer.

Die körperlichen und geistigen Anforderungen, die an die Lehrpersonen der Berufsschulen gestellt werden, sind auberordentlich.

Bei der mangelhaften Ernahrung müssen die lehrkrïte oft vormittags und nachmittags Unterricht erteflen. Neben den Vorbereitungen fur den Unterricht werden gerade $z \cdot Z t$. Facharbeiterprufungen durchgefuhrt, die ebenfalis von den Lehroersonen einen Kräfteeinsatz fordern. Ferner wird in dieser Woche und such in der nüchsten Woche von jeder Lehrkraft neben der Pflichtstundenzahl ein Arbeitseinsatz beim Umzug erforderlich sein. Jede Lehrperson setzt sich tatkräftiz ein, um diese Arbeit zu bewältigen.

Der Intzug der Schulspelsung für die Lehrkrëfte zeigt jedoch jetzt schon einen bedenklichen Krëfteverfall.

Ich bitte prüfen zu wollen, ob nicht doch eqne moglichkeit besteht, den Lehrpersonen die Teilnahme an der Schulspeisung zu gestatten. Z.B. würde bei der Speisung von $\triangle 00$ Schülern tëglich ein bestimmter Prozentsatz durch Fehlen ausfelien. Dieser Ausfell von etwa $5 \%$

könnte an die Lehrer verteilt werden, ohne, daß eine Kürung̈ fur die Schuler hierdurch eintritt.

Ich füle mich verpflichtet, auf die Gefehr aufmerksam zu machen, die durch die augenblickliche Lage entsteht und bitte deshalb um eine wohlwollende Prúfung meines Vorschlages.

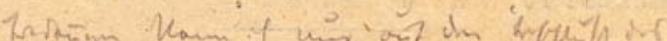

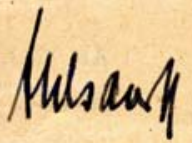

Q30: Stadtarchiv Göttingen, Schulamt Nr. 100: Schulspeisung 1945-1947.

\section{1. i) Erschreckend sohleoht war der Gesunheitszustand der Lehrer. Trotz milder Witterung fehltan stets in jeder Schule mehrere. Auch bei normaler Ernkhrung brauchen leichtie Erkrankungen Wochen b18 $\mathrm{zur} \mathrm{Ge}-$ nesung. In kurzen Abständen starben 2 akttve und 3 pensionierte Iehrer; davon 3 vrilig abgemagert, von den 2 b1s vor der Hungerzeit kaum je krank waren. Um so wichtiger und vertvoller ist die Schul- speisung. Pur die tehrer.}

Q31: Stadtarchiv Göttingen, D 44, Blatt 142. 
Götingen, am 22。 Jul1 1947

An -esices:

die Regierung

- Abteilung II B -

H $12 \mathrm{de}$ e $\mathrm{he}$ im

a.

Betr.: Gesundheitszustand und Schulspeisung der Lohrerschaft. Bezuer Verfligung vom 4. Jul1 1947.

Die eingeforderten Berichte der Schulen geben noch weit uber die bösen Brwartungen hinaus ersohrtokendes Bild. Ich lege Abschriften besonders bezeichnender Auszilge aus den Berichten be1.

\section{Mittelschule für Jungen:}

Nachlassen der Sehkraft, Schwindel, starkes Untergewicht, Versagen des Gedächnisses, besonders sehlimm sind die beiden Lehrer daran, die in Göttingen keine Wohnung finden; der eine in Nikolausberg hat iber $4 \mathrm{~km}$ Teg bei $200 \mathrm{~m}$ Hbhenunterschied; der andere in Rittmarshausen ist von 5 bis $19 \mathrm{Uhr}$ abwesend.

Mittelsohule für Mädchen:

Von den 22 Lehrikräften an meiner Schule haben nur vier eine Verwant Qte in ihrem eigenen Haushalt, die das Essen fur sie bereitet. Da nach Schulschluss mittags 13.25 Gas- und Stromzufuhr abgeschaltet sind, können die übrigen erst am Abend eine warme Mahlzeit bereiten. Die Schulspeisung ist also die einzige warme Mahlzeit, die sie bis zum Ango Abend kekommen. Die Mahlzeiten in Gaststätten einzunehmen verbietet sich, weil die Portionen im Vergleich zu den geforderten Marken zu kiein sind und für die Abendmahlzeit zu wenig ubrigbleibt.

Alle Iehrkräfte klagen darüber, dass ihr Gedächnis versagt, bel Stoffen, die sie schon jahrelang unterrichtetenm, fehlen plötzlich Namen und Zahlen. Mitten, im Lehrgespräch kommt es vor, dass erfahrene und bewährte Lehrkräfte plötzlich den Faden verlieren. Fiederholt muss eine Lehrkraft wegen Schwindels den Unterricht abbrechen oder die Schulerinnen beschäftigen. is chi,

Albanischule:

Fast alle Lehrer fuhren z.Zt. zwei Klassen und betreuen siomit 1.D. 120 Kinder. Gewichtsverlust $10-20 \%$. Ein lall von Hungerödemp. 3 sstärkere Herzschwächn. 2 Ohnmachtsanfälle im Unterricht. Lange Dienstunfähigkeit erkrankter fehrkrïfte. $Z_{\circ} B$ 。 nach Nierenentzilindurig nooh mimmer wieder Fieber und Unterrichtsfortfall, desgl. 10 Wochen nach normaler Geburt. .

\section{Pestalozzischule:}

A: 51 Jahre, ist ' in ärztlicher Behandlung wegen Magenleldens。 B: $55 \mathrm{Jahre}$ arbe1tsfahig nur durch Herzepritzeh. C: 51 Jahre; seit 6 Monaten in drztlicher Behandlung ; Vitaminspritzen, gtarke Paradentose, ärztlich verordneter Kuraufenthalt wegen Oberfủliung unmöglich, D:51 Jahre; unter Röntgenbeobachtung. $\mathrm{E}_{\text {o }} 61 \mathrm{~J}$ Jahre, uberanstrengt ; starke Mangelsymptome。 F: 51 Jahre; nach schwerer Iungenentzilndung aus Berlin geflüchtet, schonungsbediliftig, mit änsserer Anspannung an den Grenen der Kraft。G: 32 Jahre; wegen Schwäche verordnete zusatzkost hort jetzt auf.

Gewerbeschule:

Erwägt Verkibrzung des Unterrichts trotz aller Bedenken; Sorge uber Zusammenbruch weiterer Iehrkräfte.

Q32: Stadtarchiv Göttingen, Schulamt Nr. 100: Schulspeisung 1945-1947. 


\section{S. DP Enclatung.}

Seit Difingsten 1946 whure id als Turnlebreriu der Luthersolule

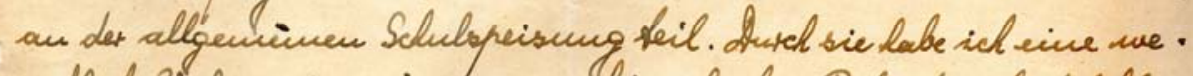

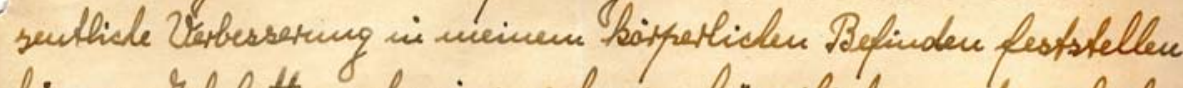

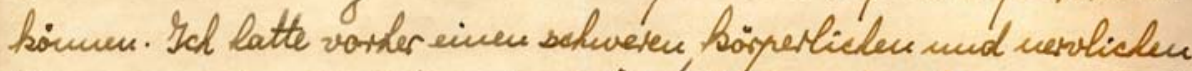

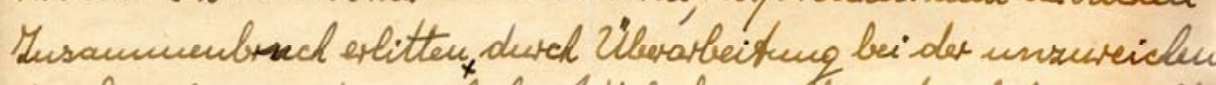

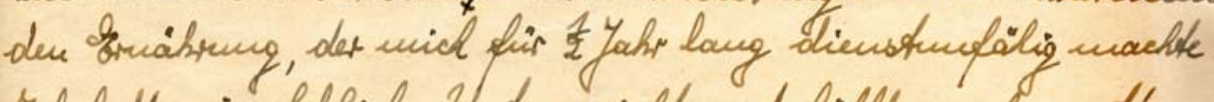
Ich latte enis erheblicles Vutergewicht und firlte wich unatt

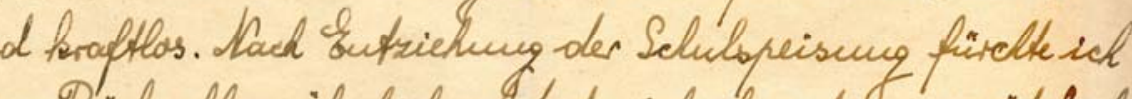
eiven Rickschlag alulicher of da ish ohue dieve zusätidiche Ipeisung vicht in Sfande sein wirde, unimen dienst vall zu vrrichteu.

$$
\text { Hildegard Lays, turculehreviu. }
$$

Q33: Stadtarchiv Göttingen, Schulamt Nr. 100: Schulspeisung 1945-1947. 



\title{
„Jungen und Mädel! Man [...] bietet euch einen Neuanfang" - Jugend in der Nachkriegszeit
}

\author{
Lisa Brill
}

\section{Einleitung}

In der Nachkriegszeit wurde der Lebensabschnitt der Jugend je nach Alter, Geschlecht, finanziellen Verhältnissen, Lebensort, Erziehung und Erlebnissen in $\mathrm{Na}$ tionalsozialismus und Krieg von Mädchen und Jungen unterschiedlich wahrgenommen und erlebt. ${ }^{1}$ Die verschiedenen Erfahrungsräume reichten von der Mitgliedschaft in Jugendgruppen und Vereinen bis hin zu gesellschaftlichem und sozialem Ausschluss. Sie alle teilten als Kinder und Jugendliche die gemeinsame Erfahrung des Krieges. Die meisten von ihnen waren außerdem Mitglied in der Hitlerjugend oder im Bund Deutscher Mädel gewesen. Im Nationalsozialismus waren Kinder und Jugendliche in der Hitlerjugend und dem Bund Deutscher Mädel instrumentalisiert worden, um sie früh mit der nationalsozialistischen Ideologie lenken und beherrschen zu können.

Das Leben der Jugendlichen wurde darüber hinaus mehr als zehn Jahre lang von den unmittelbaren Kriegsfolgen beeinflusst. Noch lange haben der Nationalsozialismus, Krieg und Nachkriegszeit in der Erinnerung und der Psyche der Jugendlichen ihre Spuren hinterlassen. Für fast alle Heranwachsenden war die Zeit nach dem Krieg bestimmt von materieller Not und psychischer und moralischer

\footnotetext{
${ }^{1}$ In die Jugendzeit fallen die Pubertät, das Ende der Schulzeit, der Beginn der Berufsausbildung, die Abnabelung vom Elternhaus und die Identitätsfindung. Siehe auch: Markus Köster, Jugend, Wohlfahrtsstaat und Gesellschaft im Wandel. Westfalen zwischen Kaiserreich und Bundesrepublik, Paderborn 1999, S. 383.
} 
Desorientierung, aber auch von einem Gefühl des Neuanfangs, der geistigen Offenheit und des kollektiven Aufbruchs. ${ }^{2}$

\section{Jugendliche und Kinder als „Miternährer der Familie“}

Die meisten Mädchen und Jungen lebten direkt nach dem Krieg in veränderten Familienkonstellationen. Eine große Anzahl der Väter befand sich in Kriegsgefangenschaft oder war im Krieg gestorben: Sie hinterließen 2,5 Millionen Waisen und Halbwaisen. Viele Kinder lebten über einen längeren Zeitraum alleine mit ihren Müttern, Geschwistern oder anderen Angehörigen oder hatten diese sogar verloren. Ungefähr 45 Prozent der Kinder wuchsen mit ihren Vätern auf, 25-30 Prozent waren dagegen zeitweise ohne ihren Vater und 25-30 Prozent mussten dauerhaft oder sehr lange auf diese männliche Bezugsperson verzichten. Stark gefordert von der Tatsache, auch Rollen der Männer übernehmen zu müssen, übertrugen die Mütter laut dem Historiker Nicholas Stargardt wichtige Aufgaben auf ihre älteren Kinder. Diese halfen im Haushalt, kümmerten sich um die jüngeren Geschwister, handelten auf dem Schwarzmarkt, stahlen Kohle oder weitere lebensnotwendige Dinge und unternahmen Hamsterfahrten ${ }^{3}$ - Aktivitäten, die die Jugendschützer beunruhigten und einen moralischen Verfall der Jugend konstatieren ließen. Bei einigen Kindern resultierten aus diesen Familienverhältnissen eine besonders enge Beziehung zu ihren Müttern und ein distanziertes Verhältnis zu ihren Vätern. ${ }^{4}$ Kamen Letztere aus der Kriegsgefangenschaft zurück, nahmen ihre Söhne und Töchter dies oft als Irritation oder Störung wahr. Häufig litten die Väter an Depressionen und physischen und psychischen Einschränkungen und waren mit der Reintegration in ihre Familie und den Veränderungen seit ihrer Rückkehr überfordert. Sie hatten mit der Vaterfigur, die ihre Kinder in Erinnerung hatten, wenig gemein. Auch dem Bild, das in ihrer Abwesenheit oftmals von den Familienmitgliedern konstruiert und hochgehalten worden war, glichen sie nicht. ${ }^{5}$ Häufig lieBen sich die familiären Autoritätsverhältnisse, die vor dem Krieg geherrscht hatten, nicht mehr wiederherstellen. Viele Väter hatten sich stark verändert und viele Kinder und Jugendliche waren durch die verantwortungsvollen Tätigkeiten, die sie für ihre Familie übernommen hatten, schnell erwachsen geworden und konnten sich schwer wieder der väterlichen Autorität unterordnen. ${ }^{6}$

\footnotetext{
2 Vgl. Friedhelm Boll, Auf der Suche nach Demokratie. Britische und deutsche Jugendinitiativen in Niedersachsen nach 1945, Bonn 1995, S. 44. Siehe dazu auch: Hermann Schulz/Hartmut Radebold/Jürgen Reulecke, Söhne ohne Väter. Erfahrungen der Kriegsgeneration, Bonn 2005, S. 115.

3 Vgl. Nicholas Stargardt, Kinder in Hitlers Krieg, Pößnek 2008, S. 403-404; Feliks Tych, Alfons Kenkmann/Elisabeth Kohlhaas (Hg.), Kinder über den Holocaust- Frühe Zeugnisse 1944-1948. Interviewprotokolle der Zentralen Jüdischen Historischen Kommission in Polen, Berlin 2008.

${ }_{4}$ Vgl. Winfried Speitkamp, Jugend in der Neuzeit. Deutschland vom 16. bis zum 20. Jahrhundert, Göttingen 1998, S. 252.

${ }^{5}$ Vgl. Radebold, Söhne ohne Väter. Erfahrungen der Kriegsgeneration, S. 127.

${ }^{6}$ Vgl. Stargardt, Kinder in Hitlers Krieg, S. 395-397.
} 
Vielen zurückgekehrten Vätern gelang es nicht, wieder ihre Rolle als „Ernährer der Familie“ einzunehmen. ${ }^{7}$ Eine große Anzahl von Ehen ging in dieser Zeit zu Bruch. Betroffene Kinder und Jugendliche verloren ihre Väter dadurch abermals und damit auch eine für ihre Entwicklung wichtige männliche Bezugsperson. Besonders vaterlose Söhne suchten sich Ersatzvorbilder unter männlichen Lehrern, Verwandten oder anderen Bezugspersonen in Filmen und Literatur (auch in den Männerwelten der sogenannten „Schund- und Schmutzliteratur") sowie in Jugendbünden. ${ }^{8}$

\section{Zwischen Freiheit und Trauma: „Umhervagabundierende“ Jugendliche}

Zu Kriegsende waren viele Mädchen und Jungen aus den Städten im Rahmen der Kinderlandverschickung in ländliche Gebiete evakuiert worden. Oftmals hatten die Reichsjugendführung und die Nationalsozialistische Volkswohlfahrt (NSV) sie in staatlichen Heimen, Schlössern und Klöstern oder bei Gastfamilien untergebracht. Die Erfahrungen, die die Kinder in dieser Zeit machten, reichen von Vernachlässigung, Misshandlungen, Missbrauch und Ausnutzung durch Gasteltern bis hin zu Geborgenheitsgefühlen und Spaß bei der Arbeit auf einem Hof und am Landleben. ${ }^{9}$

In den letzen Jahren des Krieges mussten männliche Mittel- und Oberschüler den Dienst als Flakhelfer antreten. Die Arbeit bei der Luftabwehr war besonders gefährlich, da die Flugabwehrkanonen ein primäres Ziel angreifender Flugzeuge waren. Ab dem 25. September 1944 hatten die Nationalsozialisten alle Männer ab dem 16. Lebensjahr aufgefordert am sogenannten „Volkssturm“ teilzunehmen und Deutschland als Soldaten zu verteidigen. Trotz der Altersbeschränkung nahmen auch 14- oder 15jährige Jungen freiwillig daran teil. Vielen erschien dies als Höhepunkt der Ausbildung, die sie in der Hitlerjugend erhalten hatten. ${ }^{10}$ Mädchen übernahmen nun die Hilfsdienste, die die Jungen zuvor ausgeübt hatten (z.B. als Flakhelferinnen). ${ }^{11}$ Am 12. Februar 1945 forderte Hitler auch Frauen und Mädchen auf, als Hilfsdienst am Volkssturm teilzunehmen. ${ }^{12}$

Die jugendlichen Flakhelfer und Kindersoldaten sollten eigentlich in der Nähe ihrer Heimatorte eingesetzt werden. Gerade bei Jungen aus Ballungsgebieten wurde dieses Versprechen allerdings oft nicht eingehalten. Sie wurden in Gegenden geschickt, in denen sie benötigt wurden, also teilweise weit entfernt von ihrem

\footnotetext{
${ }^{7}$ Radebold, Söhne ohne Väter. Erfahrungen der Kriegsgeneration, S. 141.

8 Vgl. Radebold, Söhne ohne Väter, S. 155-158.

9 Vgl. Stargardt, Kinder in Hitlers Krieg, S. 326-329.

${ }^{10}$ Vgl. ebd.

11 Vgl. ebd., S. 315-318.

12 Vgl. Michael Behnen, Volkssturm, in: Gerhard Taddey (Hg.), Lexikon der deutschen Geschichte. Ereignisse. Institutionen. Personen, 3. überarb. Auflage, Stuttgart 1998, S. 1301.
} 
Heimatort. ${ }^{13}$ Wie auch die Mädchen und Jungen aus der Kinderlandverschickung waren diese nach Kriegsende oftmals auf sich alleine gestellt und mussten erst einmal nach Hause zurückfinden. So irrten sie auf den Landstraßen herum, schliefen in Heuschuppen und verdienten ihren Lebensunterhalt manchmal mit Arbeit für die Besatzungstruppen - häufiger aber mit Prostitution, Schwarzmarkthandel und Eigentumsdelikten. ${ }^{14} \mathrm{Zu}$ den sogenannten , umhervagabundierenden Jugendlichen" gehörten auch Ostvertriebene und junge Flüchtlinge aus der sowjetischen Besatzungszone.

Göttingen wurde neben Braunschweig und Hannover besonders stark von heimatlosen Jugendlichen aufgesucht, denn es lag an der Zonengrenze und war kaum zerstört. Die Betreuung dieser jungen Wanderer war bis in die Mitte der 1950er Jahre eine der Hauptaufgaben der Jugendhilfe. ${ }^{15}$ Diese hatte ab dem 15. November 1945 den Auftrag, Adoleszenten ohne festen Aufenthaltsort festzuhalten. Anschließend versuchten Jugendpflege und Militärregierung diese in Lehrstellen oder Jugendhorten und Arbeitslagern unterzubringen. ${ }^{16}$ „Die Jugendlichen kommen einzeln oder in Trupps mit bis zu 5, 6 und noch mehr jungen Männern und 1 oder 2 Mädchen angeblich aus der russischen oder polnischen Zone, obwobl sich bei näheren Untersuchungen bisweilen herausstellt, daß sie aus dem Westen stammen", beschreibt Oberverwaltungsrat Kluge die Lage in einem Brief an die Regierung in Hildesheim am 2. Juli 1946 (Q1). ${ }^{17}$ Dabei klagt er auch über die mangelnde Zusammenarbeit zwischen den vier Besatzungszonen und über die Schwierigkeit, die jungen Menschen in Arbeitsoder Lehrstellen zu vermitteln: Nach wenigen Tagen würden die meisten wieder weglaufen. Gleichzeitig spricht Kluge aber auch die schlechten Verhältnisse in den Barackenlagern, den Wohnorten der jugendlichen Arbeiter, an: „Nur Menschen, die von innen heraus den Wert der Arbeit erkennen, werden sich über die Unbequemlichkeiten eines solchen Lagerlebens hinwegsetzen. "Genau diese Fähigkeit vermisse er aber bei den Jugendlichen.

Heutige Studien, die sich mit den Lebensbedingungen von Kindern in kriegsähnlichen Situationen befassen, stellen fest, dass die Heranwachsenden, die unter den extremsten Bedingungen in Flüchtlingslagern leben, am wenigsten Ängste und emotionale Beeinträchtigungen, dafür aber ein abweichendes Sozialverhalten, eine stärkere Aggressivität und ein verzerrtes Moralverständnis aufweisen als andere Kriegskinder. Dieses Phänomen wird mit einer Desensibilisierung und Anpassung

\footnotetext{
13 Vgl. Ludger Tewes, Jugend im Krieg, Von Luftwaffenhelfern und Soldaten 1939-1945, Essen 1989, S. 329 .

14 Vgl. Boll, Auf der Suche nach Demokratie, S. 33.

15 Vgl. Köster, Jugend, S. 388-390.

16 Vgl. Alfons Kenkmann, Wilde Jugend. Lebenswelt großstädtischer Jugendlicher zwischen Weltwirtschaftskrise, Nationalsozialismus und Währungsreform, Essen 1996, S. 218-219.

${ }^{17}$ Brief von Kluge an die Regierung in Hildesheim, 2.7.1946, Göttinger Stadtarchiv, C64 „Jugendamt Abteilung Jugendpflege“, Nr. 421 „Probleme der Jugendlichen“.
} 
gegen die permanent Stress erzeugenden und gewalttätigen Lebensumstände erklärt. ${ }^{18}$

Auch die umherziehenden Jugendlichen der Nachkriegszeit waren dauerhaftem Stress ausgesetzt. Es liegt nahe, dass sie sich ihren Lebensumständen angepasst und andere Moralvorstellungen angenommen haben.

Für viele der Mädchen und Jungen war ein solches Leben eine Möglichkeit, vor den Kriegserlebnissen und ihren Problemen zu flüchten. ${ }^{19}$ Kinder und Jugendliche hatten im Krieg verschiedene Traumata erlitten. Während des Bombardements hatten sie zwischen den Erwachsenen in stickigen Kellern oder Bunkern gesessen, Tote oder Verletzte gesehen, waren selber verwundet worden, hatten ihre Eltern, Verwandte oder Freunde verloren und als Flakhelfer oder Kindersoldaten lebensgefährliche Situationen durchgestanden, bei denen sie teilweise selber getötet hatten. Besonders traumatische Erfahrungen hatten die Kinder erlitten, die unter der Naziherrschaft in Konzentrationslagern inhaftiert worden waren und diese Zeit überlebt hatten. ${ }^{20}$ Kinder haben im Gegensatz zu Erwachsenen bestimmte Kompensationsmechanismen zur Traumabewältigung noch nicht entwickelt. ${ }^{21}$ Deshalb waren auch die Heranwachsenden, die den zweiten Weltkrieg erlebt hatten, sehr gefährdet, bleibende psychische Folgeerscheinungen davonzutragen.

Laut aktuellen Studien reagieren Jugendliche zwischen 14 und 18 Jahren auf Kriegstraumata oft mit Niedergeschlagenheit, Gereiztheit und antisozialem Verhalten. Sie haben veränderte Lebenseinstellungen und Wertvorstellungen und können sich ihre Zukunft nicht vorstellen. ${ }^{22}$ Diese Traumatisierungen könnten die Gründe für das „Umhervagabundieren“ und die Straftaten einiger Jugendlicher sein. Wie sollten sie den inneren Wert der Arbeit und eines sesshaften Lebens erkannt haben, wenn sie sich ihre eigene Zukunft nicht vorstellen konnten?

\section{4 „Arbeitsscheu, nachlässig und unehrlich“? Jugendarbeitslosigkeit 1950}

Nach der Währungsreform im Juni 1948 milderten sich einige Nöte der unmittelbaren Nachkriegszeit. Die Arbeitslosigkeit, besonders die der Heranwachsenden,

\footnotetext{
${ }_{18}$ Vgl. Ahmad Khatib, Kinder unter Bedrohung. Eine empirisch-psychologische Studie über die Auswirkungen von Streß durch gewalttätige kriegsähnliche Lebensbedingungen auf Kinder, Frankfurt am Main 1994, S. 296-299. Hierbei handelt es sich um eine Studie über palästinensische Kinder, die unter kriegsähnlichen Verhältnissen leben. Es wurden Stadtkinder, Landkinder, Kinder aus Flüchtlingslagern und eine Kontrollgruppe israelischer Kinder anhand von Fragebögen und psychologischen Tests untersucht. Die Flüchtlingskinder leben dabei, im Vergleich zu den anderen Gruppen, unter den schlechtesten Lebensbedingungen.

${ }^{19}$ Vgl. Kenkmann, Wilde Jugend, S. 248.

${ }^{20}$ Vgl. Stargardt, Kinder in Hitlers Krieg, (Kapitel Deportation und Das Familienlager), S. 216-284.

${ }^{21}$ Vgl. Dubravka Kochijan-Hercigonja, Kinder im Krieg. Erfahrungen aus Kroatien, in: Werner Hilweg (Hg.), Kindheit und Trauma. Trennung, Mißbrauch, Krieg, Göttingen 1997, S. 177-194.

22 Ebd.
} 
stieg aber bis zu ihrem Höhepunkt im Jahr 1950.23 „Bei diesen Jugendlichen besteht die große Gefahr des Abgleitens von der normalen Lebensbahn, da sie z:T. seit einem Jahr ohne geregelte Arbeit sind"24, schreibt Jugendpfleger Schmalstieg in einem Bericht über die jugendlichen Erwerbslosen in Göttingen im Jahr 1950 (Q2). Diese seien für eine Vermittlung in Lehrstellen nicht geeignet, da sie „charakterlich sehr schwierig, arbeitsscheu, nachlässig, unzuverlässig und unehrlich" seien und bei früheren Arbeitsstellen grundlos nicht erschienen waren.

In Niedersachsen war die Arbeitslosigkeit in den unmittelbaren Nachkriegsjahren besonders hoch, denn wegen der relativ guten Ernährungslage und Unterbringungsmöglichkeiten waren dem Land viele Flüchtlinge zugewiesen worden. Für die 18- bis 30-Jährigen unter ihnen, die aufgrund des Krieges ohne Ausbildung geblieben waren, und insbesondere für die Mädchen war der Kampf um eine Lehrstelle am härtesten. ${ }^{25}$ Nach dem Wirtschaftswunder sank die Jugendarbeitslosigkeit wieder bis hin zu einem Lehrstellenüberschuss gegen 1955. ${ }^{26}$ Zufrieden waren viele Jugendlichen mit ihren Lehrstellen allerdings nicht. Ende 1955 gab ein Drittel der jungen Erwerbstätigen an, dass sie lieber einen anderen Beruf erlernt hätten. ${ }^{27}$

\section{Der Kampf gegen die „Vergiftung der Jugend“}

„'Und dann legte er ihm eine Schlinge um den Hals und zog sie fest zu... 'Als der sechzehnjährige Herbert Reepka in Göttingen diese Stelle in „Die würgende Schlinge" [...] gelesen hatte, begab er sich zum Taxenhalteplatz und ließ sich nach einem Ort in der Nähe der Stadt fahren. Unterwegs legte er dem Taxichauffeur, einem Vater von zwei Kindern, von hinten einen Schal um den Hals und drosselte ihn“, schreibt am 19. Oktober 1951 die „Neue Zeitung“ der amerikanischen Besatzungszone. ${ }^{28}$ Am 18. Oktober 1951 ermordete Herbert Reepka in Göttingen den Taxifahrer Cjaza. Dieser erstickte an einem Halstuch, mit dem der Jugendliche ihn geknebelt hatte. Die Schuld an dieser Gewalttat gaben JugendschützerInnen und JournalistInnen den Romanen, die der Junge gelesen hatte. „Wir alle bleiben mitschuldig, wenn wir weiter zu dieser Vergiftung unserer Jugend schweigen. Bei aller Achtung der Freiheit des Geistes fordern wir eine Ausrottung der geistlosen, verbrecherischen Schundliteratur"29, schreiben am 7. Juli 1951 Vertreterinnen der Göttinger Frauenverbände in einem

\footnotetext{
${ }^{23}$ Vgl. Köster, Jugend, S. 396.

24 Jugenderwerbslosenprobleme, 1950, Göttinger Stadtarchiv, C64 Jugendamt Abteilung Jugendpflege, Nr. 59 Errichtung des Jugendhilfswerkes in Göttingen, Bl. 357.

25 Vgl. Köster, Jugend, S. 397.

${ }^{26}$ Vgl. Speitkamp, Jugend in der Neuzeit, S. 255.

27 Vgl. Köster, Jugend, S. 398.

${ }^{28}$ Vgl. Stadtarchiv Göttingen, Kampf gegen die Verbreitung jugendgefährdenden Schrifttums.

${ }^{29}$ Leserbrief Göttinger Frauen, 7.7.1951, Göttinger Stadtarchiv, C 64 Jugendamt Abteilung Jugendpflege, Nr. 436 „Kampf gegen die Verbreitung jugendgefährdenden Schrifttums“, keine Blattnummer.
} 
im Göttinger Tageblatt veröffentlichten Leserbrief (Q3). ${ }^{30}$ Auch die Einbrüche eines 17jährigen Göttinger Autoschlosserlehrlings, der mit mindestens fünf Einbrüchen Geld, Schokolade und Zigaretten erbeutet hatte, begründete die Öffentlichkeit mit der Lektüre sogenannter Schundliteratur und dem Konsum von Filmen, die man für demoralisierend hielt. „Der Täter, eine gepflegte Erscheinung, hat überall mit Handschuben gearbeitet, wie er es in Kriminalfilmen gesehen haben will. Auch schlechte Lektüre haben seine kriminellen Handlungen weitgehend gefördert. "31, schreibt das Göttinger Tageblatt am 10.7.1951 (Q4).

In der Nachkriegszeit war die Jugendkriminalität europaweit gestiegen. In Deutschland war sie in den Jahren 1946 und 1947 besonders hoch und ging Ende der 1940er Jahre nur wenig zurück. Dies veranlasste Psychologen, Kriminologen und Sozialarbeiter, die „moralische Krise der Jugend“ zu diskutieren und festzustellen, dass die Jugend den Respekt vor Eltern und der Gemeinschaft verloren hatte. ${ }^{32}$ Die Schuld dafür gaben sie dem schlechten Einfluss von sogenannter „Schund- und Schmutzliteratur“. Mit allen Mitteln sollten die Jugendlichen von den Vergnügungsgelegenheiten der Erwachsenenwelt ferngehalten werden, um ihrer Verwahrlosung vorzubeugen. Als größte Gefahren galten in diesem Diskurs Sexualität, Gewalt und Konsum. Am 9. Juni 1953 wurde ein Gesetz erlassen, das die Verbreitung jugendgefährdender Schriften verbot. ${ }^{33} \mathrm{Zu}$ diesen gehörten vor allem Erotikgeschichten, Abenteuergeschichten und Western. Bücher mit Titeln wie „Alphabet der Liebe“, „Der Herr und die Dirne“, „Freies Leben “, „Liebesabenteuer in aller Welt", „Black Jack", „Die würgende Schlinge (Tom Shark Hefte) “oder „Die drei vom FBI (Billy Jenkins Hefte) "stießen auf Protest der JugendschützerInnen, vor allem des „Arbeitskreises von Schund- und Schmutzliteratur“34. Der Göttinger Jugendring und Jugendpfleger Schmalstieg beteiligten sich mit Flugblättern und Resolutionen am Kampf gegen die „Vergiftung der Jugend“.35 Jugendliche wurden aufgefordert, sich ihrer „Schund- und Schmutzliteratur“ zu entledigen (Q5). Gerade vaterlose männliche Jugendliche fanden in den Männerwelten der billigen Heftchen dennoch manchmal Vaterfiguren, an denen sie sich orientieren konnten. ${ }^{36}$

Aber nicht nur die Lektüre, auch selbstständiges Reisen der Heranwachsenden beunruhigte die Jugendschützer. ${ }^{37}$ So versuchte das Kultusministerium die Reisen

\footnotetext{
${ }^{30}$ Vgl. Stadtverband der evangelischen Frauenarbeit, Deutsch-evangelischer Frauenbund, die Frauen der katholischen Pfarrgemeinden in Göttingen, Frauengruppe der Arbeiter-Volkswohlfahrt, Frauengruppe des DRK, Kreisverband Göttingen-Stadt, Frauenring Göttingen e.V., „Leserbrief Göttinger Frauen“, 7.7.1951, Göttinger Stadtarchiv, C64, Nr. 59, Bl. 357.

31 Geldschrankknacker mit 17 Jahren, 10.7.1951, Göttinger Stadtarchiv, C64 Jugendamt Abteilung Jugendpflege, „Kampf gegen die Verbreitung jugendgefährdenden Schrifttums“, Nr. 436, keine Blattnummer.

$32 \mathrm{Vgl}$. Stargardt, Kinder in Hitlers Krieg, S. 405.

33 Vgl. Speitkamp, Jugend in der Neuzeit, S. 269.

${ }^{34}$ Göttinger Stadtarchiv „Kampf gegen die Verbreitung jugendgefährdenden Schrifttums, die sog. Schund und Schmutz Literatur", Jugendamt Abt. Jugendpflege, Nr. 436.

35 Boll, Auf der Suche nach Demokratie, S. 118.

${ }^{36}$ Vgl. Hartmut Radebold, Söhne ohne Väter, S. 155-158.

${ }^{37}$ Vgl. Köster, Jugend, S. 412.
} 
„jugendlicher Deutscher, die ohne ausreichende Geldmittel“"waren, „sich durch Betteln und Musizieren “ ernährten und ,sich von fremden Kraftfahrern mitnehmen "ließen, einzudämmen. „Vor einigen Monaten sind 2 deutsche Abiturienten, die eine solche Fabrt unternommen hatten, in Brindisi spurlos verschwunden, obne daß es trotz aller Bemühungen der Botschaft gelungen wäre, etwas über ibren Verbleib zu ermitteln. Es ist bezeichnend, daß die Eltern der Betreffenden es nicht für nötig gehalten haben, nach Italien zu kommen, um sich an den Nachforschungen zu beteiligen"38, heißt es in einer Abschrift einer Nachricht der Deutschen Botschaft in Italien vom 30. September 1953. Diese Art des Reisens war aus den Augen der Botschafter nicht nur gefährlich, sondern schädigte ,gerade in Italien, wo keine Familie, die etwas auf sich hält, ihren Söhnen und Töchtern dies gestatten würde, das deutsche Ansehen ganz erheblich. "(Q6)

Nicht nur Behörden versuchten sich in das Leben der Kinder und Jugendlichen einzumischen. Auch viele Eltern wollten ihnen ihre moralischen und religiösen Vorstellungen vermitteln und sogar manchmal aufzwingen. „Ich muss dir nämlich sagen, liebe Marianne, dass wir zwei verschiedene Religionen haben. Du bist wie anzunehmen ist und wie ich aus deinen Gesprächen so hörte, evangelisch und ich bin katholisch und auch so streng von dabeim erzogen. Meine Eltern würden also gutwillig eine Verbindung mit einem evangelischen Mädchen nicht qugeben",39 schreibt am 10. November 1947 der Försterlehrling Horst G. aus Schotten an die achtzehnjährige Marianne Grunewald aus Witzenhausen (Q7). Nachdem das Mädchen geantwortet hatte, dass sie evangelisch bleiben und auch ihre Kinder nach dieser Religion erziehen wolle, versteckte Horsts Mutter Mariannes weitere Briefe und der Kontakt brach ab.

\section{Ein Neuanfang: Jugendarbeit, Politik, und Re-education}

„Jungen und Mädel! man gibt euch eine Chanse man bietet euch einen Neuanfang",40 mit diesen Worten richtet sich Jugendpfleger Hermann Schmalstieg im November 1945 in einem schriftlichen Aufruf an die Adoleszenten aus Göttingen und Umgebung (Q8). Ende August 1945 hatte die englische Militärregierung alle zuständigen deutschen Dienststellen dazu aufgefordert mit der Jugendarbeit zu beginnen. ${ }^{41}$ In Göttingen wurde der Sozialdemokrat Schmalstieg mit dieser Aufgabe betraut. ${ }^{42}$ Schmalstieg war gelernter Feinmechaniker. Während einer Zeit der Arbeitslosigkeit nach Abschluss seiner Lehre kam er mit dem von Arthur und Debora-Dore Jacobs gegründeten "Bund - Gemeinschaft für sozialistisches Leben" in Kontakt. Im Na-

\footnotetext{
38 Trampende deutsche Jugendliche in Italien, 30.9.1953, Göttinger Stadtarchiv, C64 Jugendamt Abteilung Jugendpflege, Nr. 23, keine Blattnummer.

39 Brief an Marianne, 10.11.1947, Privatbesitz.

40 Neuanfang, November 1945, Göttinger Stadtarchiv, C64 Jugendamt Abteilung Jugendpflege, Monatsberichte der städtischen Jugendpflege an die Militärregierung über Jugendbewegung und Jugendpflege in Göttingen, Bl. 10.

$41 \mathrm{Vgl}$. Köster, Jugend, S. 464.

42 Es war in der Nachkriegszeit schwierig, für diese Aufgabe geeignete Männer und Frauen zu finden, die politisch unbelastet waren. Vgl. Speitkamp, Jugend in der Neuzeit, S. 265.
} 
tionalsozialismus hatte er an der Technischen Hochschule und später als Feinmechanikermeister in Braunschweig gearbeitet. Nach dem Krieg verbrachte er zunächst vier Wochen in britischer Gefangenschaft und kam im Sommer 1945 auf der Suche nach einer Anstellung an einem Universitätsinstitut nach Göttingen. Am 14. November 1945 wurde er unter Fürsprache eines Professors zum Stadtjugendpfleger ernannt. Zu dieser Zeit sah er sich mit einer schwierigen Ausgangssituation konfrontiert: Größtenteils unzerstört, war die Stadt überfüllt mit Flüchtlingen, heimatlosen Jugendlichen, Studenten und Hochschullehrern. Das ehemalige Jugendheim in der Hospitalstraße wurde unter anderem von der Göttinger Nothilfe und der Unfallstelle des DRK genutzt. Der Jugendarbeit standen anfangs weder Räume noch Material zur Verfügung. ${ }^{43}$ Am 3. April 1946 verfügte der englische Jugendoffizier Major Oldham die Rückgabe des Heimes. Dieser hatte als Jugendoffizier eine wichtige Vorbildfunktion und sollte den Jugendlichen demokratisches Verhalten darbieten. ${ }^{44}$ Nach dem Krieg standen Briten und Jugendarbeiter den jungen Deutschen zwiespältig gegenüber, denn man wusste nicht, wie sich die Jahre nationalsozialistischen Einflusses auf sie ausgewirkt hatten. ${ }^{45}$ Die britischen Behörden waren den vermeintlich gleichgeschalteten Jugendlichen gegenüber misstrauisch, setzten in sie aber auch gleichzeitig die größten Hoffnungen für den Aufbau eines neuen demokratischen Deutschlands. Sie sahen es als ihre Aufgabe an, den deutschen Jugendlichen Demokratie, Toleranz und Verantwortungsbewusstsein zu vermitteln. Dieses Verständnis wurde zur Grundlage der britischen Jugendarbeit. Ohne autoritäre Befehlsstrukturen wollten sie den deutschen Jugendlichen einen Anstoß zum eigenständigen demokratischen Handeln geben. ${ }^{46}$ Besondere Bedeutung maßen sie in diesem Zusammenhang dem Aufbau demokratischer Jugendgruppen zu. „Der Neuling, der in einen Club eintritt, sollte ein, ihm ganz artgemässes, Feblen von Befehlsgeberei vorfinden, und die Disziplin, die notwendig ist, um die Ordnung aufrecht zu halten, sollte eine Disziplin [sein], die der Junge sich selbst auferlegt. Der Club sollte immer, so weit wie irgend möglich durch Selbstverwaltung gelenkt werden, sodass dadurch in den Jungen Mitglieder mit Initiative und Charakter herangezogen werden, und nicht eine Horde blasser Persönlichkeiten, die nur getreulich die Ansichten des Führers wiedergeben." ${ }^{\text {"47 }}$, schrieb Oldham in einem Brief über den Zweck des Jugendclubs in Deutschland (Q9). Politische, militärische oder paramilitärische Gruppen wurden vorerst genauso wenig zugelassen wie die Bildung von Zentralverbänden oberhalb der Kreisebene. Jugendgruppen sollten von unten aufgebaut sein, damit kein autoritärer Führer an die Macht der Verbandstrukturen gelangte. Voraussetzung für eine Zulassung war die freiwillige Mitgliedschaft. Dabei sollte niemand aus politischen, rassistischen

\footnotetext{
43 Vgl. Boll, Auf der Suche nach Demokratie, S. 106-110.

${ }^{44}$ Vgl. ebd. S. 47.

45 Vgl. Speitkamp, Jugend in der Neuzeit, S. 261.

${ }^{46}$ Vgl. Köster, Jugend, S. 433-442.

47 Der Zweck des Jugendclubs in Deutschland, 6.4.1946, Göttinger Stadtarchiv, C64 Jugendamt Abteilung Jugendpflege, Nr. 2 Wöchentliche Nachrichtenbriefe des Britischen Majors J. Oldham zur Göttinger Jugendbewegung, keine Blattnummer.
} 
oder religiösen Gründen aus den Gruppen ausgeschlossen werden. „Darf ich ein oder zwei Hinweise auf die Psychologie der Jugend machen. Rote und schwarze Wandbehänge mit gedämpftem Licht können eine böse Einwirkung auf die Seelen von Jugendlichen oder sogar auf die von Erwachsenen haben. [...] Ausserdem glaube ich nicht, dass Lieder von Schlachten, Mord und plötzlichem Tod direkt entspannend am Ende eines langen anstrengenden Tages sind", rät Major Oldham in seinem ersten wöchentlichen Nachrichtenbrief vom 12. April 1946 an die Göttinger Jugendgruppen. Statt politischer oder militärischer Profile der Gruppen waren kulturelle, religiöse oder sportliche Betätigungen zur Freizeitgestaltung und Entspannung erwünscht. „Die Hauptbetätigung ist im Augenblick Naturkunde und Zelten. Wir verbrachten einen sehr schönen Abend um ein Lagerfeuer im Hainholz sitzend am 28. März. Geschichten wurden erzählt und Lieder gesungen und wir gingen alle sehr glücklich und zufrieden nach Hause", beschreibt Oldham im selben Brief einen Abend mit einer von ihm positiv bewerteten Jugendgruppe (Q10). Auch Fahrrad- und Wandertouren sowie Zeltlager zählten zu den beliebten Aktivitäten der Jugendlichen. Auf dem vorliegenden Foto (Q11) sind vier Jungen zu sehen, die scheinbar während einer Fahrradtour eine Pause einlegen. Am 1. April 1946 wurden, wie Oldham in seinem Nachrichtenbrief mitteilt, zwei Jugendpflegerinnen eingesetzt, die sich um die Mädchen der Jugendgruppen kümmerten. So sollten sie beispielsweise die Schulen besuchen und Nähstunden zum Anfertigen von Sportkleidung organisieren. „Wenn die Jungen nachher feststellen, dass die Hosen manchmal nicht so ganz passen, dann erinnert Euch daran, dass alles für eine gute Sache geschah und dass die Mädels mit der Zeit es besser lernen werden (das hoffen wir jedenfalls)", kommentiert Oldham diese Aktivitäten. Dies zeigt einerseits die aus der Notlage geborene Kreativität der Jugendlichen und der OrganisatorInnen, andererseits die Geschlechterrollenverteilung in der Nachkriegszeit.

Die Vorstände einer Jugendgruppe mussten das Entnazifizierungsverfahren durchlaufen. ${ }^{48}$ Daraus ergaben sich allerdings Probleme: „Dieses Hauptquartier hat Berichte erhalten, dass eine Anzahl von Jugendführern in finanzielle Schwierigkeiten dadurch gerät, dass sie die Summe von 20.- DM für ein Entnazifizierungszengnis zu bezahlen haben, wenn sie die Genehmigung der Mil.Reg. erbitten, als Jugendführer tätig zu sein", heißt es in einem Schreiben der britischen Jugendwohlfahrt vom 20. Oktober 1948 an die Jugendpfleger. Die Militärregierung erlaubte deshalb ab 1948 auch das Vorlegen eines Empfehlungsschreibens ${ }^{49}$, das von dem örtlichen Bürgermeister oder Kreistagsabgeordneten, einem im Amt befindlichen Schullehrer oder Pfarrer und dem Kreisjugendamt unterschrieben werden musste (Q12).

Um zugelassen zu werden, musste eine Gruppe einen Antrag mit einer Beschreibung ihrer Ziele und der beabsichtigten Tätigkeiten bei Schmalstieg einreichen und eine Genehmigung der Militärregierung abwarten. „Wir wollen eine einheitliche Schar junger Mädel sein, die bereit ist, überall zu helfen wo Not am Mann ist"50, schlägt

\footnotetext{
48 Vgl. Boll, Auf der Suche nach Demokratie, S. 57.

${ }^{49}$ Quelle 10.

${ }^{50}$ Vorschlag Antrag Mädchengruppe, kein Datum, Göttinger Stadtarchiv, Kleine Erwerbung 149, Nr. 73, keine Blattnummer.
} 
die Jugendliche Ingrid Koch als ersten Satz des Zulassungsantrages ihrer Jugendgruppe vor (Q13). Betrachtet man den Antrag, so kann man deutlich die Unsicherheit im Hinblick auf die neuen politischen Verhältnisse erkennen. Ein aus heutiger Sicht seltsam anmutender Spagat zwischen der Sprache des Nationalsozialismus und der neuen „demokratischen Sprache“ ist erkennbar. So übernimmt sie die demokratischen Ideale der Briten wie Parteilosigkeit der Jugendgruppen, die Freiwilligkeit der Mitgliedschaft, die Miteinbeziehung der Eltern und Meinungsfreiheit. Freie Meinungsäußerung aber ist bei ihr kein Privileg, sondern eine „Pflicht für jeden", die Mitgliedschaft ist ein „Dienst“ und die Gruppe soll „,helfen unser geschlagenes Deutsches Volk wieder aufzurichten". Die nationalsozialistischen Forderungen nach Selbstverpflichtung und Aufopferung für das Vaterland haben bei dem Mädchen deutlich ihre Spuren hinterlassen. ${ }^{51}$ Dies zeigt, wie schwer es für die Jugendlichen war, den nationalsozialistischen Sprachgebrauch - und auch seine Ideen - abzulegen.

Um die Jugendgruppen untereinander zu vernetzen und ihnen die Möglichkeit zu geben, Demokratie aktiv auszuprobieren, wurde der Göttinger Jugendring ins Leben gerufen. In diesen sendete jede Gruppe einen Vertreter oder eine Vertreterin. Für die unorganisierte Jugend sprachen die Jugendpfleger. Der Jugendring hatte unter anderem die Aufgabe, darauf zu achten, dass keine Gruppe zu einer „Gefahr für die Demokratie“ wurde. Außerdem koordinierte er die Zusammenarbeit der verschiedenen Jugendclubs und organisierte Veranstaltungen wie Wandertouren, Maifeuer, Tanz, Unterhaltungsabende und den Jugend- und Briefaustausch mit der neuen Partnerstadt Cheltenham. Auch für die Ausbildung der Gruppenleiter war der Jugendring zuständig.

Im August 1946 wurde das Verbot politischer Gruppen von den Briten formal aufgehoben. ${ }^{52}$ Trotzdem interessierte sich der größte Teil der Nachkriegsjugend vornehmlich für sportliche und kirchliche Verbände. ${ }^{53}$ Rund die Hälfte von ihnen war Mitglied in Sportvereinen. Von der restlichen organisierten Hälfte waren rund drei Viertel in kirchlichen und nur ein Viertel in politischen, gewerkschaftlichen, freien oder bündischen Gruppen.

Der Nachkriegsjugend wird oft vorgeworfen, unpolitisch gewesen zu sein. ${ }^{54}$ Viele Jugendlichen waren zwar Parteien gegenüber skeptisch, ${ }^{55}$ gänzlich politisch uninteressiert waren sie aber nicht. So bestand bei einigen von ihnen durchaus eine Bereitschaft zum gesellschaftlichen Engagement. Dies kann man auch am Beispiel des Göttinger Jugendrings sehen. ${ }^{56}$ So beschlossen die Vertreter der Jugendgrup-

\footnotetext{
51 Vgl. Stargardt, Kinder in Hitlers Krieg, S. 424.

52 Vgl. Köster, Jugend, S. 472.

53 Vgl. Speitkamp, Jugend in der Neuzeit, S. 267.

${ }^{54}$ Der Soziologe Helmut Schelsky nannte sie „die skeptische Generation“ und stellte die These auf, die Jugendlichen würden, enttäuscht vom Nationalsozialismus, den Rückzug ins Private wählen und sich auf Konsum und Wohlstand konzentrieren. Vgl. Speitkamp, Jugend in der Neuzeit, S. 262.

$55 \mathrm{Vgl}$. Kenkmann, Wilde Jugend, S. 251.

56 Vgl. Boll, Auf der Suche nach Demokratie, S. 24.
} 
pen 1946 bei der Betreuung heimatloser Jugendlicher im Auffanglager Friedland zu helfen. Auch am Kampf gegen „Schmutz- und Schundliteratur" beteiligten sich Mitglieder des Jugendrings. Ebenfalls politisch motiviert waren die Ablehnung und der Ausschluss neonazistischer und gleichsam kommunistischer Gruppen aus dem Jugendring. So beschloss dieser im Oktober 1950 in Zukunft nicht mehr mit der kommunistischen Gruppe „Freie Deutsche Jugend“ zusammenzuarbeiten. ${ }^{57}$

\section{Hitlerjugend in neuem Gewand: Der Kampf gegen die Wikingerjugend}

Nach dem Krieg fiel es vielen Jugendlichen schwer, sich von den sozialen Einflüssen des Nationalsozialismus, die sie teilweise tief verinnerlicht hatten, wieder frei zu machen. ${ }^{58}$ Ein Abschnitt aus dem Buch „Herr Kramer, Gespenster“ der 1931 geborenen Göttingerin Ilse Lenge illustriert dieses Dilemma: „Eines Tages treffe ich direkt vor dem Hauptquartier eine Lehrerin. Automatisch bebe ich meinen rechten Arm und grüße sie mit „Heil Hitler“. Ich höre noch ibr „Ob Gott, Kind“", und sehe den verblüfften Gesichtsausdruck der Wachsoldaten, als ich auch schon um die nächste Ecke verschwunden bin."59

Neben Jugendlichen, die aus Gewohnheit die im Nationalsozialismus ,antrainierte" Sprache oder dementsprechendes Verhalten zeigten, gab es aber auch solche, die sich nach 1945 bewusst zu Nationalsozialismus und Militarismus bekannten. Im Jahr 1947 stellte die „Wikingerjugend“, Jugendbewegung der Deutschen Rechtspartei mit Zonensitz in Göttingen, einen Zulassungsantrag bei der Militärregierung. Statt aber den rechtmäßigen Weg über den Jugendpfleger zu wählen, umgingen Adolf von Thadden, ${ }^{60}$ Geschäftsführer der Deutschen Rechtspartei, und Karl Siemens, der Führer der Wikingerjugend, den Jugendpfleger Schmalstieg und stellten ein direktes Gesuch an die Militärregierung. Überraschenderweise erhielten sie dort eine mündliche Zusage. Zuvor war bei einem Gespräch des Geschäftsführers der DRP mit Schmalstieg deutlich geworden, dass es in den Vorstellungen von der Erziehung der deutschen Jugendlichen deutliche Unterschiede zwischen dem Jugendpfleger und den Verantwortlichen der Wikingerjugend gab.

Gründe für eine Ablehnung der Wikingerjugend gab es viele: Schon ihr Name hatte einen bitteren Beigeschmack, denn er spielte zum einen auf den Volksstamm, der „durch seine kriegerischen Raubzüge und seine Eroberungsfahrten bekannt“

\footnotetext{
57 Vgl. ebd. S. 118.

58 Vgl. ebd. S. 11.

59 Ilse Lege, Herr Kramer, Gespenster. Erinnerungen 1933-1949, Göttingen 1995, S. 131.

${ }^{60}$ Von Thadden wurde 1921 geboren und war im Zweiten Weltkrieg Offizier gewesen. Im November 1946 kam er nach seiner Entlassung aus polnischer Kriegsgefangenschaft nach Göttingen. 1949 gewann er für die DRP ein Bundestagsmandat, 1952/53 war er sogar stellvertretender Oberbürgermeister in Göttingen. 1961 bis 1964 war er Bundesvorsitzender der DRP und 1967 bis 1971 Bundesvorsitzender der NPD. (Günter J. Trittel, Göttingens Entwicklung seit 1948, in: Rudolf v. Thadden/Günther J. Trittel (Hg), Göttingen. Geschichte einer Universitätsstadt, Göttingen 1999, S. 291 354).
} 
war, und zum anderen auf die berüchtigte SS-Division „Wiking“ an. ${ }^{61}$ Auch die Tätigkeiten und geforderten Ausrüstungsgegenstände der Jugendgruppe vermittelten nicht das Bild einer friedlichen und demokratischen Vereinigung, sondern einer paramiltärischen und nationalistischen Vereinigung. Sie traf sich ,heimlich abends und zur Nachtzeit draußen in der Feldmark. Von böher gelegenen Wobnungen der Stadt, hört man deutlich das dumpfe trum, trum der Landknechtstrommeln. Gesänge wie: Haltet aus im Sturmgebraus schallen noch abends um 23.30 über die Dächer der Stadt" ${ }^{\prime 62}$, beschreibt Schmalstieg das Verhalten der Wikingerjugend (Q14). Auch in Hann. Münden habe der Kreisjugendpfleger beobachtet, wie die Jungen mit Trommeln und schwarzer Fahne, auf der zwei gekreuzte Schwerter zu sehen waren, durch die Stadt marschiert seien. Außerdem fordere die DRP für die Wikingerjugend „Landsknechtstrommeln, Signalhörner, Fanfaren, Fabrenmesser, Koppelzeng, Brotbeutel, Tornister, Sanitätszeng, usw. schwarz, weiß, rotes Fahnentuch, Speere und nationale Literatur." Auf ihren Plakaten warben die Jungen mit Sprüchen wie „Nationale Jugend rechts ran. Junge bist du deutsch komme zu uns", und dem Versprechen von Heimabenden, schwelenden Lagerfeuern, Kameradschaft und Männlichkeit: „Bist du jungenhaft und gerade in deiner Haltung - bist du deutsch, dann reihen wir dich gern in unsere Gemeinschaft ein - Wage den Schrei! Versuch's! Du triffst auf Verständnis!" Karl Siemens war 1947 fünfundzwanzig Jahre alt, studierte Psychologie in Göttingen und war ein Nachkomme der Elektro-Siemens Familie. In einem Interview mit dem Magazin „Der Spiegel“ am 05. Juli 1947 verleugnete er eine Parallele zur Hitlerjugend und ließ seine antikommunistische Einstellung deutlich werden: „Ueberhaupt wollen wir keine Neuauflage der HJ sein', sagt der Student Siemens, ehemaliger Offizier mit kurzem Scheitel und Mussolini-Kinn, ,aber wir sind auf jeden Fall national und dabei streng demokratisch. Wir möchten dafür sorgen, daß nicht etwa ein Moskauer Parteifunktionär einem deutschen Jungen näher steht, als ein anderer deutscher Junge." “63

Auf einer Sitzung des Jugendrings am 20. Juni 1947 wurde die Aufnahme der Wikingerjugend in den Ring mit 16 Stimmen und zwei Enthaltungen abgelehnt ${ }^{64}$ und von der Militärregierung ein Verbot der rechten Jugendabteilung gefordert. Die Zulassung der Wikingerjugend wurde schließlich vom Leiter der Erziehungsabteilung der hannoverschen Militärregierung für Niedersachsen zurückgezogen. ${ }^{65}$ 1950 schlossen sich in Deutschland wieder rechtsextreme Jugendgruppen zusammen und gaben sich den Namen „Wiking-Jugend“. Diese Gruppierung wurde erst 1994 erneut verboten. ${ }^{66}$

\footnotetext{
${ }^{61}$ Resolution des Jugendrings Göttingen vom 20.6.1947 über Verbot der Wikingerjugend - nationale Jugendbewegung -, 28.6.1947, Göttinger Stadtarchiv, C64 Jugendamt Abteilung Jugendpflege, Nr. 110 Diskussion um ein Verbot der Wikingerjugend.

62 Bericht über Vorfälle mit der Wikingerjugend Schmalstiegs, 20.7.1947, Göttinger Stadtarchiv, C64 Jugendamt Abteilung Jugendpflege, Nr. 110 Diskussion um ein Verbot der Wikingerjugend, Bl. 7. 27.12.2008. http://wissen.spiegel.de/wissen/dokument/dokument.html?id=39883320\&top=SPIEGEL;

${ }^{64}$ Vgl. Boll, Auf der Suche nach Demokratie, S. 121.

65 Vgl. ebd., S. 112.

${ }^{66} \mathrm{http}$ // /www.gruene-jugend.de/80548.html, 19.11.2008.
} 


\section{Literatur zum Weiterlesen}

Friedhelm Boll, Auf der Suche nach Demokratie. Britische und deutsche Jugendinitiativen in Niedersachsen nach 1945, Bonn 1995.

Nicholas Stargardt, Kinder in Hitlers Krieg, Pößnek 2008.

Ilse Lege, Herr Kramer, Gespenster. Erinnerungen 1933-1949, Göttingen 1995.

Hermann Schulz/Hartmut Radebold/Jürgen Reulecke (Hg.), Söhne ohne Väter. Erfahrungen der Kriegsgeneration, Bonn 2005.

Alfons Kenkmann, Wilde Jugend. Lebenswelt großstädtischer Jugendlicher zwischen Weltwirtschaft, Nationalsozialismus und Währungsreform, Essen 1996. 
Oberstadtairektox $x \times x \times x \times x \times x \times x \times x \times x \times x \times x$

$$
\text { 2. Ju11 } 1946
$$

An die

Regierung kilashoin

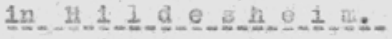

KI/

Betx. . Das fiherwandern figendicher.

Begus verflisung voni 12.0.1946- - I. IX. -

Aul die Vertigung von 12.6 .3946 wixd exgebeist folgendex Bortont exstattet:

I. Grundlasen des. Bextohts.

Jem Bexicht blogen die hriahruagen und Voraohläge der nachstehenden Anter und Behbrden zugrunde:

$$
\begin{aligned}
& \text { 1.) Sozialamt dex 3tadt witingen, } \\
& \text { 2.) Jugendant dex stadt ubtilugen, } \\
& \text { 3.) Hilatilngsant der stadt sottingen, } \\
& \text { 4.) Arbettsast Gotingen. }
\end{aligned}
$$

Sehliemlioh hat sloh der stedtrlibenlingsrat untex dem Voraliz des Unterzelchnoten mehriach mit deri Uiherwandern Jugendiccher beIalit. Des irgebnis dex Arbeit eines vora tadilidehtilngexut bearriragten

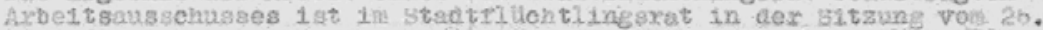

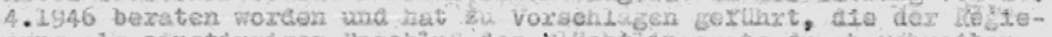
rung als einstimntger Besohiub des vliohtingssats duroh schreiben voul 9.5 .1946 gugeleitet worden sind

bux Vomeidung von wiederholungen wixd sur den lnhìt díoses chrelbens nebit palage vorwiesen.

II. Un?ang dex problemes

In dex tadt Gotfingon 1 at de sahl der wandernden Jugendilichen annehmbax ein werig zurilekgegangen. Dsis meg demit zusamenhipgen; dai die diltirroglexung Brtliohe Aloxdmingen getrolfen hat, nan denen dic Behexberzing durchwandernder Jigenaltehex ubex 16 Jahren in dex hiesigen Kgel abergsohule nioht mehr mögiteh ish. yex unterzeiohnete hat in der 2. Hikite des Juni monxmals Gelegenheit gehabt, die verhalinisse in Hannover zu studiexen. Nsoh don jindruok, den die besion. t1gung des Inuptbahnhotes, der Bohnhol'sbunker, des Bahmofe-VorpLatz's und des sogonaraten Jugendbunkers hinteriessex hat, sus der sohlub gezogen werden, des das Umherwandern Jugendischer in dex gesumten britisehen zone wohl mit kioksiont aus die Jehreszeit in bedeutendem unPange zugenomen hat. Die Mller aut dem Haxptoshnhof in livnover waron derartig ereohreokend, dak loh ein sofortiges dingrelín des dortigen Jugendeuts PUr erforderiich bolte.

Obwohl in Gottingen die Zahi der darchuradernden Jugendichon zuriekgegengen 1st, sind die sehwiexiskelten bei dé Beicantuns dieses tbels grober geworden. Diese Sohwierigkeiten liegen durin, dai die jetzt snfalienden Jugendisohen in starferen ilaie verwainlost sind und dab die unterbrinzungerng lichkeiten imex gerirgex vercon.

Whand es bich in dex exsten zeIt raoir den zasamerabruch bis made des Jshres 1945 meist un Jugondilohe handeite, die sus der verar-

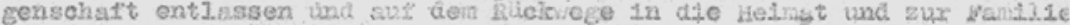
varen, werdon jetzt Jugendiliche abrgegrifien, die sejt ionaton zaik

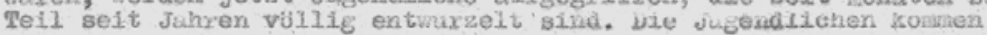

$\underline{\text { exinesin }}$

Q1: Brief Oberverwaltungsrat Kluge an die Regierung in Hildesheim, 2.7. 1946, Göttinger Stadtarchiv, C64 Jugendamt Abteilung Jugendpflege, Nr. 421. 
elrzedn oder in Jxupps weit bis zu. 5, 6 und nooh mehr juasen winnern und 1 oder 2 stidchen angeblioh aus dex russischen odex poinischen zone, obwohl sioh boi näheren untersuchungen biswellen hexilustellt, daB sie avs der. Festeri stamen. viose.jungen Leute haben keine Papiore bet gich und behaupten, aur dex suche nach Iiftern, Coschwistex" sreunden odox entremten verwandten zu sein. huf die Frage, wle ste ihre Eltorn zu suchon gedenken, blelben sle melet die Antwort schuldig. Wenn sie darubex belehrt wexden, das das Aurftnden solange unnoglion sei, als sie nioht selost einen Pesten sohnsitz haben, ericlixen tie biswelien ofren, das sie trotzden nicht beabsloht1gen, sw ort und stelle zu blelben, da ale thnen angebotene Axbelt nur unzuxeishend bezahlt witrde vad die

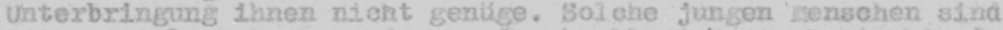
oft nonatelang kxear und quex durch aile 4 Bonen ivatschiands esrelst. Je lingez díe zelt 1nxes vagabundenlebens deuert, desto verwahrloster sina sie, seelisch, abor atuch rein litieriich. Das

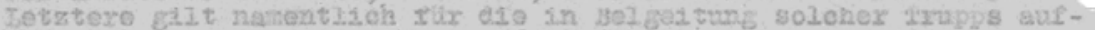
txetenden hädohen, oft 15 und 16 jahrlge jupge vinger, die in hygient scher: Beziehung eine beaondere Gerahx bilden.

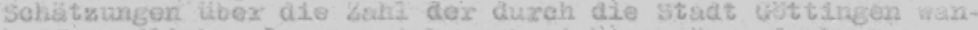
dexnden Jigondilichon lassen sich aueb nidht annikemd abgeben. Das Arbeitsant teilt mit. das im nonet menr als 300 minnilione zan derex bis etwa zum 23. Sebensjehr in ixbelt verijttelt worden sind, and zwax vorwiegend in die landwirtochart odej in die Bau-

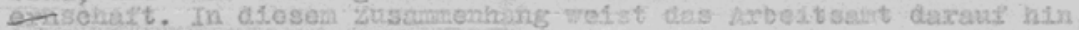

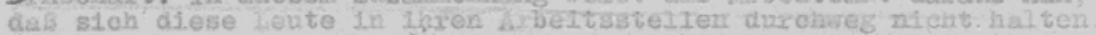

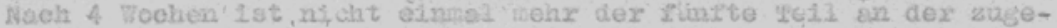
wiesenen Arboitsstello; die anderen hobon-sich erneut. aut wandexschert begeben. So wurden belsplelswolse elner hiesigen Beutirna $1 \mathrm{~m}$ Isufe von 6 Wochen 32 junge nänner zugeviesen, houte sind noch $\%$ ron Ibnen da. Das Axbeitsemt fijgt in seinem bericht hinza, dab

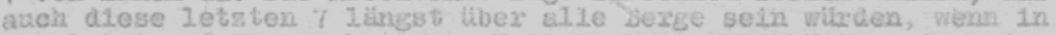
den letzton 6 Jochen besseres better geherrsoht häte. Diese jun-

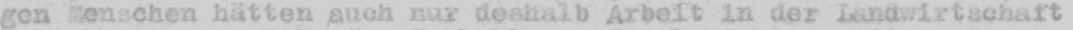
angenowinen, wa sich oine Woehe iang elinhal xichtig satt eosen zu kơnen. Die Bawwirtschatt böte desheib einen gewissen Anaiehungspunict, weil sie interkinst in dex stadt vermittele, die genigend

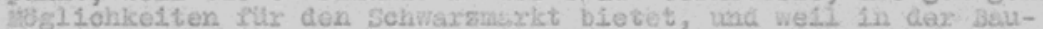
wixtschart Schwerarbeitexzulagen gewthrt wexden. Sin inaeres Interesse an dex. Axbeit se1. bel kaw elnem der in die Arbelt eingewiesenen jugendilchen Nenschen zu Pinden.

Zux welteren Iilustrution aer Versuche, junge senschen in Axbolt elnzuweisen, mag daraup hingewiesen werden, dab das Arbeitsant vox elnigen Pagen di.e Aurgebe batte, junge isannex tix elnen Arbeitseinsatz in kamburg zu verpllichten. Zu diosem Zneolce sind aus elnem 13 lichtilngotramsport 23 junge ieute ausgesucht worden. Dise Leute maßten einige rage untergebracht werden, bis ein angekindfgter Seni eItiransport nach liabuxg abgerextigt wexden leomnte. Bis zum Abgang des Sempltransports 1st ivon den 23 jungen wenschen keinex mehr ubxig geblieben. 4 worden wegen viebstehlis. verhaftet, nach 2 welteren wird wegen plebstahls gelahidet felnex davon hat 1 pierd gestohlen). 10 juxge loute habon die buxuhgargshexbexge vater mitnehme wenl ger wextvolier tegenstilnde verlassen und die restilchen 7 haben sich elnen tas vor. Abjeng des Pransyoxts entfernt, nachdem thren belcunnt geworden war, das dex zug ab nuchater Tage nach Hambuxg gehen sollte.

Q1: Brief Oberverwaltungsrat Kluge an die Regierung in Hildesheim, 2.7. 1946. 


\section{7}

Junserwerbglogen-Probleme_1950.

Unter der grossen Zahl von Brwerbslosen unserer stadt befinden sich eine ganzo Rethe von Jungerwerbelosen im Alt er von 15 18 zahren beiderzei ceschlechts.

Bef diesen Jugandilchen besteht die große Gefahr des Absleitens von दer normajen Lebensbahn, da sie z.T. seit einem Jahr ohne Gereselte Arbelt sind.

Das irbeltsamt gab folgende Auskunft uber die Lage dieser jungen Henschen:

Jungen: Alter 16 - 18 Jshre. Schulb1ldung: Volksschule 5.+ 6.KI. z.T. auch H12fsschule, kommen fur eine Lehrstelle nfoht in Frage, kơnen nur in Arbeltsstelien vermittelt werden. z.zeil haben sie schon in Arbeit gestanden, in mehreren Balien haben die Jungen die Arbeitsstellen ohne stiehhaltige Grande verlasen. Die Jungen sind charakterlich sehr schwierig und ia ailGemeinen arboftsschet und nachlsssig. Die Arbeitsscheu der Jungen wird noch durch den liangel von geel neten irbeitsstellen unterstutzt.

Hidghen: Alter 15 - 18 Jahre. Schulbildung; gbenfalls Volks- und Hilfsschuie.

Charakterlich schwieris, unzuverlissig, unehrlich, erbeltsscheu. Fur die Vermittiung in Lehrstelien und Heushait kommen diese kadel nicht in Frage. bleiben nur Arbett sstellen, aus denen sie aber auch iminer wieder ohne triftige Grinde fortbleiben.

Die Anzehl dieser charakterlich schwierigen Jungerwerbs10 sen wurde mir auf Beiten der Jungen mit 40 angegeben und bei den Midels mit cirka 35 .

F1er muss unbedingt helfend eingegriffen werden und $z$ var in erster Linie pidagogisch und in Form von Lebenshilfe.

Fienn nicht vorbeugend etwas getan wird, so muss damit gerechnet werden, dass dieso Jungen Jenschen in 1 b is 2 Jahren so abgerutscht sind, dass sie die Erziehungsheime unter Umstinden auoh die Gerungnisse bevolikern.

In der Anlage erlaube lch $\mathrm{mir}$ einen Vorechlag zur Verhutung einer Gefihzung der Jungerwerbsiosen zu unterbraiten. Die vorbeugende Maßnahme ist b 1111 ger.

Die Kosten flir 1 Jugendilchen joxx 20 Wochon Jrziehungshe im betragen $480,-$ bei dem Ublichen Tagessatz von $3,20 \mathrm{IM}$. Jur die Summe von $2700,-$ DM, die in meinem Vorschl ss zur Frhtung einer Gefthrdung in Anschlas gebracht worden sinâ, kB̈nnten nur ca. 5172 Jugendliche fur Je 20 i ochen in Brziehung she im untergebracht werden.

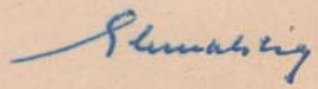

Q2: Jugendpfleger Schmalstiegs Bericht über die Jungerwerbslosenprobleme, 1950, Göttinger Stadtarchiv, C64, Nr. 59, Bl. 357. 


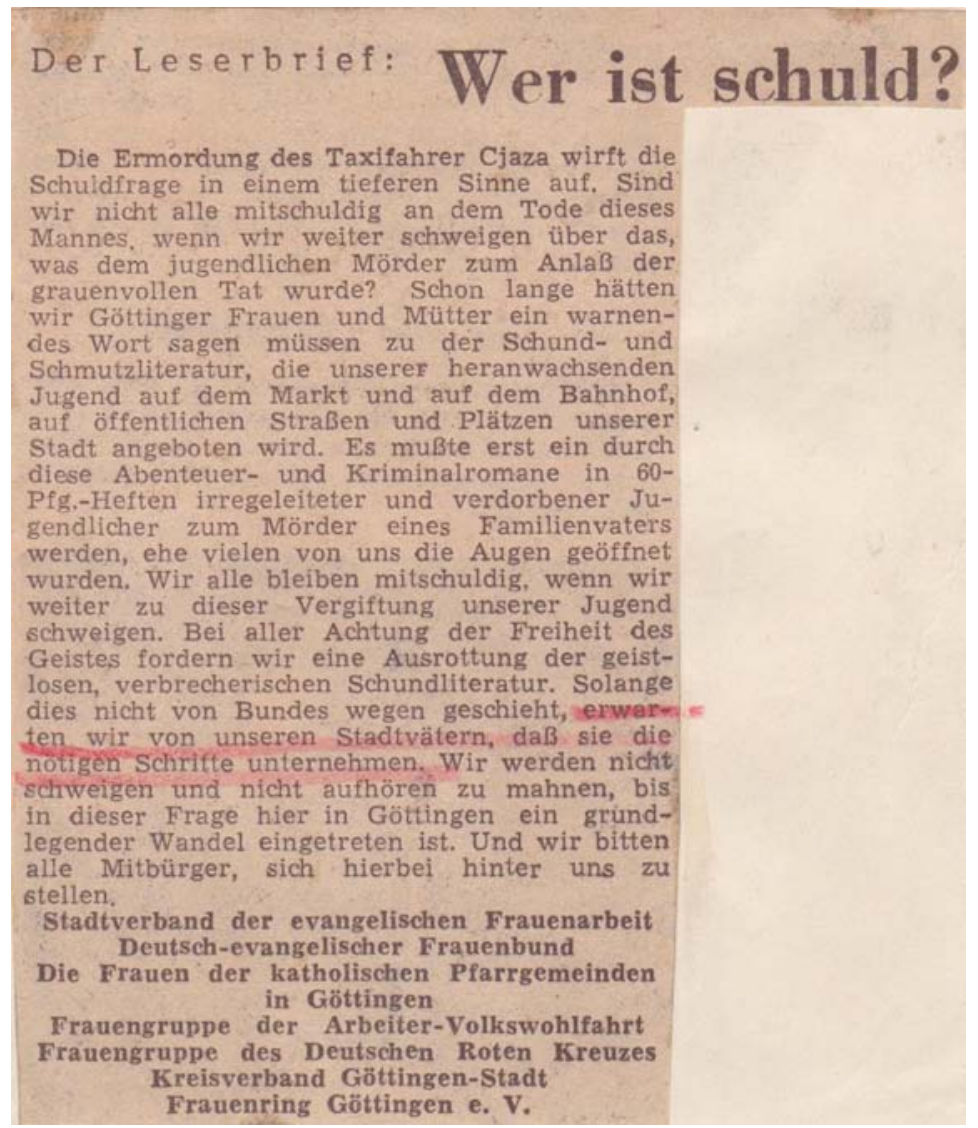

Q3: Leserbrief Göttinger Frauen, veröffentlicht im Göttinger Tageblatt (GT), 7.7.1951, Göttinger Stadtarchiv, C64, Nr. 59, Bl. 357. 


\title{
Geldschrankknacker mit 17 Jahren
}

\author{
Fünf Büroeinbrüche aufgeklärt — Starterpistole als Schreckmittel
}

Der Göttinger Kripo gelang es in Zusammenarbeit mit der Weender Polizeistation nach verhältnismäßig kurzer Fahndung eine greße Diebstahlsserie aufzuklären. Ein erst 17 jähriger Einbrecher konnte auf frischer Tat ertappt und verhaftet werden. Nach seinen Angaben hat er seit Mai mindestens fünf schwere Geschäfts- und Büroeinbrüche in Göttingen verübt, bei denen er es ausschließlich auf Geldtresore und Kassetten abgesehen hatte.

Ein Wachmann ibberraschte auf seinem mitternächtlichen Kontrollgang den jugendlichen Täter, als er im Begriff war, in die Büroräume einer Weender Firma einzubrechen. Als inn der Dieb sofort kaltblütig mit einer Pistole bedrohte, mußte er sich zunächst in sichere Deckung zurückziehen. Er kettete jedoch den Wachhund los, der den Einbrecher dann solange in Schach hielt, bis die inzwischen herbeigerufenen Weender Polizeibeamten ihn festnehmen konnten. Da erst stellte sich heraus, daß es sich bei der angeblichen Schußwaffe um eine gewöhnliche Starterpistole handelte.

Der. Täter ist ein 17 jähriger Autoschlosserlehrling aus Göttingen. Von der Kriminalpolizei konnten ihm eine Reihe ähnlicher Einbrüche nachgewiesen werden. die er im wesentlichen zugegeben hat. Auf sein Konto kommt vor allem ein schwerer Einbruch in ein Büro am Fabrikweg. bel dem er aus einer Geldkassette 1200 DM entwenden koninte. Bei Einbrüchen in Geschäftsräume in der
Kurzen Geismarstraße und in der Königsallee widerstanden glücklicherweise die Geldund Panzerschränke seinen Versuchen, sie zu öffnen. Außer einem Keineren Einsteigediebstahl in der Reinhäuser Landstraße wird ihm auch noch ein Einbruch in eine Stehbierhalle zur Last gelegt, bei dem ihm große Mengen von Schokolade und Zigaretten in die Hände fielen. Die Beute hat er größtenteils seiner Freundin geschenkt oder mit ihr gemeinsam verzehrt. Drei weitere Einbrüche, die man ihm zur Last legt, will er dagegen nicht begangen haben. Der Täter. eine gepflegte Erscheinung hat uberall mit Handschuhen gearbeitet. wie or es in Kriminalfilmen gesehen haben will. Auch schlechte Lektüre habe seine kriminellen Handlungen weitgehend gefördert.

Mit dieser zweiten schnellen Aufdeckung eines Verbrechens hat die Göttinger Kriminalpolizei einmal mehr gezeigt, daß für Berufsverbrecher der Boden in Göttingen doch ein $\mathrm{zu}$ heißes Pflaster ist.

\section{Q4: Artikel im GT: Geldschrankknacker mit 17 Jahren, 19.7.1951, Göttinger Stadtarchiv, C64, Nr. 436.}




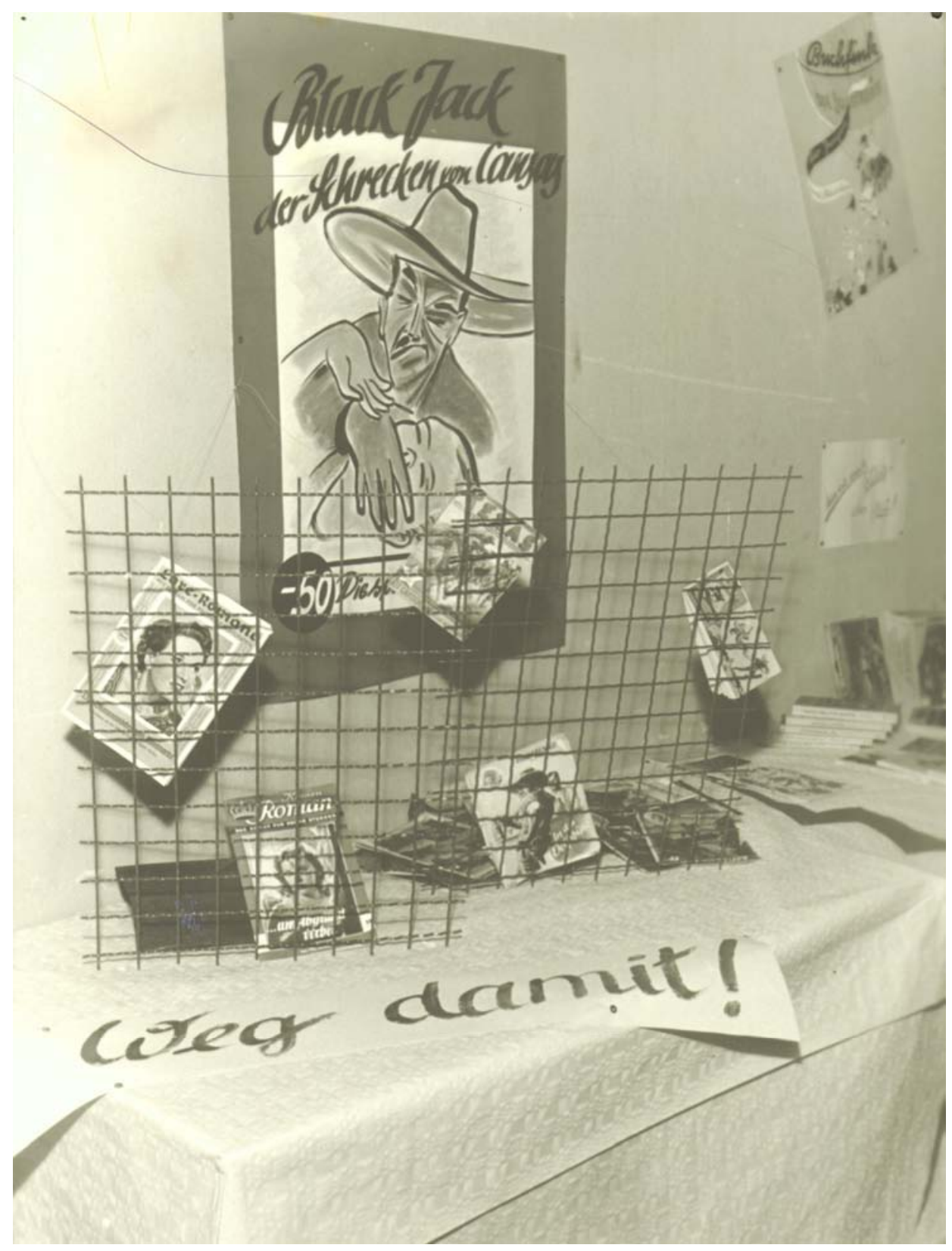

Q5: Plakat: Weg damit, Fotoarchiv Göttingen, kein Datum. 


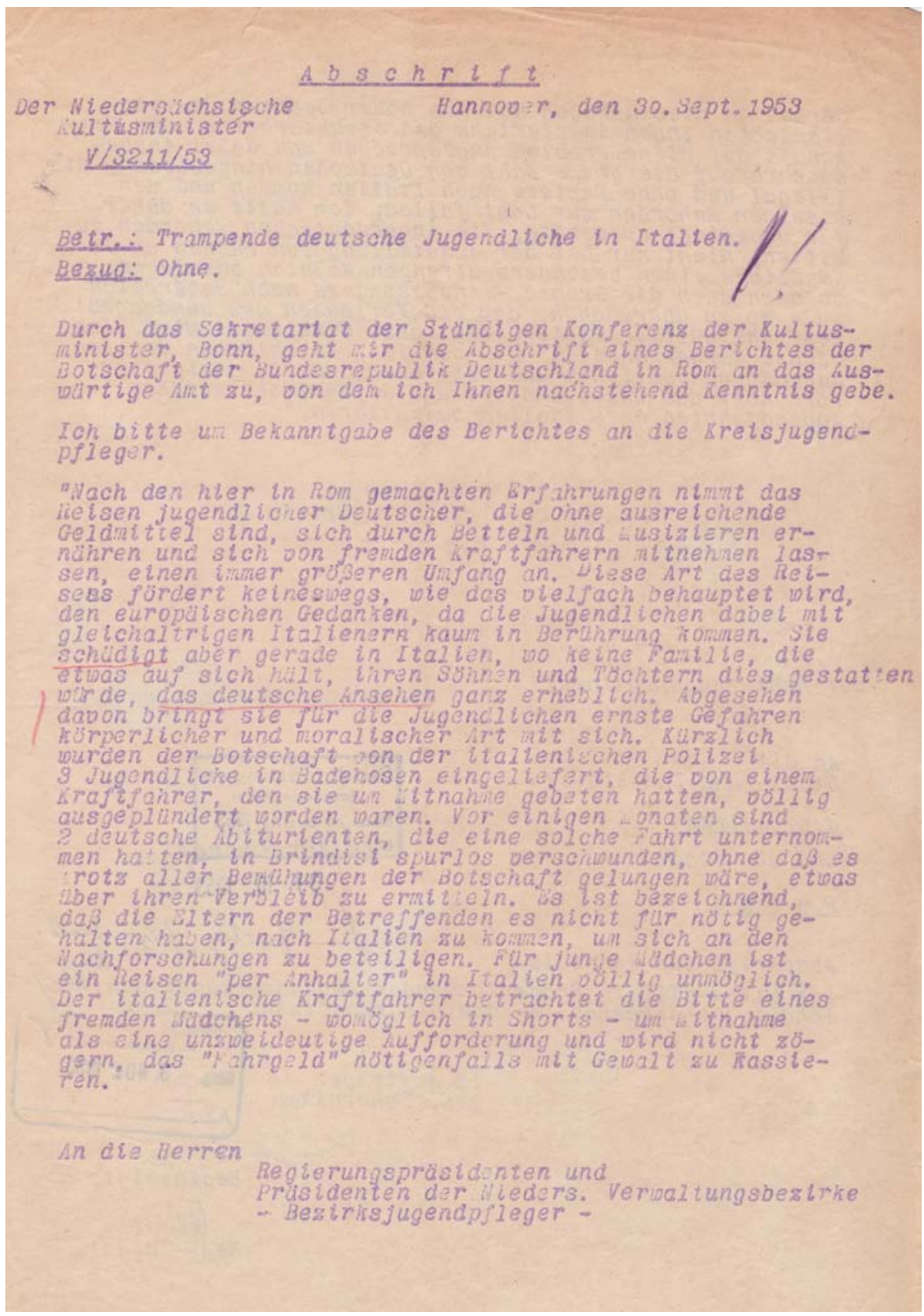

Q6: Abschrift eines Berichts der Deutschen Botschaft in Italien, 30.0.1953, Göttinger Stadtarchiv, C64, Nr. 23. 


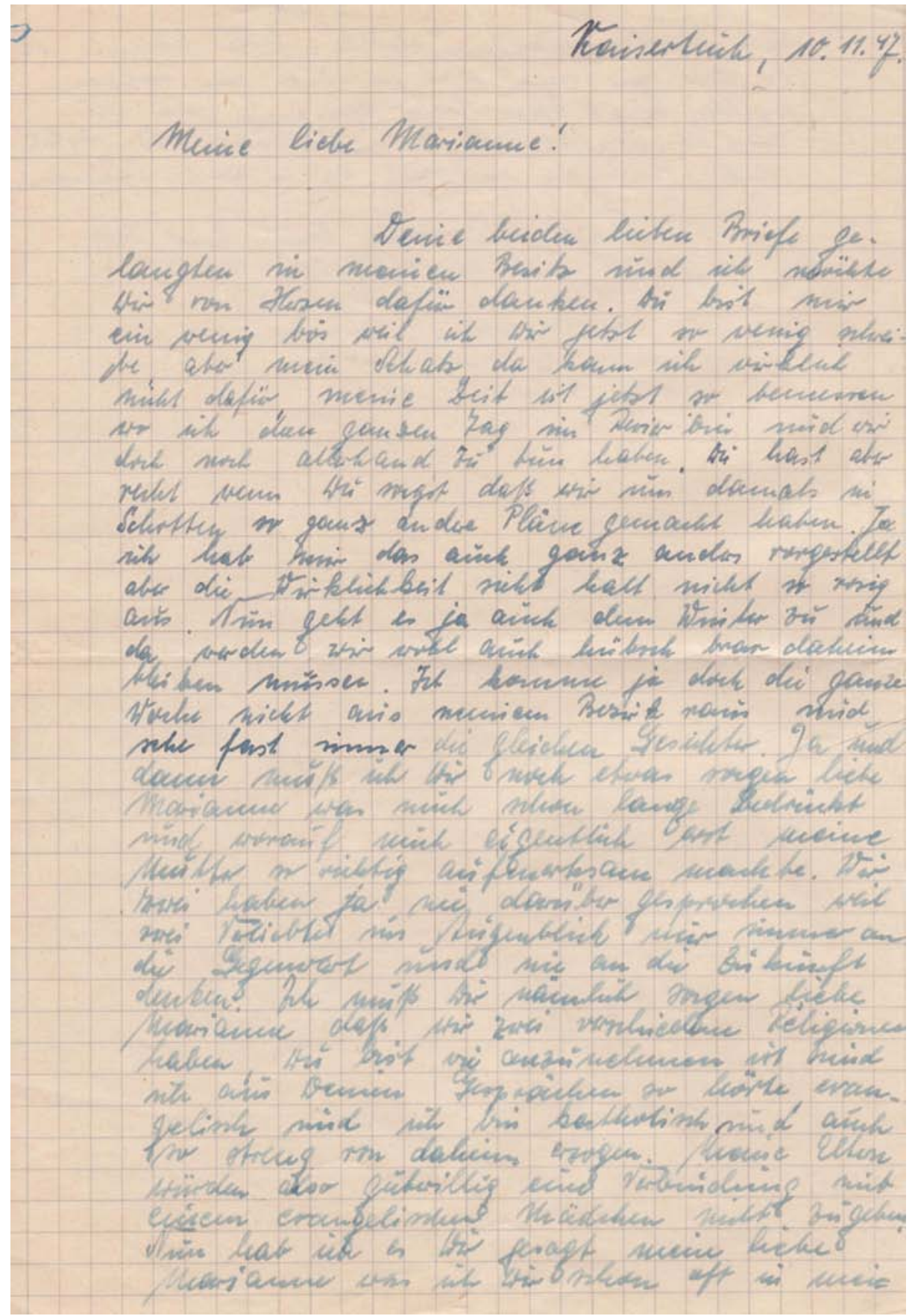

Q7: Brief an Marianne, 10.11.1947, Privatbesitz. 


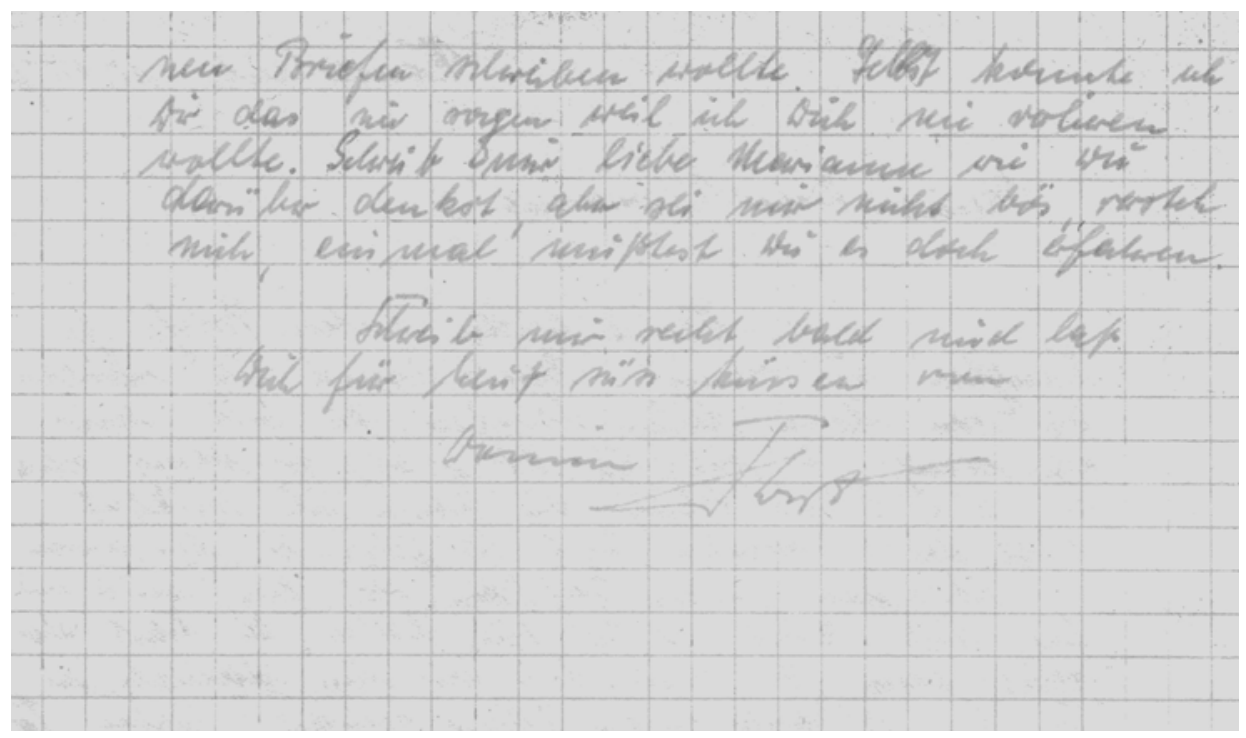

Q7: $\quad$ Brief an Marianne, 10.11.1947, Privatbesitz. 


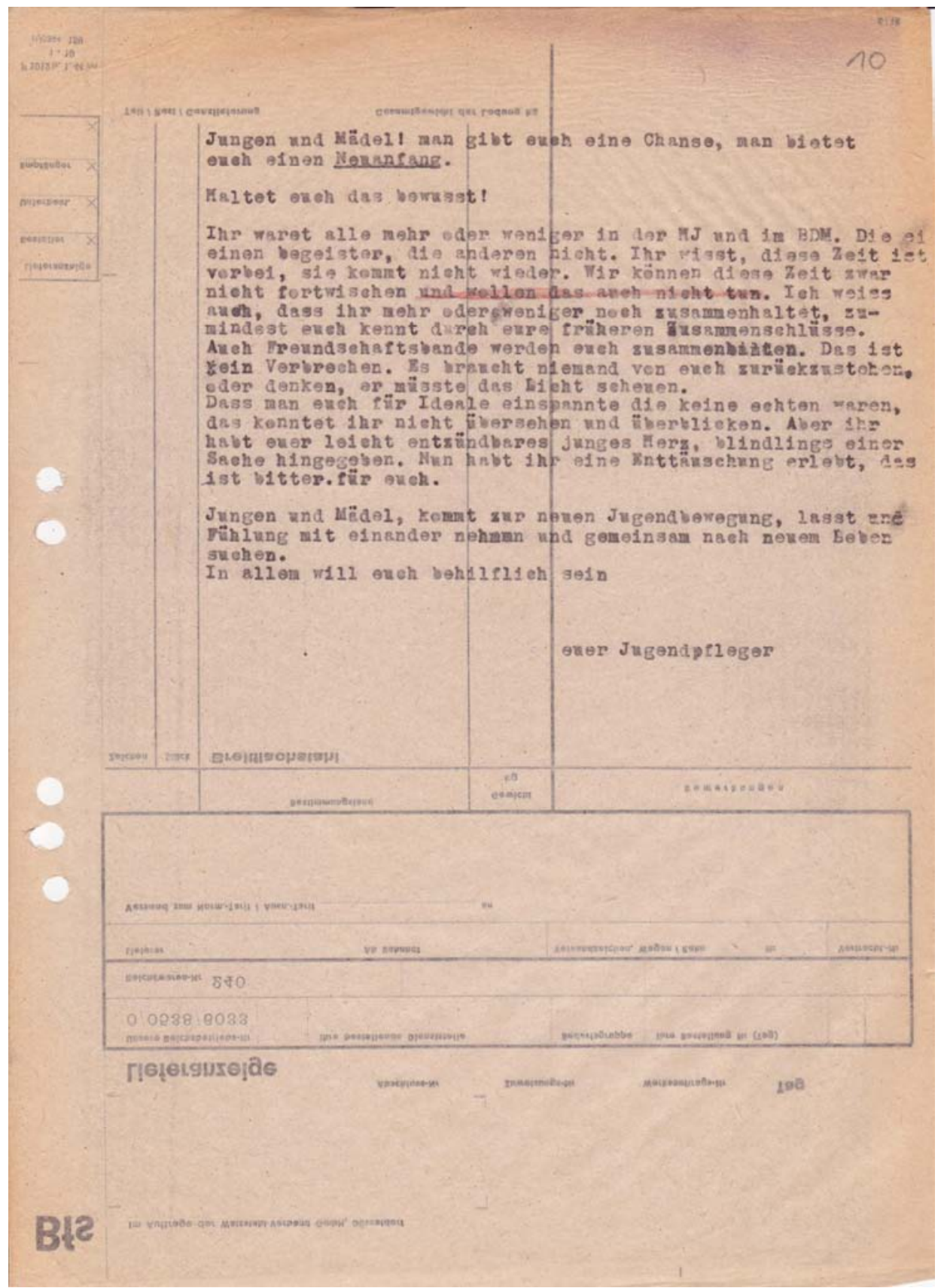

Q8: $\quad$ Aufruf Schmalstiegs an die Göttinger Jugendlichen, November 1945, Göttinger Stadtarchiv, C64, Nr. 1, Bl. 10. 


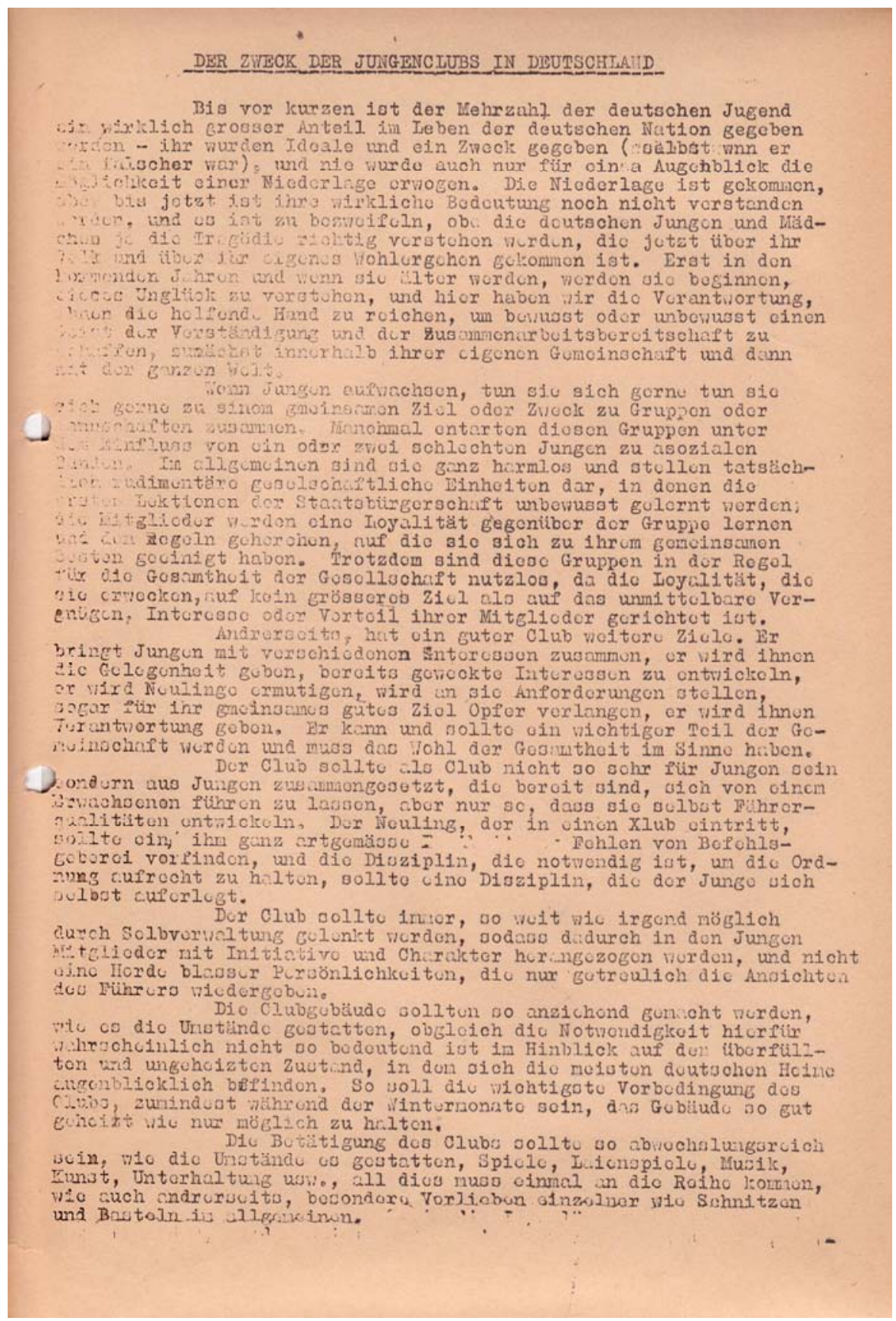

Q9: Der Zweck des Jugendclubs in Deutschland von Major Oldham, 6.4.1946, Göttinger Stadtarchiv, C64, Nr. 2. 


\section{GEIEINDE RITTMARSHAUSIEN}

Wir haben dieger sehr tatkräftigen Gemeinde 2 . Besuche abgestattet, sie umfasst die Jugengruppen von Rittmarshausen, Beienrode, Wöllmarshausen, und Kerstlingerode. Der Ausschuss setzt sich mux aus Mitgliedern der 4 Jugendgruppon zuaammen, er leistet unter der Führung seines jugnadilichen aber sehr gutunterrichteten Vorsitzenden sehr gute Arbeit. Sowohl Jungen wie Mädel sind Mitglieder ảieses Ausschusses, und die Madel sorgen bestimmt daflir, dass die Jungen nicht zu sehr die Oberhand gewinnen.

Franz Ǩerthage, ein Mitglied des Aussohusses, hat ein ausgezeichnetes Schwimbad entworfen, das durch Bindämung des Dorfbaches entsteht. Wir hoffen, dass die Arbeit bald in Angriff genommen wird. Alle Gruppen im Landkreis können daraus sehen, was die Jugendliohen selbst tun können, wern sie etwas ermutigt werden,

Wir werden im Laufe der Zeit noch mehr usex den Ausschuss Rittmarghausen hören. Sie sind entschlossen, regen Anteil an der Bewegung zu nehmen und ich wilnsche ihnen Erfolg. Ich möchte gerne, dass auch andere Gruppen dasselbe tun, ich kann Tuah nux helfen Euch selbst zu helfen.

\section{OBERSCHULE JUGENDGRUPPE}

Diese Gruppe ist guf dem besten Wege, die ideale Jugendgruppe mu werden. Sie wird gefuhrt von Hans Kammel und seinem Preund Peter (es but pir

- leid, Peter, aber ich kann Deinen Hausnahmen nie bohalten). Diese beid. Jungen sind Schuler und haben ein hohes Mass an Plihrerschalt bewiesen. Beide haben, das Geheimnis des Glücklichseins gelernt, d, h. Freundlichakeit, Duldsamkeit und die pahigkeit mit dem und uber das Lében zu lachen. Nan kann erkennen, dass sich in allen anderen Mitgliedern der Gruppe gleiche Zuge entwickein. Ausserdem lat ihr Geist beweglich und sie machen ihre Puhrer schnell darauf aufmerksam, wenn sie in ihren Debatten Fehler machen. Sie haben eine grosse Tradition von ihrem Lehrer Herm Kichemann tbernommen der so viel gelitten hat, aber trotzdem ein freundli her, kluger, geduldiger Philosoph geblieben.ist, stets bereit zu helfen und zu leiten.

Die Zusammenkün te finden im Jugendheim und im Landheim Eddigehausen statt. Wir verbrachten 2 Tage mit ihen im Landheim. Das erste Mal platzten wir in eine lathematikstunde herein (der kleingte Jungé der Klasse wusste $10 \mathrm{mal}$ so viel wie wir). Das zweite ilal erstiegen wir die Plessen und beendeten den Tag mit einer Jagd den Berg herunter (gewornen von Prau Rüping und verloren von Herrn Kuttner, dessen Pusse wohl mehr an die Bedienung des Gashebels beim Auto gewöhnt sind.)

Alle diese Zusammenkinfte sind eine grosse Preude -(dankeschön flir den Kaffee und das Brot, wir nahmen es nicht gerne, weil wir wussten, dasp le Jungen es sich absparten, um es uns zu geben, aber wir wussten, irh wil bt verletzt sein, wenn wir es nicht genommen hätten. Es war eine Freundilichkeit, die wir nie vergessen werden).

\section{DEU'SCHE JUNGKISCHAFT}

Tnter der tetkrätlgen Fuhrung von Heinz Krull ist der Rlub gut vorwärtsgeschri ten. Die Hauptbetätigung ist Im Augenblick Naturkunde und Zelten. Wir verbrachten einen sehr schönen Abend um ein Lageje feuer im Hainholz sitzend am 23. März. Geschichten wurden erzählt und Lieder gesunzen und wir gingen alle gehr glïcklich und zufriedennacia Hause.

Heinz ist nach Stuttgart zu einer Jugendtagung gefahren und wirduns wahrscheinlich in einem unserer nächsten Briefe erzählen, was er gelernt hat. Er hat in späteren Verlauf deses Monats ein Lager im Solling vorbereitet. und ich hoffe wenigstens einen Abend dort mit der Gruppe zu verbringen.

\section{Q10: Wöchentlicher Nachrichtenbrief Major Oldhams Nr. 1, 12.4.1946, C64, Nr. 2, Bl. 4.}




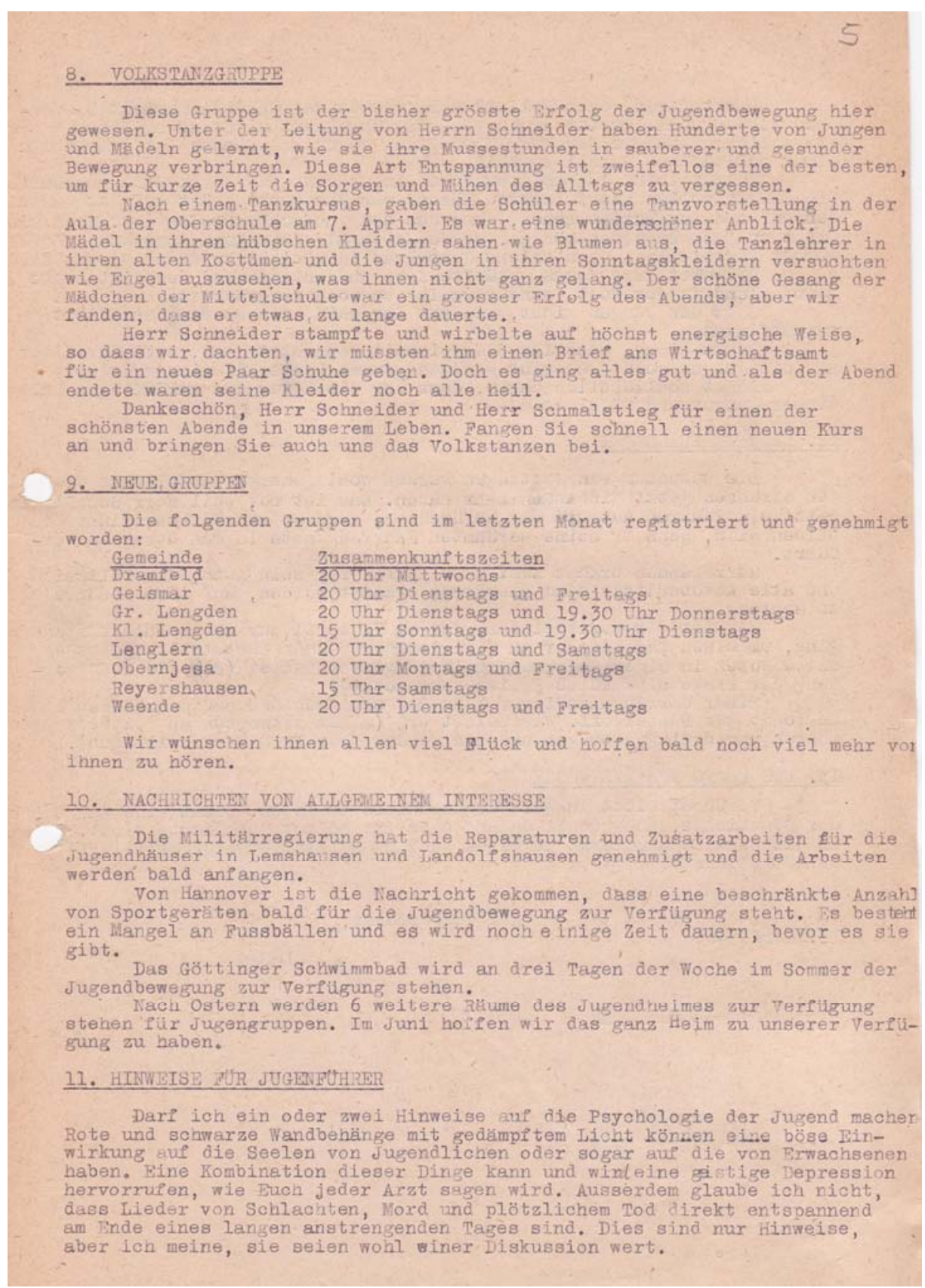

Q10: Wöchentlicher Nachrichtenbrief Major Oldhams Nr. 1, 12.4.1946, Bl. 5. 


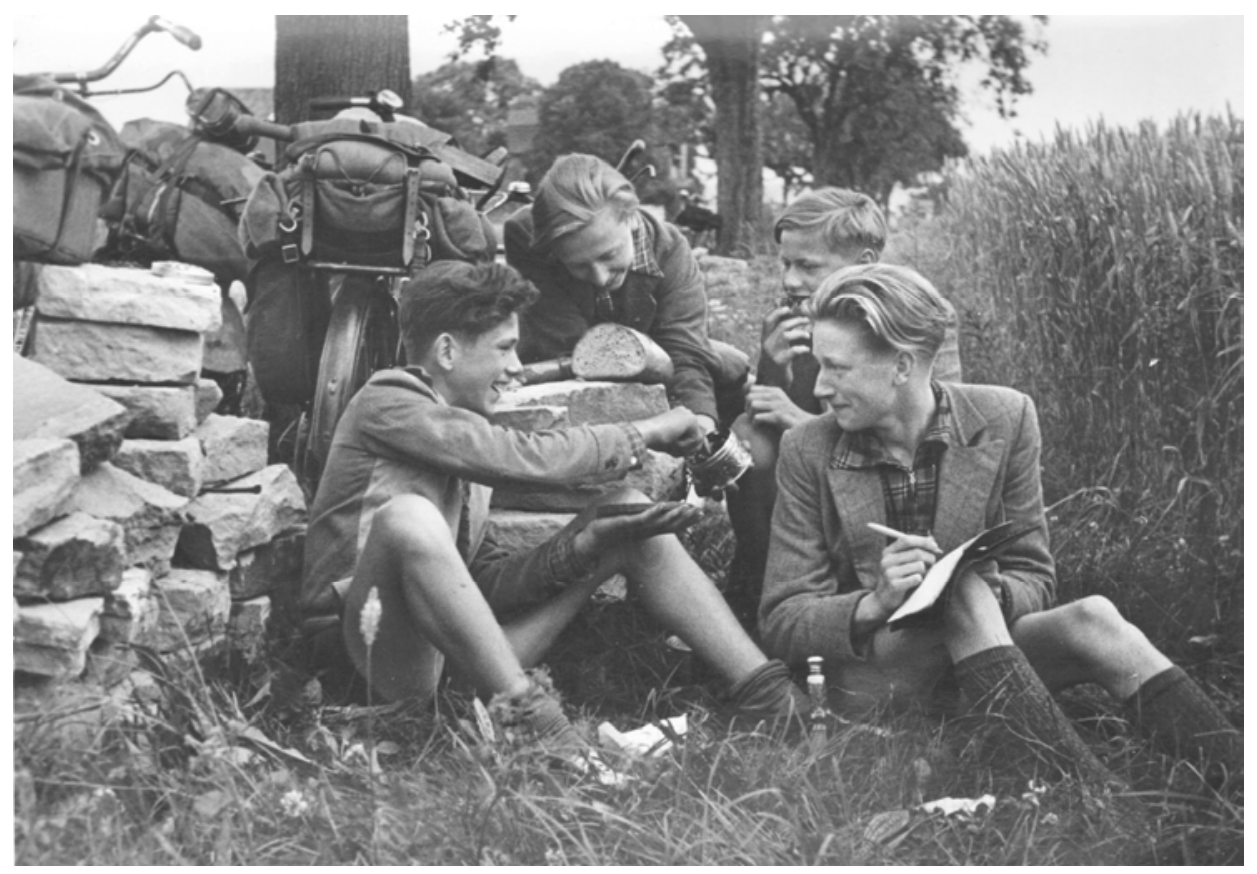

Q11: Wandernde Jugendliche, Fotoarchiv Göttingen, kein Datum. 


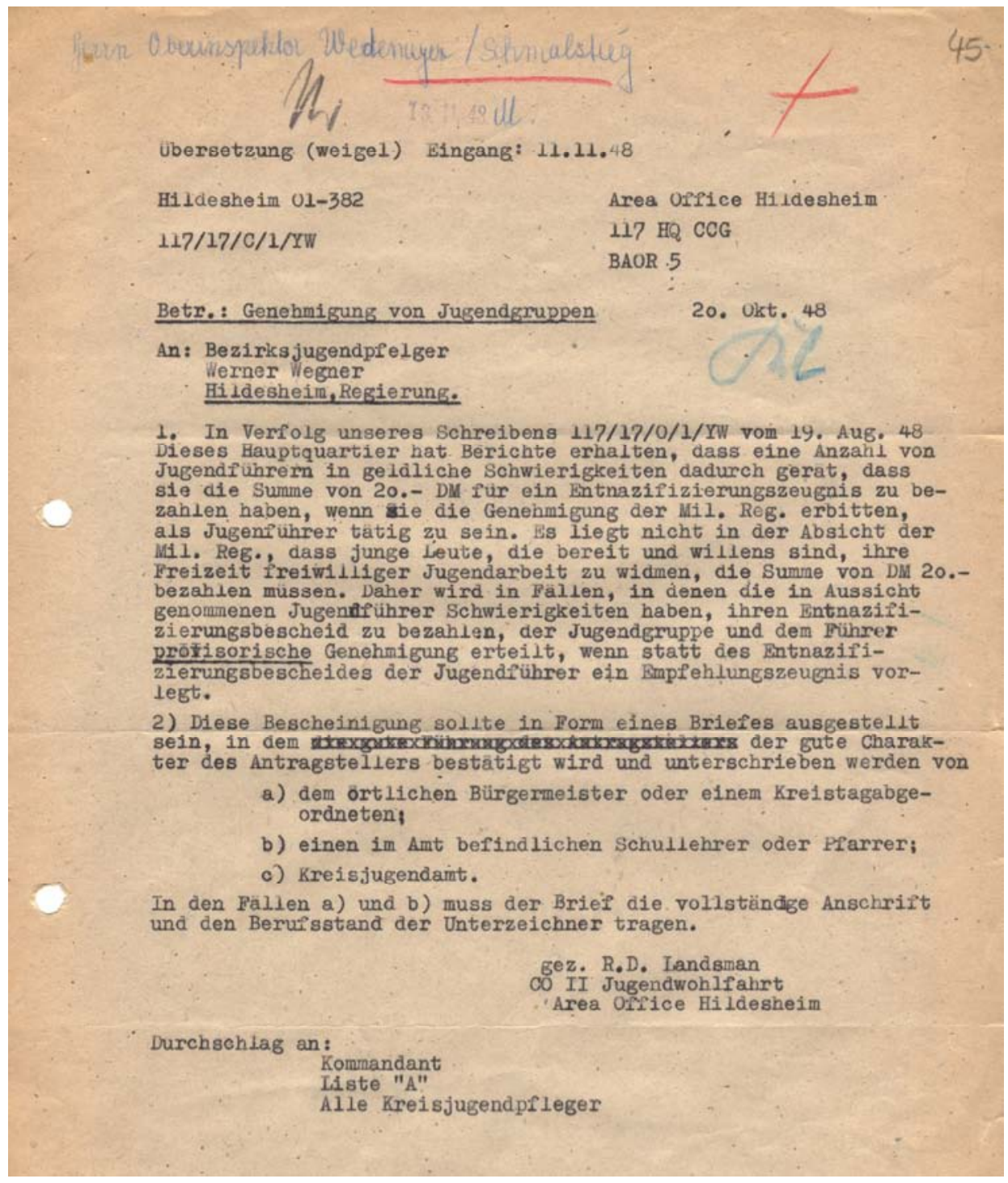

Q12: Genehmigung von Jugendgruppen, Brief der Jugendwohlfahrt (Area Office Hildesheim) an die Jugendpfleger, 13.10.1948, Göttinger Stadtarchiv, C64, Nr. 3, Bl. 38. 


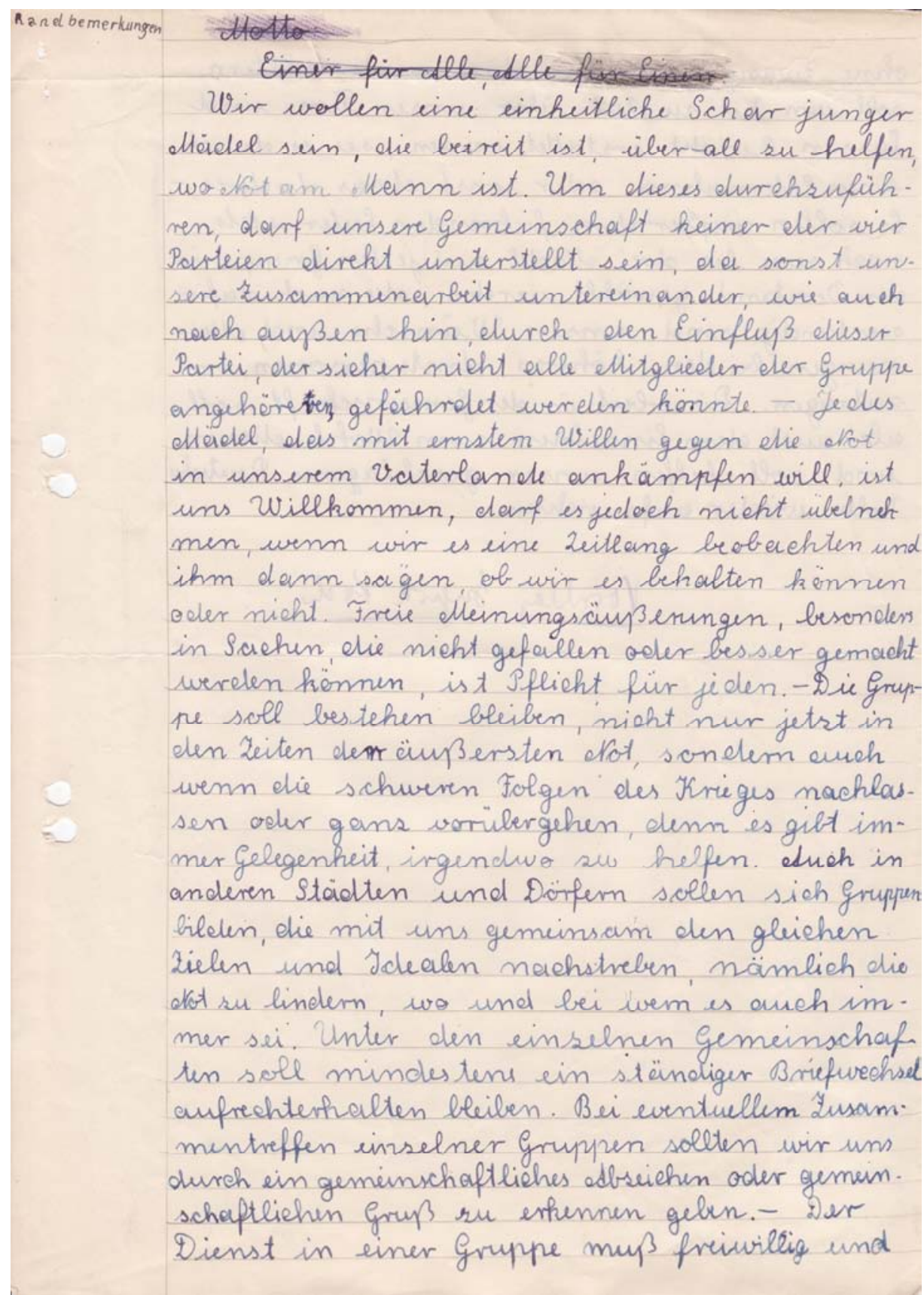

Q13: Entwurf eines Zulassungsantrags einer Mädchengruppe, kein Datum, Göttinger Stadtarchiv, Kleine Erwerbung 149, Nr. 73. 
ohne Zwang geschehen. Cluch unseren Eltern soll von teit su zeit riber unser tim und lassen Bericht erstattet werden, sei is elurch inen Elternabend oder sonst elues elneleres.is sollen auper elem fïtrenden Leiter stets noch suei bis drei Mädel eus jeder Gruppe in den Vorstand gewaihlt werden, olie euch dafïr sustëndig sind, unsere Wünsche und ettei. nungen biden höheren etmls personen, wor sutreigen. Die edrbeit in der Gemeinschaft soll aber euch dem Einselnen sum Wohle dienen und soll helfen unser geschlagenes Deutsches volk wieder eufsurichten.

\section{Vormbley bunit Rour}

Q13: Entwurf eines Zulassungsantrags einer Mädchengruppe, kein Datum. 
II. Lan fordert fur die $\mathbf{w i k i n g e r j u g e n d ~ v o n ~ S e i t e n ~ d e r ~}$ Rechtsparte1, laut, Hitteilungsblett $\mathbb{N} r$. I, Gegenstände, die fich als bililge und vor silen Dingen in diesem Augenblick der Geschichte unseres Volkes nicht brauchbare Nittel einer Jugendbeeinelußung und Brzlehung, ablehne, als da sind, Land sknechtstronimeln, Signalhörner, Fanfaren, Pahrtenmesser, Koppelzeug, Brotbeutel, Tornister, Sanitatízeug usw. schwerz, we1B, rotes Pahnentuch, Speere und nationale Iteratur.

Diese Dinge sind Pur die Junge Generation, die eben eine Zeit Ubler extrem nationalistischer, militaristischer Tendenz hinter sich hat, geradezu Gift, und bilden daruber hinaus, uberall da wo man sie der deutschn Jugend reloht, ein Verbrechen an unseren so schwer geprliften Volk und der vielt.

Es erhebt sichluberhaupt die Prage, in wie weit solche Gegenstinde $f u_{r}$ ein Jugendleben notwondig sind und ob es nicht immer zu jeder Zeit ein gefthrliches Bxperiment ist, die Jugond mit solchen Gegenstanden organisiert uns systematisch zu bedenken. Sowe1t Jugendliche Spa. an solchen Dingen haben, sollen sie sich damit abgeben, es wird eine vorlbergehende Kari May Zeit fur sie sein. Aber faul lst so etwas, wenn eine Organisation dahinter steht und das systematisch betreibt.

III. Bei aller Bemuhung ein Vertrauen aufzubringen, das man Herrn von 2 hadd en und darlber hinaus der Rechtspartei schenken wlirde, es ehrlich in Bezug auf Jugenderzlehung im demolratischen Sinn zu meinen, ist in keiner Weise gevahrleitstet, daB die Bntwicklung die diese Jugend nehmen wird, eine einwandr reie sein kann. Alle $\mathrm{B}$ rfahrungen der Vergangenhelt und ger-Zukunft sind andere. Ich mochte daher die Bohauptung aufstellen, bel aller ehrlicher Bewhung sind die Verantwortilchen der Wikingerjugend nicht in der Lage die Gefahr und die Bntwicklung zu steuern und zu meistern, die sehr zweifelhaft ob der 7 ikingerjugend einsetzen $w i r d$. Bs ist mir gehr zweifelhaft ob man sich auf Selten der Hauptversantrortilichen dieser Cefahr bewußt 18t. Das BewuBtsein dieser Gefahr 1st aber orste Vorausetzung, wenn man verantwortlich im neuenstast stehen

IV. Die Fraxis der Fikingerjugend zeigt er ste Brgebnise. Trotzdem noch keineordentlichef Zulaßung erfolgt ist und wie man inoffizieller Zeise erfahrt sogar ein Verbot der Jugend besteht. Erifft Bie sich heimlich abends und zur Nachtzeit drauBen in der Feldmark. Von höher gelegenen Fohnungen der Stadt, hört man deutlich das dumpie trum, trum dor Iandknechtstrompln. Gesbnge wie: Haltet aus Im Sturmgebraus schailen noch abends um 23.30 tber die Difcher der Stadt. Vom Stadtjugendpfloger selbat geh8rt.

Offentliches Durchmarschieren mit Trommeln, schwarzer Fahne auf der zirei gekreutzte Schwerter zu sehen sind, durch die Stadt Hann. Mlinden. Beobachtet vom Kreisjugerdpfleger Pfluger in Munden.

Ankleben von Rlakaten in Gôttingen, auf denen zu lesen steht: nationale Jugend rechts ran. Junge bist du deutsch komme $z u$ uns. Jugend auf die Strich hervor, daB die Sache whist, daB man die Jugend auf die StrBe holt, sie wiedor marschier on labt und ihnen in die Richtung die auf. Wir Jugendpfleger bemthen uns seit der Zeit wo wir im Amt sind, jegliche klassenmbige, rassenmbige und polt. Beeinflubung und vor

Q14: Bericht über Vorfälle mit der Wikingerjugend von Schmalstieg an den Göttinger Jugend und Sportausschuss, 20.7.1947, Göttinger Stadtarchiv, C64, Nr. 110, Bl. 10. 


\title{
Versorgungslage im Göttingen der Nachkriegszeit
}

\author{
Timo Stiehl
}

\section{Einleitung}

„Wir sehen uns der tödlichen Erkenntnis gegenüber: Nicht Parteien oder Gewerkschaften bestimmen unser Leben, nicht junge demokratische Regierungen oder die Besatzungsmacht, sondern einfach der Hunger, nichts als Hunger." , ${ }^{1}$ kommentierte die Kölnische Rundschau am 15. August 1947 die Versorgungslage in der rheinischen Großstadt. Kaum ein Thema hat die Menschen während der Nachkriegszeit so beschäftigt und in ihrem Alltag beeinflusst, wie die mangelhafte Versorgung. Die sechs Kriegsjahre von 1939 bis 1945 forderten nicht nur Millionen Opfer, sondern zerstörten besonders in den Städten jegliche Infrastruktur. ${ }^{2}$ Neben der Zerstörung der wirtschaftlichen Zentren und Produktionsstätten wurde auch der Flüchtlingsstrom aus den ehemaligen deutschen Ostgebieten zu einem großen Problem, da nun allein in Niedersachsen über 1,8 Millionen Flüchtlinge aufgenommen und zusätzlich versorgt werden mussten. ${ }^{3}$ Dass diese Bürde insbesondere die Göttinger traf, zeigt sich an der Not in der sonst von den alliierten Bomben verschonten Stadt, denn obwohl wenig Wohnraum zerstört wurde, war die Aufnahmekapazität der Stadt ausgereizt. Schon 1944, vor Ende des Krieges, lebten in

\footnotetext{
1 Zit. nach: Rainer Gries, Die Rationen-Gesellschaft. Versorgungskampf und Vergleichsmentalität. Leipzig, München und Köln nach dem Kriege, Münster 1991, S. 11.

2 Zur Zerstörung der deutschen Städte vgl. Edgar Wolfrum, Die geglückte Demokratie. Geschichte der Bundesrepublik Deutschland von ihren Anfängen bis zur Gegenwart, Stuttgart 2006, S. 32.

${ }^{3}$ Klaus-Dietmar Henke, Die amerikanische Besetzung Deutschlands, München 1995, S. $729 f$.
} 
Göttingen rund 3500 Flüchtlinge. ${ }^{4}$ Nach dem Krieg wurde Niedersachsen neben Schleswig-Holstein und Mecklenburg-Vorpommern zum wichtigsten Aufnahmeland für die aus den ehemaligen Ostgebieten und aus der SBZ nach Westen strömenden Flüchtlinge und Vertriebenen. ${ }^{5}$ Eine logistische Herausforderung stellte auch die große Zahl von ehemaligen Zwangsarbeitern dar, die vorwiegend in Lagern lebten. Durch die Nähe zum Durchgangs- und Aufnahmelager Friedland entstand nach und nach eine Ausnahmesituation in der Universitätsstadt. Viele, die aus dem Aufnahmelager entlassen wurden, hatten oft Göttingen als ersten Anlaufpunkt und belasteten somit, wenn auch nur vorübergehend, die Versorgungssituation der Stadt.

In den ersten Monaten nach Kriegsende fehlte es in allen Bereichen der Grundversorgung an dem Notwendigsten: angefangen bei den Lebensmitteln über die Textilversorgung bis hin zu Brennstoffen wie Kohle und Holz (Q1).

\section{Lebensmittelversorgung und Versorgungssystem}

Priorität hatte die Versorgung mit Lebensmitteln. Da dies die britische Militärregierung schnell erkannte, versuchte sie, den Handel mit Lebensmitteln von Anfang an zu kontrollieren, um eine gerechte Verteilung zu gewährleisten. ${ }^{6}$ Schon kurz nach Kriegsende wurden an die Händler und Landwirte Bestandsmeldelisten verschickt, um einen Überblick zu bekommen, welche Waren vorrätig waren und woran es besonders mangelte (Q2). ${ }^{7}$ Letztere bekamen je nach ihrem Viehbestand und ihrer Ackerfläche Ablieferungsquoten auferlegt, die sie erfüllen mussten. Dabei gab es immer wieder „schwarze Schafe“ (Q3), aber auch Bauern, die sich besonderes Lob verdienten, weil sie vergleichsweise viel Milch ablieferten. Der Göttinger Landwirt Wilhelm Klemme wurde in der Hannoverschen Presse vom 15. Mai 1948 als „Guter Milchablieferer" hervorgehoben, weil er die durchschnittlich abgelieferte Milchmenge um 81 Prozent übertraf. Er zeigte damit, dass die Bauern viel mehr Milch an die Militärregierung hätten abliefern können und somit der Mangel oft auch selbstgemacht war (Q4).

Das wichtigste Grundnahrungsmittel war die Kartoffel. Mit den umliegenden Landwirten entstand, besonders vor den Wintermonaten, ein reger Tauschhandel um das begehrte Gut (Q6); massenweise zogen die Städter in die ländlichen Gebie-

\footnotetext{
${ }^{4}$ Hans-Georg Schmeling, Die überfüllte Stadt, in: Ders. (Hg.), Göttingen 1945. Kriegsende und Neubeginn. Texte und Materialien zur Ausstellung im Städtischen Museum, 31.3.-28.7.1985, Göttingen 1985, S. 106.

5 Dieter Brosius, Niedersachsen, in: Wolfgang Benz, Deutschland unter alliierter Besatzung. 19451949/55. Ein Handbuch, Berlin 1999, S. 406.

${ }^{6}$ Günter J. Trittel, Hunger und Politik. Die Ernährungskrise in der Bizone (1945-1949), Frankfurt am Main 1990, S. 29.

${ }^{7}$ Hans-Georg Schmeling, Göttinger Nachkriegsalltag 1945, in: Ders. (Hg.), Göttingen 1945. Kriegsende und Neubeginn. Texte und Materialien zur Ausstellung im Städtischen Museum, 31.3.28.7.1985, Göttingen 1985, S. 161.
} 
te, wo die Versorgungslage besser war, und durchstreiften die Dörfer, um Hausrat, Kleidung oder Wertgegenstände gegen Butter, Speck und Kartoffeln einzutauschen. Da die Verteilung der Lebensmittel streng reglementiert war und auch nur funktionieren konnte, wenn sich die Erzeuger sowie die Verbraucher an diese Reglementierung hielten, waren diese sogenannten Hamsterfahrten zwar offiziell verboten, aber die an Bahnhöfen und Ausfallstraßen durchgeführten Kontrollen zeigten keine Wirkung. Innerhalb der Städte wiederum entstand ein blühender Schwarzmarkt, ${ }^{8}$ der genau wie die Hamsterfahrten verboten war, aber von den Ordnungskräften ebenfalls nicht unterbunden werden konnte. ${ }^{9}$

Wenn durch die Zusatzversorgung durch den Schwarzmarkt und die Hamsterfahrten auch eine Besserung der Versorgungsnot eingetreten war, so blieb die Ernährung dennoch desolat, was sich in Göttingen sehr gut anhand der Schulkinder zeigen lässt. Kinder sind immer die schwächsten Glieder einer Gesellschaft und so zeigte sich an ihnen die schlechte Ernährungssituation besonders deutlich.

In einem Entschuldigungsschreiben vom 21. Juni 1946 aus Duderstadt heißt es zum Beispiel, dass eine Mutter ihr Kind nicht zur Schule schicken konnte, weil es seit 18 Stunden nichts mehr gegessen hatte (Q7). Der Umstand, dass der Lehrer dieses Schreiben an die Schulbehörde nach Hannover weiterleitete, verdeutlicht die extremen Auswirkungen der Mangelwirtschaft. Eine Auflistung seitens der Kreisverwaltung aus dem Jahr 1947 zeigt auf, dass mehr als ein Drittel aller Kinder im Kreis Göttingen an Unterernährung litt (Q8). Infolge dessen führte die Militärregierung schließlich ab 1946 eine flächendeckende Schulspeisung ein. ${ }^{10}$

Neben einer ausreichenden Versorgung mit Kartoffeln fehlte auf den Tellern der Menschen das Fett. Fleisch war zwar schon immer sehr teuer gewesen, in Zeiten der Not wurde es jedoch fast unbezahlbar. ${ }^{11}$ Einen Eindruck davon vermittelt der Brief des Studenten Werner Schmidt, der sich wegen des zu geringen Fettgehalts im Gaststättenessen in einem Leserbrief beschwerte (Q9). Um die Verfügbarkeit von Fett zumindest annähernd zu verbessern, setzte die Militärregierung eine Fettprämie für die Ablieferung von Bucheckern aus. Die Menschen sammelten im Wald Bucheckern, für die sie im Tausch von den Versorgungsämtern Bezugskarten für Margarine oder Speiseöl bekamen (Q10).

Da die britische Militärregierung nicht imstande war, die Bevölkerung ausreichend zu ernähren, übernahm sie neben dem Bewirtschaftungssystem auch das vormalige Konzept der Rationierung mit Lebensmittelmarken aus dem Krieg. ${ }^{12}$

\footnotetext{
8 Siehe den Beitrag von Karolin Oppermann in diesem Band.

9 Vgl. Edgar Wolfrum, Die geglückte Demokratie. Geschichte der Bundesrepublik Deutschland von ihren Anfängen bis zur Gegenwart, Stuttgart 2006, S. 33.

10 Siehe den Beitrag zur Situation der Schule von Marco Dräger in diesem Band.

11 Vgl. Günter J. Trittel, Ernährung, in: Wolfgang Benz, Deutschland unter alliierter Besatzung. 19451949/55. Ein Handbuch, Berlin 1999, S. 118.

12 Das System der Bezugsscheinkarten wurde vom Reichsministerium für Ernährung und Landwirtschaft am 28.8.1939, zwei Tage vor Kriegsbeginn, in Deutschland eingeführt. Vgl. auch: Michael Wildt, Der Traum vom Sattwerden. Hunger und Protest, Schwarzmarkt und Selbsthilfe, Hamburg 1986, S. 15.
} 
Hierbei wurden die Rationen in sogenannte Zuteilungsperioden gegliedert, wobei eine Periode ungefähr einem Monat entsprach. ${ }^{13}$ Die Bevölkerung konnte während des Krieges die Lebensmittelmarken bei den Händlern eintauschen, wobei sich die Versorgung nach dem Angebot richtete. Jedoch waren in den späteren Kriegsjahren und insbesonders nach dem Krieg nicht genügend Waren auf dem Markt, so dass die Zuteilungen noch geringer als die ohnehin schon knapp bemessenen Mengen ausfielen. Die Zuteilungsrationen durch die alliierten Behörden gliederten sich nach Kriegsende je nach Bedarf in sechs Klassen:

Lebensmittelkarte für Erwachsene über 20 Jahre (Q11)

Lebensmittelkarte für Jugendliche über 10 bis einschließlich 20 Jahre

Lebensmittelkarte für Kinder über 6 bis einschließlich 10 Jahre

Lebensmittelkarte für Kleinkinder über 3 bis einschließlich 6 Jahre

Lebensmittelkarte für Kleinstkinder über 1 bis einschließlich 3 Jahre

Lebensmittelkarte für Säuglinge bis zum vollendeten 1. Jahre ${ }^{14}$

Zusätzlich gab es gesonderte Karten für Normalarbeiter, Schwerarbeiter, Schwerstarbeiter und Teilschwerarbeiter sowie eine Schwangeren- und Krankenzulagekarte. Weiterhin wurde zwischen Selbstversorgern, Teilselbstversorgern und Nicht-Selbstversorgern unterschieden und dementsprechend die Rationen eingeteilt.

Sobald ein Gegenstand Wert erhält, wird er zum begehrten Objekt für Diebe und Fälscher - so geschah es auch mit den Lebensmittelkarten. Es fanden sich in den Zeitungen immer wieder Meldungen über Diebstähle und Einbrüche in die Ausgabestellen (Q12). Schon 1946 wurde die Militärregierung dazu gezwungen, einen Erlass herauszugeben, in dem genau geregelt wurde, wie die Lebensmittelkarten aufbewahrt werden sollten, um Diebstählen vorzubeugen (Q13). Das zweite große Problem waren die zahlreichen Fälschungen, die im Umlauf waren. Hierauf reagierten die Versorgungsämter, indem sie für jede Zuteilungsperiode die Farbe der Lebensmittelkarten änderten und weitere Merkmale einführten, anhand derer die Karten eindeutig zu identifizieren waren (Q14).

\section{Versorgung mit Brennstoffen}

Ähnlich schlecht wie die Lebensmittelversorgung war die Versorgung mit Brennstoffen wie Kohle, Holz und Gas. Besonders Kohle wurde zum Schlüsselwort der Nachkriegszeit. Sie war der Lebensnerv Deutschlands und ganz Europas. Durch zerstörte Gruben, Mangel an Arbeitskräften und deren Unterernährung sank die Förderung im Januar 1946 auf rund 10\% der Kriegsproduktion. Zwar lagerten 2-3 Mio. Tonnen Kohle auf Halde, diese Mengen konnten aber wegen des zerstörten Transportwesens nicht befördert werden. Allein in der britischen Zone waren 2800

\footnotetext{
13 Günter J. Trittel, Hunger und Politik. Die Ernährungskrise in der Bizone (1945-1949), Frankfurt am Main 1990, S. 23.

${ }^{14}$ Stadtarchiv Göttingen: Ernährungsamt B43, Nr. 12.
} 
Brücken zerstört; die Schifffahrt war überall blockiert und im Juni 1945 waren nur noch $650 \mathrm{~km}$ Schienen befahrbar. ${ }^{15}$

Der Mangel traf die Bevölkerung besonders hart in den schweren Nachkriegswintern, da viele Menschen nicht ausreichend Kohlen zum Heizen hatten (Q15). In Zeiten besonderer Knappheit, wie dem Kältewinter 1946/47, kam es zu sogenannten Kohleferien, welche teilweise bis zu vier Monate andauern konnten. Hierbei wurden die Hochschulen und Schulen geschlossen, da sie nicht geheizt werden konnten (Q16). Oft wurde der Unterricht nur dann durchgeführt, wenn die Kinder ein Stück Kohle von zu Hause mitbrachten.

Die mangelnde Versorgung mit Brennmaterialen zog ebenfalls eine Stromknappheit nach sich, da Strom vornehmlich auf der Basis von Kohlekraftwerken produziert wurde. Im Herbst 1946 beschloss die Elektrizitätsgesellschaft, Göttingen in einen nördlichen und einen südlichen Bezirk einzuteilen. Je nach Bezirk, wurde der Strom in einer Woche entweder nur vormittags oder nachmittags zur Verfügung gestellt (Q17). Als wieder mehr Leistung vom Elektrizitätswerk erbracht werden konnte, erhielt jeder Bürger eine feste Zuteilung an Kilowattstunden. Hatte ein Bürger seine Ration überschritten, wurde ihm der Strom einfach abgeschaltet (Q18).

Ein deutliches Indiz für die Holzknappheit ist in den zeitweisen Überlegungen der Göttinger Tischler zu finden, Leihsärge einzuführen, da man, so die Überlegung, dadurch Holz einsparen könne (Q19). Dieser Vorschlag wurde allerdings seitens der Militärregierung abgelehnt, er zeigt uns aber deutlich den eklatanten Mangel an Brennstoffen.

\section{Weitere Gebrauchsgüter}

Eine weitere Lücke innerhalb der Versorgung der Bevölkerung bildete der Bezug von Bekleidung. Die Behörden der britischen Militärregierung teilten der Bevölkerung Kleidung und Schuhe ebenso wie Lebensmittel und Brennstoffe zu. Die Versorgung mit Bekleidung stellte ein langfristiges Problem dar. Noch 1948 gab es nicht genügend Schuhe. Besonders für Kinderbekleidung wurden zu wenige Rohstoffe bereitgestellt, so dass bereits die Materialien für die Herstellung fehlten. Die Zuteilungen für das Jahr 1948 ergaben, dass auf 1.000 Einwohner Göttingens insgesamt 63 Paar Schuhe verteilt werden konnten (Q20). Nicht besser sah es bei der Textilversorgung aus. ${ }^{16}$ So kamen 1947 auf einen Wintermantel 2.500 Männer und 2,2 Paar Socken auf 1.000 Männer, während Frauen 7 Paar Socken pro 1.000 unter sich aufteilen konnten (Q21). Wie angespannt die Lage war, zeigt schließlich eine Umfrage unter 8.729 Schulkindern aus dem Jahr 1947, die in der Gemeinschaftsschule in Herzberg am Harz durchgeführt wurde. Laut dieser Studie besaßen 18\%

\footnotetext{
15 Rolf Steininger, Deutsche Geschichte seit 1945. Darstellungen und Dokumente in vier Bänden, Band 1, Frankfurt am Main 1996, S. 72.

16 Vgl. Schmeling, Göttinger Nachkriegsalltag 1945, S. 166.
} 
der Schulkinder kein eigenes Paar Schuhe und 60\% lediglich ein Paar, 24\% besaßen keine Unterwäsche und fast die Hälfte entweder keine, bloß ein Paar oder nicht mehr ausbesserungsfähige Strümpfe (Q22).

Die unmittelbare Nachkriegszeit war in vielen Bereichen durch eine Versorgungsknappheit gekennzeichnet. 1948 gingen die Buchhändler dazu über, Bücher nur noch gegen eine zusätzlich zum Kaufpreis aufgebrachte Menge Altpapier auszugeben, was gerade in Göttingen, einer Universitätsstadt mit erhöhtem Bücherbedarf, ein schwerwiegendes Problem war (Q23). Ein anderes Thema, das die Menschen unmittelbar berührte, war die mangelnde Versorgung mit Seife. ${ }^{17}$ Es fehlte sowohl die Seife für die tägliche Körperpflege als auch Waschmittel für die Wäsche (Q24).

\section{Besserung der Versorgungslage}

Nach und nach stellte sich eine Besserung der Verhältnisse ein. Spätestens mit der Währungsreform 1948 änderte sich die Versorgungslage, da die Konsumenten nun wieder auf eine stabile Währung zurückgreifen konnten. ${ }^{18}$ In den Zeitungen fanden sich zum Beispiel Meldungen über den ersten Sekt, der wieder angeboten wurde (Q25). Ein Bild, an das man sich in den Nachkriegsjahren mehr als gewöhnt hatte, waren Menschen, die vor Geschäften oder der Lebensmittelkarten-Ausgabe Schlange standen. ${ }^{19}$ So war es ein deutliches Zeichen der Besserung, als die Hannoversche Presse am 22. März 1949 ein Bild der letzten in Göttingen zu sehenden Schlange ablichtete (Q26).

Im Mai 1950 sah sich die Regierung Adenauer schließlich imstande, das System der Lebensmittelkarten, das in Deutschland seit dem 28. August 1939 bestanden hatte, abzuschaffen. Die Ernährungsämter wurden geschlossen und die Mitarbeiter auf andere Dienststellen versetzt (Q27). Die Versorgungsnot der Nachkriegszeit war überwunden. Ab 1950 konnte man wieder mit Fug und Recht behaupten: „Es gibt wieder alles!“‘ (Q28).

\footnotetext{
17 Vgl. Ebd., S. 166.

18 Die Reichsmark wurde wegen der zurückgestauten Inflation im Zweiten Weltkrieg und der anschließenden Nachkriegszeit wertlos, weshalb in dem Gebiet der westlichen Besatzungszonen am 21.6.1948 eine Währungsreform durchgeführt wurde. Dabei wurden Guthaben in Reichsmark im Verhältnis 100:6,5 auf D-Mark umgestellt und Schulden im Verhältnis 10:1 umgerechnet. Mit der neuen D-Mark konnte die Bevölkerung wieder auf eine stabile Währung zurückgreifen, ohne Angst vor einem Wertverfall haben zu müssen.
}

${ }^{19}$ Wolfrum, Die geglückte Demokratie., S. 33. 


\section{Literatur zum Weiterlesen}

Rainer Gries, Die Rationen-Gesellschaft. Versorgungskampf und Vergleichsmentalität. Leipzig, München und Köln nach dem Kriege, Münster 1991.

Hans-Georg Schmeling, Die überfüllte Stadt, in: Ders. (Hg.), Göttingen 1945. Kriegsende und Neubeginn. Texte und Materialien zur Ausstellung im Städtischen Museum, 31.3.-28.7.1985, Göttingen 1985, S. 149-198.

Günter J. Trittel, Ernährung, in: Wolfgang Benz, Deutschland unter alliierter Besatzung. 1945-1949/55. Ein Handbuch, Berlin 1999, S. 117-123.

Günter J.Trittel, Hunger und Politik. Die Ernährungskrise in der Bizone (19451949), Frankfurt am Main 1990.

Michael Wildt, Der Traum vom Sattwerden. Hunger und Protest, Schwarzmarkt und Selbsthilfe, Hamburg 1986.

Edgar Wolfrum, Die geglückte Demokratie. Geschichte der Bundesrepublik Deutschland von ihren Anfängen bis zur Gegenwart, Stuttgart 2006. 


\section{Schlechte Versorgungslage}

\section{Nur Rasierklingen demnächst wieder frei}

Ouglejch alle fragen des Ernährungssektors zentral selefelt werden, kam es auch hier zu lokalen Schwierigkeiten kommen. So ist zur zeit eine Belieferung der laufenden Kartoffelmarken in den Geschäften nicht mögljch. Dea größte Teil del Göttinger Bevölkerung hat Kaltoffeln einkellein können: nur etwa 5000 Persomen, vorwiegend stydenten und Werktätige, müssen in Gaststä́tten essen und komnten fon der rinkellerungsmöglfchkeit keinen Gebrauch machen. Werkküchen und Gastsläten haben jedoch noch genugend Kartoft'eln vorrätig.

Auch an Fleison herrsoht in ciottingen Nangel. $k$ wurate vorsorglich Freibankfleisch in Dosen bestellt, wovon jeweils liöhere Mengen abgeyeben werden. Der Verbraucher igt nicht verpflichtet, dieses Fleisch zu kaufell. - Seit den Juntausch del Baufscheine in Punkt. malken, der in Göttingen schr reibungslos und schnell durchgeführt wurde, ka!n von ejner Textilwarenversorgung tiserhaupt wicht, ment gesprochen werden. Dem Wirtschstsanit steht iberhaupt kein einciger Punkt zur Vertigung. so daß auch in dringendsten Fällen nicht geholten weiden kamn.

Fibenso ist die Versorgurg mit Hoiz und Kohle immer. noch mauneicheid. Das Holzkontingent ist zur Schonung des deutschen. Waldes erheblich herabgesetzt worden. Zum Ausgleid konnte hierfür Stockholz (Stubben) zeföluert werden; aber das war in letzter Zeit auch nicht mehr nö̈glich, da hierfür bereits seit zwei Nonaten der Splengstoff fehlt. Fine ausreichende Kohlenversorgung scheitert vorwiegend an den Transportschwierigkeiten. So ist auch hier ein Mangel spilibar. Die Backer und Einährungsbetriebe lraben jiur noch für wenige Tag'e Kohle, während die Krankenhüuser und Kliniken noch zwei bis dret wochen mit inren Vorräten auskommen weiden. - Nach der Belieferung der. kürzlich ausgegebenen Bezugscheine fü Rasierklingen sollan diese wieder" frel verieut, werded. e. b.

Q1: „Schlechte Versorgungslage“, HNN vom 20.01.1948, S. 4. 


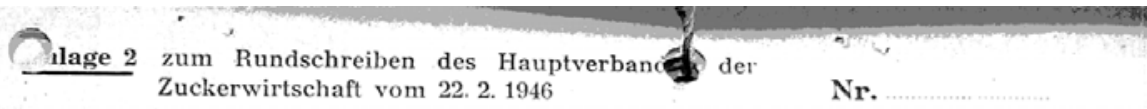

\section{Bestandsmeldung der Kleinhändler zum 31. März 1946 für Zucker, Marmelade usw.}

Am 31. März 1946 befanden sich in meinem Besitz (in meinem Laden, Lager, auf Fremdlägern, einschl. der auf dem Transport befindlichen, mir bereits berechneten Mengen)
a) Zucker $\mathrm{kg}$
b) Bienenhonig $\mathrm{kg}$
c) Marmelade $\mathrm{kg}$, umgerechnet in Zucker im Verhältnis von $180: 100=$
d) Kunsthonig $\mathrm{kg}$, umgerechnet in Zucker im Verhāltnis von $125: 100=\ldots \ldots \ldots . . .$.
e) Zuckersyrup $\quad \mathrm{kg}$, umgerechnet in Zucker im Verhāltnis von $125: 100=\ldots . . .6 \mathrm{~kg}$
f) Obstsyrup $\quad \mathrm{kg}$, umgerechnet in Zucker im Verhāltnis von $150: 100$ g) Mischsyrup mit $50 \%$ Zuckergehalt $\mathrm{kg}$,
umgerechnet in Zucker im Jerhältnis von $200: 100=$
h) Sonstige zuckermarkenpflichtige Waren in Zuckerwert Zusammen Zuckerwert:

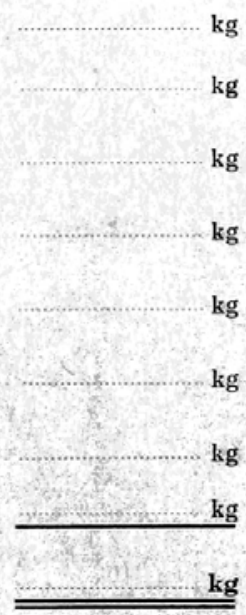

Ich versichere an Eidesstatt, daß die vorstehenden Angaben richtig sind. Es ist mir bekannt, daß unrichtige oder unvollständige Angaben nach den Gesetzen der Militär-Regierung strafbar sind.

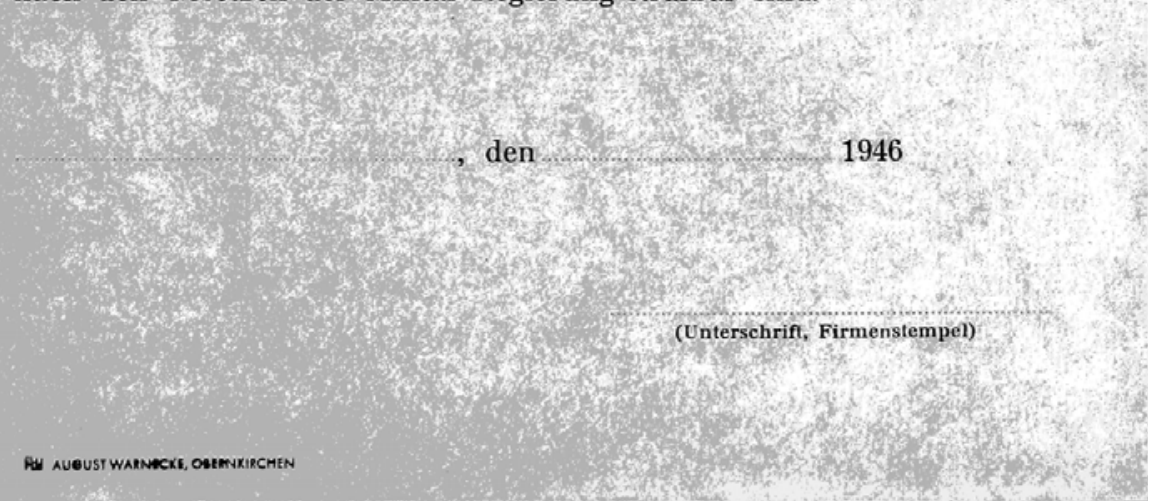

Q2: Bestandsmeldung der Kleinhändler zum 31. März 1946 für Zucker, Marmelade usw. vom 22.2.1946, Stadtarchiv Göttingen: Ernährungsamt B43, Nr. 7. 


\section{Mitschuldige om Hunger}

hp GOTTINGEN, Der Vorsitzende des. Lardwirtschaftsausschusses beim Kreislandwirtschaftsamt gab die Namen der zehn schlechtesten Ablieferer aus dem Landkrois Göttingen bekannt:

August Leonhardt, Esebeck 22; Heinrich Aue, Volkerode 27; . Hermann Kohlstedt, Atzenhausen 2.5; Hermann Margraf, Nikolausberg 13; Johannes Geiser, Dahlenrode 7; Stripping, Knuthbühren 2; August Grube, Elliehausen 54; Helene Häpe, Lemshausen 17; Rudolf Jäp, Rosdorf 62; Willy Hampe, Bremke 41.

Es sei nur noch am Rande vermerkt, daß z. B. der Bauer Aue nicht ein Gramm Kartóffeln geliefert hat und über 100 Zentner Brotgetreide einfach verschwinden lieB. Der Abgeordnete Grüneklee stellt zu diesen Zahlen folgende Fragen:

„Wer ist für die Duldung dieser Žustände verantwortlich? Wer hat die Schlachtgenehmigungen für alle zehn
Bauern erteilt, die nach dem Gesetz Schlachtverbot hatten? Welche Maß. nahmien werden vom Kreislandwirtschaftsamt ergriffen, um für, die $\mathrm{Zu}$ kunft derartiges zu verhindern?" Kreistag gewählt,

\section{So wurde abgëllofert}

hp GOTTINGEN. Nachstehend die prozentuale Aufteilung, was von den landwirtschaftlichen Erzeugnissen im Landkreise abgeliefert wurde:

Weizen 82, Roggen 71, Gerste 101, Hafer 45 , Hülsenfrüchte 56 und Kartoffeln 61 Prozent. Die zurückgehaltenen -Mehgen liegen aber in Wirklichkejt noch höher, da hier nur die Summen der auferlegten Lieferungssolls angenommen wurden.

Q3: „Mitschuldige am Hunger“, HP vom 03.04.1948, S. 4.

\section{Cutor Milchablloforor}

hp SPANBECK. Der Berginvalide Wilhelm Klemme von hier bewirtschaftet 7,5 Morgen Land, er" lieferte in 12 Monaten - van Február 1947 bis Januar 1948 - von einer Kuh 2426 Liter Milch, das sind täglich 6.65 Liter - an die Molkerel ab. Der Ortsdurchschnitt von 1340 Iiter (teglich 3,67) wird damit von $\mathrm{Kl}$. um 81 Prozent übertrofien.

\footnotetext{
Q4: „Guter Milchablieferer“, HP vom 15.05.1948, S. 4.
} 


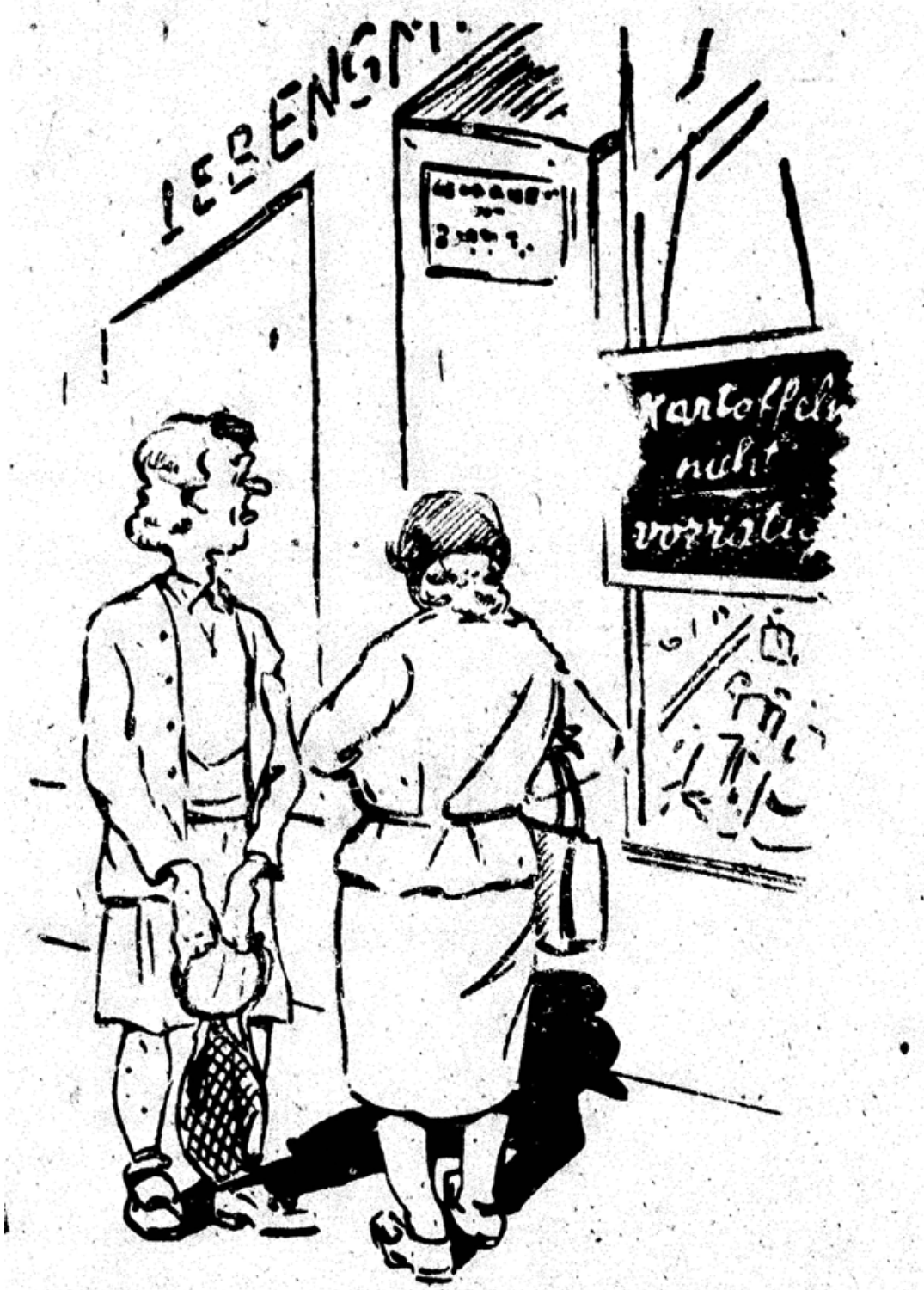

"Hab'n se uns nich immer erzäht, wenn wir den Krieg verliern, dann machen die aus Deutschland einen einzigen großen Kartoffel. acker? Schivindel, auch das noch Schwindel..."

Q5: Karikatur „Kartoffeln nicht vorrätig“, HP vom 13.5.1947, S. 2. 


\section{Auf der Jagd nach Kartoffeln}

\section{Furcht vor dem kommenden Winter / Kartoffeln zu Märchenpreisen} Wenn morgens zwischen 6 und 7 Futtermangels nicht durch den Winter
Uhr die Rostomnibusse zum zweiten bringen kann und deshaib an einen Male in die Dörfer des Landkreises Neuerwerb im Frühjahr - natürlich Göttingen fahren, um Berufstätige zur zu erhöhten' Preisen - denken muß. Arbeit zu bringen, steigen an den Hundérte von Zentnern werden jeeinzeinen Haitestellen der Bauern- den Tag auf Fahrrädern, in Ruckdörfer viele Göttinger Hausfrauen mif săcken, Pappkoffern und EinkaufsSăcken, Taschen und Kisten aus, um taschen weggeschleppt. Sie laufen ihr Tegewerk, die Jagd nach Kar- durch keine Ablieferungskartei, wertoffeln. zu beginnen. Manche sind den von-keiner Amtsstelle gewogen anderen Geschäften bekanit: wer Jeder dieser abgehetzten Stadtmenerstmalify - noch unsicher und zag* schen hat gegen unendlich viel Behaft - sich einem Bauern nähert, stimmungen und Verordnungen verwird mit miBtrauischem Blick und stoBen. Aber velcher Polizist wollte sehr reserviert empfangen.

den Versuch machen, diesen (Leuten
die Kartoffeln wegzuhehmen?

Selten wird eine Frage nach den die Kartoffeln wegzunehment

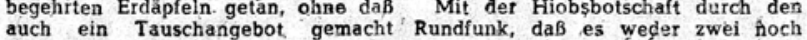
wird. Man weiß, daß die. Ernte nicht drei, sondern vorerst nur einen Zentsehr rosig ausgefallen ist, ind stellt ner Einkellerungskartoffeln geben sich darauf ein. Es wird alles ange- solle, fing es an. Organisierte Einboten, was' ein Stadthaushalt nur her- Käuferkolonnen kamen aus dem Ruhrgeben kann; die Furcht vor dem gebiet und boten für einen Zentner kommenden Wirfter läBt alle Be- bis zu 300 Mark, einen selbst in denken ob dés ungleichen Tausches Schwarzhändlerkreisen märchenhaften beiseite treteh. Doch eine erstaunliche Preis. Aber diese Leute wollen ihr Beobachtung wurde gemachti die Kapital anlegen, welches sie in den Bauern nahmen auch Geld, sogar sehr GroBstädten während der kalten Hun. gern. Das war bisher nicht der Fall gertage des Winters vielfach zu erund ist nur so erklärlich, daB man- höhen gedenken. Sie- steckten mit cher in diesem Jahr'sein Vieh wegen ihrer Kaufpsychose selbst ruhige

Q6: „Auf der Jagd nach Kartoffeln“, HP vom 30.09.1947, S. 3.

Menschen an, die nun auch an ihren eeren Keller dachten und eilends aufs Land fuhren.

Die Landleute aber werden zwischen Pflichterfüllung, eigenen Sorgen und Mitueid für die Stadtbevölkerung hin und her gerissen. Sie müßten manchmal-härter sein, wenn es fich um offizielle Schwarzhändler hande!t, und dürften hie und da ihtem Herzen einen Stok geben; wenn es um nackte Not ohne Gegenware.geht Hier zwischen Recht und. Unrecht zu unterscheiden ist äuBerst. schwer. Und es ist kein Trost, weder für die einen poch für den anderen, zu wissen, daß der kommende Winter der schlimmste werdien soll

$\mathrm{Mb}$.

\section{Abschrift}

Werter Herr Lehrer.

Ich konnte am Mittwoch mein Kind nicht zur Schule schicken, denn meine Kinder hatte fast $18 \mathrm{Std}$. nichts gegessen, und ich muBte erst gehèn um was zu holen.

\section{Mit GruB}

\section{gez. Frau Ringing}

Duderstadt, d.21.6.1946

Q7: Entschuldigungsschreiben vom 21.06.1946, NDS. 20 Hildesheim Acc.166/86 Nr. 519. 


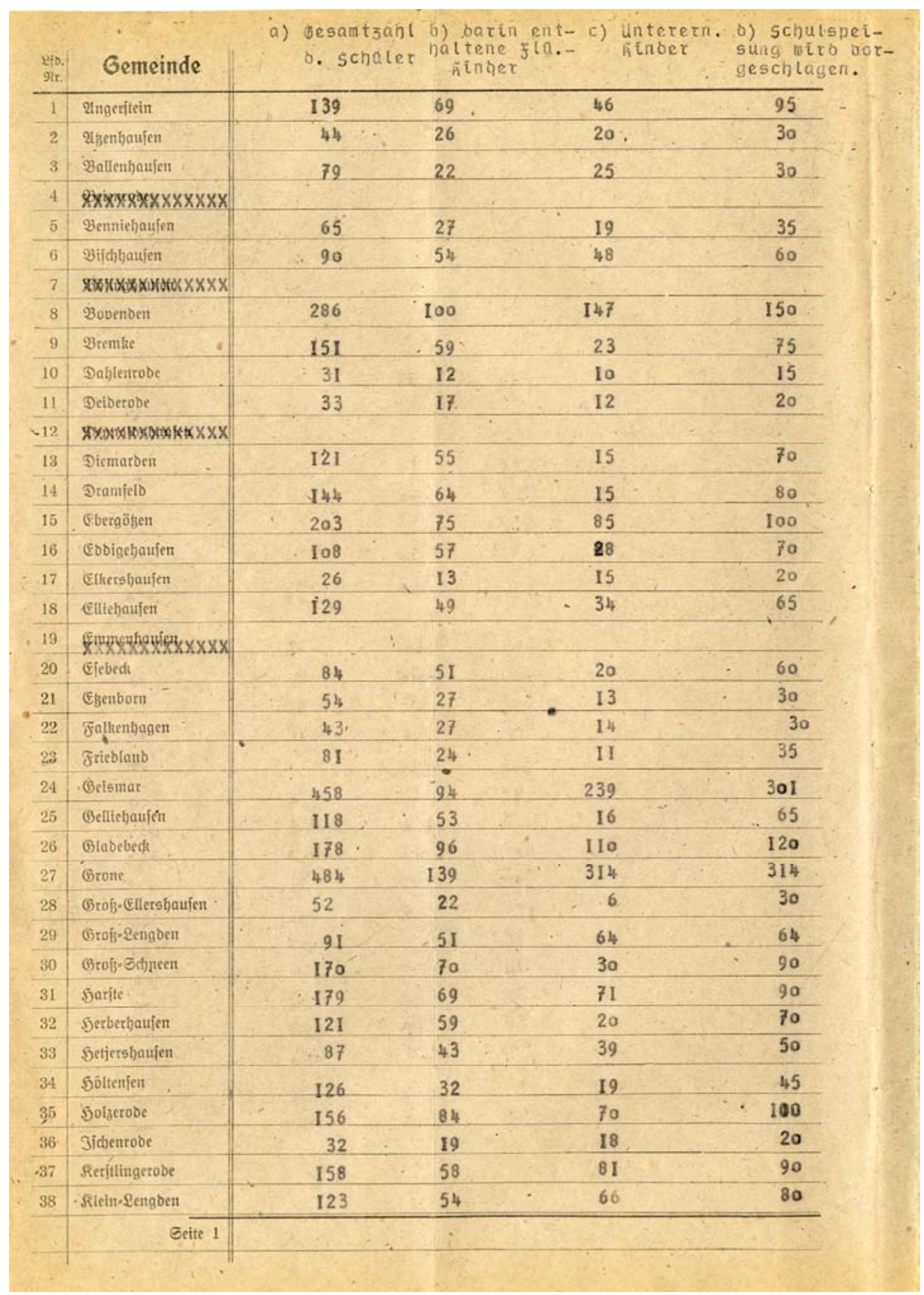

Q8: Ernährungssituation der Schulkinder 1947, NDS. 20 Hildesheim Acc.166/86 Nr. 519. 


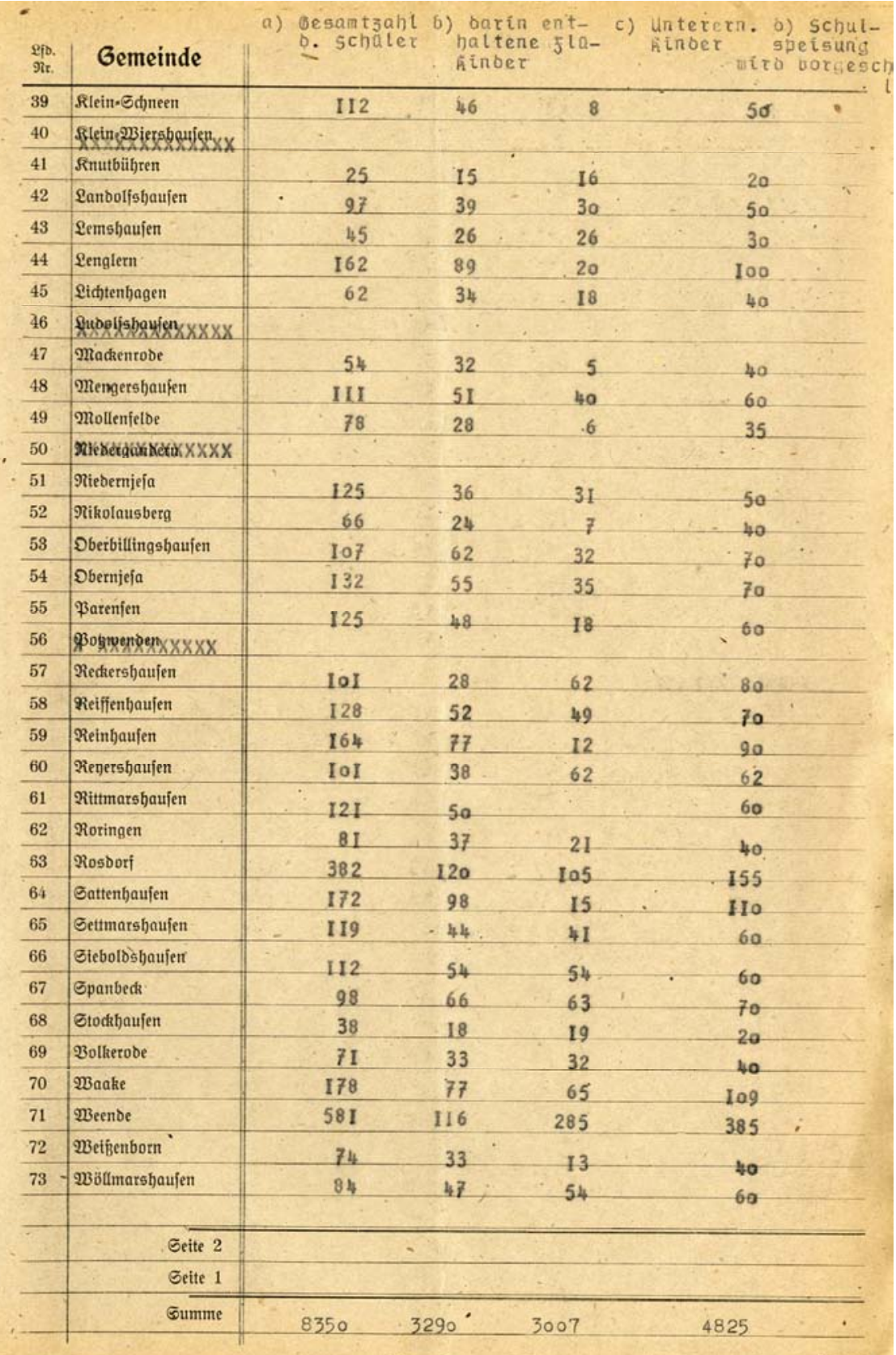

Q8: Ernährungssituation der Schulkinder 1947, NDS. 20 Hildesheim Acc.166/86 Nr. 519. 


\section{Eine dringende Bitte an das Göttinger „Gaststättengewerbe"!}

Die bisherige Fettration ist $\mathrm{um}$ die Hälfte gekürzt. Wir Studenten und mit uns zahlreiche Berufstätige, die mit Normalverbraucherkarten auf Gaststättenessen angewiesen sild, werden dayon besonders hart getrofien. Jedoch schèinen die Göttinger Gaststätten hiervon uberhaupt keinerlei Kenntnis genommen, $z u$ haben. Weiterhin fordern sie, wie bisher, $5, g$ Fett und $z$. $T$. 10. $\mathrm{g}$ Fett, das sind $3 \mathrm{~g}$ ü be $\mathbf{r}$. der zustehenden Gie. samttages ration.

Stichproben haben ergeben, daß in zahlreichen Essen verschisdener Gaststätten keinerlei Fettgehalt ist. Diese Untersuchingei sollen Tortgesetzt werden.

Is: es unter den jetzigen UnsiJnden noch angänglg. Fettmarken für Mittagessen zu lordurn? Soll man nicht zum guten .Stamm" zurückkwiren! Minnche Gast. stätte hat uns ja bewiesen, daß es auch o h n e Fett geht '(wenn auch $m$ it Fettmarkien').

in vemen vieler hungriger Stulenten!

Werner Srhmidt.

Q9: Eine dringende Bitte an das „Gaststättengewerbe“!“, HP vom 13.08.1946, S. 4.

\section{Fett aus dem Walde}

\section{Erfolgreiche Bucheckernernto}

Ganze Menschenkarawanen verlassen Göttingen am frühen Morgen mit Autobus und Rad, mit Eiseñbahn und auf Schusters Rappen, um Bucheckern zu sammeln. Ungefähr 1000 Leute haben sich auf dein Ernährungsamt für die gesammelten und verlesenen Bucheckern Oelberechtigungsscheine geholt. Durcbschnittlich gerechnot, hat feder rund $6 \mathrm{~kg}$ abgeliefert, das macht $6000 \mathrm{~kg}$, für die fast 1000 Liter Oel ausgegeben werden. Es gibt jedoch unter den Sammlern aucin besondere Talente, die es auf 30 bis $\mathbf{4 0}$ Kilo gebracht haben. Abgesehen von der Bereicherung der eigenen Fettöpfe durch den Umtausci, der Bucheckern in Oelberechtigungsscheine, kommt der Segen des Waldes auch noch dadurch der Allgemeinheit zugute, dä bei der Gewinnung des Buchöls aus den Rückständen ein wertvolles Futtermittel, der Oelkuchen. hergestelit wird.

Allen Gerüchten zum Trotz wird betont, daB es auf jeden Fall Oel auf die Berechtigungsscheine geben wird. Wer sofort Fett haben wjil, kann Margarine bekomme.., die die Einzelhändler auf die Oelberechtigungsscheine im Verhältnis $160 \mathrm{~g}$ Oel $=200 \mathrm{~g}$ Margarine ab. geben.

Q10: „Fett aus dem Walde“, HP vom 29.10.1946, S. 4. 


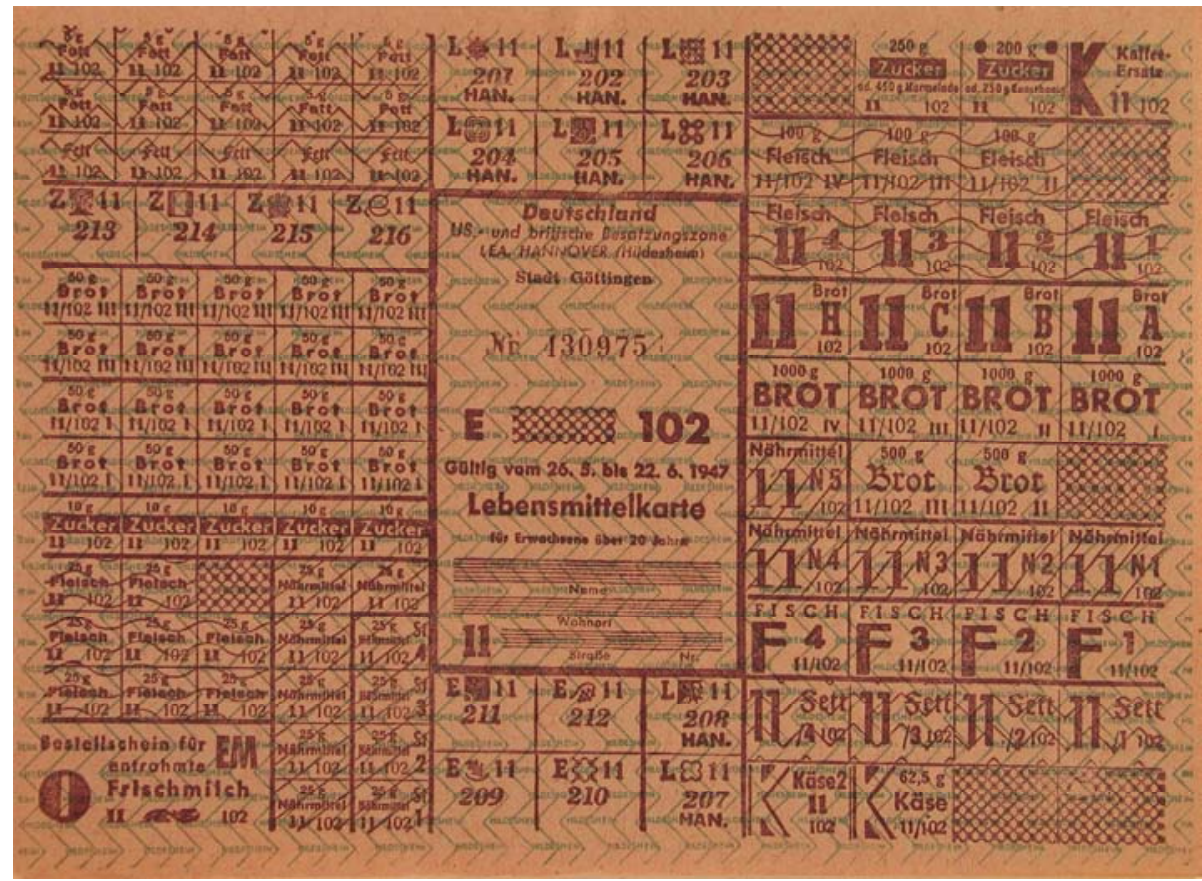

Q11: Lebensmittelkarte für Erwachsene über 20 Jahre der 102. Zuteilungsperiode, Stadtarchiv Göttingen: Ernährungsamt B43, Nr. 12.

\section{Lebonsmittolkarton-Dlebstahl}

Beim Kreiserährungsamt $B$ in Duderstadt sind nach Sprengung eines Stahlschrankes erhebliche Mengen Lebensmittelkarten gestohlen. Es handelt sich um nachstehende Mengen: Nr. 70 Mütterkarten Nr. 2584-3000, Nr. 66 Ergänzungskarten für Scliwerarbeiter (Selbstversorger. Fleisch und Fett entwertet) Nr. 4001 bis 4500 , Nr. $6 f$ Schwerstarbeiter (Selbstversorger, Fleisch und Fett entwertet) Nr. 1501-1600); No. 67 Schwerstarbeiter (Normalverbraucher) Nr. 2501--2700. AuBerdem wurden Tagesverpflegungskarten und Reisemarken entwendet, ferner 150 Berechtigungsscheine für Süßwaren, außerdem Seifenkarten," dio die Bezugsabschnitte 24 und 95 nochenthaiten.

Dio Karten sind mit dem Vermerk „Ernahrungsamt Kreis Duderstadt" versehen, sle dürfen von den Kleinverteilern nicht beliefert werden. Das Kreisernährungeamt Duderstad hat eine hohe Belohnung für denjenigen ausgesetzt, đer dazu beiträgt, daß die Festnahme des Täters erfolgen kann. Auch ist als Sonderbelohnung eine doppelte Lebensmittelkarte für ein Jahr in Aussicht gestelit.

Q12: „Lebensmittelkarten-Diebstahl“, HP vom 31.12.1946, S. 4 


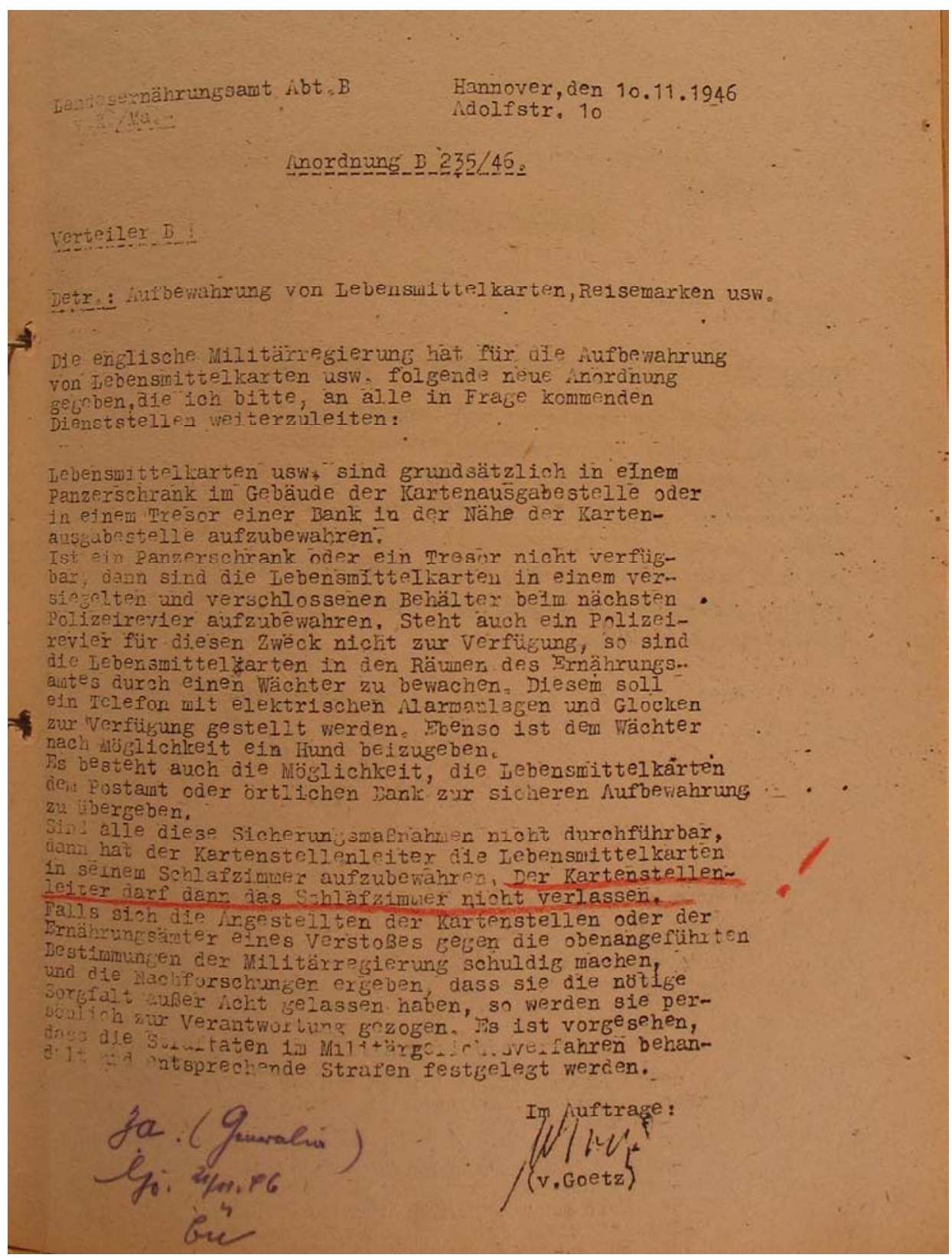

Q13: Aufbewahrung von Lebensmittelkarten, Reisemarken usw. vom 10.11.1946, Stadtarchiv Göttingen: Ernährungsamt B43, Nr. 7. 


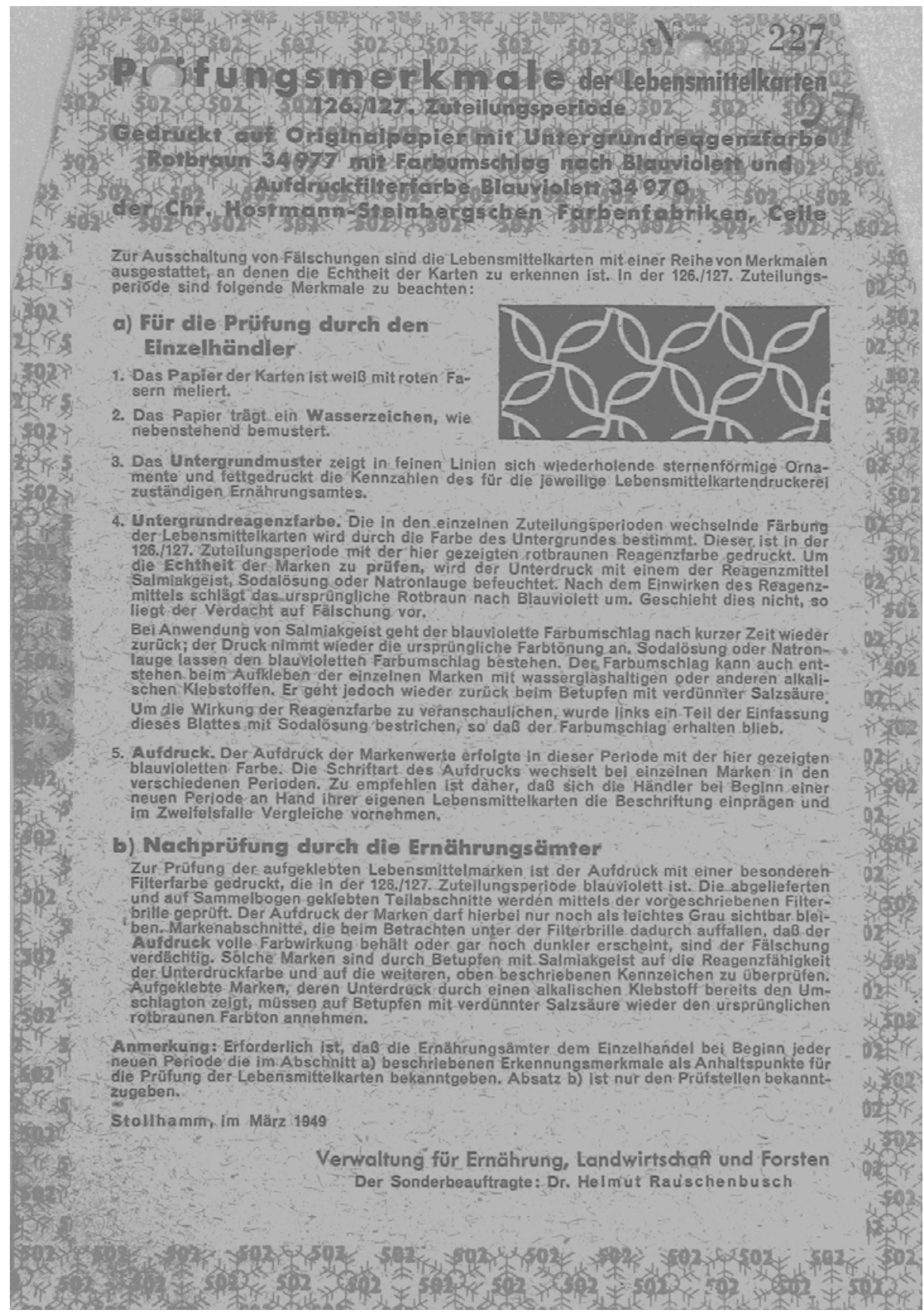

Q14: Prüfungsmerkmale der Lebensmittelkarten 126.-127. Zuteilungsperiode [Stadtarchiv Göttingen: Ernährungsamt B43, Nr. 28]. 


\section{Kohlenkrise ohne Ende?}

Noch immer ist es um die Kohlen schlecht bestellt. Die Stadt Göttingen erreicht mit den bisher eingegangenen Transporten kaum 25 v. $\mathrm{H}$ der normalen Lieferungen, Jetzt ist es gelungen, eine kleine Zuweisung aus den Beständen der Zuckerfabriken Northeim und Obernjesa zu erhalten, die jedoch nur an Bäckereien und Kliniken weitergeleitet wurde, da eine Verteilung an weitere Betriebe nicht möglich war. Man hofft jedoch dadurch, den Anschluß an den Monat Februar zu erhalten. Der Leiter des Wirtschaftsamtes konnte uns nichts darüber mitteilen, wann mit der Wiedereröffnung der Schulen zu rechnen ist, da immer noch keine bindenden Zusagen für genügende Breinstofflieferungen vorliegen. Nur die Voigtsch"le wird derzeitig mit Heizmaterial beliefert, weil dort Abiturientenkurse laufen, deren Einstellung möglichst vermieden werden soll.

Q15: „Kohlenkrise ohne Ende?“", HP vom 04.02.1947, S. 3.

\section{Kohlenferien}

Göttingen, 9. Januar.

Infolge der Verschärfung in dèr Kohlenlage stellen ab sofort sẩmtliche Schulen den Unterricht ein:

Es ist lediglich ftur die Abiturientenklasse Unterricht, dex in der Mittelschule stattfindet.

Die pädagogische Hochschule hat den voraussichtlichen Vorlesungsbeginn, ebenfalls durch Kohlenmangel bedingt, auf den 4. 2. verlegt.

Die Betriebe arbeiten vorläufig bis zum 20. 1: nicht.

Eine Ausnahme machen lebenswichtige Betriebe, wie Bäckereien, Fleischer, Kliniken usw.

Q16: „Kohlenferien“, HV vom 10.01.1947, S. 3. 


\section{Wann geht das Licht aus?}

Gottingen, 17. Oktober.

Zur täglichen Sorge ist in Göttingen die Stromsperre geworden. Täglich geh tas Licht aus, und niemand weiß, zu welchem Zeitpunkt es sein wird.

Von der Elektrizitätsgesellschaft arhielten wir die Auskunft, daß - abgesehen von den letzten Abenden, an denen der plötzliehe Stromausfall auf technische Störungen zurückzuführen ist, folgende Regelung getroffen wurde:

Die Stadt ist in zwei Bezirke eingeteiit, in einen nördilichen und in einen südlichen. Die Grenzlinie führt ungefähr vom Bahnhof zum Theaterplatz. Sobald Stromüberlastung eintritt, wird der Strom abgeschaltet. Das erfolgt wechselweise bei den beiden Stadtbezirken vorund nachmittags.

In-dieser Woche wird im nördlichen Stadtteil der Strom vormittags abgeschaltet, in der nächsten Woche wechselt das dann wieder. Es ist nicht möglich, die genauen Zeiten der Stromsperrung anzugeben, da natürlich nicht bekannt ist, wann die Stromüberlasfung eintritt.

Q17: Wann geht das Licht aus?“, HV vom 18.10.1946, S. 6. 


\title{
- Gedanken um den Zähler
}

\author{
Wie teilt die Hausfrau ihren Stromverbrauch praktisch ein?
}

G ot t Ing en, 14. Oktober.

Die Sorgen und Gedanken unserer Hausfrauen kreisen zum Ende des Monats immer wieder - um den elektrisohen Zahler. Und täglich wird der Stand dieses unbestechlichen Apparates abgelesen, der unerbittlich anzeigt, wieviel man noch verbrauchen darf. Mit der zunehmenden Jahreszelt und der aamit verbundenen trühen Dunkelheit wird dieses Problem immer schwerwiegender - die zugeteilte Strommenge ist bel 'weitem zu gering. Sie ist aber abhängig von der zug eteilten Kohlenmenge und solange qie Milităr-Regierung diese nicht erhöht, muß unser Stromverbrauch auch derartig beschrilnkt bleiben.

Wie dem auch sel, um nicht in Konflikt mit der Anordnung Nr.1 der MilitärRegierung zu 'kommén, dię den Ueberverbrauch von Strom bestraft, müssen wir darauf sehen, daß wir die knappe Stromzuteilung möglichst. vielseitig und sinngemä $B$ yerwenden.

Die Arbeitsgemeinschaft zur Förderung der Elektrowirtschaft hat ein Merkblatt herausgegeben, das zahlreiche praktische Winke für die Hausfrauen enthält. Es ist selbstverständlich, da $\beta$ man das Licht nur dann brennen läßt, wenn man es wirklich benötigt. Wenn. es auch nur wenige Minuten unnötig brennt, so ergeben sich am Monatsende doch eine stattliche Anzahl von Wattstunden, die nutzlos verbraucht wurden. Es ist durchaus nicht nötig, da $B$ in einem kleinen Raum eine 100-Watt-Birne brennt, éine 25- oder A0-Watt-Birne erfunlt genau denselben Zweck,

Ein heikles Kapitel sind die elektrischen Bügeleisen. Es ist wénig bekannt, daß der Hauptstromverbrauch beim Anheizen entsteht, Es ist zweckmäßig, die gesamte Wäsche auf einmal zu bügeln, und diese Arbeit nicht auf mehrere Male zu ver teilen.

Unsere Radiofreunde mússen sich auch mehr einschrănken. Das Rundfunkgerät braucht durchaus nicht von morgens bis abends in Betrieb zu sein. Abgesehen davon, daß die Röhren leiden, ergibt sich daraus am Monatsende ein erheblicher Stromverbrauch. Also nür den Radioapparat einschalten, went man wirklich die Absicht hat, die Rundfunksendung, zu hören.

Viel Strom wird durch das elektrische Kochen verbraucht. Gerade hier ist es möglich, durch Beachtung einiger praktischer Winke erheblich viel Strom zu sparen. Wenn elektrisch gekocht werdẹn muß, d. h. wenn keine andere Kochmöglichiceit vorhmden ist, werden pro Tag für einen Haushalt 1,2 $\mathrm{Kw}$-Stunden zusătzlich genehmigt: Dazu, kommen für fede zum Haushalt gehörende Person nochmals $0,4 \mathrm{Kw}$-Stundèn. Aunk mit diesen-Strommengen muB bußerst sparsam umgeigangen werden. Sehr zu emrfehlen ist in'diesem Zusammenhange die Kochkiste. Sie ist mit einfachsten Mitteln, wenn eine Kiste fehlt, sogar aus einem Pappkarton oder Wäschekörben, herzustellen.

In Göttingen steht eine Beratungsstelle allen Hausfrauen zùr Verfüung, Hier kann die Hausfrau sich Auskunft über alle. Fragen die mit Stromverbrauch elektrischem Kochen usw. im Zusammenhang stehen, holen. Dlese Stelle beflndet sich in der Theaterstraße 4, und in der Zeit von 9-12 und 15-17 Uhr (außer Sonnabends) ist die Beraterin gern bereit, Auskunft zu geben.

Fur den, der immer noch nicht weiß, weIche Strommenge ihm täglich zusteht, sei es nochmals. gesagt. Pro Tag dürfen $0,5 \mathrm{Kw}$-Stunden, zusätzlich $0,05 \mathrm{Kw}-\mathrm{Stun}$ den für jede zum Haushalt gehörende Person verbraucht werden. Ein Haushalt mit sechs Personen darf aîso tăglich 800 Wattstunden gleich 0,8 Kilowattstunden yerbrauchen.

Diese Rationierung muß im Interesse der Allgemeinheit unbedingt eingehalten werden, und die Militär-Regierung hat empfindliche Strafen für Stromsünder festgesetzt. Von' einer 'Geldstrafe, die die hundertfache Höhe der Normalgebühr einer Kilowattstunde beträgt, über. die Stromsperrung können sogar Gefängnisstrafen bis zu drei Monaten verhängt werden.

Es : liegt im Interesse jedes Einzelnen, eine tägliche Kontrolle durchzufuhren, vielieicht helfen unsere ivinke mit zum sparsamen Stromverbrauch.

\section{Mordiversuch mit Salzsắure}

dpd Hamburg, 20. Oktober.

Unter dem dringenden Verdacht, einen Mordversuch an der 19jährigen Sekretärin Lotte Pagels unterommen zu haben, wurde die 39jăhrige Elisabeth Tepper von der Mordkommission der Hamburger Kriminalpolizei verhaftet, Die 27 . Jahre alte Ruth Schliebitz wurde wegen Verdachts der Beihilfe festgenommen. Die Ermittlungen der Mordkommission sind noch nicht abgeschlossen.

\section{Penicillin flir die Żivilbevölkerung} dpd-reuter Hamburg, 21. Oktober.

Peuiciiiin ikann, in dringenden Krankheitsfüllen für die deutsche Zivilbevolkerung und fur verschleppte Personen in der britischen Zone verwendet werden wie jetzt - veranlaBt durch høhere Einfuhren diéses Heịlmittels - von den britischen Behbrden verfilgt, wurde,

Das Penicillin wird gegen Zahlung in Reichsmark an die Gesundheitsbehörden geliefert. 


\section{Ein Leihsarg gefällig? \\ Göttingen, 30. Januar.}

Das Tischlerhandwerk hat sich an die Militär-Regierung mit der Bitte um sofortige Holmzutailung gewrondt. Fo ist niticht mehr möglich, die nötigen Särge für Bestattungen herzustellen.

Es wurde abgelehnt, das Leihsargverfahrep einzuführen, da die dafür benötigte kleine Holzmenge auf jeden Faill bewilligt werden könnte. Die Militär-Regierung "hat den Antrag bereits weitergeleitet.

Q19: Ein Leihsarg gefällig?“،, HV vom 31.01.1947, S. 5.

\section{Stellt die Sïnder!}

Bevölkerùng und Polizei in gemeinsamer Front Mit sanften Ermahnungen und guten Ratschlägen allein ist der Tod auf der Straße nicht zu bekampfen, hier bedarf es stärkerer Mittel. Die Aktion "Kampf dem Verkehrsunfall" hat gefade für Göttingen insofern erböhte Bcdeutung, als manche verkehrsreiche Straßen durch ihre Anlage für Vorkehrsunfälle prädistiniert $\mathrm{zu}$ sein scheinen.

111 Todesopfer und 686 Verletzte sind 1947 in Regiertngsbezirk Hildesheim eine erschütternde Verkehrs-Bilanz. Dazu kommen der erhebliche Sachschaden und der Ausfall im Transportwesen. Die Verkehrspolizei wird alle Verkehrsteilnehmer in der Verkehrserziehungs- und Unfallverhütungswoche, die vom 28. Mai bis 3. Juni durchgeführt wird, auf das richtige Verhalten im Straßenverkehr hinweisen. Filmvorführungen laufen in allen Lichtspieltheatern, ferner wird ein Schaufensterwettbewerb der Göttinger Schulen in der Weender und Groner Straße mit Prämilierung die Bestrebungen der Polizei unterstützen.

Jeder-Passant kann sich und andere zur Verkehrsdisziplin erziehen, wenn e: in den Mittagsstundeo z.wischen 12 und $15 \mathrm{Uhr}$ seine Augen weit offen hält und nach Verkehrssündern ausspäht. Diese wcrden in Gestalt von als Zivilisten verkletdeten Verkehrspolizisten sich auf den Straßen so verhalten wie sie sich im Interesse des geordneten Verkehrs nicht verhalten sollen. Wer einen Sünde: ausmacht, stelle ihn. Hat er den "ríchtigen“, also den verkleideten Bearnten erwischt. winkt ihm eine Belohnuns. Ilat er aiver einen wirklichen Verkehrssünder geschnappt, kann er des Dankes der Allgemeinheit gewiB sein.

63 Paar Schuhe fur 1000 Grttinger

Von zelt zu Zeit liest man, daB in Gottingen Schuhkontingente für Kinder zur Verfagung stehen. Diese Bckanntmachungen dürfen aber nicht zu der Ansich wirde, Fur 1907 wurden 5809 Par Kinderschuhe vorwarde. Fur. 1897 , wurden 5869 Par Kind crschuhe ver- der wie Erwachsene, nicht viel geändert. Man wird zufrieden sein müssen, wenn sich die diesiährigen zuteilungen aut der Hohe des Vorjahres halten werden. 5869 Paar Kindersehuhe hört sich vielleicht ganz gut an. Was diese $\mathrm{Z}$ ahl aber wirklich bedeutet. ist erst zu erkennen, wenn sie in ein Vcrhältnis - nicht etwa zum Bedarf, denn diefer wird in absehbarer Zeit auch nicht entifernt gedeckt werden konnen - eu der $Z$ ahl der vorhandenen Kinder gebracht wird. Auf 1000 Kinder ent fallen $512 \mathrm{Paar}$, mit anderen worten: jedes Kind kann damit rechnen, alle zwei Jahre ein Paar Schuhe zu ber kominen., Kinder wachsen aber schnell, der Verschleiß ist bei innen normalerweise auch RröBer als bei Erwachsenen.

Daß diese weit länger warten müssen, bis sie aut ein Paar neue Schuhe rechnen durfen, ist bekannt. Die Rechnung für Lederschuhe ist zur Zeit folgendermasen aufzusteliten: 4003. insigesamt fur 1947. das sind $\& \mathrm{Paar}$ auf tausend Einwohner. Und die Hoffnungen auf $\mathbf{A r}$ beitsschuhe sind auch nicht allzu groB, denn $\mathbf{3 6 3 6} \mathrm{er}-$ geben 36 pro Tausend.

Fin fuhjbarer Ausgleich ist von dem Fingang der UsWare auch nicht zu erwarten. denn 118 Paar Schuhe seit Januar machen so gut wie nichts auss. Be! Textilen aus dieser Quelle ist die situation auch nicht so, Ws werden fol gende $\mathrm{Z}$ ahlent Arbeits340, Kleinkinderme 340, Kleink indermintel 120 , Regenmantel 8 . Wollmäntel 28s, Regen acken 30, Arbcitsiacken 105. Flanelibemden unterzeyr 228 seit Januar 1948.

\section{Sommersplelplan des 'Stadtebund-Theaters}

Das Städtebund-Theater Ostcrode-Northeih-Duderstadt hat beteits mit den Komödien ,"Wenn der Hahn krsht" und .Ingeborg" die Eintuhrung in einen leichten som merspielplan gegeben. Nach dém Schauspiel ,Johannisfeuer" von Sudermann sind ftir die Sommermonate folgende Stacke vorgesehen: Fine Schnur geht durchs Zimmer" von Katajew, "Die vertagte Nacht" von Arnold und Bach. Shakespeares, Was inr wollt" scampolo Niccom, Shampolo von Mariza" von Kalman, "Der Juxbaron" von Leo Fall.

Im Juli wird dic bekannte Hamburger Tanzbuhne unter der Leitung von Joseffa Stephani an den spielorten des Stadeound-Theaters gastieren.' Durch ein Sommerfest des gesamten operettenensembles soll allen Freunden 


\section{Ein Wintermantel für 2500 Männer 1948 keine Aussicht auf Besserung in der Textilversorgung}

Wie ein schlechter Witz mutet es an, wenn das Göttinger Wirtschaftsamt jetzt zur Aufklärung der ungeduldigen Bevölkerung einige Verhältniszahlen veroffentlicht, die die unhalibare Lage' auf dem Textilsektor schlagartig beleuchten. Aber es ist nur die ungeschminkte bittere Wahrheit, die es den Verantwortlichen unmöglich macht, ihrer Verteileraufgabe auch nur im entferntesten gerecht zu werden. Denn wie kann man von pvertellen" sprechen, wenn die zur Verfügung stehenden Bezugsscheine oder Punkte im Vergleich zum allerdringendsten Bedarf hb̈chstens den Wert einer Groteske haben? Und dabei spiegeln die Zahlen nicht einmal die ganze Not, denn fast die Hälfte aller ausgegebenen Scheine hat sich nicht einlösen lassen, weil der Einzelhandel nicht einmal diese geringen Mengen beschaffen kann. Und dieser Punktuberhang ist auch die Ursache, daB in diesem Jahr bisher nicht das geringste zugetellt wurde, und vor Ablauf des ersten Vierteljahres in Göttingen mit keinem einzigen Textilpunkt zu rechnen ist.

Auf Eleganz achtet heute schon längst keiner mehr; wer kann an einen so entlegenen Zweck der Bekleidung denken, solange die dringendsten Bedürfnisse unbefriedigt bleiben müsser? Wenn 2500 Mănner einen Wintermantel erhalten, bleibt den andern nichts übrig, als weiter zu frieren, Auf je tausend Personen kamen im Jahre 1947 7,3 Anzuge, 4,2 Unterhosen, 2,2 Paar Socken, und die 30 Hemden stellen demgegenuber schon eine kaum faßbare Großzugigkeit dar. Aehnlich bei den Frauen, die sich mit einem Wintermantel, 12,6 Kleidern, 0,8 Taghemden, ganzen $\nabla$ Paar Strümpfen und 5,5 Hüfthaltern zufriedengeben mußten

Die Kinder von 1 bis 8 Jahren scheinen etwas besser daran zu sein, aber was sind 7 Măntel, 230 Sommer- und 25 Winterkleider, 22 Taghemden, 51 Leibchen und 84 Paar Strümpfe für tausend, wenn jeder etwas braucht? Und was soll ein Săugling mit einem Hemdchen (genau 1040), knapp anderthalb Windeln (1450), genau einer zehntel Gummiunterlage und einem füntel Jäckchen? Das Wirtschaftsamt versucht hier vor allem bei Erstgeburten zu helfen, und selbstverständlich hler-zuerst bei Flitchtlingep und anderen, die sich mit nichts behelfen können, weil sie einfach nichts mehr besitzen. Aber im ganzen ist alles nur ein Tropfen auf den heißen Stein!

Das Wirtchaftsamt fühlt sich durchaus nicht wohl als Prediger unermüdlicher Geduld aber es wieibt ihm nicht anderes tibrip. genau so wie der Verbraucher auf das zu warten, was von Minden aus zugewiesen wird.

\section{Universitatsprofessor}

wegien Unterschlagung verurtel

Der 'bisherige Direktớ des Institutes für Jagdkunde und Naturschutz an der Forstl. Fakultát der Universital G ot ingen in $H$ a n n.-M unden, a, o. Professor Dr. Friedrich Kroning, wurde vom Lanagericht Gottingen in der Berufuhgsinstanz wegen Unterschlagung zu drei Monaten Gefängnis verurtellt. Kröning hatte sich aut unrechtmaBige Weise in den Besitz eines Wildschweines gesetzt und das. Fleisch offensichtlich für sich verwenden wollen. $\mathrm{Er}$ war in erster Instanz wegen Diebstahls zu ebenfalls drei Monaten Gefánenis verurteilt worden. Der Verteidiger hatte auf Anwendung des Paragraphen 51 plädiert. Von zwei mit Krơning angeklagten Assistenten erhielt der eine wegen Be angeklagten Assistenten erhielt der eine wegen Begunstigung 200 Mark Geldstrafe. der andere wurde freigesprochen. Kroning ist, wie in der Verhandiung be-

\section{Solides Spiel}

Es ist immer bedenklich, wenn bei Violinsonaten die Ansätze zur musikalischen Gestaltung von der Geige ausgehen. Alice $\mathbf{s}$ ch on f eld (Violine) zeichnete mit aicher. Alichnete mit sicherem Bogenstrich die melodische Linie in den Sonaten Becthovens (Op. 26) und straus inde aur die Einformigkeit des Klaviersplels Helmut indelis belebend elnwirken zu konnen. Mabvolies dunst, wenn die Fulle der Lebensglut noch eben durch den Geis der Form bezwungen wird, und nicht umgekehrt die Form unzulanglich mit Leben muhsam erfunt werden muß: Eln Mangel, der in der Straủß-Sonate den Komponisten, in der Beethoven-Sonate die Interpreten traf Werner Morik

Q21: „Ein Wintermantel für 2500 Männer“, HNN vom 24.02.1948, S. 4. 


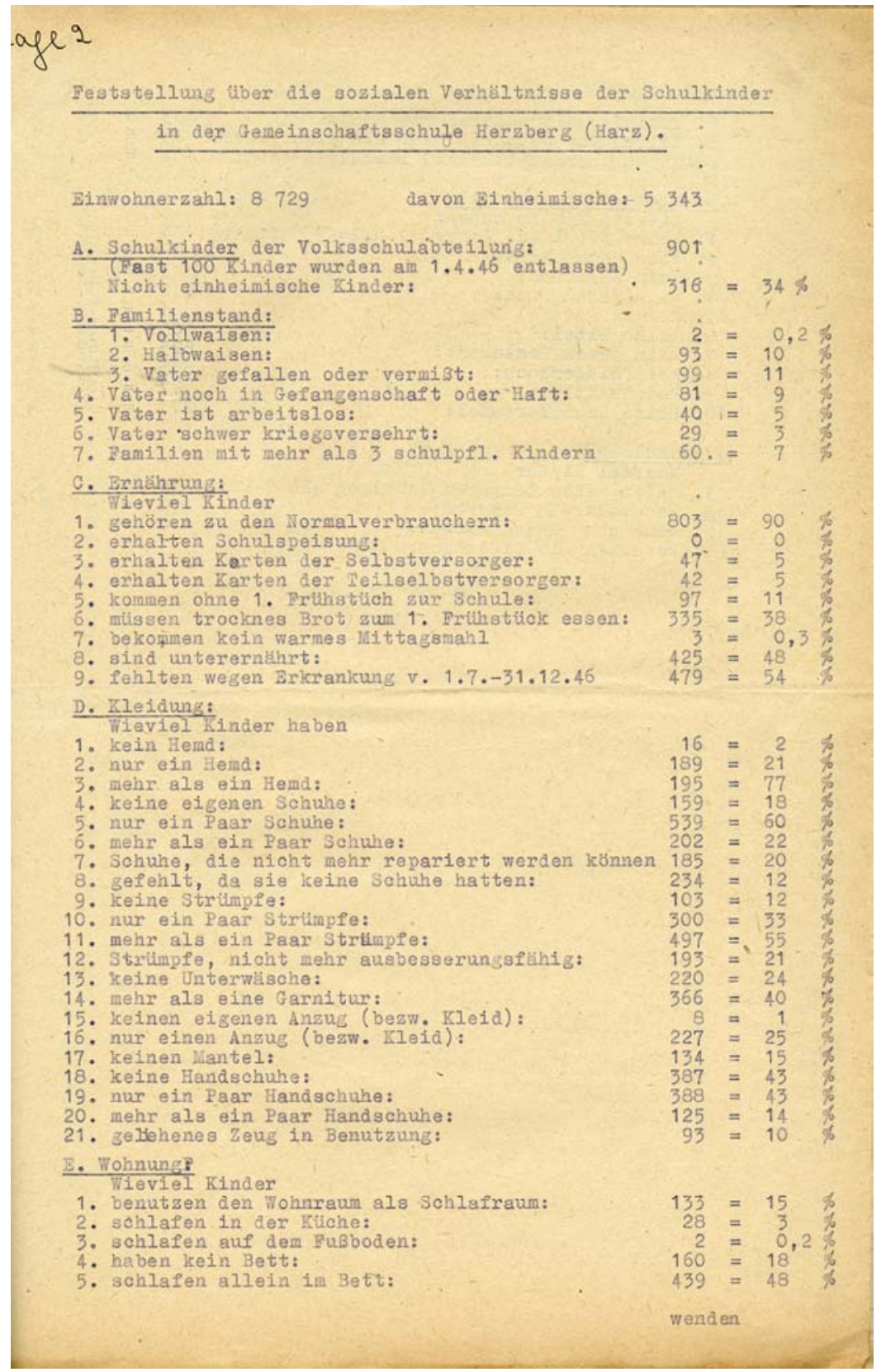

Q22: Feststellung über die sozialen Verhältnisse der Schulkinder in der Gemeinschaftsschule Herzberg (Harz) vom 24.04.1947, NDS. 20 Hildesheim Acc.166/86 Nr. 519, S. 1. 


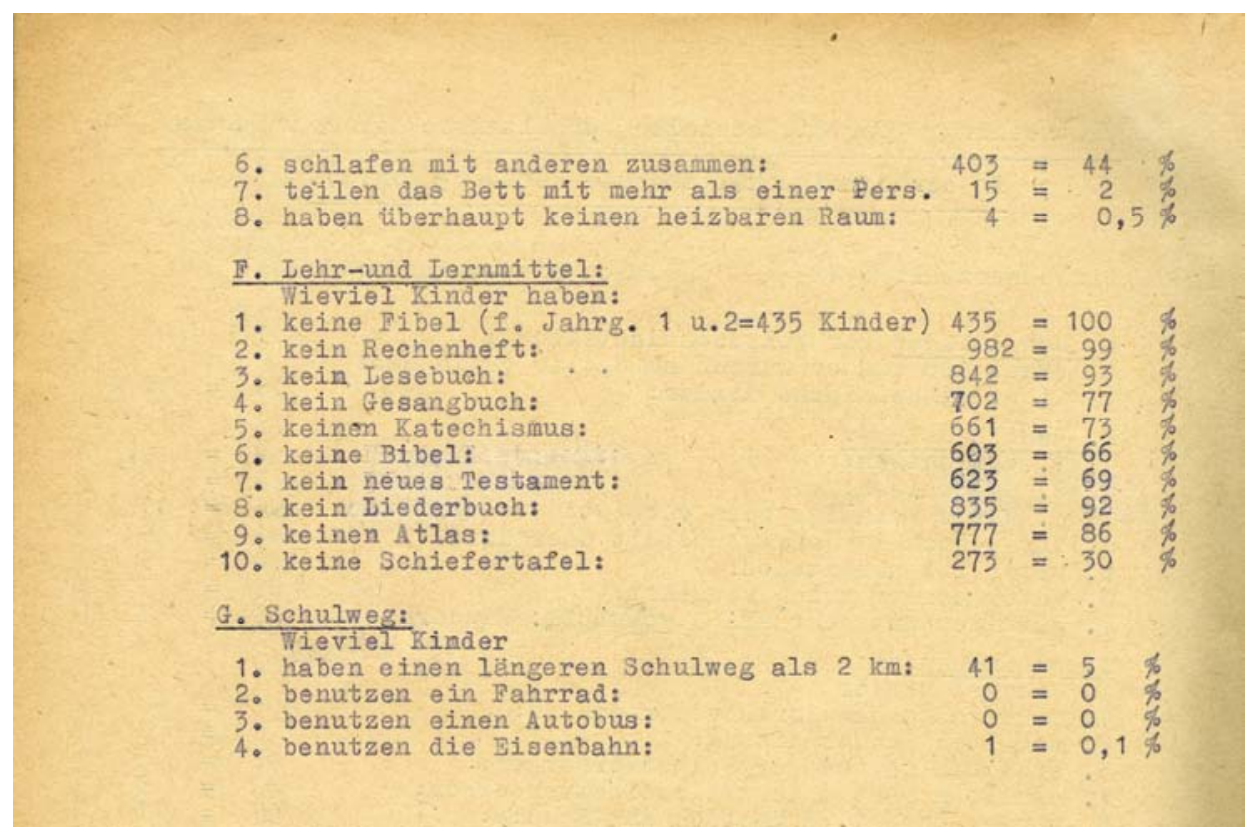

Q22: Feststellung über die sozialen Verhältnisse der Schulkinder in der Gemeinschaftsschule Herzberg (Harz) vom 24.04.1947, S. 2. 


\section{Bücher gegen Alipapier}

hp GOTTINGEN. Nun ist es endich so weit. Nachdem es Schuhkreme, Zahnpasta und 4711 nur noch gegen Altpapier gibt, haben sich bestimmte Verlage diesem Treiben angeschlossen und verkaufen Bücher nur noch, wenn die Buchhandlungen entsprechende Mengen (und nicht geringe!) Altpapier dagegen zu bieten haben. Diese legen das natürlich wieder auf ihre Kunden um, und so sicht sich der Göttinger Student und Wissenschaftler um die letzte Möqlichkeit des. Kaufs der so dringend benötigten Literatur gehracht, weil er einfach soviel Altpapier nicht aufbringen kann. Leider hat sich auch ein Götnnger Verlag den wenig quten Vorbildern angeschlossen. Es ist um so bedaúérlicher, als es sich um ein heute verhältnismäßig wenig begehrtes belletristisches Buch, handelt. Wie uns bekannt ist, bekommen die Verlage Papierzuteilungen für ihre Produktion. Die Forderung nach Altpapier ist also völlig unbegründet.

Q23: „Bücher gegen Altpapier“, HP vom 8.1.1948, S. 4.

\section{Der erste Selst}

Reisende bekannter Schaumweinfirmen boten heute Göttinger Hoteliers nach langen Jahren wieder Sekt an.

Q25: „Der erste Sekt“, HP vom 10.07.1948, S. 4. 


\section{- Grau wie die heutige Wäsche...}

\section{. . . sind die Aussichten auf eine Solfonzutollung}

Die Mittellung der Wirtschaftsverwaltung, daB auch in den Monaten Juli und August keine Waschmittel zugeteilt werden können, hat bei den Hausirauen tiefe Bestürzung hervorgerufen. Das łetzte Stüek Schwimmseife wurde in April aufgeruten, konnte aber nicht einmal an alle Personen aúsgegeben werden, da die Bestände nicht ausreichten. Es gab lediglich für die Monate April, Mai und Juni je 125 Gramm "Seliennoulver". Diese geringe. Menge täll nun auch noch weg. Womit soll sich der arbeitende Mensch waschen? Womit soll et seine Wäsche reinigen?

„Ich schäme mich, meine Wäsche. ster und ich." Der unterernährte ouf die Leine zu hängen", sagt heute braungebrannte Körper hätte eine die Hausfrau, deren Stolz es einmal chemische Reinigung nötig gehabt.

war, ihre schlohweißen Schătze der Nachbarschaft zu zeigen. „Womit soll ich große Wäsche halten? Soll ich das letzte heile Handtucin auch noch mit dem Scheuersand, den man als "Seifenpulver" anzublieten wagt, zerreiben? Seit zehn tahren ist kein neues Stück mehr dazugekommen."

Glücklich die Frau, die am Waschtag, der seit langem schon keine Freude mehr macht, noch diose Antwort geben kann. Wie viele geraten in dumpfe Verzweiflung, wenn sio darạn erinnert werden, daß die Bettwäsche vor acht Wochen aufgezoqen wurde. Wie viele Frauen und Mädchen haben 8 it nur eine einzige Garnitur Unterwäsche, nämlich die, die sie auf dem Körper tragen und aus dem Krieg oder auf der Flucht fetteten. Den Männern geht es nicht besser.

Daß es einmal für dic wohlgebün. delten Wäschestapel-Pflegemittel wie echtes Parsil, Schmier- und Kernseife Bleichsoda, Seifenflocken und Stärke gegeben hat, erscheint ihnen wie ein Märchen, wenn'sie die Wäsche aus dem Korb „angraut”. Die "flüssige Seife", auf die man heute als Notbehelf zurückgreift, enthält etwa dre Prozent Fettsäure. Schmierseife hatte frühẻr 38 bis' 40 Prozent. Flứssige Seife zerstört den Stoff, anstatt ihn zu - reinigen. "Wasserglas, das In állen diesen Chemikalien enthalten ist, zerbricht die Gewebefaser.

Die gründliche Körperreiniqung macht noch größere Schwierigkeiten Ein Stück Schwimmseife reicht höchstens fünf Tage. In fünf Monaten gib es ein Stück. Bei einer ärztlichen Untersuchung antwortete dieser Tage ein schmächtiges Kerlchen: „Womit ich mich wasche? Mutti tut uns einen Löffel Waschpulver in die Schüssel. Aber nicht jeden Tag. Dann waschen wir uns, mein Bruder, meine Schwe-

Anforderung lieferte, Zuteilungen von

1500 Stück und weniger erhält. 50000

Bezugscheine für Rasierseife liegen Wohlfahrt und der Jugendfürsorge diese Unterstützung ermöglicht. Im vergangenen Jahr wurden bei einer ähnlichen Aktion Gewichtszunahmen bis zu 10 Pfund erzielt.

Taqsuber, d. h. von 9 bis $17 \mathrm{Uhr}$, tummeln sich die Kleinen bei frohem Spiel im Garten. des Jugendheims Spiel im Garten. des Jugendheims derungen, sind vorgesehen. Bei schlechtèm Wetter stehen ihnen die Räume im Jugendheim offen.

Die 200 Teilnehmer der Juli-Kur, die im Einvernehmen mit den Schulen und dem Sozialamt ausqewählt sind, wurden von Medizinalrat Dr. Bodtländer ${ }_{-}^{-}$in dessen Hănden auch die ärztliche Betreuung wăhrend der vier Wochen lieqt, auf ihren Gesundheits und Ernährungszustand untersucht. Es soll verhindert werden, daB sich ansteckende Krankheiten, : Ausschlăge usw. unter den Kindern ausbreiten.

Die Arbeiter-Wohlfahrt hat bereits an 5. Maí den ersten Antrag für den vor und 1500 Stück sind da. Wie 6ollen sie gerecht aufgeteilt werden?

Auch die Währungsreform hat an der schlechten Lage nichts geändert" fährt er fort und legt ein Antwortschreiben der Seifenfabrik auf seine Anfrage vom 23. Jun! vor. "Die Fabrik hat keine Bestănde mehr. Nur meine quten Beziehungen machen es, da $\beta$ ich noch einmal 1000 Stück Schwimmseife bekomme - fär hunderttausend Menschen. Wir möchten gern helfen. Der Verbraucher solite sich einmal in unsere Lage versetzen, bevor er schimpit."

Und doch gibt es Ceschäfte, die in diesen Tagen plötzlich wieder Seifen pyramiden im Schaufenster aufgebaut haben.

\section{Ferien im Jugendheim}

hp GOTTINGEN. Die Arbeiter- sofortigen Beginn der Speisung geWohlfahrt Göttingen führt in stellt. Zwei. Monate sind seitdem dẹn Monaten Juli, August, nutzlos verstrichen. Bis heute konnSeptember und Oktoher im Stădit- ten aber noch nicht alle Widerstände schen Jugendheim in der Bürger- der. Stadtverwaltunq, nicht' des Rats. straße eine ganztägige Speisung für beseitigt werden. Das letzte Hinder200 Schulkinder durch. Der Schul- nis 'soll nun durch die Neueinrichtung unterricht fallt für diese Zeit jeweils einer zweiten Küche für die städtiaus. Auslăndische. Spenden haben schen Angestellten, dí im Jugendneben den Zuschüssen der Arbeiter- heim Mittag essen, beseitigt werden.

\section{Göttinger Notizon}

Nach einer Mitteilung der Stadtverwaltung mutssen Gaslstatten ab solort die Preisverzeichinisse - in grokier. lur - Jeden Gast lesbaret Schritt in den Lokaien anbingen. Für tageuszulegen.

Die nächste Ratssitzung findet am Freliag Uhr, in der Volgtschule, Bürger: rabe, statt.

Die Ausstellung „Werke alter Meister" im Musoum am Theaterplatz bleibt weiterhin go. bund angosetzte 6. Abonnementskonzert findet in der zweiten Julihalfto sfatt. Am Preitag spielt für das ausgefallene 3. Abonnengents. konzert um 20 Uhr in der Oberschule f. J. das Sciratiquartett.

Die Erobifnungsvorstellimg des Circus A!thoN findet am 2. Juli, 19 Uhr, auf deru Schützen.

An' 30. Junt wird Hinton Thonias, Dozent der Germazistik an der Universität Birming. ham, auf Einladung des englisch-amerikanischen Kulturkreises taber den deutschen

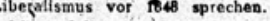

Mitito Juli wird Prof. Butterkield, tet be. Kannte Cambridge-Historiker, als Gast des

Q24: „Grau wie die heutige Wäsche.......sind die Aussichten auf eine Seifenzuteilung،, HP vom 29.06.1948, S. 4. 


\section{Die letzte Schlange}

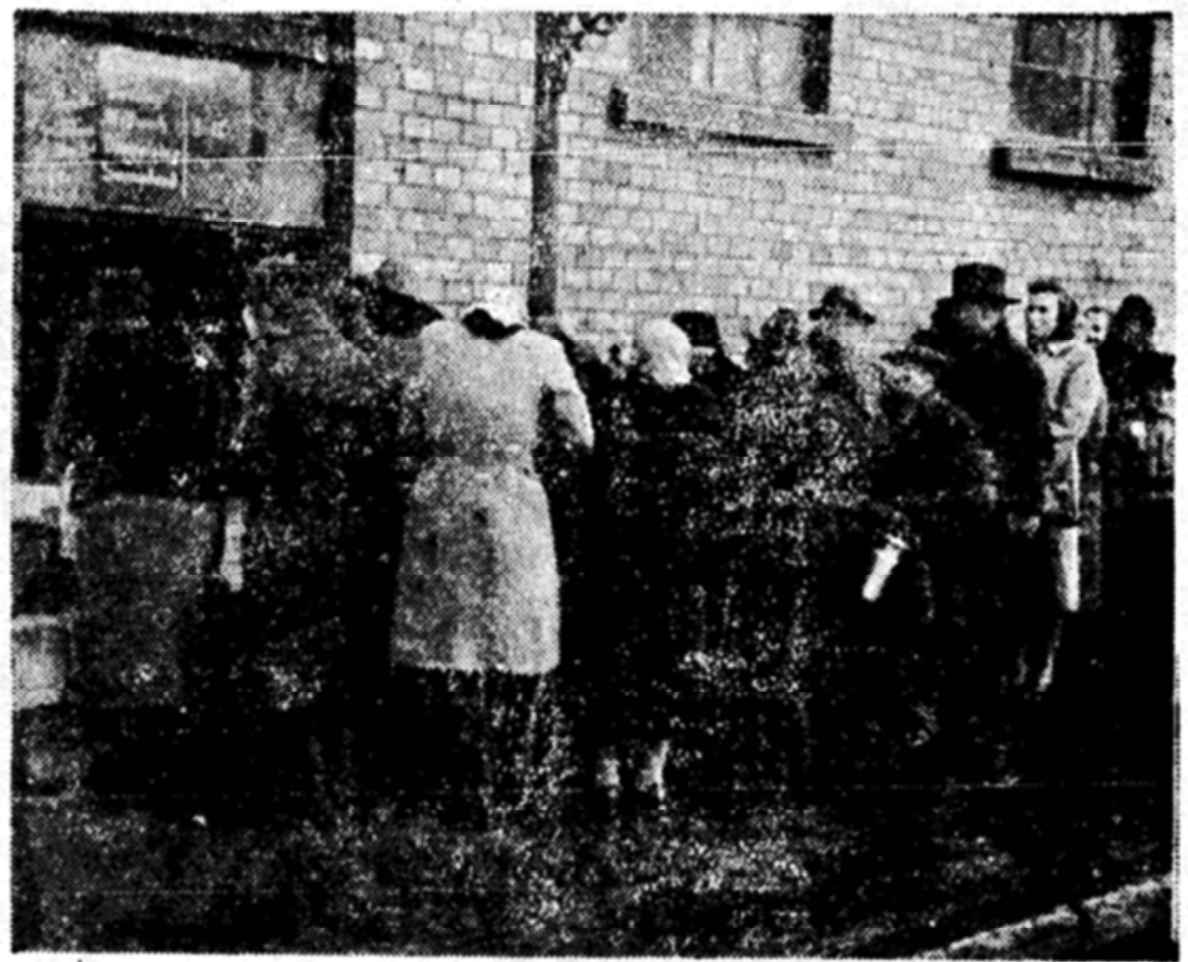

Poto: Kawe

Jeden Tag, an dem beim Städtischen Schlachthol Konserven ausgegeben werden, warten seil den irühen Morgenstunden Frauen aller Stände. Dies ist dic lotzle Schlunge, der man in Göttingen begegnen kann.

Q26: „Die letzte Schlange“, HP vom 22.03.1949, S. 5. 


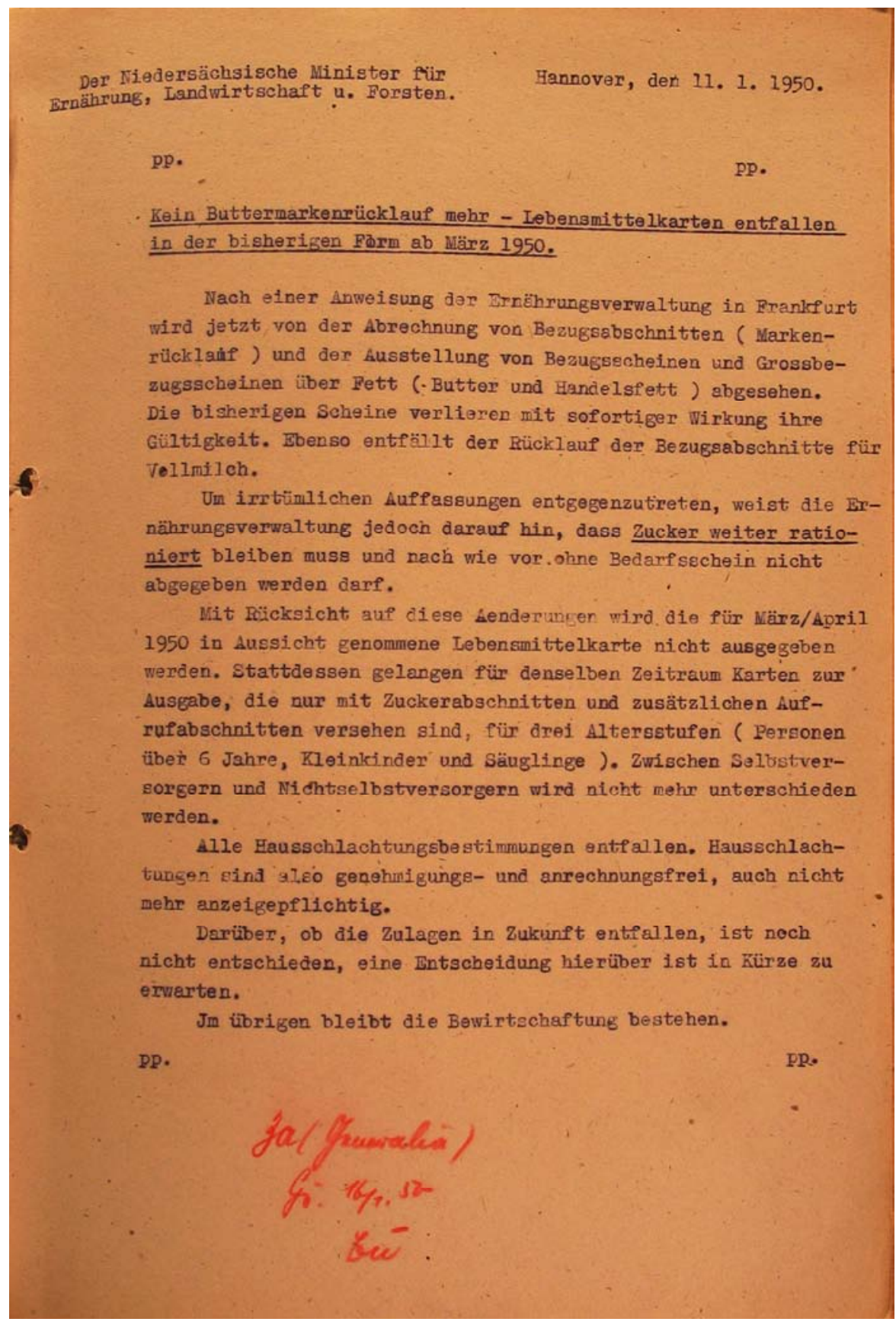

Q27: Lebensmittelkarten entfallen ab März 1950, vom 11.1.1950, Stadtarchiv Göttingen: Ernährungsamt B43, Nr. 10. 


\section{Es gibt wieder alles}

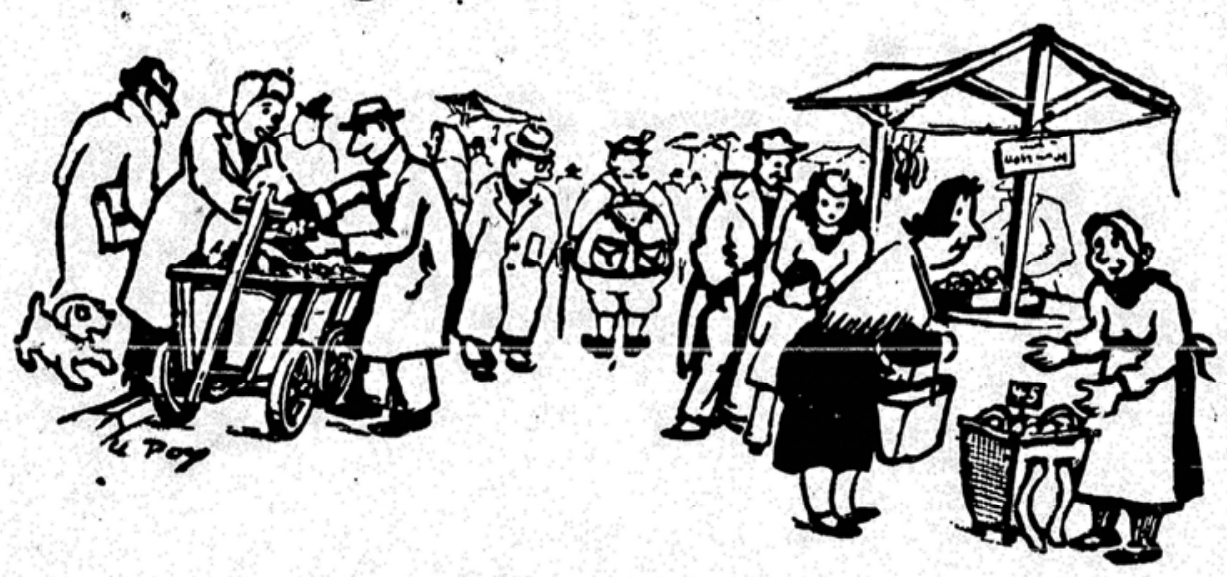

„Noch oln paàr Dier getallig, oder noeh etwas von diesor ausgezeichneten Schwartenwurst?" Dlese Pragen sind auf dem Gsttinget Wochenmarkt wieder alltäglich geworden und wenn man sich dazu entschlieBt, ein halbes Pfund von der Schwartenwurst zu kaufen, dann kann man sogar noch die Frage hören: "Dart es noch etwas mehr sein'"

Wenn nicht alles täuscht, mi Bten wir tatsachlich das Gröbsle hinter uns hajen. Denn auf dem' Göttinger Woekienmarkt herrscht augenblicklich ein reiches Angebot. Die Landfrau mit threr Kiepe voll Eiern und der Stand mit der Hausschlachtewurst sind Jedenfalls ein Zoichen dafür. daß wir langsam wieder zu normalen Verhallenissen kommen. Aber nicht feder kann auch kaufen.

Q28: Karikatur „Es gibt wieder alles“, HP vom 26.03.1949, S. 5. 


\title{
Die Verwaltung des Mangels - Wohnungsnot in der Göttinger Nachkriegszeit
}

\author{
Ulf Gerrit Meyer-Rewerts
}

\section{Einleitung}

Der Zweite Weltkrieg zeitigte eine beispiellose Dynamik von Flucht, Vertreibung und Migration in Europa. Diese enormen Wanderungsbewegungen waren mit dem Ende des Krieges nicht zum Stillstand gekommen, sondern sollten gerade in Deutschland bis in die 50er Jahre fortwirken. Hier kamen zu den Gruppen der „Displaced Persons“ (DP), „Prisoners of War" (POW) und Heimkehrer die Flüchtlinge aus den ehemaligen deutschen Ostgebieten, im Falle der Westzonen außerdem die Flüchtlinge aus der Sowjetischen Besatzungszone hinzu. ${ }^{1}$

Göttingens Situation in der Nachkriegszeit war durch zwei Sonderaspekte gekennzeichnet. Erstens war die Stadt durch alliierte Luftangriffe kaum zerstört worden - gegenüber 1943, als die Stadt noch unversehrt war, sank der Wohnungsbestand bis 1946 nur um 2,2 Prozent. Zum Vergleich: Im stark zerstörten Hannover war dieser Bestand um 49,2 Prozent gesunken. ${ }^{2}$

\footnotetext{
1 Allein DPs gab es Ende 1945 rund 10000 in Göttingen. Siehe hierzu den Artikel von Hagen Stöckmann in diesem Band. Mehr zu den Migrationsbewegungen: Hans-Georg Schmeling, Die überfüllte Stadt, in: Hans-Georg Schmeling (Hg.), Göttingen 1945. Kriegsende und Neubeginn. Texte und Materialien zur Ausstellung im Städtischen Museum 31. März - 28. Juli 1985, Göttingen 1985, S. 105136, hier S. 108-118. Siehe auch: Holger Lüning, Das Eigenheim-Land. Der öffentlich geförderte Soziale Wohnungsbau in Niedersachsen während der 1950er Jahre, Hannover 2005, S. 40ff.

2 Zahlen aus: „Der Wohnungsbestand in den Groß- und Mittelstädten der Britischen Besatzungszone, Anfang 1943 und Anfang 1946“. Stadtarchiv Göttingen Amt für Wohnungswesen, Nr. 221.
} 
Zweitens lag die Stadt nach dem Besatzungswechsel von Amerikanern zu Briten, der bis zum 20. April 1945 weitgehend abgeschlossen ${ }^{3}$ war, zwischen der „Grünen Grenze“ zur SBZ und der Amerikanischen Besatzungszone. Dadurch wurde sie zu einem Flucht- und Durchgangspunkt: Die Einwohnerzahl Göttingens sollte in dieser Folge von knapp 50.000 (1939) auf rund 80.000 (1949) ansteigen. ${ }^{4}$

\section{Die Wohnungspolitik der britischen Militärregierung}

Die britische Besatzungsmacht versuchte schnell, das zunehmende Problem der Unterbringung von Flüchtlingen in den Griff zu bekommen: Am 20. September 1945 erging von der Militär-Regierung im Gebiet Hannover die „Housing Order No 2“: Danach sollten nur die nötigsten Reparaturen an Wohnhäusern durchgeführt werden, was aufgrund des Rohstoffmangels außerdem mit starken Materialbeschränkungen verbunden wurde. In Erwartung eines starken Zustroms von Flüchtlingen setzte die Militärregierung den Wohnraum auf $3,25 \mathrm{~m}^{2}$ pro Person fest (exklusive der Kinder). ${ }^{5}$ Wie auch schon die Zahlen zum Wohnungsbestand (s. o.) deutlich machen, bemühte sich die Besatzungsmacht von Anfang an um möglichst genaue Daten, um die Versorgungslage der Bevölkerung einschätzen zu können. Im Chaos der unkontrollierten Bevölkerungsbewegungen gelang es jedoch nie, exakte Zahlen zu erheben. ${ }^{6}$ Die Göttinger Bevölkerung musste trotz der Versuche, den zerstörten Wohnraum schnell wiederherzustellen, immer enger zusammenrücken. Diese Situation konnten die Zuzugssperre vom 30. Juni 1945 und das kurzzeitige Verbot, die Stadt zu betreten („out of bounds“) am 26. September 1945 nur bis maximal Anfang $1946^{7}$ ein wenig entspannen.

Am 8. März 1946 folgte der für die Wohnraumverwaltung der unmittelbaren Nachkriegszeit wesentliche Erlass, das „Gesetz Nr. 18 (Wohnungsgesetz)“ des Alliierten Kontrollrats. ${ }^{8}$ Dieses stellte den Wohnraum in den Besatzungszonen lückenlos unter die Bewirtschaftung der Wohnungsämter. Somit mussten der Einsatz von Baumaterial und Bauvorhaben von den Besatzungsmächten eingeleitet oder zumindest genehmigt werden. ${ }^{9}$ Es wurden in allen Gemeinden und Kreisen Wohnungsämter und Ausschüsse eingerichtet, der vorhandene Wohnraum sollte

\footnotetext{
${ }^{3}$ Vgl. Wiebke von Thadden, Göttingen und seine Militärregierung, in: Schmeling, Göttingen 1945, S. 78. Überblick zur britischen Besatzungspolitik: Volker Koop, Besetzt. Britische Besatzungspolitik in Deutschland, Berlin 2007.

4 Vgl. Günter J. Trittel, Göttingens Entwicklung seit 1948, in: Rudolf von Thadden/Günther J. Trittel (Hg.), Göttingen. Geschichte einer Universitätsstadt. Band 3. Von der preußischen Mittelstadt zur südniedersächsischen Großstadt, Göttingen 1999, S. 291-356, hier S. 291.

5 Siehe Stadtarchiv Göttingen, Stadtverwaltung und Militärregierung, E57,1, Blatt 3.

${ }^{6}$ Vgl. Hans-Georg Schmeling, Die überfüllte Stadt, S. 120. Die Genauigkeit der Zahlen, die das Sozialamt erhob, ist umstritten.

${ }^{7}$ Vgl. Wiebke Fesefeldt, Der Wiederbeginn des kommunalen Lebens in Göttingen. Die Stadt in den Jahren 1945 bis 1948, Göttingen 1962, S. 70.

8 Siehe Amtsblatt des Kontrollrats in Deutschland, Nr. 5, 31, 3.1946, S. 117-121.

${ }^{9}$ Vgl. Schmeling, Die überfüllte Stadt, S. 118.
} 
erfasst und verteilt werden. ${ }^{10}$ Die (Wieder-)Herstellung von Wohnraum konnte mit den Flüchtlingsströmen, die sich gegen Ende des Jahres 1945 verstärkten, jedoch nicht Schritt halten; den Unmut der Bevölkerung provozierten außerdem die umfangreichen Beschlagnahmungen, die schon mit der amerikanischen Besatzung eingesetzt hatten. Schulen, Restaurants, Kasernen und andere halböffentliche Räume wurden z. T. von DPs bewohnt, auch fanden Beschlagnahmungen zur Unterbringung Göttinger Studenten statt ${ }^{11}$ und für die Zwecke der Besatzer selbst. In den ersten Nachkriegsmonaten waren davon zeitweise rund 1000 Wohnungen betroffen ${ }^{12}$ - auch die Nachkriegspresse nahm durchaus Notiz von der Problematik $^{13}$, obwohl kritische Töne darin aufgrund der alliierten Zensur zunächst eher die Ausnahme waren. ${ }^{14}$

\section{Sozialer Stress, Platzmangel, Genehmigungsschreiben: Göttinger Wohnalltag in der Nachkriegszeit}

Soziale Spannungen waren an der Tagesordnung. Die Notsituation der Bevölkerung in einer weitgehend intakten Stadt wie Göttingen brachte zwei entgegengesetzte Wahrnehmungen hervor, die die Integration der Flüchtlinge erschwerten: Die Göttinger Einwohner sahen sich in ihren Besitz- und Platzansprüchen bedroht, während die Flüchtlinge ihre Heimat und ihren Besitz verloren hatten und sich trotzdem - selbst unter ihren Landsleuten - nicht willkommen sahen. ${ }^{15}$ Die teils ohne Wissen der Militärregierung Zugezogenen, die von den Behörden nicht weitergeschickt wurden in das Lager Friedland ${ }^{16}$ oder in Gebiete mit einer geringeren Bevölkerungsdichte, stießen - gewollt oder ungewollt - tief in die Privatsphäre der Stadtbevölkerung vor. Der begrenzte Wohnraum pro Person (s. o.) bedeutete, dass jeder Raum, zumindest aber jede Wohnung mit mehreren Wohnparteien belegt wurde. Ein Zeitungsbericht von 1948 spricht von 1,5 Personen pro Raum (Q1) - der Artikel zeigt zugleich, wie zäh und ungerecht Streitigkeiten um Wohn-

\footnotetext{
${ }^{10} \mathrm{Vgl}$. Lüning, Eigenheim-Land, S. 44ff.

11 Vgl. Jens-Uwe Brinkmann, „Das Vorlesungsverzeichnis ist noch unvollständig...“. Der Wiederbeginn an der Georgia-Augusta, in: Schmeling, Göttingen 1945, S. 309.

${ }_{12}$ Mehr zu den Beschlagnahmungen: Schmeling, Die überfüllte Stadt, S. 106-108; Wiebke von Thadden, Die Stadt Göttingen unter Militärverwaltung 1945 - 1947, in: Böhme, Göttingen, S. $281 \mathrm{ff}$.

13 Z. B. in der Hannoverschen Volksstimme vom 31.1.1947 der Artikel „Wieder Beschlagnahmung“. Stadtarchiv Göttingen Film Ztg. 629.

14 Vgl. Hans-Georg Schmeling, Göttinger Nachkriegsalltag 1945, in: Schmeling, Göttingen 1945, S. 190.

15 Vgl. Thomas Grosser/Sylvia Schraut, Vertriebene, in: Werner Weidenfeld/Karl-Rudolf Korte (Hg.), Handbuch zur deutschen Einheit. 1949 - 1989 - 1999, Bonn 1999,S. 829-838, hier S. 831ff.; Fesefeldt, Wiederbeginn, S. 72.

${ }_{16}$ Mehr zum Lager Friedland: Dagmar Kleineke, Entstehung und Entwicklung des Lagers Friedland 1945-1955, Göttingen 1994; Helga Hagelüken/Rainer Rohrbach, Hilfe in der Not. Friedland 1945, in: Schmeling, Göttingen 1945, S. 137-148. Bis Ende September 1945 hatten bereits rund 820000 Flüchtlinge das Lager passiert, was einen Eindruck vom Umfang der Migration gibt. Siehe Fesefeldt, Wiederbeginn, S. 71.
} 
raum werden konnten: Viele arteten in Kleinkriege zwischen Nachbarn auf engstem Raum aus. Dabei befanden sich sowohl die Flüchtlinge als auch die Göttinger in einer beklemmenden Situation, und entsprechend verhielten sich beide Seiten nicht immer tadellos. Besonders der Fall der Frau B. (Q2-4) macht deutlich, wie groß die Belastung durch Einquartierungen werden konnte - bis hin zu einem mutmaßlichen Selbstmordversuch.

Im Dezember 1945 machten die Flüchtlinge 27,5 Prozent der deutschen Stadtbevölkerung aus. ${ }^{17}$ Einquartierungen fanden ungeachtet persönlicher Sympathien, der beruflichen Situation ${ }^{18}$ und privater Wünsche statt. Neben den Einwohnern gab es auch seitens der Wohnungseigentümer starke Bedenken gegen die Einweisung Fremder in ihre Objekte, zumal durch die Überbelegung häufig nicht nur das Mobiliar der eigentlichen Mieter, sondern auch die Substanz des Hauses insgesamt litt. Insofern stießen selbst Versuche der Flüchtlinge, ihr Leben in den provisorischen Unterkünften erträglicher zu gestalten, auf Widerstand: Die Installation von Notöfen beispielsweise wurde erst durch den Druck der Militärregierung möglich ${ }^{19}$. Gleichzeitig war diese darauf angewiesen, dass frei gewordener Wohnraum auch ordnungsgemäß gemeldet wurde: Auf den 25. Dezember 1945 datiert ist eine Anweisung darüber, dass an jeder Tür ein Anschlag mit Informationen über Bewohner und mögliche freie Räume des Hauses angebracht werden sollte. ${ }^{20}$ Die „Verordnung zur Durchführung des Gesetzes Nr. 18“ vom November $1947^{21}$ schrieb die Meldepflicht freien Wohnraums unter Androhung von Strafen fest. Wie konsequent Verstöße gegen diese Anweisung geahndet wurden, ist nicht überliefert; möglich waren Strafen bis zu 10.000 Reichsmark oder einem Jahr Gefängnis.

Die Nachkriegszeit war eine Phase des blühenden Schwarzmarkthandels. ${ }^{22}$ Auch die illegalen Flüchtlinge ${ }^{23}$ mussten sich - irgendwie - einen Platz zum Leben verschaffen. Die so genannten „Schwarzwohner“ sollten nicht nur durch die Androhung von Strafen dazu gebracht werden, sich bei den Behörden zu melden das Problem des illegalen Zuzugs erklärt auch die Anweisung des Stadtkommandanten Bankart, Umzugsformulare nur außerhalb Göttingens drucken zu lassen. ${ }^{24}$

\footnotetext{
${ }^{17}$ Zahlen aus: Hans-Georg Schmeling, Die überfüllte Stadt, in: Schmeling, Göttingen 1945, S. 133.

18 Wie z. B. die Quellen zu dem Physiker Dr. Möller zeigen: Stadtarchiv Göttingen, Amt für Wohnungswesen, Nr. 153, Teil 1, Blätter 44, 71, 72, 73. Dr. Möller klagte gegen die Beschlagnahmung des zweiten Zimmers in seiner Wohnung. Er gab an, dies als freiberuflicher Physiker für seine Experimente zu brauchen.

19 Vgl. Stadtarchiv Göttingen, Stadtverwaltung und Militärregierung, E57, 1, Blatt 58.

${ }^{20}$ Stadtarchiv Göttingen, Stadtverwaltung und Militärregierung, E57, 1, Blätter 23, 35.

${ }^{21}$ Entwurf im Stadtarchiv Göttingen, Stadtverwaltung und Militärregierung, E57, 2, Blatt 10.

22 Mehr dazu im Artikel von Karolin Oppermann in diesem Band. Außerdem: Alfred Oberdiek. Nicht Kaufen, sondern Tauschen war 1945 die Devise. in: Schmeling, Göttingen 1945, S. 199 ff.

${ }^{23}$ Es existieren keine Zahlen; wegen des akuten Platzmangels dürften jedoch nur relativ wenige eine Unterkunft in der Stadt gefunden haben, zumal damit die Möglichkeit, sich zu verstecken, kaum gegeben war.

${ }^{24}$ Stadtarchiv Göttingen, Stadtverwaltung und Militärregierung, E57,1, Blatt 161.
} 
Die Nachfrage nach solchen Formularen ging offenbar deutlich über das verfügbare Maß hinaus, weswegen Maßnahmen gegen Fälschungen getroffen wurden.

Wer auf legalem Wege versuchte, Wohnraum in der Stadt zugewiesen zu bekommen, musste eine Zuzugsgenehmigung beantragen. Die vorliegende Quelle zeigt den Antrag einer Flüchtlingsfamilie aus Schlesien (Q5). Anträge von Familienmitgliedern, die außerhalb Göttingens wohnten und zu ihren Angehörigen ziehen wollten, wurden nicht vorrangig behandelt. Familienzusammenführungen hatten nach dem „Wohnungsgesetz“ keine Priorität; die Berücksichtigung erfolgte aufgrund sogenannter „Dringlichkeitsstufen“. An erster Stelle standen im Nationalsozialismus politisch Verfolgte oder Benachteiligte bzw. Personen, die dem Regime Widerstand geleistet hatten; in der Praxis wurden weiterhin gesundheitsgefährdete Personen und die Räumung der Notquartiere vorrangig behandelt. ${ }^{25}$

Stadtverwaltung und Bevölkerung versuchten auch dort Wohnraum nutzbar zu machen, wo es vorher keinen gegeben hatte. Im Göttinger Stadtarchiv finden sich Fälle wie ein Antrag auf Nutzbarmachung einer geplünderten Wohnung im Göttinger Schwimmbad ${ }^{26}$, der einer Familie, die einen Kohlenkeller bewohnt (Q6), von Wohnungen, deren Beschlagnahmung in Abwesenheit des Mieters drohte (Q7-8) ${ }^{27}$ oder von Plänen zum möglichst schnellen Ausbau von Kasernen. ${ }^{28}$ Diese zum Teil hektischen, aus der Not geborenen Maßnahmen und Reaktionen zeigen: Der Platzmangel war neben der Lage auf dem Arbeitsmarkt und der Ernährungslage das Problem, das die Mehrheit der Bevölkerung tagtäglich am stärksten in ihren vitalen Bedürfnissen bedrohte.

Ein Zeitungsartikel aus den Hannoverschen Neuesten Nachrichten vom 10. Mai 194929 berichtet über eine „Werbewoche“ zur TBC-Bekämpfung und vom Zusammenhang zwischen der Wohnungsnot und dem Anstieg der Zahl der Tuberkulosekranken; „Tuberkulose als Volkskrankheit“ lautete der Titel einer gehaltenen Rede. ${ }^{30}$ Krankheiten verbreiteten sich unter den auf engstem Raum lebenden Menschen schneller, und auch die medizinische Versorgung konnte den Erfordernissen kaum entsprechen. In der Tat war das Wohnraumproblem nicht das einzige Platzproblem: Ebenso schwierig gestaltete sich die Unterbringung öffentlicher Einrichtungen wie Kranken- und Waisenhäusern, die die Versorgungslage der Bevölkerung betrafen. Es konnten nicht genügend Praxisräume geschaffen werden $^{31}$ und auch Krankenhausbetten waren Mangelware, was in Anbetracht der

\footnotetext{
${ }^{25}$ Das Gesetz erwähnt außerdem als bevorzugte Gruppen: Kinderreiche, Alte, Invalide u. körperlich Behinderte sowie Facharbeiter (bei Mangel an solchen). In der Praxis wurden außerdem bei der Besatzungsmacht Beschäftigte häufig bevorzugt behandelt. Fallbeispiel unter Stadtarchiv Göttingen, Stadtverwaltung und Militärregierung, E57,1, Blatt 349.

${ }^{26}$ Stadtarchiv Göttingen, Stadtverwaltung und Militärregierung, E57,1, Blatt 404.

27 Siehe auch: Stadtarchiv Göttingen, Stadtverwaltung und Militärregierung, E57,1, Blätter 55, 69.

28 Stadtarchiv Göttingen, Stadtverwaltung und Militärregierung. E57,1, Blatt 338.

${ }^{29}$ Stadtarchiv Göttingen Film Ztg. 624, Ausgabe Süd-Hannover, S. 3.

${ }^{30}$ Vgl. Quellen 7-8: Die Tuberkuloseerkrankung des Sohnes der Frau Katrakis stellt keinen Grund zu einem Wohnungswechsel dar, solange es sich nicht um eine ansteckende Variante handelt.

31 Vgl. Schmeling, Die überfüllte Stadt, S. 133.
} 
vielen Flüchtlinge, die sich in einer schlechten körperlichen Verfassung befanden, besonders dramatisch war. Die deutschen Stadtbehörden, die die laufenden Geschäfte der britischen Militärregierung erledigten, ${ }^{32}$ zeigten hier Eigeninitiative: Sie mieteten das Gasthaus der Brauerei Rohns und richteten ein Hilfskrankenhaus ein, ${ }^{33}$ und in einer Baracke in Eddigehausen entstand das Flüchtlingswaisenhaus „Kinderheimat“, 34 beides bereits im Jahr 1945.

Die britische Militärregierung traf zwar die maßgeblichen Regelungen und konnte den gesetzlichen Rahmen festlegen, auf der Verwaltungsebene war sie jedoch auf deutsches Personal angewiesen, genauso wie auf Facharbeiter und die Initiative der Stadtbevölkerung, die für den Wiederaufbau und Neubau von Wohnraum immer wichtiger wurde.

\section{Bevölkerungsinitiative, Sozialer Wohnungsbau und die „Siedlung am Hagenberg““}

Der Materialmangel und das Quasi-Verbot der Militärregierung für Neu-, Aus- und Umbauten führten dazu, dass neuer Wohnraum in einem wesentlichen Umfang in ganz Niedersachsen erst um 1949/50 entstand. ${ }^{35}$ Das Primat lag zunächst bei der Wiederherstellung beschädigten Wohnraums, und das „Wohnungsgesetz“ (s. o.) hatte keinerlei direkte Regelungen für die Erstellung neuer und dauerhafter Unterkünfte getroffen. So beschränkte sich die Bautätigkeit der ersten Nachkriegsjahre auf Behelfsunterkünfte wie Baracken (s. o.) oder „Nissenhütten“.

Seit 1945 bemühte sich die „Göttinger Nothilfe“ als Hilfsinitiative darum, Flüchtlinge einzukleiden und ihnen zumindest für eine Nacht eine Ruhestätte zu verschaffen: Sie betreute u.a. ein Auffanglager in der Egelsbergschule ${ }^{36}$ und bis 1946 die Flüchtlinge, die in den damals am Bahnhof befindlichen Baracken lebten. ${ }^{37} \mathrm{Im}$ Lager Friedland, wo sich auch die studentische „Friedlandhilfe“ der Göttinger Universität engagierte, ${ }^{38}$ durften sich die Flüchtlinge aufgrund des hohen Andrangs höchstens 36 Stunden aufhalten, bevor sie weiterziehen mussten.

Während die Bautätigkeit also nur langsam voranging, stieg die Zahl der Flüchtlinge in Göttingen kontinuierlich. Waren es im April 1945, als Göttingen unter britische Verwaltung kam, noch rund 10.500 gewesen, stieg ihre Zahl bis Dezember 1946 auf knapp 24.000 an. ${ }^{39}$ Dieser Trend setzte sich in den nächsten

\footnotetext{
32 Mehr zu den administrativen Strukturen in der Göttinger Nachkriegszeit: Wiebke von Thadden, Göttingen und seine Militärregierung, S. 69ff.

${ }^{33}$ Schmeling, Die überfüllte Stadt, S. $121 \mathrm{ff}$.

${ }^{34}$ Ebd., S. $128 f f$.

35 Vgl. Lüning, Eigenheim-Land, S. 49ff. Dies hing auch mit der Währungsreform zusammen.

36 Später wurde daraus ein weiteres Hilfskrankenhaus.

${ }^{37}$ Mehr zur „Göttinger Nothilfe“: Fesefeldt, Wiederbeginn, S. 65ff.; Hannah Vogt, Die „Göttinger Nothilfe" - eine frühe Bürgerinitiative, in: Schmeling, Göttingen 1945, S. 205-214.

38 Brinkmann, Vorlesungsverzeichnis, S. 312ff.

39 Vgl. Schmeling, Die überfüllte Stadt, S. 135.
} 
Jahren fort: Im Januar 1948 registrierten die „Statistischen Berichte der Stadt Göttingen" ${ }^{40} 3.575$ noch unterzubringende Personen. Im Januar 1951 sollten es schon 14.101 Personen sein, und im Januar 1954 sogar 20.418.41

Die bloße Wiederherstellung bzw. der Ausbau vorhandenen Wohnraums waren also völlig unzureichend. Mit der Gründung der Bundesrepublik im Mai 1949 wurde zwar der Soziale Wohnungsbau forciert ${ }^{42}$, womit die Phase der Provisorien und Eigenbauten der ersten Nachkriegsjahre bald ihrem Ende entgegenging. Dennoch griffen die Mittel in einer Stadt mit derart stark gewachsener Bevölkerung wie Göttingen nicht schnell genug, um alle Einwohner menschenwürdig unterzubringen. So war auch 1949 noch Initiative „von unten“ gefragt. In diesem Jahr begann der Bau der „Siedlung am Hagenberg“, vom 31. Juli bis zum 25. September unter Mithilfe der Organisation „Service Civil International“ (SCI) (Q9-11). Die 38 z. T. ausländischen Teilnehmer des Internationalen Zivildienstes halfen beim Bau dieser Nachkriegssiedlung. ${ }^{43}$ Baumaterialien und ein Teil des Kapitals wurden zuvor in einer „Werbeaktion“ einer Göttinger Bürgerinitiative gewonnen (Q12-13).

Die Wohnungsbautätigkeit stieg seit den 50er Jahren kontinuierlich an. Während für das erste Halbjahr 1947 in ganz (!) Niedersachsen nur 60 Zweifamilienhäuser, 30 Vierfamilienhäuser und 125 ausgebaute Dachgeschosse geplant waren, ${ }^{44}$ wurden allein im Jahr 1954 nur in der Stadt Göttingen insgesamt 723 Wohnungen fertig gestellt. ${ }^{45}$ In Anbetracht der oben beschriebenen anhaltenden Flüchtlingsströme und Umsiedlerströme war zwar auch dieser signifikante Anstieg des Wohnungsbaus lange Zeit nicht ausreichend, ${ }^{46}$ doch spätestens mit der Fertigbauweise vorprojektierter Wohnblocks in den 1960er und 1970er Jahren, die sich in Göttingen heute z. B. in Grone finden, nahm die Wohnungsnot ein Ende.

\footnotetext{
40 Stadtarchiv Göttingen, Statistische Berichte (Monatsberichte) der Stadt Göttingen 1948 - 1958, ZA 10.

${ }^{41}$ Die hohe Zahl erklärt sich z. T. daraus, dass unter die Statistik auch Personen fielen, die lediglich den Wohnort wechseln wollten und entsprechend bereits eine Unterkunft außerhalb Göttingens hatten (die Relation wird aus den Berichten nicht ersichtlich). Dennoch wird deutlich, dass der Zuzug nach Göttingen noch bis Mitte/Ende der 1950er Jahre stark anstieg.

${ }^{42}$ Das Erste Wohnungsbaugesetz vom 24.4.1950 unterschied „den öffentlich geförderten Sozialen Wohnungsbau, den steuerbegünstigten und den frei finanzierten Wohnungsbau“". Lüning, S. 72.

43 Service Civil International. International Archives. B (49 0925 - 1 01). Online einsehbar unter: http://www.service-civil-international.org/index.php?page $=$ collection-germany-list $\& \mathrm{f}=0 . \quad$ Stand: 12.3.2009.

${ }^{44}$ Vgl. Lüning, Eigenheim-Land, S. 51. Zur gleichen Zeit wurden 812 „Nissenhütten“ geplant.

${ }^{45}$ Stadtarchiv Göttingen, Statistische Berichte (Monatsberichte) der Stadt Göttingen 1948 - 1958, ZA 10.

${ }^{46}$ Erst in den 1960er Jahren wurde das Vorkriegsniveau von 3,5 Einwohnern pro Wohnung (1939) wieder erreicht. Vgl. Trittel, Entwicklung, S. 308.
} 


\section{$5 \quad$ Fazit}

Insgesamt ist herauszustellen, dass die beklemmende Wohnsituation im Nachkriegs-Göttingen mit der besonderen Lage der Stadt zwischen den Zonengrenzen und ihrem niedrigen Zerstörungsgrad korrelierte. Damit unterscheidet sich die Göttinger Nachkriegssituation erstens von der der meisten größeren deutschen Städte, die durch Bombardements oft stark zerstört waren; zweitens erklärt sich daraus das starke Wachstum der Einwohnerzahl. Das „Eindringen“ der Flüchtlinge in einen weitgehend intakten Stadtkörper war ein zusätzliches Hindernis für die Integration.

Die Schaffung von Wohnraum durch Wiederauf- und Ausbau fand vor dem Hintergrund der strengen Wohnungsgesetze der britischen Militärregierung statt. Der Neubau von Wohnraum - und damit die Möglichkeit, die Flüchtlinge dauerhaft zu integrieren - setzte erst mit Gründung der Bundesrepublik ein. In beiden Phasen ist die Initiative aus der Bevölkerung nicht zu unterschätzen. Die relativ schnelle Übertragung von Eigenverantwortlichkeit an Deutsche auf den unteren Verwaltungsebenen förderte die oben genannten Initiativen.

\section{Literatur zum Weiterlesen}

Rudolf von Thadden/Günther J. Trittel (Hg.), Göttingen. Geschichte einer Universitätsstadt. Band 3. Von der preußischen Mittelstadt zur südniedersächsischen Großstadt, Göttingen 1999.

Wiebke Fesefeldt, Der Wiederbeginn des kommunalen Lebens in Göttingen. Die Stadt in den Jahren 1945 bis 1948, Göttingen 1962.

Hermann Glaser, So viel Anfang war nie. Deutsche Städte 1945 - 1949, Berlin 1989.

Volker Koop, Besetzt. Britische Besatzungspolitik in Deutschland, Berlin 2007.

Hans-Georg Schmeling (Hg.), Göttingen 1945. Kriegsende und Neubeginn. Texte und Materialien zur Ausstellung im Städtischen Museum 31. März - 28. Juli 1985, Göttingen 1985. 


\section{Herr M. sucht eine Wohnung}

Das Wohnungsamf steht machtlos vis-à-vis

In der Stadt Göttingen wird ein Raurn nach Erhebungen des Wohnungsamtes von 1,5 Personen bewohnt. Was sich hinter dieser Durchschnittszahl verbirgt, erleble der hp-Reporter bef sinem Besuch in einem Nolquarller der Dringlichkeitsstufe 1 in der Unteren Karspüle.

Im Juni 1945 kam Frau B. mit acht Kindern als Flüchtling nach Guttingen, um in ihrem Haus in der Unteren Karspüle, das ihr durch Erbschaft zu einem Teil zugefallen war, unterzukommen. Der Mieter M. war aber nicht bersit, der kinderreichen Familie ein unbewohntes Zimmer zu räumen. Frau B. mußte für zehn Tage ins Flüchtlingslager, bis das Bergungsamt eingriff. In dieser Zeit starb das jüngste Kind. Nach sechs Monaten gelang es der schwergeprüften Mutter, einen zweiten Raum dazuzubekommen. Nachdem der Mann im Juni 1946 aus franzỏsischer Kriegsgefangenschaft zurückgekehrt war, hausten neun Personen auf einer Wohnfläche von 31 Quadratmetern. Der Mieter $\mathbf{M}$. im ErdgeschoB hatte mit zwei Personen. bevor er die Familie des Schwiegersohnes zufnahm, fünf Răume zur Verfügung.

Seit April 1947, als sich wegen der hohen Kinderzahl sämtliche Aussichten für den Mann zerschlagen hatten. auBerhalb Göttingens eine Anstellung zu finden, wurde die Familie ununterbrochen beim Wohnungsamt vor steilig, um eine Umquartierung des Mieters $M$. zu erreichen. $\mathrm{Da}$ dieser sich jedoch ständig weigerte, au Vorschlăge des Wohnungsamtes einzugehen und fortfuhr, seine Vermieter als Untermieter zu bezeichnen, kam es zu einer Răumungsklage, die unverstăndlicherweise mit einem Vergleich endete. Der Mieter verpflich. tete sich darin, auszuziehen, wenn ihm eine andere angemessene Wohnung gegeben würde. Dreimal hat ihm das Wohnungsamt in letzter Zeit drei Zimmer mit Küche angeboten, die wohl angemessen waren, aber nicht der Vorstellung entsprachen, die Herr $M$. von seinem neuen Heim hatte.

Als M. von einem Angestellten des Wohnungsamtes gebeten wurde, ein Formular über seinen Familienstand ausszufüllen, lehnte er dies $a b$ mit der Begründung, er sei es ja nicht, der eine Wohnung suche. Ein Schrei- ben an das Wohnungsamt nech dem gerichtlichen Vergleich enthielt wieder die alte Auslegung, das $\varepsilon ;$ keine Wohnung beantragt habe, sondern lediglich seinen "Intermietern" hilfreiche Hand leisten wollte. Welch" schöne Worte. Der Untermieter ist Eigentümer des Hauses.

Inzwischen verstrich Monet auf Monat, in denen sich die Familie B. wiederum um einen Erdenbürger vermehrte, ohne daB es eine gesetzliche Handhabe gab, den Mieter zu be. wegen, seine leeren Versprechunge: in die Tat umzusetzen.

In der Unteren Karspüle sind die Tapeten lāngst von den Wānden gefault. Auf dem Behelfsherd kocht das tăgliohe Essen fūr zehn Personen. Die Kleinsten lärmen im Laufstall. Andere versuchen Schularbelten zu machen. Alle sind sie gesundheitlich schwer gefährdet. Ein Eltern-, drel Kinder. schlafzimmer, ein Wohnraum und eine Küche stehen ihnen rechtmäBig zu. Es wird höchste Zelt, daB dieser Schandfleck für Göttingen auf dem Wege der Zwangsvollstreckung be. seitigt wird, ehe die angekfindigten Dānemarkflûchtlinge dem Wohnungs amt neues Kopfzerbrechen bereiten.

Q1: Stadtarchiv Göttingen, Film Ztg. 628, Hannoversche Presse, Ausgabe Göttingen Stadt, 2. November 1948. 


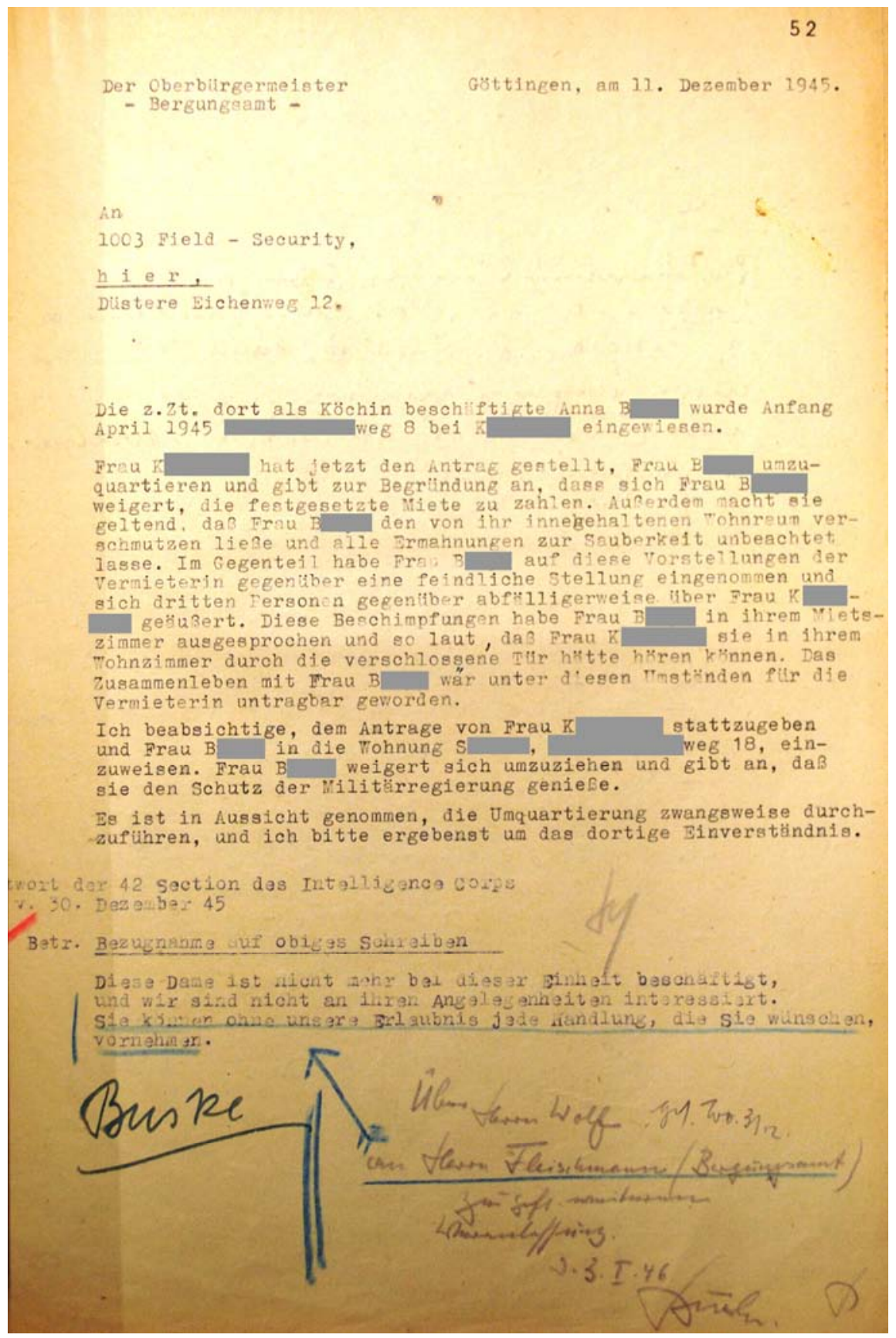

Q2: Stadtarchiv Göttingen, Stadtverwaltung und Militärregierung, E57,1, Blatt 52. 


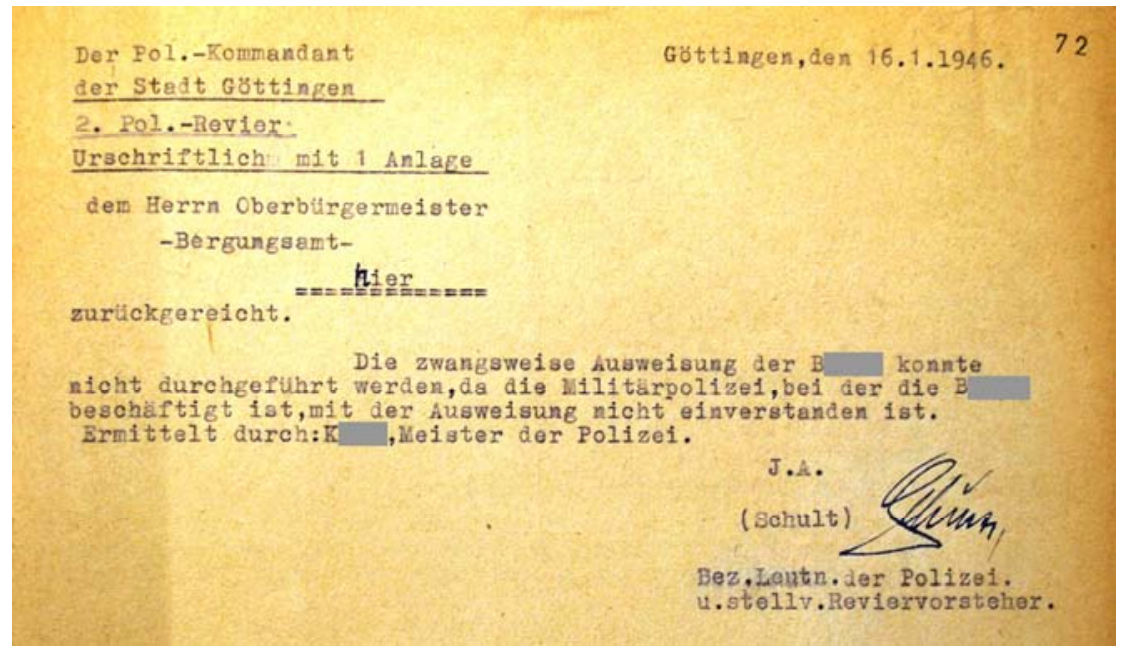

Q3: $\quad$ Stadtarchiv Göttingen, Stadtverwaltung und Militärregierung, E57,1, Blatt 72.

NIEDERSACHSISCHE VOLKSSTIMME

\section{Kohlenkeller als Wohnraum}

Göttingen (Eig. Ber.) Dem Pförtnerhaus Fläche mehr freizumachen, um Wintervordes Reichsbahnzentralamtes schräg gegenüber, räte z: lagern.

befindet sich ein zum Teil zerstörtes Gebäude. Mit dem Wohnungsamt hat sich M. selbstDer linke Flügel dieser halbzerstörten Bau- versțändlich schon öfters in Verbindung gelichkeit, diente früher dazu, die Kohlen bezw. setzt. Dort wurde inm lediglich der Trost den Koks für die gleichfalls zerstörte zutell, daß er mit seiner Familie in die Heizungsanlage aufzunehmen. Heute beher- Dringlichkeitsgruppe II eingestuft werden bergt dieser Raum die Familie M. Vater, könne, um dann evt. später, wenn die Reihe Mutter, eine 20jährige Tochter und der der vor ihm befindlichen untergebracht ist, 23jährige Sohn essen schlafen und bewegen auch eine andere Wohnung zugewiesen zu sich in einem Raum Die Tcil tte befindet bekommen. Inzwischen aber tropft es weiter sich etwa fünfzig Meter entfernt in einem durch die Decke, pfeift der Wind durch die zum Reichbahnzentralamt gehörenden Ge- notdürftig eingesetzten Fenster und verbäude. Das Wasser muß ebenfalls dort ge- schimmeln die Lebensmittel in dem feuchtigholt werden. Falls einer der Fanilienange- keitziehenden Schrank. Der kranken Frau hörigen das Bedürfnis hat. eine gründliche M. mag die Hoffnung auf eine merschenWaschung vorzunehmen, muß der andere würdige Unterkunft ihre Krankheit leichter solange die Räumlichkeit verlassen. Die ertragen lassen.

Feuchtigkeit ist so stark, daß die Lebens- Hoffentlich hofft sie nicht vergebens und mittel verschimmeln und die Kleider sich koffentlich hofft sie nicht vergebens und stets in einem klammen Zustand befinden. trockenen Wohnung. Die Entwürfe für ein $\mathrm{Da}$ die Räumlichkeit nicht überdacht ist, umfassendes Wohnungsbauprogramm liegen regnet es bei stärkerem Regen ständig durch. umfassendes Wohnungsbauprogramm liegen $M$ selbst ist 40 Prozent kriegsbeschädigt. seiner Schauspiele "Was sind schon HoffnunSeine Frau schwer nierenkrank. Feuchtigkeit und Kälte tragen das Ihre hinzu, das Leiden ständig zu verschlimmern. Wo die Bewohner ihre Kohlen und Kartoffeln für den Winter lagern sollen, wissen sie heute noch nicht, denn trotz der geringen Mobiliare der Flüchtlingsfamilie, ist beim besten Willen keine gcn, sind Entwürfe"

Hauptsache - unser Bundestag hat seinen Glaspalast. Das hat er zwar nicht gesagt, aber es ist nun mal so.

Und das dürfte doch manchen nachdenklich stimmen.

Q6: Stadtarchiv Göttingen, Film Ztg. 630, Niedersächsische Volksstimme, 15.Oktober 1949. 


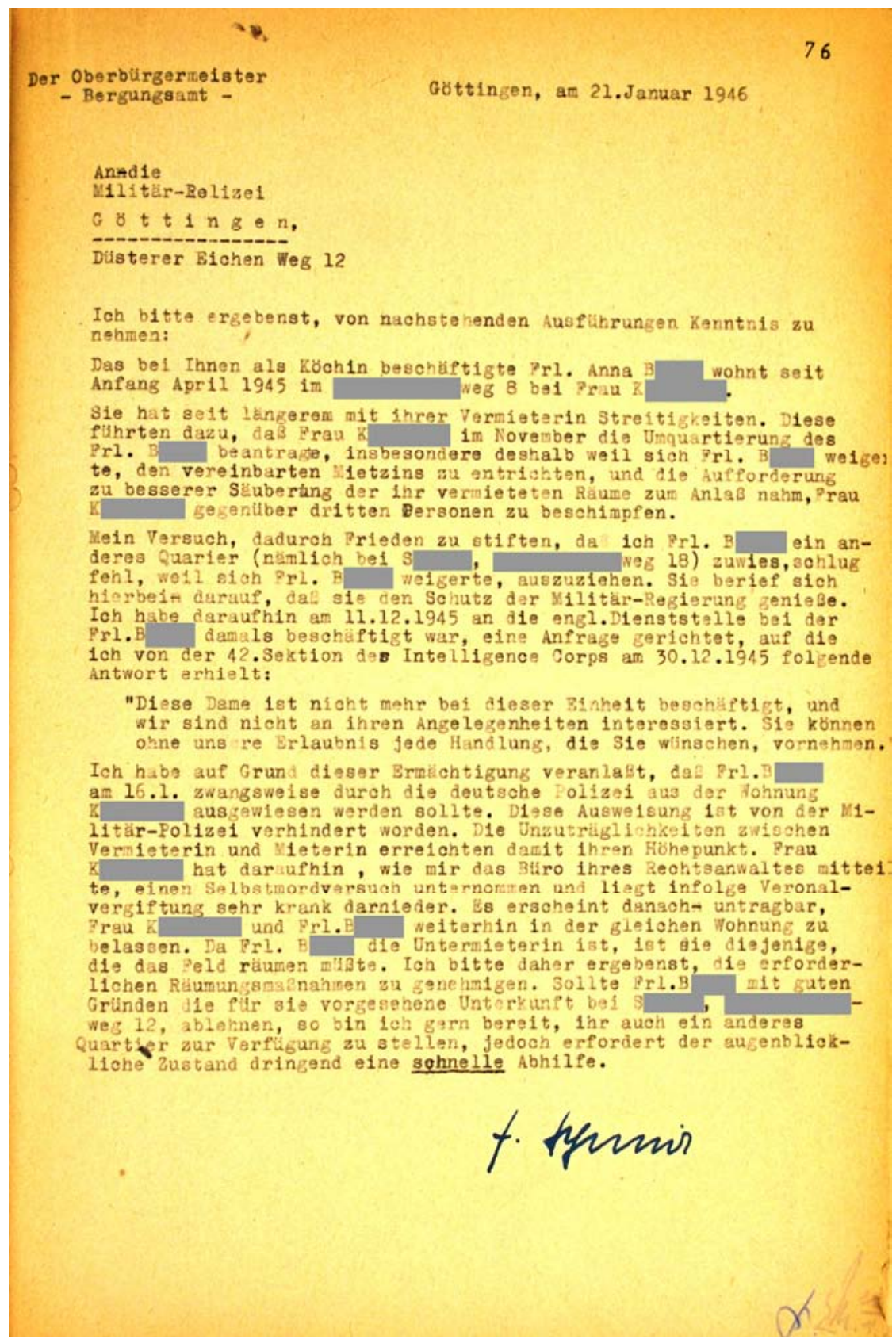

Q4: Stadtarchiv Göttingen, Stadtverwaltung und Militärregierung, E57,1, Blatt 76. 

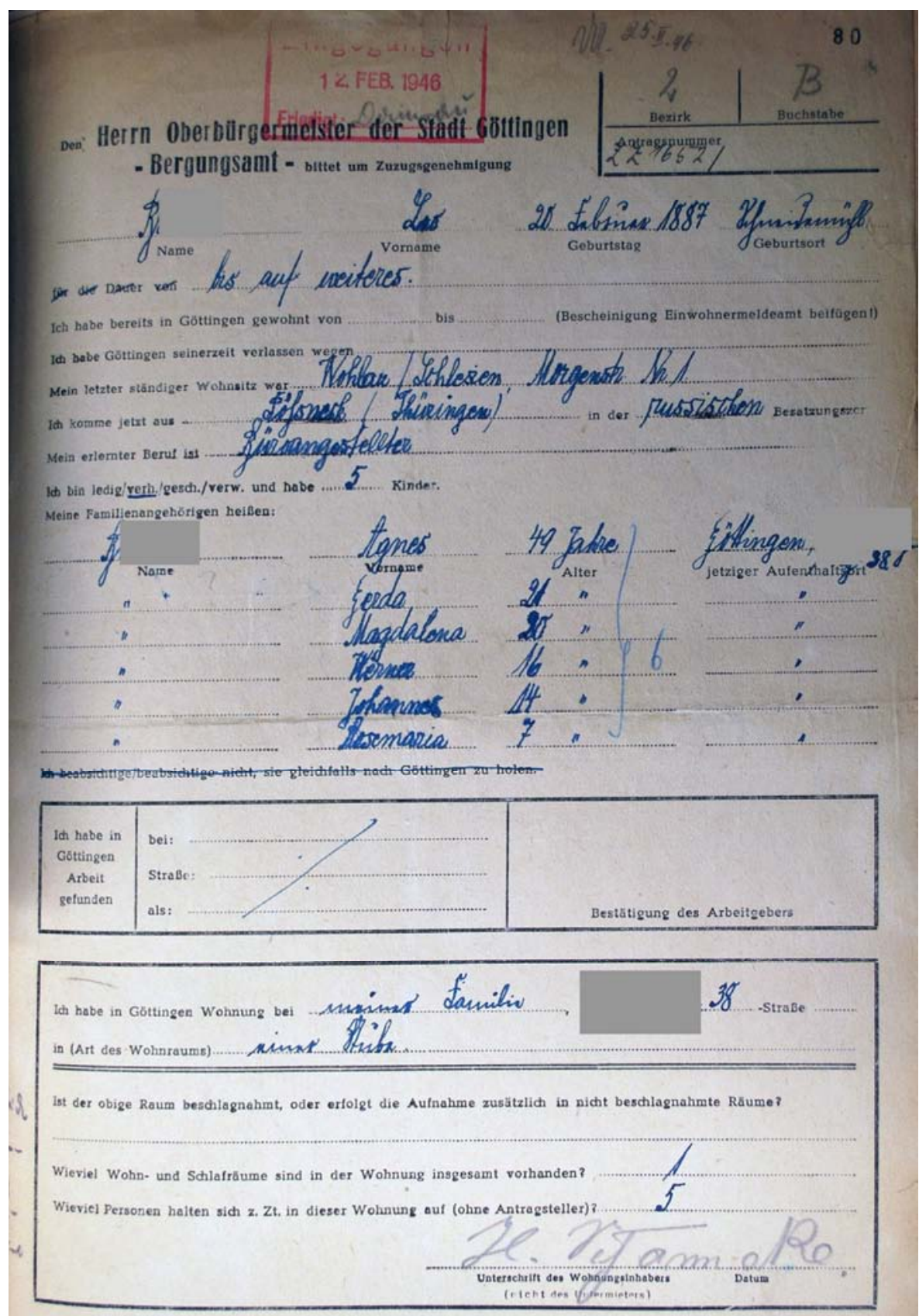

Q5: Stadtarchiv Göttingen, Stadtverwaltung und Militärregierung, E57,1, Blatt 80. 


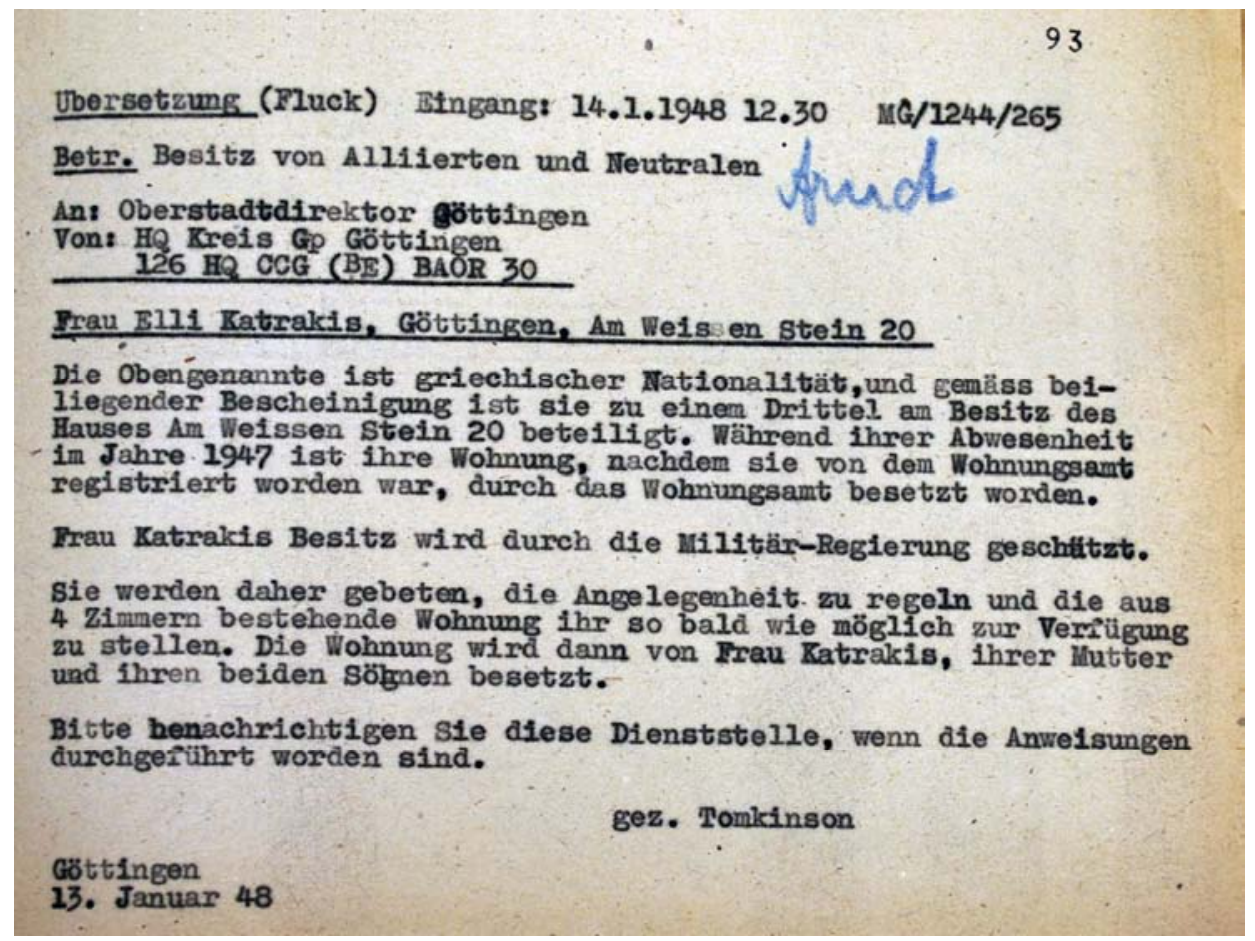

Q7: Stadtarchiv Göttingen, Stadtverwaltung und Militärregierung, E57,2, Blatt 93. 


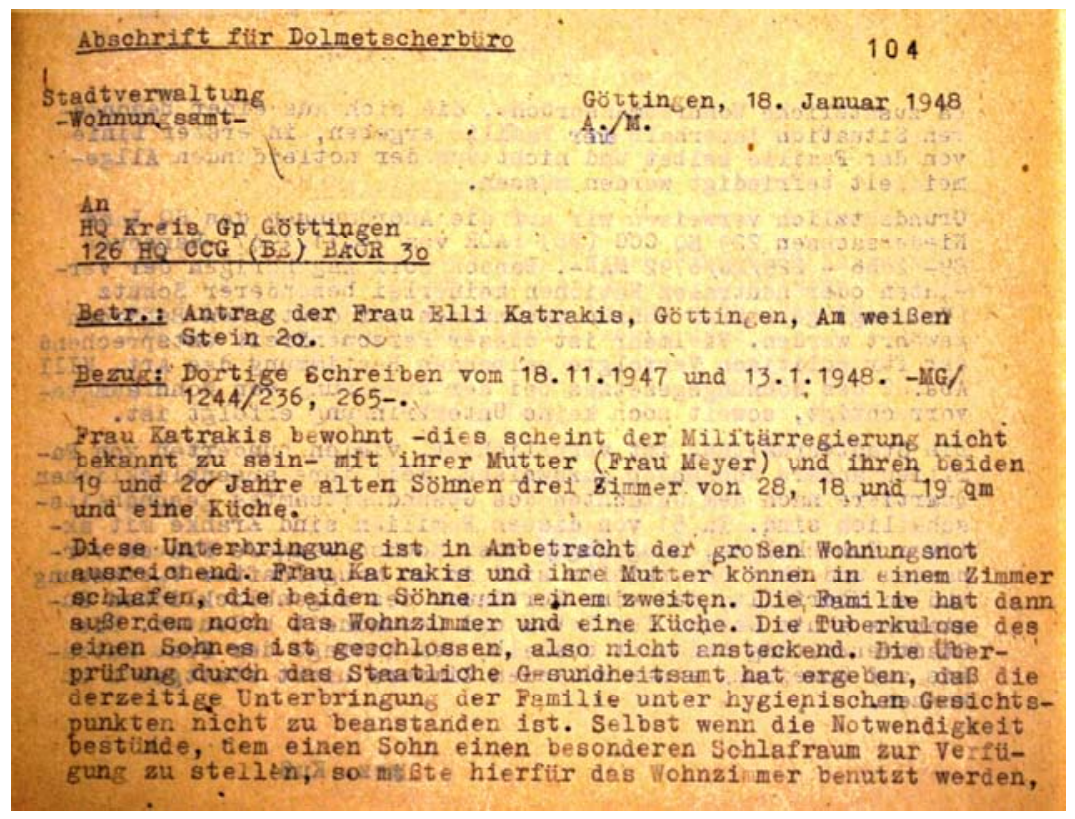

da zustiteliche wohnraumansprüche, die sich aus einer besonceren Situation innerharb erer Femilie ergeben, in erster Iinfe von der Pamilie selbst tud nicht von der notleidenden Allge-. meinheit befriedigt werden milssen.

Grundsätzlich verweisen wir auf die Anordnungen des HQ I nd Niedersachsen 229 HQ CCG (BE) EAOR vom 24.11.1947-Hannover 89-2066 - 229/MG/6792 MAAl-. DanacL. Sol1 Angehorigen der vereinten oder neutralen Nationen keinerlei besonderer Schutz (Vorrang) gesentber Wohnungsuaßnahmen der deut schen Behörden Eewahrt werden. Vielmehr ist dieser Personenkreis entspcechend cer fur politisch Verfolgte geltenden Bestinmung des Art. VIII Abs. 2 des Tohnungsesetzes Dei der Zuweisung von Mohrraum bevorrechtigt, soweit noch keine Unterbringuns erfolgt ist.

Die stadtverwaltune ist verpelichtet, viefen humerten von Familien andere wohnun en zuzuweisen, weil ihre augenblicklichen Qusrtiere nach dem Gutaciten des Gesundheitsamtes gesundheitsschädich sind. In 51 von diesen Panilien sind Kranke mit ak-

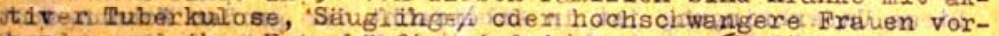
Whanden und dhre Unterkinete is ind in iso mange Ihafter Vorfassung und do libdrfint $t$, daik eine Kortuauer desraugenblicklichen $\mathrm{Zu}$ standes dikute Gefahr IUr Leben und Gesundhed t bedeutet. Die r. Stadtiverwal tung bedauert deshal $b$, dem Antrage der Frau Katra$\mathrm{kis}$ aue $\mathrm{Zuwe}$ iswing eines weiteren Zinmers nicht stattgeben zu

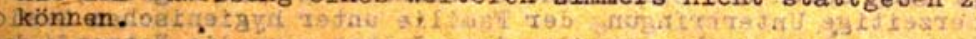

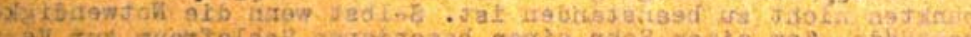

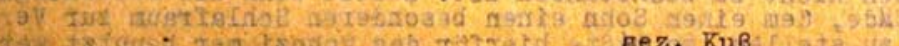

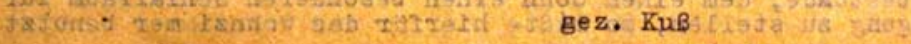

Q8: $\quad$ Stadtarchiv Göttingen, Stadtverwaltung und Militärregierung, E57,2, Blatt 104. 


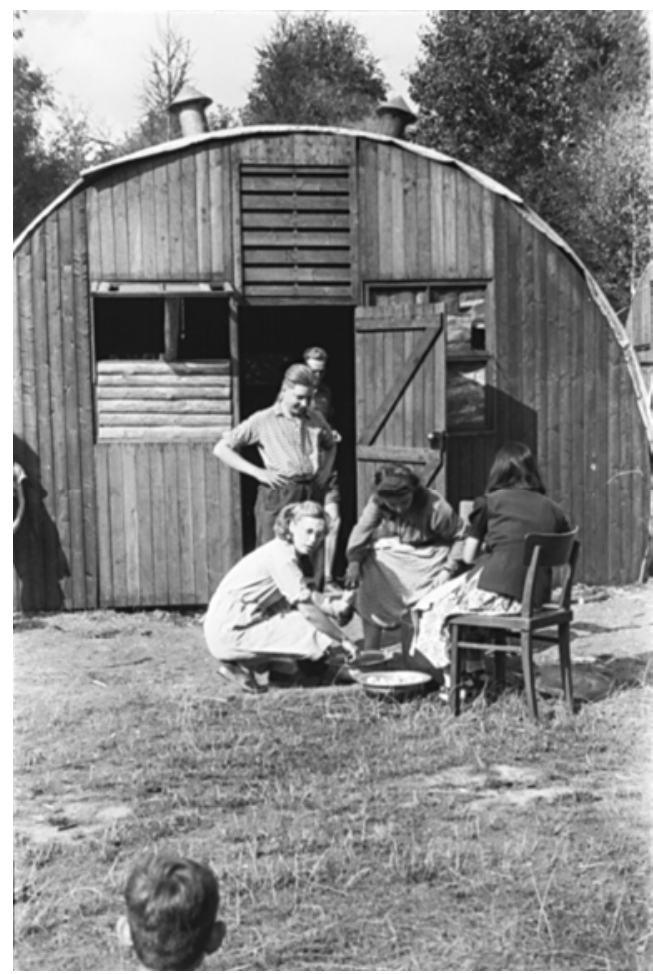

Q9: $\quad$ Stadtmuseum Göttingen.

\section{Reges Leben am Hagenberg Siedlungshäuser wachsen aus dem Boden}

Göttingten. Wer heute über den Hagensberg geht, kann feststellen, daß dort eine lebhafte Tätigkeit herrscht. An der Kanalisation wird gearbeitet. Die Ausschachtungsarbeiten bei einigen Siedlurıgshäuser im Gange, bei einigen ragen die Kellermauern bereits über den Erdboden. Der Betrag von $12000 \mathrm{DM}$, den die Selbsthilfeaktion der Stadt durch Fußballspiel und Bausteineaktion aufgebracht hat, darf als ein erfreuliches Zeichen tätiger Mithilfe der Bevölkerung an der Verwirklichung des Facharbeitersiedlungsplanes betrachtet werden. Es ist zu hoffen, daß die eigenen Anstrengungen nun auch die noch erforderliche Unterstützung des Landes finden. - mgr

Q12: Stadtarchiv Göttingen, Film Ztg. 624, Hannoversche Neueste Nachrichten, Ausgabe Süd-Hannover, 2. Oktober 1948. 


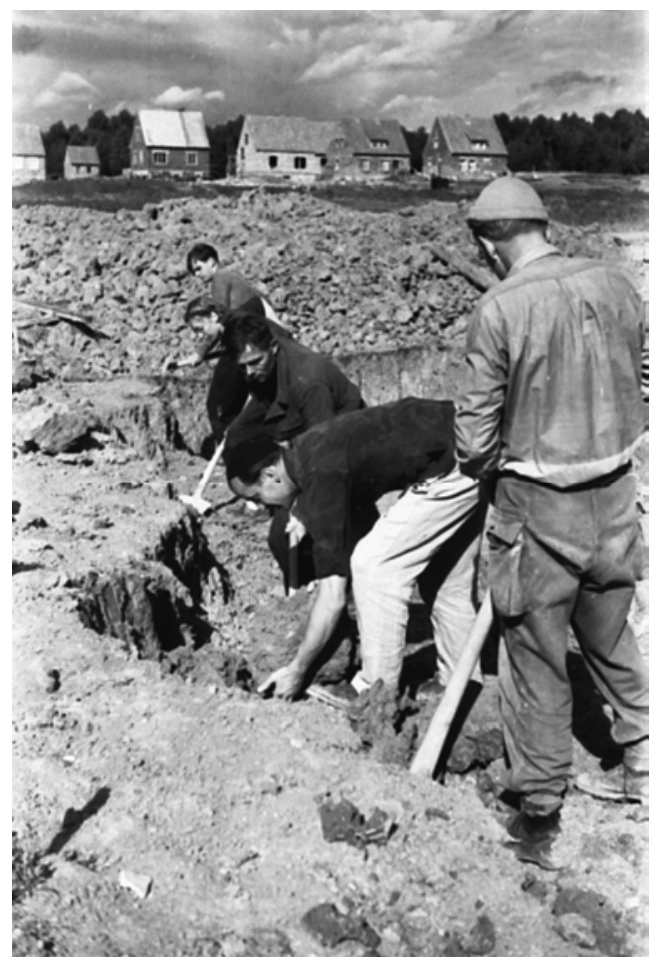

Q10: Stadtmuseum Göttingen.

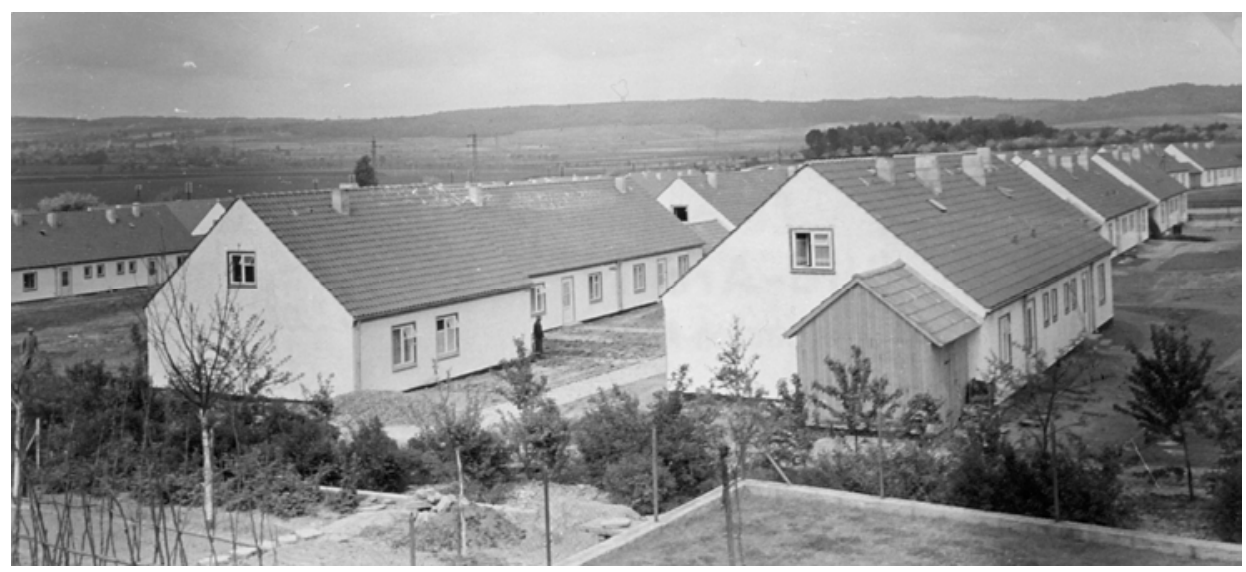

Q11: Stadtmuseum Göttingen. 


\section{Göttingen hilft sich selbst}

\section{Bausteine für den Kleinen Hagen}

Göttingen macht mit der Finanzierung der Siedlung am Kleinen Hagen Ernst! In der Woche vom 5. bis 12. September wird vom Bauausschuß eine große Werbeaktion unter dem Motto: "Göttingen hilft sich selbst! “ durchgefuhrt. Die Bemuhungen, beim Land Irgendwelche Bauzuschtisse zu bekommen, sind ohne Erfolg geblieben. Trotzdem soll in Kürze mit den Arbeiten begonnen werden. 50 Prozent der Baukosten wili die Verwaltung durch den Verkauf von "Bausfeinen". aufbringen, der Rest müßte durch Hypotheken gedeckt werden.

Wenn jeder Göttinger Einwohner nur etwa 1 DM geben würde, käme eine Summe zusammen, die zur Errichtung von zehn Wohnhäusern mit 20 Wohnungen ausreicht. $\mathrm{Da}$ dieser Duichschnittsbetrag aber schon als hoch gegriffen erscheint, rechnet der Bauausschuß dinit, daf die bessergestellten Einwohner etwas tiefe in den Säckel greifen, um die kleineren auszugleichen.

In diesen Tagen werden Plakate, Kinoreklame und sonstige Werbemittel die Sammelwoche, vom 5. bis 12. September einleiten und die. Bevölkèrung auf Sinn und Bedcutung dieser Aktion hinweisen. Freiwlllige Helfer werden die "Bausteine" vertreiben, aus deren Verkauf die Baugelder aufgebracht werden sollen. Der Bauausschuß glaubt zuversichtlich an die positive Elastellung der Göttinger Bevölkerung. Der elnmalige Verzicht auf die monatliche Aufwandsentschädigung durch die Ratsherren zugunsten der Bausteine-Aktion soll sbenfalls zur Stärkung des Baufonds beitragen. Außerdem soll eine neue "Fußballsensation" "Rat gegen Verwaltung " mit. Ihrem finanziellen Ergebnls ebenfalls zum Gelingen der Selbsthilfeaktion belsteuern. mgr

Q13: Stadtarchiv Göttingen, Film Ztg. 624, Hannoversche Neueste Nachrichten, Ausgabe Süd-Hannover, 26.August 1948. 


\title{
Schildersturm - Göttinger Straßenumbenennungen nach dem Zweiten Weltkrieg
}

\author{
Marco Dräger
}

\section{Einleitung}

Straßen sind eine „begehbare“ Quelle und bieten zugleich einen Zugang zur Lokalgeschichte, denn Straßen und Straßenschilder sind im Alltag immer gegenwärtig. Durch ihre Omnipräsenz und ihre alltägliche Nutzung werden Vorstellungen und Werte, die mit ihren Bezeichnungen konnotiert sind, fast beiläufig in das Denken der Benutzer eingeführt. Dieses Potential hat eine lange Tradition und wurde auch von den Nationalsozialisten erkannt und genutzt.

Während der nationalsozialistischen Herrschaft wurde eine Vielzahl von StraBen nach deren Protagonisten und politischen Führern benannt. Diese umfangreichen Umbenennungen wurden nach dem Ende des Zweiten Weltkrieges sowohl seitens alliierter Politik als auch später seitens der deutschen Behörden wieder rückgängig gemacht. Die Umbenennung der Göttinger Straßen war kein einmaliger Akt, sondern vollzog sich als kontinuierlicher Prozess, an dem die lokal beteiligten Akteure regen Anteil nahmen.

\section{Die ersten Umbenennungen 1945}

Bereits im April 1945 fanden die ersten Umbenennungen auf Befehl der provisorischen amerikanischen Militärregierung in Göttingen statt. Der von ihr eingesetzte Oberbürgermeister Erich Schmidt diente bei diesen Vorgängen lediglich als De- 
klamationsorgan und gab die Umbenennungen im „Göttinger Mitteilungsblatt", einer von der Militärregierung zwecks Information der Bevölkerung herausgegebenen Zeitung, bekannt. ${ }^{1}$ Die erste Ausgabe erschien am 20. April 1945 und die Tatsache, dass die Umbenennungen als erste Nachricht bekannt gegeben wurden, verdeutlicht, dass die politischen Akteure dem Thema eine große Relevanz beigemessen haben (Q1).

Laut Wilhelm van Kempen seien diese drei Straßen bereits am 17. April umbenannt worden, ${ }^{2}$ also innerhalb der ersten zehn Tage nach Besetzung der Stadt. Zwar lässt sich der Grad der deutschen Beteiligung an diesen ersten Umbenennungen nicht mehr eruieren, dennoch vermutet die Historikerin Wiebke von Thadden „weit verbreitete Zustimmung in der Stadt" . Eine zweite Umbenennungswelle erfolgte im August 1945, ebenfalls auf Anordnung der Militärregierung; ${ }^{4}$ sie wurde erneut im „Göttinger Mitteilungsblatt" bekanntgegeben (Q2-Q3). ${ }^{5}$

\section{Vom Diktat zur Diskussion}

Nachdem im Dezember 1945 zum letzten Mal auf Veranlassung der Militärregierung eine Straße umbenannt worden war $(\mathrm{Q} 4)$, verlagerte sich die Initiative allmählich auf die Göttinger Bevölkerung. Im Februar 1946 wurde auf Beschluss des Göttinger Oberbürgermeisters die „Mackensenstraße“ in „Plesseweg“ umbenannt (Q5).

Die ersten Kommunalwahlen fanden am 13. Oktober 1946 statt, politische Parteien hatte die Militärregierung bereits im Dezember 1945 zugelassen. ${ }^{6}$ So konnte der neu gewählte Göttinger Rat seine Tätigkeit aufnehmen und musste

\footnotetext{
1 Wiebke von Thadden, Göttingen und seine Militärregierung, in: Göttingen 1945. Kriegsende und Neubeginn - Texte und Materialien zur Ausstellung im Städtischen Museum 31. März - 28. Juli 1985, Göttingen 1985, S. 69-92, hier S. 73.

2 Wilhelm van Kempen, Göttinger Chronik. Göttingen zur Tausendjahrfeier gewidmet, Göttingen 1953, S. 82.

${ }^{3}$ Von Thadden, Militärregierung, S. 74.

${ }^{4}$ Ebd. Anm. 17.

5 Obwohl die Umbenennungen aufgrund der Mitteilungsblätter und der Eintragungen im „Straßenund Nummernbuch der Stadt Göttingen“" eindeutig auf April 1945 und August 1945 datierbar sind, werden sie im Verzeichnis „Straßenumbenennungen in Göttingen 1937-1973“ (Stadtarchiv Göttingen B 19) auf den 8.8.1946 datiert. Christian Plath erklärt dies mit einem zu diesem Zeitpunkt gefassten Ratsbeschluss (Christian Plath, Göttinger Straßennamen als Ehrennamen, in: Göttinger Jahrbuch 45 (1997), S. 179-194, hier S. 187 Anm. 77). Zu diesem Zeitpunkt war Göttingen zumindest in lokalpolitischen Angelegenheiten teilweise wieder autonom handlungsfähig, so dass der Rat als autokephales Gremium vermutlich beschloss, die Umbenennungen nachträglich zu legitimieren. Gleichwohl bleibt die unterschiedliche Datierung bemerkenswert, sagt sie doch - unter der Prämisse, dass Plaths Erklärung stimmt - einiges über das Göttinger Selbstverständnis bzw. Selbstbewusstsein und das Verhältnis zur Militärregierung aus.

${ }^{6}$ Vgl. Barbara Marshall, The Democratization of Local Politics in the British Zone of Germany: Hanover 1945-47, in: Journal of Contemporary History 21 (1986), S. 413-451, hier S. 418. Es existierte zwar seit November 1945 wieder ein Rat, seine Mitglieder waren jedoch von der Militärregierung ernannt worden (Wiebke Fesefeldt, Der Wiederbeginn des kommunalen Lebens in Göttingen. Die Stadt in den Jahren 1945 bis 1948, Göttingen 1962, S. 107-111).
} 
gleich zu Beginn die Direktive Nr. 30 des Alliierten Kontrollrates vom Mai 1946 umsetzen, der mit dieser Anweisung die „Beseitigung deutscher Denkmäler und Museen militärischen und nationalsozialistischen Charakters" verfügt hatte. ${ }^{7}$ Die Rück- bzw. Umbenennungen wurden nun zum Gegenstand der lokalen politischen Diskussion (Q6-Q8).

Federführend bei den durchzuführenden Maßnahmen war die Fraktion der SPD, die die Initiative ergriff und die Umbenennungspolitik und -praxis durch ihre Anträge maßgeblich vorantrieb. Sie favorisierte als Namenspatrone verstorbene Politiker des eigenen politischen Lagers (August Bebel, Carl von Ossietzky, Friedrich Ebert, Walter Rathenau, Karl Marx und Leonard Nelson), topographische Bezeichnungen (Wall, Am Geismartor, Plesseweg), kulturelle Größen (Beethoven, Heine), die Geschwister Scholl sowie den Mediziner Robert Koch, der in Göttingen studiert hatte.

Die CDU-Fraktion wollte diese konsequenten und weitreichenden Änderungen nicht mittragen und stattdessen diejenigen Namen, die in der militärischen Tradition standen, beibehalten. So diskutierten die Parlamentarier sowohl im Plenum als auch in den verschiedenen Ausschüssen die diversen Vorschläge recht kontrovers und heftig. Man stritt darüber, was erinnernswert sei, was getilgt und wodurch es ersetzt werden sollte, vor allem aber, wer darüber bestimme. So bildeten sich zwei Lager: Die eine Seite war restaurativ ausgerichtet und wollte eine Neuordnung verhindern, ${ }^{8}$ die andere Seite wollte den Aufbruch und ein neues, pazifistisches Lebensgefühl vermitteln. ${ }^{9}$ Auf diese Weise wurde die Auseinander-

7 Amtsblatt des Kontrollrates in Deutschland Nr. 7 (1946) vom 31.5.1946, S. 154-155: Direktive Nr. 30: Beseitigung deutscher Denkmäler und Museen militärischen und nationalsozialistischen Charakters; Der Kontrollrat verfügt wie folgt:

I. Von dem Zeitpunkt des Inkrafttretens dieser Direktive an ist untersagt und als gesetzwidrig erklärt die Planung, der Entwurf, die Errichtung, die Aufstellung und der Anschlag oder die sonstige Zurschaustellung von Gedenksteinen, Denkmälern, Plakaten, Statuen, Bauwerken, Straßen- oder Landstraßenschildern, Wahrzeichen, Gedenktafeln oder Abzeichen, die darauf abzielen, die deutsche militärische Tradition zu bewahren und lebendig zu erhalten, den Militarismus wachzurufen oder die Erinnerung an die nationalsozialistische Partei aufrechtzuerhalten, oder ihrem Wesen nach in der Verherrlichung von kriegerischen Ereignissen bestehen. [...]

II. Sämtliche bestehenden [...] Straßen- oder Landstraßenschilder [...] sind bis zum 1. Januar 1947 vollständig zu zerstören und zu beseitigen. [...]

V. a) Die Ausdrücke „militärisch“ und „Militarismus“ sowie der Ausdruck „kriegerische Ereignisse“ im Sinne dieser Direktive beziehen sich auf Kriegshandlungen nach dem 1. August 1914 zu Lande, zu Wasser oder in der Luft und auf Personen, Organisationen und Einrichtungen, die mit diesen Handlungen in unmittelbarem Zusammenhang stehen.

b) Der Ausdruck „National-Sozialistische Partei“ im Sinne dieser Direktive bezieht sich auf die ehemalige Nationalsozialistische Deutsche Arbeiterpartei und auf die in unmittelbarer Verbindung mit ihr stehenden Personen, Organisationen und Einrichtungen. [...]

VI. Diese Direktive tritt mit dem Tage ihrer Verkündung in Kraft.

Ausgefertigt in Berlin, den 13. Mai 1946. (Die in den drei offiziellen Sprachen abgefassten Originaltexte dieser Direktive sind von B. H. Robertson, Generalleutnant, L. Koeltr; Armeekorpsgeneral, M. I. Dratwin, Generalleutnant, und Lucius D. Clay, Generalleutnant, unterzeichnet.)

8 Vgl. Marshall, Democratization, S. 414.

9 Vgl. hierzu die „Militarismus“-Definition der SPD-Fraktion, die weit über das in der Direktive genannte Datum (1.8.1914) hinausgeht und bereits bei dem Ulmer Erfinder und Flugpionier Albrecht 
setzung um die Straßennamen zu einem besonderen Beispiel für die ,politische Pädagogik" 10 des parlamentarischen Neubeginns.

Aufgrund ihrer absoluten Mehrheit ${ }^{11}$ konnte sich die SPD-Fraktion im März 1947 durchsetzen. Die lokale Presse bewertete die Umbenennung unterschiedlich (Q9-Q11): Während die „Hannoverschen Neuesten Nachrichten“ die Aktion negativ kommentierten, weil man „umlernen müsse“, und daher mutmaßten, dass diese Umbenennungen nicht „dem Wunsche und Willen des überwiegenden Teils der Göttinger Bevölkerung“ entsprächen (Q9), konstatiert die „Hannoversche Presse“ den Sachverhalt lediglich lapidar und nüchtern in einer Randbemerkung (Q10), erst in der darauffolgenden Ausgabe teilt sie die Umbenennungen mit (Q11).

Trotz der intensiven Auseinandersetzung um die Straßennamen wurde die Umbenennungspraxis allerdings oftmals von anderen, koinzidierenden Problemen überlagert, ${ }^{12}$ so dass die Göttinger Straßen nicht immer zeitnah und unverzüglich neue Namen erhielten. Die damals noch selbstständige Gemeinde Geismar meldete ihre „verbale Abrüstung“ der so genannten „Frontkämpfersiedlung“ erst im Januar 1948 an das Göttinger Vermessungsamt (Q12).

\section{Die Kontroverse um den „82er Platz“}

Dennoch war die Einstellung der Einwohner keineswegs indifferent. Privatpersonen, Vereine und Verbände traten hervor und wollten ihre Namenswünsche berücksichtigt wissen, wie z. B. die „Gesellschaft der Freunde Wilhelm Raabes“, die den Schriftsteller als Namenspatron vorschlug (Q13).

Zeitungsartikel wiesen immer wieder auf Missstände hin und beklagten die Diskrepanz zwischen dem Ideal entnazifizierter Straßennamen und dem tatsächlichen Gebrauch der Bezeichnungen in der alltäglichen Praxis; die Redakteure mahnten mehrfach die noch immer gebräuchliche Verwendung obsoleter Namen an und kritisierten, dass diese noch nicht aus dem öffentlichen Stadtbild getilgt worden seien (Q14-Q15).

Aber nicht nur sie wirkten durch ihre Artikel den sprachlichen Entgleisungen und Fauxpas entgegen, auch engagierte Leser meldeten sich zu Wort (Q16). Besonders deutlich werden Bedeutungszuschreibungen hinsichtlich der Funktion und der Wirkung von Straßennamen in einer Leserbrief-Kontroverse über die korrekte Bezeichnung des Platzes „Am Geismartor“.

Ludwig Berblinger (1770-1829) ansetzt und die „militärische Tradition“ über Bismarck (1815-1898) bis in die Gegenwart fortgesetzt sieht. Auch die aus dem 19. Jahrhundert stammende Bezeichnung „Kasernenplatz“ sollte ersetzt werden.

${ }^{10}$ Hartmut Boockmann, Alte Straßen, neue Namen, in: GWU 45 (1994), H. 9, S. 579-591, hier S. 587.

11 Vgl. van Kempen, Göttinger Chronik, S. 85..

12 Vgl. zu diesen Aspekten vor allem die Beiträge von Timo Stiehl zur Versorgungslage und von UlfGerrit Meyer-Rewerts zur Wohnungssituation in diesem Band. 
Der 1864 so benannte Platz wurde 1934 auf Beschluss des Oberbürgermeisters in ,82er-Platz“ umbenannt, ${ }^{13}$ um an das „2. Kurhessische Infanterie-Regiment Nr. 82 “ zu erinnern, das von 1871 bis 1920 in Göttingen stationiert gewesen war. ${ }^{14}$

Diese Benennung wurde im Rahmen der Entmilitarisierungsstrategie bereits 1947 rückgängig gemacht, seitdem hieß der Platz wieder „Am Geismartor“. ${ }^{15}$ Umgangssprachlich hat sich jedoch der Name „82er Platz“ - bis heute - erhalten, obwohl er seit 1992 Hiroshima-Platz heißt.

Auf diesem Missverständnis bzw. Missverhältnis zwischen umgangssprachlicher und offizieller Bezeichnung begründet sich ein zweiter Leserbrief als Reaktion auf den vorherigen (Q17), der für die Beibehaltung des nicht mehr existenten $\mathrm{Na}$ mens plädiert. Die Bevölkerung mischte sich durchaus in die Diskussion ein; sie stimmte keineswegs immer den neuen Namen zu. Sie kritisierte die Benennungskriterien und formulierte stattdessen eigene, wie z. B. der Göttinger Pfarrer Albrecht Saathoff, der als Auswahlelement besonders den Lokalbezug der Namenspatrone betont bzw. bei topographischen Bezeichnungen die Namen ,ostdeutscher Städte“ als Erinnerung für die „Neubürger" an ihre „Heimat" präferiert (Q18). Des Weiteren fordert er, dass der Name zu den Straßen in der Umgebung passt und die Anwohner bei der Namensfindung einbezogen werden.

\section{$5 \quad$ Straßennamen - kollektives Gedächtnis und Erinnerungsort?}

In den recherchierten Leserbriefen steht die Erinnerungsfunktion von Straßennamen stark im Vordergrund, wenngleich die Auffassungen an verschiedene Aspekte von Göttinger Traditionen anknüpfen. So bieten Straßennamen neben der räumlichen vor allem auch kulturelle Orientierung. ${ }^{16}$

Die Bezugnahme auf lokale Namenspatrone - seien es Personen, topographische oder historische Bezeichnungen - wirkt identitätsstiftend ${ }^{17}$ und fördert die „Selbstkonstitution von Sozietäten“18. Straßennamen werden auf diese Weise vom „Ortsgedächtnis“ zum „,Gedächtnisort“.19

13 Akte „Hausnummern- und Straßenverzeichnis Okt. 1897-Mai 1955“ (Stadt Göttingen, Fachdienst 61.2: Bodenordnung, Vermessung und Geoinformation).

${ }^{14}$ Göttinger Einwohnerbuch 1936, 3. Teil, Straßenverzeichnis, S. 231.

15 Siehe Q6-Q8, dort taucht der „,82er Platz“ unter der Bezeichnung „(Alter) Kasernenplatz“ auf, weil er sich neben dem ehemaligen Kasernengebäude befand, in dem das Regiment untergebracht war. Das Ringen um den „,82er Platz“ war 1957 keineswegs beendet, noch 1983 wurde in einem Leserbrief im Göttinger Tageblatt gefordert, wieder einen Platz nach dem 82. Regiment zu benennen.

16 Johanna Sänger, Heldenkult und Heimatliebe. Straßen- und Ehrennamen im offiziellen Gedächtnis der DDR, Berlin 2006, S. 43.

17 Vgl. Dietz Bering/Klaus Großsteinbeck, Kulturgeschichte von Straßennamen. Neue Perspektiven auf altem Terrain, gewonnen am Beispiel Köln, in: Muttersprache 104 (1994), H. 2, S. 97-117, S. 98.

18 Ebd., S. 97.

${ }^{19}$ Der Begriff „Gedächtnisort“ bzw. sein Pendant „Erinnerungsort“ wird sowohl in der wissenschaftlichen als auch in der populären Literatur oft kritiklos, inflationär und meist undefiniert als Argumen- 
Laut Dietz Bering und Klaus Großsteinbeck ist das Interesse an Straßennamen immer dann besonders stark, wenn eine Veränderung droht und mit dem ,,selbstverständlichen Hintergrund“ auch ein Stück Identität in Frage gestellt werden soll. ${ }^{20}$ Das Phänomen des starken Interesses bei Veränderungsgefahr bezeichnen sie in Anlehnung an Jan Assmann als „mnemische Potenz“21, also als Kraft der Erinnerung bzw. des Gedächtnisses. Die Bedeutung, die bislang nur noch unterbewusst vorhanden war, wird wiederaktiviert. Mit diesem Modell der Identitätsstiftung bzw. der Konstruktion eines kommunalen Gedächtnisses lässt sich die Vehemenz des Streits erklären, sowohl auf der parlamentarischen als auch auf der publizistischen Ebene, die in Saathoffs Forderung nach „Straßennamen obne Politik" ${ }^{\text {“22 }}$ kulminiert. Ferner kritisiert er die Vorliebe des „,motorisierten Biedermeier" ${ }^{\text {“23 }}$ für die romantische Blumenidylle ${ }^{24}$ und mahnt eine angemessene, zeitgemäße und neutrale Namensgebung an.

Doch ebenso interessant wie die diskutierten Objekte der Erinnerung sind die Auslassungen, Leerstellen und Athetesen, die Teil einer damnatio memoriae wurden. Das Vergessen unerwünschter Erinnerungen, die als nicht erinnerungswürdig galten und daher nicht nennenswert sein sollten, war ebenso ein Teil dieses Prozesses der „Vergangenheitsbewältigung“ wie die identifikatorische Neuausrichtung.

$\mathrm{Zu}$ diesem komplexen Diskussionsprozess über Straßenumbenennungen merkt der Historiker Rainer Pöppinghege an: „Ein Straßenname sagt nicht nur etwas aus über jenes historische Phänomen, auf das er hinweist. [...] Ein Straßenname sagt viel mehr aus über die Epochen, die er unbeschadet überdauert hat.“25

tationsmittel und Schlagwort gebraucht. Dies führt zu einer Gefahr der Überbewertung des genius loci. Seine dominante Stellung im Diskurs erweckt einen falschen Eindruck von Homogenität. In den vergebenen Namen werden nur Erinnerung und Gedächtnis der Vergabeinstanzen repräsentiert. Es bleibt fraglich, inwiefern die Erinnerung derjenigen Gruppe, die ihre Interessen bei der Benennung durchgesetzt hat, verallgemeinerbar ist. Zur weiteren Kritik an diesem Begriff siehe Sänger, Heldenkult, S. 34-44.

${ }^{20}$ Bering/Großsteinbeck, Kulturgeschichte, S. 98-100.

${ }^{21}$ Ebd. S. 100. Jan Assmann spricht von „mnemischer Energie“: So genannte „Objektivationen von Kultur“, zu denen auch Straßenschilder gehören, besäßen eine „mnemische Energie“; durch „kulturelle Formgebung“ habe sich „kollektive Erfahrung kristallisiert, deren Sinngehalt sich in der Berührung [womit keineswegs nur haptischer Kontakt gemeint ist, MD] blitzartig wieder erschließen kann [...]" (Jan Assmann, Kollektives Gedächtnis und kulturelle Identität, in: Jan Assmann/Tonio Hölscher (Hg.), Kultur und Gedächtnis, Frankfurt am Main 1988, S. 9-19, hier S. 12). Demzufolge hätten kulturelle Objektivationen die Kraft, ein kulturelles Gedächtnis zu stabilisieren; „objektivierte Kultur“ habe also eine Gedächtnisfunktion (Assmann, Gedächtnis S. 13), so dass eine Gesellschaft durch ihre kulturelle Überlieferung für sich und für andere sichtbar werde und das, was sie an ihrer Vergangenheit sichtbar und hervortreten lasse, sage etwas aus über das, was sie sei und worauf sie hinauswolle (Assmann, Gedächtnis, S. 16).

22 Siehe Q18.

${ }^{23}$ Vaterland, Muttersprache. Deutsche Schriftsteller und ihr Staat seit 1945. Zusammengestellt von Klaus Wagenbach, Winfried Stephan, Michael Krüger und Susanne Schüssler, Berlin 1994, S. 132. Das Zitat stammt aus Erich Kästners „Heinrich Heine und wir".

${ }^{24}$ Siehe die Umbenennungen vom August 1945 in Q3.

25 Rainer Pöppinghege, Wege des Erinnerns. Was Straßennamen über das deutsche Geschichtsbewusstsein aussagen. Münster 2007, S. 116-117. 
Als Hauptkriterium für die Benennung nach Personen nennt er deren Leistungen und bejaht eine Namenspatronage in dem Falle, dass sich die „,heutige Gesellschaft" noch zu diesen Leistungen bekenne. Dies sei aber keinesfalls als „uneingeschränkte Bewunderung“ zu verstehen, sondern der Namenspatron müsse eine kritische Gesamtwürdigung erfahren: ${ }^{26}$

„Wo eine solche Grenze [Entscheidung, ob eine Benennung angemessen ist; MD] anzusetzen ist, muss jede Generation neu aushandeln. Und wenn sie sich eben an Treitschke stößt, dann ist auch dies nicht mehr und nicht weniger als der Ausdruck eines Geschichtsbewusstseins, das in anderer Form täglich aufs Neue konstituiert wird. Jede Briefmarke, jeder Gedenktag, jede Museumspräsentation beweist Tag für Tag, dass sich historisches Bewusstsein ständig wandelt. Nur: Bei Straßennamen steht die aktuelle Wahrnehmung deutlicher vor Augen.“27

\section{Glossar}

\subsection{Q3}

Braunau: Geburtsort Hitlers.

Dietrich Eckart (1868-1923): völkischer Dichter, Anhänger des Nationalsozialismus und Ideengeber Hitlers.

Hermann Göring (1893-1946): Jagdflieger im Ersten Weltkrieg, führender Nationalsozialist und Oberbefehlshaber der Luftwaffe im Zweiten Weltkrieg.

Hanna Wollenweber: Zu ihr liegen keine Informationen vor.

Herbert Norkus (1916-1932): Hitlerjunge, bei Straßenkämpfen mit Kommunisten in Berlin ums Leben gekommen und von den Nationalsozialisten mythisch verehrt. Heinrich Schrader (1876-1935): Gründungsmitglied der Göttinger NSDAPOrtsgruppe.

Karl Litzmann (1850-1936): General im Ersten Weltkrieg, NSDAP-Mitglied.

Ludolf Haase (1898- unbekannt): Gründungsmitglied der Göttinger NSDAP-

Ortsgruppe, Gauleiter des Gaues Hannover-Süd, Ehrenbürger Göttingens von 1937 bis 1952.

Otto Bellstädt: erster nationalsozialistischer Aktivist in Göttingen.

Erich Ludendorff (1865-1937): General im Ersten Weltkrieg und Mitglied der Obersten Heeresleitung, Förderer Hitlers und Teilnehmer des Hitlerputsches.

Wilhelm Gustloff (1895-1936): Landesgruppenleiter der NSDAPAuslandsorganisation in der Schweiz, 1936 ermordet.

Hermann Kautz (1856-1938): Gründungsmitglied der Göttinger NSDAPOrtsgruppe.

\footnotetext{
${ }^{26}$ Ebd., S. 117.

${ }^{27}$ Ebd.
} 
Franz Seldte (1882-1947): Mitbegründer des Stahlhelm (Bund der Frontsoldaten), NSDAP-Mitglied, Reichsarbeitsminister.

\section{$6.2 \mathrm{Q} 4$}

Albert Leo Schlageter (1894-1923): Träger des Eisernen Kreuzes Erster und Zweiter Klasse, Freikorpskämpfer, Teilnehmer des Kapp-Putsches, wegen Spionage und Sabotage von einem französischen Militärgericht 1923 zum Tode verurteilt, weswegen er im Dritten Reich zu einer Märtyrerfigur wurde.

\subsection{Q5}

August von Mackensen (1849-1945): Generalfeldmarschall im Ersten Weltkrieg.

\subsection{Q6-Q8}

Otto von Bismarck (1815-1898): Ministerpräsident von Preußen (1862-1890), Kanzler des Norddeutschen Bundes (1867-1871) und erster Reichskanzler des Deutschen Kaiserreiches (1871-1890), als dessen Begründer er gilt.

Oswald Boelcke (1891-1916): Jagdflieger im Ersten Weltkrieg, von den Nationalsozialisten mythisch als Kriegsheld verehrt.

Max Immelmann (1890-1916): Jagdflieger im Ersten Weltkrieg, von den Nationalsozialisten mythisch als „Adler von Lille“ verehrt.

Langemarck: Ort in Belgien, an dem die deutsche Armee am 10. November 1914 eine Niederlage erlitt, die aber propagandistisch zu einem Sieg umgedeutet wurde und den „Mythos von Langemarck“ schuf (heldenhafter Opfertod junger Soldaten).

Lüttich: Am 6. August 1914 wurde die Zitadelle in Lüttich von Ludendorff besetzt.

Masuren: In der Schlacht an den Masurischen Seen vom 6. bis 14. September 1914 siegte die deutsche Armee über die russische in einer Vernichtungsschlacht.

Manfred Freiherr von Richthofen (1892-1918): Jagdflieger im Ersten Weltkrieg, Beiname „Der rote Baron“, von den Nationalsozialisten mythisch als Kriegsheld verehrt.

Sedan: In der Schlacht von Sedan am 2. September 1870 besiegte die deutsche Armee das französische Heer und nahm den französischen Kaiser Napoleon III. gefangen. Der Sedanstag war bis 1918 ein Feiertag in Deutschland.

Tannenberg: In der Schlacht bei Tannenberg vom 26. bis 30. August 1914 gewannen die deutschen Truppen trotz zahlenmäßiger Unterlegenheit gegen die russische Armee.

Ernst Udet (1896-1941): Jagdflieger im Ersten Weltkrieg.

Walther Wever (1887-1936): Generalstabsoffizier im Ersten Weltkrieg. 
Hans Joachim von Zieten (1699-1786): preußischer General unter Friedrich dem Großen.

Paul von Hindenburg (1847-1934): Generalfeldmarschall im Ersten Weltkrieg, Reichspräsident von 1925-1934.

Albrecht Ludwig Berblinger (1770-1829): Erfinder und Flugpionier aus Ulm.

Carl von Ossietzky (1889-1938): Publizist und Pazifist; Redakteur und Herausgeber der Zeitschrift „Die Weltbühne“. Nach dem Reichstagsbrand 1933 verhaftet und von 1934 bis 1936 im Konzentrationslager Esterwegen bei Papenburg inhaftiert; 1935 mit dem Friedensnobelpreis ausgezeichnet, dessen Annahme ihm untersagt wurde, 1938 an den Haftfolgen gestorben.

\subsection{Q12}

Paul von Hindenburg (1847-1934): Generalfeldmarschall im Ersten Weltkrieg, Reichspräsident von 1925-1934.

Otto Eduard Weddigen (1882-1915): U-Boot-Kommandant im Ersten Weltkrieg, von den Nationalsozialisten mythisch verehrt.

Maximilian Reichsgraf von Spee (1861-1914): Vizeadmiral der deutschen Kriegsmarine im Ersten Weltkrieg.

Alexander Adolf August Karl von Linsingen (1850-1935): Generaloberst im Ersten Weltkrieg.

Reinhard Scheer (1863-1928): Marine-Admiral im Ersten Weltkrieg, Oberbefehlshaber in der Schlacht von Skagerrak.

Albert Theodor Otto von Emmich (1848-1915): Soldat im DeutschFranzösischen Krieg (1870-1871), seit 1909 Infanterie-General der preußischen Armee, „Eroberer von Lüttich“.

\subsection{Q13}

Wilhelm Raabe (1831-1910): Schriftsteller gesellschaftskritischer Romane und Novellen, Pseudonym: Jakob Corvinus, bedeutender Vertreter des deutschsprachigen Realismus, 1901 Verleihung der Ehrendoktorwürde durch die Georg-AugustUniversität Göttingen aufgrund seiner literarischen Verdienste.

\subsection{Q16-Q17}

Das 2. Kurhessische Infanterie-Regiment Nr. 82 wurde am 27.9.1866 als Infanterie-Einheit der preußischen Armee errichtet. Laut Allerhöchster Kabinettsorder vom 24.1.1889 sollte es identisch mit demjenigen 2. Kurhessischen InfanterieRegiment sein, das von Landgraf Wilhelm von Hessen am 30.11.1813 anlässlich der Befreiungskriege gestiftet worden war. 
Im Deutsch-Französischen Krieg 1870-1871 kämpfte das Regiment bei Wörth (6.8.1870) und Sedan (1.9.1870), es belagerte Paris und Pfalzburg. Ein FüsilierBataillon nahm am Siegeseinmarsch in Paris teil.

Nach Stationierungen in Frankfurt und Hanau war Göttingen seit 1871 das Hauptquartier der Garnisonen.

Im Ersten Weltkrieg (1914-1918) war das Regiment zunächst an der Eroberung Lüttichs an der Westfront beteiligt (6.8.1914), Anfang September 1914 wurde es an die Ostfront verlegt und, unter anderem, in der Schlacht an den Masurischen Seen eingesetzt (6.-14.9.1914). Es blieb bis 1917 im Osten, wurde dann aber wieder im Oktober 1917 an die Westfront verlegt, kämpfte bei Verdun und verteidigte bis 1918 die so genannte „Siegfriedstellung“.

Der ehemalige Exerzierplatz des Regiments in Göttingen hieß „82er Platz“; 1934 wurde der Platz „Am Geismar Tor“ zur Erinnerung an dieses Regiment in „82er Platz“ umbenannt, diese Umbenennung wurde jedoch 1947 rückgängig gemacht. Seit 1947 gibt es also den „82er Platz“ nicht mehr, sondern wieder den Platz „Am Geismar Tor“. Seit 1992 heißt er „Hiroshima-Platz“.

An dieser Stelle beginnt das Göttinger Missverständnis, denn der alte Name wurde im täglichen Sprachgebrauch weiter benutzt; Langlebigkeit, alltägliche Gewohnheit und Vertrautheit mit einer Bezeichnung, die sich eingeprägt hat, setzten sich über ,political correctness“ bei diesem Beispiel vielfach hinweg.

[zusammengestellt nach: Dermot Bradley/Hans Bleckwenn (Hg.), Günther Voigt, Deutschlands Heere bis 1918. Ursprung und Entwicklung der einzelnen Formationen, Bd. 3: Die Infanterie-, Füsilier- und Grenadier-Regimenter 61 - 99 der preußischen Armee, Osnabrück 1982, S. 246-263.]

Das Geismar Tor war neben dem Weender Tor und dem Groner Tor einer der wichtigsten mittelalterlichen und frühneuzeitlichen Stadteingänge Göttingens. Nach der „Entfestigung“ der Stadt in der zweiten Hälfte des 18. Jahrhunderts hatte das Geismar Tor die primäre Funktion der Eingangskontrolle weitgehend eingebüßt, es wurde in den Jahren 1784 und 1788 zu einem repräsentativen Durchgang umgestaltet. Das alte Tor wurde abgerissen und durch ein Holztor zwischen zwei steinernen Säulen, die mit Löwen gekrönt waren, ersetzt (Ernst Böhme, Göttingen verändert sein Gesicht. Stadtentwicklung zwischen 1650 und 1866, in: Ernst Böhme/Rudolf Vierhaus (Hg.), Göttingen: Geschichte einer Universitätsstadt, Bd. 2: Vom Dreißigjährigen Krieg bis zum Anschluss an Preußen - Der Wiederaufstieg als Universitätsstadt (1648 - 1866), S. 429-450, hier S. 438-442). 
Am 21. April 1945 wurde das Geismar Tor von amerikanischen Panzern zerstört, weil es ein „Verkehrshindernis“ darstellte (Wiebke von Thadden, Göttingen und seine Militärregierung, in: Göttingen 1945. Kriegsende und Neubeginn - Texte und Materialien zur Ausstellung im Städtischen Museum 31. März - 28. Juli 1985, Göttingen 1985, S. 69-92, hier S. 71).

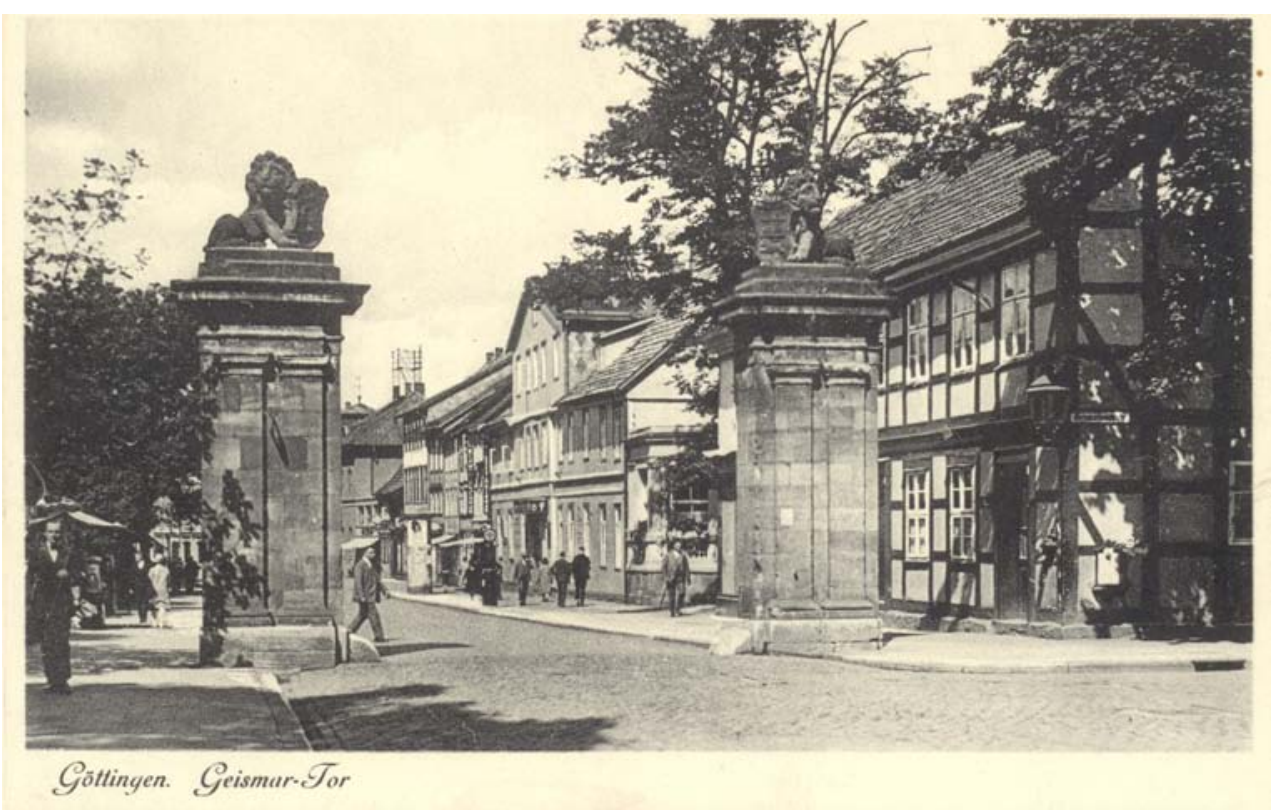

Das Geismar Tor als Postkartenmotiv (1939). Quelle: Städtisches Museum Göttingen, Fotoarchiv, Akte: „Am Geismartor““.

\section{Literatur zum Weiterlesen}

Christian Plath, Göttinger Straßennamen als Ehrennamen, in: Göttinger Jahrbuch 45 (1997), S. 179-194.

Rainer Pöppinghege, Geschichte mit Füßen getreten. Straßennamen und Gedächtniskultur in Deutschland, in: P. Freese (Hg.), Paderborner Universitätsreden, H. 94, Paderborn 2005.

Rainer Pöppinghege, Wege des Erinnerns. Was Straßennamen über das deutsche Geschichtsbewusstsein aussagen. Münster 2007.

Johanna Sänger, Heldenkult und Heimatliebe. Straßen- und Ehrennamen im offiziellen Gedächtnis der DDR, Berlin 2006. 
Gerd Tamke, Göttinger Straßennamen. Familien, Bürger, Personen, Göttingen 1997. 


\section{Stralienumbenennung \\ Dis strabie dor SA." helst" von der Groner Streble bis zum Auditorium wieder . WWeender Straike". \\ Die "Franz-Seldte-Straße $e^{\text {i }}$ und der "Adolf- Eiftler-Platso erhalten wieder thro alte Be- selchnung "Thesterstrabec und "Theater- plate".}

\section{Gotilngen, am 17. April 1945.}

Der,oberbürgermelater.

Q1: Göttinger Mitteilungsblatt Nr. 1 vom 20.4.1945 (Stadtarchiv Göttingen, Film Ztg. Nr. 215).

\footnotetext{
Straßenumbenennungen

Foigende Straßenbezeichnungen in Göt-

tingen sind abgeändert - worden:

Braunauerstraße, jetzt Kantstraße;

Dictrich-Eckart-Winkel, jetzt Rosenwinkel;

Göringstraße, jetzt Berblingerstraße;

Hanna-Wollenweber-Straße, jetzt Tulpenweg;

Herbert-Norkus-Straße, jetzt Rosmarienweg;

Heinrich-Schradar-Straße, jetzt Mathildenweg;

Litzmannstraße, jetzt Keplerstraße;

Ludolf-Haase-Allee, jetzt Pfalz-GronaBreite;

Otto-Bellstaed-Straße, jetzt Margueritenweg;

Ludendoffring, jetzt Kreuzbergring;

Wiltelm-Gustloff-Straße, jetzt Nelkenwinkel;

Fermann-Kautz-StraBe, Jetzt Gutenbergstraße.

Göttingen, am 7. August 1945.

Der Oberbürzermeister.
}

Q2: Göttinger Mitteilungsblatt Nr. 21 vom 11.8.1945 (Stadtarchiv Göttingen, Film Ztg. Nr. 215). 


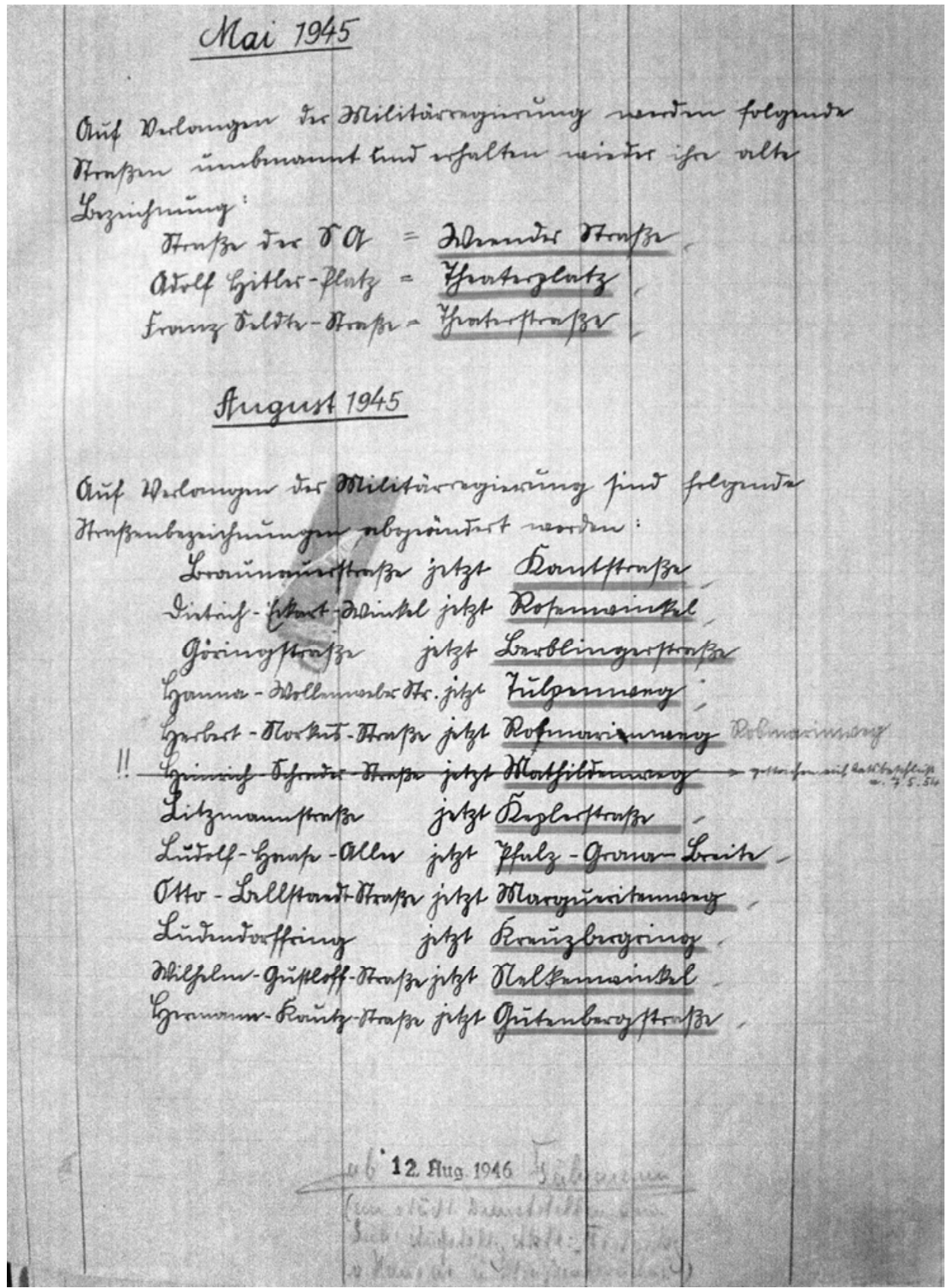

Q3: Akte „Hausnummern- und Straßenverzeichnis Okt. 1897 - Mai 1955“ (Stadt Göttingen, Fachdienst 61.2: Bodenordnung, Vermessung und Geoinformation). 


\section{$\underline{\text { Mai } 1945}$}

Auf Verlangen der Militärregierung werden folgende

Straßen umbenannt und erhalten wieder ihre alte

Bezeichnung:

Straße der SA = Weender Straße

Adolf Hitler-Platz = Theaterplatz

Franz Seldte-Straße = Theaterstraße

\section{$\underline{\text { August } 1945}$}

Auf Verlangen der Militärregierung sind folgende

Straßenbezeichnungen abgeändert worden:

Braunauerstraße jetzt Kantstraße

Dietrich-Eckart-Winkel jetzt Rosenwinkel

Göring-Straße jetzt Berblingerstraße

Hanna-Wollenweber-Straße jetzt Tulpenweg

Herbert-Norkus-Straße jetzt Rosmarienweg Rosmarinweg

Heinrich-Schrader Straße jetzt Mathildeweg gestrichen auf Ratsbeschluß v.

7.5 .54

Litzmannstraße jetzt Keplerstraße

Ludolf-Haase-Allee jetzt Pfalz-Grona-Breite

Otto-Bellstädt-Straße jetzt Margueritenweg

Ludendorffring jetzt Kreuzbergring

Wilhelm-Gustloff-Straßejetzt Nelkenwinkel

Hermann-Kautz-Straße jetzt Gutenbergstraße

n.b. 12. Aug. 1946 Führmann

(an städtische Dienststellen usw.

Siehe Aufstell[un]g Akte: „Festsetz[un]g

v[on] Hausn[umme]r u[nd] Straßenbezeichn[un]g“)

\section{Umschrift Q3}




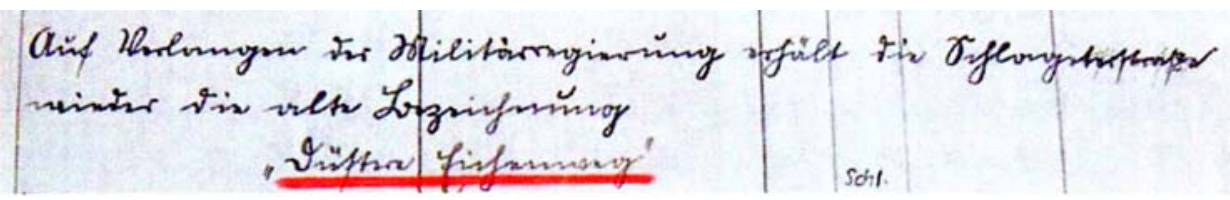

Q4: Akte „Hausnummern- und Straßenverzeichnis Okt. 1897 - Mai 1955“ (Stadt Göttingen, Fachdienst 61.2: Bodenordnung, Vermessung und Geoinformation).

Auf Verlangen der Militärregierung erhält die Schlageterstraße wieder die alte Bezeichnung

„Düstere Eichenweg““

Umschrift Q4

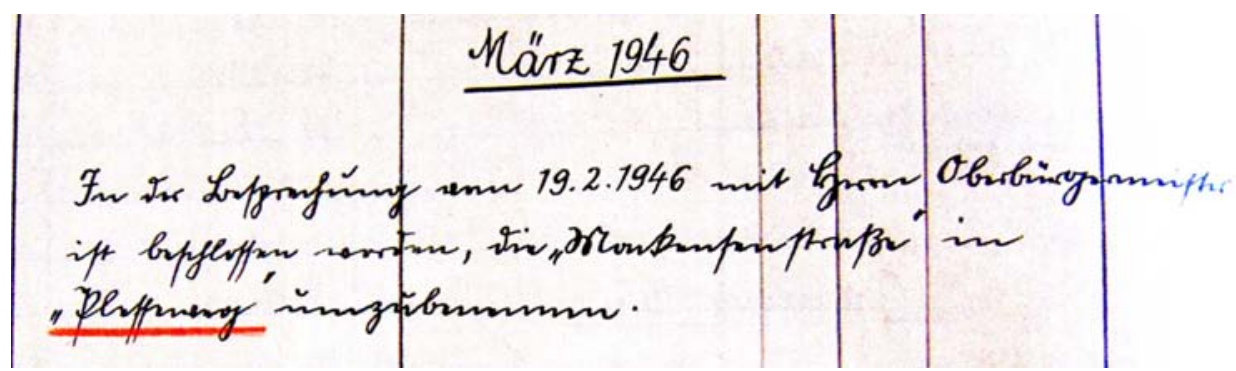

Q5: Akte „Hausnummern- und Straßenverzeichnis Okt. 1897 - Mai 1955“

(Stadt Göttingen, Fachdienst 61.2: Bodenordnung, Vermessung und Geoinformation).

In der Besprechung am 19.2.1946 mit Herrn Oberbürgermeister ist beschlossen worden, die „Mackensenstraße“ in

„Plesseweg“ umzubenennen.

Umschrift Q5 
19. Antrag der SPI-Fraktion auf Umbennung von Straßen, Entfernung 7 on Bildern und Symbolen der fruheren Zit in Schulen und stradtischen Gebäuden sowie Einsetzung eines ständigen Ausschusses flur die. Städtische Bucherei.

Iie Stedtvertretung wolle beschließen:

1. Der Bauausschuss wird beauftragt, Vorschläge zu machen, fúr eine Umbernnung folgende Straßen: Bismarckstr., Boelckestr., Immelmannstr., Iangemarckstr., Littichstr., Masurenstr., Richthofenstr., Sedanstr., Tannenbergstr., Undetstr., Weverstr., Ziethenstr., Hindenburgwail und Alter Kasernenplatź.

2. Der Kulturausschuss wird beauftragt, die Bilder und Symbole zu ermitteln, die cus den städtischen Gebsuden und Schulen entfernt werden sollen und neu Vorschläge zu machen uber Symbole und Wandschmuck, in denen das Gute und Schöne aus der Vergangenheit und das demokratische Wollen der Gegenwart zum Ausdruck kommt.

3. Der Kulturausschuss errennt einen aus 5 Personen bestehenden Bibliotheksunterausschuss. Er soll eine stänige Iinrichtung zur Kontrolle sein. Nur mit seiner Zustimmung können Bücher der städischen Bibliothek heraus- und eingestellt werden.

Ratsherr Körber begrüdet den Antrag.

Ratsherr Berg beantragt, uber Absatz 1 besonders abzustimmen. Iie CIU-Fraktion könne nur dem Antrage zu 2 und 3 zustimmen. Ir hält die unter Absatz 1 beantragten Umbennungen nicht für erforderlich, da nicht alle Bezeichnungen unter der Begriff "Militarismus" fielen.

Ratsherr Reichardt erklärt, daß auch die FDB-Fraktion dem Absatz 1 in cer vorliegenden Fassung nicht zustimien könne. Ratsherr Ellermeier ehlfeßt sich dem Antrag der SPI an. Ratsherr Brijller weist eus die Einwände Berg und Reichardt zuriuck.

Der Antrag Berg auf getrennte Abstimmung wird mit 18 gegen 11 Stimmen abgelehnt.

Dem Antrag dor SPD-Fraktion wird mit 18 Stimmen gegen 10 Stimmen bei einer Stimmentraltung zugestimmt.

Q6: Protokoll 01/1947 der Ratsversammlung der Stadt Göttingen vom 17./24.1.1947 (Stadtarchiv Göttingen). 
zu Punkt 6): Herr Graer lept elnen DeschluB der SPD-Praktion vor, der colgende Umberennungen der Strason vorschilizt:

Boelokestrabe Iame I wannatraie Langeaarckstraße Luttichatrabe Mas urese trage Rich tho fenstraise Sedanstrase Tannenberestrabe Jdetatrable Zle teastrabe foverstraise Kasernenplats Hindenburgrall ... Tourbingerstratse

- August Bebelatraße - Gustar 3tresemannstraBe - Beethovenatra3e

- Rlesiseweg

- Teonbard telsonstraje

- Geschwister Schollatraje

* Friearich Ebertatraje

- Frledrieb quarnatraze

= valter athensustraise

* Heinrich Heineatrabe

- Robert Rocbatrajo

= Aa Gelssartor

$=$ พall

= Karl varxatraje

Lerr Elleraeler bittet, die SpD-praition abge ihre: Berchlus dahingehend abincora, das die sistarcistrabe mit usbenannt wird.

kerr Grabenhorat teilt alt, da 3 saf antrag des Inatituts fur sed. Chessio und lygiene der universitat dottingen berelts 1w Jahre 1940 die Benennung des varlingerten KIrebsegs al zobert Jochotrabe in susulcht genormen sel and bittet, das zu berileksichtigen.

Jer Ausachus einfgt sch dahingehend, das der verlingerte Kirchag die Eezolchning kobert Lochatrabs erhalten goll. Die zeveratrabe soll sodann in Heinrich fiblnestrabe ubenannt werien, und die zietenatraje 11 e Bateichnung v. Osaletzhistrabe bekoasen. git Sen ubrigen Jabenennugigen erslurt sich der AusschuB ebenfalls olnverstanden.

Q7: $\quad$ Protokoll des Bauausschusses der Stadt Göttingen vom 14.2.1947 (Stadtarchiv Göttingen). 
5.) Antrag des Bauausschussas auf Umbenennung von Strasen.

Antrag: Während des Naziregimes wurden verschiedene StraBen mit Namen belegt, die einen bestimmten $\mathrm{Z}$ weck des sogenannten dritten Reiches dienen und den Militarismus verkörpern oder verherrlichen soliten. Anstelle dessen sollen die Straßen+ Namen verdienstvolier großer Mënnes des deutschen Volkes aus Tissenschaft, Kunst, Musik, Dichtung und Politik erhalten.

Die Stadtrertretung wolle deshalb folgende Umbenennung der Straben beschließen:

1. Immelmann-Str.

2. Tannenberg-str.

3. Boelcke-str.

4. Richthofen-Str.

5. Udet-Str.

6. Berblinger-Str.

7. Sedan-Str.

6. Tever-Str.

9. Iangemarck-Str.

10. Nasuren-Str.

11. Itittich-Str.

12. verl. Kirchweg

13. Viethen-Sir.

14. Hind enhurgwall

15. Tasemenplatz

Stresemann-Str. Friedrich Naumann-Str. Bebel-Str.

Geschwister Scholl- Str. Rathenau-Str.

Karl Uarx-Str. Friedrich Ebert-Str. Feinrich Heine-Str. Beethoven-Str. Lèonard Nelson-Str. Plesseweg Robert Koch-Str. Osgietzki-Str. Tall

Am Geismartor.

Ratsherr Graef begriunet den Antrag.

Ratsherr Ellennejer weist darauf hin, daß diese Sache schon einmal in Plenum beraten sei. Damals sei für eine Xnderung auch die Bigmarckgtraße vorgeschlagen und das Plenum habe dem zugestimmt. Die Umbenennung der Berblingerstrabe wirke komisch, da Berblinger bekanntlich der beruhmte Schneider aus Ulm sef, der die ersten Flugversuche unternommen habe.

Ratsherr Kohlbacher empfiehlt, Straßen und Plä.tze nicht nach politisch zur Zeit umstrittenen Männern $z u$ benennen und von der Umbenennung von StraRen zur Zeit uberhaupt abzusehen.

Ratgherr Berg teilt mit, daß diese Angelegenheit wohl im Bauausschuß, aber nicht im Kulturausschuß.beraten se1. Dies sei notwendig und er beantrage tberweisung an den KulturausschuB.

Ratsherr Bretgchneider unterstützt diesen Antrag, der mit 18 geger 9 stimmen abgelehnt wird.

Der Antrag deg Bauausschusses wird mit 18 gegen 9 Stimmen angenommen.

Ratsherr Ellermeler beantragt, der Witwe Karl von Ossitzki's die Ehrung ihres vor den Nazis ermordeten Gatten mitzuteilen.

Frau Wagener untergtützt den Antrag, der mit 18 gegen 8 Stimmen angenommen wird.

Q8: $\quad$ Protokoll 04/1947 der Ratsversammlung der Stadt Göttingen vom 7.3.1947 (Stadtarchiv Göttingen). 


\section{Neue Straßennamen in Göttingen}

Eine Reihe von Straßen in Göttingen, „die einem bestimmten Zweck des sogenannten Dritten Reiches dienen und den Militarismus verkörpern oder verherrlichen sollten", sind nach dem Beschluß der letzten Sitzung der Stadtvertretung gegen die Stimmen der CDU und der FDP umbenannt. Man wird also wieder einmal umlernen müssen, wobei der Ansicht Raum gegeben sei, daß diese Umbenennung wohl kaum dem Wunsche und Willen des überwiegenden Teils der Göttinger Bevölkerung entspricht. Un.benannt wurden: Immelmann- in Stresemann-Straße, Tannenberg- in Friedrich-Naumann-Straße, Boelcke- in BebelStraße, Richthofen- in Geschw.-Scholl-Straße, Udet- in Rathenau-Straße, Berblinger- in KarlMarx-Straße, Sedan- in Friedr.-Ebert-Straße, Wever- in Heinrich-Heine-Straße, Langemarckin Beethoven-Straße, Masuren- in LeonardNelson-Straße, Lüttich-Straße in Plesseweg, verl. Kirchweg in Robert-Koch-Straße, Zietenin Ossietzki-Straße, Hindenburgwall in Wall und Kasernenplatz in Am Geismartor.

Q9: Hannoversche Neueste Nachrichten, Ausgabe G Südhannover, 2. Jg., Nr. 20 vom 12.3.1947, S. 4 (Stadtarchiv Göttingen, Film Ztg. Nr. 623).

\section{Der Rat setzt sich für die Sportler ein}

\section{Umfangrelche Tagesordnung der Göttinger Ratssitzung}

In der Ratssitzung am 7. März machte der Oberbürgermeister Prof. Dr. Düker u. a. die Mitteilung, daß die Militärregierung der Bitte des Rates um Freigabe des Sportplatzes der "Göttingia" nicht entsprochen habe, weil dieser Platz noch vom Nordhamptonshire-Regiment benötigt werde.

Die sozialdemokratische Ratsfraktion hatte einen Antrag auf Wiedereröffnung des Städt. Freibades eingebracht. Ratsherr Bohnhaus (SPD) führte dazu aus, daß im Göttinger Schwimmsport traurige Zustände herrschten, und es dringend notwendig wäre, sportgerechte Anlagen zu schaffen. Die Notwendigkeit wurde auch von anderen Rednern anerkannt, jedoch wurde auf die Schwierigkeiten hingewiesen, die bei der Beschaffung des Baumaterials für das Bassin auftreten würden. Der Rat beauftragte den BauausschuB, alle notwendigen Vorbereitungen $\mathrm{zu}$ treffen.

Der Oberbürgermeister teilte mit, daß die Wiedergutmachung für Schäden, die durch das Nazi-Regime entstanden sind, geselzlich durch den Niedersächsischen Landtag geregelt werden soll. Der Rat bewilligte die Anschaffung eines Dampfdrehkrans für das Gas-- und Wasserwerk. Ebenfalls einstimmige Annalıme fand ein Antrag auf Ablösung des Erbbaurechts der Anlieger und Siedler am Fliederweg, der Iheringstraße, der Kommendebreite und Gerichtlinde.

Auf Antrag des: Bauausschusses wurden die Straßennamen, dle auf das Dritte Reich zurückgehen oder den Militarismus verherrlichen. beseitigt. Hierüber entspann sich eine längere Aussprache. Der von bürgerlicher Seite eingebrachto Antrag, diese Angelegenheit dem KulturausschuB $2 \mathrm{u}$ uberweisen, wurde abgelehnt. Dem Kulturausschuß 2u úberweisen, wurde abgeiehnt. Dem zustăndigen AusschuB wurde dann ein weiterer. Antrag der sozialdemokratischen Ratsfraktion uberwiesen, ${ }^{*}$ der die
Aufnahme von Vorarbeiten zur Schaffung einer zweiten Ausfahrtstraße parallel zu: Weender LandstraBe bezweckt.

Wegen der Errichtung einer àrztlichen Notdienststelle lag ein never Dringlichikeitsantrag vor. Wie bei der Behandlung dieser Frage ausgefüht vrurde, gibt es in Göttingen genügend Aerte, die aber keine Zulassung bekommen können, obwobl die z'rgelassenen Aerzte stark überlastet sind. Der Antrag wurde an den GesundheitsausschuB zurùckverwiesen. Ein SPD-Antrag auf $\mathrm{Ab}$ trennung des Jugendamtes vom Sozialamt wurde an den WohlfahrtsausschuB weitergeleitet.

Q10: Hannoversche Presse. Die Zeitung aller Schaffenden, Ausgabe Südhannover, 2. Jg., Nr. 21 vom 14.3.1947, S. 3 (Stadtarchiv Göttingen, Film Ztg. Nr. 627). 


\section{Straßenumbenènnung in Göttingen}

In der letzen Stadtratsitzung owurde eine Reihe von, Straßennamen umgeändert und zwar: Immelmann- in Stresemannstraße, Jannenberg- in Friedrich-Naumann-Straße, Boelkein Bebelstraße, Richthofen- in Geschw.-SchollStraße, Udet- in Rathenaustraße, Berblingèr- in Karl-Marx-Ștraße, Sedan- in Friedrich-EbertStraße, Wever- in Heinrich-Heine-Straße, Langemarck- in Beethovenstraße, Masuren- in Leonard-Nelson-Straße, Lüttichstraße in Plesseweg, verl. Қirchweg in Robert-Koch-Straße, Zieten- in Ossietzkistraße, Hindenburgwall in Wall und Kasernenplati in Am Geismartor.

Q11: Hannoversche Presse. Die Zeitung aller Schaffenden, Ausgabe Südhannover, 2. Jg., Nr. 22 vom 18.3.1947, S. 3 (Stadtarchiv Göttingen, Film Ztg. Nr. 627).

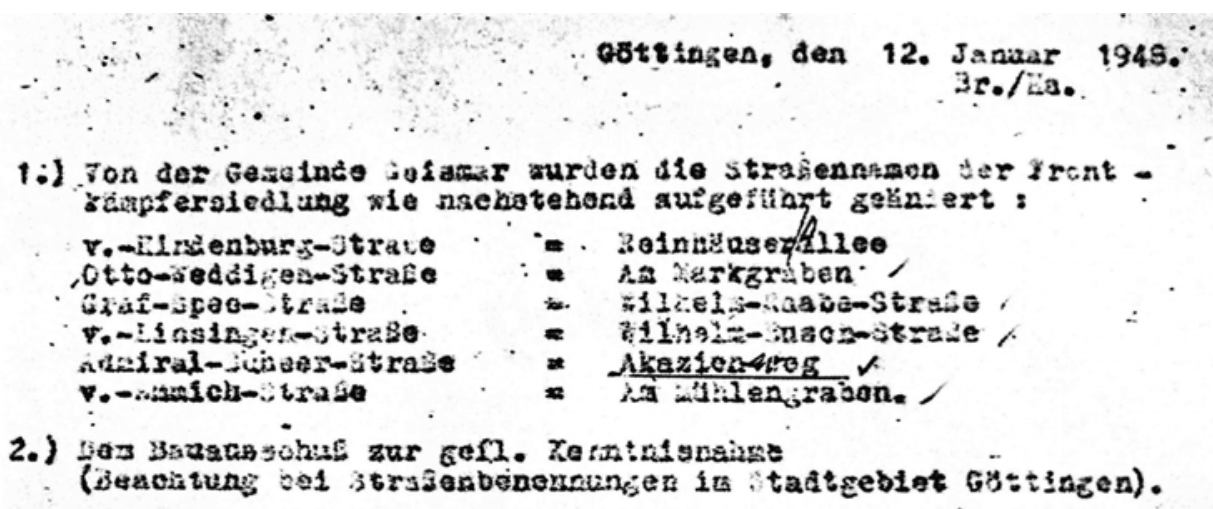

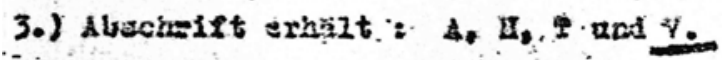

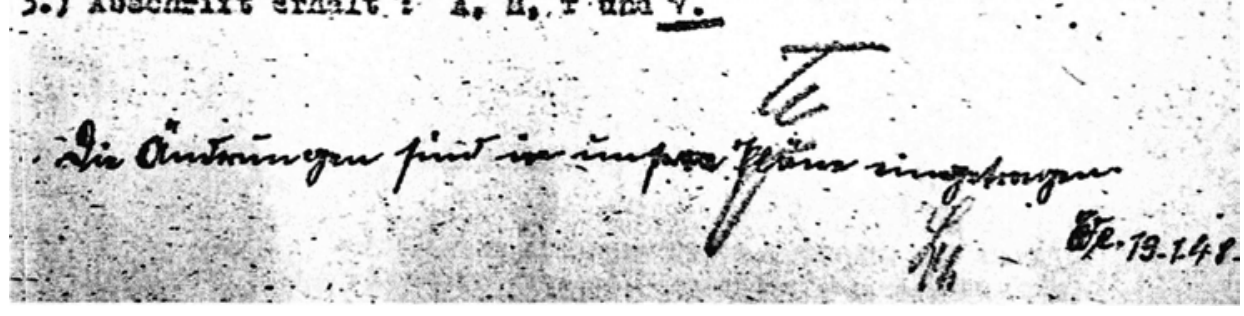

Q12: Aktenordner „Straßennamen A,1, Akazienweg“ (Stadt Göttingen, Fachdienst 61.2: Bodenordnung, Vermessung und Geoinformation).

Die Änderungen sind in unsere Pläne eingetragen.

Umschrift der Notiz in Q12 
GLSELISCHAFT DER FHEUNDEWILEELM RAABBS

Göttingen, - den 2.Dez.1947

Zweig Göttingen

732.

Aî̀ 'die

Stadtrerwaltung

Go.t $t$ i $\sin$

Betr.: Aenderung von Strassen-Namen.

Fir die Neubennung einer Strasse erlaube ich mir, den Namen

- des Dichters "Wi lihelm habe" vorzuschlagen.

ys wird nicht viele bedeutende kinner geben, die diese Lhrung

der stadt Göttingen in Gleichem Masse verdienen.'

Wilhelm Raabes allgemeine Anerkennung als Kun'st'ler wie als Lensch, sowie insbesondere die lebendige Wertschätzing, die ihm in seiner niedersächsischen Heimat zuteil wird, erturigen wohl eine nühere

Besrindung.

Erwahnt sei nur, dass Gottingen in seinen schriften wiederholt genannt und in der besonderen Bedeutung als Universitätsstadt gewirdigt wird, ferner, dass Wilbelm Rabe Ihrendoktor unserer Universität ist.

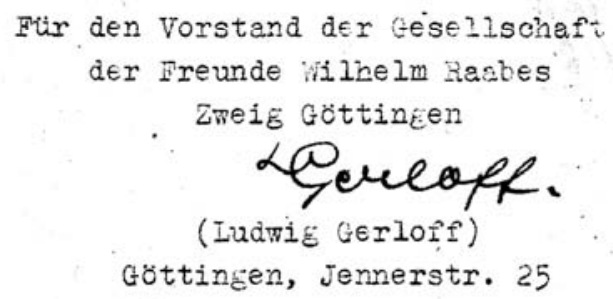

(Iudwig Gerloff)

Göttingen, Jennerstr. 25

Q13: Aktenordner „Straßennamen W,2, Wilhelm-Raabe-Straße“ (Stadt Göttingen, Fachdienst 61.2: Bodenordnung, Vermessung und Geoinformation). 


\section{Das fiel uns auf ....!}

Göttingen, 7. November.

Reklame muB sein, allerdings - und das erscheint wichtig - muB die Art und Weise gegenwartsnah und fortschrittlich sein. Möglichkeiten gibt es dabei in Unzahl und auch die Reichspost stellt sich in den Dienst der „reklamedürstenden" Geschäftswelt.

In Gö̀ttingen scheint den maßgeblichen Beamten ein kleines Versehen unterlaufen zu sein - möchten sie unseren kleinen Hinweis auch als solchen auffassen

Die Stehpulte in der Hauptpost tragen auf den Löschblattunterlagen wirksam die Reklame verschiedener Göttinger Firmen. Sollte man diese nicht doch einmal von Zeit zu Zeit auf ihr€ "Gegenwartśnähe" hin prüfen? Sicherlich "könnte es dann mehr als 11/2 Jahre nac's dem Ende des dutzendjührigen Reiches nicht vorksmmen, $\mathrm{da} B$ dort geschrieben steht. daB die Firma Eoto-Lanz ihr Iadengeschäft in der "StraBe der SA" hat, während die Dietrichsche Universitätsbuchhandlung ihren Freunden mitteilit, da Franz-Selote-Straße besuchen möchte. Die Firmen wird hierbei keine schuld treffen, und es wäre sicherlich verfehlt, wollte man die zahllosen vorhandenen s. sicherlich raren Lbschbogen fortwerfen - Mit einem einfachen Klebestreifen wäre diese kleine Unschönheiten behoben und man würde sich dennoch freuen, zu wissen, daß es diese Firmen in Göttingen giht. Und finden werden wir sie sicherlich auch, dafür sind sie gut genug in Göttingen bekannt.

Q14: Hannoversche Volksstimme. Die Zeitung für die Interessen der Werktätigen, Ausgabe Südhannover, 1. Jg., Nr. 25 vom 8.11.1946, S. 3 (Stadtarchiv Göttingen, Film Ztg. Nr. 629).

\section{Immer noç Schönheitsfehler \\ cottinizen. 2s: November.}

Schon ofter frón We daraut hingewiesen, da B a ûf Briefbogen hur di alten Straßeńbézéchnungen aus Qer. Nazizeit noch zu lesen sind. Erst wern man eine Firma 5 ffentlich, mahnt, reagiert sio darauf.

Langram aber müsen wir arnekmen; đ̆a es sich nicht nur ữ Gedankénlösigkoit handelt, OSer solite Dr. Thiele der Eesitzer der Weender-Tor-Apotheke, immer noch nicht bemerkt haben, daB sein Geschäft sjeh nicht in der Straß- der SA Nr. 106 befindet.

Scheinbar nein - derm auf seinen Arzneiflaschion kann man es immer noch lesen.

Q15: Hannoversche Volksstimme. Die Zeitung für die Interessen der Werktätigen, Ausgabe Südhannover, 1. Jg., Nr. 30 vom 26.11.1946, S. 3 (Stadtarchiv Göttingen, Film Ztg. Nr. 629). 
In der Ausgabe Ihrer Zeitung vom 12. II. 1957 bringen Sie ein Bild von der Aufrichtung des Richtkranzes am Verwaltungsgebäude des Landkreises am „82er-Platz". In der Zeitung vom 13. II. 1957 "wird im Zusammenhang mit der Schaffung eines neuen Marktplatzes wieder vom "82er-Platz" gesprochen. Es scheint Ihrer Aufmerksamkeit bisher entgangen zu sein, daf dieser Platz seit Jahren wieder die alte vertraiste Bezeichnung "Am Geismartor" trägt. Da eine gut redigierte Zeitung nicht nur. Tagesfragen erörtern, sondern auch erzieherisch wirken soll, wăre es zu begrüßen, wenn Sie mit gutem Beispiel vorangehen würden und den ehemaligen 82er-Platz auch aus den Spalten Ihrer Zeitung verschwinden lassen würden. Ich glaube, keiner wird diesem Sprachmonstrum nachtrauern, sondern jedermann wird gern dazu beitragen, unser leider dem Verkehr zum Opfer gefallenes schönes Geismartor wenigstens auf diese Weise dem Gedächtnis lebendig zu erhalten.

Frau Els Röttscher, Göttingen, Am Feuerschanzengraben 5

Q16: Göttinger Tageblatt, 69. Jg., Nr. 39 vom 15.2.1957, S. 6 (Stadtarchiv Göttingen, Film Ztg. Nr. 277).

\section{Namen belassen}

In Nr. 39 Ihrer Zeitung wünscht eine Frau, da $\beta$ man den 82er-Platz in Geismartor umbenennen sollte. Geismartor ist aber eine Sache für sich und 82er-Platz auch. Zur Erinnerung an das Regiment sollte man diesen Platz ruhig tei dem bisherigen Namen belassen. - Es wäre im übrigen tiefbedauerlich, wenn man aus dem abgetragenen Wall (vor dem GauB-Weber-Denkmal) einen Marktplatz machen wollte. Sollte sich nicht in der Geiststraße der große Hof dafür eignen? Rudolf Ludwig, Wiesenstraße 30

Q17: Göttinger Tageblatt, 69. Jg., Nr. 55 vom 6.3.1957, S. 4 (Stadtarchiv Göttingen, Film Ztg. Nr. 277). 


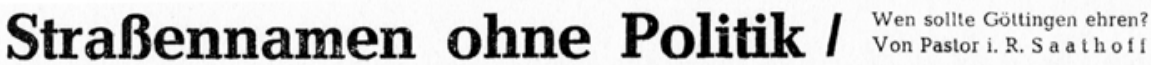

\begin{abstract}
Namen geben oder besser gesagt Namen verleihen, ist eine wichtige Sache. Das gilt von Personennamen, aber noch mehr von Straßennamen. Sie sind für eine lange Zukunft, wenn die Welt sic erlebt, bestimmt. Das sollte ein erster Gesichtspunkt bei aller Namengebung sein: werden die Namen noch ein oder zwei Menschenalter, vielleicht noch länger den Einwohnern der Stadt bedeutsam sein? Man sagt, solche Benennung solle für den Namentrïger eine Ehrung sein. Ist das wirklich nach allgemeinem Urteil der Fall?
\end{abstract}

Nun haben wir in Göttingen nach 1933 einige merkwürdige Namen⿳亠口冋derungen erlebt. Unsere ehrwtirdige, schon 1338 bezeugte Weender Straße, mußte es sich gefallen lassen, dic auch sprachlich häiliche, ja unmögliche Bezeichnung: Strabe der SA 12 Jahre zu tragen. Warum? Aus parteipolitischen Gründei. Ebenso wurde der mit einem sehr alten Namen (1377) benannte Düstere Eichen Weg. Schlageter Straße benannt - was hat der mi Cótungen zu tun? Die Theaterstraße wurde Franz-Seldte-Stralse umbenannt - wer weil heute noch etwas von inm, sein Name steht nicht einmal im Kleinen Herder. Dab es einmal eine coring-straise segeben hat, werden ist nur, das dieser Brauch Schule gemech ht nur, das dieser Brauch schule gemach hot. die wichtige Straßenbenennung partelpolitisch zu verwenden, um nicht zu sagen: Namentzent solisen in do Straße, die in $v$. Ossietzly-Straße umbenannt Straße, die in $v$. Ossietzky-Strabe umbenann wurde, fur unsere Gottinger schon sprachlich werden schon Viele gefragt haben. Nun, werden wenigstens im Kleinen Herder: Publizist, 1880-1933 (t im KZ), Herausgeber de linksradikalen Wochenschrift Weltbühne; inm wurde die Annahme des Friedensnobelpreises 1935 untersagt (von Hitler). Also: ein scharfer

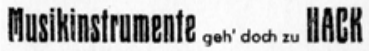

Kommunist, dẹ meines Wissens mit Göttingen nichts zu tun hat! Vielleicht ist das ein besonders schwerer Fehler in der Benennun gewesen. Unsere Gottinger Bürger werden ist auch - nach 1945 - eine Straße Heinrichist auch - nach 1945 - eine Straße Heinrichin Gottingen studiert worden. Heine hat zwa in Gottingen studiert und sicherlich einige schoone Lieder gedichtet, aber mit seiner fri-
volen Spötterei hat er auch Göttingen nich verschont und viele Schmáhworte über unsere Stadt geschrieben, und man fragt sich kopischütteind: Den muß Göttingen ehren? Dicse sehr anfechtbare Namengebung ist auch deswegen sehr zu bedauern, weil dadurch di: Ehrung eines Mannes unmöglich ist, de 1763-1812 als Professor in Göttingen die grölsten Verdienste um die Göttinger. Universithi und ihre Bibliothek gehabt und zu dem Weltruf Grotungens im 18. Jahrhundert beigetragen hat Heinrich-Heine-strabe und colliobHeyne-Strabe, das ware

Nun machen die Benennungen der vielen neuen Straßen dem Rat der Stadt große Not Woher wirkilch gecigncte, bedeutsame, sprach-

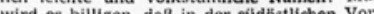
wird es billigen, das in der sudbsulchen vorstadt die Namen ostdeutscher Stadte verTrinnerung an die Heimat! Und mon wird es verstehen und vielleicht verzeihen, daß in einer 'Leit, da parteipolitische Gesichtspunkt bel der Wahl der Namen so starke Rucksicit erfuhren, man zu dier Wahl harmloser Blumennamen kam: Rosmarinweg, Nelkenwinke, Margueritenweg, Tulpenweg: das ist ja seh niedlich und mag wohl gelegentlich sinnbild einmal die Anwohner, ob sie nicht gern ander Namen hätten! Jelzt scheint die parteipolitische Namengebung wieder Oberwasser zu gewinnen, obwohl Oberbürgermeister Föge al Ratsherr im Anfang dieses Jahres die seh gern gebilligte Losung ausgegeben hat: Stranennamen on Plo um den Antrag der SPD zwei Kreuzungen am Dastere Eichen Weg zu benennen: Alberttab in gab damals im Rat cine lebharte Auseinanderhat - las Goutinger Tageblatt hat darte hat - das cotinger Tageblatt hat daruber jeizt wieder die Sache vom Rat verhandelt und Albert Einstein und Thomas verhandelt, gewiß inre Verdienste, aber meines Wis gewis inre Verdienste, aber meines Wissens mit Gottingen nichts zu tun haben, erhieins Leben gerufenen Vergntigungsausschu der Stadt" war in der Zeitung das Ansinne gestellt, die Verlăngerung der Ewald-Straße zu nennen: Ernst-August-StraBe! Wir wolle uns freuen, da $B$ Gottingen vor einer gan schweren Fehlbenennung bewahre geblieben ist. Es war wohl ein necklscher Zufall, da zwel Tage später im Tageblatt ein Aufsatz ve offentincht wurde: Der Protest der Göttinge Sieben und dort über Ernst August gesagt wurde, was wohl Viele nicht wissen - man dies das Entscheidende: Der König hat nach dem Vertassungsbruch 1837 die sieben Profeswiesen , einzelne solort des Landes vermeßlichen Schaden augetügt, so dae es viele Jahre dauerte, bis die Universităt wieder die alte Höhe erreichte! Und diese Schmach, die Göttingen damals erlebt hat, sollte nun damit lich gedeutet werden. Aber man frage doch berechtigte und wohl von den meisten Bürmöge es dort nachlesen! Für unsere Stadt is soren, die den Mut hatten, dagegen Elnspruch zu erhen, kurzersand versitit und dadurch der Stadt einen Uner- belohnt werden, đaß Göttingen dem König zu Ehren eine Straße benennt! Der Rat ist selbstverstandlich nicht auf diesen ..Scherz" eingcgewesen, wenn a a ach geradezu dro die Straßengruppe der "Gcttinger Sieben" ingrenzt, Ernst-August-Straße genannt hătte.

Aber nun ist bei dieser Gelegenheit der Platz, der voikstümlich vielleicht scherzweise Polsdamer Platz heibt, mit der Bezeichnung Elchendor and Januar Fó jar $k$ chlat, wie schon im Jas erinnert betonte. Aber Potsdamer Platz! an den Potsdamer Geist' So etwas ist doch in unserer Zeit untragbar"! Und nun hat Elchen urft seinen" Niagenendiesen Tagen von den Schlesiern der Wunsch diesen Tagen von den Schlesiern der Wunsch gebracht, man möge aus Anlaß von Eichengebracht, man möge aus Anlaß von Eichen-
derffs Todettag am 26. November vor 100 Jahren am Hainberg eine Eichendorfthöhe schaffen und es war dafür persönliche Arbeit der Schlesier war dafur personliche Arbeit Gedanke! Ich weiß nicht, ob die Schlesier einen besonderen "Heimatbaum" " haben, sonst whire die Pflanzung einer "deutschen Linde“ am Hainberg für solche Gedächtnissthitte sehr zu empfehlen. Mir scheint der Platz etwa 50 Meter sudllich des Friedensplatzes auf der Hŏhe, von der das Rodeln nach der Bismarckstraße eifrig betrieben wird, durch seine Abgeschlossenheit recht geeignet. Und noch einen schönen Brauch schlage ich vor. Die Schlesier möchten im Sommer an einigen, schönen Sonntagen einladen zu einer Feierstunde auf der Eichendorff-Hohe und die herrlichen Lieder singen, und es könnte sich vielleicht Erzählung oder Bericht von ihrem Heimatlande anschließen - das wäre fein: Den Namen für den Potsdamer Platz sollte man stillschweigend fallen lassen. Es geschah so etwas schon einmal, 1937. Der Willhelmsplatz sollte auf höheren Befehl seinen Namen verlieren, ich weiß nicht mehr, wic er heißen neues Schild nicht anbrinsen und nien ein etwas. Es ließe sich nie niemand Namen unserer Straßen sagen. Abschlu auf ein Buchlein ven. Es sei zum Wissenswertes bringt, Góttingern unbekannt ist: Das tausendjuhrige Gottingen, Ursprung und Entwicklung im Splegel seiner Straßen und Bauten, 84 S. mit vielen Bildern und Plänen, von Deppe, Jager, Dr. Troe. Preis nur 2,10 DM.

Saathoff, P. i. R.

Q18: Göttinger Tageblatt, 69. Jg., Nr. 273 vom 23./24.11.1957, S. 18 (Stadtarchiv Göttingen, Film Ztg. Nr. 280). 



\title{
Heimkehr aus Krieg und Gefangenschaft
}

\author{
Anne-Katrin Poppe
}

\section{Die Situation am Kriegsende}

Am 8. Mai 1945 war der Krieg für die kämpfenden Soldaten in Europa offiziell zu Ende. Schon vor diesem Datum hatte eine gewaltige zivile Fluchtbewegung aus den ehemaligen deutschen Ostgebieten begonnen. Zu diesen Flüchtlingen gesellten sich nun auch die Wehrmachtssoldaten, die der Gefangennahme durch die Rote Armee bislang entgehen konnten. Sie hofften, der Gefangenschaft auch weiterhin zu entkommen oder - als mutmaßlich kleineres Übel - in den Gewahrsam der westlichen Alliierten zu gelangen. Ebenso verließen im Westen Soldaten ihre Truppen, um nach Hause zurückzukehren. Von den etwa elf Millionen Soldaten, die zu Kriegsende noch in der Wehrmacht kämpften, schafften es jedoch nur die wenigsten ohne zumindest vorübergehende Gewahrsamnahme bis an ihr Ziel. So befanden sich am Ende des Zweiten Weltkrieges weit über acht Millionen Deutsche in alliierter Kriegsgefangenschaft. Der weitaus größte Teil von ihnen wurde innerhalb eines Jahres entlassen: 1945/46 strömten mehrere Millionen ehemalige Soldaten in die Westzonen zurück, 1947/48 noch mehrere hunderttausend, bis 1955/56 nahmen die Zahlen bis auf wenige tausend ab. ${ }^{1}$

Der Begriff Heimkehrer bezeichnet nicht die große Masse der zurückkehrenden Soldaten, sondern bezieht sich auf diejenigen Soldaten, die nach 1947/48 spe-

\footnotetext{
1 Traugott Wulfhorst, Der „Dank des Vaterlandes“ - Sozialpolitik und -verwaltung zur Integration ehemaliger Wehrmachtsoldaten und ihrer Hinterbliebenen, in: Rolf-Dieter Müller/Hans-Erich Volkmann (Hg.), Die Wehrmacht. Mythos und Realität, München 1999, S. 1037-1057, hier S. 1038.
} 
ziell aus sowjetischer Gefangenschaft entlassen wurden. ${ }^{2}$ Anders als es diese Sammelbezeichnung nahe legt, handelte es sich bei ihnen jedoch keinesfalls um eine homogene Gruppe. Soziokulturelle Unterschiede, wie z.B. die soziale Schichtung, spiegelten sich auch bei den Heimkehrern wieder. Zudem differierten die individuelle Wahrnehmung und Deutung von Krieg und Gefangenschaft innerhalb dieser Gruppe.

Die Forderung nach Entlassung der Gefangenen - die sogenannte Kriegsgefangenenfrage - war eines der zentralen Themen der deutschen Nachkriegsgeschichte, das mit der „Heimkehr der Zehntausend“ im Herbst 1955 seinen Abschluss fand. Verbunden mit der Frage nach der „Heimkehr“ waren auch die Sorgen um den Verbleib verschollener Soldaten. Nach dem Überfall der Wehrmacht auf die Sowjetunion im Jahr 1941 war die Anzahl der „vermissten“ Soldaten stark angestiegen: 1943 betrug sie bis zu zwei Drittel der so genannten „Ausfälle“, die das Oberkommando der Wehrmacht in einer Statistik veröffentlichte. ${ }^{3}$ Der Status des „Vermissten“ ließ den Angehörigen immerhin die Hoffnung, der Betreffende könne sich noch irgendwo in der Sowjetunion in Gefangenschaft befinden. Die relativ ungenauen Angaben, die die Regierung der Sowjetunion über die tatsächliche Zahl der internierten deutschen Soldaten machte, und die eingeschränkten Informationsmöglichkeiten schürten sowohl Hoffnungen als auch Gerüchte. ${ }^{4}$

Die Repatriierung der Kriegsgefangenen sollte bis zum 31. Dezember 1948 abgeschlossen sein, so einer der Beschlüsse der Moskauer Außenministerkonferenz im Frühjahr 1947, zu der sich die Alliierten zusammengefunden hatten, um über die Zukunft Deutschlands zu beraten.

Die Sowjetunion verschob diesen Termin eigenmächtig um ein Jahr auf Ende 1949. Neben organisatorischen und logistischen Problemen des Rücktransports lag ein Grund hierfür in den ökonomischen Interessen der Sowjetunion: Die Internierten wurden zunächst weniger als politisch-strategisches „Pfand“ denn als Arbeitskräfte betrachtet, die ihren Anteil am Wiederaufbau der sowjetischen Wirtschaft leisten sollten. Die „Kriegsgefangenen“ wurden offiziell bis zu diesem Zeitpunkt nach Hause geschickt. Diejenigen, die über diesen Zeitpunkt hinaus in Gefangenschaft blieben, waren aus sowjetischer Perspektive (noch nicht) verurteilte Kriegsverbrecher. Damit hatte sich die Bewertung der Kriegsgefangenenfrage spätestens ab 1949 auch für die Sowjetunion in den politischen Bereich verschoben. ${ }^{5}$

\footnotetext{
2 Zur juristischen Definition des Begriffes „Heimkehrer“ im Heimkehrergesetz vom 19.6.1950 siehe Leonid Ischenin, Die deutschen Heimkehrer und die Maßnahmen zu ihrer Eingliederung unter Berücksichtigung der Umsiedler aus dem Osten, Diss., Köln 1966, S. 30-33. Weiterhin: Heimkehrergesetz. Kommentar und sonstiges Heimkehrerrecht von Dr. Kurt Draeger. 2. neubearbeitete, erweiterte Auflage, Berlin/Frankfurt am Main 1953.

3 Peter Steinbach, Die sozialgeschichtliche Dimension der Kriegsheimkehr, in: Annette Kaminsky (Hg.), Heimkehr 1948. Geschichte und Schicksale deutscher Kriegsgefangener, München 1998, S. 325-340, hier S. 325.

${ }^{4}$ Bis in die frühen fünfziger Jahre hielt sich unter anderem das Gerücht, in der Sowjetunion gäbe es „Schweigelager“ deutscher Kriegsgefangener. Vgl. Steinbach, Kriegsheimkehr. S. 325f.

5 Vgl. Dietmar Sauermann/Renate Brockpähler (Hg.), „Eigentlich wollte ich ja alles vergessen...“ Erinnerungen an die Kriegsgefangenschaft 1942-1955, Münster 1992, S. 368.
} 


\section{Die ersten Heimkehrer}

Praktisch hatte die deutsche Wehrmacht mit der Kapitulation des Reiches aufgehört zu existieren, formal wurde die Auflösung der Armee durch das Kontrollratsgesetz Nr. 34 vom 20. August 1946 nachträglich deklamiert. ${ }^{6}$ Die ehemaligen Soldaten, soweit sie nicht besonderen Arrestkategorien unterstanden, wurden demobilisiert, entlassen und hatten sich einer amtlichen Registrierung zu unterziehen (Q3). In der britischen Besatzungszone lief dieser Vorgang unter dem Codenamen „Operation Clobber“. Die ehemaligen Soldaten sollten möglichst für den Wiederaufbau der deutschen Infrastruktur mit den Schwerpunkten Bauindustrie und Bergbau zur Verfügung stehen (Q1).

Schon im Oktober 1945 befanden sich im Stadtkreis Göttingen knapp 4.000 entlassene Wehrmachtssoldaten, die dort ihren Wohnsitz hatten. Weitere 3.142 hatten auf ihrem Weg zurück an ihren Wohnort im Stadtkreis Göttingen Station gemacht, so berichtete es das Einwohnermeldeamt der Stadt am 1. Oktober 1945 dem Captain der Militärregierung Bertram (Q2). Auch aus Großbritannien kehrten im Herbst des Jahres 1945 ehemalige Soldaten zurück. Sie gehörten zu den Kriegsgefangenen, die während des Zweiten Weltkrieges interniert und in Lager außerhalb Deutschlands verbracht worden waren, wo sie an Reeducation-Maßnahmen teilgenommen hatten. Diese Männer sollten die „Erkenntnisse aus britischer Gefangenschaft" nach ihrer Rückkehr in die Praxis umsetzen und sich am wirtschaftlichen und politischen Wiederaufbau beteiligen (Q4).

Die Diskrepanz, die unter anderem zwischen den Heimkehrern aus einerseits westlicher und andererseits sowjetischer Gefangenschaft herrschte, wurde bereits bei diesen ersten Rückkehrern deutlich. Während sich die „britischen“ Gefangenen in einem guten physischen Zustand befanden - die Ernährung in Kriegsgefangenschaft konnte durchaus besser sein als die, die sie in der Heimat erwartete - erschienen die ersten Heimkehrer aus sowjetischer Gefangenschaft bei schlechter Gesundheit und in einem desolaten Allgemeinzustand: „Obne Gepäck, obne Decke, obne Mantel" erreichte beispielsweise ein Transport 1946 das Entlassungslager Friedland (Q5, 6). Bei diesen Soldaten handelte es sich in erster Linie um kranke, verwundete oder invalide deutsche Unteroffiziere oder Mannschaftsgrade. Sie waren kurz hinter der Front festgesetzt und von sowjetischer Seite als nicht arbeitsfähig eingestuft worden. ${ }^{7}$ Das häufigste Krankheitsbild, das diese Männer zeigten, wurde unter dem Begriff Dystrophie als Kriegsgefangenen-Krankheit bekannt. Darunter wurden Symptome, die sich aus Mangelernährung ergaben, verstanden.

\footnotetext{
6 Kontrollratsgesetz Nr. 34 (Auflösung der Wehrmacht) vom 20.8.1946, http://www.verfassungen.de/de/de45-49/kr-gesetz34.htm. <23.9.2008>

7 Stefan Karner, Deutsche Kriegsgefangene und Internierte in der Sowjetunion, in: Die Wehrmacht, S. 1012-1036, hier S. 1033f. Außerdem: Hilger, Kriegsgefangene, S. 315f.
} 
Neben den körperlichen Symptomen führte man teilweise auch psychische Auffälligkeiten der Kriegsteilnehmer auf diese Ursache zurück. ${ }^{8}$

Die Entlassung der Kriegsgefangenen in die westlichen Besatzungszonen verlief anfangs ohne größeren bürokratischen Aufwand, was unter anderem der Tatsache geschuldet war, dass es zunächst keine zentrale Zuständigkeit für die Entlassung der Gefangenen gab. Erst 1948 wurde Friedland zum einzigen Entlassungslager für die britische Zone, später in der Bundesrepublik für Niedersachsen. Als die Repatriierung aus den westeuropäischen Staaten 1948 nahezu abgeschlossen war, sollte die Entlassung der Kriegsgefangenen aus der Sowjetunion komplett über Friedland verlaufen. Alle Heimkehrer aus der Sowjetunion wurden nun über das nahe der Zonengrenze liegende Durchgangslager in die westlichen Zonen und später in die Bundesrepublik entlassen. ${ }^{9}$ Dort erhielten sie die ersten Dokumente, die für ihren weiteren Weg durch die Verwaltung von Bedeutung waren. Das „Certificate of Discharge“ (D.2-Schein) beispielsweise musste immer wieder bei den Behörden vorgelegt werden, wenn Unterstützungsleistungen in Anspruch genommen werden wollten. In diesem Dokument fanden sich neben Einträgen über den Empfang des Entlassungsgeldes auch die Ergebnisse der ersten ärztlichen Untersuchung im Entlassungslager Friedland. Der Befund „Dystrophie“ scheint häufig genug festgestellt worden zu sein, um ihn per Stempel in das Formular einzutragen (Q12).

Außerdem erfolgte in Friedland eine erste Befragung durch den Suchdienst des Deutschen Roten Kreuzes, durch die Informationen über Vermisste oder Gefallene, die bislang nicht in Statistiken oder offiziellen Verlautbarungen aufgetaucht waren, gewonnen werden sollten. Die Verbindung zwischen Göttingen und Friedland wurde von verschiedenen Seiten immer wieder hergestellt. Vor allem Mitte der 1950er Jahre, als die letzten Gefangenen aus der Sowjetunion erwartet wurden, betonte der Göttinger Rat immer wieder die Nähe zum Durchgangslager und die Bereitschaft zur Hilfe.

Für die Angehörigen von Gefangenen und Vermissten wurde Friedland zum Symbol ihrer Hoffnungen. Hier erwarteten sie die Rückkehr ihrer Angehörigen oder zumindest Informationen über deren Schicksal: Mit Schildern, Fotos und Suchzetteln versuchten sie, von den Rückkehrern Hinweise zu bekommen (Q911).

\footnotetext{
8 Arthur Smith, Heimkehr aus dem Zweiten Weltkrieg. Die Entlassung der deutschen Kriegsgefangenen, Stuttgart 1985, S. 109. Zum Zusammenhang von Unter- bzw. Mangelernährung und den psychischen Folgen siehe auch folgende zeitgenössische Aufsätze: Ernst Friedrich, Jugend in Gefangenschaft. Bericht eines aus Russland heimgekehrten Studenten, in: Deutsche Universitätszeitung, Jg.5, H. 1 (1950), S. 13-25; Friedrich Hassenstein, Der Mensch in der Gefangenschaft, in: Studium Generale, Jg. 3, H. 1 (1950), S. 5-8.

9 Daneben erlangte Friedland auch als Durchgangslager für Vertriebene und Flüchtlinge aus den ehemaligen Ostgebieten eine zentrale Bedeutung, ebenso als erste Station für Flüchtlinge aus der sowjetischen Besatzungszone. Dazu: Dagmar Kleineke, Entstehung und Entwicklung des Lagers Friedland 1945-1955, Diss., Göttingen 1992. Zu Friedland läuft zur Zeit an der Universität Göttingen ein Projektseminar mit dem Ziel, ein Museumsprojekt vorzubereiten und digital zu begleiten.
} 


\section{Versorgung von Heimkehrern und Angehörigen von Kriegsgefangenen}

Insgesamt etwa 2 Millionen Menschen hätten nach dem Krieg Anspruch auf staatliche Unterstützung gehabt, hätte man die Maßstäbe der Vorkriegszeit anlegen können. Zu ihnen zählten neben den ehemaligen Soldaten auch die Kriegsbeschädigten der Wehrmacht, außerdem die Witwen, Waisen und Eltern der toten Soldaten und die Angehörigen der Vermissten, die vor 1945 anspruchsberechtigt gewesen waren. Allein im Gebiet des heutigen Niedersachsens stieg die Zahl der Versorgungsberechtigten bis 1949 im Vergleich zu 1938 um das Vierfache, die Zahl der Schwerbeschädigten sogar um das Achtfache. ${ }^{10}$

Die Heimkehrer des Zweiten Weltkrieges konnten nach ihrer Demobilisierung jedoch keine öffentliche Hilfe bei ihrer individuellen Reintegration in die Gesellschaft erwarten. Zum einen fehlten in der unmittelbaren Nachkriegszeit die entsprechenden staatlichen Institutionen, zum anderen die finanziellen Mittel. Des Weiteren waren sich die Alliierten einig, dass ehemalige Soldaten, anders als nach dem Ersten und bis zum Ende des Zweiten Weltkrieges, keine Sondervergünstigungen erhalten sollten. Die früheren Versorgungsgesetze wurden nachträglich aufgehoben. ${ }^{11}$ Es gab zunächst also keine speziellen oder gar regelmäßigen Hilfen für Heimkehrer oder die Angehörigen von Kriegsgefangenen oder -beschädigten. Stattdessen versuchten die Behörden vor Ort, möglichst unbürokratisch zu helfen. In Göttingen lebten nach einer Zählung des Sozialamtes 1946 gut 400 Personen, die als Kriegsgeschädigte einzustufen waren und 766 Parteien, deren „Ernährer“ sich in Kriegsgefangenschaft befanden (Q7). Vor allem private Initiativen spielten in diesen ersten Jahren bei der Versorgung von Heimkehrern und Angehörigen eine entscheidende Rolle, zum Beispiel die Göttinger Nothilfe, die unter anderem durch die Sammlung von Kleidern zur Versorgung der Heimkehrer beitrug. Erst 1947 wurde in der britischen Besatzungszone der Versuch unternommen, auf Landesebene Vereinbarungen über eine zentrale Regelung der Fürsorge zu treffen. ${ }^{12}$ Um Beihilfen zu bekommen, musste der Heimkehrer eine Bescheinigung vorlegen, die seinen Status bestätigte (Q13).

Mit der Gründung der Bundesrepublik Deutschland 1949 wurde hinsichtlich der Heimkehrer eine umfassende Integrationspolitik möglich. Schon 1950 beschloss der Bundestag einstimmig das Heimkehrergesetz (HKG). 1953 wurde der Kreis der Begünstigten erweitert, um dem geänderten Status zahlreicher Kriegsgefangener gerecht zu werden und diese nicht von eventuellen Ansprüchen auszuschließen. Im HKG waren verschiedene Leistungen vorgesehen, zum Beispiel ein

\footnotetext{
10 Wulfhorst, „Dank des Vaterlandes“, S. 1037, hier Anmerkung 3.

${ }^{11}$ Ziel der alliierten Politik war es, den deutschen Militarismus zu beseitigen und eine Sozialpolitik zu etablieren, die sich nicht mehr wie unter dem NS-Regime am Militärwesen ausrichtete, sondern auf Integration der verschiedenen Gruppen abzielte. Dazu: Wulfhorst, „Dank des Vaterlandes“, S. 1040f. 12 Vgl. Wiebke Fesefeldt, Der Wiederbeginn des kommunalen Lebens in Göttingen. Die Stadt in den Jahren 1945 bis 1948, Göttingen 1962, S. 65-69.
} 
Entlassungsgeld (in Höhe von 150, später 100 DM), Bekleidung und Gebrauchsgegenstände als Übergangsbeihilfen, bevorzugte Zuteilung von Lebensmitteln oder Wohnraum. Besonders wichtig im Hinblick auf die Reintegration der Heimkehrer war der $\int 7$, in dem die Sicherung des früheren Arbeitsverhältnisses beziehungsweise das Wiederaufleben eines erloschenen Arbeitsverhältnisses festgelegt wurde. ${ }^{13}$ Allerdings bedeutete diese Regelung keineswegs, dass alle Arbeitsverhältnisse wieder aufgenommen werden konnten beziehungsweise dass der ehemalige Arbeitgeber an einem Aufleben interessiert war, wie das Beispiel eines Prozesses um die Wiedereinstellung bei der Stadt Göttingen zeigt (Q14).

Mit dem Kriegsgefangenenentschädigungsgesetz vom 30. Januar 1954 wurden weitere Unterstützungsmöglichkeiten geschaffen. Für jeden nachgewiesenen Monat Gefangenschaft stand dem Antragssteller eine Entschädigung von $30 \mathrm{DM} z u$, nach weiteren zwei Jahren ausländischen Gewahrsams sollte der Betrag sich auf 60 DM verdoppeln. Die Auszahlung sollte innerhalb von sechs Jahren nach Verkündung des Gesetzes erfolgen, und zwar in der Reihenfolge der sozialen Dringlichkeit. Für die Bearbeitung eines Antrages (Q15) waren zahlreiche Dokumente vorzulegen, so die schon erwähnten Entlassungspapiere (Q12) und die Bescheinigung der Heimkehrereigenschaft (Q13). Es konnten aber auch Nachweise über die Dauer der Gefangenschaft von der Wehrmachtsauskunftsstelle (WAST), alliierten Behörden oder Briefe und Karten aus der Gefangenschaft (Q8) verlangt werden, ebenso wie ärztliche Gutachten. Die Prozedur der Antragsstellung wurde von vielen ehemaligen Kriegsgefangenen als zu langwierig und entwürdigend empfunden. Nicht verständlich war für viele der Gang der Verwaltung, der unterschiedlichste Formulare, Stempel und Bescheinigungen erforderte. ${ }^{14}$

In den 1950er Jahren verbesserten sich die Möglichkeiten des Kontaktes zu den noch in der Sowjetunion befindlichen Gefangenen, regelmäßige Post- und Paketsendungen wurden möglich. In verschiedenen Städten Niedersachsens veranlassten die Behörden den monatlichen Versand von so genannten Liebesgaben Päckchen mit Lebensmitteln und Kleidung im Wert von 10 DM - an diejenigen Kriegsgefangenen, deren Angehörige selbst nicht für solche Gaben aufkommen konnten. Im November 1952 sollten zwanzig Kriegsgefangene aus Göttingen ein solches Paket bekommen, darin enthalten waren unter anderem: Schokolade, Leberwurst, Tabak, Zigarettenpapier und Kerzen (Q16). Diese Pakete wurden von den Heimkehrern selbst nach ihrer Rückkehr immer wieder thematisiert. Sie bedeuteten eine enorme Erleichterung der Lebensumstände in den Lagern und retteten wahrscheinlich manchem das Leben. Neben dem materiellen Wert war es vor allem die Gewissheit, dass sich ,in der Heimat" jemand kümmerte, die vielen geholfen haben dürfte. Und umgekehrt bot sich hier für die ansonsten hilflosen Angehörigen eine Möglichkeit der Unterstützung. ${ }^{15}$

\footnotetext{
${ }^{13}$ Heimkehrergesetz. Kommentar und sonstiges Heimkehrerrecht von Dr. Kurt Drager. 2. neubearbeitete, erweiterte Auflage, Berlin/Frankfurt am Main 1953.

${ }^{14}$ Dazu: Zeitzeugenberichte bei Sauermann/Brockpfähler, Erinnerungen, S. 386f. und S. $406 \mathrm{f}$.

${ }^{15}$ Dazu: Hilger, Kriegsgefangene, S. 339f.
} 


\section{Die letzten Heimkehrer}

Auf politischer Ebene war das Thema Heimkehrer und Kriegsgefangene durchaus präsent, bis 1949 jedoch wurde es hauptsächlich innenpolitisch verhandelt. 1950 war mit dem Verband der Heimkehrer, Kriegsgefangenen und Vermißtenangehörigen Deutschlands e.V. ( $\mathrm{VdH})$ eine eigene Vertretung zur Durchsetzung sozialpolitischer Interessen gegründet worden. ${ }^{16}$ Außenpolitisch bemühten sich eher humanitär ausgerichtete Organisationen, v. a. das Deutsche Rote Kreuz und die Kirchen, um Informationen und Kontakte zu den Gefangenen und, wo es möglich war, um deren Freigabe. Die Forderung nach Freilassung der Gefangenen und nach einer besseren Unterstützung der Heimkehrer versprach eine breite Zustimmung der Bevölkerung. Dementsprechend findet sich das Thema quer durch das Parteienspektrum der Nachkriegszeit, von der SPD bis zum BHE ${ }^{17}$. Im Bewusstsein der Bevölkerung war die „Kriegsgefangenenfrage“ ohnehin präsent. Bis Mitte der 1950er Jahre fand im Oktober jeden Jahres eine „Woche der Kriegsgefangenen" statt. ${ }^{18}$

Im Herbst 1955 rückte Friedland und damit verbunden Göttingen noch einmal in den Blickpunkt der Welt: Man erwartete die „Rückkehr der Zehntausend“ aus der Sowjetunion. Im Sommer desselben Jahres war aus Moskau die Einladung an die Regierung der Bundesrepublik ergangen, sich zu Gesprächen zu treffen. Thema sollte vor allem die Aufnahme diplomatischer Beziehungen zwischen den beiden Ländern sein. Adenauers Ziel war es allerdings auch, in der Kriegsgefangenenfrage eine Lösung zu erreichen; aus bundesdeutscher Perspektive konnte das nur die Freilassung der Internierten bedeuten. ${ }^{19} 1955$ befanden sich noch etwa 9.600 Gefangene in sowjetischen Lagern. Bei ihnen handelte es sich hauptsächlich um durch die sowjetische Justiz verurteilte Kriegsverbrecher, zahlreiche von ihnen waren Mitglieder der Waffen-SS gewesen. ${ }^{20}$

Adenauer konnte sich der Zustimmung der Bevölkerung zu Verhandlungen mit der Sowjetunion sicher sein, wie eine vertrauliche Umfrage von 1954 zeigte: Nur 22 \% der Bevölkerung lehnten direkte Gespräche ab. ${ }^{21}$ Das Ergebnis der Verhandlungen in Moskau schließlich war für Adenauer ein großer Erfolg, er konnte der deutschen Bevölkerung die Repatriierung der letzten Gefangenen bis Ende des Jahres 1955 versprechen. ${ }^{22}$

\footnotetext{
16 http://www.bagso.de/heimkehrer.html <1.12.2008>

${ }_{17}$ Bund der Heimatvertriebenen und Entrechteten

18 Steinbach, Kriegsheimkehr, S. 329.

19 Werner Kilian, Adenauers Reise nach Moskau, Freiburg 2005, S. 290.

${ }^{20}$ Hilger, Kriegsgefangene, S. 359f.

${ }^{21}$ Michael Borchard, Die deutschen Kriegsgefangenen in der Sowjetunion. Zur politischen Bedeutung der Kriegsgefangenenfrage 1949-1955, Düsseldorf 2000, S.212f.

22 Aus heutiger Perspektive geht man davon aus, dass die Gefangenen ohnehin frei gelassen worden wären; sie waren laut Werner Kilian der „Preis“ für die Aufnahme diplomatischer Beziehungen zwischen SU und BRD. Dazu: Kilian, Adenauers Reise nach Moskau, S. 303.
} 
Die Stadt Göttingen betonte, dass alles getan werden sollte, um die erwarteten achtzehn Göttinger Heimkehrer willkommen zu heißen. Neben einem so genannten Kulturbeutel mit Busfahrkarten, Kino- und Theatertickets sollte der Heimkehrer eine Übergangsbeihilfe in Höhe von 300 DM erhalten, außerdem Sachgeschenke. Die weiteren Hilfen, wie zum Beispiel die Kriegsgefangenenentschädigung, sollten möglichst unbürokratisch geregelt werden (Q18).

Das Interesse der Öffentlichkeit an der Heimkehr dieser „Letzten“ war 1955, während es zwischenzeitlich abgeflaut war, beträchtlich. Das Göttinger Tageblatt widmete dem Thema ganze Seiten und druckte lange Listen mit den Namen der Heimkehrer. Betont wurde hierbei immer wieder der „Durchhaltewille“ der Deutschen. Die Veränderung, die in der öffentlichen Diskussion um die Heimkehrer in den ersten Jahren der Bundesrepublik stattgefunden hat, zeigt sich in dieser Bewertung. Die Heimkehrer aus sowjetischer Gefangenschaft wurden zu „Überlebenden" des sowjetischen Systems stilisiert. Danach verschwand das Thema weitgehend aus der Tagespresse. Die Probleme, die nicht nur die „Zehntausend“, sondern fast alle Heimkehrer vor ihnen bewältigen mussten, fanden in der breiten Öffentlichkeit keine größere Beachtung. ${ }^{23}$ Die Unterschiede, die zwischen verschiedenen Gruppen von Heimkehrern gemacht wurden, beziehungsweise der Mangel an Wertschätzung, den manch einer zu erkennen glaubte, verdeutlicht ein Brief an die Redaktion des Göttinger Tageblatts vom 2. Januar 1956, in dem ein „aus tschechischen Zuchthäusern " entlassener Mann sich über die Ungleichbehandlung von „Russlandheimkehrern“ und „,anderen“in Göttingen beschwert (Q19).

\section{$5 \quad$ Fazit}

Im Jahr 1950 betrug der Anteil der Heimkehrer an der männlichen Bevölkerung bundesweit 21,5\%. ${ }^{24}$ Allein diese Zahl verdeutlicht, dass fast jede Familie in der Nachkriegszeit in irgendeiner Form mit diesem Thema konfrontiert wurde. Private Schwierigkeiten - zerrüttete Familien und Konflikte zwischen Ehepartnern (Q18), zwischen Kindern und Vätern - waren oftmals die Folge. Die soziale Integration der Heimkehrer erfolgte nicht mittels finanzieller Hilfestellungen, sondern durch die Familien. In ihnen spielten sich die eigentlichen Dramen ab, hier fand die Pflege der Kriegsinvaliden statt, hier wurden zum großen Teil die psychischen Konsequenzen von Krieg und Gefangenschaft aufgefangen: Die Kriegsfolgen wurden

\footnotetext{
${ }^{23} \mathrm{Vgl}$. Kleineke, Friedland, S. $146 \mathrm{ff}$.

24 Ischenin, Heimkehrer. S. 33. Zu aus der Gefangenschaft zurückgekehrten Frauen werden dort keine Angaben gemacht.
} 
weitgehend „privatisiert“.25 Die psychischen Folgen von Krieg und Massengewalt fanden in der Person des dystrophischen Heimkehrers ihre Verkörperung. ${ }^{26}$

Die Heimkehrer-Thematik wurde in Literatur und Film häufig verarbeitet. Ein prominentes Beispiel ist Wolfgang Borcherts Drama „Draußen vor der Tür“, das filmisch unter dem Titel „Liebe $47^{\text {“ }}$ umgesetzt wurde. ${ }^{27}$ Weiterhin setzte sich Heinrich Böll in seinem Roman „Haus ohne Hüter“ mit den Problemen der Angehörigen von Kriegsgefangenen auseinander.

Nicht nur diese künstlerischen Auseinandersetzungen machen deutlich, wie unterschiedlich die Heimkehrer wahrgenommen wurden und mit welcher Diskrepanz sie selbst ihre Situation interpretierten. Der Historiker Peter Steinbach kommt zu folgender Analyse: Die westliche Gefangenschaft wurde oft als eine Art Gewahrsam gedeutet, in dem man sich in demokratischen Tugenden üben konnte. Die Kriegsgefangenen in der Sowjetunion stellten sich dagegen, soweit sie die Möglichkeit der Artikulation hatten, oft als Opfer des Kommunismus im Sinne des aufziehenden Kalten Krieges dar. ${ }^{28}$ Der Diskurs um die Heimkehrer steht damit im Zusammenhang der westdeutschen Vergangenheitspolitik. Nicht die Frage nach individueller oder kollektiver Schuld stand im Mittelpunkt der öffentlichen Diskussion. Vielmehr lässt sich vor allem für die unmittelbare Nachkriegsphase die Konstruktion eines „Opferdiskurses“ feststellen, in dem die Heimkehrer als physisch und psychisch geschädigte Personen dargestellt wurden, die ihrer traditionellen Männerrolle nicht mehr entsprechen konnten. Das schon erwähnte Krankheitsbild der Dystrophie bildet den Kern dieses Diskurses. ${ }^{29}$ In den 1950 er Jahren veränderte sich das öffentliche Bild des Heimkehrers vom „Opfer“ des Sowjetkommunismus zum „Überlebenden“ des Gefangenenlagers, der durch seine moralische Überlegenheit die Zeit der Gefangenschaft meistern konnte. Damit verbunden war die Diskreditierung derjenigen Heimkehrer, die sich in sowjetischen Lagern an der antifaschistischen Arbeit beteiligt hatten. ${ }^{30}$ Die deutsche Gesellschaft stand dem Thema also durchaus auch mit einer gewissen Distanz gegenüber - trotz der verbreiteten persönlichen Betroffenheit.

Überwog am Ende des Krieges noch zumindest teilweise das Bewusstsein einer deutschen Kriegsschuld und die Deutung der Gefangenschaft als „Sühne“ für

\footnotetext{
25 Dazu: Vera Neumann, Kampf um Anerkennung. Die westdeutsche Kriegsfolgengesellschaft im Spiegel der Versorgungsämter, in: Klaus Naumann (Hg.), Nachkrieg in Deutschland, Hamburg 2001, S. 364-383.

${ }^{26}$ Dazu: Svenja Goltermann, Im Wahn der Gewalt. Massentod, Opferdiskurs und Psychiatrie 19451956, in: Nachkrieg, S. 343-363. Außerdem erscheint 2009: Svenja Goltermann, Gegenwärtige Vergangenheiten. Kriegsheimkehrer, Psychiatrie und Erinnerung in der westdeutschen Gesellschaft 1945-1970, München 2009.

27 Siehe dazu den Beitrag von Maneja Yazdani in diesem Band.

${ }^{28}$ Vgl. Steinbach, Kriegsheimkehr. S. 327.

${ }^{29}$ Vgl. Elisabeth Klaus, Ernst Friedrich. Widerspenstige Erinnerung, in: Maren Büttner/Magnus Koch (Hg.), Zwischen Gehorsam und Desertion. Handeln, Erinnern, Deuten im Kontext des Zweiten Weltkrieges, Köln 2003, S. 108-160, hier S. 120-123.

${ }^{30}$ Ebd.
} 
das begangene Unrecht, so lässt sich mit Gründung der Bundesrepublik immer stärker eine Verdrängung dieses Deutungsmusters feststellen und eine zunehmende Instrumentalisierung der Kriegsgefangenen für politische und gesellschaftliche Zwecke. Der Zusammenhang von Schuld, Zweitem Weltkrieg und Gefangenschaft wurde lange Zeit geleugnet bzw. nicht öffentlich thematisiert. Im Vordergrund des politischen Interesses stand nicht die Aufarbeitung der jüngsten Vergangenheit, sondern die Etablierung der Bundesrepublik als gleichberechtigtes Mitglied der westlichen Staatengemeinschaft. Eine umfassende Auseinandersetzung mit den individuellen Erfahrungen der ehemaligen Soldaten musste so ausbleiben. Für den Bereich der öffentlichen Diskussion lässt sich festhalten, dass eine Entkopplung von Schulddiskurs und Heimkehrerdiskurs stattgefunden hat, deren Begründung in den weltpolitischen Rahmenbedingungen des entstehenden Kalten Krieges zu sehen ist.

Gleichzeitig wurden die Erinnerungen an Krieg und Gewalterfahrung, die buchstäblich verkörpert wurden durch die Heimkehrer, in den privaten Bereich verlagert. Viele der Männer, die für den Rest ihres Lebens an den Folgen des Krieges litten und sich zumindest teilweise differenziert mit ihrer persönlichen Verantwortung auseinandersetzten, hatten in der öffentlichen Deutung der Kriegsgefangenschaft keinen Platz und keine Stimme.

\section{Literatur zum Weiterlesen}

Frank Biess, Homecomings. Returning POWs and the Legacies of Defeat in Postwar Germany, Princeton/Oxford 2006.

Michael Borchard, Die deutschen Kriegsgefangenen in der Sowjetunion. Zur politischen Bedeutung der Kriegsgefangenenfrage 1949-1955, Düsseldorf 2000 .

Andreas Hilger, Deutsche Kriegsgefangene in der Sowjetunion, 1941-1956. Kriegsgefangenenpolitik, Lageralltag und Erinnerung, Essen 2000.

Elisabeth Klaus/ Ernst Friedrich. Widerspenstige Erinnerung. in: Maren Büttner/Magnus Koch (Hg.), Zwischen Gehorsam und Desertion. Handeln, Erinnern, Deuten im Kontext des Zweiten Weltkrieges, Köln 2003, S. 108-160.

Arthur L. Smith, Heimkehr aus dem Zweiten Weltkrieg. Die Entlassung der deutschen Kriegsgefangenen, Stuttgart 1985. 


\section{tbersetzung: Steffens}

An

Liste "A"

Regierungspràsident Hildeshoim

Betreff: Operation Clobber

\section{Definition und Daten}

Operation Clobber ist der Code-Name, der der Massnahme gegeben ist, die die tintlassung jeden Wehrmachtsmitfiledes in der englischen Zone ausser denen die unter besondere Arrestkathegorien fallen, vorsieht. 2. Dieser Vorgang soll zwischen dem 9.12 .45 und 20.1.46 beendet sein.

3. Der,Regierungabezirk Hildesueim hat den Auftrag erhalten, 24.000 Mann bei diesem Vorgang aufzunehmen. Diese hasamtzahl ist auf die Kreise verte1lt worden in Beratung mit dem bobrotroct Landesarbeitsant, und die folgende Vertellung auf de kreise ist vorgenommen worden:

\begin{tabular}{|c|c|}
\hline $\begin{array}{l}\text { Alfeld } \\
\text { Holzminden } \\
\text { Stadeöttingen } \\
\text { Land Göttingen } \\
\text { Hann.Mllnden } \\
\text { StadtHildeshe Im } \\
\text { Land Hildesheim } \\
\text { Marienburb } \\
\text { Peine } \\
\text { Blnbeck } \\
\text { Duderstadt } \\
\text { Northeim } \\
\text { Osterode }\end{array}$ & $\begin{array}{r}1650 \\
5100 \\
1100 \\
500 \\
2700 \\
500 \\
2500 \\
5800 \\
950 \\
200 \\
1000 \\
1000\end{array}$ \\
\hline & 3000 \\
\hline
\end{tabular}

Die veroleibenden 1000 werden getrennt an die Ireise verteilt nach Belieben des Iandesarbeitsamtes Hannover.

( Diese Zahlen heben diejenigen unseres Schreibens MG/5 101730A auf)

4. Abgesehen von diesen festgesetzten Zahlen können die Kreise eine Anzahl von ininzelpersonen aufnehmen, die seitens der 26 Korps durch 25 DCU (Entlassungseinheit) im Land Braunschweig entlassen werden. und denen Anweisung gegeben ist, sich selbatänig auf den Heimweg zu machen. Bs wird gehofft, dass diese Anzahl nicht zu gross sein wird.

\section{Tàzlicher Zustrom}

5. Der Zustrom in den Regierungsbez1rk wird bis zu 2000 jeden zweiten Tag betragen. Das He1sst, das Kein Krels wh mebr als dieser Anzahl bleichzeitig abzufertigen hat, und in den meisten. Pällen werden die 2000 jedesmal auf verschiedene Rreise verteilt werden.

\section{Weitere Behandlung}

6. Alle Personen, die unter dieser Massnahme entiassen werden, sind als Flüchtlinge zu behandeln.

Q1: Operation Clobber, Stadt A Gö, B 43 (Stadtverwaltung und Miltärregierung), Film-Nr. AB 311, Sign. I 73, B1. 49. 
7. Be1 ihrer Ankunft im Krelse haben sie sich auf dem Arbeitsamt zs melden, auf dem Brnährungsamt, Wohnungsamt nach den normalen Bestis. mungen.

8. Die betreffenden deutachen Behörden sind verantwortlich für inn Vertellung im Kreise im Bezug auf Unterbringung sowohl als auch Arbe

9. Ausser der normalen Arbeitslenkung sind die Arbeitsämter angewlea geeignete Kräfte für die folgenden Arbeitsmärkte auszusuchen?

a) Buhr Bergbau

b) Baunternehmen im Bezirk Hawnover

c) Monteure, N1eter und Errichter für Brücken und Schwexkonstruktionen im Ruhrgebiet.

Diese Information wird durch deutsche Behörden dem Landesarbeitsamt Hannover mitgeteilt unter Beifügung $e$ nes Durchschlages zwecks Infos mation durch die Kreis-Detachements an das Hauptquartier.

Weitere Informationen

10. Weitere Einzelheiten über die Massnahme als Ganze sind noch nich eingetroffen, aber die folgenden Punkte, die von der 5.Division In Verbindung mit der Entlassung des 26. Korps we lche im Zusammenhang mil der Operation Globber steht, festgesetzt wurden, werden Ihnen zur Information und nötiser Veranlassuag mitiseteilt, da sie wabrscheinll für die ganze Operation zutreffen.

11. Die fol genden Wehrmachtsklassen werden in der Britschen Zone entlassen:

a) Deut.sche Klasse A.B.F.D.

b) Sudetendeutsche

12. Wenn die 25 DCU (Bntlassungseinhe1t) die Bntlassang des 26.Konpo durchgefürt hat, wird sie mit der Entlassung des Lazarettpersonals und der Patienten in SITU beginnen. Bin Plan hierfür wird zur Zeit von 25 DCJ ausgearbeitet.

13. Alle gejenwärt1gen Arbeitskommandos des 26. Korps haben sofort zu dem 26. Xorps Durchgangs lager Berkl Ingen D 0596 zurückzukehren. Zur Zeit wird ein Plan vorbereitet, nach welchem 3o deutsche Zivily personen jedem kommandierenden Oberstleutnant in den 5 Divisionsge bieten zur Verfügung gestellt werden, um als Arbeitsmannschaft id alligenelnen zu dienen.

14. Das Aussuchen hat vor der Bntlassung zu geschehen und die M111. tärrefierung ist NICHT hierfür verantwortiloh.

15.Deutsche aus der B und D Klasse werden gänzl1ch entlassen und NICHF vortiberiehend, wie dies bisher bei Klasse B der Pall war.

16. 25 DCU gibt allen, die durch sie entlassen werden, olnen Prelly schein für Kleidung, das Erteilen von Genehmigungen einer Zeitspan in der diese ungefirbt getragen werden darf, 13t NICHT gestattot.

8̈z. B.J.Loishman Najox SO II IA \& C

Q1: $\quad$ Operation Clobber, Stadt A Gö, B 43 (Stadtverwaltung und Miltärregierung), Bl. 50. 
Herrm

$$
\text { Capt. B e r t } r \text { am der Militärregierung, h료. }
$$

Betrifft: Feriohte uber Fluchtlinge .

- Reㅇ._-126/GA/6-

a) Bèrölkeinung des Stadtkreises Gbttingen an 1.9.1939

b) Zahl der deutsohen Plijohtlinge und Evakulerten, die

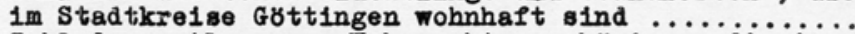

c) Zahl der entlassenen Wehrmachtsangehorigen, die im

d) Zahl der auf Wanderschaft sich befindenden deutsohen Flischtlinge, die in der Woche vom 24.9.1945*30.9. 1945 durech den Stadtkre1s Göttingen gekommen sind

e) Zahl der s1ch auf der Wandersohaft befindenden Tehrmachtsangehbrigen, die in der Toohe vom 24.9.1945 30.9.1945 durch den Stadtkre1s Grttingen gekormen sind $=3.142$

Ausserdem haben in der Woche vom 24.9.b1s 30.9.1945 4.960 Fluchtlinge hiesige Betreuungs-bezw. Verpliegungsetelien ohne Uebernachtung aufgesucht.

Bs wird nooh bemerkt, dass seit etwa einer Woche die Zahl der durahwandernden Flichtlinge ausserordentlich stark zurijokgegangen ist ( $50 \%$ und mehr).

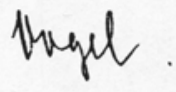

Q2: $\quad$ Statistik über die Anzahl von Flüchtlingen vom 1.10.1945, Stadt A Gö, B 43 (Stadtverwaltung und Militärregierung), Film-Nr. AB 311, Sign. I 74, Bl. 18. 


\section{MILITÄRREGIERUNG DEUTSCHLAND}

\section{BEKANNTMACHUNG}

\section{BINTRAGUNG UND ENTLASSUNG ANGEHÖRIGER DER DEUTSCHEN WEHRMACHT UND DER MILITÄRÄHNLICHEN .ORGANISATIONEN}

1. Alle männlichen Personen, die aus der deutschen Wehrmacht (Heer, Marine und Luftwaffe) seit dem 3. September 1939 durch deutsche Stellen entlassen oder freigegeben worden sind, haben sich gemöß. den folgenden Bestimmungen zwecks Eintragung zu melden.

2. Alle aktiven männlichen Angehörigen der deutschen Wehrmacht (Heer, Marine und Luftwaffe), der Waffen-SS, des NSKK (NS-Krafffahrkorps), des NSFK (NSFliegerkorps), des RAD (Reichsarbeifsdienst) und der OT (Organisation Todt), die nicht im Besits eines amtlichen britischen Entlassungsscheins (Vordruck D 2) sind, haben ihre Entlassung und Eintragung gemäß den folgenden Bestimmungen zu beantragen.

3. Alle in den Absäben 1 und 2 aufgeführten Personen, die sich im Stadt-/Landkreis - an einem der unten festgelegren Tage aufhalten, müssen sich zwecks Eintragung oder Entlassung an $\mathrm{Nr}$. DCU (Wehrmachtauflösungsüberwachungseinheit) in _._. (Stadt)_. (Straße) zwischen und am (Tage) meiden.

4. Alle in Absäben 1 und 2 aufgeführten Personen, die sich in den Stadt-/Landkreis nach dem ohne im Besib eines britischen Entlassungsscheins (Yordruck D 2) zu sein, begeben, müssen bei der $\mathrm{Nr}$. DCU (Wehrmachtauflösungsüberwachungseinheit) in (Stadt) (Straße) innerhalb 7 Tagen nach erfolgtem Eintritt zwecks Eintragung oder Entlassung vorstellig werden.

5. Personen, die sich zwecks Eintragung oder Entlassung melden, haben die folgenden Urkunden vorzulegen:

a) deutschen Entlassungsschein (soweit es sich um die im Absats 1 aufgeführten Personan handelt),

b) alle Dokumente, die sich auf den Militärdienst beziehen,

c) alle Personalpapiere, gleichviel ob sie von zivilen oder anderen Behörden ausgesteilt sind.

6. Zur Zeit der Meldung müssen die Meldungspflichtigen alle Uniformteile und Ausrüstungsstücke, Abzeichen, Medaillen, Ordensbänder und andere Distinktionen, die von einer der in den Absäben 1 und 2 aufgeführten Organisationen herausgegeben wurden, diesen gehören oder ein Dienstverhältnis in diesen kennzeichnen, vorlsgen, damit sie untersucht werden können, und auf Verlangen abgeben.

7. Wer den Bestimmungen dieser Bekanntmachung nachkommt, wird wegen Fahnenflucht von den im Absats 2 aufgeführten Organisationen nicht belangt werden, vorausgeselst, daß diese vor dem 16. Juni 1945 stattfand.

Wer den Bestimmungen dieser. Ánordnung nicht nachkommt, kann angeklagt werden, und das Gericht kann auf jede gesebliche Strafe einschließlich des Todes erkennen, wenn es von der Schuld des Angeklagten überzeugt ist.

Im Auftrage der Militärregierung.

Q3: $\quad$ Militärregierung Deutschland: Bekanntmachung, Stadt A Gö, Plakatsammlung (1946-1949), Sign. 1946-28², 17.7.1946. 


\title{
Alle wollen nach Deuischland zurück
}

\author{
Erlebrisse und Erkenntnisse in englischer Kriegsgefangenschaft
}

Munsterlager, 1. Oktober (DPD)

¿Lleber bel Wasser und. Brot in der Heimat, als bel Kaffee und Kuchen In Gefangenschaft! Ist, wie die aus England heimkehrenden Kriegsgefangenen abereinstimmend berichten, der allgemeine Wunsch der noch in englischen. Lagern Lebenden deutschen Kriegsgefangenen. Zwar gabe es. einzelne, dit freiwillig In England bleiben wollten, doch selen dies vor allem diejenlgen, die in Deutschland
keing Angehorigen mchr hatten.

Vom Meinungsstreit der Partelen haben die Kriegsgefangenen, die in der Lage waren, sich aus deutschen Zeitungen aller. Zonen zu unterrichten, keinen besonders guten Eindruck. In den Lagern. dagegen seien politische Diskussionen immer sachlich und unter Achtung auch gegenteiliger Meinungen gefuhrt worden. Durch die zahlreichen. Entlassungsversprechungen, die nicht gehalten worden wären, habe allerdings die politische Aktlvitalt stark gelltten. Ein jeder habe nur den einen Gedanken gehabt: "Ich will erst an Ort und Stelle sein und mich selbst "von den Zuständen in Deutschland unterrichten."

Post ans der Heimat - ein Erlebnis

Es ist der sehnlichste Wunsch aller noch in Eng land, zurückgebliebenen Kriegsgefangeren, so betonen die eptlassenen Soldaten, daB ihre Angehörigen thnen so viel wle möglich schreiben möchten; denn die Anzahl der Briefe sel keinen Beschrănkungen unterworfen. Post von der Familie und den. Freunden in Deutschland set immer wieder ein Erlebnis. Ueber die Behandlung der Kriegsgefangenen in England sind keine Klagen laut geworden. Es habe woh. einmal Zwischentalle gegeben; aber das konne man wohl uberall erleben. Sehr starik habe sich die YMCA, die Vereinigung Christlicher Junger Mânner. in den Lagern tur die Gefangenen eingesetzt und alles getan, thnen ihr schweres Los zu erleichtern. Die englische Bevolkerung selbst sel immer freundlich und hilfsbereit gewesen. Die Verpflegung, die immer gut gind ausreichend war, habe sich allerdings nach der Kapitulation verschlechte:t.

Ueber das englische Erzlehungslager wilton-Park bei London, in dem deutsche Kriegsgefangene mit

den Grundsaltzen und Ideen der Demokratie vertraut gemacht wurden, gingen die Melnungen weit auseinąnder. Besonders, so stellte einer der Entlassenen fest, habe die, Idee dieser ,kleinen Universită “ darunter gelitten, daß zunlichst die „D-Zug-Demokraten“, auch "Blitz-Demokraten" "genannt, sich um einen Kursus in diesem Lager bemuht hătten. Der eine sagte, nur Konjunkturpolltiker selen dort hingegangen, wăhrend ein anderer "dlese Methode der Umerziehung als gut und richtlg bezeichnete. Allgemein jedoch wurden die Bemuhungen der englischen Behörden anerkannt, den Deutschen durch. einen Lehrgang in Wilton-Park ein-neues und weiteres Blickfeld zu geben.

Schwere Vorwarfe richteten alle Helmkehrer, die lăngere oder kürzere Zelt in belgíschen Lagern unter deutscher, Lagerfuhrung gelebt hatten, gegen die deutschen Kriegsgefangenen, the dort die fuhrenden Stellungen inne hatten. Wer diesen Leuten $200 \mathrm{Ziga-}$ retter bleten konnte; sei auf die Entlassungsliste gekommen und auch tatsăchlich entlassen worden. Sie hatten es auch verstanden, selbst entlassen zu werden. Heute isind diese Lager; aufgelost.

Wir rollen eine ehrliche Zukunft schaffien

Einer dieser Männer, die nun lange Jahre der Gefangenschaft hinter sich haben, sprach unter allgemeiner Zustimmung. für alle, als er sagte: „Wir wissen, $d a B$ wiz nicht ins Paradies kommen: W"yn wir eines in der Gefangenschaft gelernt baben, so dies: uns schnell in jede neue Lage hineinzufinden. Wir sind alle gleich schlecht, dran und können nur durch Remeinsames Anpacken eine ehrliche und friedliche neue Zukunft schaffen."

Q4: Artikel: „Alle wollen nach Deutschland zurück“, Hannoversche Neueste Nachrichten, 2.10.1946, S. 5, Stadt A Gö, Film-Nr. Ztg. 623, Bl. 43. 


\section{Das Elend der RuBland-Heimkehrer}

Nur 17 Prozent voll arbeitsfähig! / Ueter zwei D́rittel bedarf monatelanger Pflege

F r I e d l a a d. 22. November,

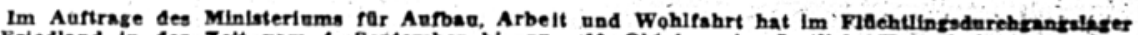

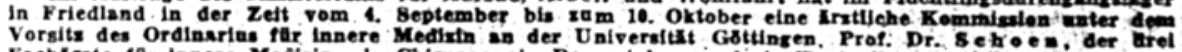

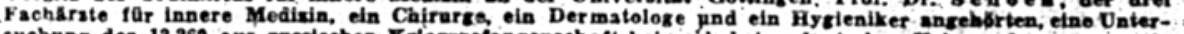
suchung der 12260 aus russischer Kriegsefangenseh aft heimgékehrten deutachen Kriersefangenen otath-

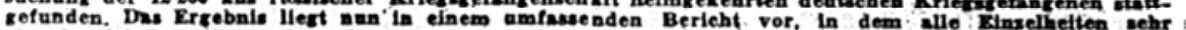

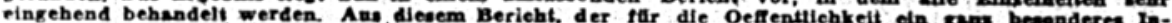
leresse hat, ceben wir Im Augxug efneh Tell der Untersuchungsersebnlsse wieder: Der Berteht kommt

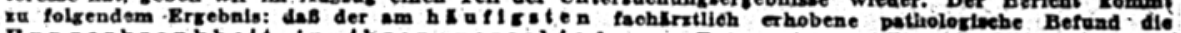

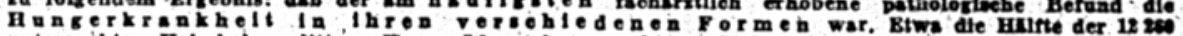

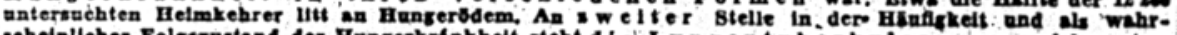

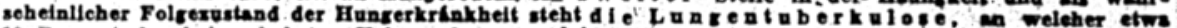

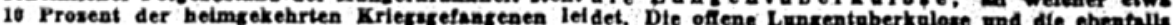

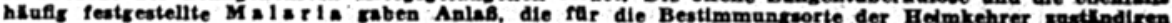

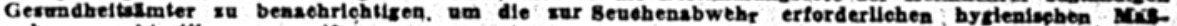
nahmen reobtseltic su ercreifen.

Ueber eln Drittel der Untersuchten hat walhrend der Gefangenschaft rum Teu vehr e $\mathrm{r}$ a t e K rankhel t e n durchgemacht. Etwas aber 70. Prozent von innen befanden sich in den Altersklasen zwischen 30. und 49 Jahren. Um einen zuverläsaigen MaBstab tar the Unterernahrung, zu erhalten, 1 st von der arztlichen Untermuichungskominission eine Berechnung des Unterge w f chts vorgenommen worden. Hierbel ergab sich da $B$ did relativ starkere Untergewichtickeit bed den alteren Leurten footruotellen ist. Auftallend ist. das die Untersuchten. In allen Alteraklaswen ziemilich glefchmäbig durch die H u $\mathrm{gerkrankh}$ e $1 \mathrm{t}$ betroften sind. Dio molsten der bis ouf weiteres arbeltounfahigen. Hungertranken maseen erst durch entsprechende Ernlhrung lind Pflege'wleder zu Krafien gebracht werden und daften dann vorauaslchtuck Innerhalb von $6 \mathrm{Mo}$ naten wieder arbeltstahlg werden konnen, eln kledner'Tell scheldet Jedoch far tie. Wieder einscheltung In den Arbeltsbetrleb v $8111 \mathrm{x}$. a $\mathbf{s}$.

Von 1005 Unterwachten batten 227 . eloe a $\mathbf{k} t \mathbf{v e}$ Lungentuberkulase. Aus rwel Trunoporten wurden 280 Manner gerontet. Dabed ergab alch bel 82 von 289 ein posityver Betund. In elner weiterec Gruppo ron So4. Minnern Litten e0, d. 1. 11,1 Probent. an ektiver Luncentubertulese. Von 902 nicht au-

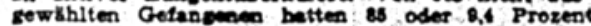
inen aktiven tubericulowen Lungunprores, stark ist

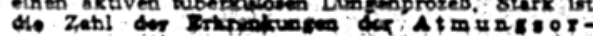

g a ne. Elne groBe Rolle ab Urwache der Arbette-

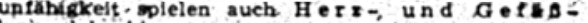
krank helten.

Unter Berdicksichtigung aller for dio Beurtellung wichtigen Tatsachen, insbesondere der Vorzeschichte und des fachlirztlichen Befundes, hat die Kotmmission die Arbeltseinsatzingrgkelt der Helmkehret erinittelt. Dabel kam sie zu dem Ergebnis. die Untersuchten in vier. G r u p'en aufzutellen. In der Gruppe $I$ befinden sich 2116 Helmkehrer, d: 1 17 Prozent, die als arbeitefahig auf dem liligenieinen Arbeitsmarkt angesehen, werjen konnen. Div Gruppe II zahlt 1886 oder If Prozent der Unterruchten. Diese sind nur zu leichten oder bestimmten Arbeiten fâhig, teils durch Gebrauchsbeschrinkung oder Verlust voh Gliedern. In der Gruppe III. befinden $\mathrm{kich}$ die weitaus meisten der Heimkehrer.

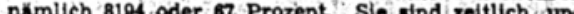
namlich sior der on prostich, und zwar etwa bis zu sechs Monaten, Intolge thres kor perlichen Zustandes nicht arbeltafuhig. Die da uernd Arbeit cunfabtgen als Folge- Phrer chweren Krankheit sind dor Gruppo IIrb' rugeteflt. Thre : Zaht betragt 64 oder 5 Prozent. Aus der'Tatsache, das als Grund der. Entlassing aus der Krieca-

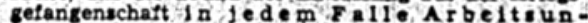
I a b I k e it mabsebend war, gebt bervor, ins bat

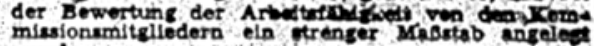
mission

Q5: Artikel: „Das Elend der Rußland-Heimkehrer“, Hannoversche Neueste Nachrichten, 23.11.1946, S. 1, Stadt A Gö, Film-Nr. Ztg. 623, Bl. 77. 


\title{
Ohne Gepäck, ohne Decke, ohne Mantel
}

\author{
Der' erste Helmkehrerschub aus Rusland in Filediund, elngetrofien \\ GoTringes: 15. August.
}

Schon am 10. August sollten die ersten Transporte der aus RuBland entlassenen und tût dia britische Zone bestimmten deutschen Kriegsgefangenen an der englisch-russischen Zonenschleuse Friedland-Arenshausen eintreffen. Die vielen Angehörigen, die aus Köln und Harnburg, Dortmund und Labeck zum Emplang threr Liebén nach Frledland geellt waren, mubten jedoch unverrichteter Dinge wieder heimfahren, denn die Aktion verschob sich erst au! un. bestimmte Zeit und dann auf.den 13. August nachmittags.

Puinktlich um 14 Uhr gab der. englische Wachoffizier dem Posten ein Zeichen, und der Sanilatswagen, angefullt mit Schwérkranken und Marschunfahigen. Dann dahinter in langen Reihen, mujde und matt, zit leerem Blick und kahlgeschorenen Haaren diejenlgen, -die so lange aut diesen Augenbllck gewartet hatten. Sle kamen ohne jedes Gepăck, ohne Decke und ohne Mantel, feder nur mit sclnem aus elner alten Konservendose selbst angefertigten $E B$ napt In der Hand, wenige nur ein armsellges, klêines Bündelchen tragend, viele mit Stöcken, auf die sie sich beim Gehen stützten. Die Gesichter waren alt und zerfurcht, manche auch von Hautekzemen zerfressen. Sle trugen,weiße Milutardrillichhosen und dazu gebrauchte Zivil- oder Uniformstucke, die man thnen in Frankfurt a. d. Oder gegeben hatte. Die. PuBe steckten in meist neuen, mit Segeltuch bespannten Holzschuhen. Mitgegeben war lhnep auch noch efne groBe Anzahl-politischer'Broschüren, Zeitschriften und sonstiges SED-Propagandamaterial.

\section{Nur Kranke werden entlassen}

Kaùm auf ,englischem Boden" angekommen, begann das . Uhrwerk einer gut elngesplelten Organisation. Dle fahrbaren Kantinea der Heilsarmee waren aufgefahren, und jeder Heimkehrer bekam zuerst elnen halben Liter heiBer Schokolade. Dann ging es mit bequemen Omnipussen zum Lager Friedland, das derzeit leer-steht und für den Emplang gerustet war. Hier wurde nun der polltische Fragebogen at sgofinlt, registriert, entlaust, brztich untersucht und Verpflegung ausgegeben. AuBerdem erhlelt jedor, da kelner der Helmkehrer Barrittel bel sich trug, einen Gutscheln, der rum Losen elner Fahrkarte nach seipem Heimatort berechtigte Das olles ging aqfialleng schnell und ohne grose Verrogerungen, 10 daB schon ein betratchtucher Tell dfa splen Abendzilge tur die Heimfallit benutzen konnte. ReichHcha. Marschverplegung wurde verabralcht und fur dig Reise mitgegeben.

Dio Masso der helmkehrenden Soldaten war schrelfrsm,. abgestumpft und apathisch. Sio antworioten auf Fragen nur zogernd und bliobac bet der Antwort celbat karg und verschlossen.

Da war ein lontalgjuhilger abemallner Ober. gefrelter aus Hortord. Fo Marx 1945 getangen. genommen, kam or in eln Lagez in Odessa und hatte as, wile or selbat ragte, nicht schlecht gehabt Mit elnein p'elfen Arm konnto or In dar AuBenarbalt nfcht beechifutot werden

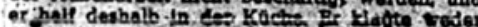
abar echlechtes Elew noch obar nncierechto Behend Bahandlung and Job die rusalsche Lege: leftung. Der S4 Jature nite obemolige bbehini mefater tin glalchoc Glied Kommt von stalin. grad und will nach Omabreck Br sagt ghr.

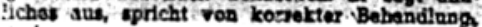

ertrăglicher Arbeit, wenn auch mäigem Essen. Er bedauert nur, daß die russischen Behördên keine Gesunden entlassen, sondern nur Kranke und solche, die für harte körperliche Arbelt nicht melr zu gebrauchen sind. Und da ist der ehemailige Unteroffizler aus einem Lager bel Moskau. Er war ruerst in einem groBen Stein. bruch, dann als Holzfäller elngesetzt, wurde beim StraBenbau verwendet und stach zuletzt bis zu 14 Stunden am Iag Torf. Er hatte Immet schwere Arbeit gehabt und sprach von schlechter Verpflegung und minimalen Rationen an dunner Suppe und Brot. Wassersucht war die Folge.

Ande'e erzahlten von langer Arbeitszelt, schwierigen und mühseligen. Anmarschwegen zur Arbeitssitatte, aber auch von Vortragsabenden und Tabakzuteilungen als Belohnung. Post aus der Heimat hotten. nur wenlge erhalten dazwischen, waren welche, die bisher keine' Schreibmöglíchkeit gehabt hatten. "Im allgemeinen darl jedoch jeder.Kriegsgệangene alle drel Monate eino Karte nach Hous schreialle drel Monate eino Karle nach Hous sthrelgab es. Auch elno Kriegsgeforngenenzeitung DIE LESER !

\section{"Elend In Sorsum"}

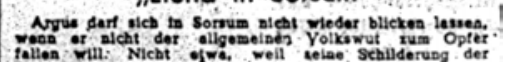
follon rill: Nicht of wh. weit viae Schilderubg der

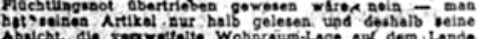

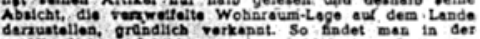

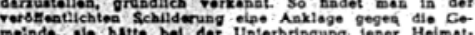
meindo. olo batte bel der Unterbringung jener Heimat-

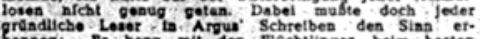

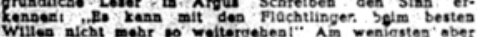
Wiles nicht mobr of moltorgetest" An wemigstes aber odet dea Gemothdoctroktos, dor bel dor Unterbringeng ron: 1000 . Premdes pois, moglichstes leiptote und aun;

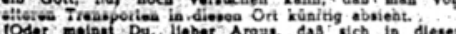
IOdor moinar Du, liober Argas. das sich is dieser

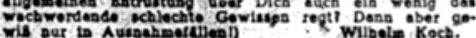

Dle 5. Zone Deutschlands

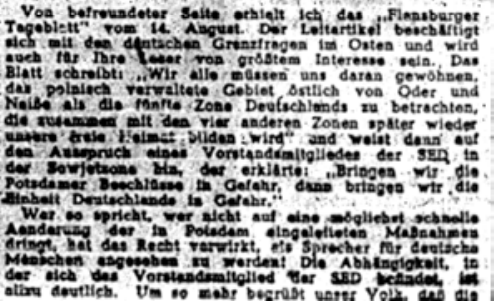

Q6: Artikel: „Ohne Gepäck, ohne Decke, ohne Mantel“, Hannoversche Presse, 16.8.1946, S. 2, Stadt A Gö, Film-Nr. Ztg. 627, Bl. 22. 
Sie können sich denken, daß nur Familien, die in auBerster Not sind, zum Sozlalamt kommen und ihre Anträge auf Bewilligung von Unterstütaungen stellen. Die Prufung, ob Arbe1taunfahigke1t vorliegt oder Vermögen vorhanden 1at, 1st sehr elngehend.

B1s 31.7.1946 hat das Sozialamt folgende Parteien unterstutzt:

\begin{tabular}{|c|c|c|}
\hline Kriegerwitwen, Kriegsbeschäigte & $\frac{\text { Parteien }}{128}$ & $\frac{\text { Personen }}{.402}$ \\
\hline $\begin{array}{l}\text { PU. (Pamilien, deren Brp. noch in } \\
\text { Gefangenschaft fory. }\end{array}$ & 766 & 2325 \\
\hline Evakulerte und Fluchtlinge & 690 & 1274 \\
\hline Sozialrentner & 221 & 299 \\
\hline Kleinrentner u. Gleichgestellte & 155 & 171 \\
\hline Allgemeine Plirsorge & 125 & 203 \\
\hline Tuberkulose-Hilfe, P & $3 I$ & 37 \\
\hline Politisch und rassisch Verfolgte & 49 & 76 \\
\hline & 2165 & 4787 \\
\hline
\end{tabular}

Seit dem 1. August 1946, nachdem also die Renten forgefallen sind, sind 350 neue Anträge gestellt worden und täglich kommen noch neue Anträge hinzu. Wir rechnen deshalb mit einem $\mathrm{zu}-$ gang von 1000 bis 1200 Parteien, so daB demnkchst vom Sozialamt rund 3700 Pamilien mit 7000 und mehr Personen unterstützt werden, die sämtlich nur die oben angefuhrten Unterstutzungsrichtsätze erhalten. Da diese Pamilien, wie wir alle, erhebliche Ausgaben zur Deckung des Winterbedarfa mit Kartoffeln und Holz haben werden, hat das Sozialamt vorgeschlagen, allen diesen Pamilien eine einmalige Zuwendung von 50,-- Ra fur den Haushalt und 10,-- RM fü jede weitere vorhandene Person zukommen zu lassen. Dieser Betrag 1st unbedingt erforderlich, damit die Pamilien die auf Jeden Pall entatehenden Ausgaben decken können. Der Betrag ist nur eine kleine Hile.

Die voraussichtlich Gesamtausgabe wird 208.000,-- RU betragen.

Q7: Aufgaben des Sozialamtes, Stadt A Gö, C50 (Sozialamt), Nr. 439,2 (keine Blattzählung). 

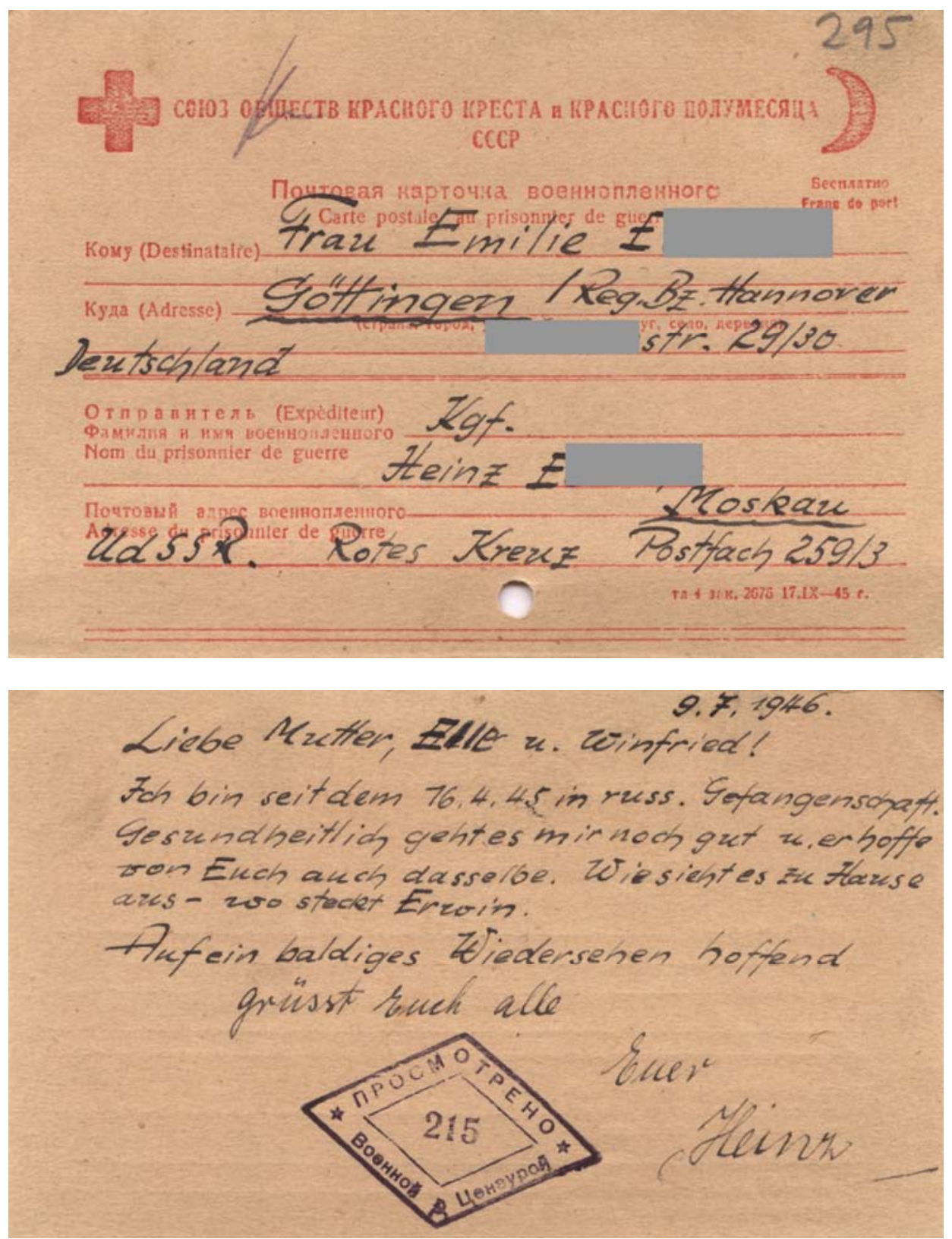

Q8: Postkarte aus russischer Gefangenschaft, B 46 (Ausgleichsamt), Nr. 7, Bl. 295. 


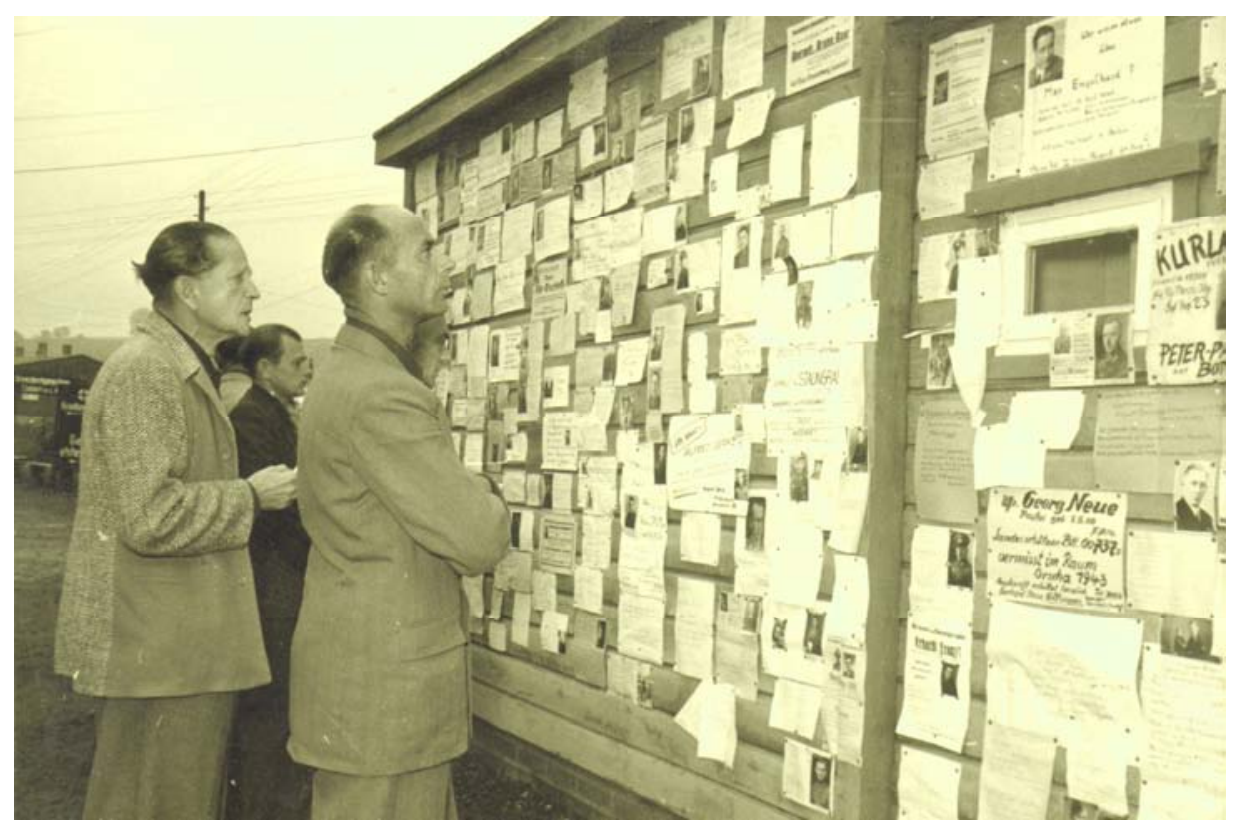

Q9: Bild: Pinnwand im Grenzdurchgangslager Friedland, Fotoarchiv Gö.

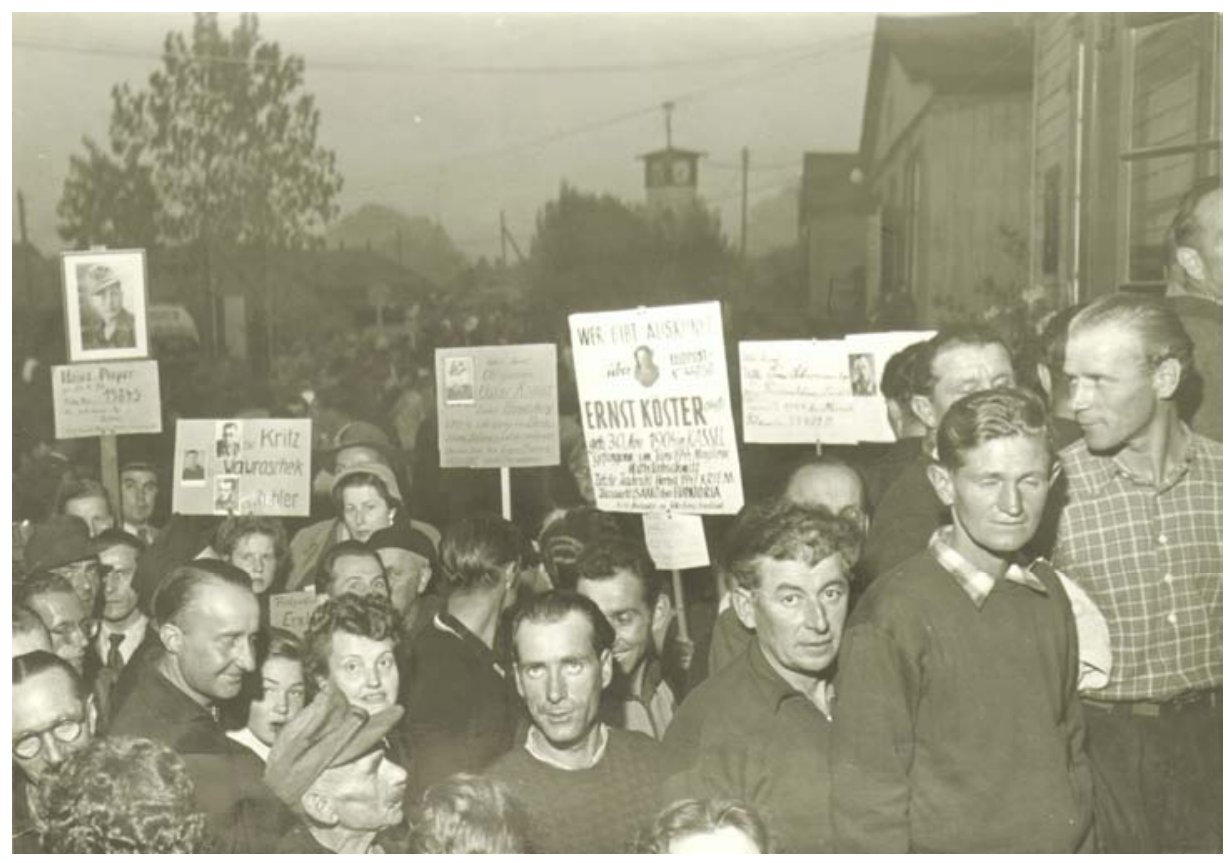

Q10: Bild: Angehörige mit Plakaten, Fotoarchiv Gö. 


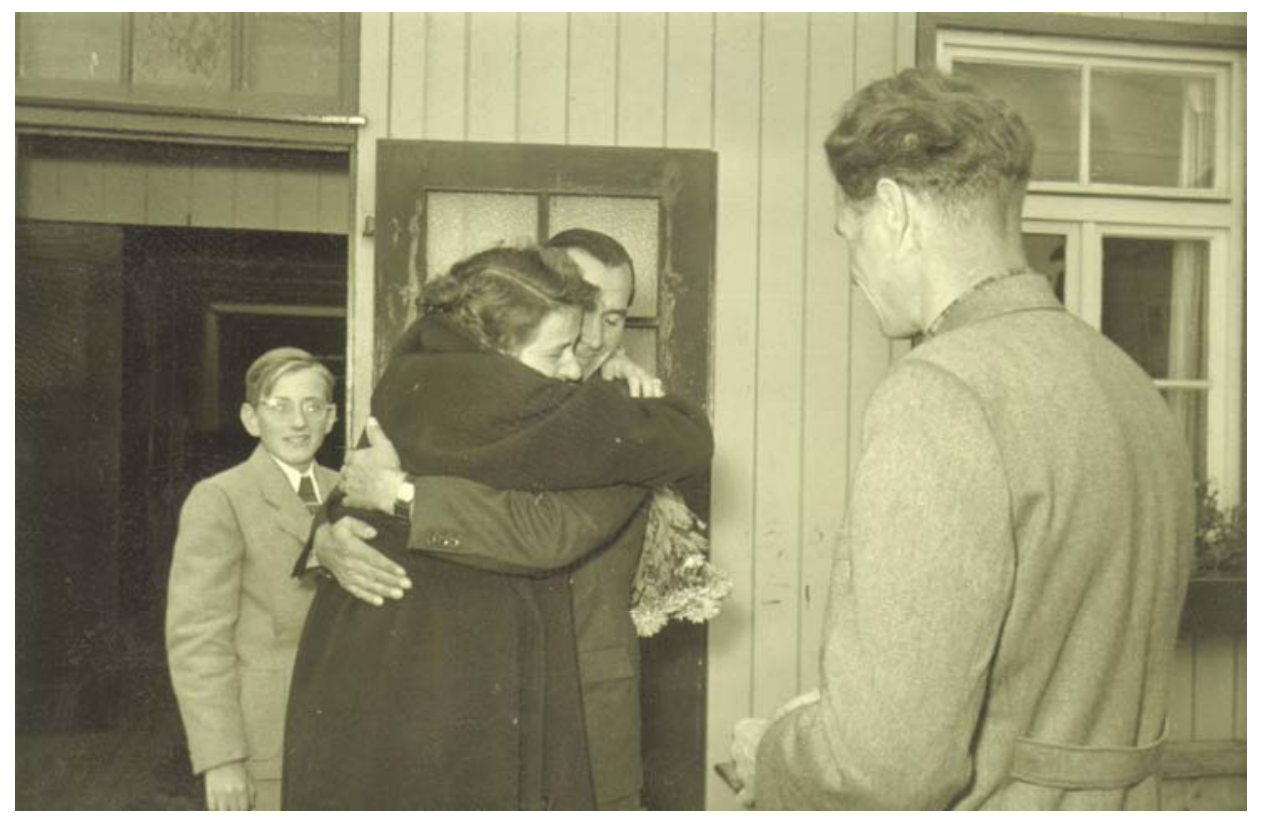

Q11: Bild: Szene im Lager Friedland, Fotoarchiv Gö. 


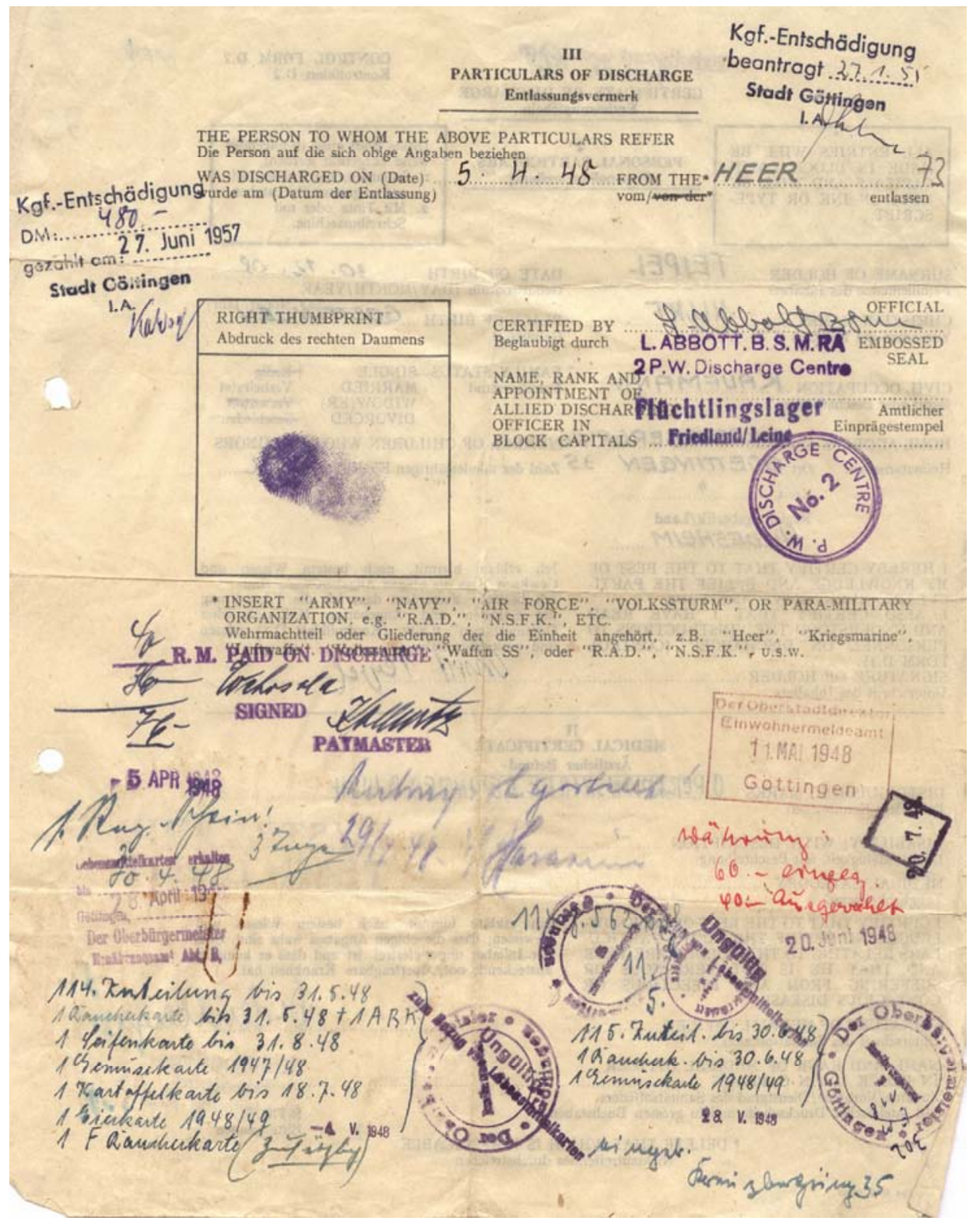

Q12: $\quad$ Certificate of Discharge, Stadt A Gö, B 46 (Ausgleichsamt), Nr. 7, Bl. 73. 


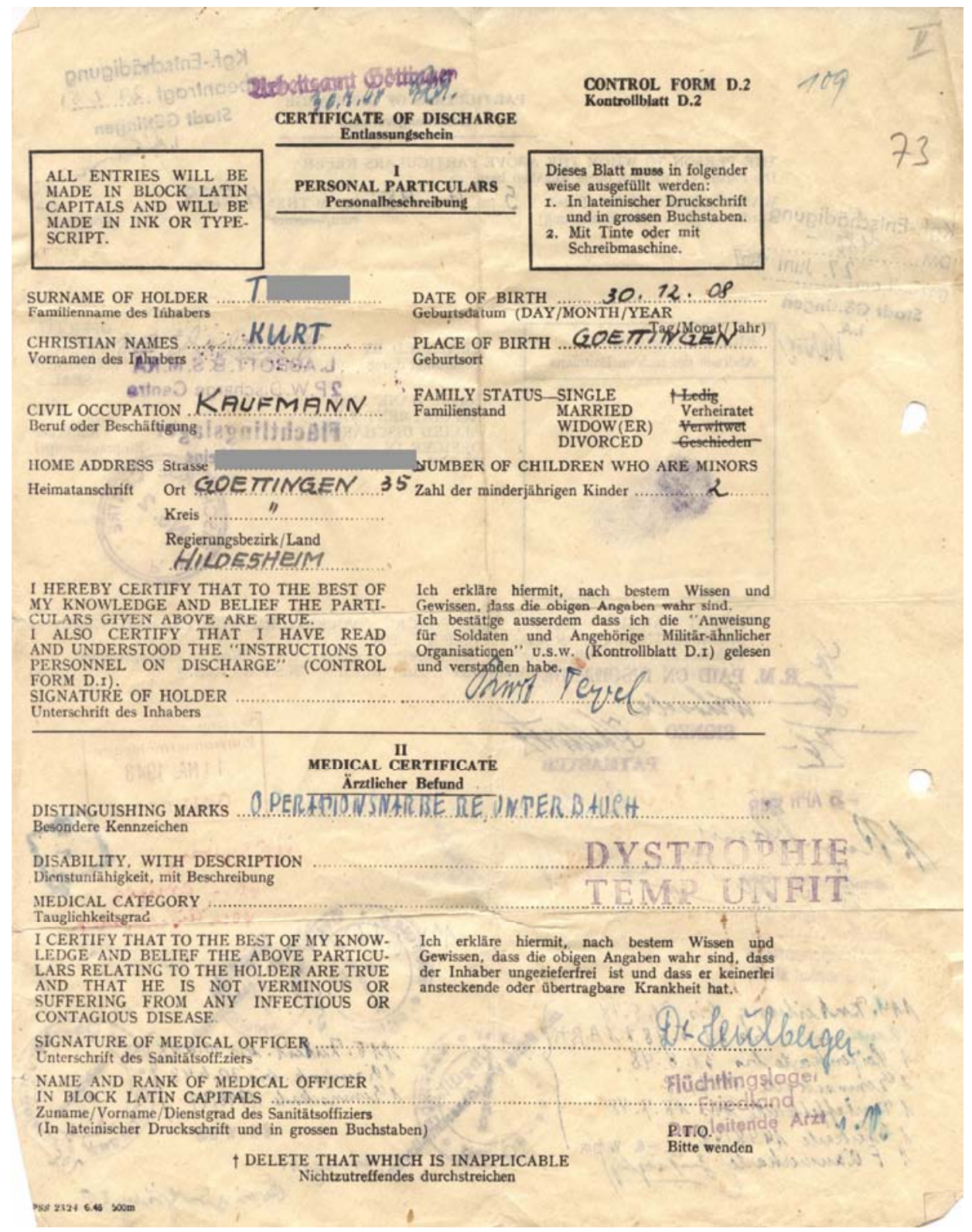

Q12: $\quad$ Certificate of Discharge, Stadt A Gö, B 46 (Ausgleichsamt), Nr. 7, Bl. 73. 


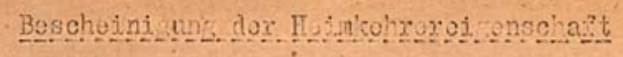

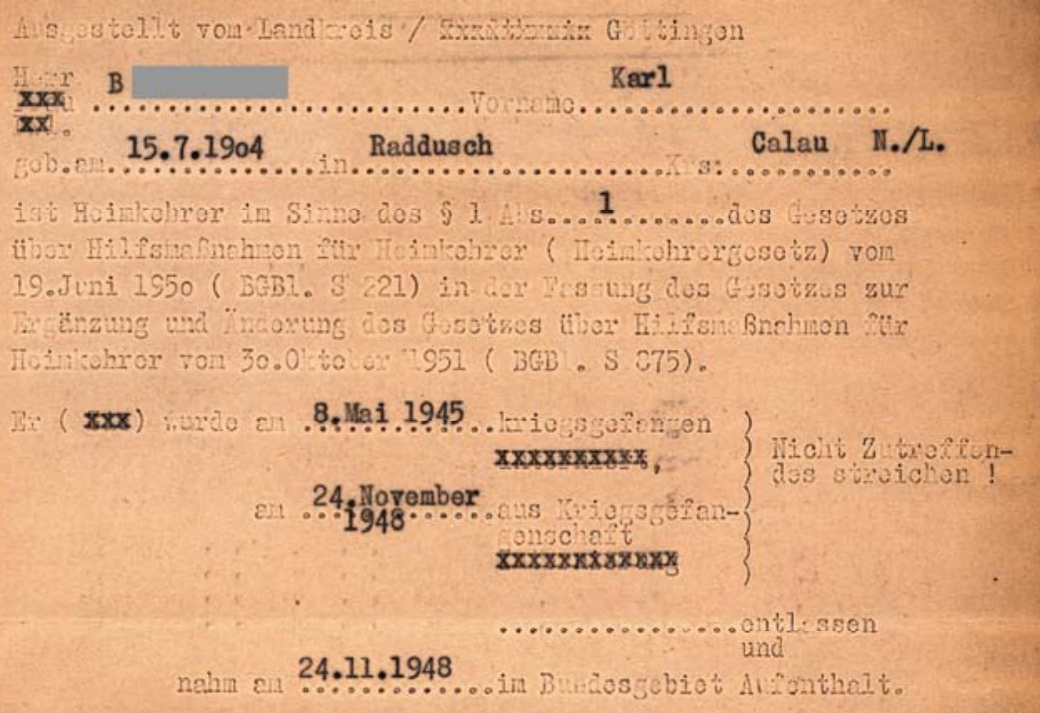

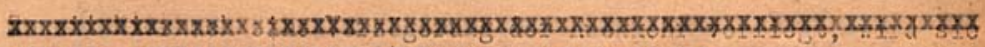

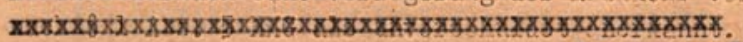

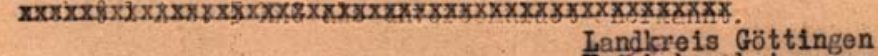

(1) 12. Ilovember $1952 \ldots \ldots$.

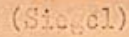

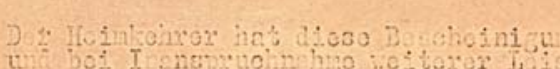

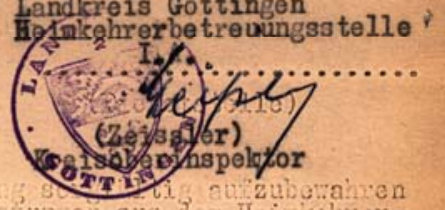

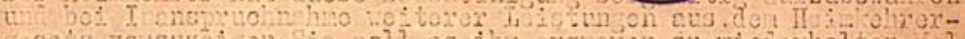

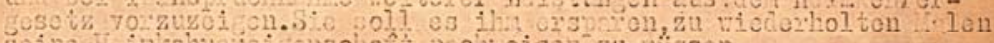
soino it Ancohno:

Anmerkung: der obengenannte Heimkohrer ist im Besitz des Fluchtlingsausmeises (B) AT 965929 KOW, ausges telit vor Fii..Amt Stadt Ilor the in 1. Hann. u.14. Januar 1950 Seine Bhofrau Rosine Beuche, gob.röth, geb.21.6.1909 in Hammelbach Krs. Heppenhein/Odenwald 'igt in Besitz des Flightlingsausweises (A) Ir. MHA-BG 102520 aus-
gestellt vom Flü.Amt der Stadt Göttingen u. 17.12 .1951 .

Soz.A. (९) 51

Q13: Bescheinigung der Heimkehrereigenschaft, Stadt A Gö, B 46 (Ausgleichsamt), Nr. 6, Bl. 56. 
Reinhart Rath Assessor

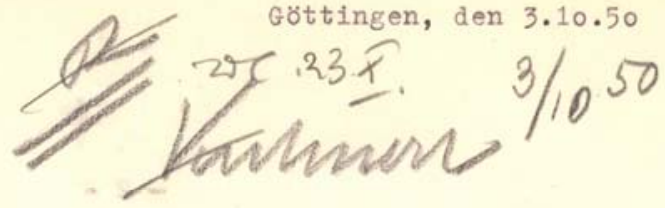

Sehr verehrter Herr oberstadtarektor !

Der Frlass des Heimkehrergesetzes veranlasst mich, auf mein Verhaltnis zur Stadtverwaltung, das mehrmals Gegenstand meiner Vorsprachen bei Ihnen war, zurlickzukommen.

Mein Arbeitsverhaltnis, das seit 1.1 .1937 bestand, endete mit der Kapitulation. Im Nai 1945 erhielt meine Frau die letzte Gehaltszahlung, also mit dem Zeitpunkt, in dem ich in russische Kriegsgefangenschaft geriet. Das Arbeitsverhaltnis erlosch, weil es mir wegen Zuriuckbehaltung im fremden Gewahrsam unmöglich war, der Stadt Dienste zu leisten.

In solchen Fullen bestimmt § 7 des Heimkehrergesetzes vom 19.6.50 (Bundesgesetzbl. Nr $27 \mathrm{S.} 221 \mathrm{fl.}$ ), dass das Arbeitsverhaltnis rifolwirkend wieder auflebt. Ich habe mich bei Ihnen sofort nach Rikckehr aus der Gefangenschaft am 10.9.46 zur Dienstleistung zurickgemeldet.

Da ich mich nicht als entlassen betrachten kann, biete ich hiermit meine Dienste der Stadtverwaltung an und bitte sehr ergebenst um baldgefl. Nachricht uber die Art meiner Verwendung.

Indem ich zum Ausdruck bringe, dass mir nunmehr ein langgehegter Wunsch in Brfillung geht,

bin ich mit votzliglicher Hochachtung

Ihr sehr ergebener

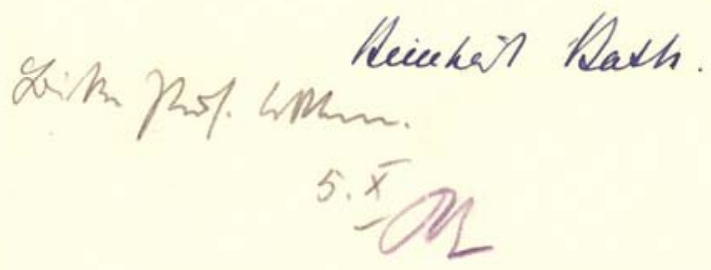

Q14: Briefwechsel. Stadt A Gö, C 34 (Rechtsamt), Nr. 96 (keine Blattzählung). 


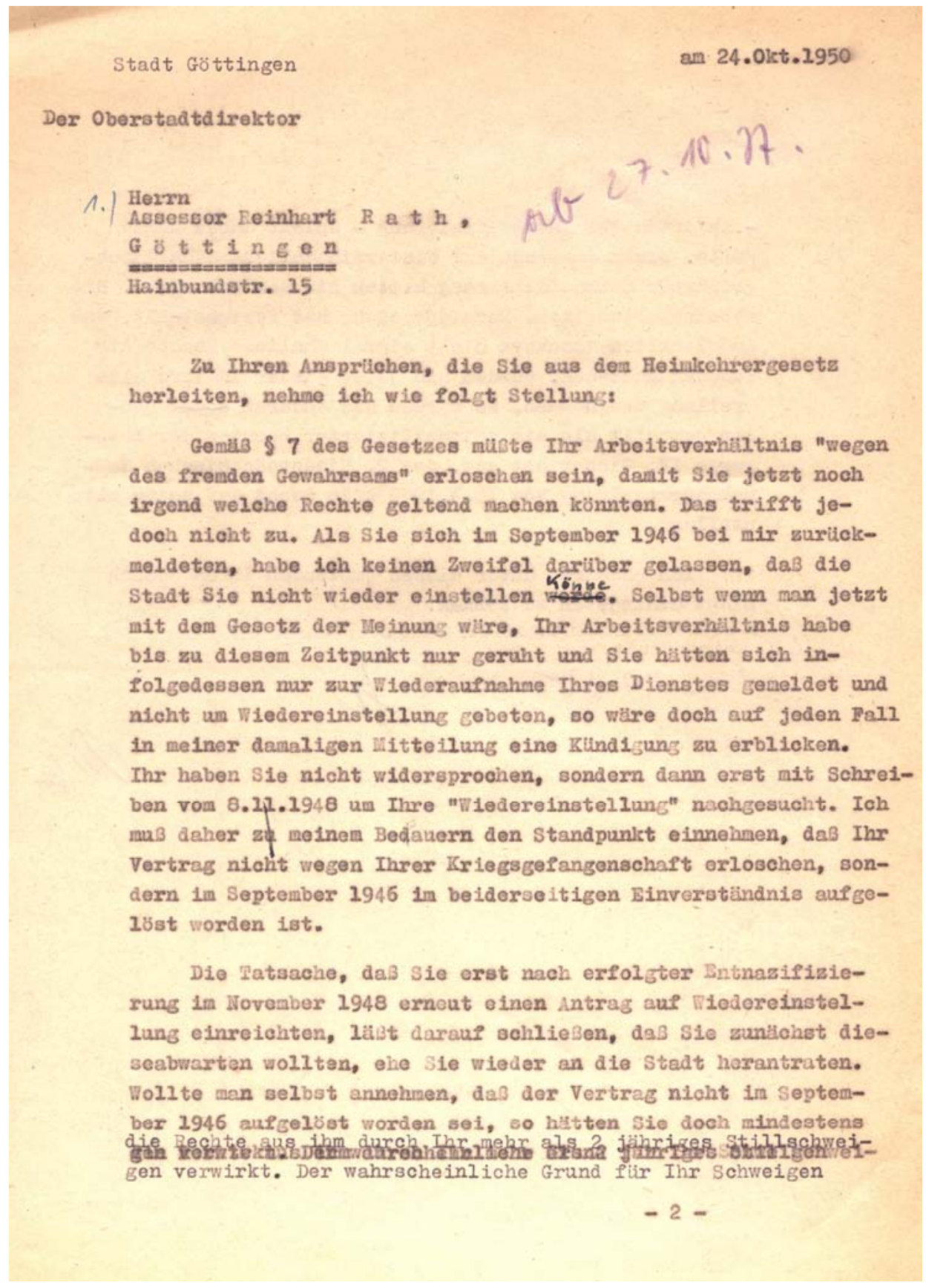

Q14: Briefwechsel. Stadt A Gö, C 34 (Rechtsamt), Nr. 96 (keine Blattzählung). 


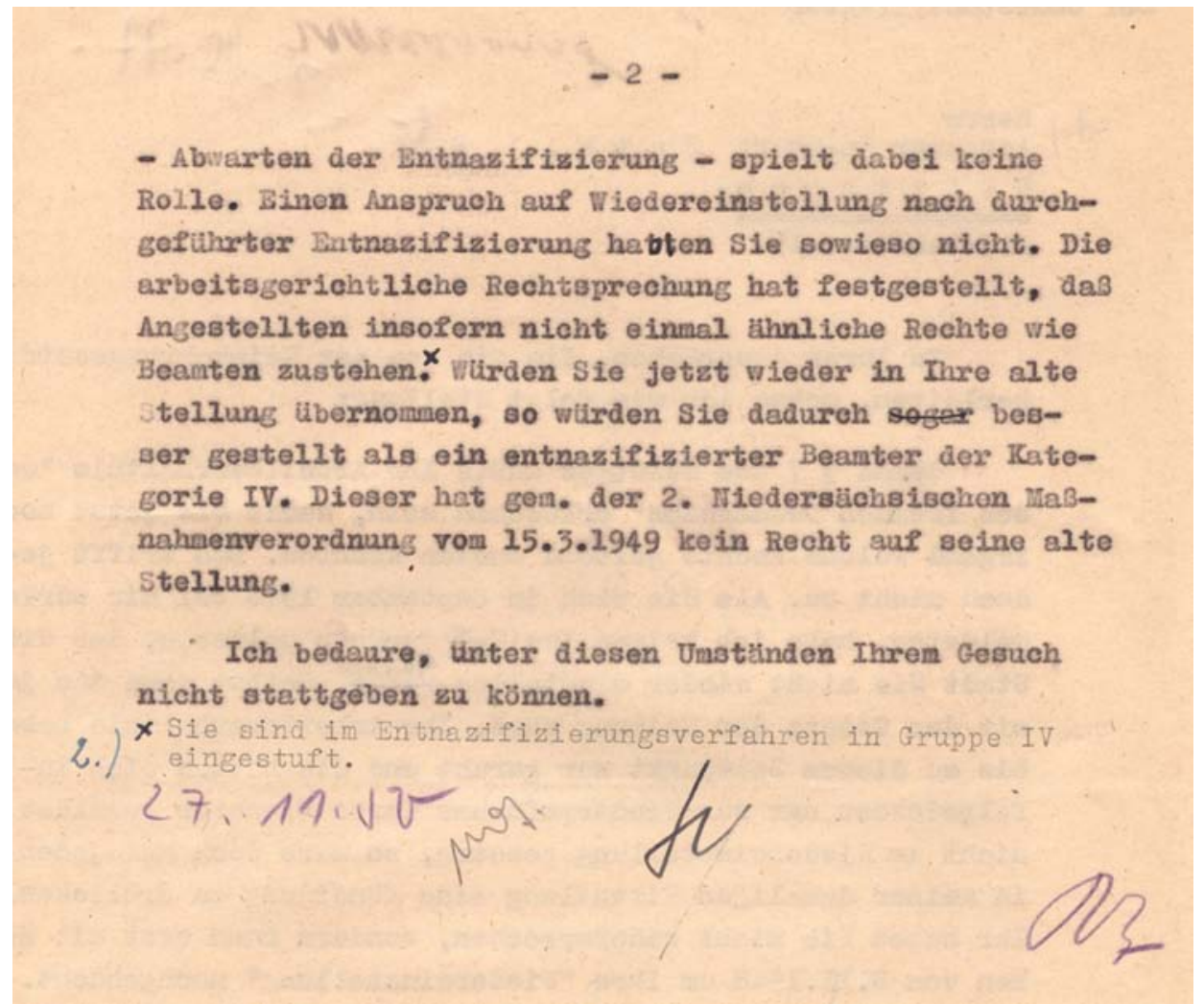

Q14: Briefwechsel. Stadt A Gö, C 34 (Rechtsamt), Nr. 96 (keine Blattzählung). 


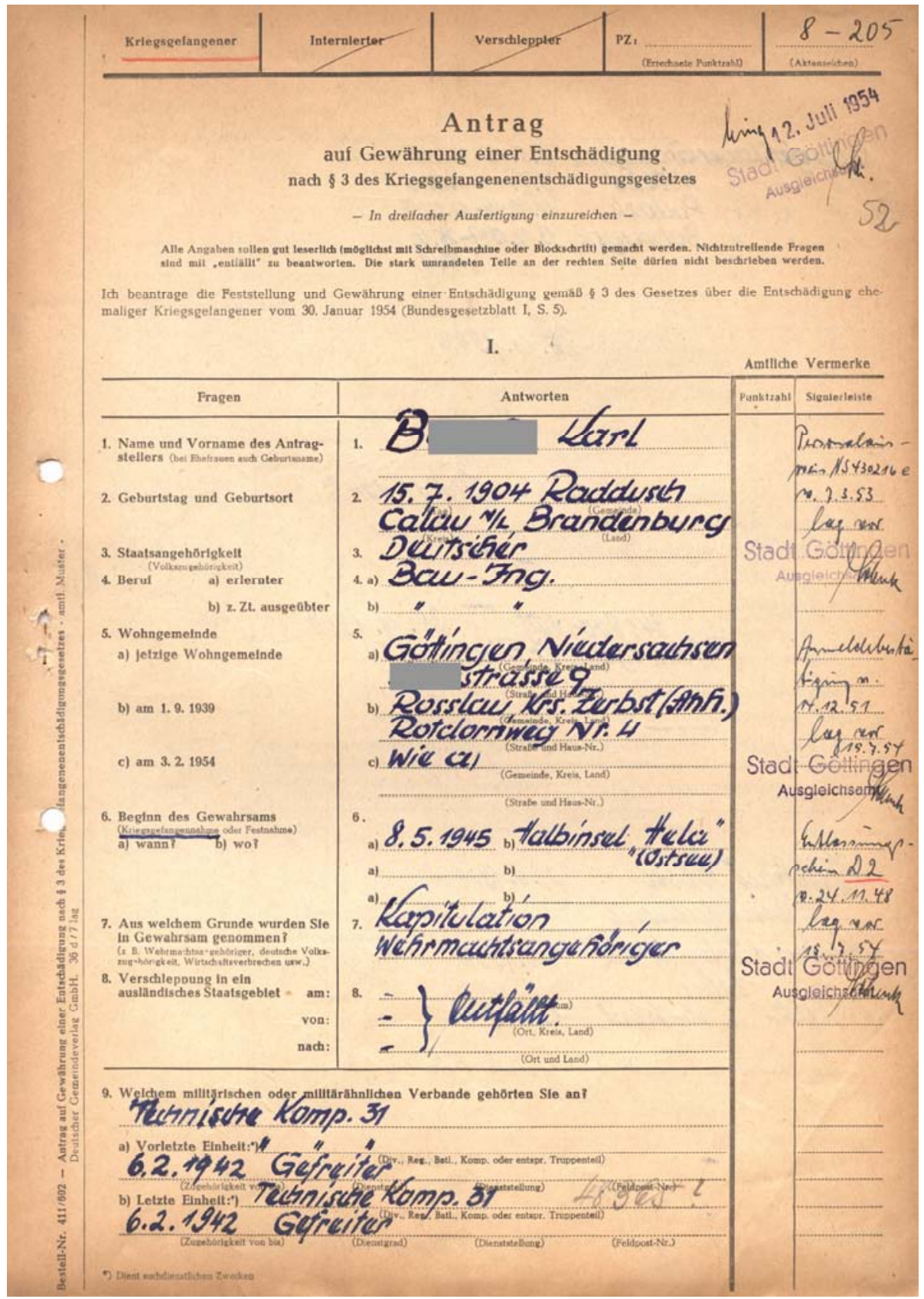

Q15: Antrag auf Kriegsgefangenenentschädigung, Stadt A Gö, B 46 (Ausgleichsamt), Nr. 6, Bl. 52. 


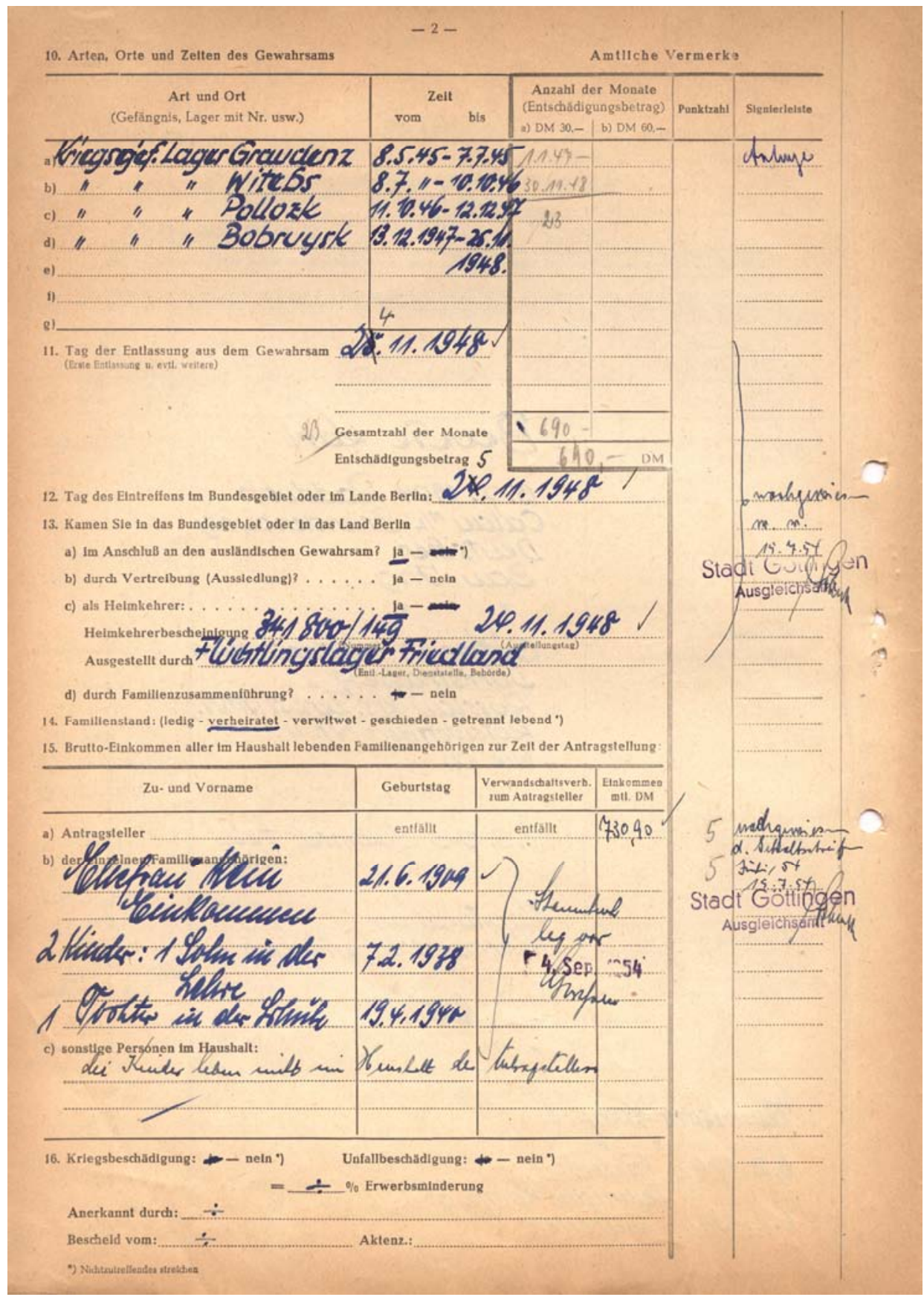

Q15: Antrag auf Kriegsgefangenenentschädigung, Stadt A Gö, B 46 (Ausgleichsamt), Nr. 6, Bl. 52. 


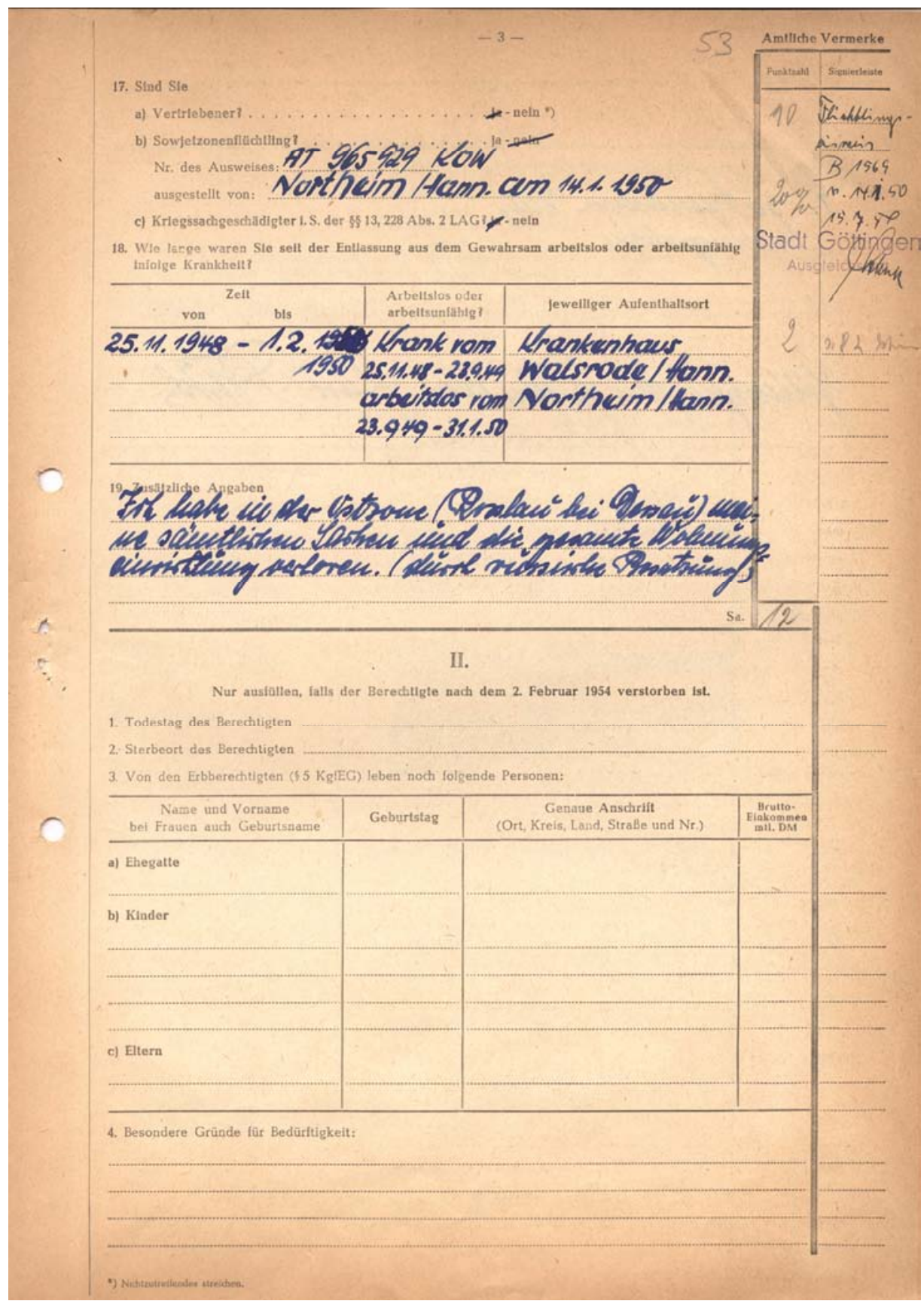

Q15: Antrag auf Kriegsgefangenenentschädigung, Stadt A Gö, B 46 (Ausgleichsamt), Nr. 6, Bl. 53. 


\section{$-4-$}

III.

Ich versichere, dab dle vorstehenden Angaben unter I-II vollstandlg sind und in allen Tellen der Wahrhelt entsprechen. Als Bewelsmittel fuhre Ith an (Originalunterlagen sind erst auf Aniordern vorzulegen):

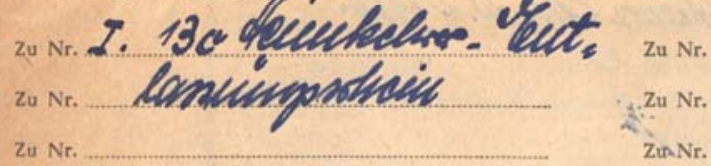

I th ermähtige die Finanzbehörden, ubber meine steuerlichen Verhaltnisse die eriorderlichen Auskünfte zu geben.
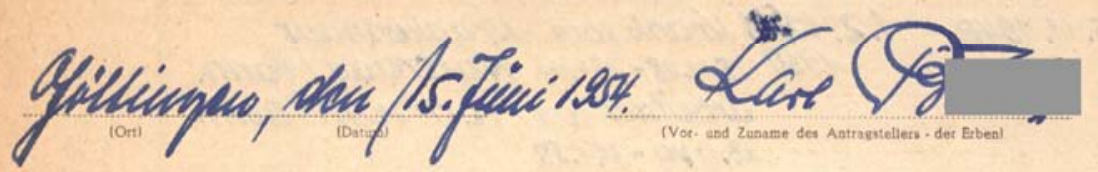

Raium far amtlitie Vermerke

Q15: Antrag auf Kriegsgefangenenentschädigung, Stadt A Gö, B 46 (Ausgleichsamt), Nr. 6, B1. 53. 


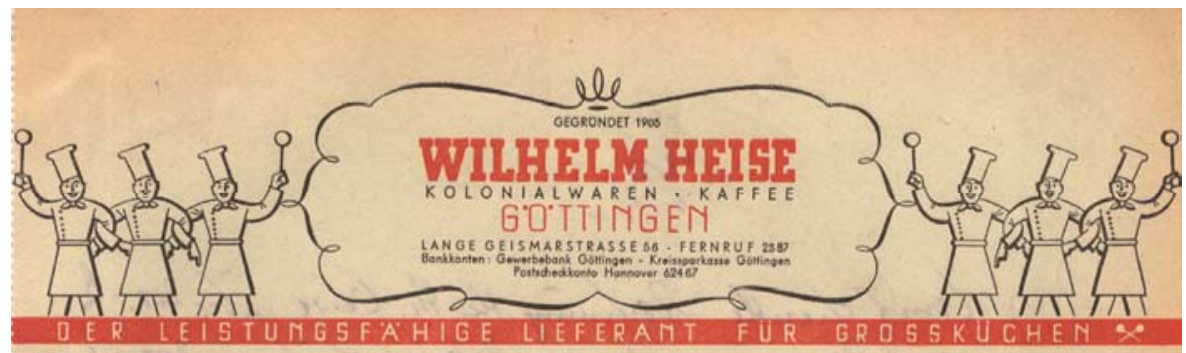

\section{Lieferschein}

$$
\text { № } 308742
$$

Göttingen, den 3. Dezember $\quad 19 \quad .52$ für... das Sozialamt der Stadt Gottingen

Fol. G 6 t $t$ in $B$ en

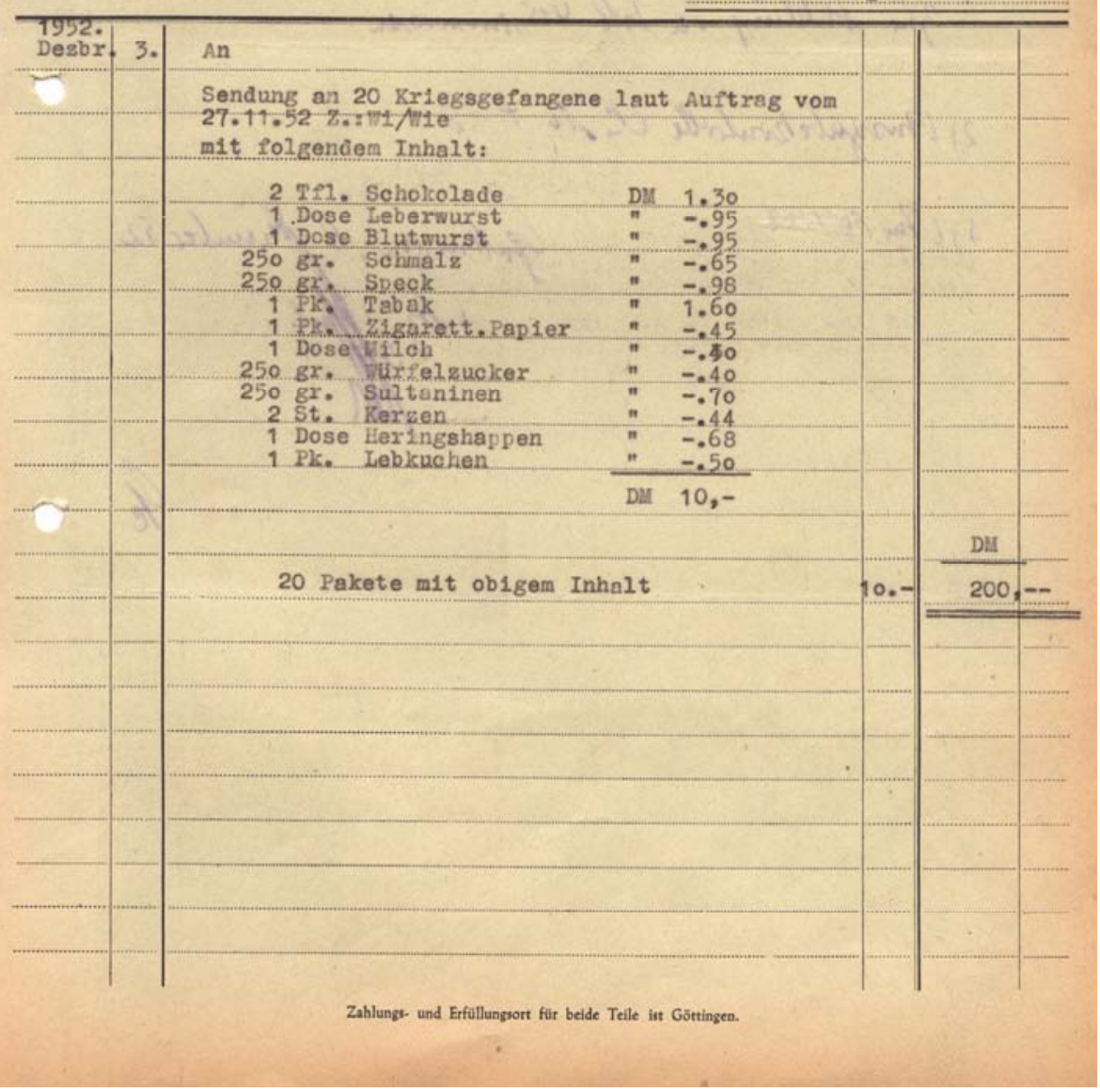

Q16: Rechnung über die Versendung von „Liebesgaben“, Stadt A Gö, C 50 (Sozialamt), Acc. Nr. 434/510, Fach 26, Band I: 1951-1954 (keine Blattzählung). 


\section{Sie sollen sich wie zuhause fühlen}

\section{Was Göttingen für die Heimkehrer tun wird}

Wie wird die Stadt Göttingen ihre Heimkehrer empfangen und betreuen? Diese Frage stand gestern im Mittelpunkt einer Pressekonferenz mit namhaften Vertretern der Stadt. Denn im Blickpunkt der westlichen Welt steht in diesen Tagen das Heimkehrerlager Friedland bei Göttingen. Und jedesmal, wenn in der Westpresse das Wort "Friedland" genannt wird, so wird dem hinzugefügt "bei Göttingen".

Damit ist die nahe Verbundenheit von Heimkehrerschicksal und zur Universitätsstadt an der Zonengrenze bereits angedeutet. Es hätte also keiner Erklärung bedurft, daß die Stadt den Spätheimkehrern jede wirtschaftliche und kulturelle Hilfe gibt, weil die Begriffe "Göttingen" und "Heimkehrerlager "Friedland", Schicksalsstation der Deutschen, bereits eine Einheit sind.

Die 18 Göttinger Heimkehrer, deren Namen durch jahrelange Betreuungsarbeit bekannt sind, sollen von der Stadt ein besonderes Geschenk erhalten. Was? Darüber soll noch beschlossen werden.

Die Stadt gab das Versprechen, daß sie ihren Heimkehrern später alles gibt, um sie in das wirtschaftliche und kulturelle Leben wieder einzuführen.

Was erhalten die Heimkehrer sonst noch? Aufgrund vieler Bestimmungen und Erlasse bekommt jeder Heimkehrer in Friedland 100 Mark Begrü-
Bungsgabe der Bundesrepublik, 200 Mark Entlassungsgeld und auf Antrag eine Uebergangsbeihilfe von 300 DM.

Die Entschädigung nach dem Kriegsgefangenenentschädigungsgesetz richtet sich nach der Dauer der Haftzeit. Sie beträgt für zehn Jahre Kriegsgefangenschaft etwa 5000 Mark.

5000 Mark für die zermürbende und verzweifelte Ungewißheit zehnjähriger Gefangenschaft unter der Aufsicht der Sowjets. Aber immerhin: 5000 Mark sind ein kleiner Anfang für das neue Leben. Ferner wurde mitgeteilt, daß Sonderbeihilfen von den Heimkehrern noch beantragt werden können. Daß sich die Männer innerhalb von acht Tagen in ihrem heimatlichen Gesundheitsamt zu melden haben, daß die Gesundheitsfürsorge einen breiten Rahmen einnehmen soll.

Aber das wichtigste der Erklärungen war wohl, daß die 5000 Mark oder mehr auf dem schnellsten Wege und völlig unbürokratisch ausgezahlt werden, Keine qroßen Antrăqe..." Wir freuen uns unsagbar darüber, daß ihr alle wieder da seid - nehmt die kleine Gabe für das große Schicksal". So etwa erfolgt die Auszahlung. Und wenn ihr euch richtig ausqeschlafen habt und wieder Menschen geworden seid, dann wollen wir uns ganz für Euer Wohlergehen einsetzen. Ihr sollt freien Theaterbesuch haben, ihr sollt euch wie zuhause fühlen.

Q17: Göttinger Presse“, Stadt A Gö, C 28 (Stadtkämmerei), Nr. 583 (keine Blattzählung). 


\section{"Wir lassen uns scheiden ..." 1200 Scheidungsprozesse in knapp. 10 Monaten}

Wer einmal die schwarze Anschlagtafel für Termine im Landgericht Göttingen einer năheren Prufung unterzieht, wird mit Erschrecken die lange Reihe der Scheidungsklagen feststellen. "Das ist für 'uns nun schon ein gewohntes Bild", erklärt Landgerichispräsident Meyerhoff. "Als im Oktober 1945 die Eröffnung der Zivilkammern erfolgte, muBte die Zahl der Ehekammern sofort auf fünf er- höht werden und wöchentlich sieben Sitzungen mit fünf Richtern (früher waren es zwei) waren nōtig, da wir einen wahren Ansturm von Ehescheidungen zu bewältigen hatten, der auch noch immer unvermindert anhält."

Hamburg hat monatlich etwa 1000, Berlin rund 3500 Ehescheidungen aufzuweisen; Göttingen steht dem prozentual gesehen nicht noch, denn innerhalb knapp zehn Monaten wurden' insgesamt 1200 Scheidungsprozessé (einschl. Anfecbtungen der Ehelichkeit der Kinder) gefürt, wogegen es in Friedenszeiten auf hôchstens $200 \mathrm{im}$ Jahr kam. Wa liegen die Gründe dafür?

„In erster Linie sind es die unüberlegten Ehen des Krieges“, sagte der Präsident, „die an der Härte des heutigen Daseins zerbrechen. Vielfach kannten sich die 'Partner kaum, oft führt jahrelanges Getrenntsein zu einer vôlligen Entfremdung, nicht zuletzt ist die gesunkene Moral daran schuld, daß es mit der ehelichen Treue nicht mehr so genaú genommen wird". Hinzukommt, daß während des Krieges eine große Anzahl Klagen dieser Art bewuBt żurückgestellt wurden, die jetzt natürlich -auf eine Entscheidung drăngen. Sühnetermine sind vorgeschrieben ind werden auch nach Mŏg. lichkeit abgehalten. Doch der Erfolg ist tatsächlich gleich Null.

Was wird nun aus den gegebenenfalls vorhandenen Kindern? Das neue Ehegesetz des Alliierteh Kontrollrates (Gesetz Nr. 16) sieht vor, daß allein das Wohl der Kinder ihren weiteren Verbleib entscheidet, wobei ein Einigungsvorschlag der Eltein vom. Richter zu prüfen ist. Der Zuspruch kann also an beide Teile, gleich ob schuldig oder nichtschuldig. erfolgen. Ein Ende dieser Nachkriegskrankheit ist noch nicht abzusehen, denn täglich gehen sicben bis acht neue Klagen ein, und viele Prozesse, sind noch in Vorbereitung. Mb.

Q18: Artikel: „Wir lassen uns scheiden“, Hannoversche Presse, 12.8.1946, S. 4, Stadt A Gö, Film-Nr. Ztg. 627, Bl. 21. 
Wilhelm Sohincke VDI Oberingenieur i.R.

An die

Redaktion des Göttinger Tageblatt

G 6 t $t$ in ${ }^{\circ}$ n.

Betr.: Rat der Stedt Göttingen - Heimkehrer.

\section{$26 / 44076 F$

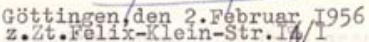

Ich bihk Spätheimkehrer,ergt am 9.Juli I955 nach wehr als Io jahriger Kerkerhdft if 7 tschechischen Zuchthäusern, an Leib und Seele gebrochen in die Heimat zurijckgekehrt, und hier In Göttingen zunëchst boi Verwandten untergekommen,bis ich,da ich Göttingen als meinen neuen Heimetsort gewihlt habe, hier für mich und meine in Ost und West zerstreute Familie eine Wohnung zugewiesen erhalte, was ich schon täglich zu erwarten habe.-

Als im Herbst v.J.im G.T.die Notiz erschien, dass der Rat der Stadt becshlossen habe den noch zu erwertenden Heimkehrem eine Sonderentschädigung (30o.-Dur) und eine Geschenkmappe zu überreichen, meldete mein Bruder mich als Spätheimkehrer beim Stadtamt an, wo ihm jedoch von dem zuständigen Beanten erklürt wurde, dass diese Sondoraktion eigentlich nur für "Göttinger" bestimnt sei,- er wolle sich aber meine Anschrift notieren und später noch Bescheid geben.Bei einer nochmaligen, späteren Vorsprache wurde erklärt,ioh sei wohl vorgemerkt, die Angelegenheit,d.h.ob auch "Níchtgöttinger" in Frage kommen, sei noch nicht entschieden.-

Ich war daher sehr iberrascht,als ioh in G.T.vom 3I.I. oder I.2.d.J.1as, dess inzwischen 29 Heimkehrer, darunter I4 "Nichtgöttinger", die sich G. als neuen Heimatsort ausgesucht hatten (so wie ich)eine Geschenkgabe der Stadt erhalten haben, und kiess im Stadtant nochmals nachfragen (ich selbst bin infolge der mir wihrend der lengen Kerkerhaft zugezogenen Gebrehen leider nichtimstande dies persönlich zu tun) weshalb ich unter den "Nichtgöttingern" nicht dabe de:"Ja, das betreffe nur die Russland - Heimicebter." !

Đe fragt man sich" wohl mit'Recht, weshalb dieser Unterschied; der von allen Staatsund sonstigen Ämtern nicht gemecht wird.-

Gewiss, es handelt sich hier un eine Sonderaktion dek Stadt, die sichi den Kreis der damit zu Bedenkenden wählen kann, und ich hätte Verständnis daftix Gehabt, wenn sie nur fur alteingesessene Göttinger bestimmt gewesen wäre, die von der Stadt schon vorher laufend unterstutzt worden waren. (Ich selbst bin Auslandsdeptscher, geb.ilagdeburger) Aber nechdem sie auch auf "Nichtgöttinger" ausgedeht murde, die sich hier erst neu sesshaft machen wolleh, Ist es weder gerecht noch berechtigt einen Unterschied zwischen Heimkehrern aus Sowj-etrussland und solchen aus den Ostblockstaaten zu machen.Oder ist der Rat der Stadt der Ansicht,dass nach mehr als Io jährigor Kerkerhaft aus der Tschechei Heimicehrendek woniger gelitten häten und weniger bedirftig seien, als die 3 Monate später, meistens aus Arbeitslagern Heimkehrendek aus Russland? Ich könnte als Kenner der Verhältnisse mehr dariber sagen, was jedoch zu weit fuhren

Q19: Brief an das Göttinger Tageblatt, Stadt A Gö, Stadt A Gö, C 50 (Sozialamt), Acc. Nr. 434/510, Fach 26, Band II: 1954-1959 (keine Blattzählung). 
würde, liesse mich aber gern darüber belehren weshalb dieser Unterschied gemacht wurde, und dass er berechtigt ist.

Wicht, dass ich denen, die bei dieser Aktion bedacht wurden, das nicht gönnte,-im Gegenteil, das, was wir in den verflossenen Io und mehr Jahren erlitten und verloren haben, kann uns niemand ersetzen, aber mir der Unterschied und dessen Berechtigung nicht klar gemacht werden kenn, muss ich mich als schwerkranker, uberalterter Mann (75), der von allem Hab und Gut beraubt, mit dem was er auf dem Leibe hatte in die Heimat zurickkehrte, zurïakgesetzt und benschteiligt fühlen.-

Ich wäre Thnen zu Dank verpflichtet, wenn Sie diese Angelegenheit klären könnten und zeichne

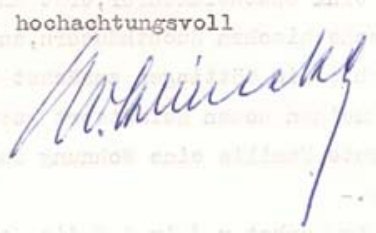

Q19: Brief an das Göttinger Tageblatt, Stadt A Gö, Stadt A Gö, C 50 (Sozialamt), Acc. Nr. 434/510, Fach 26, Band II: 1954-1959 (keine Blattzählung). 



\title{
„Displaced Persons“ in Göttingen
}

\author{
Hagen Stöckmann
}

\section{Einleitung}

Das 20. Jahrhundert in Europa ist gekennzeichnet durch Vertreibungen, Flucht, Zwangsaussiedlungen, ethnische Säuberungen und Deportationen. ${ }^{1} \mathrm{Zu}$ den Leidtragenden dieser Phänomene gehören zweifelsohne auch die „Displaced Persons“ (DP) am Ende des Zweiten Weltkrieges. Nachdem die alliierten Armeen 1945 Deutschland besetzt hatten, hielten sich in den drei westlichen Besatzungszonen schätzungsweise sieben Millionen DPs auf. ${ }^{2}$ Sie bildeten die große Gruppe derjenigen „Zivilpersonen, die sich wegen Kriegseinwirkungen außerbalb der nationalen Grenzen ibres Landes befinden, die zwar nach Hause zurückkehren oder ein neues Zubause finden wollen, jedoch nicht in der Lage sind, dies obne fremde Hilfe zu tun. "3 Damit umfasste diese Definition alle Zwangsarbeiter, die während des Krieges als Arbeitskräfte durch deutsche Betriebe ausgebeutet wurden, ehemalige Konzentrationslagerhäftlinge, Kriegsgefangene (ex-Prisoners of War; PWX) und Osteuropäer, die entweder nach Kriegsbeginn freiwillig die deutsche Wirtschaft unterstützt hatten oder 1944 vor

\footnotetext{
1 Siehe hierzu auch das Lexikonprojekt des Instituts für Kultur und Geschichte der Deutschen im östlichen Europa der Heinrich-Heine-Universität in Düsseldorf: Das Jahrhundert der Vertreibungen. Deportation, Zwangsaussiedlung und ethnische Säuberung in Europa 1912-1999. Ein Lexikon.

2 Vgl.: Leonard Dinnerstein, America and the Survivors of the Holocaust, New York 1982, S. 9.

3 SHAEF, Administrative Memorandum No. 39 (18.11.1944), zitiert bei Wolfgang Jacobmeyer, The „Displaced Persons“ in West Germany, 1945-1951, in: Göran Rystad (Hg.), The Orprooted, Forced Migration as an International Problem in the Post-War Era, Lund 1990, S. 271-288, hier S. 287.
} 
der sowjetischen Armee nach Westen geflohen waren. ${ }^{4}$ Explizit ausgeschlossen waren deutsche Flüchtlinge, wie beispielsweise Ostpreußen, Sudetendeutsche oder Schlesier, deren Zahl in die Millionen ging.

Höchste Priorität hatte für die Alliierten insbesondere die schnelle Rückführung der verschleppten Personen in ihre Heimat. Im Hinblick auf französische, belgische, niederländische und italienische DPs - generell bei den west- und nordeuropäischen Staaten - erwies sich dieses Vorhaben als relativ problemlos und Ende Juni war ihre Repatriierung im Groben abgeschlossen. Als weitaus komplizierter zeigte sich die Rückführung all jener ehemaligen Zwangsarbeiter und Konzentrationslagerinsassen aus dem Osten Europas. Dabei waren die Transportschwierigkeiten das kleinere der Hindernisse. Viele der Ukrainer, die schon recht bald nach Kriegsbeginn ins nationalsozialistische Deutschland gekommen waren, befürchteten Vergeltungsmaßnahmen der nun kommunistischen Regierungen. Die zweite große Gruppe der DPs, die polnischen Deportierten und ehemaligen Zwangsarbeiter, weigerten sich, in die nun sowjetisch kontrollierten Gebiete zurückzukehren. Besonders heikel erwies sich die Situation hinsichtlich einer vergleichsweise nur noch sehr kleinen Gruppe, nämlich der jüdischen DPs. Eine Repatriierung konnte, wenn überhaupt, nur in westliche Herkunftsländer erfolgen. Eine Rückführung in östliche Gebiete stand zunächst nicht zur Debatte. ${ }^{5}$ Aufgrund der Verzögerungen bei der Repatriierung oder weil diese im Hinblick auf die jüdischen Überlebenden schlicht unmöglich war, sahen sich die Alliierten gezwungen, die DPs in sogenannten DP-Camps unterzubringen, für deren Betreuung die am 9. November 1943 gegründete Hilfsorganisation der Vereinten Nationen, die United Nations Relief and Rehabilitation Administration (kurz: UNRRA) federführend war. ${ }^{6}$ Ihre Nachfolge trat im Juli 1947 die International Refugee Organization (kurz: IRO) an. ${ }^{7}$ Unter Obhut der UNRRA standen Ende 1945 rund 227 DP-Camps in den westlichen Verwaltungszonen Deutschlands, deren Zahl sich bis Juni 1947 auf 272 erhöhte; eine Steigerung, die auf die Zuwanderung der osteuropäischen Juden seit Sommer 1946 zurückgeht. ${ }^{8}$ Diese jüdische Migrations-

\footnotetext{
4 Diese Großgruppe muss eigentlich noch weiter unterteilt werden in: United Nations Displaced Persons (Staatsbürger von UN-Staaten), „ex-enemy DPs“ (Italiener, Finnen, Rumänen, Bulgaren und Ungarn), „enemy DPs“ (Deutsche, Österreicher, Japaner), Staatenlose (solche Personen, die ihre behauptete Nationalität nicht nachweisen konnten); eine Gruppe ganz eigener Art bildeten nach der Konferenz von Jalta die sowjetischen DPs; hinzu kamen noch UN-DPs, die sich vor Kriegsbeginn bereits in Deutschland aufhielten; nicht-internierte Briten und Amerikaner; Personen, deren Nationalität durch Territorialverschiebungen berührt war; rassisch, religiös oder politisch Verfolgte. Alleine diese Aufstellung zeigt, mit welchem Massenproblem man es zu tun hatte. Vgl. hierzu auch Wolfgang Jacobmeyer, Vom Zwangsarbeiter zum heimatlosen Ausländer. Die Displaced Persons in Westdeutschland 1945-1951, Göttingen 1985, hier S. 30.

5 Siehe hierzu auch: Angelika Königseder/Juliane Wetzel, Lebensmut im Wartesaal. Die jüdischen DPs (Displaced Persons) im Nachkriegsdeutschland, Frankfurt am Main 1994.

${ }^{6}$ Vgl. hierzu auch Wilfried Mähr, Von der UNRRA zum Marshallplan, Wien 1985.

${ }^{7}$ Louis W. Holborn, The International Refugee Organization, Oxford 1956.

8 Vgl. Juliane Wetzel, „Displaced Persons“. Ein vergessenes Kapitel der deutschen Nachkriegsgeschichte, in: Aus Politik und Zeitgeschichte, B 7-8/95, 10.2.1995, S. 34-39, hier S. 36.
} 
bewegung nach Deutschland mag zunächst überraschen, lässt sich aber schnell erklären, hält man sich vor Augen, dass die Gefahr für diese Menschen durch das Aufflammen antisemitischer und nationalistischer Splittergruppen in ihren Ursprungsländern stetig zunahm. Als Beispiel können hier die „Nationalen Streitkräfte" in Polen dienen. Deutschland wurde so zur Drehscheibe für jüdische Flüchtlinge, die in die USA oder eben nach Israel auszuwandern suchten. Die maßgebliche Lenkung der Flüchtlingsströme aus dem östlichen Europa leistete hier die von Polen bis nach Palästina vernetzte Organisation „Brichah“ („Flucht“). Nachdem die UNRRA zwischen Kriegsende und dem 30. Juni 1947 bereits 741.987 DPs, darunter vornehmlich Polen, aus den westlichen Zonen repatriieren konnte, ${ }^{9}$ belief sich die Zahl der in Deutschland Verbliebenen am 1. Juli 1947 noch immer auf 611.469 DPs, wovon sich 336.700 in der amerikanischen Zone, 230.660 in der britischen und 44.109 in der französischen Zone aufhielten. Schon ein Jahr später, am 1. August 1948, betrug ihre Zahl nur noch 493.928 Personen, wobei die Polen (131.961) und die Juden (122.708) noch immer die größten Gruppen bildeten. ${ }^{10}$ Aus dieser großen Menge von DPs entfielen auf Göttingen laut einer Aufstellung vom 2. Juli 1945 des Ernährungsamtes 10.509 Personen, wobei auch hier die Polen mit 6320 gezählten Versorgungsberechtigten die größte Gruppe stellten. ${ }^{11}$

Entspannen konnte sich die Lage aber erst zu Beginn der fünfziger Jahre, als die meisten DPs mit Ausnahme noch immer vieler Polen in ihre Heimatländer zurückkehren konnten. Die Vereinten Nationen waren mittlerweile von der Repatriation-Policy zu einer Politik des Resettlements übergegangen und DPs wurden in den USA und Australien, aber auch Kanada, Israel und dem United Kingdom angesiedelt. Gegenüber der Repatriierungspolitik betrachteten die Alliierten diese Variante allerdings immer als „Notlösung“.

\section{Versorgung der DPs in Göttingen}

Um deren Versorgung mit den nötigsten Lebensmitteln und Verbrauchsgütern zu gewährleisten, war die Militärregierung, unter deren Verwaltung Göttingen seit dem Einmarsch der alliierten Truppen am 8. April 1945 stand, auf die Unterstützung der Stadtverwaltung angewiesen. Nachdrücklich wies man diese zur Mitarbeit an:

„Sie werden sofort eine entsprechende Menge der unverderblichen Nahrungsmittel beschlagnahmen für den Gebrauch der Ausländer, basierend auf der Zabl der ausländischen und deutschen Konsumenten, jedoch immer bedenken, daß die ausländischen Arbeiter der Vereinten Nationen den Vorrang haben. "12

\footnotetext{
9 Vgl. Mark Wyman, DP, Europe's Displaced Persons, London 1989, S. 58.

${ }^{10}$ Vgl. Eberhard Jahn, Das DP-Problem. Eine Studie über die ausländischen Flüchtlinge in Deutschland, Tübingen 1950, S. 34 f.

11 Stadtarchiv Gö A 75,1.

12 Stadtarchiv Göttingen: Stadtverwaltung und Militärregierung I 75 1, Blatt 29 Vorderseite.
} 
Mit Bezug auf die „Erklärung in Anbetracht der Niederlage Deutschlands und der Übernahme der obersten Regierungsgewalt hinsichtlich Deutschland“ vom 5. Juni 1945 unterstrichen die Alliierten nochmals ausdrücklich: „... die deutschen Bebörden und die deutsche Bevölkerung wird sie (Displaced Persons und ehemalige Kriegsgefangene, d. Verf.), als Personen ebenso wie ihr Eigentum, schützen und wird sie mit angemessener Nahrung, Kleidung, Unterkunft, sowie medizinisch und finanziell versorgen (... ". ${ }^{13}$ Bewusst setzten die Alliierten den Bedarf der DPs höher an als den der Deutschen. Die Kleidung der ehemaligen Zwangsarbeiter war in schlechtem Zustand und die Gesundheit besonders der ehemaligen Häftlinge war besorgniserregend. Trotz ihrer „Bevorzugung“ durch die Militärregierung wurden die DPs durch die Rationen wohl kaum satt. Zu Ihrer Verpflegung konnte man nicht mehr als grob 2.000 Kalorien pro Tag bereitstellen, was umgerechnet auf eine Woche etwa 3,8 $\mathrm{Kg}$ Kartoffeln, $3 \mathrm{Kg}$ Brot, 350 Gramm Fleisch, 125 Gramm Fett oder Butter, etwas Zucker, etwas Gemüse und einige wenige weitere Lebensmittel bedeutete (Q1). Setzt man den eingeplanten Bedarf von 2027 Kalorien am Tag für die 10.509 DPs in Göttingen an, so musste täglich eine Nährwertmenge von ca. 21 Millionen Kalorien bereitgestellt werden. Dementsprechend ungehalten reagierte die Militärregierung auf Verspätungen bei den Lieferungen durch die Deutschen, zu denen es nicht selten kam, weil diese erst einmal ihre eigenen Leute versorgen wollten (Q2). Um die Verteilung der Lebensmittel sorgten sich so die Angehörigen der Militärverwaltung respektive der UNRRA und brachten die Lieferungen entweder in eigens eingerichtete Lager oder zu Sammelstellen im Stadtgebiet. Die Erfassung der Versorgungsberechtigten erfolgte mittels standardisierter Fragebögen, deren Ausfüllen den Betroffenen aber mit großer Wahrscheinlichkeit schwergefallen sein dürfte. Nicht nur aufgrund der Tatsache, dass diese Bögen scheinbar nur in deutscher und englischer Sprache vorlagen, vielmehr fragt man sich auch, wie ehemalige KZ-Häftlinge auf die Frage, ob sie Opfer von Misshandlungen geworden seien, in drei Zeilen antworten sollten (Q3). Nichtsdestotrotz erlaubten diese Fragebögen den Zugang wenigstens zur Minimalversorgung. Ein Grund, weswegen auch einige Unberechtigte versuchten, in den Genuss dieses bescheidenen Privilegs zu kommen. So kam es, dass ein Mechaniker aus Göttingen sich als ehemaliger (politischer) KZHäftling ausgegeben hatte, um Bezugsscheine zu erschwindeln, woraufhin er zu neun Monaten Gefängnis verurteilt wurde. ${ }^{14}$

Besonderer Fürsorge bedurften diejenigen Displaced Persons, die durch jahrelange Zwangsarbeit oder Lagerhaft soweit geschwächt waren, dass sie eine Unterbringung in Lagern nicht verkraftet hätten. Für diese Härtefälle hatte man in Göttingen Plätze im gerade eingerichteten Lazarett und eben auch im DPKrankenhaus auf dem Rhons eingerichtet. Hierbei handelte es sich um das früher

\footnotetext{
13 Regarding the defeat of Germany and the assumption of supreme authority with respect to Germany by the governments of the United Kingdom, the United States, the USSR, and the provisional government of the French Republic", June $5^{\text {th }}, 1945$, Article 6 (a), in: Documents on Germany under Occupation 1945-1954, London 1955, S. 29-35, hier S. 32.

${ }^{14}$ Hannoversche Neueste Nachrichten vom 20.9.1946.
} 
beliebte Ausflugsziel und Tanzlokal Rhons im heutigen Göttinger Ostviertel (Q4). Die Stadt hatte Betten und medizinische Gerätschaften im großen Tanzsaal aufgestellt und die Gaststätte so in eine provisorische Krankenstation umgewandelt. Dort versorgte Pflegepersonal aus den umliegenden Krankenhäusern deutsche Kriegsgefangene ebenso wie die DPs. Ob die Militärregierung einer einseitigen Perspektive, die allein in den deutschen Kriegsversehrten Opfer sehen wollte, vorzubeugen suchte, indem auch die geschwächten DPs vor Ort zu behandeln waren, kann man nur vermuten, es scheint aber plausibel. Zumal, wenn man die Bilder von ausgemergelten Männern und Frauen sowie kranken Kleinstkindern (Q5) betrachtet, die von ortsansässigen Fotografen zu Dokumentationszwecken geschossen wurden. Wer allerdings diese Fotos zu Gesicht bekam, lässt sich heute nicht mehr zweifelsfrei rekonstruieren. Vermutlich waren sie für interne Zwecke aufgenommen worden. Die Insassen des DP-Krankenhauses durften im Übrigen nur in Begleitung des Personals das Gebäude verlassen (Q6) und hatten sich generell auf dem Gelände des neuen „Krankenhauses“ zu bewegen.

\section{Die Wohnsituation der DPs}

Die Unterbringung der Displaced Persons gestaltete sich beinahe so schwierig wie die Lebensmittelversorgung. Aus organisatorischen Gründen, insbesondere hinsichtlich der beabsichtigten Repatriierung, und zur Sicherstellung der Ernährung und Gesundheit betrachtete die Militärverwaltung Lager als die beste Unterbringungsform. Hierbei ist anzumerken, dass der statische Begriff „Lager“ die eigentliche Bestimmung, welche die Alliierten den Camps zudachten, nicht ganz trifft: Die Militärregierung sprach hier von „Assembly Centers“, was soviel wie „SammelZentren" bedeutet und auf den temporären und den auf die kommende Rückführung hinweisenden Charakter verweist. ${ }^{15}$ In Göttingen hatten sich vor allem die ehemaligen Kasernen als geeignete Lagerstandorte herausgestellt, nämlich die Lüttich-Kaserne, die Wörth-Kaserne und die Barackengebäude auf dem Lohberg, da sie den Bedürfnissen der Alliierten entgegenkamen: Nutzung bestehender Lager oder öffentlicher Gebäude wie Kasernen, günstige Verkehrsanbindung ohne Behinderung militärischer Routen für den Transport von Versorgungsgütern sowie Garantie für alle hygienischen und medizinischen Einrichtungen. ${ }^{16}$ Bereits vor der Einrichtung der Lager war darauf geachtet worden, dass ,alle Personen registriert und (...) in nationale Gruppen aufgeteilt werden “. ${ }^{17}$ Die DPs sollten ihrer Nationalität nach getrennt in Lagern untergebracht werden und so hinsichtlich der Repatri-

\footnotetext{
15 Vgl. Wolfgang Jacobmeyer, Zwangsarbeiter. S. 25.

16 Ebd.

17 PRO: WO 171, Nr. 7955, Befehl des 229 MilGovDets (Hannover) als Anlage zum War Diary für den Monat April 1945, zitiert nach Ullrich Schneider, Niedersachsen unter britischer Besatzung 1945, Besatzungsmacht, deutsche Verwaltung und die Probleme der unmittelbaren Nachkriegszeit dargestellt am Beispiel des späteren Landes Niedersachsen von April bis Oktober 1945, Hannover 1980, S. 36.
} 
ierung als Gruppe besser handhabbar sein. Stellte man sich die soeben befreiten Häftlinge und Zwangsarbeiter doch als leicht lenkbare, weil geschwächte Personengruppe vor, worin man sich allerdings täuschte. Die Nationalität wurde - wie bei den 6.300 Polen, ${ }^{18}$ die man gemeinsam in Lagern unterbrachte - zur einzigen Identifikationsgröße im Bewusstsein der DPs. Hatte man anfangs hohe Erwartungen mit der Befreiung durch die Alliierten verbunden, musste die Monotonie des Lagers, die am Ende von Haft und Zwangsarbeit nun abermals auf die DPs wartete, demoralisierend auf sie wirken. Dies wurde durch die Ausgangssperre noch verschärft. Die räumliche Segregation von DPs und Deutschen sorgte zudem für eine Atmosphäre des gegenseitigen Misstrauens. Auf deutscher Seite pflegte man ein Feindbild der DPs, das sich aus einem Pool nationalsozialistischer Diskriminierungen der Zwangsarbeiter speiste. Folge war eine äußerst vorgefasste Wahrnehmung der Realität und Vorschub für die Verdrängung eines Schuldbewusstseins, das sich in der Konfrontation mit den Opfern der NS-Zwangswirtschaft hätte ergeben müssen. ${ }^{19}$ Leidtragende dieser Effekte waren nicht zuletzt jene Ausnahmen unter den DPs, die eben nicht in Lagern, sondern in geräumten Wohnungen oder Hotels im Göttinger Stadtgebiet wohnten.

\section{Die Wahrnehmung der DPs durch die Bevölkerung}

Wie bereits angedeutet sahen die Deutschen in den DPs eine Nachkriegslast und nahmen sie als potentielle Gefahr war. Schnell machten ebenso haarsträubende wie übertriebene Gerüchte über stehlende und raubende Banden die Runde, deren Mitglieder man in den Reihen der DPs zu verorten suchte. Die Kreisbauernschaft beklagte sich über das anhaltende Verschwinden von Schweinen, ${ }^{20}$ wertvolle Zuchtbullen sollen sinnlos abgeschlachtet worden sein. Bei der Schilderung der Fälle ist signifikant, dass die Täter in den meisten Fällen unerkannt blieben und die Ankläger die DPs wenn überhaupt nur verdächtigen konnten. Entsprechend vorsichtig muss man mit der Quelle zur „Aufstellung über Viehverluste“ vom 10. August 1945 umgehen, aus der hervorgeht, dass durch Raub und wildes Abschlachten der Stadt und dem Landkreis zwischen dem 8. April und dem 15. Juli 1945 etwa 89 Tonnen Fleisch abhanden kamen, eine Menge, die dem städtischen Bedarf von sechseinhalb Wochen entspricht (Q7). Möglicherweise waren auch DPs an diesen Diebstählen beteiligt, doch hinsichtlich der antizipierten Häufigkeit ihrer Beteiligung ist Vorsicht angeraten, da es sich bei den Anschuldigungen nur um Vermutungen handelte. Wahrscheinlicher ist es, dass es sich bei diesen Berich-

\footnotetext{
18 Stadtarchiv Göttingen: Stadtverwaltung und Militärregierung I 751.

19 Vgl. hierzu Wolfgang Jacobmeyer, Zwangsarbeiter, S. 50 ff. und ders., Ortlos am Ende des Grauens. „Displaced Persons“ in der Nachkriegszeit, in: Klaus J. Bade (Hg.), Deutsche im Ausland, Fremde in Deutschland, S. 367-373. Außerdem Alexander u. Margarete Mitscherlich, Die Unfähigkeit zu trauern. Grundlagen kollektiven Verhaltens im 20. Jahrhundert, München 1967.

${ }^{20}$ Hans Georg Schmeling, Göttinger Nachkriegsalltag 1945, in: Jens-Uwe Brinkmann/Rainer Rohrbach (Hg.), Göttingen 1945. Kriegsende und Neubeginn, S. 149-199, hier S. 171.
} 
ten vielmehr um gezielte Denunziationen mit doppelter Stoßrichtung handelte: Konnte man doch die unliebsamen DPs in Verruf bringen und hoffen, die Besatzer würden sich überzeugen lassen, hart durchzugreifen und gleichzeitig ließen sich die eigenen Leute bequem entlasten indem man solcherlei Straftaten auf die DPs schob. Darüberhinaus weist die DP-Kriminalität eine gänzlich andere Ätiologie als die deutsche Kriminalität auf, die sich vornehmlich auf den Diebstahl von Wertgegenständen richtete. Im Vergleich dazu handelte es sich bei der Diebstahlskriminalität der DPs vornehmlich um Aktionen zur existentiellen Essensbeschaffung. ${ }^{21}$

Welche beunruhigende Wirkung von den DP-Lagern und auch von im Stadtgebiet wohnhaften DPs ausging, belegt der Bericht über eine Wohnungsverwalterin, die sich durch Überfalle von „Polenbanden“ soweit belästigt fühlte, dass sie die deutschen Kriegsgefangenen, welche gerade als Erntehelfer zur Untermiete bei ihr wohnten, quasi als Leibgarde in ihrer Wohnung behalten wollte, um sich vor befürchteten Übergriffen zu schützen (Q8). Hier verquickten sich die allgemeine Beunruhigung über die geschwundenen staatlichen und polizeilichen Strukturen mit alten Ressentiments, die die Bevölkerung gegenüber den Zwangsarbeitern und KZ-Insassen hegte. Zumal diese ja nun, da sie „auf freiem Fuß“ waren, sich hätten rächen können, wie es wohl einige befürchteten. Solche Racheakte sind zumindest in Göttingen nicht verzeichnet. In der Wahrnehmung der Göttinger Bevölkerung nahmen sich die ehemaligen Zwangsarbeiter jedoch als kardinale Bedrohung aus: „Fast Zehntausend befreite Zwangsarbeiter leben in der Stadt und den umliegenden Dörfern. [...] Die Militärpolizei kann nicht gleichzeitig überall sein. Die deutschen Hilfskräfte sind nur mit Stöcken ausgerüstet und richten wenig oder gar nichts gegen die plündernden, zum Teil bewaffneten Gruppen aus. Die halten sich schadlos, wo sie können. Wie Heuschreckenschwärme, kommt es uns vor, fallen sie über Geschäfte und Wobnungen her und verbreiten Angst und Schrecken."22 Dass an solchen Plünderungen auch Göttinger beteiligt waren, daran vermochten sich später freilich die Wenigsten zu erinnern. ${ }^{23}$

Abschließend lässt sich also konstatieren, dass die deutsche Bevölkerung und auch die Göttinger die DPs zumindest als störend, meistenteils aber als kriminell empfanden. So sollten sie doch in den von ihnen bewohnten Häusern enger zusammenrücken, um Platz für deutsche Familien zu machen (Q9), oder besser noch gleich ganz ins Lager gehen, damit deutsche Heimkehrer die Wohnungen belegen könnten (Q10). Ganz eindeutig hängt diese Reaktion mit dem tatsächlichen Wohnungsmangel in Göttingen zusammen. Die Lage entspannte sich erst Mitte der Fünfziger Jahre mit großangelegten Wohnungsbauprojekten, denen teilweise Eigenarbeit der Göttinger vorausgegangen war. ${ }^{24}$

\footnotetext{
${ }^{21}$ Jacobmeyer, Zwangsarbeiter, S. 49.

22 Zitiert wird hier der anonymisierte Bericht einer Zeitzeugin nach Cordula Tollmien, Nationalsozialismus in Göttingen (1933-1945), Göttingen 1999, S. 245.

${ }^{23}$ Ebd.

${ }^{24}$ Vgl. hierzu den Artikel von Ulf Gerrit Meyer-Rewerts in diesem Band.
} 


\section{Literatur zum Weiterlesen}

Wolfgang Jacobmeyer, Vom Zwangsarbeiter zum heimatlosen Ausländer. Die Displaced Persons in Westdeutschland 1945-1951, Göttingen 1985.

Angelika Königseder/Juliane Wetzel, Lebensmut im Wartesaal. Die jüdischen DPs (Displaced Persons) im Nachkriegsdeutschland, Frankfurt am Main 1994.

Hubert Schneider, Jüdische Displaced Persons in Deutschland nach 1945:

Selbstverständnis und Wahrnehmung durch die deutsche Bevölkerung, in: Hans-Christoph Seidel/Klaus Tenfelde (Hg.), Zwangsarbeit im Europa des 20. Jahrhunderts: Bewältigung und vergleichende Aspekte, Essen 2007, S. 39-58.

Atina Grossmann, Victims, villains and survivors: gendered perceptions and selfperceptions of Jewish displaced persons in occupied postwar Germany, in: Dagmar Herzog (Hg.), Sexuality and German fascism, New York 2005, S. 291 318.

Post-War Europe: refugees, exile and resettlement 1945 - 1950/The National Archives, UK and the Wiener Library, London. (Online-Resource: Datenbank)

(Zentrales Thema der Datenbank ist die Geschichte der Displaced Persons (DP) in Europa. Zu diesem Zweck wurden etwa 3.000 Dokumente zusammengetragen, die als Bilddateien und über Volltextsuche angeboten werden. Die Daten stammen im Wesentlichen aus der Wiener Library in London und aus den National Archives of the UK mit Beständen aus der General Correspondence des Foreign Office, dem Control Office for Germany and Austria und der Control Commission for Germany. Durch die Bestände aus der Wiener Library liegt ein gewisser Schwerpunkt auf der jüdischen DP-Geschichte.) 


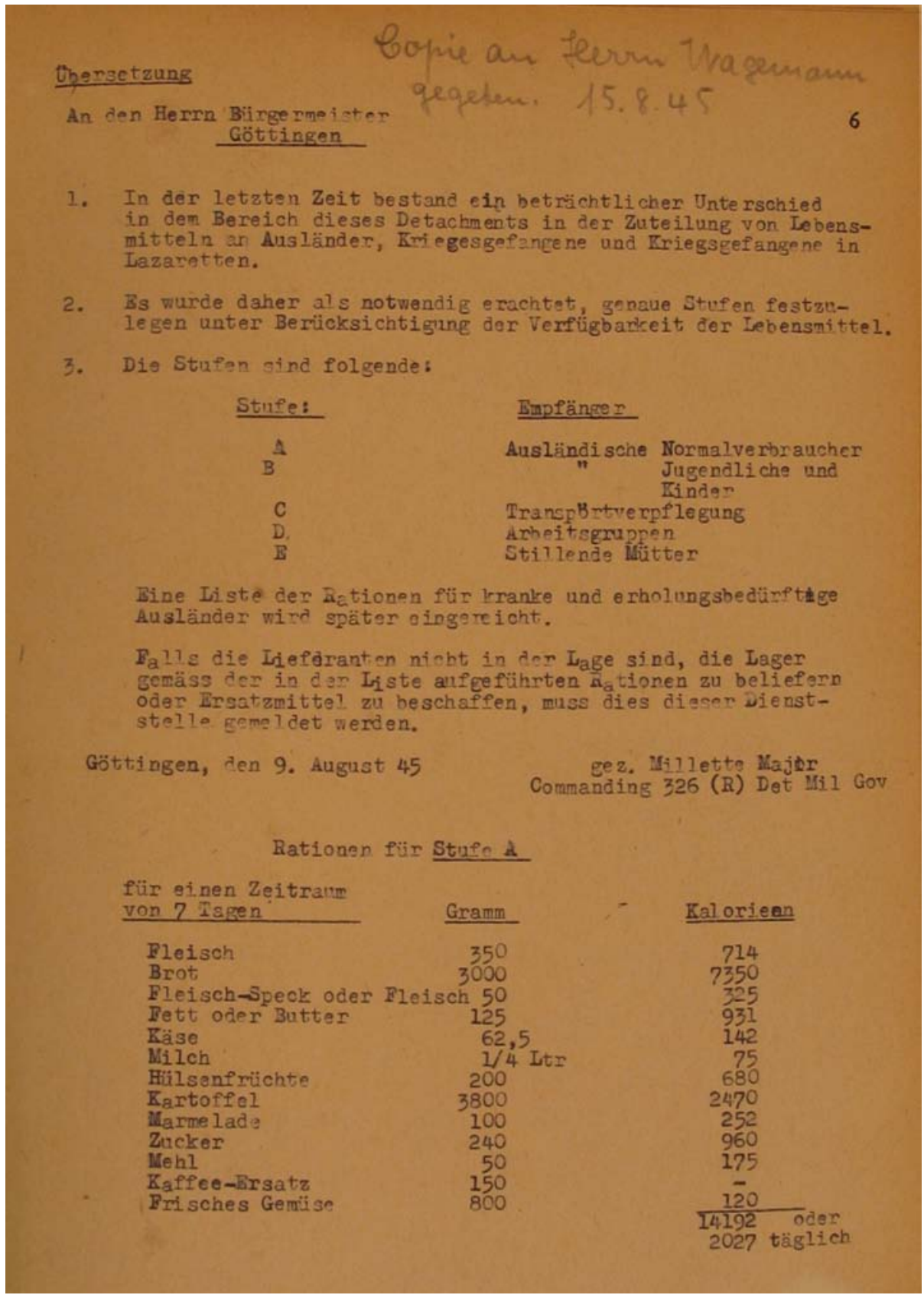

Q1: Rationierung von Lebensmitteln: Stadtarchiv Göttingen: Stadtverwaltung und Militärregierung I 75 1, Blatt 6. 


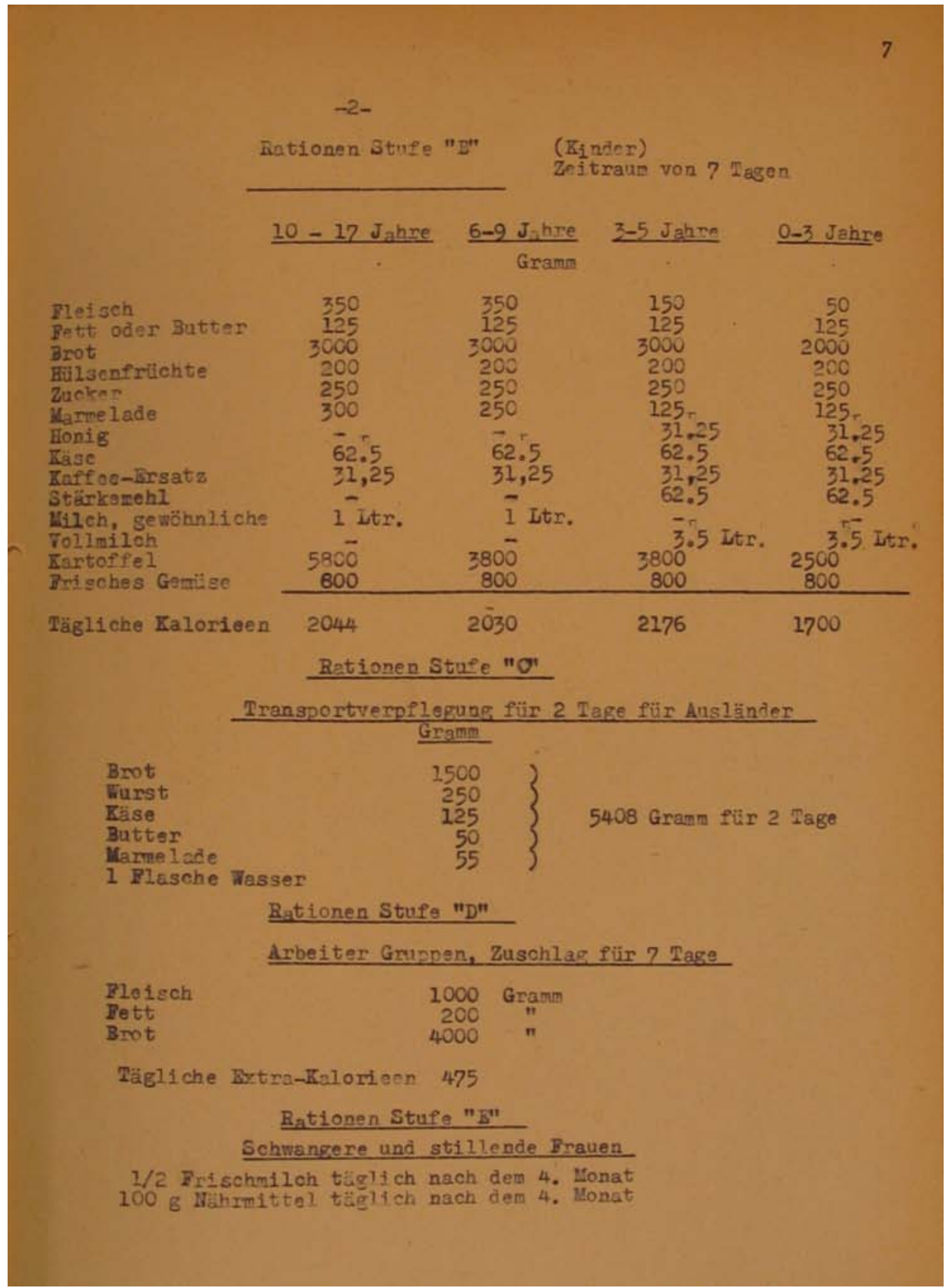

Q1: Rationierung von Lebensmitteln: Stadtarchiv Göttingen: Stadtverwaltung und Militärregierung I 75 1, Blatt 7. 


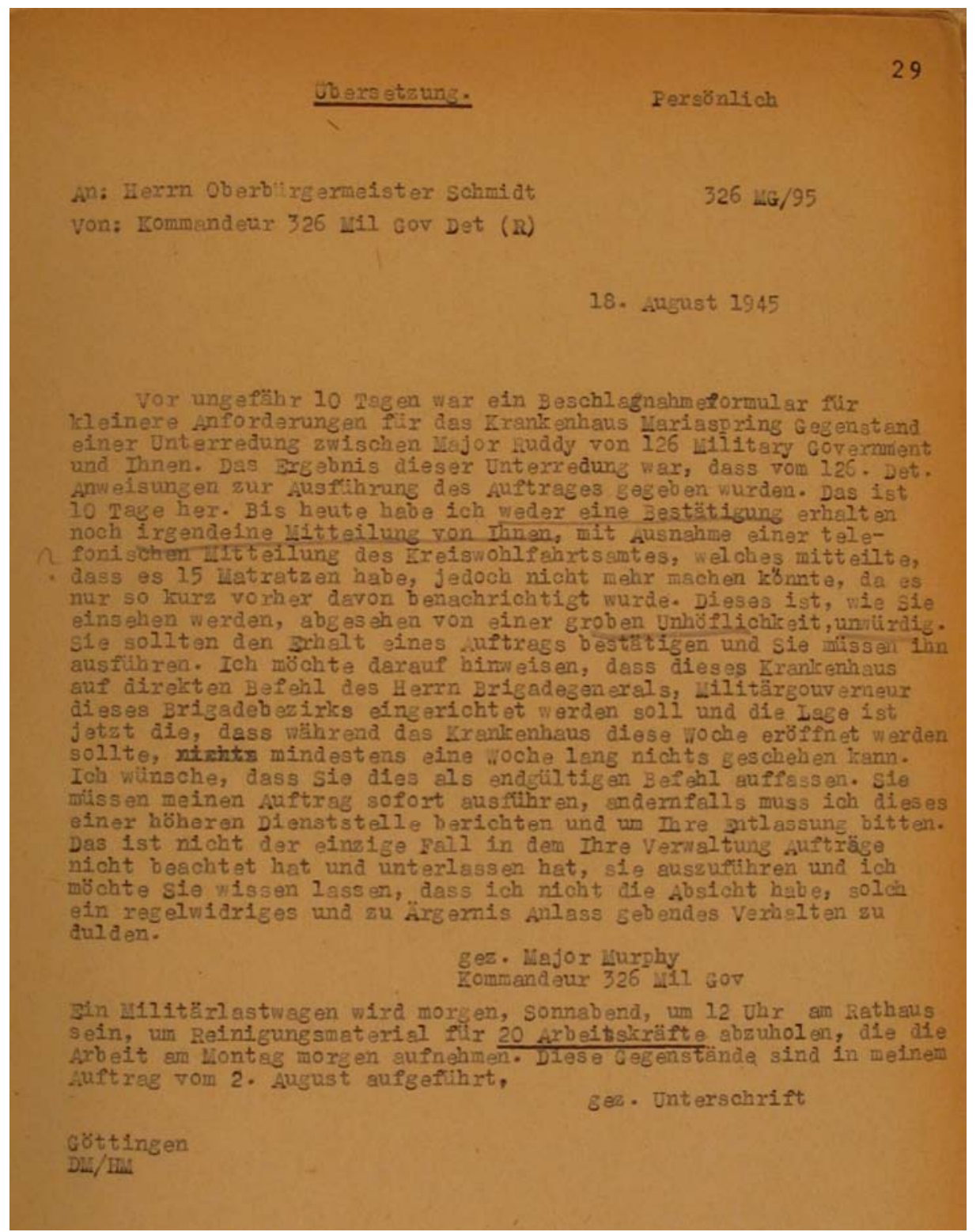

Q2: Zusammenstöße mit der Militärregierung: Stadtarchiv Göttingen: Stadtverwaltung und Militärregierung I 75 1, Blatt 29. 


\section{Sonderhilfs-Ausschuf}

für den Kreis

\section{Antrags-Formular für frühere Häftlinge der Konzentrationslaser.}

fontienname:

bed Frouen auch Geburtsname)

Gebutatad -

Cogenwairtleo Anschrilt

wif und Beschältigung:

ti des Personalausweises und dessen Nummer:

inahl der Kinder (mil Aitersangaben) und sonstiger abhăngiver Angehöriger:

rund der Gefangensetrung:

In Halt in.

vom

bis

Name der Person, die Sie angezelgt hat:

Anchilit det Person, die Sie angezeigt hat

Veruteif durch:

$\min$

Ihre Konzentrationslager-Hötlings-Nummer:

Wurden Sie mibhandelt und in welcher Weise?

$U$ selche Weise wurde der Lebensunterhalt lhrer Familie während lhrer Haft bestritten?

Volle Einzelheiten aber die Art threr Haft unter Angabe von Zeugen und Belfügung von Abschriften von Dokumenten:

des Sonderhilfsolanes zur Inanspruchnahme der Sonderhilfe berechtigt bin.

Ch erkltire, dab tch gemab Absatz

kh verichere, dab ich die oblgen Angaben nach bestern Wissen und Gewissen gemacht habe und dab diese voll und onne der Wobitheit entsprechen. Ich bin mir dessen bewubt, dad unwahre Angaben meinen Ausschlub von der Inanspruchnahine des Sonderhillsplanes und meine strairechtiche Vertoigung noch sich ziehen.

Q3 Fragebogen: Stadtarchiv Göttingen: Stadtverwaltung und Militärregierung I 761 Blatt 20 Vorderseite. 


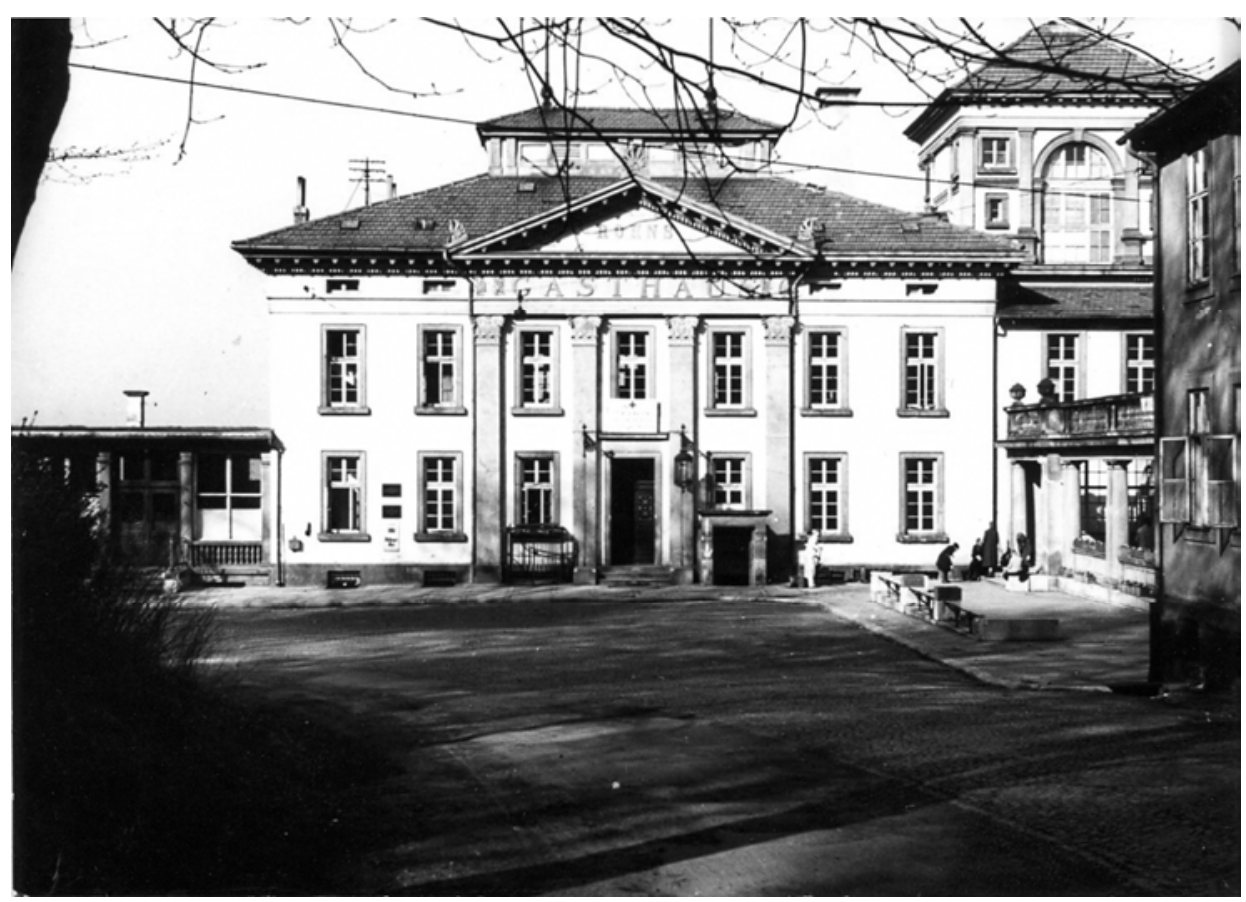

Q4: Außenansicht des damaligen Hilfslazaretts auf der „Rhons“ (Fotoarchiv Göttingen). 


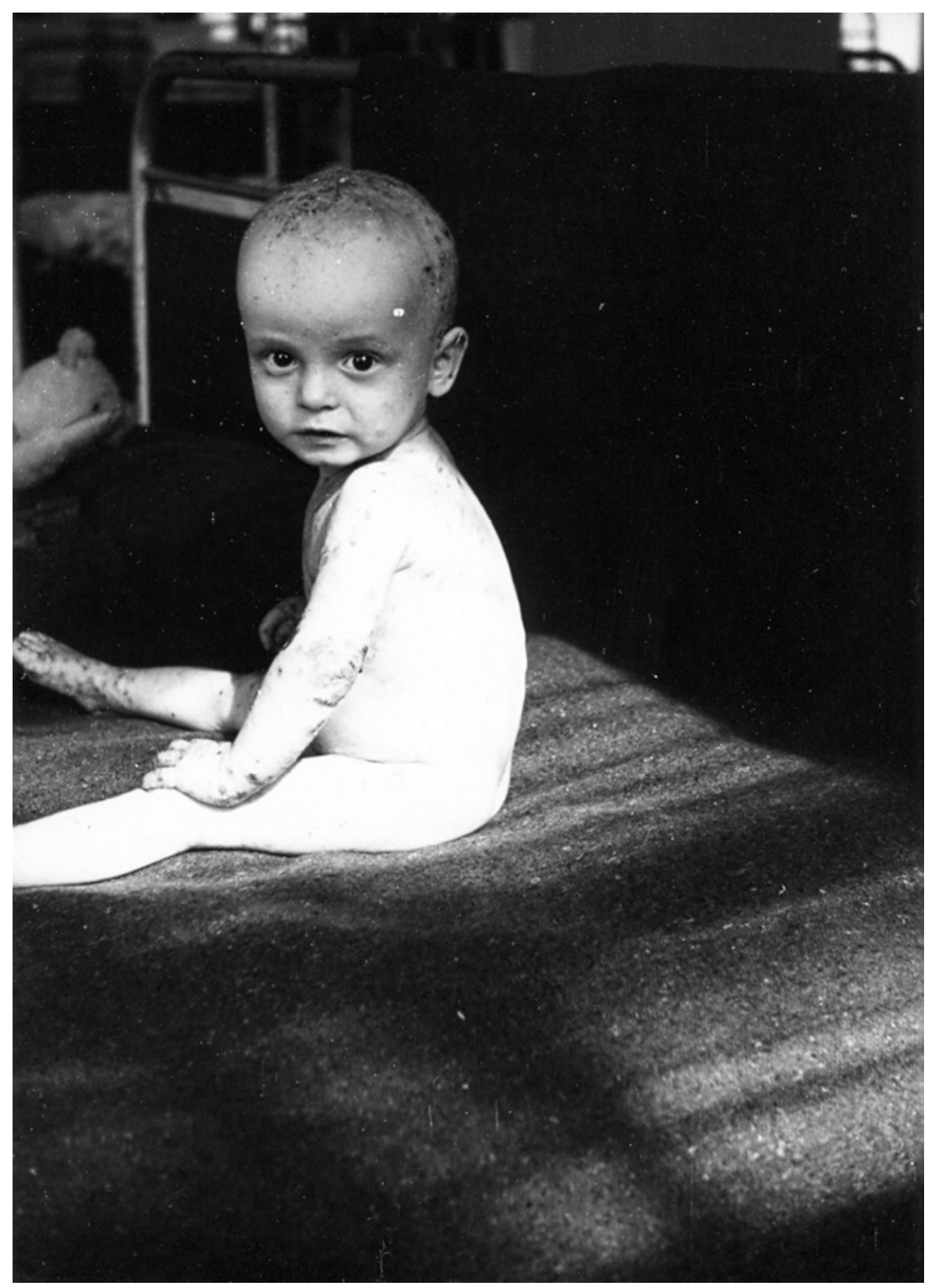

Q5: Krankes Kleinstkind aus einer DP-Familie zur Behandlung im Hilfslazarett auf der „Rhons“ (Fotoarchiv Göttingen). 


\section{Auszug aus aem Berohl wr. 14}

des Reserve Lazasotts GJttingen rom 24.6 .45 .

2. Batre: Binfuhren von Besuohszoi fon in don Zagarett-Abtte1 langen.

Ab sofort konnon dio Patienfen aus aen Lazarett-lbtaliunien Besuch omplangonjund zwax:

IIftrwoohs and Sonntags yon 14.30 bis 17.00 .

Bg wird trotz dieses Vorgirstsigune zur priloht gemacht, dass die von den anerikanisohen bezv, onglisohen Konmissionen erlassenen Bestimungen Eenaustens beachtet wertier.

Dio Besuohszeiton sind strongstons einzuhalton.

2d- 3d pp.

4. Botr.: Iransport von Patienter.

Ss wire nochmals daraus hingeviesen, dass Lazarettikranke nur in Bogleitung von Sohwertern bezw. 1in Sankrawagen dio LazarottAbteilungen vorlassen dürơn.

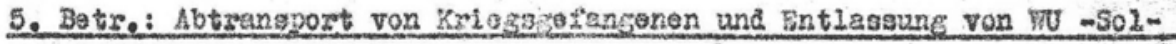
daten.

Wift dom Abtrangport von Kriggsgefangenon und der Entlassung von wU - Soldaten fst in den nisohsten Fagen zu reshnen. 6.) pg.

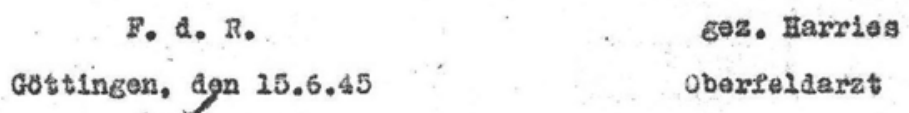$$
\text { s. A. R. }
$$$$
\text { gez. Harrios }
$$$$
\text { Gostingen, agn } 15.6 .45
$$$$
\text { obexpeldarzt }
$$

Q6: Anweisungen zum Hilfslazarett auf der „Rhons“ (Fotoarchiv Göttingen). 
Der Landrat

Göttingen, August 13th. 1945

Copy

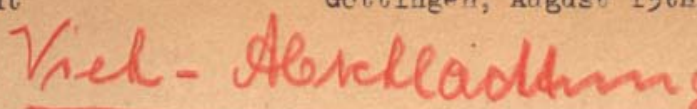

Between April 8th, 1945 and July 15th, 1945 the following cattle, pigs and sheep have been slughtered by D.P!s in the Iendkreis of Götting̣en:

18 pigs

1 boar

31 sows

390 hogs

59 small pigs

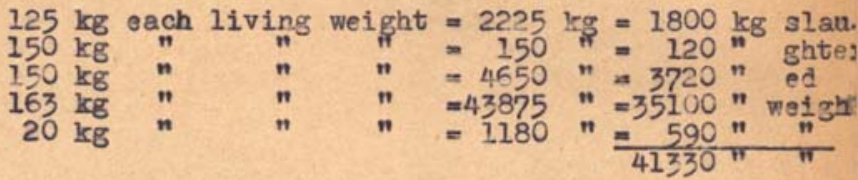

2 bulls $700 \mathrm{~kg}$ each $=1400 \mathrm{~kg}$ living weight $=840 \mathrm{~kg}$ slaughtered

470

88 cows

$700 \mathrm{~kg}$

$500 \mathrm{~kg}$

34 calves

$60 \mathrm{~kg}$
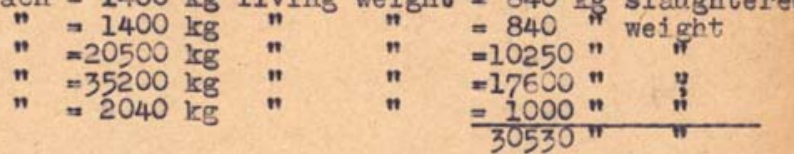

11 rams

641 sheep

29 lambs

94 sheep

26 lambs

$60 \mathrm{~kg}$ e ach $=560 \mathrm{~kg}$ living v
$45 \mathrm{~kg}=28845^{n}$
$30 \mathrm{~kg} "=870^{n} \quad "$
$45 \mathrm{~kg} "=4230^{n} \quad "$
$30 \mathrm{~kg}=780^{n} \quad "$

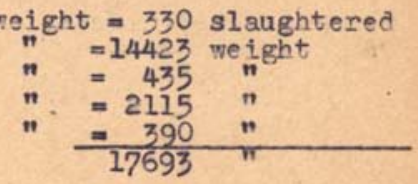

That is:

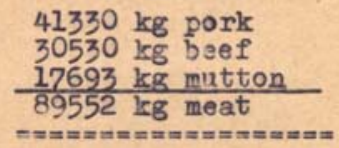

The amount of meat whi ah has thus been stolen would have been sufficient to cover the demand of the 110000 normal consumers of the town and $L_{a}$ ndkreis of Göttingen (excluding self-producers) for $61 / 2$ weeks considering that the normal ration per week is now $125 \mathrm{gr}$.

$$
\begin{aligned}
& \text { snd. FiSchmidt } \\
& \text { (B.Schmidt) }
\end{aligned}
$$

To the Commanding Officer. of Mil Gov 1002 Det. Göttingen

Q7: $\quad$ Aufstellung über Viehverluste: Stadtarchiv Göttingen: Stadtverwaltung und Militärregierung A 10 Blatt 380. 


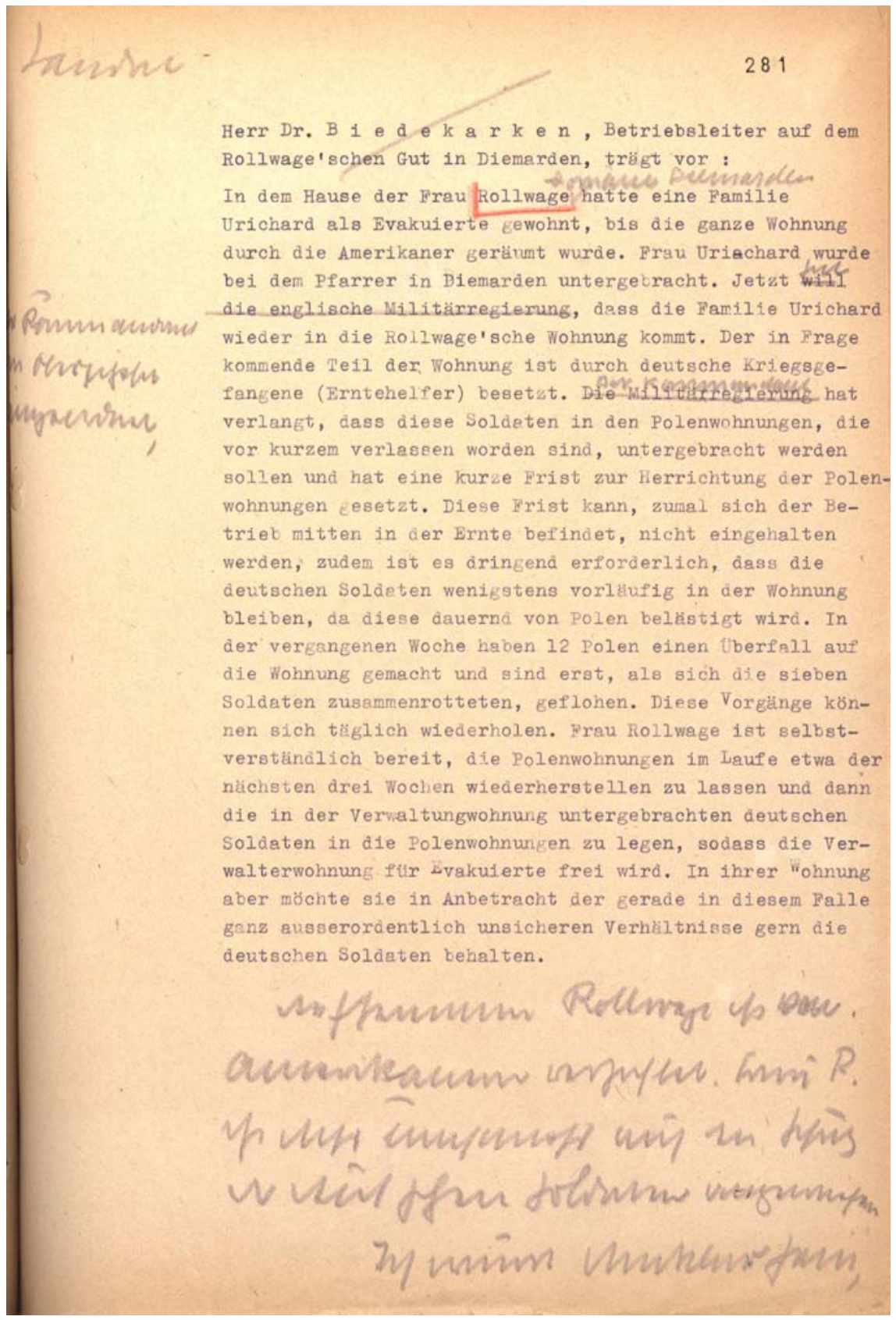

Q8: Wohnungskonflikte: Stadtarchiv Göttingen: Stadtverwaltung und Militärregierung A 10 Blatt 281. 


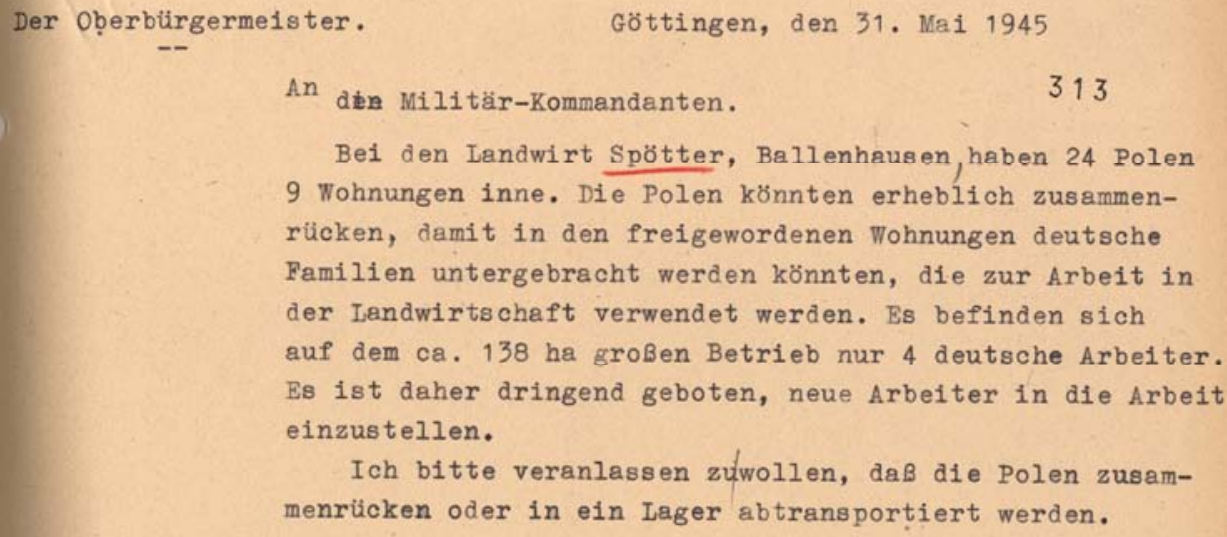

Bei den Landwirt Spötter, Ballenhausen, haben 24 Polen 9 Wohnungen inne. Die Polen könnten erheblich zusammenrücken, damit in den freigewordenen Wohnungen deutsche Familien untergebracht werden könnten, die zur Arbeit in der Landwirtschaft verwendet werden. Es befinden sich auf dem ca. 138 ha groBen Betrieb nur 4 deutsche Arbeiter. Es ist daher dringend geboten, neue Arbeiter in die Arbeit einzustellen.

Ich bitte veranlassen zuwollen, daß die Polen zusammenrücken oder in ein Lager abtransportiert werden.

an byt. Reverech an $\$ 1.645$

Q9: Räumung von Wohnungen 1: Stadtarchiv Göttingen: Stadtverwaltung und Militärregierung A 10 Blatt 313.

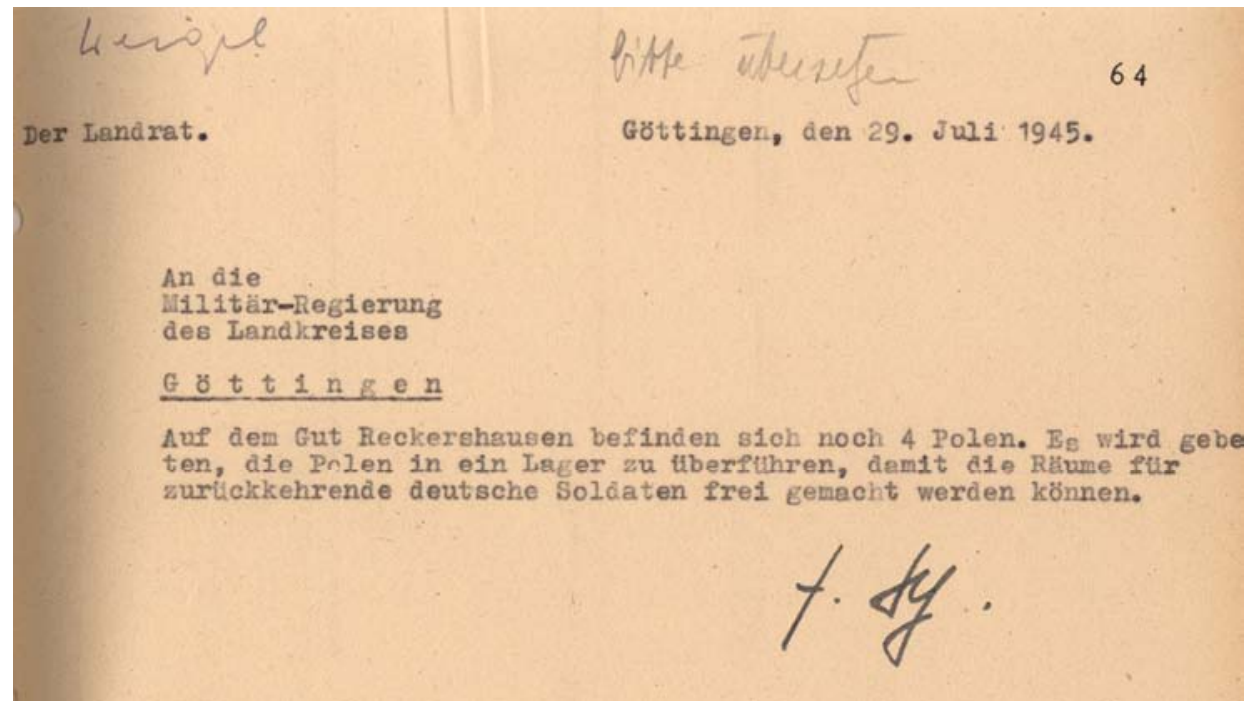

Q10: Räumung von Wohnungen 2: Stadtarchiv Göttingen: Stadtverwaltung und Militärregierung A 10 Blatt 64. 


\title{
Theater und Kultur in Göttingen in den Nachkriegsjahren 1945-1955
}

\author{
Maneja Yazdani
}

\section{Einleitung}

In der Reeducation-Phase nach dem Zweiten Weltkrieg spielte der Bereich Kultur eine große Rolle. Die maßgeblichen Akteure des Kulturbereichs in den Besatzungsbehörden waren alliierte Offiziere, die durch Studium und Beruf eng mit der deutschen Geschichte und Mentalität vertraut waren. Vielfach wurden auch deutsche Remigranten administrativ eingebunden. ${ }^{1}$

Große Teile des Bildungsbürgertums waren davon überzeugt, dass der Nationalsozialismus dem „deutschen Geist“ nichts hatte anhaben können. Der Aufbau einer intakten demokratischen Kulturszene sollte helfen, sich von der NSVergangenheit, die in weite Bereiche der kulturellen Aktivitäten hereinragte, zu distanzieren und zu lösen. Schriften deutscher Gelehrter wie Geist aus der Mitte Das andere Deutschland (1946) von August Blume und Der geistige Wiederaufbau Deutschlands (1946) von Johannes Hessen machten eine angenommene Ausbreitung des Atheismus für die „deutsche Katastrophe“ verantwortlich. Auch andere Literaten und Philosophen verstanden Kultur als Rückkehr zu den Werten der westlichen Welt.2 Die Topoi „westliche Kultur“ respektive „Abendland“ standen dabei

\footnotetext{
${ }^{1}$ Vgl. Hermann Glaser, Deutsche Kultur 1945-2000, Bonn 1997, S. 91 f.

2 Siehe hierzu Reinhold Schneider, Heimkehr des deutschen Geistes, Baden-Baden 1946; Alfred Müller-Armack, Das Jahrhundert ohne Gott, Münster 1948; Albrecht Haushofer, Moabiter Sonette, Berlin (Privatdruck) 1945; Alfred Döblin, Der unsterbliche Mensch, Freiburg 1946.
} 
mit einem dezidierten Antikommunismus und einer „Verchristlichung“ der Geschichte in enger Verbindung. ${ }^{3}$ Aus politischer Sicht bedeutete für viele Deutsche die Umerziehung in der Kulturszene zunächst Rehabilitierung des „verdrängten, exilierten deutschen Geistes“.4

\section{Theater}

Die Alliierten erkannten sehr schnell den Wert des Theaters, das neben dem Museum und der Universität als wichtigster Kulturort erschien - einerseits als Vergnügen für die Bevölkerung, eine Gelegenheit den Alltag zu vergessen, der durch Entbehrungen und Einschränkungen gekennzeichnet war, andererseits um den Brückenschlag nach „draußen“, wovon Deutschland zwölf Jahre lang kulturell abgeschnitten war, zu vollbringen. Die Voraussetzungen schienen aber nicht die besten zu sein: Von den 179 Staats-, Landes- und Stadttheatern waren 98, also über die Hälfte nicht bespielbar, da sie entweder zerstört, zerbombt oder anderweitig beschädigt waren. ${ }^{5}$ Die Ensembles hatten sich seit dem 1. September 1944, als Goebbels den Spielbetrieb der deutschen Bühnen mit einem Erlass eingestellt hatte, vielfach aufgelöst. ${ }^{6}$

Bei der Besetzung Göttingens am 8. April 1945 kam das kulturelle Leben fast völlig zum Erliegen. Durch das Gesetz 191, das am 20. April 1945 von den alliierten Besatzungsmächten erlassen worden war, wurden jegliche kulturellen Aktivitäten wie Lichtspielhäuser, Theater, Musik und Zusammentreffen zu dem Zweck desselben zunächst bis auf weiteres verboten. Erst zwei Monate später, am 14. Juli 1945, erteilte die Militärregierung die Erlaubnis, Vorführungen des Theaters, von Musik und von Filmen beizuwohnen und zu veranstalten. In der „Neuen Zeitung“ vom 1. November 1945 findet sich ein Brief aus Frankfurt, der treffend feststellt, dass die große Chance für die Zukunft nicht im Fortführen von Traditionen, sondern im Neuanfang liege: „Vielleicht wird [...] gerade aus dem Zwang zum primitivsten Neubeginn eine Rückkehr zu den Elementen des Theaters zustande kommen, eine neue Form, ein neuer Stil entstehen, den das Publikum nicht mehr, wie

\footnotetext{
${ }^{3}$ Vgl. Sabine Horn, Documenta I 1955 - Die Kunst als Botschafterin der Westintegration, in: Johannes Paulmann (Hg.), Auswärtige Repräsentationen. Deutsche Kulturdiplomatie nach 1945, Köln 2005, S. 45-61; Siehe ferner zum Abendland-Begriff in der frühen Bundesrepublik: Axel Schildt, Zwischen Abendland und Amerika. Studien zur westdeutschen Ideenlandschaft der 50er Jahre, München 1999; Dagmar Pöpping, Abendland. Christliche Akademiker und die Utopie der Antimoderne 1900-1945, Berlin 2002.

${ }^{4}$ Glaser, Kultur, S. 97.

${ }^{5}$ Günther Rühle, Die Wiederherstellung des Theaters, in: Hilmar Hoffmann/Heinrich Klotz (Hg.), Die Kultur unseres Jahrhunderts 1945-1960, Düsseldorf, Wien, New York 1991, S. 70-95, hier S. 73.

${ }^{6}$ Birte Kundrus, Totale Unterhaltung? Die kulturelle Kriegsführung 1939-1945 in Film, Rundfunk und Theater, in: Jörg Echternkamp (Hg.), Die deutsche Kriegsgesellschaft 1939-1945, 2. Halbband, München 2005, S. 93-158, hier S. 119.
} 
heute, schlechtweg als Ruinenstil bezeichnen kann [...] Not zwingt zum Wesentlichen."

Von den Heimkehrerstücken, darunter u.a. Wir heißen Euch hoffen von Fred Denger, wurde lediglich Wolfgang Borcherts Stück Draußen vor der Tür ein Erfolg. Das Stück zählt zur Trümmerliteratur und behandelt die Rückkehr des aus Russland heimgekommenen Beckmann, der sich in der Nachkriegsgesellschaft Deutschlands mit sozialen Integrationsproblemen konfrontiert sieht. Sein Versuch, sich ein neues Leben aufzubauen und den Tod seiner Kameraden zu verarbeiten, scheitert. Allein im Jahre 1948 wurde es auf über 40 Theaterbühnen in Deutschland aufgeführt und konnte ebenfalls filmische Erfolge aufweisen.

Während in den westlichen Besatzungszonen die Theaterszene mit Aufführungen vor allem der Klassiker die Menschen der Nachkriegszeit von den Sorgen des Alltags abzulenken versuchte, wurde in der SBZ vor allem experimentiert. ${ }^{8}$ Ostberlin wurde mit dem Brechtensemble (ab 1948) zum Schauplatz eines politisch und sozial engagierten Sprech- und Musiktheaters. Den größten Erfolg auf der Bühne erlangte Carl Zuckmayer mit seinem Stück Des Teufels General. ${ }^{9}$ General Harras war ein Idol für die Massen, mit dem sich ,,auch der kleine Mitläufer gerne“10 identifizierte: Eine tragische, unpolitische Person, die von dämonischen Mächten verführt worden ist und danach tapfer büßt.

Das Stadttheater in Göttingen war ab dem 1. August 1946 wieder im städtischen Besitz und eröffnete am 4. August mit der Oper Figaros Hochzeit eine neue Spielzeit, die aber privat inszeniert worden war. ${ }^{11}$ Das Plakat, das für die Vorstellung warb, ist sehr schlicht gehalten, Farbe und Druck sind einfach. Bilder und Verzierungen fehlen und zeugen von der Knappheit der Druckmaschinen und den eingeschränkten Möglichkeiten des Druckes (siehe Q1).

Verschiedene Konzert- und Vortragsveranstaltungen nahmen ihren Anfang. ${ }^{12}$ Im Mai 1945 hatte die Stadtbibliothek schon ihre Pforten geöffnet, in der Marienkirche wurde unter der Leitung Dohrmanns die erste Kantate wieder aufgeführt; das Städtische Museum durfte zunächst durch Schulklassen, dann ab Oktober ebenfalls durch Erwachsene besucht werden. Auf Initiative des wieder eingesetzten Hochschullehrers Hermann Nohl, der in weiten Bereichen der Universität, der Erwachsenenbildung und der Volkshochschule tätig war, wurde der „Arbeitskreis der Göttinger Kunstfreunde“ gegründet, der die Akademische Orchestervereinigung, den Kunstverein, das Stadttheater, die Händelgesellschaft und die Stadtkan-

\footnotetext{
${ }^{7}$ Gertrud Becker, Frankfurter Brief, Die Neue Zeitung, 1.11.1945.

${ }^{8}$ Glaser, S. 120.

${ }^{9}$ Ebd., S. $121 \mathrm{ff}$.

${ }^{10}$ Ebd., S. 121.

${ }^{11}$ Gidion, Jürgen, Kulturelles Leben in Göttingen, in: Rudolph von Thadden, Günther J. Trittel (Hg.), Göttingen. Geschichte einer Universitätsstadt. Von der preußischen Mittelstadt zur südniedersächsischen Großstadt. 1966 - 1989, Göttingen 1999, S. 535-590, hier S. 571.

12 Jens-Uwe Brinkmann, Nach Jahren der Entbehrung. Kultur und Schule, in: Göttingen 1945. Kriegsende und Neubeginn. Texte und Materialien zur Ausstellung im Städtischen Museum 31. März - 28. Juli 1985, Göttingen 1985, S. 215-256, hier S. 215.
} 
torei beherbergte. ${ }^{13}$ Neben dem „Arbeitskreis“, der den bestehenden Institutionen und Vereinigungen vorbehalten blieb, gründeten Göttinger Bürger im gleichen Jahr den „Kulturbund“, der es sich zur Aufgabe machte, die „Kultur zur lebendigen und befreienden Kraft im gegenwärtigen Schicksal der Menschen“"14 werden zu lassen. Zunächst war aber das Problem der Raumfrage zu klären, um den Neuaufbau des Kulturlebens beginnen zu können. In Göttingen gab es zwar nicht vergleichsweise große Bombenschäden wie in vielen Orten der Umgebung, doch waren die vorhandenen Räume vielfach von der Militärregierung beschlagnahmt. Sie dienten u.a. den Flüchtlingen aus dem Osten, den Heimkehrern aus der Kriegsgefangenschaft und nicht zuletzt den „Displaced Persons“"15 als Unterkunft. Einige der Gebäude wurden dazu genutzt, um Kultureinrichtungen für die Besatzungstruppen unterzubringen. So war u.a. der „Toc H-Club“16, ein Verein für britische Soldaten, im Stadtpark am Albaniplatz untergebracht und sollte den Mitgliedern ein reiches Unterhaltungsprogramm bieten. Später organisierten die Briten hier die Theatervorstellungen der Truppenangehörigen. Schnell wurde das Gebäude aber wieder der Stadt zurückgegeben. Das größte Kino der Stadt, das „Capitol“ mit 866 Plätzen, hatten die Army Welfare Services für Besatzungsangehörige beschlagnahmt. ${ }^{17}$

An vielen Orten wurden nach dem Zweiten Weltkrieg die Theatertraditionen schnell wieder aufgenommen oder neu begründet, vielerorts durch die Hilfe alliierter Theateroffiziere. Im Herbst 1947 bestanden mehr Theater als je zuvor. ${ }^{18}$ Gespielt wurde in provisorischen Räumen, in denen Technik, Bestuhlung und Ausstattung karg waren. Die Not wurde zur Tugend gemacht; man spielte meist in Ermangelung von Kostümen in Alltagskleidung, mit wenigen Requisiten und spartanisch eingerichteten Bühnen. Noch bis ins Jahr 1949 stellte die Materialknappheit in Göttingens Theatern eine Herausforderung dar, die das Ensemble und die Bühnenbildner mit immer neuen Ideen meisterten. Nicht nur Schuhwerk und Bühnenkleidung, die oftmals aus dem „Allerweltsmaterial“ Nessel bestand und nach Bedarf immer wieder umgeschneidert, umgefärbt und bedruckt wurde (Q10), waren knapp, auch die Kulissenbauten stellten nicht nur die Bühnenbildner, sondern ebenfalls die Regisseure und die Intendanz vor neue Aufgaben. Bei ihnen hieß es „aus alt mach neu“ und das „,bisschen Pappe und Farbe“ sollte den Theaterbesuchern, die das improvisierte Bühnenbild in seiner Gesamtheit auf sich wirken lie-

\footnotetext{
${ }^{13}$ Gidion, S. 570.

${ }^{14}$ Text eines Handzettels des „Göttinger Kulturbundes“. Zitiert in: Brinkmann, S. 216.

${ }^{15}$ Siehe den Beitrag von Hagen Stöckmannn diesem Band.

${ }^{16}$ „Toc H“: „Talbot House“, Soldatenclub, der in Erinnerung an den im Ersten Weltkrieg gefallenen Gilbert Talbot 1915 gegründet wurde; ab 1920 wurde daraus eine Gemeinschaft mit karitativen Zielen.

${ }^{17}$ Brinkmann, S. 219.

18 Siehe Rühle, S. 75: 133 Staats-, Landes- und Stadttheater mitsamt 84 Behelfsbühnen, 125 gewerblich betriebene Privattheater und 20 Behelfsbühnen, 57 Wanderbühnen, Bauerntheater, Gastspielbühnen.
} 
Ben, stets daran erinnern, wie viel Arbeit und Liebe hinter den kleinen Details steckte. ${ }^{19}$

Mit dem Ende der Spielzeit 1949/50 wurden die Sparten Operette und Oper aufgelöst, das künstlerische Personal entlassen und das Theater in eine $\mathrm{GmbH}$ umgewandelt. Es nannte sich nun Deutsches Theater. Zudem ermöglichte man ,interessierten Flüchtlingen den Besuch beliebiger Aufführungen einmal monatlich" 20 , indem die Verwaltung des Deutschen Theaters in Zusammenarbeit mit dem Stadtund Kreisflüchtlingsamt Karten für Aufführungen des Theaters für Geringverdiener und Arbeitslose verbilligte (siehe Q4).

Mit dem Ende der Spielzeit 1950/51 entließ man aufgrund der schlechten finanziellen Lage der Stadt das Orchester. Deutlich zeigt sich hier das Bestreben der Göttinger Bürger, auf das Orchester nicht verzichten zu wollen, obwohl zu dieser Zeit durchaus andere Sorgen wie Wohnungsnot und Traumata des Krieges zu bewältigen waren. Einen eindrucksvollen Brief einer Leserin druckte das Göttinger Tageblatt vom 2. Februar 1951 ab (Q9), in dem sie den Sorgen vieler an der musikalischen Kultur Göttingens interessierter Bürgerinnen und Bürger Ausdruck verleiht. Der Gedanke, auf das Symphonieorchester verzichten zu müssen, brachte Teile der Bevölkerung und die Universität dazu, mithilfe von privaten Spenden, trotz der fehlenden Gewährung der finanziellen Unterstützung durch die Stadt, das Orchester erhalten zu wollen. Durch den Trägerverein „Verein zur Förderung des Göttinger Symphonieorchesters", den die Göttinger Bürger gründeten, war es schließlich im Jahr 1951 möglich, die Existenz des Orchesters zu sichern. Die Musiker blieben beisammen, das Orchester wurde unter dem Namen „Göttinger Symphonieorchester" - kurz GSO - neu gegründet und bestand als eigene Institution, die nicht mehr vom Theater abhängig war, fort.

\section{Kino}

Nach dem Ende des Zweiten Weltkrieges war auch die deutsche Kinolandschaft fast völlig zerstört. In Hamburg beispielsweise standen von ursprünglich 119 nach 1945 nur noch 47 Kinos. $^{21}$ Wie viele große Gebäude waren die Lichtspielhäuser und vor allem die Produktionsstätten von der Beschlagnahmung durch die Besatzungstruppen betroffen. Durch die schlechte Gesamtsituation fand sich unmittelbar nach Kriegsende kein Markt für erhalten gebliebene Filmkopien. Die Filmwirtschaft war während des Dritten Reiches zunehmend zentral durch den Staat geregelt worden, weswegen das Kapital der Filmindustrie als Reichsvermögen galt und nach der Gesetzgebung der Alliierten von diesen beschlagnahmt wurde. Demzufolge fehlte es nicht nur an technischen Einrichtungen, sondern vor allem an der

\footnotetext{
19 Ebd.

${ }^{20} \mathrm{Q} 4$.

21 Andreas Gaw, Entwicklung und Bedeutung der Filmproduktion, Göttingen 1989, S. 1.
} 
Finanzierung. ${ }^{22}$ Das Kino war sowohl in Ost- als auch in Westdeutschland ein Medium für die Massen, die einerseits unterhalten, andererseits aber auch informiert werden wollten. In der Stadt und auf dem Land bildete es den Mittelpunkt des gesellschaftlichen und kulturellen Lebens. Allerdings war nach dem Krieg eine kritischere Herangehensweise an die Filme und die Filmindustrie bemerkbar. ${ }^{23}$

Nach 1949/50 wandte sich die Produktion der Spielfilme aber vor allem der Masse zu, die nach idyllischer, einfacher Kost fragte und sowohl die Trümmer als auch die Auseinandersetzung mit der NS-Vergangenheit nicht mehr sehen mochte. Sehr bezeichnend sind die Heimatfilme, die in dieser Zeit en masse entstanden. Der erste Nachkriegs-Heimatfilm, der dazu noch in Farbe gezeigt wurde, heißt Schwarzwaldmädel (1950). Göttingen profitierte von dieser Entwicklung - am Rande der Stadt entstand ein Zentrum der deutschen Spielfilmproduktion. Die Gründung der Filmaufbau GmbH unter Rolf Thiele und Hans Abich im Jahre 1945 in Göttingen machte aus der Kleinstadt für lange Jahre eine bedeutende Filmstadt. Im Studio des ehemaligen Wehrmachtflugplatzes zwischen Grone und Holtensen, dem heutigen Industriegebiet, wurde ein zunächst improvisiertes Filmstudio errichtet und zwischen 1949 und 1961 wurden dort über 100 Spielfilme gedreht. ${ }^{24}$ Viele Faktoren begünstigten die dortige Ansiedelung einer Filmindustrie in der Nachkriegszeit: Die Stadt war weitestgehend intakt und von überschaubarer Größe. Vor allem die wenigen Bombenschäden machte sie zu einem begehrten Drehort, an dem die „,heile Welt“, nach der die Masse fragte, gut inszeniert werden konnte. Die Universität lieferte viele studentische Statisten und das Theater einen qualifizierten Pool von Schauspielern. ${ }^{25}$

Beim ersten in Göttingen gedrehten Film - Liebe 47, die filmische Umsetzung von Draußen vor der Tür unter der Regie Wolfgang Liebeneiners - erhielt ein Statist 3 RM pro Arbeitstunde, in einer kleinen Sprechrolle sogar 5 RM. Weitere Filme wie Die Nachtwache (1949) mit Dieter Borsche, Franenaržt Dr. Prätorius (1950) und Das Haus in Montevideo (1951) unter der Regie von Curt Goetz - markierten einen Erfolg der kleinen Filmstadt. Das städtische Orchester und das Schauspielensemble des Theaters sollten für den Film genutzt werden, während die Filmgesellschaft dem Theater einen jährlichen Zuschuss zahlte. Durch den Plan des Kulturdezernenten des deutschen Städtetages, Otto Beneke, und des Kultusministers Richard Voigt (s. Q3) wurde neben der Sanierung der Göttinger Kulturlandschaft auch die Zusammenarbeit der verschiedenen Kultursparten angestrebt. Trotz der hohen Belastung der Filmtheater durch die sogenannte Vergnügungssteuer, die in Niedersachsen 40 Prozent der Bruttoeinnahmen betrug, entstanden in Göttingen in den Jahren 1945 bis 1955 neun Kinos. Q6 zeigt die Außenansicht des Lichtspielhauses „Capitol“, in dem viele der in Göttingen produzierten Spielfilme uraufgeführt

\footnotetext{
${ }^{22}$ Kundrus, S. $93 \mathrm{f}$.

${ }^{23}$ Vgl. Hermann Kadow, Kino von innen und außen, Frankfurter Hefte (5/1946), S. 7.

${ }^{24} \mathrm{Gaw}, \mathrm{S} .3$.

25 Vgl. Gustav Meier, Filmstadt Göttingen. Bilder für eine neue Welt. Zur Geschichte der Göttinger Spielfilmproduktion 1945-1961, Göttingen 1996, S. 21.
} 
wurden. Hier fand die Tagung des Wirtschaftsverbandes der Filmtheaterbesitzer der Bezirke Göttingen, Braunschweig und Hildesheim statt, die als Hauptpunkt die hohe steuerliche Belastung der niedersächsischen Filmtheater besprach. (siehe Q8)

Die Diskussion über den Bau von neuen Lichtspielhäusern ging quer durch die Bevölkerung und hatte ebenso Befürworter wie auch Gegner. Q7 zeigt die Diskussion in einem Artikel aus dem Göttinger Tageblatt vom 15. August 1950 auf. Es gab genügend Stimmen, die aufgrund der sinkenden Besucherzahlen und Einnahmen den Bau weiterer Kinos nicht befürworteten. Anderseits versprachen sich die Göttinger durch den Bau der Kinos und durch die neue Filmgesellschaft, die im Aufbau begriffen war, eine neue Geldeinnahmequelle für ihre Stadt und rechneten ebenfalls mit einer Bedarfssteigerung in der Bevölkerung, da man die Eintrittspreise nicht erhöhen wollte. Nach der Rückkehr der alten Firmen auf den Markt konnte sich die Filmgesellschaft aber nicht mehr behaupten und wurde 1961 aufgelöst.

Nach 12 Jahren Nationalsozialismus, der nicht nur die Kultur der Kleinstadt geprägt hatte, war es eine schwierige Aufgabe, einerseits den Aufbau der Kulturszene zu bewerkstelligen, andererseits den Anschluss an die Kunst, die Musik und das Theater der übrigen Welt zu finden. Eine Neuorientierung war notwendig. Trotz der meist fehlenden und schwer beschaffbaren finanziellen und materiellen Mittel wurde in den ersten Jahren der Nachkriegszeit eine intakte Kulturlandschaft geschaffen, die es den folgenden Generationen ermöglichte, sich mit den Geschehnissen des Dritten Reiches und des Nationalsozialismus filmisch, literarisch und künstlerisch auseinander zu setzen.

\section{Literatur zum Weiterlesen}

Jens-Uwe Brinkmann, Nach Jahren der Entbehrung. Kultur und Schule, in: Göttingen 1945. Kriegsende und Neubeginn. Texte und Materialien zur Ausstellung im Städtischen Museum 31. März - 28. Juli 1985, Göttingen 1985, S. $215-256$.

Ernst Böhme, Geschichte und gesellschaftliches Leben der Stadt Göttingen, in: K. H. Kaufhold (Hg.), 1801-2001. 200 Jahre Sparkasse Göttingen. Älteste kommunale Sparkasse, Göttingen 2001, S. 165-182.

Hermann Glaser, Deutsche Kultur 1945-2000, Bonn 1997.

Jürgen Gidion, Kulturelles Leben in Göttingen, in: Rudolph von Thadden/Günther J. Trittel (Hg.), Göttingen. Geschichte einer Universitätsstadt. Von der preußischen Mittelstadt zur südniedersächsischen Großstadt 1966-1989, Göttingen 1999, S. 535-590.

Gustav Meier, Filmstadt Göttingen. Bilder für eine neue Welt. Zur Geschichte der Göttinger Spielfilmproduktion 1945-1961, Göttingen 1996. 


\section{Stadtheater Böttingen}

Sonnabend, 4. August 1945. 18.30 I hr ERST ILFFL HRI IG;

\section{Die Godjerít des fingro}

Nächste weitere Aufführungen:

Sonntag, 5. August Donnerstag, 9. August

Dienstag, 7. August Sonnabend, 11. August Sonntag, 12. August

Kartenververkauf:

An Spieltagen 10-13 Uhr (onntags 11-13 Lhr) und eine Stunde vor Beginn der Vortellung, an den übrigen Tagen von 10.13 und 16-18 $1 \mathrm{hr}$

Beginn des Ververkaufs: 3 Tage vor der Vorstellung

ANFANG SÄMTLICHER VORSTELLUNGEN UM 18.30 UHR Be

Sin

Q1: Theaterplakat des Stadtheaters: Plakatsammlung des Stadtarchivs Göttingen. 


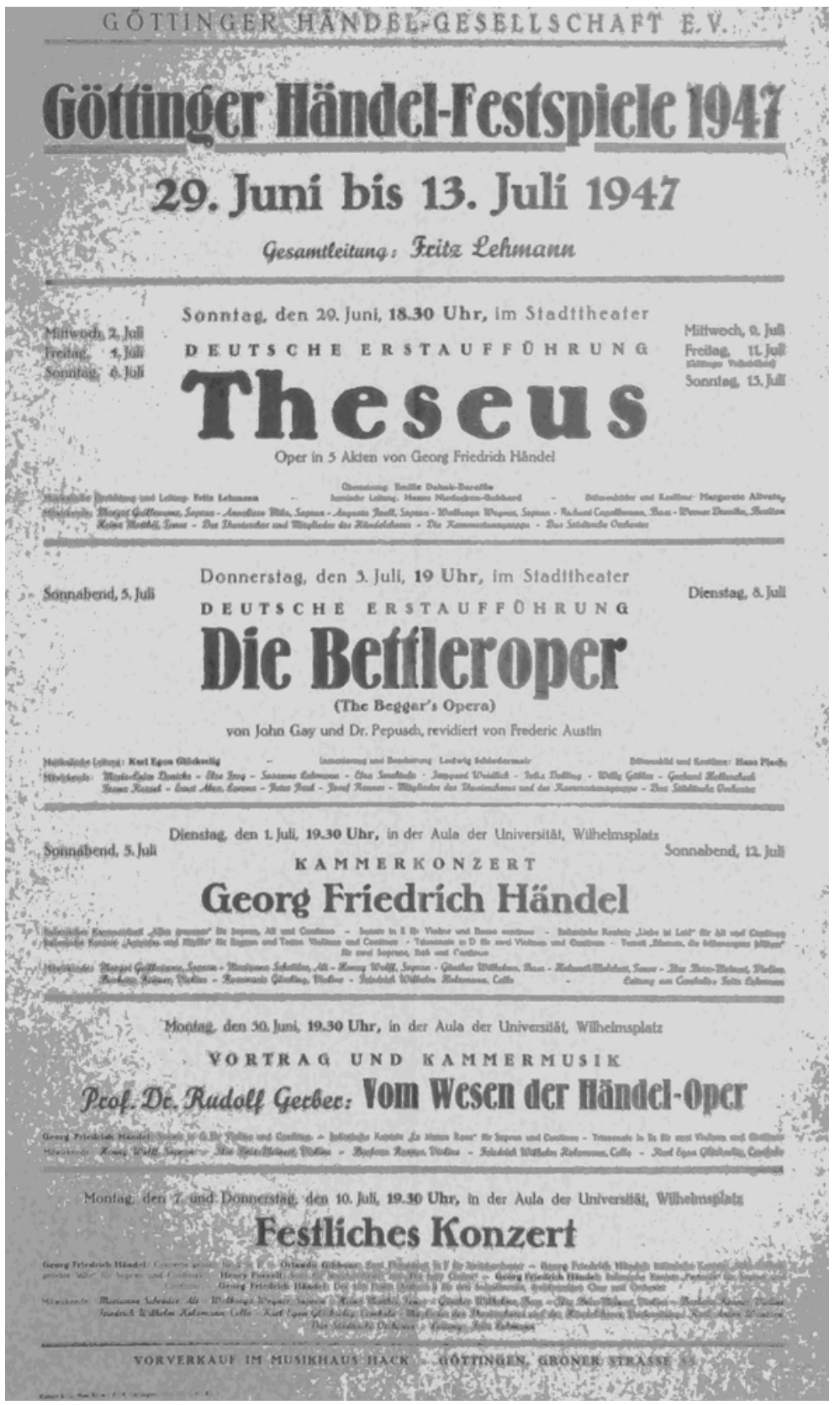

Q2: Plakat zu den Händelfestspielen 1947: Plakatsammlung des Stadtarchivs Göttingen. 


\section{Göttinger Ehe zwischen Film und Theater heginnt}

\section{„Beneke-Plan" im Kommen - Werden die Stadtvatter 350000 DM bewilligen?}

Die Theatersituation in Göttingen, der Gesprăchsstoff der vergangenen Wochen, dürfte nach den letzten ErWochen, dūrfte nach den letzten Erdie "hp" bereits meldete, sollen die Kammerspiele unter Beachtung. des sogenannten "Beneke-Planes" zum ersten April als Filmtheater verpachtet werden, wobei allerdings die Stadt sich vorbehalten bat, zwel Tage in der Woche das Schausplel in diesem Hause spielen zu lassen. Wenn die Stadtvāter einem ZuschuB von etwra 350000 DM zustimmen und der Film helfend eingreift (auch das ist ein Teil des Planes), ist das große Haus fúr die năchste Zukunft gesichert.

\section{Eln kuhnes Wagnis}

Es kann nicht bestritten werden, daB die Eröffnung des zwelten Hauses im September vorigen Jahres, zu einer Zeit also, wo andere Theater bereits schlleßen muBten oder zumindest große Geldsorgen hatten, ein kühnes Wagnis war. Die Hoffnung, daß sich die finarizielle Lage der Göttinger Theaterfreunde und damit auch des Theaters verbessern würde, hat sich leider nicht erfullt. In den fünf Monaten ihres Bestehens haben fünf Monaten ihres Bestehens haben
sich die Kammerspiele einen festen Besucherkreis geschaffen, woran die Leistungen des Ensembles, von einigen Pannen abgesehen, einen guten Antell haben.
Der Plan des Kulturdezernenten des deutschen Staldtetages, Beneke, ūber die Sanierung des Göttinger Theaters sleht unter anderem eine Ehe mit dem Film, gewisse Einschränkungen im Personal und Gastsplele in der Um gebung vor. Alle drai Punkte sollen verwirklicht werden, Auch Kultusminister Volgt, der in den letzten Tagen inofiziell oich in Góttingen Tagen inofiziell oich in Gottingen uber die Lage des Theaters infor-
mierte, hieB diesen. Plan gut. Die mierte, hieB diesen. Plan gut. Die
Stadt hat allen zur Erhaltung des Niveaus unbedingt notwendigen Kunstlern und Angehörigen des tech nischen Personals aine Entscheidung aber dle Verlăngerung der Verträge uber die Verlăngerung der Vertrăge wird sich um etwa 30 Stellen han deln, die eingespart werden mulssen. Prominente Kanstler kommen

In den năchsten Wochen sollen Besprechungen zwischen den Theaterleuten und Männern vom Film stattfinden, in denen die technischen Einzelheiten geklärt werden. Unter anderem denkt man daran, das städtische Orchester und das Schauspielensemble für den Film zu benutzen, wăhrend der Film dem Theater einen fährlichen Zuschü zahlt. Prominente Künstler der. Leinwand werden in Göttingen gastieren; was dem Theater einen nicht zu unterschätzenden Auftríeb geben würde, wofür das
Gastspiel Otto Wernickes ein guter Beweis ist. Auch die Relsen in andere Städte brachten schöne Erfolge. Göttingen genieBt als Kulturzentrum nicht nur in Deutschland einen Ruf und hat damit Verpflichtungen ubernommen, die eingehalten werden müssen. Sie im Rahmen der Möglichkeiten zu erfallen, ist eine der schwerea Aufgaben, der sich die Stadt jetzt unterziehen muß. Zum unerlä. lichen Bestandteil der Stadt gehört das Theater. Man sollte nichts unversucht lessen, es - wenn auch unter gewissen Einschrănkungen - zu erhalten.

\section{Neue Autobusse}

hap GOTTINGEN. Das Stãdische Betriebsamt hofft nach Eintreffen von zwei neuen Autobussen im April die Stadtlinien weiter ausbauen zu kőnnen. Es ist geplant, die Linie nach der Herzberger-LandstraBe und die nach Grone halbstündlich laufen zu lassen.

Zur Frage der Theaterautobusse erklärte Direktor Niemann vom Städischen Betriebsamt, daB man es Stadtischen Betriebsamt, dab man es lichen Gründen noch nicht leisten könne, das Risiko von iaerfahrten auf sich zu nehmen.

Q3: Artikel aus der Hannoverschen Presse vom 3.02.1949, S. 5, Stadtarchiv Göttingen (FilmZtg 628). 


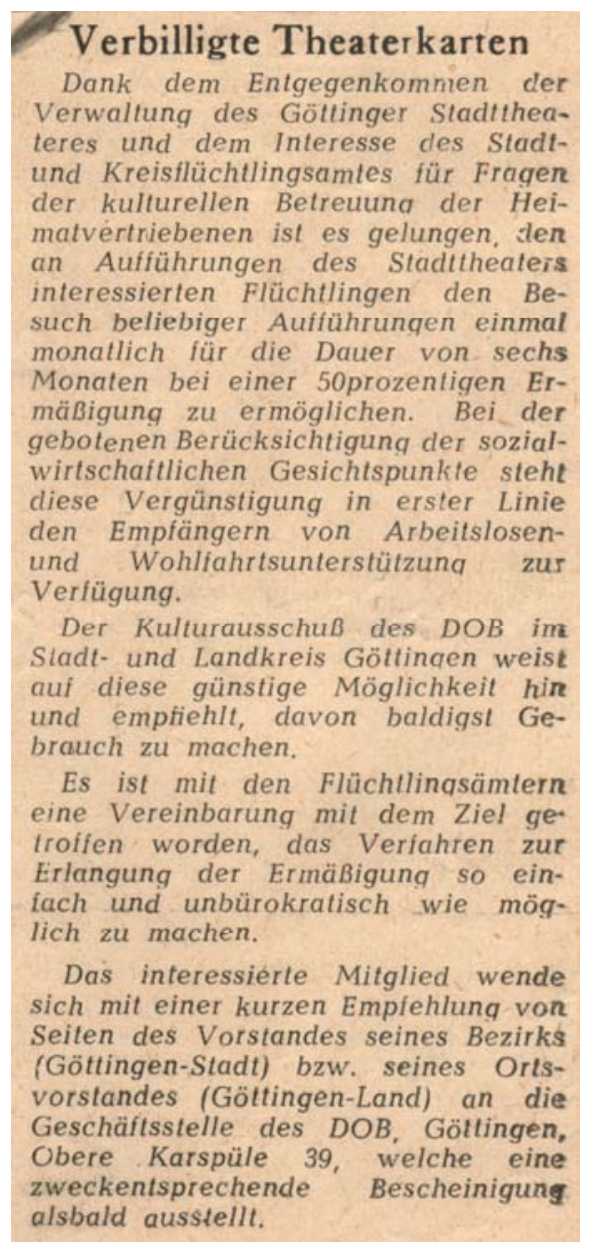

Q4: Artikel aus der Zeitung „Der Heimatvertriebene“ vom Februar 1950: Materialien des Kulturamtes, in: Konzert- und Theaterkritiken von Göttinger Aufführungen, Nr. 604. (Stadtarchiv Göttingen). 
Die Direktionen der Panorama Film und des Capitol-Theaters Göttingen beehren sich, zu der am Montag, dem 7. März 1949, 16.30 Uhr stattfindenden

\title{
URAUFFÜHRUNG
}

\author{
IM \\ CAPITOL \\ G Ö T T I N G E N \\ ergebenst einzuladen.
}

Die Einladung berechtigt zum Eintritt von zwei Personen

in Verbindung mit den beiliegenden Platzkarten

Panorama Film

Capitol-Theater

Q5a: Einladung zur Uraufführung von Liebe 47 am 7.03.1949. 


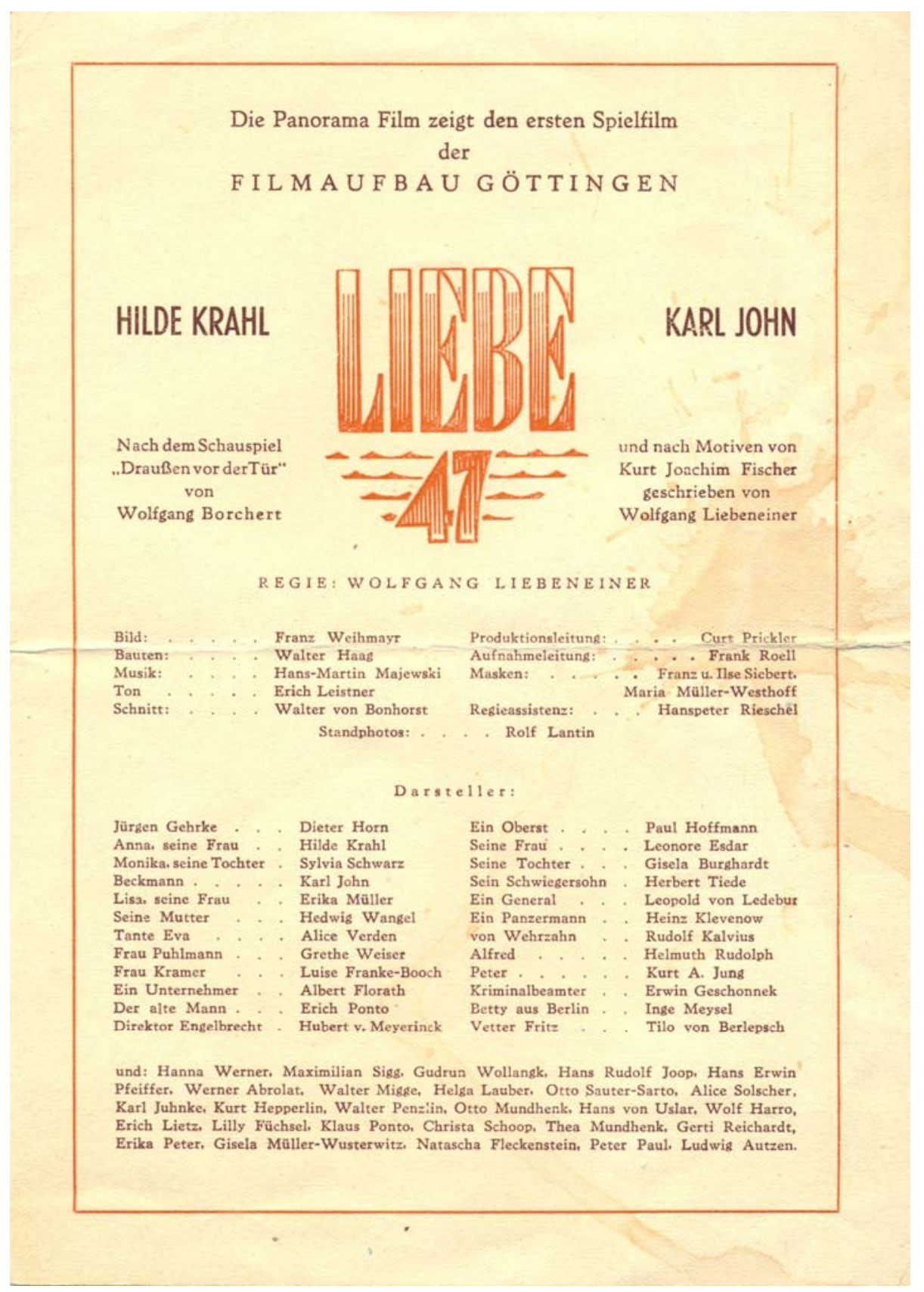

Q5b: Einladung zur Uraufführung von Liebe 47 am 7.03.1949 (Städt. Museum Göttingen). 


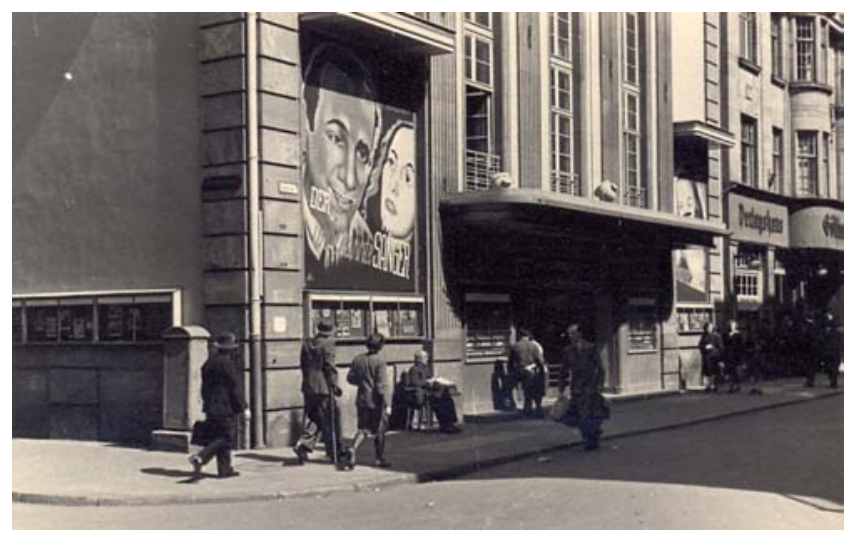

Q6a: Außenansicht und Kinoreklame vor dem „Capitol“, April 1949 (Städt. Museum Göttingen).

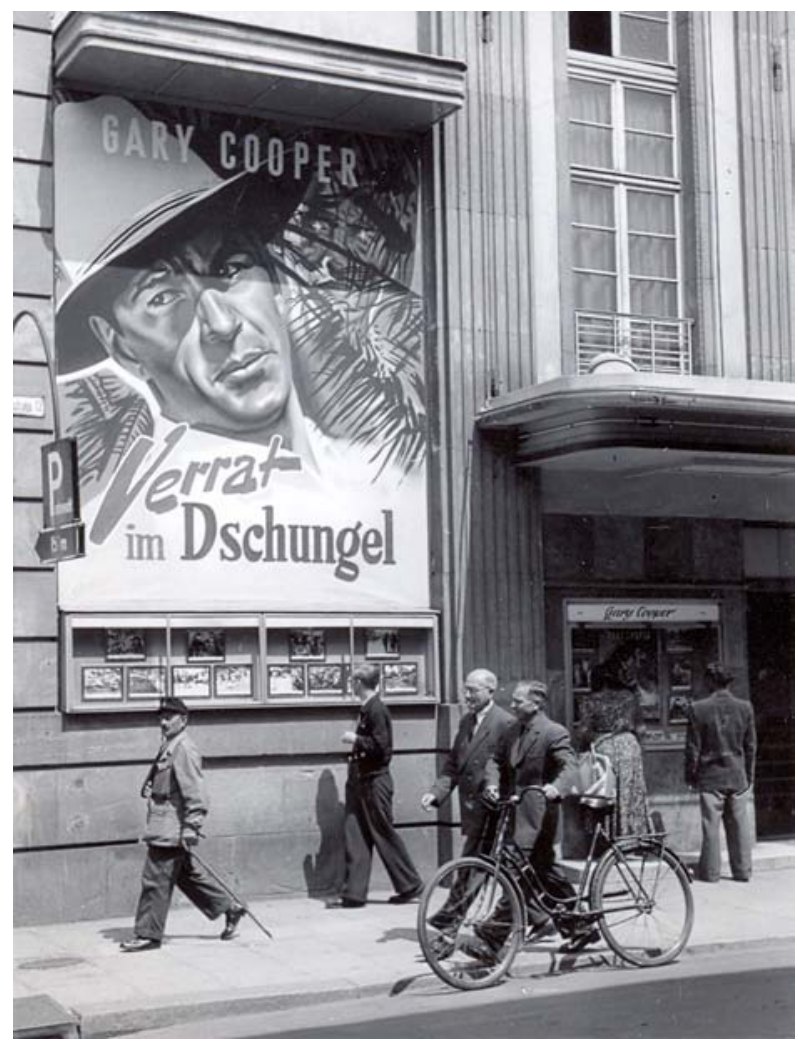

Q6b: Außenansicht und Kinoreklame vor dem „Capitol“, April 1949, (Städt. Museum Göttingen). 


\title{
Für und wider das siebente Kino
}

\author{
Eine Debatte um das Tageskino in der Ladenstraße
}

Dem "Göttunger Tageblatt" gingen ein Leserbrief des Kinobesitzers Ernst Heidelberg sen. und eine Entgegnung der Kreissparkasse zu. Wir veröffentlichen beide Schreiben, da sie zweifellos das Interesse der Offentlichkeit finden werden.

Wie in diesen Tagen bekanntgegeben wurde, soll bel dem Umbau des historischen „Hotel zur Krone“ ein weiteres Kino eingerichtet werden. Dann würde neben den hier bestehenden sechs Filmtheatern ein siebentes entstehen. Ein weiteres ist für den Groner Raum geplant, das am Sonnabend und Sonntag geöffnet sein soll. Damit würde Göttingen acht Filmtheater aufweisen. Für den Hagen-Bezink ist außer einer Schule und einer Kirche auch noch ein Filmtheater-Bau vorgesehen. Dann hätte unsere Stadt neun Filmtheater. Woher sollen die Besucher für diese Kulturstätten kommen? Diese Frage taucht nicht nur bei der Einwohnerschaft, sondern auch bei den Filmtheaterunternehmern auf.

Allgemein dürfte bekannt sein, daß in Niedersachsen die Eintrittspreise der Filmtheater 20 Prozent unter den vor dem Kriege üblichen Preisen liegen. Die Besucherzahlen gehen ständig zurück, die Einnahmen sinken und es besteht eine allgemeine wirtschaftliche Notlage in der Kinobranche. Trotz dieser Notlage müssen die Kinobesitzer heute noch auf ihre eigenen Kosten Kriegsschäden an ihren Gebäuden und Einrichtungen beheben lassen. Diese wirtschaftlich unhaltbaren $\mathrm{Zu}$ stände in der Kinobranche werden durch die hohen Steuern und Abgaben sowie die Filmleihgebühr derart gesteigert, soda $B$ die Filmtheater-Verbandsorganisation vor Monaten einen Hilferuf an die Landesbehörde richtete. Es ist untragbar daß - wie bisher - durch die hohen Steuern, Filmleihmieten usw. 85 Prozent der Kinoeinnahmen abgeschöpft werden und nur 15 Prozent zur Bestreitung der Generalunkosten für das Personal, für die Erhaltung der Kinoeinrichtung und die notwendigen Erneuerungsausgaben verbleiben.

Heute sind ungezählte Unternehmungen mit den Steuern im Rückstand und an manchen Orten in Niedersachsen haben Filmtheaterbesitzer ihre Betriebe wegen Unrentabilität schließen müssen.

In dieser Zeit der Wirtschaftsmisere des Kinogewerbes geht man in unserer Stadt dazu über, neue Filmtheater zu errichten, die von vornherein mit größten Existenzschwierigkeiten rechnen mïssen.

Wenn in dieser Situation beim Umbau des „Hotel zur Sonne“ die Kreissparkasse Göttingen erhebliche Beträge für die Installierung eines siebten Filmtheaters aufwenden-will; so kann man sich des Eindrucks nicht verschlieBen, daß hier Spargroschen der Einwohner des Land- und Stadtkreises Göttingen un- zweckmäßig angelegt werden. Hierauf aufmerksam zu machen, ist die Fachorganisation der Filmtheaterbesitzer die berufene Institution, und deshalb erhebt sie hiermit ihre warnende Stimme - in Sonderheit im Interesse der heimischen Wirtschaft. Bei der allgemeinen Geldverknappung, bei der jeder Pfennig nur nach wohlweiser Uberlegung investiert werden darf, können wir es uns nicht erlauben, flüssige Mittel unsachgemäß zu verwenden.

Ernst Heidelberg, sen.

Vorstandsmitglied des Wirtschaftsverbandes der Filmtheater Norddeutschlands.

In dieser Zeit der Wirtschaftsmisere (Herr Heidelberg schreibt das wörtlich) und der angeblichen Notlage der Kinobesitzer baut dic Familie Heidelberg, die ja drei Kinos in Göttingen besitzt, ein Freilicht-Kino auf und das Capitol aus. Wie das Herr Heidelberg begründet, ist seine Sache. Daß Herr Heidelberg die Eingabe als Vorstandsmitglied des Fachverbandes unterzeichnet, kann nicht darüber hinwegtäuschen, daß das wahre Motiv Konkurrenzneid ist. $\mathrm{Da} B$ er sich das Recht nimmt, von unzweckmäßiger Anlegung der Spargelder zu reden, liegt auf derselben Ebene, zumal er noch nicht einmal ein Kunde der Kreissparkasse ist. Es sei dem Vorstand der Kreissparkasse schon soviel Einsicht und wirtschaftliche Vernunft gestattet, daß nichts zu Lasten der Sparkasse geschieht, was nicht unbedingt der gesamten Bevölkerung gegenüber verantwortet werden kann. Schon garnicht der Ausbau des neuen Lichtopieltheaters in der "Krone!" Wenn sich aber ein Kaufmann mit seinen eigenen Mitteln bereit und für weitsichtig genug findet, ein Kleinkino mit billigsten Eintrittspreisen, die auch die minderbemittelte Bevölkerung aufbringen kann, zu schaffen, so müßte das im Zeichen der freien Wirtschaft doch wohl nur begrüßt und bejaht werden.

Es wird sich zeigen, daß dieser Schritt zum Ausbau eines Tageskinos in der Ladenstraße richtig war, und darüber urteilen dann später objektiv, nicht subjektiv, wie das Herr Heidelberg tut, alle beteiligten Einwohner von Göttingen Stadt und Land.

Hierbei wird noch bemerkt, daß der Vorstand der Kreissparkasse ohne die geringste Schmälerung'der Mittel für Kredite und für den Baumarkt durch Baukostenzuschüsse von anderer Seite eine dringend notwendige $\mathrm{Ar}$ beit - nicht zuletzt auch im Interesse der Unterbringung von zirka 300 Arbeitslosen durchführt. Hier liegt eine saubere und durchaus richtige rentable Verwendung der Mittel zur Arbeitsbeschaffung für Handwerk, Geschäftswelt, Arbeiter und Wirtschaft.

Kreissparkasse Göttingen.

Q7: Artikel aus dem Göttinger Tageblatt (GT) vom 15.08.1950, S. 3, Stadtarchiv Göttingen. (FilmZtg 253). 


\section{Filmtheater zu hoch belastet}

Aber keine Erhöhung der Eintrittspreise - Tagung im „Capitol”

Die hohe steuerliche Belastung der niedersăchsischen Filmtheater rangiert unter allen Lindern der Bundesrepublik an oberster
Stelle. Diese Feststellung stand im MittelStelle. Diese Feststellung stand im Mittel-
punkt einer Tagung des Wirtschaftsverbandes punkt einer Tagung des Wirtschaltsverbandes
der Filmtheaterbesitzer der Bezirike Gottingen-Braunschweig-Hildesheim, die gestern Foritager Folge dieser Belastung ist, dab eine ganze beträgen im Rückstand ist. Von den beiden Hauptreferenten der Tagung, dem Verbandsvorsitzenden Will, Hannover, und dem Geschäftafuhrer des Verbandes Dr. Rose wurde die Situation eingehend beleuchtet und $\mathrm{MaB}$ nahmen besprochen, die zu einer Begrenzung der Vergnugungssteuer auf ein erträgliches $\mathrm{MaB}$ erforderlich sind. Die Lănder NordrbeinWestfalen, Schleswig-Holstein, Bayern u. a.

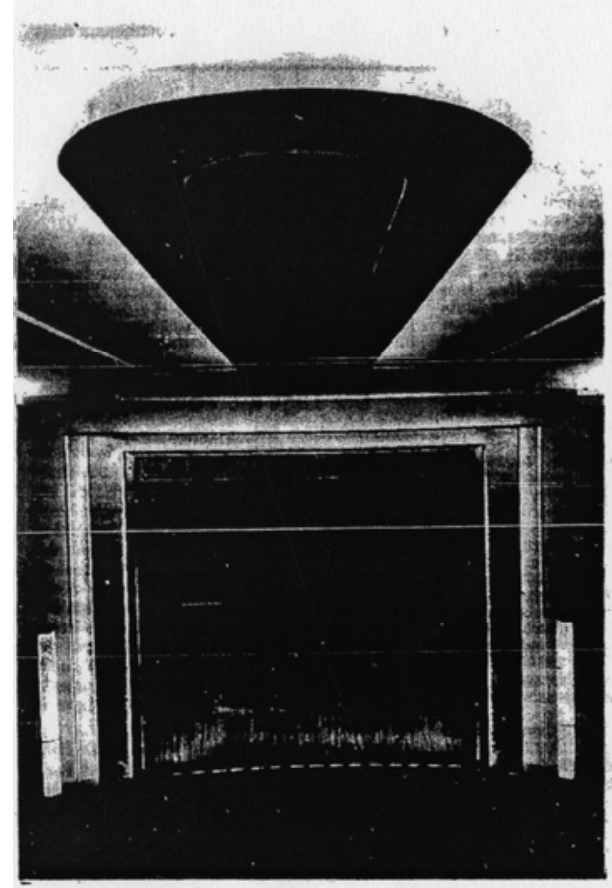

Dieser Blick in den $\mathrm{Zu}$ sochauerraum des "Capitols" zeigt die Anordnung der neuen indirekten Deckenbeleuchtung. die ein mildes, diffuses Licht verbreitet. Eine weitere Lichtquelle wurde in der Form eines Leuchtstreifens am unteren Rand der Logenbrilstung angebracht. Die vier Kugeln links und rechts des Proszeniums, ther deren Bedeutung sich schon mancher Besucher vergebtheh den Kopf zerbrochen hatte, sind zum Vorteil der Gesamtwirkung des schönen Raumes entfernt worden. Der Kassenraum erhielt eine geschmackvolle Holzvertäfelung und im Foyer wurden neue beigefarbene Polsterbeigefarbene Polste
möbel aufgestellt. Aufn.: Hundertmark sind bcreits mit gutem Beispiel vorangegangen. Im Vergleich $2 u$ der 40prozentigen Vergnügungssteuer in Niedersachsen betrăgt diese 2. B. in Bayern nur 18 Prozent der Bruttoeinnahmen. Unter dem Druck der Verhaltnisse hat sich auch die niedersilchsische Regierung zu einem entsprechenden Gesetrentwurf belitger Auffassungen auf Grund der verschiedenen sicher. Eine Erhöhung der Eintrittspreise wird von den Filmtheaterbesitzern entschieden abge!ehnt. Die beste Losung wäre eine generelle Regelung der Steuer auf der Bundesebene, die den Filmtheatern die Existenz sichert und eine gesunde Entwricklung des gesamten deutschen Filmschaffens möglich macht.

Bel der Erörterung der Frage der Zulassung neuer Filmtheater wurde darauf hingewiesen, daß neben der fachlichen und personlichen die Bedarfsfrage einehmers besonders auch Zusammenhang hier für Göttingen angekündigte neue KronenTheater zu sprechen. Das GT hat in dieser Angelegenheit vor wenigen Tagen und heute beide Parteien zu Worte kommen lassen. Im weiteren Veriauf der Tagung, die sich mit den. verschiedensten fachlichen problemen befaste, wurde aul die vom 20 . September bis S. Oktohingewiesen, die die volle Unterstützung der hingewiesen, die die volle Unterstützung der der deutschen Nachkriegsproduktion sollen gezeigt werden. Man erwartet von dieser Woche einen Auftrieb für das gesamte deutsche Filmwesen.

Im AnschluB an die Tagung sahen die Teilnehmer die ${ }^{\text {I }}$ ondion Film"-Produktiou Staatsgeheimnisa, die demnächst im "CapiVorgänge in einem von einer Diktatur beberrschten Land machen diesen Film zu einem Zeitbild von höchster, aber auch erschütternder Aktualităt.

\section{Göttinger waren dabel}

Am Sonntag fand bel herrlichem Wetter der wohl groble westdeutsche SegeiflugDörnberg bei Kassel statt. Aus zanz WostDeutschland waren Molelnilezer erschienen. Selbst aus Oster:eich traf am sphiten Nachmittag ein Teilnenmer ein. Insgesamt waren etwa 300 Modellnlieger mit fast 100 Modellen am Start. Göttingen war mit 4 Modellen und 20 schlachtenoummiern vertreten. Ein Göttinger Modell ging wihrend des Wettbewerbs zu Bruch, ein zweites flog auf und davon, bis es in den Wolken verschwand. Nach Abschlus des offiziellen Telles wurde von einem Hannoveraner ein Fesselflugmodell, d. h. ein kle'nes Motorflugmodell an der Leine, vorgefuhrt, Die Organisation war Wher Antor per Rad ging es am Montag wieder heim.

Q8: Artikel aus dem GT vom 22.08.1950, S. 4, Stadtarchiv Göttingen. (FilmZtg 253). 


\section{Noch einmal:
Göttinger Symphonie-Orchester}

Der in so sachlicher und vornehmer Weise geschriebene Artikel von Herrn Günther WeiBenborn (im "GT" 25. 1. 51) wirkte bei mir und ich hoffe" bei vielen, die ihn lasen - wie eine Erlösung, daß es „vielleicht so doch einen Ausweg gibt".

Der "Paukenschlag", der uns durch die so uberschriebenen Zeilen im "GT" am 12. 1. 51 versetzt wurde, rumort und grummelt - abebbend und anschwellend je nach dem mir Zeit bleibt, bei den immerfordernden Pflichten des Tages in einer großen, vielseitig zusammengesetzten Familie - seitdem in Kope und Herzen und war in später Abendstunde oft so stark, daß ich mir durch ein Briefchen an die Lokalredaktion Luft zu machen wünschte. Doch da ich fürchtete, inhaltlich und formal nicht sachlich genug sein zu können, mußte es in mir weiter grollen - keineswegs beschwichtigt durch die inzwischen

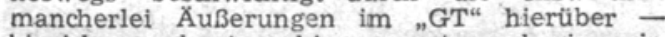
bis ich nun heute ruhiger zu atmen beginne in dem Gedanken, daß die gewiesene Möglichkeit ein gangbarer Weg wird, und da $\beta$ die vielen, vielen, die gleich mir an der Angst vor baldiger Verstummung des Göttinger Symphonie-Orchesters leiden müssen, merken wie ich, daß wir es nicht leiden können und nicht leiden dürfen, wenn einer der echtesten Werte Göttingens verloren geht: das eigene Orchester - dieses Orchester, von dem ich niemanden persönlich kenne, das mir aber als Ganzes und in einzelnen Teilen (im Theater, im Konzert, in den "Serenaden" und wo sonst seine unersetzliche Gabe wirkt) so innig bekannt ist und mir erscheint wie eine hochkultivierte, harmonisch (,symphonisch") Werte spendende Persönlichkeit, deren Antlitz Göttingen nicht entbehren kann, ohne etwas Wesentliches einzubüßen!

Obwohl ich nicht Göttingerin bin und allen irdischen Besitz im Osten verlor - oder gerade deshalb doch? wage ich es, meine Gedanken und Empfindungen hier auszudrücken, weil ich bange um die Herabminderung des Wertes der so vielseitig hochstehenden Stadt, die mir nun Heimat wurde, nachdem ich durch alle Erlebnisse und Verluste in Kriegs- und Nachkriegszeit lernte, daß dauernde Werte ins Geistige gewendet sein und in Herz und Seele wurzeln müssen. So soll dies ein Gruß aus Dank und voll Hoffnung an das Göttinger Symphonie-Orchester sein!

A. v. B.

Q9: Leserbrief als Reaktion auf die Entlassung des Symphonieorchesters, in: GT vom 2.2.1951 (Materialien des Kulturamtes, in: Konzert- und Theaterkritiken von Göttinger Aufführungen, Nr. 604) (Stadtarchiv Göttingen). 


\section{"Tannhäuser macht sich immer so schmutzig" Lỉebespaare mögen den Malersaal nicht / Alte Kostüme werden geschlachtet}

Es ist überall das gleiche Lied, und ein verunglücktes Theaterkostüm tot lür lngeborg Grafi, die Kostümbildnerin des Theaters, genau so schlimm, wie ein Dreieck in Fritzchens Sonntagshose. „ScheuBlich, daß der Venusberg immer so abfärbt", sagt sie mil leisem Seuizer, als sie Tannhäusers Rock, den arge Farbkleckse verunzieren, aut dem Schneidertisch ausbreitet. Aber Phantasie, Eriahrung und eine Werkstatt mit tünt tüchtigen Helierinnen bringen auch das wieder in Ordnung.

Uberhaupt ist das Improvisieren und künstlerische Note zu geben. Der das Jonglieren zwischen Idee und Weg von der ersten Farbskizze bis rauher Wirklicbikeit hier der Weis- zur Premiere führt nie in gerader heit letzter Schluß. Seit der wertvolle Linie und verlangt immer wieder AbKostümfundus, der den Krieg heil stimmungen mit der Intendanz, dem überstanden hatte, 1945 mit einer Regisseur und nicht zuletzt mit den amerikanischen Fronttheater-Truppe Bühnenbildnern Margarete Altvater entschwand, haben die Nöte nicht und Hans Ploch. aufgehört. Ganz behutsam zeiqt uns Frau Graff ein "gerettetes“ Brokatkostüm. "Solches Material können wir uns heute nicht mehr leisten. Wir machen es gerade für die "Aida" zurecht. Es wird seine 20 . Rolle sein." Die alten Kostüme sind inzwischen alle geschlachtet, das Allerweltsmaterial ist einfarbiger Nessel, der nach Bedarf bemalt, bedruckt oder umgefärbt wird.

Ein ganz großes Sorgenkind sei die Fußbekleidung, versichert sie uns. Ein einziges Paar Damenstiefel - für den Rosenkavalier - ist während der letzten drei Spielzeiten neuangefertigt worden, sonst hilft man sich mit billigen Stoffschuhen, Bastlatschen und eiqenem Schuhwerk. Es qehört schon eine große Liebe zum Theater und ein noch größeres Können dazu, um jeder Ausstattung eine eigene dierter Leinwandtláciıen kann man ganze Spielpläne abjesen. In einem eieganten Schuhgeschä:t streicht eir Mann ägyptische Säulen - die Kulissen für Meine Schwester und Ich" lehnen fertig an der Wand, während
"Aida" noch in Arbei i ist. Farbiöpfe "Aida" noch in Arbeit ist. Farbiöpfe und Pinsel von nicht geringerem AusmaB sind das Werkzeug. In den Privatateliers von Fräulein Altvater und in lustiger Höhe über dem Arbeitssaal hăufen sich Entwürfe und beschrif'ete Malanwois:ungen, und

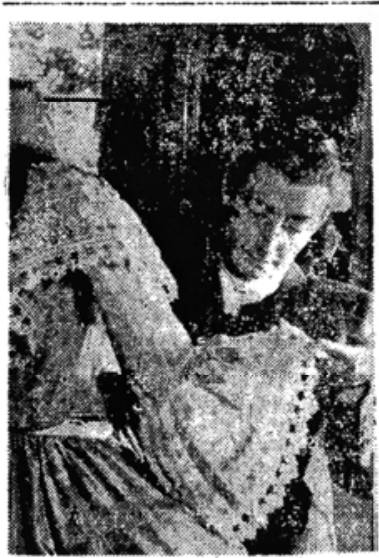

Mit Sorgen prüft Ingebiorg Graft, ob das Staatskleid mit Snitzen und Perlen noch einmal auftreten kann. Foto: ESG

Q10: Artikel aus der Hannoverschen Presse vom 27.08.1949, S. 5, Stadtarchiv Göttingen (FilmZtg 628). 


\title{
Protestieren muss (wieder) gelernt sein
}

\author{
Andreas Brieger
}

\section{Einleitung}

Nach dem Ende von Krieg und NS-Herrschaft entstanden für die BürgerInnen Göttingens neue Möglichkeiten und Formen der öffentlichen Meinungsäußerung. In Anbetracht der anderen Themen dieses Sammelbandes - etwa Entnazifizierung, Wohnungs- und Versorgungslage und die Situation der Vertriebenen - ließen sich aus heutiger Perspektive zahlreiche mögliche Protestanstöße finden. Inwiefern gab es aber öffentlichen Protest in Göttingen zur Nachkriegszeit? Inwieweit schränkten rechtliche Rahmenbedingungen Protestbemühungen ein oder ermöglichten sie? Welche Themen zogen möglichen Protest nach sich? Und nicht zuletzt, besonders aus alltagsgeschichtlicher Perspektive: welche Beteiligten gestalteten öffentlichen Protest unter den Bedingungen der Nachkriegszeit?

Zunächst scheint jedoch eine begriffliche Abgrenzung sinnvoll. Der Begriff Protest (lateinisch protestari „öffentlich bezeugen“, „verkünden“) ist allgemein verstanden ein Akt des Widerspruchs gegen private oder gesellschaftliche Missstände. Streng genommen ist also jede Widerspruchsäußerung, z.B. in einem Nachbarschaftsstreit oder auch im Gespräch zwischen Eltern und Kindern, alltagsgeschichtlich als Protest zu verstehen. Während der NS-Diktatur waren politischer Protest und andere so genannte politische Straftaten unter strenge Strafen gestellt, nicht selten sogar unter Todesstrafe. ${ }^{1}$

${ }^{1}$ Die gerichtliche Zuständigkeit in erster Instanz lag bei den Oberlandesgerichten bzw. dem Reichsgericht (später Volksgerichtshof). Direkte, aktive politische Betätigung in verbotenen Organisationen wurde meist als Hoch- bzw. Landesverrat behandelt. Andere sogenannte politische Straftaten wurden 
Unter den Bedingungen der Nachkriegszeit scheinen in dieser Hinsicht insbesondere Proteste gegen politische Entscheidungen oder Entscheidungsträger, politische oder soziale Tendenzen, oder gegen bestimmte ökonomische oder soziokulturelle Entwicklungen interessant. Auch politischer Protest kann in äußerst unterschiedlichen Formen geäußert werden: von Einzelpersonen, Gruppen, aber auch politischen Zusammenschlüssen wie Parteien und Gewerkschaften. Demonstrationen (lateinisch demonstrare ,hinweisen“, ,deutlich machen“) sind nur eine mögliche Form des öffentlichen Protests, die durch öffentliche Versammlungen (meist unter freiem Himmel) ihre Positionen bzw. Forderungen untermauern. Beispiele für andere Protestformen sind die Verbreitung von Flugblättern oder -schriften, Protest in Form politischer Plakate, zivilen Ungehorsams oder schriftlich geäußerter Protest. Viele dieser Formen lassen sich auch in den alltagsgeschichtlichen Quellen aus Göttingen wiederfinden.

\section{Bedingungen}

Die Bedingungen für öffentlichen Protest in der unmittelbaren Nachkriegszeit waren bis September 1945 deutlich eingeschränkt. Nach der Besetzung wurde den Bewohnern Göttingens ,,jede öffentliche Versammlung von mehr als fünf Personen verboten“, einzige Ausnahme blieb die Erlaubnis zur Teilnahme an Gottesdiensten. $^{2}$ Das „erste öffentliche Kommunikationsmittel“ zwischen britischen Besatzungstruppen und der deutschen Bevölkerung stellten Anschläge als eine Form von politischen Plakaten dar, auf denen die Verordnungen und Gesetze der Militärregierung z.B. zu Meldepflichten oder Ausgangssperren bekannt gemacht wurden. ${ }^{3}$ Auch die Organisation und Durchführung von politischen Versammlungen wurde durch solche Anschläge wie die Verordnung Nr. 10 der britischen Mili-

als „,heimtückische Angriffe“, „Wehrkraftzersetzung“, „Rundfunkverbrechen“, aber auch durch die „Volksschädlingsverordnung“ bestraft. Vgl. Inge Marßolek/René Ott, Bremen im Dritten Reich. Anpassung - Widerstand - Verfolgung, Bremen 1986. Dabei stellen Marßolek und Ott in ihrer Regionalstudie fest, dass ,eine Reihe von Äußerungs- und Verhaltensformen allein durch Kriminalisierung eigene Bedeutung gewannen, die ihnen unter andersartigen politischen Verhältnissen niemals zugekommen wäre“ (S. 387-88). Zur Rolle der Sondergerichte vgl. Wolf-Dieter Mechler, Kriegsalltag an der „Heimatfront“. Das Sondergericht Hannover im Einsatz gegen „Rundfunkverbrecher“, „Schwarzschlachter“, „Volksschädlinge“ und andere „Straftäter“ 1939 bis 1945, Hannover 1997. Laut Mechler wurden zwischen 1939 und 1945 von den insgesamt 3000 Verfahren am Sondergericht Hannover 210 mit dem Urteil Todesstrafe verabschiedet, d.h. mehr als $90 \%$ mit Gefängnis- und Zuchthausstrafen (S. 23).

2 Hans Otte, Die Geschichte der Kirchen, in: Rudolf von Thadden/Günther Trittel (Hg.), Göttingen. Geschichte einer Universitätsstadt, Bd. 3: Von der preußischen Mittelstadt zur südniedersächsischen Großstadt: 1866-1989, Göttingen 1999, S. 591-674, hier S. 655.

3 Klaus Wasmund, Politische Plakate aus dem Nachkriegsdeutschland. Zwischen Kapitulation und Staatsgründung, Frankfurt am Main 1986, S. 14. Wiebke von Thadden, Die Stadt Göttingen unter britischer Militärverwaltung 1945-1947, in: Rudolf von Thadden/Günther J. Trittel (Hg.), Göttingen. Geschichte einer Universitätsstadt, Bd. 3: Von der preußischen Mittelstadt zur südniedersächsischen Großstadt: 1866-1989, Göttingen 1999, S. 275-290, hier S. 276-78. 
tärregierung vom 8. Januar 1946 geregelt (Q1). ${ }^{4}$ Eine politische Versammlung ist dort definiert als ,jedes öffentliche Zusammentreffen, das zu politischen Zwecken abgehalten wird, gleichmal ob in geschlossenen Räumen oder unter freiem Himmel. Der Ausdruck schließt politische Kundgebungen ein, jedoch nicht öffentliche Umä̈ge. "5

Die Anmeldung von solchen Veranstaltungen wurde in der Kommunalverwaltung der jungen BRD beibehalten, ein Beispiel findet sich in dem an das Göttinger Ordnungsamt gerichteten Schreiben der KPD zur Anmeldung einer Kundgebung anlässlich der Weltfestspiele der Jugend in Ost-Berlin 1951 (Q2). Die Anmeldungsbedingungen unterschieden sich nur unwesentlich: neben den zentralen Angaben des Ortes, des Themas und der Redner, die auch in Q2 gemacht werden, verlangte die Militärregierung zusätzlich nur eine Antragsfrist von 7 Tagen vor Veranstaltungsbeginn sowie Angaben zu Adressen der VeranstalterInnen und die namentliche Nennung von allen politischen Gruppen, die von den veranstaltenden Personen unterstützt wurden. Seit Ende 1945 galten diese Regelungen nach ihrer Erlaubnis auch für die neu- oder wieder gegründeten Parteien.

Vor 1949, also vor Gründung der Bundesrepublik, bestanden offensichtlich wenig Gründe für den Gebrauch von Veranstaltungsverboten in Göttingen - die Quellenlage hinterlässt den Eindruck einer wenig protestbereiten Göttinger Bevölkerung. Über nicht-öffentliches Unbehagen kann nur spekuliert werden, öffentliche Protestäußerungen waren jedoch selten. Politische Betätigung oder „Übungen in engagierter Sachlichkeit" fanden vornehmlich in Form von Kirchenkreisen und anderen (oft akademischen) Foren statt. „Eine Stadt lernte auf diese Weise langsam Politik. " 6 Göttinger BürgerInnen mussten nach der Zeit des politischen und gesellschaftlichen Neubeginns nach Kriegsende das Recht auf freie Meinungsäußerung und die neuen, wenn auch immer noch eingeschränkten, Möglichkeiten zum politischen Protest wieder einüben. Erst Anfang der 1950er Jahre finden sich vermehrt auch größere Demonstrationen und die Vielfalt an Protestformen nahm zu. Ein Beispiel für eine Massenkundgebung zeigt ein Foto der politischen Kundgebung zum 1. Mai 1951 (Q7). Die aus der Arbeiterbewegung stammende Tradition der Kundgebungen und Streiks zum 1. Mai wurde in der NS-Zeit weitgehend von den Nationalsozialisten in Beschlag genommen und zu Propagandazwecken missbraucht. Der Erklärung des 1. Mai zum „Feiertag der nationalen Arbeit“ im April 1933 folgte die Gleichschaltung der Gewerkschaften im Mai. Nach Kriegsende versuchten die Gewerkschaften, Sozialdemokraten und Kommunisten die Maifeiern wieder neu zu beleben. So wird z.B. als traditionelle Kernforderung der Maifeiern auf einem Transparent die 40-Stunden-Woche gefordert. Der 1. Mai der Gewerkschaften steht in der sozialdemokratisch-gewerkschaftlichen Tradition der

\footnotetext{
${ }^{4}$ Q1 ist eine Abänderung der Verordnung Nr. 10, die bereits am 15. September 1945 bekannt gegeben wurde.

5 Verordnung Nr. 10 der Militärregierung Deutschland Britisches Kontrollgebiet (Erste Abänderung), 8.1.1946, Stadtarchiv Göttingen, PS 1956-1949 A 75/1946-1.

${ }^{6}$ Jürgen Gidion, Stunde Null? Zur Kulturgeschichte der Nachkriegszeit in Göttingen, in: Neue Sammlung 36 (1996), S. 413-433, hier S. 433.
} 
Maifeiern der Weimarer Republik, deren Charakter eher der eines Festtages war. Ein SPD-Plakat von 1951 zeigt das Verständnis von der Mai-Demonstration als einer Familienveranstaltung mit Blick auf eine bessere Zukunft (Q10).

\section{Beteiligte}

Die Beteiligten selbst, ihre Motivationen, Ziele und Handlungsweisen stehen in einer alltagsgeschichtlichen Betrachtung von öffentlichem Protest im Mittelpunkt. Im Falle von Göttingen als traditioneller Universitätsstadt verwundert es wenig, dass Protestäußerungen häufig von studentischer Seite hervorgebracht wurden. Besonders Fotos von Demonstrationen geben Aufschluss über studentische Proteste. Zum Beispiel provozierte der Fackelzug farbentragender Burschenschaftler anlässlich der 1.000-Jahr-Feier Göttingens am 8. Juli 1953, der vorher vom Rektor der Universität untersagt worden war, eine Gegendemonstration der Studierenden (Q5). Die Proteste richteten sich gegen öffentliche Zurschaustellung der Verbindungsfarben, denn das Verbindungswesen stand in ihren Augen für restaurative Bestrebungen an der Universität.7 Ein weiteres Beispiel für studentische Protestkundgebungen zeigt das Foto von einer Demonstration gegen die Ernennung von Leonhard Schlüter zum niedersächsischen Kultusminister am 27. Mai 1955 (Q6). Schlüter, der zur Zeit des Nationalsozialismus als so genannter Halbjude selber Opfer nationalsozialistischer Verfolgung gewesen war, betätigte sich nach 1945 politisch in Parteien des rechtsradikalen Milieus ${ }^{8}$ bevor er in die niedersächsische FDP eintrat und bot rechtsradikalen Autoren eine Anlaufstelle in seinem Göttinger Verlagshaus. ${ }^{9}$ Der „Sturm der Entrüstung“ darüber, dass ein Politiker aus dem rechtsradikalen Milieu einen Ministerposten in einem bürgerlichen Kabinett erhielt, führte schließlich zum Rücktritt Schlüters am 11. Juni 1955. ${ }^{10}$ Beide Beispiele zeigen allerdings auch eine gemeinsame Linie der Studierenden und dem liberalen Teil der Göttinger Professoren. So galt der Protest gegen den Fackelzug der Burschenschaftler als Solidaritätsbekundung mit dem Rektor, um dessen Verbot zu unterstützen. ${ }^{11}$ Die Schlüter-Kundgebung ist eine Reaktion auf den geschlossenen Rücktritt von Rektor und Senat, die aus politischen Gründen die Person Schlüter als Kultusminister für untragbar hielten und sich um das Ansehen und die Entwick-

\footnotetext{
7 Hans Joachim Dahms, Die Geschichte der Universität Göttingen 1918 bis 1989. Vom „Goldenen Zeitalter" der Zwanziger Jahre bis zur „Verwaltung des Mangels“ in der Gegenwart, in: Rudolf von Thadden/Günther J. Trittel (Hg.), Göttingen. Geschichte einer Universitätsstadt, Bd. 3: Von der preußischen Mittelstadt zur südniedersächsischen Großstadt: 1866-1989, Göttingen 1999, S. 395-456, hier S. 436.

${ }^{8}$ Schlüter war Mitglied in den Parteien Nationale Rechte und Deutsche Reichspartei.

${ }^{9}$ Dahms, S. 437. Vgl. auch Heinz-Georg Marten, Der niedersächsische Ministersturz, Göttingen 1987 (Göttinger Universitätsschriften).

${ }^{10}$ Dahms, S. 437-38.

${ }^{11}$ Ein Transparent z.B. trug die Aussage „Verbrennt euch nicht die Pfoten, der Rektor hat's verboten!“.
} 
lung der Universität sorgten. ${ }^{12}$ Des Weiteren weist auch die Tatsache, dass mehrere Professoren mit Redebeiträgen auf der studentischen Kundgebung vertreten waren, auf Übereinstimmungen in den Haltungen der Studierendenschaft und den Lehrenden hin. Daneben darf aber auch das antifaschistische Engagement von Jugendgruppen nicht vergessen werden, so z.B. von den Falken gegen den ersten Nachkriegsfilm des „Jud Süß“-Regisseurs Veit Harlan „Die unsterbliche Geliebte“ (Q8).

Nicht Harlans Filme, die in Göttingen produziert und uraufgeführt wurden, sondern die Person Harlans selbst provozierten in Göttingen scharfe Proteste. ${ }^{13}$ Besonders viel Medienöffentlichkeit erreichten die Bestrebungen gegen die Aufführung von „Hanna Amon“, der „Geschichte einer aufopferungsvollen Geschwisterliebe, die vor dem Hintergrund traditions- und verantwortungsbewußtem Bauerntums entfaltet wird." 14 Eine Reihe von Prozessen gegen Veit Harlan, die sich mit seiner Mitverantwortung für die nationalsozialistische Judenverfolgung befassten, und ein landesweit Aufsehen erregender Boykottaufruf eines Hamburger Senatsmitglieds bilden die Vorgeschichte dieses Protestes, der sich mehr auf die Kritik an Harlans NS-Verbindungen bezog als auf den eigentlichen Inhalt des Films. ${ }^{15}$ Harlan polarisierte auch die Göttinger Bevölkerung, eine komplette Seite an Leserbriefen im Göttinger Tageblatt dokumentiert die öffentliche Kontroverse um die Ereignisse des 25. Januar 1952 (Q3). Die Bandbreite der dort zu vernehmenden Stimmen umfasst sowohl die klare Ablehnung der Proteste in ihren Zielen und Methoden als auch die prinzipielle Zustimmung. Ein Leser drückt den Wunsch aus sich selber ein Bild über Harlans Film zu bilden, ein anderer, der spätere Göttinger Bürgermeister Arthur Levi, prangert antisemitische Äußerungen an. Während der Nachmittagsvorstellung war es zwar außerhalb des Kinos „Central“ schon zu einer Demonstration des „Ring freier Studentenvereinigungen“ mit Sprechchören und Transparenten gekommen, die Filmvorführung wurde jedoch nicht gestört. Das änderte sich mit der Abendvorstellung, bei der im Kinosaal Stinkbomben gezündet wurden sowie der Versuch gestartet wurde, mit steigenden Luftballons die Filmprojektion zu unterbrechen. Während die Aktion im Inneren mit Festnahmen endete, entfaltete sich draußen eine Gegendemonstration, die die Protestierenden unter teilweise antisemitischen Beschimpfungen, Nazi-Liedern und Morddrohungen durch die Stadt trieb - 23 Protestierende wurden dabei verletzt, 6 davon schwer. Diese Ausschreitungen führten schließlich zum Verbot weiterer Aufführungen. Auch diese Kundgebungen deuten auf eine gemeinsame Linie zwischen protestierenden StudentInnen und der Professorenschaft hin, denn der Rektor sowie 48 weitere Professoren veröffentlichten eine Erklärung, in der sie ihr

\footnotetext{
12 Das Rücktrittschreiben von Rektor Prof. Dr. Woermann an den damaligen niedersächsischen Ministerpäsidenten Hellwege, siehe Marten, S. 38-41.

13 Gustav Meier, Filmstadt Göttingen. Bilder für eine neue Welt? Zur Geschichte der Göttinger Spielfilmproduktion 1945 bis 1961, 6. Aufl., Hannover 1996, S. 132.

${ }^{14}$ Ebd., S. 141.

15 Zur Vorgeschichte vgl. ebd., S. 132-36.
} 
grundsätzliches Einverständnis mit den Motiven, dem Eintreten gegen antidemokratische und antisemitische Tendenzen, bekundeten, wenn auch wahrscheinlich nicht mit allen Methoden. ${ }^{16}$

Antifaschismus, wie er in den Harlan-Protesten zu Tage trat, aber auch der Kampf gegen die Remilitarisierung der BRD bildeten in der Nachkriegszeit Schwerpunkte des studentischen Protests. Mit der Parole „Göttinger Bürger seid einig! Schützt Eure Freiheit! Trotzt dem Terror! Rettet den Frieden!“ wenden sich drei Studenten und eine Studentin gegen das Verbot von Volksbefragungen zur Remilitarisierung (Q4). Das Flugblatt richtet sich v.a. an ArbeiterInnen und Studierende und betrachtet eine Remilitarisierung als eine neuerliche Vorbereitung zum Völkermord: „Lässt sich das Volk zum Schweigen bringen, so wird sein Schweigen noch einmal das des Massengrabs und der Gaskammern sein."

Auf Fotos kommt darüber hinaus zum Ausdruck, dass der politische Protest in der Nachkriegszeit keine rein männlich dominierte Sphäre gewesen ist. Nicht nur bei Kundgebungen anlässlich des 1. Mai, sondern auch bei der Anti-SchlüterDemonstration oder bei einer Demonstration von Hausfrauen gegen die Unterbewertung der Hausarbeit nahmen Frauen eine aktive Rolle als Protestierende ein (Q6 und Q7).

Auch das politische Plakat stellt eine Ausdrucksform des Protestes dar. Obwohl es üblicherweise eher als politische Werbung angesehen wird, drücken politische Parteien in ihrer Selbstdarstellung stellvertretend für ihre Mitglieder (bzw. AnhängerInnen) oft auch Protest aus. Dies trifft in besonderem Maße auf Plakate zu, die sich eher mit politischen Inhalten als mit Personen beschäftigen, wie es in der jungen Bundesrepublik oft der Fall war. Eine wichtige Unterscheidung kann zwischen Plakaten, die sich mit eigenen, inhaltlichen politischen Botschaften befassen, und solchen, die sich mit dem politischen Gegner auseinandersetzen, getroffen werden. ${ }^{17}$ Die beiden vorgestellten SPD-Plakate z.B. betonen eine friedliche, freiheitliche und bessere Zukunft im Vergleich zur zurückliegenden NS-Diktatur (Q9 und Q10). Schwerpunkte anderer Plakate in der Nachkriegszeit finden sich in den Themen Krieg und Frieden, Remilitarisierung, Versorgungslage, Aufbau und Wohnungslage, aber auch Besatzung und Besatzungskosten und der Vertriebenenund Kriegsgefangenenproblematik. Beispiele für Plakate, die den politischen Gegner diskreditieren, sind das KPD-Plakat „Weg mit Adenauer“ und das bekanntere CDU-Plakat „Alle Wege des Marxismus führen nach Moskau“, das sich eher gegen die SPD als gegen die KPD richtete (Q11 und Q12). ${ }^{18}$ Ein dezidierter Antikommunismus wurde als Integrationsideologie der bürgerlichen Parteien benutzt. Er diente aber auch dazu, die SPD, die sich erst mit dem Godesberger Programm von 1959 offiziell vom Marxismus verabschiedete, als innenpolitischen Gegner zu diffamieren.

\footnotetext{
16 Ebd., S. 144.

17 Wasmund, S. 19.

18 Ebd., S. 23.
} 


\section{$4 \quad$ Fazit}

Die Äußerung von öffentlichem Protest war unter den Bedingungen der Nachkriegszeit aus verschiedenen Gründen schwierig. Zum einen setzten anfänglich Verordnungen der Militärregierung enge Rahmenbedingungen, die Erlaubnis zur Abhaltung von politischen Versammlungen allerdings war schon ab Ende 1945 gegeben. Die Bedingungen zur Anmeldung von politischen Kundgebungen in der BRD unterschieden sich später kaum von denen der britischen Militärregierung. Besonders die sozialistischen, aber auch die extrem rechts gerichteten Parteien und Gruppierungen waren nach 1949 von der Rechtsauslegung betroffen. Zum anderen verlangten die neuen Möglichkeiten zur freien öffentlichen Meinungsäußerung Verhaltensänderungen der Göttinger Bevölkerung im Vergleich zu den Jahren 1933-45. Es fällt hierbei auf, dass viele der seit Anfang der 1950er Jahre immer häufiger stattfindenden öffentlichen Kundgebungen von jungen Menschen getragen wurden. Obwohl deren Erziehung und Sozialisation erheblich unter den Bedingungen des Dritten Reichs stattfand, traten sie auf der Straße für ihre demokratischen Werte und Prinzipien ein. Die Protestbereitschaft in der Bevölkerung Göttingens stieg, die Vielfalt der Protestformen nahm zu. Langsam erlernten GöttingerInnen die Möglichkeiten des politischen Protests.

\section{Literatur zum Weiterlesen}

Hans Joachim Dahms, Die Geschichte der Universität Göttingen 1918 bis 1989. Vom „Goldenen Zeitalter“ der Zwanziger Jahre bis zur „Verwaltung des Mangels“ in der Gegenwart, in: Rudolf von Thadden/Günther J. Trittel (Hg.), Göttingen. Geschichte einer Universitätsstadt, Bd. 3: Von der preußischen Mittelstadt zur südniedersächsischen Großstadt: 1866-1989, Göttingen 1999, S. 395-456.

Inge Marßolek/René Ott, Bremen im Dritten Reich. Anpassung - Widerstand Verfolgung, Bremen 1986.

Wolf-Dieter Mechler, Kriegsalltag an der „Heimatfront“. Das Sondergericht Hannover im Einsatz gegen „Rundfunkverbrecher“, „Schwarzschlachter“, „Volksschädlinge“ und andere „Straftäter“ 1939 bis 1945, Hannover 1997.

Wiebke von Thadden, Die Stadt Göttingen unter britischer Militärverwaltung 1945-1947, in: Rudolf von Thadden/Günther J. Trittel (Hg.), Göttingen. Geschichte einer Universitätsstadt, Bd. 3: Von der preußischen Mittelstadt zur südniedersächsischen Großstadt: 1866-1989, Göttingen 1999, S. 275-290.

Klaus Wasmund, Politische Plakate aus dem Nachkriegsdeutschland. Zwischen Kapitulation und Staatsgründung, Frankfurt am Main 1986. 
Military Government - Germany British Zone of Control

\section{Ordinance No. 10 \\ (Amended (1) ) \\ POLITICAL MEETIMGS}

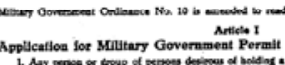

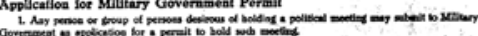

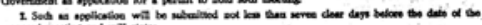

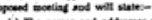

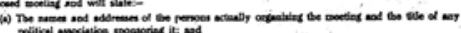

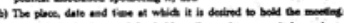

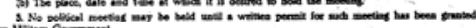

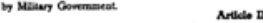

Names and addresses of speakers

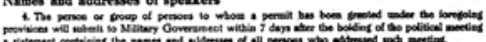

(1)

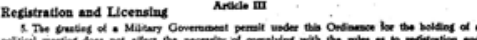

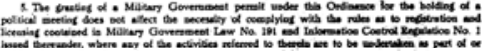

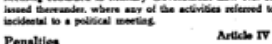

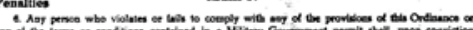

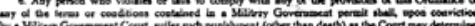

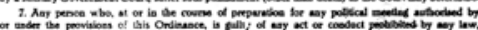

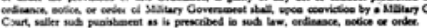

Deftlition Arecle $v$

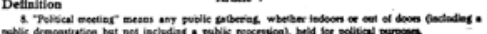

Elfective Drte

Arede $v$

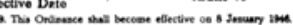

BY ORDER OF MILITARY GOVERNMENT
Militärregierung Deutschland Britisches Kontrollgebiet

Verordnung Nr. 10 (Erste Abänderung)

\section{Politische Versammlungen}

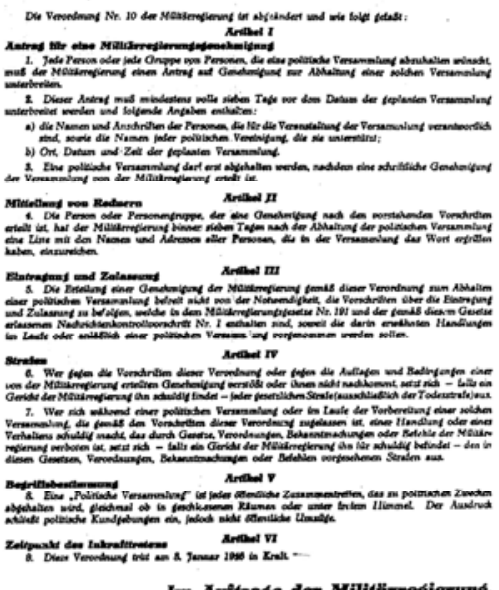

Im Auttrage der Milithrresierung.

Q1: Verordnung Nr. 10: Politische Versammlungen (Erste Abänderung) der Militärregierung Deutschland Britisches Kontrollgebiet, 8.1.1946, Stadtarchiv Göttingen, PS 1956-1949 A 75/1946-1. 
11

K. P. D.

Kreisvorstand

G öt $t$ ing $\mathrm{g}$.

Johniskirchhof 1
Stadt Gottingen

ORDNUNGSAMT

An das

Göttingen, den 20. Aug. 1951

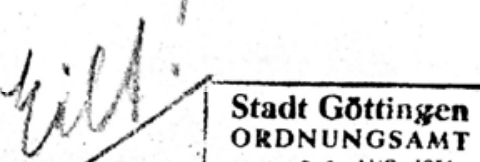

3ag. 2 1 ALG :351

A whand II $x$

G öt $t i n g e n$

Betr. Anmeldung von Kundgebungen unter freiem Himmel.

Wir teilen Ihnen mit, dass wir am 21. 8. $5120 \mathrm{Uhr}$ auf dem Albanikirchplatz eine öffentliche Kundgebung durchführen:

Thema: Was bedeuten die Weltfestspiele der Jugend und Studenten für Deutschland.

Referent: Hugo $P$ a u 1 MaB.

Gleichzeitig ersuchen wir um die Genehmigung eines Lautsprecherwagens in der Zeit von $15 / 30$ bis $18 \mathrm{Uhr}$ für das Stadtgebiet Göttingen,

\section{Kreisvorstand der KPD \\ $G$ ö $t i n g \in n$}

IA

L

Q2: Brief Kreisvorstand der KPD Göttingen an Ordnungsamt Göttingen, 20.8.1951, Stadtarchiv Göttingen, C 35 Nr. 174, 12. 


\title{
Niemand billigt die Methoden
}

\author{
Was sagt die Offentlictikeit zu den Demonstrationen gegen den Harlan-Film
}

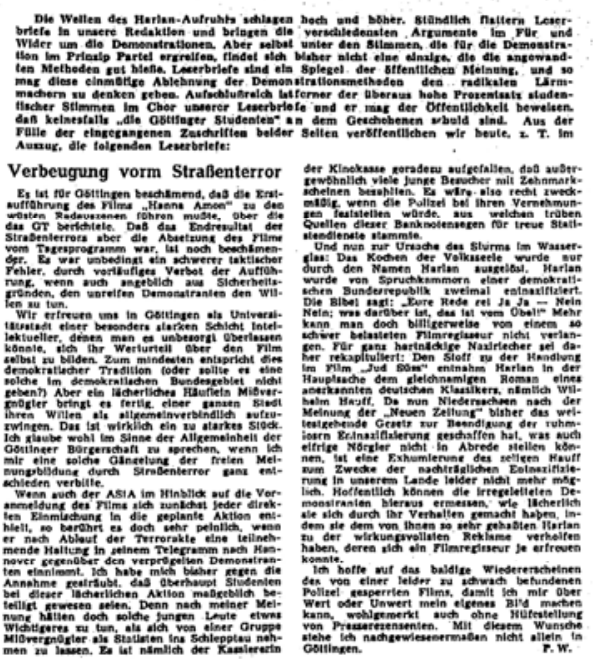

Die „Generalprobe” in der Burse

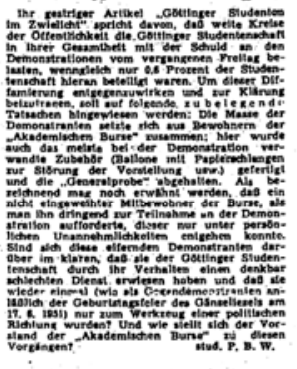

Fine Frage des Anstandes

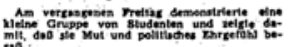

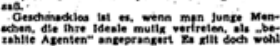
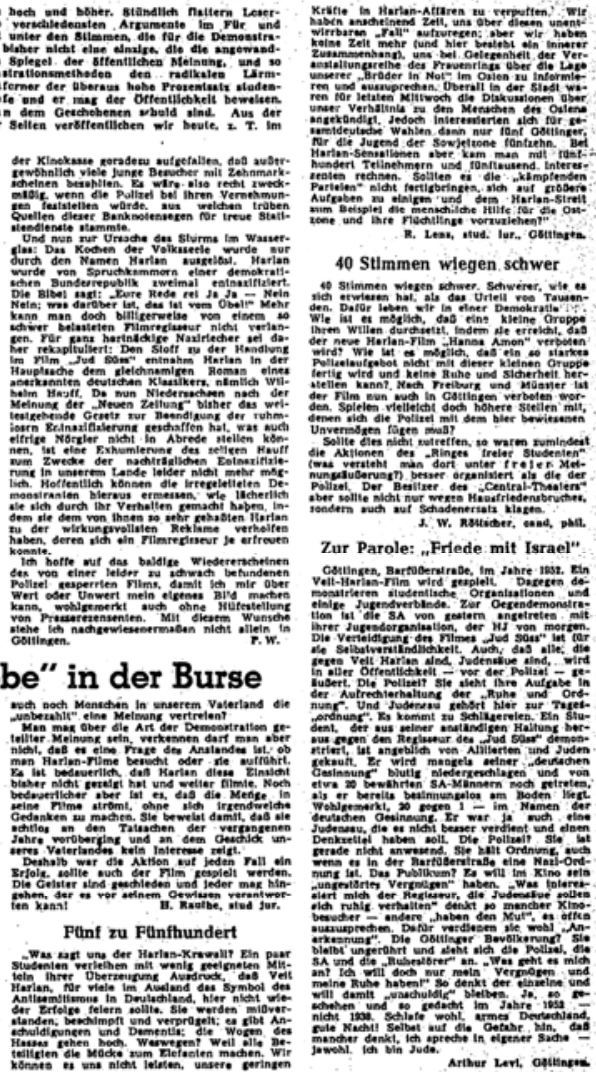

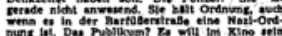

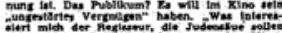

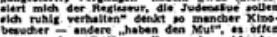

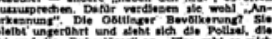

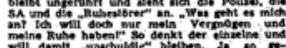

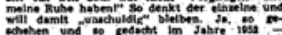

and

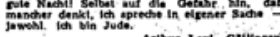
Arthur Lew, oquinger

\section{Demonstration und Polizei}

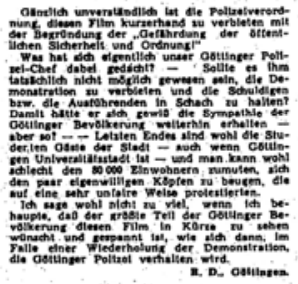
Terror unter

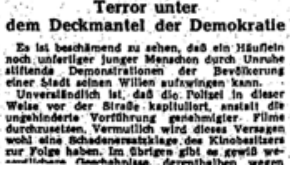

Q3: Niemand billigt die Methoden. Was sagt die Öffentlichkeit zu den Demonstrationen gegen den Harlan-Film, in: Göttinger Tageblatt, 29.1.1952. 
G ö t t 1 n g e r l

Fratien und Mànerer, Arbe1terinnen und Apbeiter, Studentipnen und strdenten. D1e Adenauerregiepung hat fode Volksbetragung gegen dic Ferflitarisisrung dis kommistisch verleumdet, als stagsieindlich verb ten. sind Niemöller, Hel nemann, Manfred Hausmann, Rolnhold schneider, Ha fred vo: Brauchitsch, sind sie alle, die eln offenes Nein zho Wiederauf rüstur. fordérn, Kommunisten?

Eel Nusterschmid stimmten $80 \%$ der Belegschaft gegen die purili tarisierung.

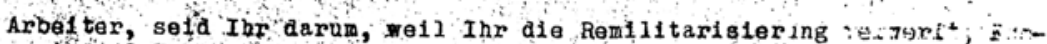

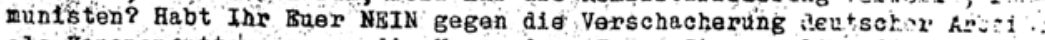
als Renonenentter, gegen die Verwendung Eurer Stevergulden fin Jceb in Zan als Kommisten gesagt? Als $D$ o $u$ t $s$ c h $\theta$ hajt Irr gerescer 1 : gesagt zup Verrat Eures Vaterlandes, zun Vorbereltung necen V isarer.., Ist das Landesverrat?

16 Gồtinger professoren riefex auf gegen die Renllitarisiardrz

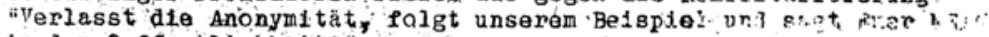
in der Oeffentilonka1t! u

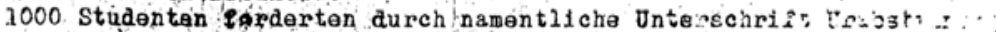
gegen Remilitarisierung.

Sird sta darum Staatsfefnder Ist es Landesverrat, den Briferketeg iur 1

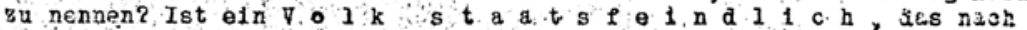

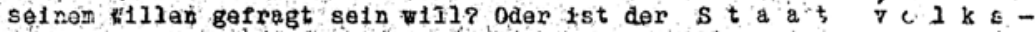
$f: a$ a 21 c b. der das Voxk nioht frören w111? Hier gilt nicht die Frage nach partei oder Herkunet!

Hier gilt die frage: Neuer Faschiemus in Deútechland: Ja de a

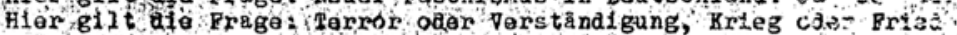

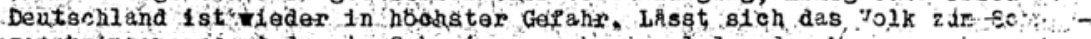
genpolngen, so wtra seln schelgen noch einmal das des Messenzrsps

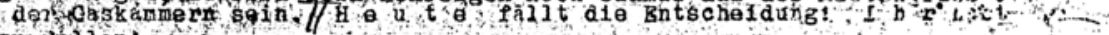
su 2 lien!,

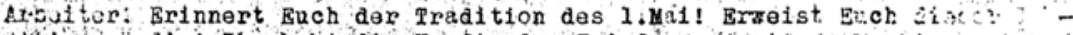
cltich vilrdig! Ihr habt die Kraft, den Frleden zu retten Nach c i". Gebravch /varhindert die Remiliterisiemnefleordert dis Aurrabing tas Verbctes der Volksabst1mmung! Rettet Doutschland, und es aird ' $\mathrm{g}$ u 0 : Dertschlend sein!

SGlden:en! Erinnert Euch der Tradition der Göttinger Sioben, ass $5 \mathrm{c}^{\circ}$

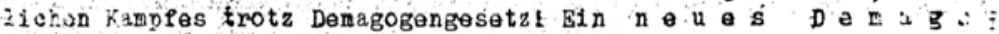
$g$ a $s$ t $z$ lst erlassen. Nicht die Kommunisten sind gereint $I_{\text {..F }}$ airgegrteen, die Ihr NEIN gagt zur Rem1litarisierung. Bohsrrt uf car Proteatiert gegen das Verbot der Volksbefragung, und ntem and $7^{4}$ rt ger, Buch an die Fronten- ¿es Bürgerkrieges zu fiuhren:

$$
\text { Göt } 1 \text { ng er Bürger sie } 1 \mathrm{~d} \text { e } 1 \mathrm{n} 1 \mathrm{~g} \text { ! }
$$

$\overline{7}$ Schüzt.Bure F re $1 \mathrm{~h}$ e $1 \mathrm{t} !$

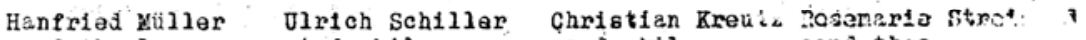
cend theol. stud.phil. cond.phil... cann thon: 


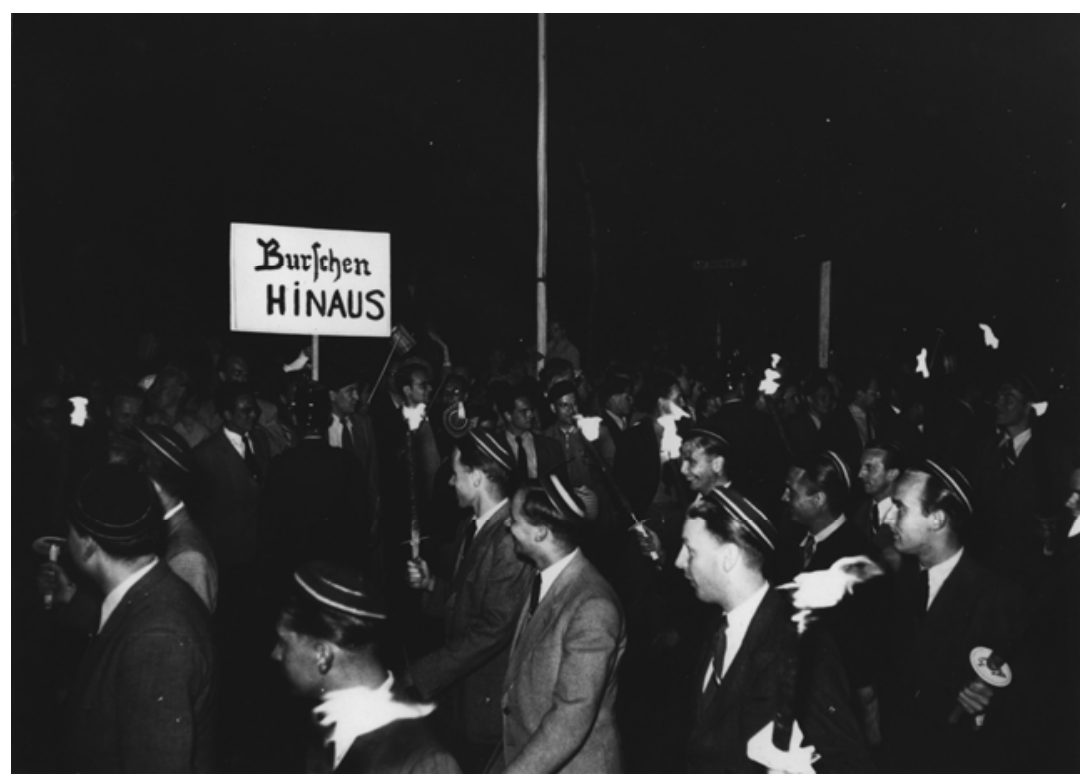

Q5: Fackelzug farbentragender Studenten, 8.7.1953, Stadtmuseum Göttingen, Fotoarchiv.

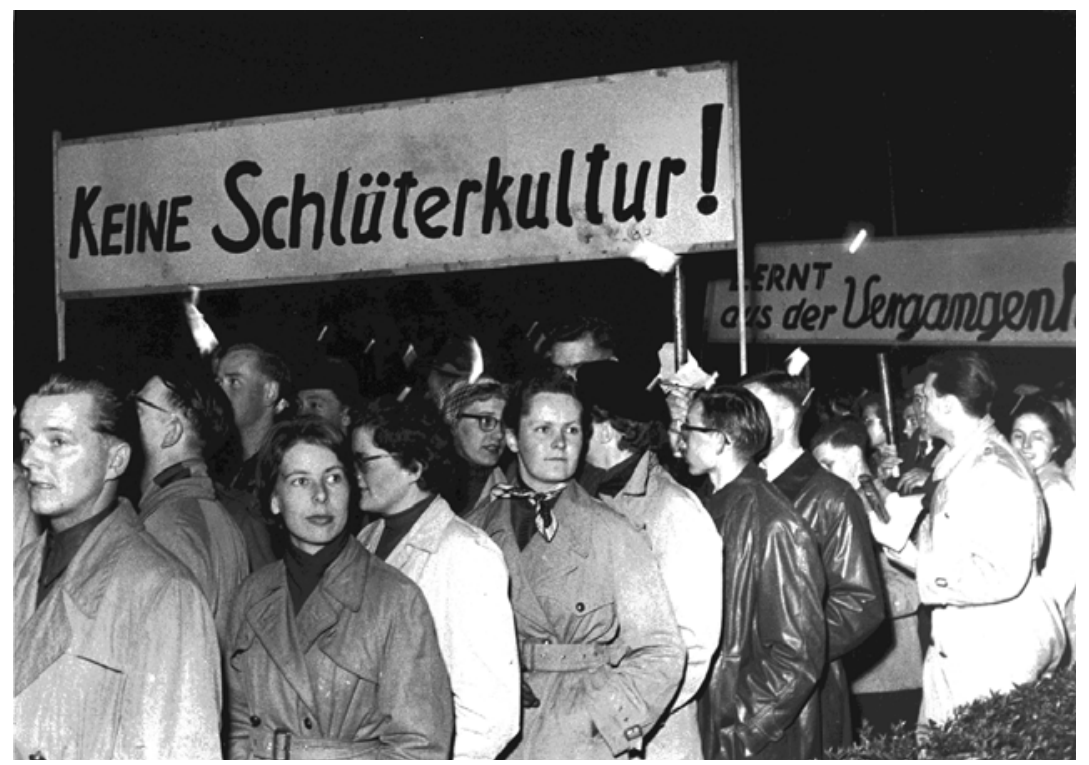

Q6: Demonstration gegen die Ernennung von Leonard Schlüter zum niedersächsischen Kultusminister, 27.5.1955, Stadtmuseum Göttingen, Fotoarchiv. 


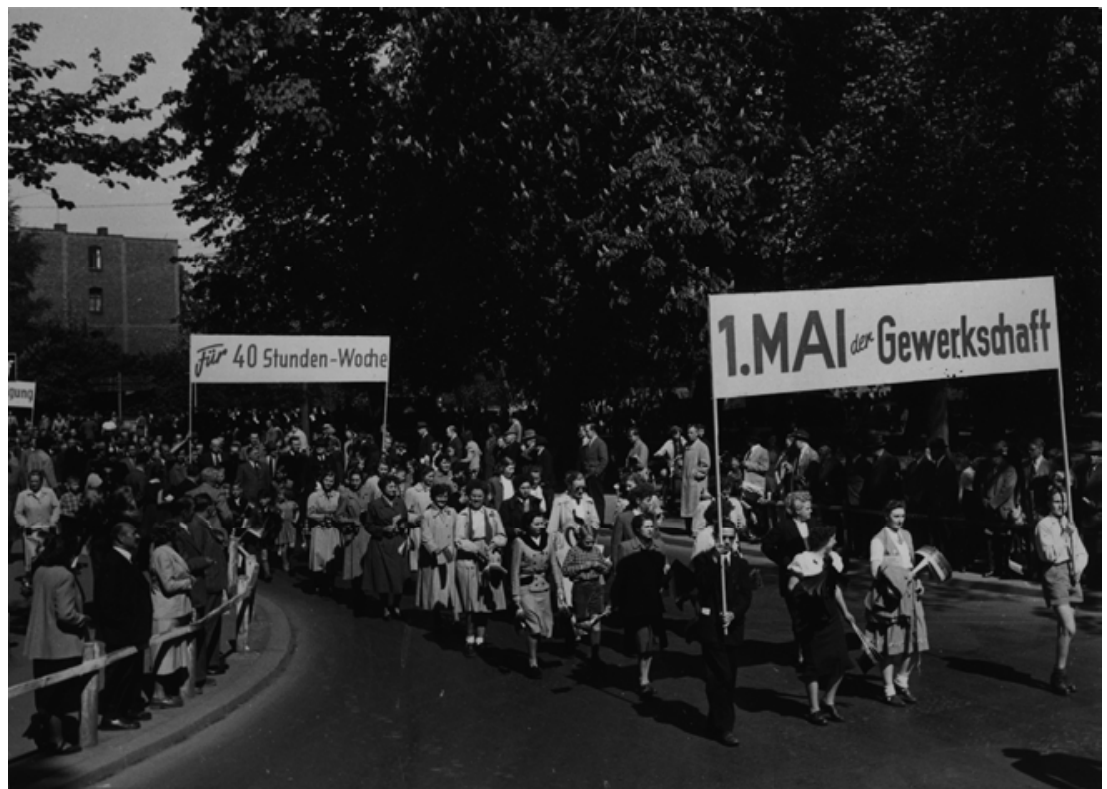

Q7: Demonstration anlässlich des 1. Mai, 1.5.1952, Stadtmuseum Göttingen, Fotoarchiv.

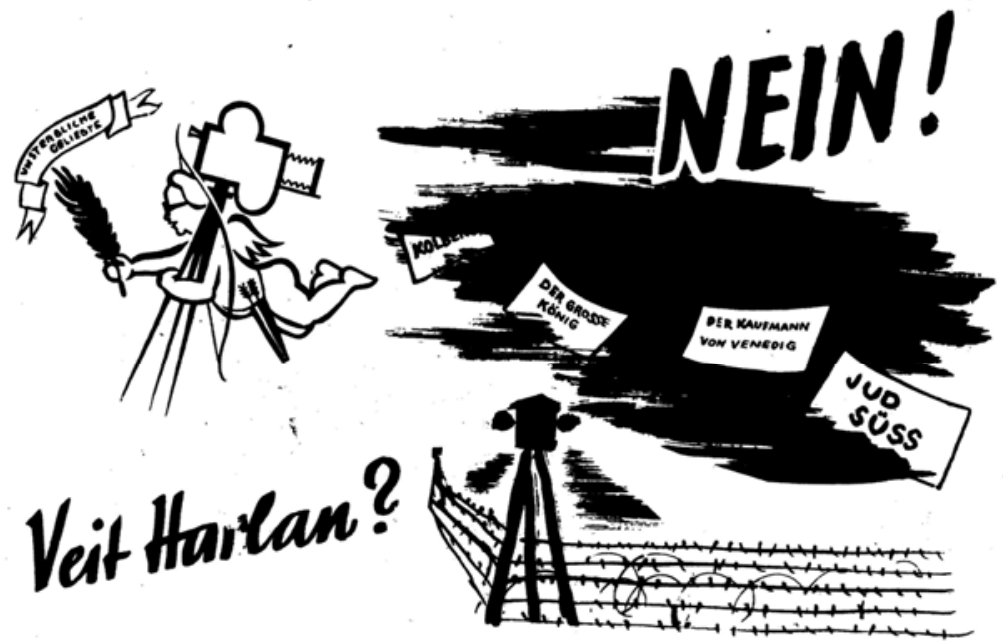

DIE FALKEN - SOZIALISTISCHE JUGENDBEWEGUNG DEUTSCHLANDS

Q8: $\quad$ Flugblatt Die Falken "Veit Harlan? Nein!", 1951, Stadtmuseum Göttingen, Fotoarchiv. 


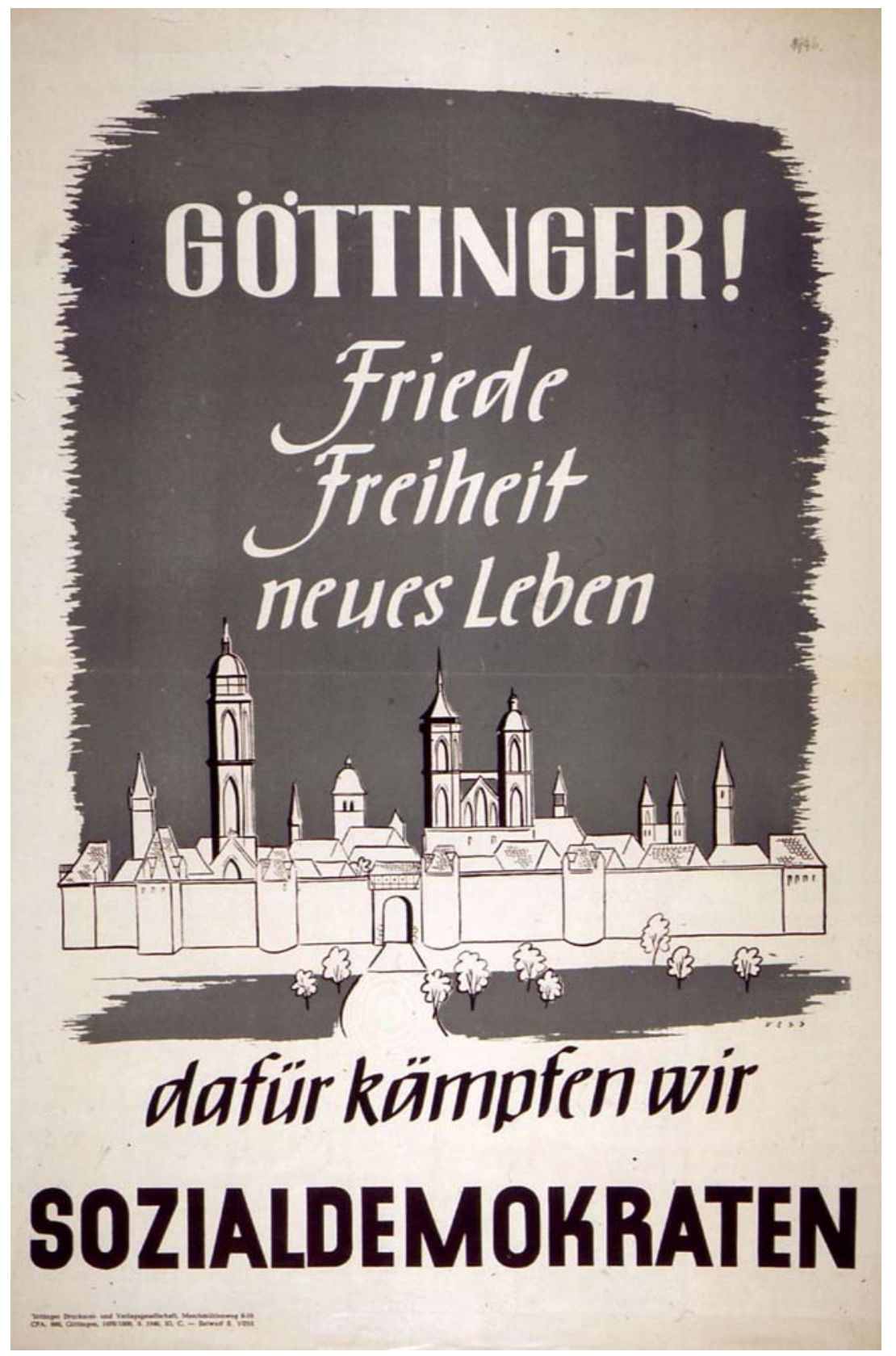

Q9: Plakat SPD "Göttinger! Friede, Freiheit, neues Leben", 1947, Stadtarchiv Göttingen, PS 1946-1949 B2.1/1947-1. 


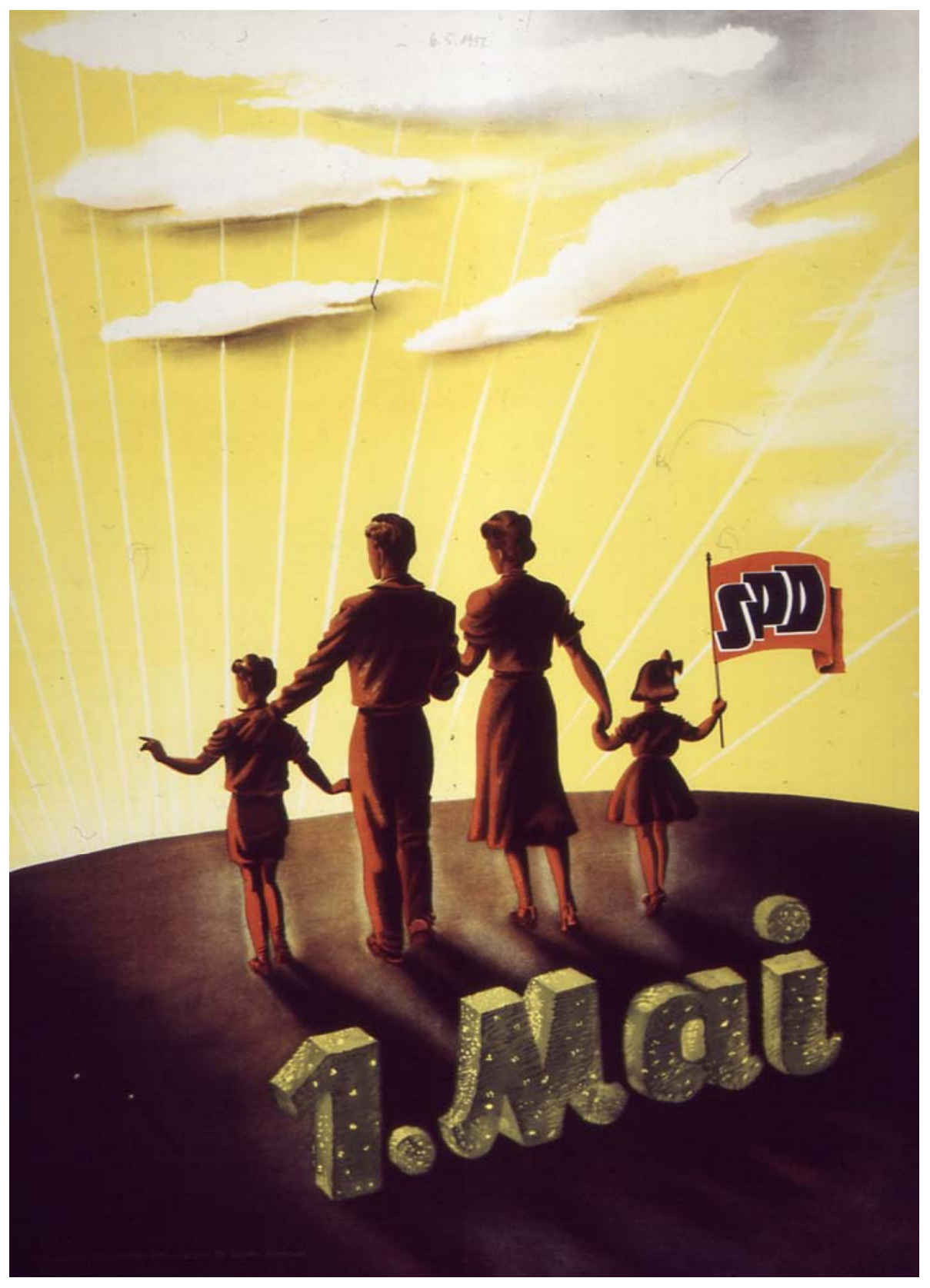

Q10: Plakat SPD "1. Mai", 1951, Stadtarchiv Göttingen, PS 1950-1959 B2.1/1951-4. 


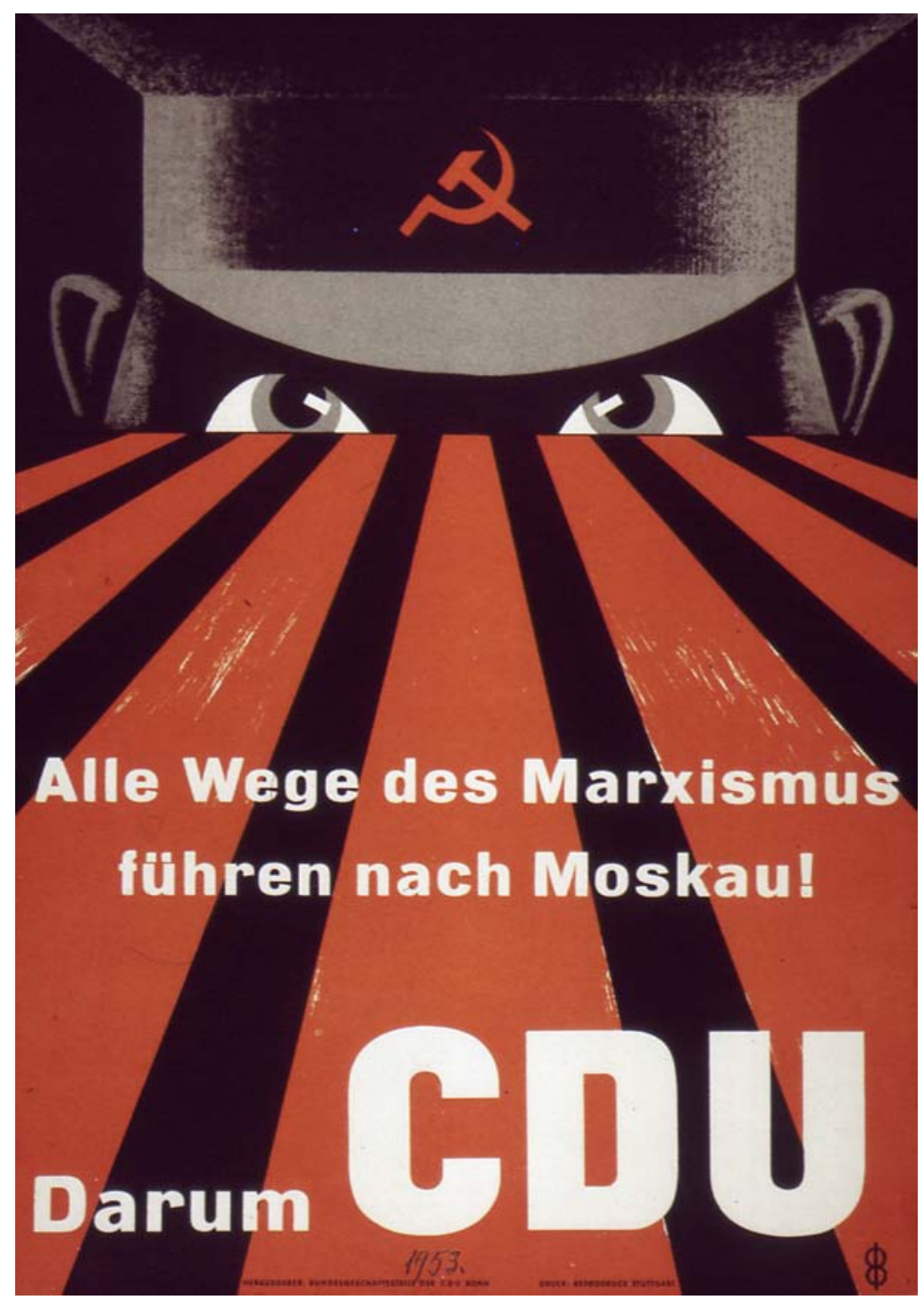

Q11: Plakat CDU "Alle Wege des Marxismus führen nach Moskau", 1953, Stadtarchiv Göttingen, PS 1950-1959 B1.2/1953-1. 


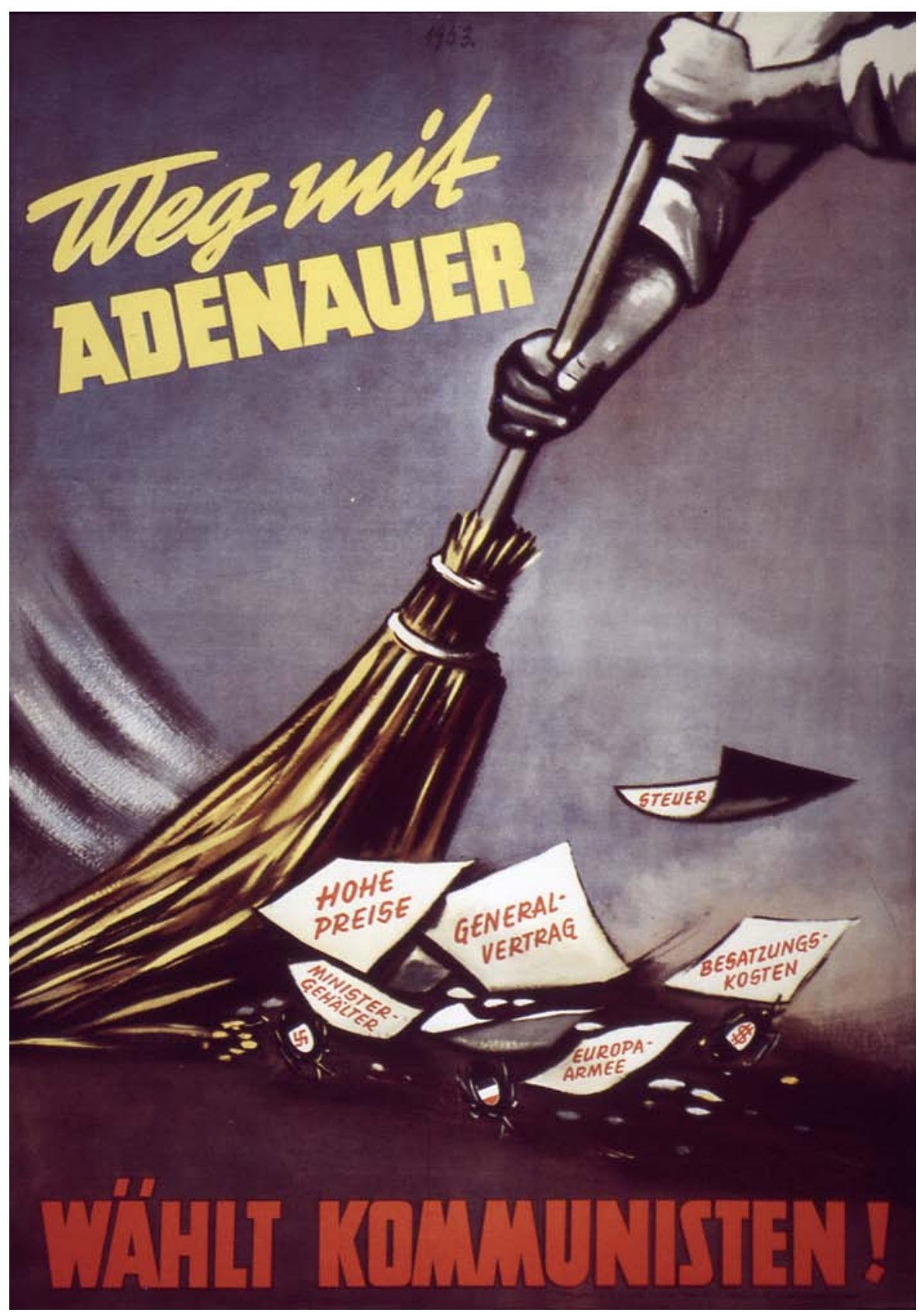

Q12: $\quad$ Plakat KPD "Weg mit Adenauer", 1953, Stadtarchiv Göttingen, PS 19501959 B1.5/1953-2. 
öttingen nach Kriegsende 1945 - Wie gestaltete sich der Nachkriegsalltag aus Sicht der Bevölkerung und der alten und neuen Behörden? Welche Formen und Auswirkungen hatten die neuen politischen Verhältnisse, die Flüchtlinge, die Mangelwirtschaft, die Wohnungsnot, die Umgestaltung des Bildungssektors und welche Neuordnungen des öffentlichen und kulturellen Lebens stießen auf Akzeptanz oder Ablehnung? Diesen und anderen Fragen geht der vorliegende Sammelband nach. Er beruht auf Beiträgen eines Seminars im Fach Geschichte der Georg-August-Universität Göttingen, die von den Herausgeberinnen redigiert und durch ein Vorwort ergänzt wurden. In verschiedenen Archiven stießen die Studierenden auf zahlreiche bislang unveröffentlichte Quellen und analysierten diese mit Hilfe aktueller Forschungsansätze zur Alltagsgeschichte. 